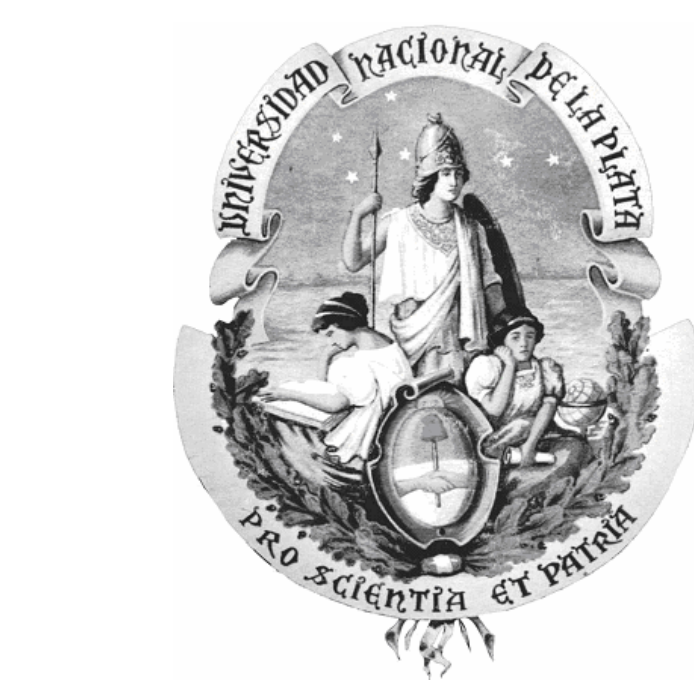

UNIVERSIDAD NACIONAL DE LA PLATA

FACULTAD DE INFORMÁTICA

\title{
MODELO DE CICLO DE VIDA PARA EL APRENDIZAJE BASADO EN COMPARTICIÓN DE CONOCIMIENTOS EN SISTEMAS AUTÓNOMOS DE ROBOTS
}

TESIS DOCTORAL EN CIENCIAS INFORMÁTICAS

Tesista: M.Ing. Jorge Salvador IERACHE

Directores: Profesor Armando DE GIUSTI y Profesor Ramón GARCÍA MARTÍNEZ.

La Plata, Buenos Aires, Argentina 
<smiles>C=C=C=C</smiles> 


\section{DEDICATORIA}

A mis padres Pascual y Elvira. A mi hijos Guido Tomás y Rocío de la Paz.

A mi esposa María Alejandra. A mis Amigos y familiares.

A la memoria de Edgardo Raúl Claverie, mi compañero de cursos de doctorado de la UPM. A mis Alumnos, por compartir esta pasión por la robótica acompañándome en mis ideas y enseñándome. A Hugo, por apoyar mis pasos en la robótica. A Ramón, por su consideración y consejos en pos de mi crecimiento profesional.

A Tito, Marcelo y Patricia por recibirme con generosidad y permitirme desarrollar mi formación de posgrado. A Luna, quien me acompañó durante las noches y horas de preparación de la tesis. 
<smiles>C=C=C=C</smiles> 


\section{AGRADECIMIENTOS}

A mi país le entrego esta pequeña contribución por darme la oportunidad de estudiar.

A mis seres queridos por el apoyo y empuje en los momentos difíciles.

A la Facultad de Informática de la Universidad Nacional de la Plata por brindarme, a través de los cursos del doctorado, un mayor conocimiento en mis estudios del doctorado en ciencias informáticas.

Al personal de la secretaría de posgrado de la Facultad de Informática de la Universidad Nacional de la Plata por su asistencia y comprensión.

A la Facultad de Informática, Ciencias de la Comunicación y Técnicas Especiales de la Universidad de Morón, por brindarme el espacio para desarrollarme y ayudar a crecer a nuestros alumnos a través del Instituto de Sistemas Inteligentes y Enseñanza Experimental de la Robótica.

A mis directores de Tesis Armando De Giusti y Ramón García Martínez por dirigirme y apoyarme para la realización de este trabajo.

A mi compañero de doctorado el M.Ing Claudio Rancan por sus consideración y apoyo, a Patricia Pesado y Marcelo Naiouf por su consejos, a María Alejandra Iglesias y María Laura González por la lectura de revisión, a Maria Tarletta y Julio Cortese por su ayuda en la impresión de los ejemplares de esta tesis.

A los Ingenieros Berman Milton, Torres Fernando, Yagi Leonardo de la Facultad de Ingeniería de la Universidad de Buenos Aires, Martín Dittler de la Universidad de Morón por participar en la experimentación y apoyar la discusión de mis ideas.

A mis alumnos por la confianza y apoyo que me depositaron durante la organización de los Campeonatos Argentinos de Fútbol de Robots 2005 y 2009, como así también en la dirección de sus trabajos, al permitirme disfrutar y renegar juntos observando el comportamiento de un robot. 
<smiles>C=C=C=C</smiles> 


\section{RESUMEN}

En esta tesis se distinguen los estados de evolución y niveles de actuación en el contexto de un ciclo de vida para el aprendizaje de Sistemas Autónomos de Robots (SAR). Sobre estas bases, resulta conveniente especificar mecanismos de aprendizaje por colaboración entre SARs, definiendo un ciclo de vida de aprendizaje que considere arquitecturas y modelos que caractericen al SAR y su actuación en el ambiente de operación, en particular SARs más evolucionados colaborando con SARs receptores menos evolucionados. Centrado en el mecanismo de aprendizaje especificado resulta conveniente estudiar experimentalmente la colaboración entre SARs, validando la tesis que éstos tienen un mejor comportamiento utilizando colaboración que cuando no la usan.

\section{ABSTRACT}

In this thesis we distinguish the stages of evolution and levels of action in the context of a learning life cycle for Autonomous Robots Systems (ARS). On this basis, it is advisable to specify learning mechanisms of collaboration among ARSs, defining a learning life cycle which considers architectures and models that characterize the ARS and its performance in the operating environment, including more advanced ARSs working with less evolved ARSs receptors. Focused on the specified learning mechanism it is experimentally convenient to study the collaboration among ARSs, validating the thesis that they have a better performance when using collaboration than when it is not used. 
<smiles>C=C=C=C</smiles> 
En mi opinión, para comprender la inteligencia hay que comprender cómo se adquiere, se representa y se almacena el conocimiento; cómo se genera y se aprende el comportamiento inteligente; cómo se desarrollan y se usan las motivaciones, las emociones y las prioridades; cómo las señales sensoriales son transformadas en símbolos ;cómo se manipulan los símbolos para aplicar la lógica, para razonar sobre el pasado y planificar el futuro, y cómo los mecanismos de la inteligencia producen los fenómenos de la ilusión, las creencias, las esperanzas, los temores y los sueños y, sí ,incluso la bondad y el amor. Comprender estas funciones en nivel fundamental sería, creo yo, un logro científico de la misma escala que la física nuclear, la relatividad y la genética molecular.

James Albus 13 de febrero de 1995.

"El aprendizaje es un simple apéndice de nosotros mismos; dondequiera que estemos, está también nuestro aprendizaje”. 
<smiles>C=C=C=C</smiles> 


\section{INDICE}

CAPITULO 1: INTRODUCCIÓN 1

1.1 Contexto de la tesis 1

1.2 Objetivos de la tesis 2

1.3 Visión general de la tesis 3

1.4 Producción científica derivada de resultados parciales de la tesis 4

$\begin{array}{ll}\text { CAPITULO 2: ESTADO DE LA CUESTIÓN } & 7\end{array}$

$\begin{array}{lll}2.1 & \text { Introducción a los Robots Autónomos } & 7\end{array}$

2.2 Propuestas de Sistemas Inteligentes para Robots Autónomos 16

2.2.1 Sistema inteligente autónomo 16

2.2.2 Sistema inteligente autónomo con aprendizaje basado en formación y 18 ponderación de teorías

2.2.3 Sistema inteligente autónomo con aprendizaje basado en intercambio de 19 teorías

2.3 Robots operando en ambientes aéreos, marítimos y terrestres 21

2.3.1 Robots voladores 21

2.3.2 Robots acuáticos 24

$\begin{array}{lll}2.3 .3 & \text { Robots terrestres } & 25\end{array}$

2.3.4 Robots de exploración extraterrestre 28

CAPITULO 3: DESCRIPCIÓN DEL PROBLEMA 29

3.1 Introducción $\quad 29$

3.2 Sistema Autónomo de Robot (SAR) 31

3.3 Colaboración entre Sistemas Autónomos Robots 31

3.4 Modelo y arquitectura para múltiples sistemas autónomos de robots 32

3.5 Estadísticas de aprendizaje y métricas asociadas a la actuación del sistema 32 autónomo de robots

3.5.1 Cuestiones relevantes en relación a la colaboración del SAR 32

3.5.2 Cuestiones relevantes en relación a la arquitectura del SAR 34 
4.1. Sistema Autónomo de Robot (SAR) 35

4.1.1 Introducción sistema autónomo de robots 35

4.1.2 Modelo de teoría 36

4.2 Ciclo de vida de aprendizaje de un Sistema Autónomo de Robot 37

4.3 Arquitectura y modelo MultiSAR 44

$\begin{array}{lll}\text { 4.3.1 Arquitectura MultiSAR } & 44\end{array}$

4.3.2 Modelo MultiSAR 46

4.3.3 Ontología preliminar del sistema autónomo de robot 51

4.4. Sistema autónomo de robot 51

4.4.1 Introducción $\quad 51$

4.4.2 Sistema autónomo de robot propuesto 52

4.4.2.1 Configuración del sistema autónomo de robot 57

4.4.2.2 Selección del sistema autónomo de robot y sus métodos asociados 59

$\begin{array}{lll}\text { 4.4.3 Utilidad de una teoría } & 60\end{array}$

4.4.3.1 Utilidad basada en la Situación 60

4.4.3.2 Utilidad con coeficientes o basada en la acción 62

4.4.4 Registro de teorías 66

$\begin{array}{lll}\text { 4.4.5 Mutación de teorías } & 67\end{array}$

$\begin{array}{lll}\text { 4.4.6 Comparación de teorías } & 70\end{array}$

4.4.6.1 Comparación de valores por umbral común $\quad 70$

$\begin{array}{lll}\text { 4.4.6.2 Comparación de valores por umbral individual } & 71\end{array}$

4.4.7 Planificación de Acciones del Sistema Autónomo de Robot $\quad 73$

$\begin{array}{lll}\text { 4.4.7.1 Planificador y ponderador de planes } & 75\end{array}$

$\begin{array}{lll}\text { 4.4.7.2 Planificador Ranking de Teorías } & 77\end{array}$

4.4.8 Compartición de conocimiento 80

4.4.8.1 Intercambio de teorías (cooperación) 80

4.4.8.2. Colaboración 83

4.4.9 Registro de Estadísticas de Aprendizaje del Sistema Autónomo de Robot 88

4.4.10 Evolución del Sistema Autónomo de Robot 92

4.5. Escenarios del Sistema Autónomo de Robot $\quad 94$

4.5.1 Escenario Layer BIO $\quad 94$

4.5.2 Escenario Layer TBO 95

4.5.3 Escenario Layer WIO 96

4.6. Características del robot y simulador empleado 96 
4.6.1 Características generales del mini robot e-puck $\quad 97$

4.6.2 Características del simulador Webots 99

4.7 Configuración y tipos de SARs 101

4.7.1 Identificación de SARp en función de la configuración y tipo 102

4.7.2 Identificación de SARr en función de la configuración y tipo 102

4.7.3 Taxonomía de las Extensiones de SARs aplicadas 103

$\begin{array}{ll}\text { CAPITULO 5: EXPERIMENTOS } & 105\end{array}$

$\begin{array}{lll}5.1 & \text { Introducción } & 105\end{array}$

$\begin{array}{lll}5.2 & \text { Diseño Experimental } & 105\end{array}$

5.2.1 Variables Independientes 107

5.2.2 Variables Dependientes 111

5.2.3 Arquitectura de Sistema Autónomo de Robot (SAR) 112

5.2.3.1 Arquitectura de Sistema Autónomo Robot con planificador 112 clásico (SARp).

5.2.3.2 Arquitectura de Sistema Autónomo Inteligente con Ranking 113 (SARr)

5.2.4 Grupo de Experimentos 113

$\begin{array}{lll}5.3 & \text { Gráficas y su interpretación } & 114\end{array}$

5.3.1 Gráficas del Sistema Autónomo de Robot con planificador y su 114 interpretación

5.3.1.1 Primer Grupo de Experimentos del SARp 115

5.3.1.2 Segundo grupo de experimentación del SARp. 122

$\begin{array}{lll}\text { 5.3.1.3 Tercer grupo de experimentación del SARp. } & 128\end{array}$

5.3.2 Gráficas del Sistema Autónomo de Robot con ranking de teorías su 134 interpretación

5.3.2.1 Primer grupo de experimentos del SARr 135

5.3.2.2 Segundo grupo de experimentos del SARr 141

5.3.3 Comparación de los resultados obtenidos por ambas arquitecturas de $\quad 147$

Sistema Autónomos de Robots (SARs)

$\begin{array}{lll}\text { 5.3.3.1 Cantidad de ciclos exitosos para SARs neutros. } & 147\end{array}$

5.3.3.2 Cantidad de ciclos exitosos para SARs que aplican colaboración 148

5.3.3.3 Cantidad de ciclos exitosos para SARs que aplican mutación y 149 colaboración

5.3.3.4 Cantidad de ciclos exitosos para SARs que aplican intercambio y 149 
colaboración

5.3.3.5 Cantidad de ciclos exitosos para SARs que aplican mutación, intercambio y colaboración

5.3.3.6 Discusión de los resultados de la comparación de rendimiento de ambas arquitecturas (SARp y SARr)

5.3.4 Relación entre cantidad de teorías, cantidad de planes y cantidad de ciclos usando estos son exitosos

5.3.4.1 Cantidad de Cantidad de Planes Exitosos (CPE) y Teorías Exitosas (CTE) para un SARp

5.3.4.2 Cantidad de Cantidad de Ciclos Exitosos (CPE) y Teorías Exitosas (CTE) para un SARp

5.3.4.3 Cantidad de Cantidad de Planes Exitosos (CPE) y Ciclos Exitosos (CCE) para un SARp

5.3.4.4 Cantidad de Cantidad de Planes Exitosos (CPE) y Teorías Exitosas (CTE) para un SARr

5.3.4.5 Cantidad de Cantidad de Ciclos Exitosos (CCE) y Teorías Exitosas (CTE) para un SARr

5.3.4.6 Cantidad de Cantidad de Planes Exitosos (CPE) y Ciclos Exitosos (CCE) para un SARr

\section{CAPITULO 6 CONCLUSIONES}

6.1. Propuesta de modelo ciclo de vida para el aprendizaje de sistemas autónomos de robots

6.2. Propuesta de sistema autónomo de robot

\section{CAPITULO 7 REFERENCIAS}

\section{ANEXOS}

A Ontología preliminar del Sistema Autónomo de Robot

B Ejemplo de cálculo utilidad con coeficientes o basado en la acción

C Estructura de la base de conocimientos de teorías 
D Ejemplo de mutación de teorías $\quad 185$

E $\quad$ Ejemplo de comparación de situaciones y acciones entre teorías 189

F Ponderación de planes 193

G $\quad$ Ejemplo de planificador por ranking de teorías $\quad 197$

H Ejemplo de cooperación entre sistemas autónomos de robots 199

I Ejemplo de colaboración entre sistemas autónomos de robots 203

J Registro de estadísticas del sistema autónomo de robot 207

K Configuración, tipo de sistema autónomo de robot y métodos asociados 211

L Registro de estadísticas de los experimentos 215

M Características de las bases de conocimientos de teorías de SARs utilizadas durante la experimentación $\quad 237$

N Soporte Digital $\quad 245$

Ñ Aspectos de movilidad y sensorística del robot e-puck en el entorno Webots. 247

O Aspectos generales relacionados con la interfase del robot y el sistema desarrollado 261

P Vehículos robots de Braitenberg. 
<smiles>C=C=C=C</smiles> 
A:

AIS:

ARS:

BCCRAB: Base de Conocimiento Cooperación Robot A, Robot B.

BCCRR: Base de Conocimiento Colaboración Robot Receptor.

BCRA: Base de Conocimiento Robot A.

BCRB: $\quad$ Base de Conocimiento Robot B.

BIO: Built-In Operators.

CCE: $\quad$ Cantidad de Ciclos Exitosos.

CEA: $\quad$ Porcentaje de Ciclos Exitosos Alcanzado.

CPE: $\quad$ Cantidad de Planes Existosos.

CTE: $\quad$ Cantidad de Teorías Exitosas.

K: $\quad$ Parámetro (K) de la Teoría.

LBIO: $\quad$ Layer Built-In Operators.

LLC: $\quad$ Learning Life Cycle.

LTBO: $\quad$ Layer Trained Base Operators.

LWIO: $\quad$ Layer World Interaction Operators.

MSARs: Múltiples Sistemas Autónomos de Robots.

MultiSAR: Múltiples Sistemas Autónomos de Robots.

O: Operador.

P: $\quad$ Parámetro (P) de la Teoría.

RA: Robot A.

RB: $\quad$ Robot B.

RC: $\quad$ SAR Colaborador.

RCE: $\quad$ Porcentaje de Rendimiento de Ciclos Exitosos.

RE: $\quad$ SAR Receptor.

RTN: $\quad$ Porcentaje de Rendimiento de Teorías Nuevas.

S: $\quad$ Situación.

SAR: $\quad$ Sistema Autónomo de Robot.

SARp- PM: Sistema Autónomo de Robot planificador clásico con Ponderación y Mutación.

SARp- PMI: Sistema Autónomo de Robot planificador clásico con Ponderación, Mutación e Intercambio. 
SARp- PMIC: Sistema Autónomo de Robot planificador clásico con Ponderación, Mutación, Intercambio y Colaboración.

SARp: $\quad$ Sistema Autónomo de Robot planificador clásico.

SARr: $\quad$ Sistema Autónomo de Robot planificador por ranking de teorías.

SARr-M: $\quad$ Sistema Autónomo de Robot planificador por ranking con Mutación.

SARr-MI: Sistema Autónomo de Robot planificador por ranking con Mutación e Intercambio.

SARr-MIC: Sistema Autónomo de Robot planificador por ranking con Mutación, Intercambio y Colaboración.

SARs: $\quad$ Sistemas Autónomos de Robots.

SC: Sistema Autónomo de Robot planificador clásico con ponderación y Colaboración.

SCp: $\quad$ Sistema Autónomo de Robot planificador clásico con Colaboración.

SCr: Sistema Autónomo de Robot planificador por ranking con Colaboración.

Sf: $\quad$ Situación final.

SI: $\quad$ Sistema Autónomo de Robot planificador clásico con ponderación e Intercambio.

Si: $\quad$ Situación inicial.

SIA: $\quad$ Sistema Inteligente Autónomo.

SIC: $\quad$ Sistema Autónomo de Robot planificador clásico con ponderación, Intercambio y Colaboración.

SICp: $\quad$ Sistema Autónomo de Robot planificador clásico, Intercambio y Colaboración.

SICr: Sistemas Autónomo de Robot planificador por ranking con Intercambio y Colaboración

SIr: $\quad$ Sistema Autónomo de Robot planificador por ranking con Intercambio.

SMCr: Sistema Autónomo de Robot planificador por ranking con Mutación y Colaboración.

SMICr: $\quad$ Sistema Autónomo de Robot planificador por ranking con Mutación, Intercambio y Colaboración

SMr: $\quad$ Sistema Autónomo de Robot planificador por ranking con Mutación.

SN: $\quad$ Sistema Autónomo de Robot Neutro, planificador clásico.

SNp: $\quad$ Sistema Autónomo de Robot planificador clásico, Neutro.

SNr: $\quad$ Sistema Autónomo de Robot Neutro, planificador por ranking.

SPM: $\quad$ Sistema Autónomo de Robot planificador clásico con Ponderación y Mutación.

SPMC: $\quad$ Sistema Autónomo de Robot planificador clásico con Ponderación, Mutación, y Colaboración. 
SPMCp: $\quad$ Sistema Autónomo de Robot planificador clásico, Ponderación, Mutación y Colaboración.

SPMI: Sistema Autónomo de Robot planificador clásico con Ponderación, Mutación e Intercambio.

SPMIC: Sistema Autónomo de Robot planificador clásico con Ponderación, Mutación, Intercambio y Colaboración.

SPMICp: Sistema Autónomo de Robot planificador clásico, Ponderación, Mutación, Intercambio y Colaboración

T: $\quad$ Teoría.

TBO: $\quad$ Trained Base Operations.

TNA: $\quad$ Porcentaje de Teorías Nuevas Alcanzado.

U: $\quad$ Utilidad Teoría.

VB: $\quad$ Velocidad Braitenberg.

VT: $\quad$ Velocidad Teoría.

WIO: $\quad$ World Interaction Operators. 
<smiles>C=C=C=C</smiles> 


\section{INTRODUCCIÓN}

Se presenta en este capítulo el contexto de la tesis (sección 1.1), su objetivo (sección 1.2), la visión general de la tesis (sección 1.3) y la producción científica derivada de resultados parciales de la misma (sección 1.4).

\subsection{CONTEXTO DE LA TESIS}

Para aprender en un mundo real, un sistema necesita formular una teoría [Hayes-Roth, 1983] acerca de los efectos de las acciones sobre su entorno. El aprendizaje es necesario porque en un nuevo entorno, el sistema no puede saber “a priori” las consecuencias de sus acciones ni las relaciones existentes entre las acciones y las percepciones [Shen, 1989;Shen y Simon, 1989].

Se puede establecer que, para que un robot sea autónomo es necesario que sea capaz de reaccionar ante situaciones no consideradas en la programación de su control, sin ninguna supervisión del exterior. En este sentido se dice que el robot autónomo debe ser no totalmente preprogramado. [Santos José y Richard J. Duro, 2005].

Como reflexionan Hiton y Nowlan [1987] “El argumento más comúnmente utilizado a favor del aprendizaje es que algunos aspectos del entorno son impredecibles, de forma que es positivamente ventajoso dejar algunas decisiones al aprendizaje más que especificarlas”.

El gran problema de la robótica basada en comportamiento es generar mecanismos que relacionen los sensores y los actuadores y que lleven a un nivel de coordinación capaz de generar un comportamiento autónomo en el entorno real [Phil Husbands et al, 1994]. La robótica basada en comportamientos no utiliza modelos del entorno en los que el robot debe llevar a cabo sus acciones, en contraposición a la alternativa tradicional centrada en la planificación sobre modelos simbólicos previamente establecidos.

Además hasta cierto punto el desarrollo de la robótica basada en comportamientos ha venido marcado por una idea que se puede resumir en la frase de Brooks "el mejor modelo de entorno es el mismo entorno”, para resaltar la característica de que los comportamientos se deben obtener con el robot inmerso en el entorno, no como módulos separados que después se prueban en el entono, esté o no modelizado [Santos José y Richard J. Duro, 2005]. 
Como dice Mataric [1992], reactivo y basado en comportamientos, aunque a veces se confunden en la literatura, no son sinónimos. Los sistemas basados en comportamientos pueden contener componentes reactivos, pero su computación no tiene porqué estar limitada a simples tablas de decisión “información sensorial-acciones”, sino que estos sistemas pueden utilizar diferentes formas de representaciones internas a la hora de decidir qué acción realizar.

Algunos trabajos precursores de estas ideas fueron las tortugas de Walter [Walter 1953] y los "Vehículos de Braitenberg” [1984], ambos demostraron la capacidad de obtener una serie de comportamientos complejos.

De acuerdo con los investigadores franceses Jerome Kodjabachian y Jean Arcady Meyer [1995], “La naturaleza ya ha inventado y utilizado tres procedimientos de diseño automático: evolución, desarrollo y aprendizaje. Los dos primeros permiten la creación del organismo y su organización interna, mientras que el tercero se utiliza para el propósito de una adaptación a corto plazo”.

\subsection{OBJETIVO DE LA TESIS}

El propósito de esta tesis es formular el modelo de ciclo de vida de aprendizaje de sistemas autónomos de robots, la colaboración desde un sistema autónomo de robot, que se encuentra en un estado de evolución superior en el contexto del ciclo de vida propuesto, a un sistema autónomo de robot receptor, explorar una arquitectura para sistemas autónomos de robots (SARs) con un nuevo módulo de planificación en relación a los trabajos de autores anteriores.

La colaboración entre sistemas autónomos de robots se debe considerar en el marco de los trabajos anteriores, comenzando Fritz W (1989), el que considera un sistema autónomo inteligente representado por un robot con un planificador clásico, al que García Martínez R (2000), le incorpora la ponderación de planes y mutación de teorías similares, luego Maceri P (2001), incorpora el intercambio de teorías. Sobre estas bases resulta conveniente considerar la extensión y experimentación de mecanismos de colaboración entre SARs en el marco de un ciclo de vida de aprendizaje, donde SARs más evolucionado colaboran con SARs receptores menos evolucionados.

Se presenta un modelo y la arquitectura para un ambiente de múltiples sistemas autónomos de robots, experimentándose la actuación del SAR en el marco de la propuesta. Finalmente, considerando que existen propuestas anteriores enunciadas en el marco de sistemas autónomos de robots, resulta necesario la comparación en términos del rendimiento del aprendizaje del sistema autónomo de robot (SAR), entre las propuestas de autores anteriores las que consideran la 
planificación, ponderación de planes, métodos de mutación de teorías e intercambio de teorías entre SAR y la propuesta de sumar el mecanismo de colaboración para un SAR.

\subsection{VISIÓN GENERAL DE LA TESIS}

En el capítulo 2 se establece una introducción a los sistemas autónomos, las propuestas de autores anteriores en el contexto de aprendizaje por refuerzo, sobre la base de la valoración de teorías aplicadas por el sistema autónomo inteligente (SIA), en este caso representado por el sistema autónomo de robot (SAR), se presenta luego la descripción de proyectos de robots representativos del estado actual del desarrollo tecnológico, operando en ambientes del tipo aéreo, marítimo y terrestre. Finalmente se ilustra el futuro de los sistemas autónomos de robots de exploración operando en ambientes no terrestres.

En el capítulo 3 se presenta una introducción a la importancia del problema en el contexto de los sistemas autónomos, la necesidad de contar con un ciclo de vida de aprendizaje de sistemas autónomos de robots, la conveniencia de extender el trabajo de autores anteriores considerando la colaboración entre sistema autónomos robots, la importancia de contar con un modelo y arquitectura para múltiples sistemas autónomos de robots, las estadísticas de aprendizaje y métricas asociadas a la actuación del sistema autónomo de robots en relación a los métodos aplicados en sus arquitecturas.

En el capítulo 4 se presentan las características de un sistema autónomo de robots, el modelo de ciclo de vida de aprendizaje de un sistema autónomo de robots (SARs), la arquitectura y el modelo MultiSARs, se detalla cada uno de los componentes que integran el SAR propuesto, se describen los escenarios aplicados, se presentan las características generales del robot y del simulador empleado, finalmente se identifican los SARs en función de su configuración y tipo.

En el capítulo 5 se presentan los resultados experimentales del comportamiento de un Sistema Autónomo de Robot (SAR) que recibe colaboración. El SAR fue implementado sobre la base de una plataforma E-Puck, se experimentaron dos tipos de arquitectura de SAR, la primera con planificador clásico (SARp) y la segunda con el planificador de acciones propuesto, por ranking (SARr). Se realiza una introducción de la experimentación, se describe el diseño experimental, se presentan gráficamente los resultados obtenidos, su interpretación y la comparación de los resultados obtenidos en la experimentación entre la arquitectura de SARp y la arquitectura propuesta de SARr.

En el capítulo 6 se presentan las conclusiones del presente trabajo, destacándose los aportes y resultados obtenidos y las futuras líneas de investigación. 


\subsection{PRODUCCIÓN CIENTÍFICA DERIVADA DE RESULTADOS PARCIALES DE LA TESIS}

Durante el desarrollo de esta tesis se han comunicado resultados parciales a través de diversas publicaciones que a continuación se detallan:

Series Internacionales y Capítulos de Libros

Ierache, J., García-Martínez, R., De Giusti, A. (2008). Learning Life-Cycle in Autonomous Intelligent Systems. In Artificial Intelligence in Theory and Practice II, ed. M. Bramer, (Boston: Springer), pp 451- 455, ISSN 1571-5736.

Ierache, J., Garcia-Martinez, R., De Giusti, A. (2009). A Proposal of Autonomous Robotic Systems Educative Environment. Communications in Computer and Information Science 44: 224-231. Springer-Verlag Berlin Heidelberg. ISSN 1865-0929 / ISBN: 978-3-642-03985-0.

Ierache, J., García-Martínez, R., De Giusti, A. (2010), Learning by Collaboration in Intelligent Autonomous Systems”. IFIP Advances in Information and Communication Technology, Artificial Intelligence in Theory and Practice III, ed. M. Bramer, (Boston: Springer), Volume 331/2010, 143-152, DOI: 10.1007/978-3-642-15286-3_14

Congresos Internacionales:

Ierache, J., Naiouf, M., García Martínez, R., De Giusti, A. 2008. Un Modelo de Arquitectura para el Aprendizaje y Compartición de Conocimiento entre Sistemas Inteligentes Autónomos Distribuidos. Proceedings VII Jornadas Iberoamericanas de Ingeniería de Software e Ingeniería del Conocimiento. Pág. 179-187. ISSN 1390-292X. 


\section{Congresos Nacionales}

Ierache, J., Dittler, M. (2008). Sistemas Autónomos de Programación Abierta a Partir de Juguetes Bípedos en el contexto de Fútbol de Robots, Anales del V Workshop de Inteligencia Artificial aplicada a la robótica móvil, Universidad Nacional del Comahue, Pág 105-111, ISBN: 978-987-604-100-3.

Ierache, J., Bruno, M García-Martínez, R,. (2008). Ontología para el aprendizaje y compartición de conocimientos entre sistemas autónomos. XIV Congreso Argentino de Ciencias de la Computación 6 al 10 octubre CACIC 2008, Universidad Nacional de Chilecito, ISBN 978.987-24511-0-2

Ierache,J., Dittler M., Pereira G., García Martínez R.,(2009) Robot Control on the basis of Bio-electrical signals. XVI Congreso Argentino de Ciencias de la Computación 5 al 9 octubre CACIC 2009, Universidad Nacional de Jujuy, Facultad de Ingeniería, ISBN 978-897-24068-3-9 ,pag 30.

Ierache, J., Garcia Martinez, R., Aprendizaje y Compartición de Conocimientos entre Sistemas Inteligentes Autónomos. (2009) Proceedings XI Workshop de Investigadores en Ciencias de la Computación. Pág. 580-583. ISBN 978-950605-570-7. 


\section{ESTADO DE LA CUESTIÓN}

"Antes no tenían tantos sensores. Los predecesores no tenían gracia para moverse y además se manejaban con control remoto, pero ahora son absolutamente autónomos. Además, están guiados por su propia inteligencia artificial"

Prof. Huosheng Hu University of Essex

En este capítulo se presenta una introducción a los sistemas autónomos en la sección 2.1, las propuestas de autores anteriores en el contexto del aprendizaje por refuerzo, sobre la base de la valoración de teorías aplicadas por el sistema autónomo inteligente (SIA), en este caso representado por el sistema autónomo de robot (SAR), en la sección 2.2. En la sección 2.3 se presenta la descripción de proyectos de robots representativos del estado actual del desarrollo tecnológico, operando en ambiente aéreo (sección 2.3.1), en ambiente acuático (sección 2.3.2), ambiente terrestre (sección 2.3.3), finalmente se ilustra el futuro de los sistemas autónomos de robots de exploración operando en ambientes no terrestres (sección 2.3.4).

\subsection{INTRODUCCIÓN A LOS ROBOTS AUTÓNOMOS}

La robótica puede clasificarse en cinco generaciones en función de la división hecha por Michael Cancel, 1984 (director del Centro de Aplicaciones Robóticas de Science Application Inc.). Las dos primeras, ya alcanzadas en los ochenta, incluirán la gestión de tareas repetitivas con autonomía muy limitada. La tercera generación incluiría visión artificial, en lo cual se ha avanzado mucho en los años ochenta y noventa. La cuarta incluiría movilidad avanzada en exteriores e interiores y la quinta entraría en el dominio donde los robots utilizan las técnicas de inteligencia artificial para hacer sus propias decisiones y resolver problemas.

Los robots Sojourner, (1997) Figura 2.1, Rover Spirit y Opportunity (2004) Figura 2.2 enviados por la NASA a Marte, son los más conocidos en orden al logro de sus expediciones, sin embargo estos robots no son plenamente autónomos, sus órdenes de actuación eran enviadas vía radio, desde la tierra. Si bien ambos robots conservan cierto grado de autonomía al controlar sus 
comportamientos por ejemplo evitar obstáculos peligrosos a través de sus sensores de visión y proximidad.

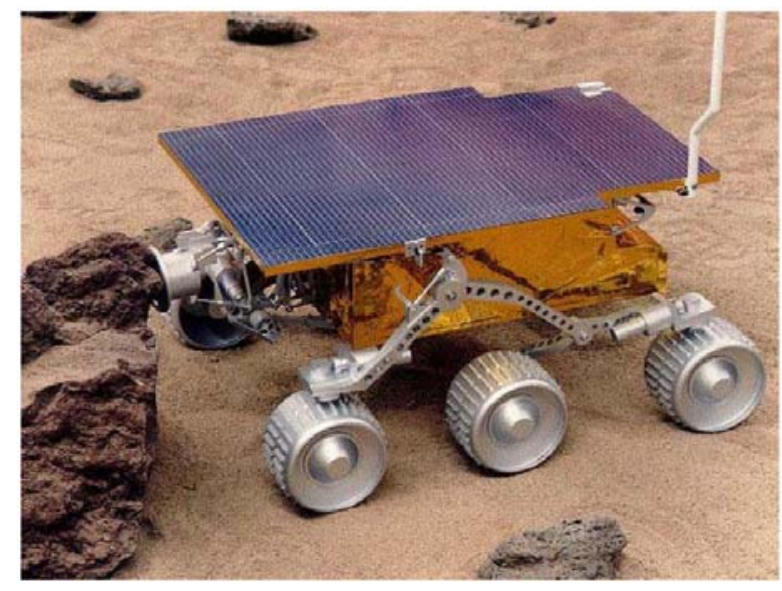

Figura 2.1 Robot Sojourner

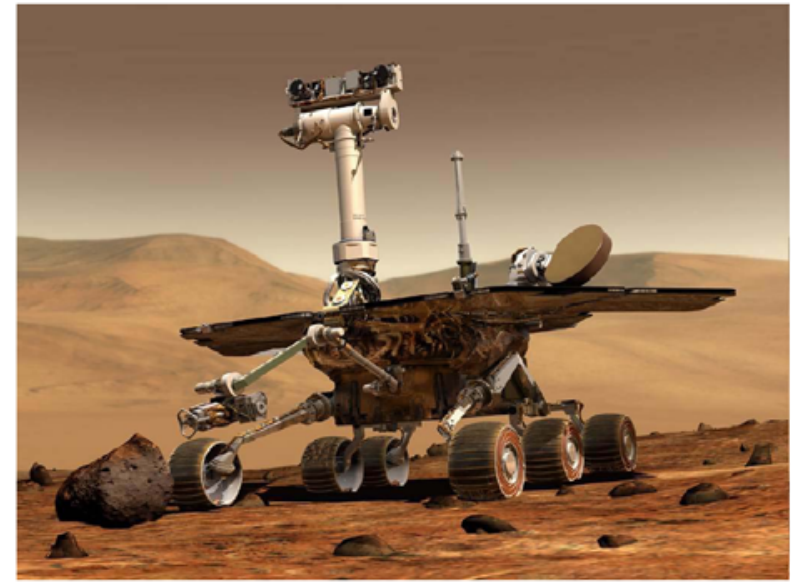

Figura 2.2 Robot Rover

Un robot autónomo es capaz de reaccionar ante situaciones no consideradas estrictamente en la programación de su control, sin recurrir a supervisión o teleoperación del exterior. Su programa no puede definir explícitamente todas las acciones posibles frente a las posibles situaciones que el robot puede encontrar en su ambiente de operación.

Robots como el bípedo Asimo Figura 2.3 y el cuadrúpedo Aibo Figura 2.4, son verdaderos desafíos de la ingeniería, si bien no son plenamente autónomos, el robot Asimo alcanza capacidades de autonomía limitada para desplazarse caminando en diferentes superficies, subir y bajar escaleras.

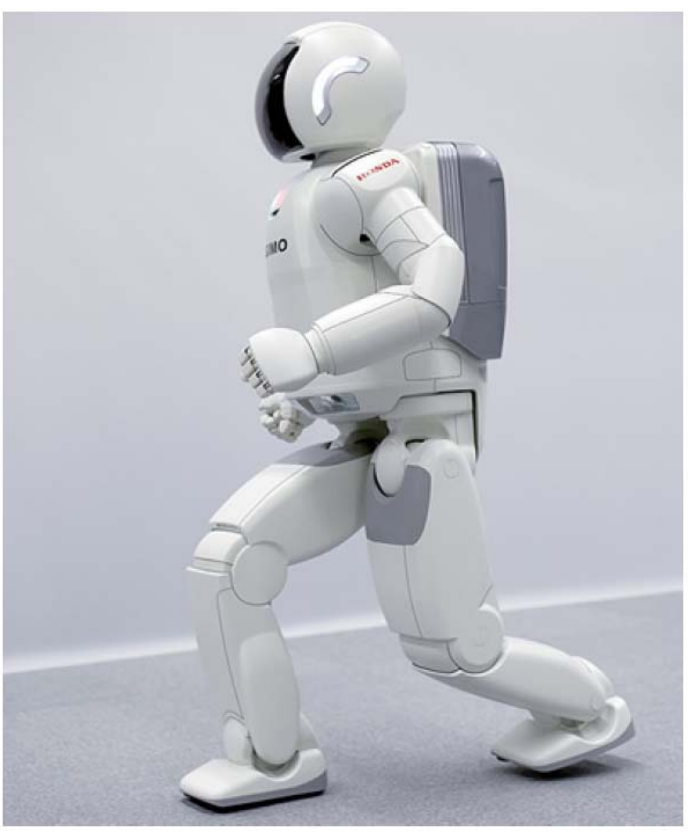

Figura 2.3 Robot Asimo

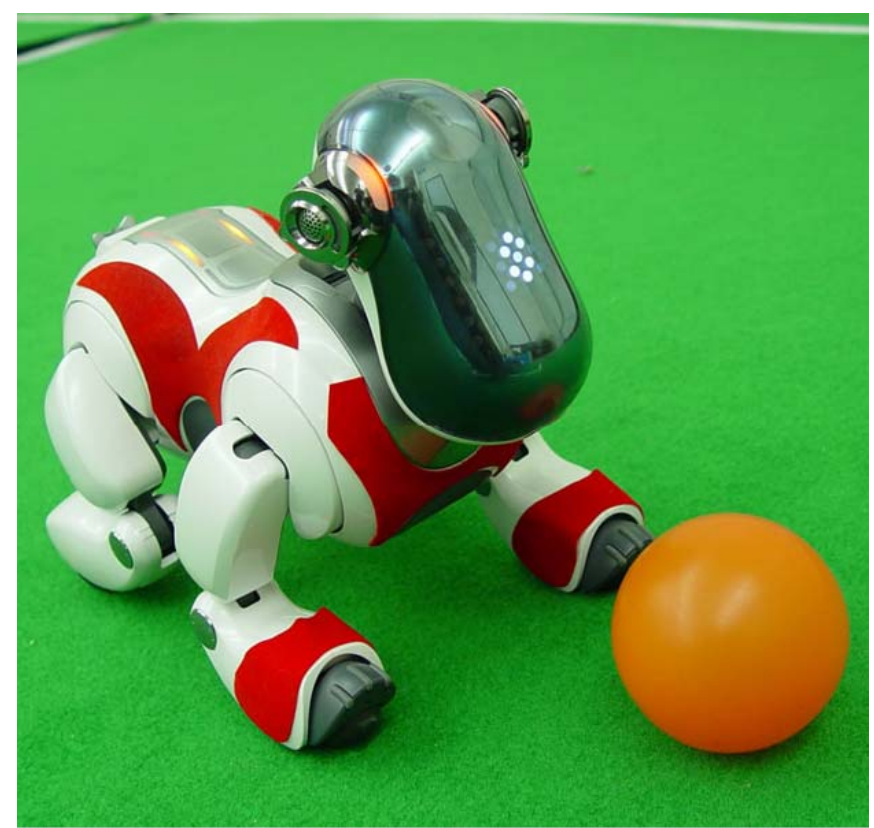

Figura 2.4 Robot Aibo 
El robot Aibo, a través de su sistema de visión, evita obstáculos y busca objetos de color, utiliza sensores infrarrojos para medir distancias, en su cabeza tiene unos sensores de precisión para reconocer caricias o premios de su amo o un golpe ligero correctivo, además cuenta con micrófonos y medidores de aceleración e inclinación.

Un sistema es autónomo en la medida en que su comportamiento está determinado por sus entradas actuales y por sus experiencias pasadas, antes que por sus diseñadores. Un sistema verdaderamente autónomo debería ser capaz de operar correctamente en cualquier entorno, siempre que se le de tiempo para adaptarse. Por ello, las estructuras de conocimiento internas del sistema deberían ser construibles, en principio, a partir de su experiencia en el mundo. Un punto medio razonable consiste en diseñar sistemas cuyo comportamiento está predeterminado en gran parte, al menos inicialmente, por el conocimiento del diseñador, pero haciendo que estas suposiciones sean tan explícitas como sea posible y susceptibles de ser cambiadas por el agente. Este sentido de autonomía parece corresponderse razonablemente bien con nuestra noción intuitiva de inteligencia. [Russell, S., Wefald, E., (1991)].La capacidad de aprender es, junto con la capacidad de planificar, uno de los aspectos básicos de la inteligencia, según Russell y Wefald quienes describieron: El aprendizaje es una parte importante de la autonomía.

Los robots autónomos son entidades físicas con capacidad de percepción sobre un entorno y que actúan sobre el mismo en base a dichas percepciones, sin supervisión directa de otros agentes [Farid Fleifel Tapia, 2002].

Los robots autónomos están situados, es decir, éstos perciben el entorno a través de su sistema de sensores y actúan sobre el mismo con sus efectores, ellos no actúan sobre abstracciones o modelos del entorno. Por otro lado, los robots son entidades corpóreas, que actúan en un mundo conformado por uno o más ambientes y otros robots. La actuación del robot en el mundo real, virtual o híbrido es directa haciendo uso de sus efectores (ruedas, patas, alas, aletas, entre otros).

Los robots autónomos suelen ser móviles, actuando éstos en ambientes aéreos, marinos (de superficie, submarino) o terrestres. Sin embargo un robot móvil no siempre es autónomo, éstos pueden ser teleoperados total o parcialmente.

En términos de robótica situada, el fútbol de robot presenta una oportunidad para los investigadores en un contexto de múltiples sistemas autónomos de robots (MSARs), éste se desarrolla en un escenario donde se presentan estrategias en oposición y en cooperación en un ambiente de juego dinámico donde los robots llevan adelante roles, sub objetivos y objetivos para alcanzar su meta final que es ganar el juego. Diversas categorías integran al fútbol de robots, entre éstas a nivel de simulación se destacan la SIMUROSOT de la FIRA (Federation of International Robot-Soccer Association), [FIRA, 2010]. y a nivel de robots físicos la F-180 de RoboCup, [RoboCup, 2010] 
entre otras. La elección del fútbol no es casual. Esta actividad reúne características que posibilitan desarrollar y evaluar tecnologías que permiten a los robots desempeñarse en tareas tales como rescate, exploración, tareas en ambientes peligrosos, manipulación de elementos tóxicos o explosivos, entre otros.

La figura 2.5 muestra a robots de la categoría F-180 de fútbol robots, éstos actúan sin intervención humana, son autónomos con sistema de visión global, la participación de humanos sólo es permitida fuera del tiempo de juego. La Figura 2.6 muestra distintos robots categoría F-180 participantes del VII Campeonato Argentino de Fútbol Robots organizado por el Instituto de Sistemas Inteligentes y Enseñanza Experimental de la Robótica de la Universidad de Morón durante el año 2009 [CAFR 09, 2009].

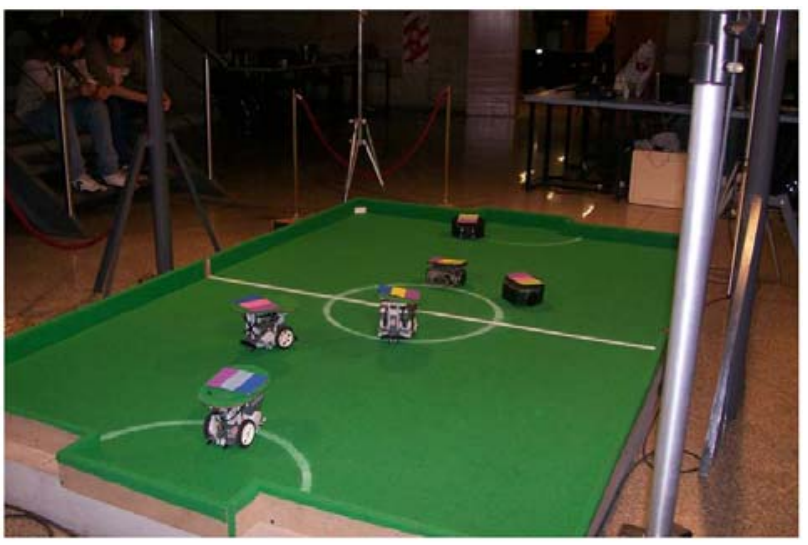

Figura 2.5 Fútbol de robots F-180

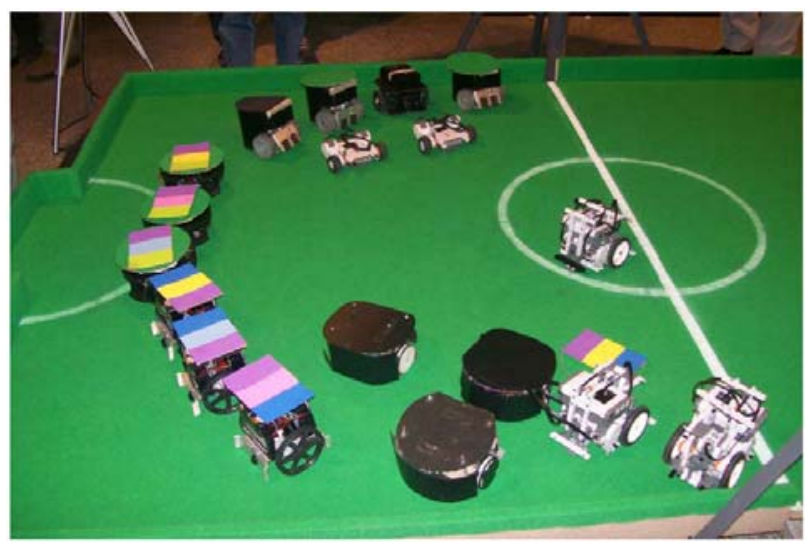

Figura 2.6 Robots F-180 CAFR 09

Para el desarrollo de un ambiente educativo en materia de sistemas autónomos que permita la construcción de robots autónomos se debe considerar el paradigma, las metodologías, técnicas, herramientas de simulación y robots [Ierache, J., García-Martínez, R., De Giusti, A,. 2009a], en este orden para la conformación del ambiente, se rescatan entre los robots más utilizados en la formación inicial por las universidades el kit LEGO RCX [RCX MINDSTORMS,2010], Figura 2.7, el kit LEGO MINDSTORMS NXT [NXT MINDSTORMS, 2010], Figura 2.8.

Otros esfuerzos en la materia se desarrollan a través de la adaptación de juguetes bípedos, cuadrúpedos convirtiéndolos en sistemas autónomos de programación abierta. Se observa en la Figura 2.9 el robot bípedo Robosapien V1, adaptado con un microcontrolador BX-24p,. [Ierache, J., Dittler, M. 2008c].Desarrollos de sistemas autónomos de robots con una mayor cantidad de grados de libertad facilita la ejecución de comportamientos asociados a su sistema sensor motriz más complejo [Zamo L, Ierache J, 2009], en este orden el kit de la plataforma robótica modular Bioloid, es adecuado para construir robots avanzados de hasta 18 grados de libertad, como los humanoides. Se caracteriza por ser una plataforma robótica que emplea tecnología inteligente servocontrolada en 
serie, que permite retroalimentación y control sensorial de posición, velocidad, temperatura, corriente y tensión de cada servomotor.

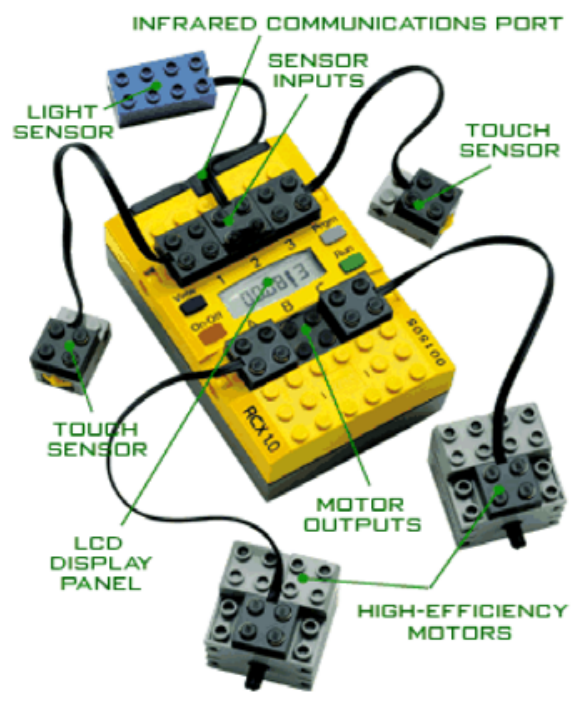

Figura 2.7 Lego RCX

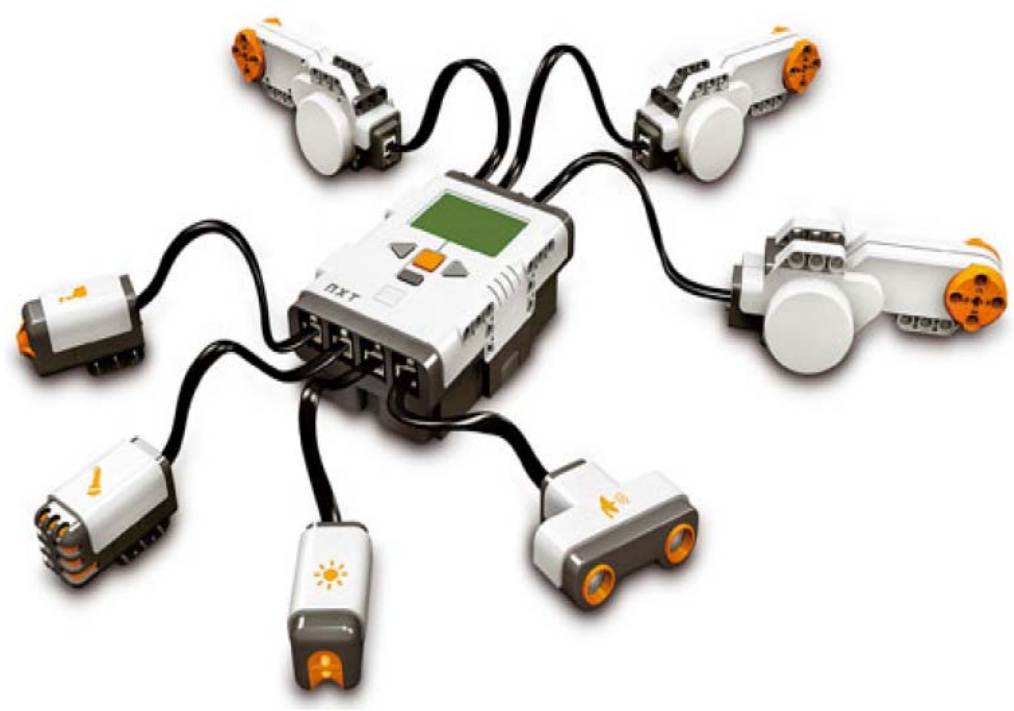

Figura 2.8 Lego NXT
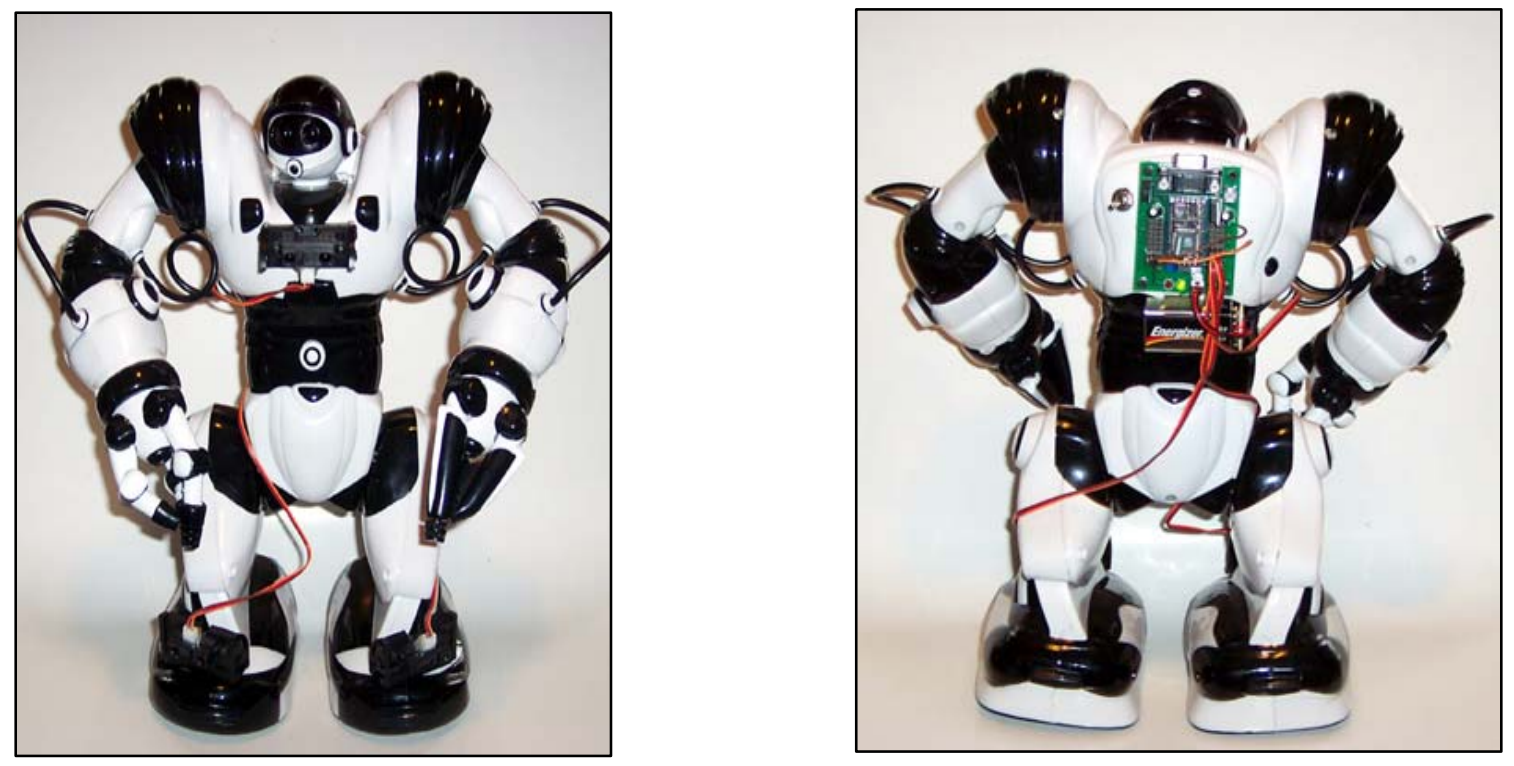

Figura 2.9 Robosapien V1-Microcontrolador BX-24p

El kit Bioloid [Bioloid, 2009] permite construir una gran variedad de configuraciones robóticas, incluyendo robots exploradores autónomos, cuadrúpedos (Puppy), robots hexápodos (Spider), robots dinosaurios, y por supuesto robots humanoides bípedos. Los robots avanzados del kit son: Dinosaur, Puppy, King Spider y Humanoid, entre otros, los que se muestran en la Figura 2.10 a y 2$10 \mathrm{~b}$. 

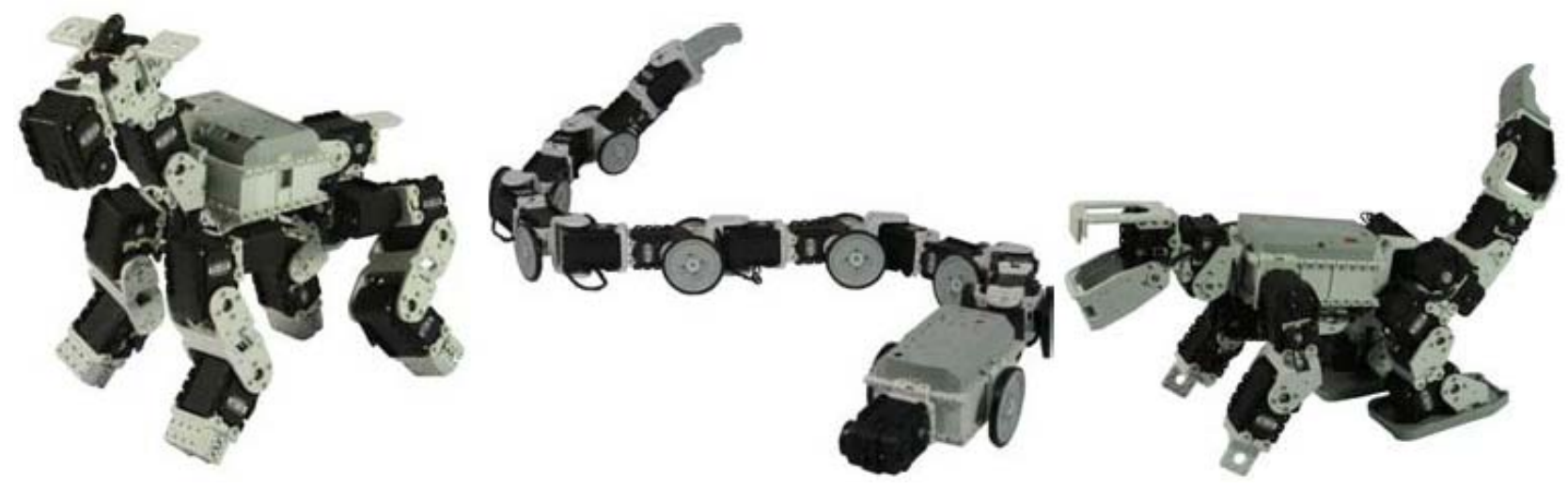

Figura 2.10 a Prototipos de Robots avanzados Bioloid
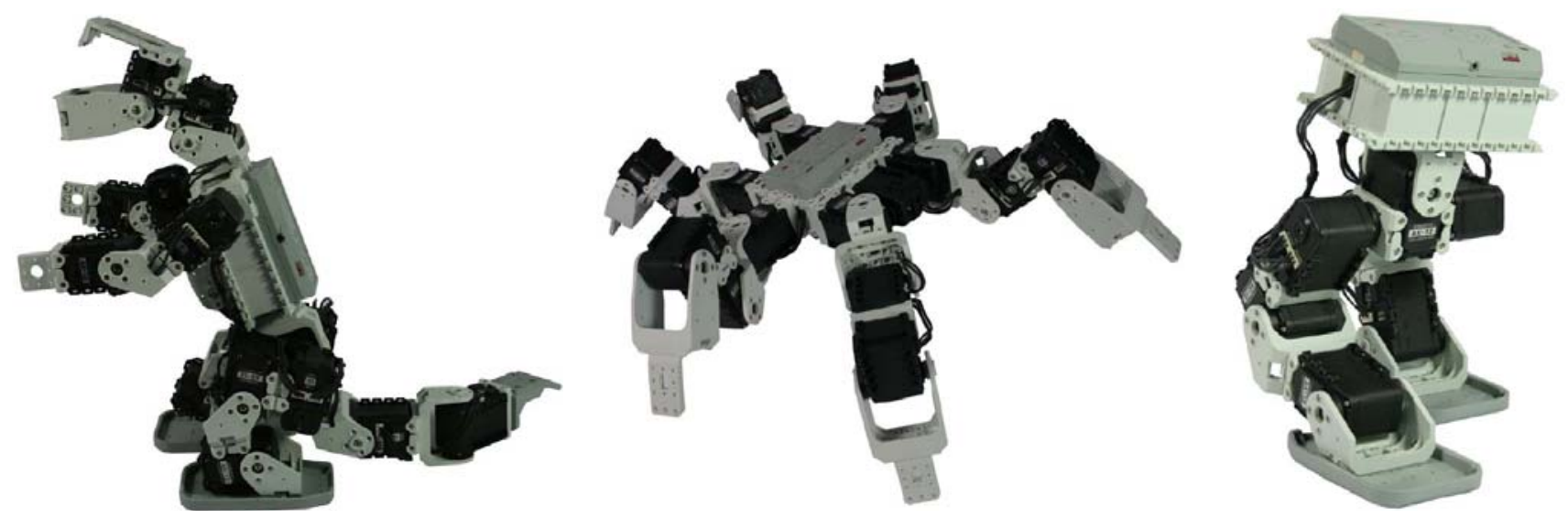

Figura 2.10 b Prototipos de Robots avanzados Bioloid

Entre los mini robots aplicados para la investigación en sistemas autónomos, especialmente en robótica evolutiva, por parte de universidades e institutos de investigación, se distinguen los robots Khepera [Khepera III, 2010], Figura 2.11 y el robot e-puck [Mondada et al., 2009], Figura 2.12, éste último aplicado durante la experimentación de la presente tesis. Ambos robots cuentan con sus ambientes de simulación.

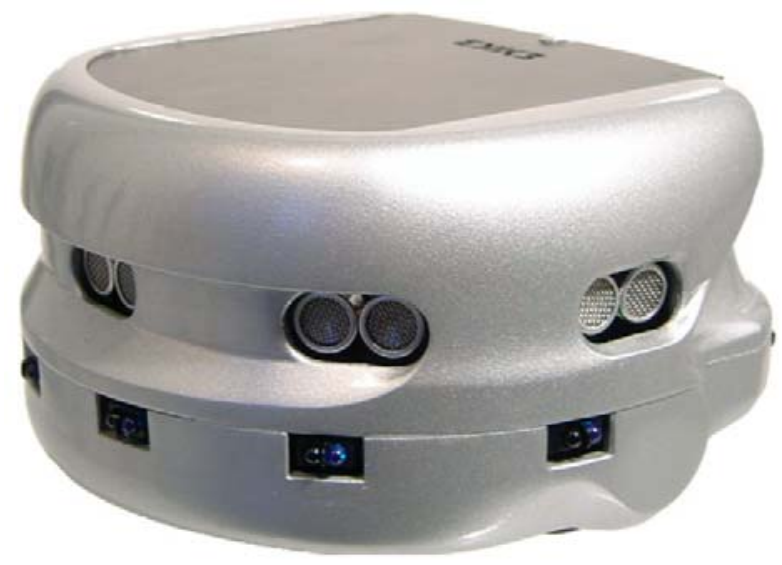

Figura 2.11 Robot Khepera III

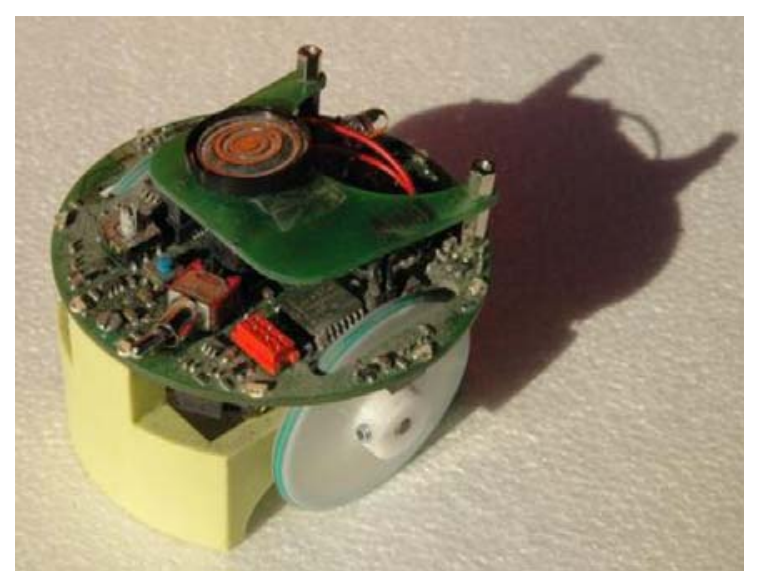

Figura 2.12 Robot e-puck 
Los paradigmas principales en robótica son el jerárquico, el reactivo y el híbrido. El paradigma jerárquico es el más antiguo (décadas de los 60 y 70), este paradigma se denomina también paradigma Percepción, Planificación, Acción. La denominación de jerárquico se debe a que las tres operaciones que acabamos de mencionar se llevan a cabo siempre secuencialmente. Para poder efectuar la planificación, las percepciones deberán haber sido preprocesadas y transformadas en una abstracción del entorno. En este paradigma se considera que el problema fundamental es el de la planificación de tareas en base a un razonamiento simbólico, que requiere de un complicadísima tarea de abstracción para proveer a la capa de planificación con los símbolos de alto nivel, con los que ésta trabaja. Como respuesta al paradigma jerárquico, en los años ochenta se presenta el paradigma reactivo, se basa en correspondencias directas entre percepción y acción, se denomina también paradigma Percepción-Acción, de esta forma los robots se desarrollaron sobre una inteligencia más práctica, ligada a la acción directa a partir de las percepciones, sin un preprocesamiento intensivo de las mismas. Este paradigma presenta unos requerimientos mucho menores para las tareas de percepción, ya que al no haber planificación no resulta necesario abstraer lo percibido transformándolo en símbolos, con lo que se evita la explosión combinatoria.

Todo esto queda resumido en el título de un famoso artículo de Rodney Brooks, apóstol de este paradigma: "Los elefantes no juegan al ajedrez" [Brooks 90]. Con esto, Brooks quiere decir que un animal, como el elefante de su ejemplo, no necesita llevar a cabo razonamientos simbólicos de alto nivel para sobrevivir en su entorno. Lo realmente imprescindible es que el animal disponga de una manera de percibir su entorno y actuar sobre el mismo reactivamente, sin llevar a cabo un razonamiento intensivo. Rodney Brooks [Brooks, 1986; 1987; 1990; 1991a; 1991b], propone la arquitectura subsumida, donde el módulo de acción trabaja en base a entradas subsimbólicas y a partir de ellas genera un comportamiento, las acciones primarias o "actos reflejos", como el de evitar los obstáculos. Esta arquitectura interconecta comportamientos que reciben información de los sensores y pueden actuar sobre los actuadores. Los comportamientos se conectan mediante una red de inhibiciones de forma que los comportamientos de un determinado nivel pueden inhibir a comportamientos de niveles inferiores.

Una vez que el robot consigue manejarse y es capaz de llevar a cabo tareas rudimentarias, una progresión natural nos lleva a intentar conseguir comportamientos más complejos. El paradigma reactivo no permite conseguir esto. Por ello resulta necesario dar un paso más y buscar una manera de conseguir ese aumento de capacidades en los robots.

El módulo de acción trabaja en base a estas entradas subsimbólicas y a partir de ellas genera un comportamiento. Este módulo suele dividirse en varios niveles que se encargan de tareas de distinta prioridad. La acción de "evitar obstáculos" suele ser la de mayor prioridad. Por encima de esta 
acción se sitúan las acciones más abstractas, relacionadas con los objetivos finales del robot, pero que tienen menor prioridad comparadas con evitar obstáculos. A pesar de su mayor sencillez, o precisamente debido a ella, los robots construidos empleando este paradigma sólo pueden emplearse para llevar a cabo tareas moderadamente sencillas, y que no implican razonamientos complejos. De hecho, algunos de los mayores éxitos de la robótica hasta el momento fueron desarrollados siguiendo el paradigma percepción-acción. Por ejemplo, el Mars Explorer, que aunque en parte era teleoperado también contaba con cierta dosis de autonomía desarrollada siguiendo el paradigma percepción- acción.

El razonamiento abstracto no es la prioridad en un robot autónomo, éste requiere contar con cierta inteligencia práctica que le permita sobrevivir y manejarse en su entorno.

El paradigma hibrido es el llamado Planificación, Percepción, Acción. Surge como la unión de ambos paradigmas en la búsqueda de un compromiso entre las tareas deliberativas y las reactivas. En este caso el robot está compuesto, por un lado, de una cadena deliberativa típica (Percepción Planificación Acción) y por otro lado de un modelo reactivo (Percepción Acción). En el proceso deliberativo del robot, se lleva a cabo la planificación de alto nivel, reduciendo la abstracción de las percepciones del paradigma jerárquico, a través de la identificación de los comportamientos que adopta el robot, los cuales se realizarán a través de la cadena reactiva.

En este modelo el robot planifica cómo descomponer una tarea en subtareas y elige cuáles son los comportamientos más adecuados para cumplir con esas tareas. En ese momento dichos comportamientos empiezan a ejecutarse a través del paradigma reactivo. En este caso las percepciones también se ponen a disposición del módulo de planificación.

El desarrollo de un robot no sólo debe observar un paradigma desde un punto de vista abstracto sino que para su implementación debe responder a una arquitectura que esté basada en los principios del paradigma escogido, y programar los comportamientos deseados del robot sobre esa arquitectura.

Para el desarrollo de un robot autónomo bajo la arquitectura de subsunción se debe elaborar un conjunto importante de reglas que se incorporan para su autonomía, esto representa un esfuerzo similar al planteado en las aplicaciones de la IA simbólica, en realidad no se cuenta con una aproximación correcta y más aún, ni siquiera podemos decir que "una mezcla de las dos" sea suficiente para solucionar este tipo de problemas, sobre todo en el aprendizaje, y más concretamente, en el aprendizaje y la creación de símbolos a partir de entradas sub-simbólicas.

Resumiendo, los sistemas de robots con control deliberativo dependen fuertemente de la calidad de la representación de su entorno (sistemas simbólicos) en su base de conocimiento, generando una respuesta más lenta, con mayor capacidad de predicción que aquellos robots reactivos en razón a 
que éstos conservan una independencia del entorno, lo que les permite brindar respuestas en tiempo real.

El problema de la robótica basada en comportamientos es que generar mecanismos que relacionan sensores y actuadores para llegar a un nivel de coordinación capaz de generar comportamiento autónomo en el entorno real no es fácil. [Husbands et al, 1994].En este orden se trabajan nuevas arquitecturas evolutivas, tras la búsqueda de soluciones que permitan un diseño automático de sistemas de robots autónomos, es decir esquemas que escapan de la intuición o competencia del diseñador humano, alejándonos del esquema puramente reactivo, a fin que los robots puedan sobrevivir en los entornos en los que se encuentran, siempre con la menor intervención humana posible. Dave Cliff y colegas [Cliff et al, 1992], utilizan esta nueva aproximación, que toma el nombre robótica evolutiva, se cambia el punto de vista y, en vez de decir cómo van a ser generados los comportamientos adaptativos, se pasa a decir ahora qué comportamientos van a ser generados.

En esta aproximación cuando un comportamiento evoluciona, la solución más adecuada surge de la evaluación del robot real en una variedad de entornos representativos en los que el robot actuará. La robótica evolutiva trata de obtener de modo automático tanto los niveles de comportamiento como la interrelación entre ellos.

Darío Floreano y Francesco Mondada (1998), investigadores del grupo de Lausanne, y al referirse a la vida artificial parafraseando a Chris Langton, “desde la perspectiva de vida artificial, la investigación en robótica evolutiva explora la vida tal como es y la vida tal como podría ser”. A diferencia de la vida artificial, la robótica evolutiva, impone que los sistemas obtenidos mediante evolución funcionen correctamente en un entorno real. [Floreano y Mondada, 1998].

Marvin Minsky, lleva años abogando por una nueva teoría de la mente, descrita en su libro "Society of mind" [Minsky, 1986]. Dicha teoría tiene como objetivo explicar el funcionamiento de la mente humana y del sentido común, y para ello subdivide la mente misma en un conjunto de agentes que cooperan entre sí. Esta teoría llevada a la práctica podría conducirnos algo más cerca del objetivo de lograr robots verdaderamente autónomos.

Los robots autónomos deben aprender de su propio entorno, y además, aprender mientras se encuentran inmersos en dicho entorno. Este método se denomina aprendizaje por refuerzo, surge por un lado y conceptualmente, de una rama de estudios de psicología experimental, que puede remontarse a las experiencias de Ivan Petróvich Pavlov con el refuerzo condicionado, [Pavlov, 1928].

El aprendizaje por refuerzo es el problema de conseguir que un robot actúe en un entorno de manera que maximice la recompensa que obtiene por sus acciones. Cada vez que el robot ejecuta una acción, recibe un valor de recompensa. Estas recompensas no tienen porqué estar asociadas 
directamente con la última acción ejecutada, sino que pueden ser consecuencia de acciones anteriores llevadas a cabo por el robot. La suma de la recompensa se denomina "retorno". El objetivo final del aprendizaje por refuerzo es conseguir un robot que maximice el retorno a largo plazo.

\subsection{PROPUESTAS DE SISTEMAS INTELIGENTES PARA ROBOTS AUTÓNOMOS}

En esta sección se presentan los trabajos desarrollados sobre Sistema Inteligente Autónomo (sección 2.2.1), Sistema Inteligente Autónomo con Aprendizaje Basado en Formación y Ponderación de Teorías (sección 2.2.2) y Sistema Inteligente Autónomo con Intercambio de Teorías (sección 2.2.3).

\subsubsection{SISTEMA INTELIGENTE AUTÓNOMO}

Uno de los puntos involucrados en el problema de la modelización de Sistemas Inteligentes [Fritz, 1984; 1992; Fritz et al; 1989] es lograr una base axiomática que describa formalmente los fenómenos que tienen lugar en este tipo de sistemas. Esta descripción formal apunta a proporcionar un instrumento para clasificar, medir y calcular en el campo de la inteligencia. Formalmente, no es relevante la clasificación en natural o artificial. El propósito del trabajo es abstraer los rasgos comunes, si los hay, de todos los procesos inteligentes. Luego, clasificar como inteligentes a los sistemas capaces de dar lugar a procesos inteligentes.

Un rasgo comúnmente asociado con la inteligencia es la capacidad de adquirir nuevos conocimientos. Esto se manifiesta en los procesos de aprendizaje, que aceptan ser descritos en términos de asimilación e incorporación de información extraída del contexto. Una forma de adquirir conocimiento nuevo es el llamado "método del ensayo-error"; esta técnica permite descubrir leyes simples cuya verdad se deduce a partir de la experiencia. En la teoría presentada por los autores citados, esta adquisición de conocimiento está centrada alrededor de la asimilación de experiencias, siendo las leyes empíricas las unidades de experiencia. El esquema del sistema inteligente autónomo (figura 2.13.) permite visualizar la interacción entre sus distintos componentes. 


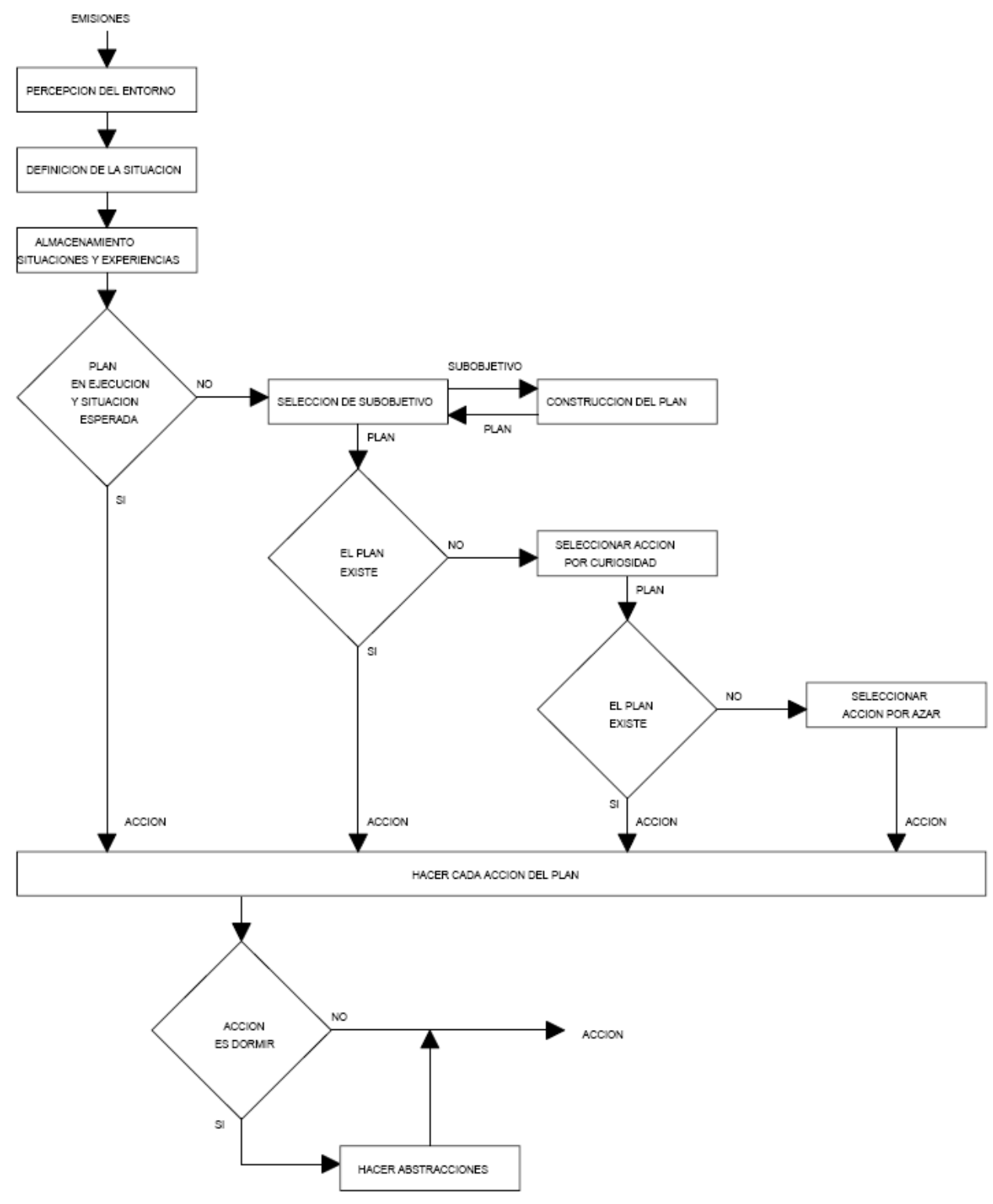

Figura 2.13 Esquema del sistema inteligente autónomo

Los Sistemas Inteligentes tienen objetivos, que consisten en acceder a una situación que les conviene. Están capacitados además para elegir sus acciones según tales objetivos y son capaces de aprender qué acción es útil efectuar en cada situación en relación a los mismos. La situación es el conjunto de los rasgos esenciales del estado de las cosas, en relación a los objetivos del sistema. Se elabora sobre la base de todas las entradas sensoriales del momento y sobre su conceptualización. Sobre la base de esta modelización se elige cada acción. Para lograr sus objetivos, los Sistemas Inteligentes actúan, y para poder elegir acciones adecuadas deben contar con una memoria en la cual archivan sus experiencias.

Una unidad de experiencia se compone (por lo menos) de la situación vivida, la acción realizada, la situación resultante y el hecho de que las consecuencias de la acción hayan sido beneficiosas o no para lograr el objetivo. Este beneficio, o la falta del mismo, se traduce en utilidad resultante. La 
decisión sobre la acción que conviene realizar se toma en función de las experiencias acumuladas, si es que están en relación con las circunstancias actuales (pueden ser tanto experiencias directas del sistema como también experiencias conocidas a través de lo que se verificó en otros). Si en lo archivado como experiencia tal relación existe y la acción elegida en aquél entonces resultó beneficiosa, habrá una tendencia de elegir nuevamente esa misma acción o a optar por alternativas distintas si la acción resultó perjudicial.

Cuando se trata de una situación nueva, esto es, no existe experiencia previa de la misma, se efectúan acciones razonadas guiándose por los resultados obtenidos en actuaciones anteriores, o si no, por intuición, instinto o incluso al azar. Frente a situaciones conocidas, los Sistemas Inteligentes tienden a desarrollar una actuación que (por experiencia) consideran óptima (no necesariamente es la óptima). Esta tendencia se denomina hábito. Un mal hábito se da cuando el sistema persiste en un cierto actuar aún cuando éste ya no corresponde a la situación.

\subsubsection{SISTEMA INTELIGENTE AUTÓNOMO CON APRENDIZAJE BASADO EN FORMACIÓN Y PONDERACIÓN DE TEORÍAS}

El sistema puede ser descrito como un robot de exploración que percibe el entorno a través del sistema sensor, registra la situación, y arma una teoría local con la situación previa y la acción ejecutada [Garcia-Martínez y Borrajo; 1997; 2000]. Si la teoría local es igual a alguna teoría registrada, ésta se refuerza. Si es similar, se registra la teoría local, se pondera y se crean teorías mutantes. Si existe un plan en ejecución, se verifica que la situación obtenida sea la esperada; si no ocurre esto, se aborta el plan y el control es devuelto al planificador. Si no existe un plan en ejecución, el planificador genera uno, lo envía al ponderador y mediante un criterio heurístico (Optimizar las acciones a ejecutar por el SAR, sobre la base del umbral adoptado para la ponderación del plan), se determina si el plan es aceptable. En caso afirmativo, se pasa el control al controlador de planes en ejecución, cuya función es determinar la siguiente acción a ser ejecutada y establecer si las situaciones obtenidas son las situaciones esperadas. Si el plan no es confiable, se genera un nuevo plan. La arquitectura del sistema puede ser presentada mediante el esquema que se presenta en la Figura 2.14 


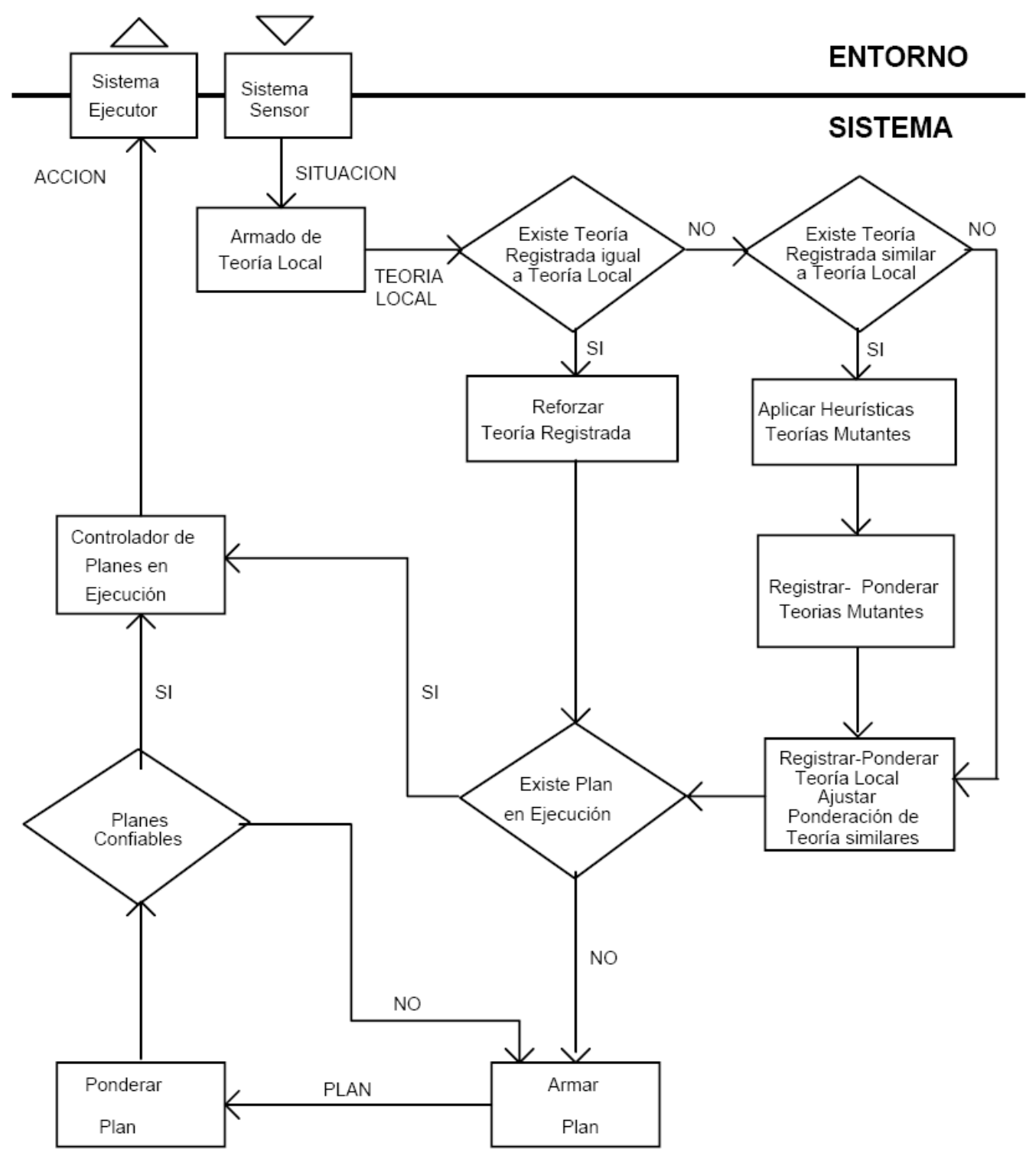

Figura 2.14 Esquema del sistema inteligente autónomo con aprendizaje basado en formación y ponderación de teorías

\subsubsection{SISTEMA INTELIGENTE AUTÓNOMO CON APRENDIZAJE BASADO EN INTERCAMBIO DE TEORÍAS}

Esta arquitectura de sistema inteligente autónomo percibe el entorno a través del sistema sensor. Antes de realizar cualquier acción se pregunta si es necesario intercambiar operadores con otro sistema inteligente autónomo [García-Martínez et al., 2006]. Este proceso se lleva a cabo mediante un módulo de intercambio de operadores. Luego, se registra la situación percibida del entorno, y arma una teoría local con la situación previa y la acción ejecutada. Se presenta la arquitectura del sistema donde se observa su interacción con el entorno, y el funcionamiento general de los módulos de aprendizaje, planificación, ponderación, control e intercambio de operadores en la Figura 2.15. 


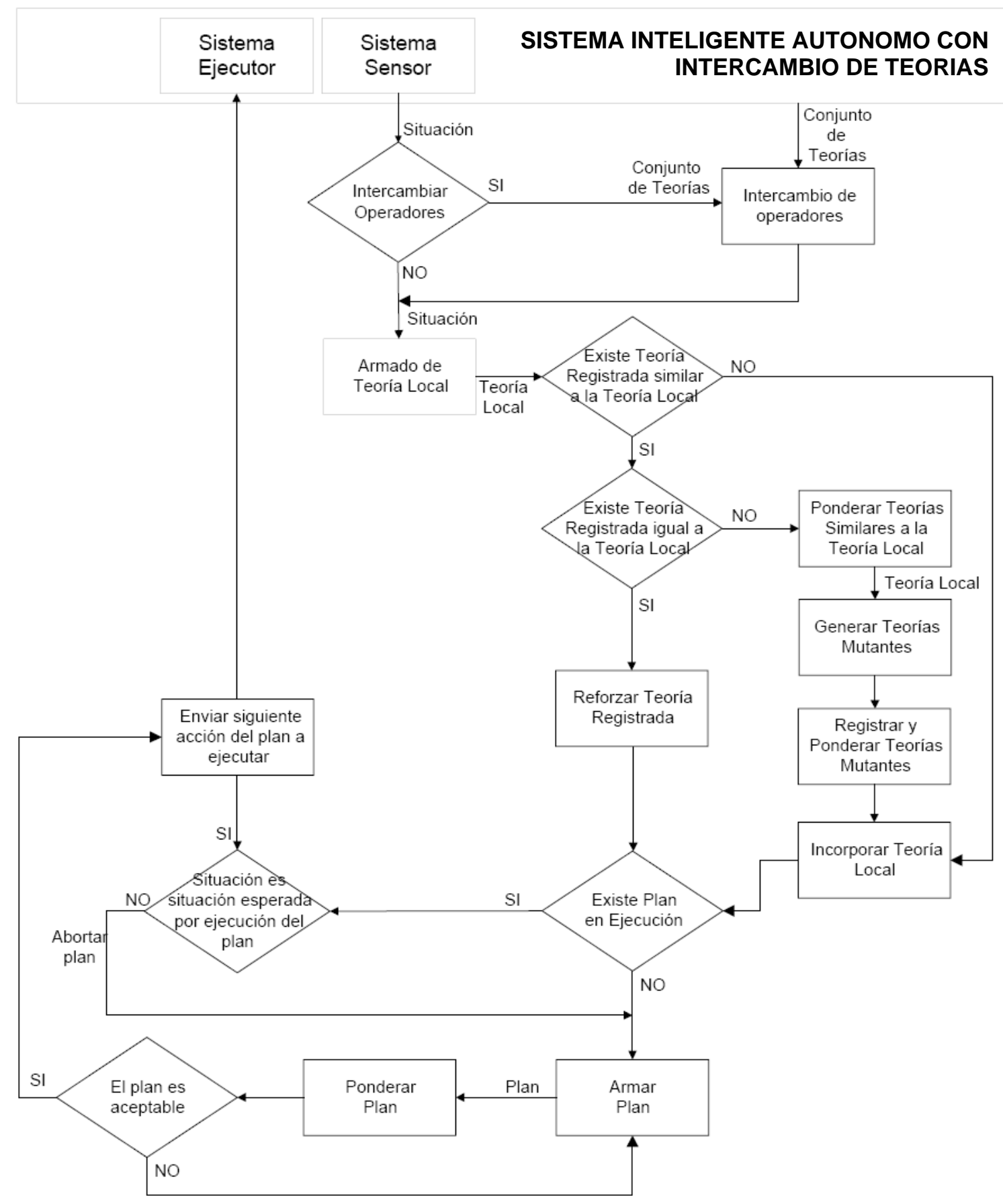

Figura 2.14 Esquema del sistema inteligente autónomo con aprendizaje basado en formación y ponderación de teorías

Si la teoría local es igual a alguna teoría registrada, ésta se refuerza, si no existe una teoría igual pero existen similares, éstas se ponderan y se generan teorías mutantes las cuales son registradas y ponderadas de la misma forma. Por último (luego del proceso de generar teoría mutantes o si no existen teorías similares) se incorpora la teoría local y se pasa el control al subsistema controlador.

Si existe un plan en ejecución, se verifica que la situación obtenida sea la esperada; si no ocurre esto, se aborta el plan y el control es devuelto al planificador. Si no existe un plan en ejecución, el planificador genera uno, lo envía al ponderador y mediante un criterio heurístico, se determina si el plan es 
aceptable. En caso afirmativo, el controlador de planes en ejecución determina la siguiente acción a ser ejecutada, la cual es pasada a la plataforma para que ésta la aplique en el entorno.

\subsection{ROBOTS OPERANDO EN AMBIENTES AÉREOS, MARÍTIMOS Y TERRESTRES}

El desarrollo de estos robots autónomos implica la intervención de diversas áreas desde la informática, la mecatrónica, biología, etología, zoología, anatomía entre otras.

Los sistemas autónomos de robots móviles se desplazan por su entorno, utilizando ruedas, orugas, piernas, patas, aletas, alas, o mecanismos similares a los enunciados. Estos sistemas de robot pueden cumplir diversas tareas desde asistir al personal en un hospital, movilizar y ubicar contenedores, ayudar en zonas de catástrofe en el rescate de personas atrapadas, cumplir funciones de vigilancia y reconocimiento en un área de operaciones, explorar otros planetas, entre otras varias tareas que asistan al ser humano. En la actualidad se categorizan a diversos sistemas, como no tripulados, y en función del entorno de operación se reconocen como vehículos terrestres sin tripulación (unmanned land vehicle, ULV), vehículos aéreos sin tripulación (unmanned land vehicle, UAV), vehículos marinos sin tripulación (unmanned water vehicle, UWV). Estos sistemas son capaces de realizar tareas complejas como perseguir objetos en movimiento, aterrizar en base a sus sensores y otras actividades con poca o sin ayuda humana, lo que los constituye en sistemas no plenamente autónomos.

Si bien se considera generalmente como vehículo autónomo a cualquier vehículo no tripulado con cierto nivel de autonomía integrada (ello incluye desde vehículos teleoperados hasta vehículos totalmente inteligentes). La diversidad actual de robots es muy amplia, en este orden se detallan en las subsecciones siguientes algunos ejemplos de robots que actúan en un ambiente aéreo, como lo son los robots voladores (2.3.1), en un ambiente acuático, como lo son los robots pez (2.3.2), en ambiente terrestres (2.3.3) como lo son los robots ofídeos y mini robots. Como así también, los futuros robots exploradores, que operarán en ambientes extraterrestres (2.3.4). Si bien se presentan en estas secciones sistemas de robots autónomos colectivos, es importante tener presente que el trabajo de tesis se orienta al ciclo de vida de aprendizaje y compartición de conocimiento entre robots alcanzado a través de la ejecución de una tarea especifíca y no colectiva.

\subsubsection{ROBOTS VOLADORES}

En el campo experimental se registran hoy diversas experiencias de sistemas autónomos de robots, como las realizadas por. STARMAC, (Stanford Testbed of Autonomous Rotorcraft for Multi- 
Agent) [STARMAC, 2008 ], a través de pequeños robots voladores de forma cuadrada, dotados de cuatro hélices, GPS, sensores de proximidad, los que se mueven en grupo reconociendo el terreno, al detectar el objetivo envían una señal a los demás y en poco tiempo el ambiente se llena de mini robots voladores (figura 2.16). Se comunican entre sí, comparten información y pueden evitar obstáculos y actuar como un equipo tomando decisiones según las circunstancias para cumplir su misión .

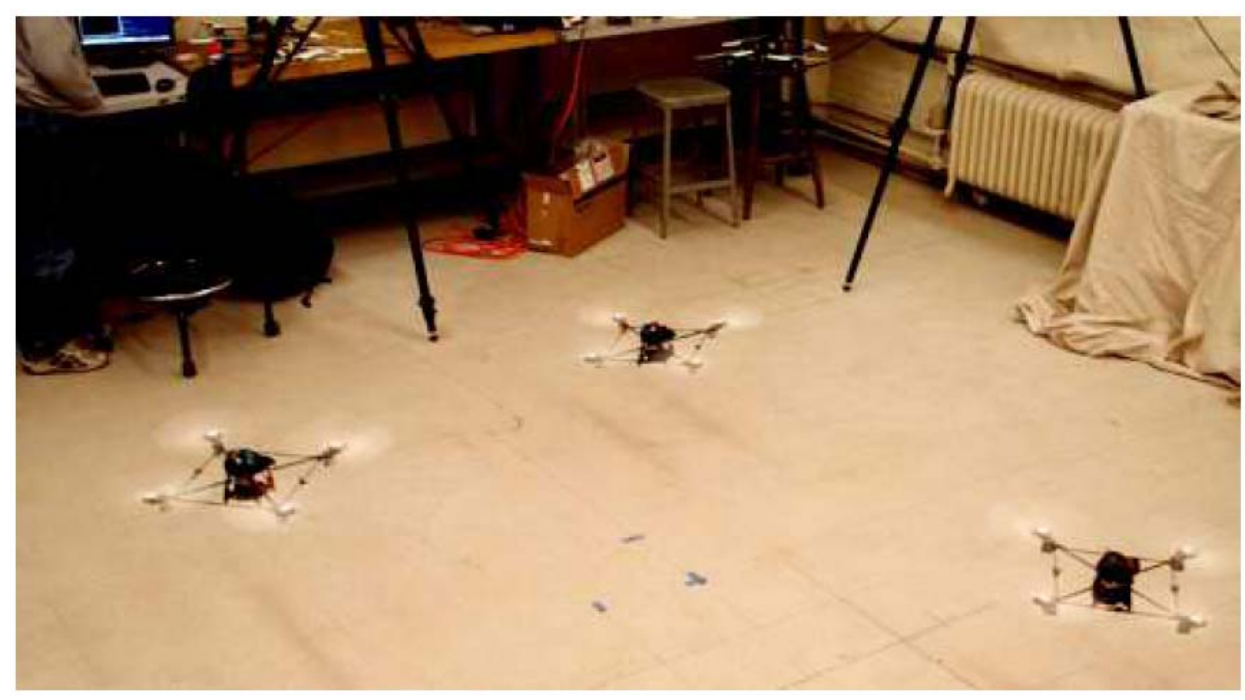

Figura 2.16 Mini robots voladores.

Un vehículo no tripulado (por sus siglas del inglés UAV Unmanned Aerial Vehicle), conocido en castellano por sus siglas como VANT, es un vehículo aéreo autónomo, capaz de volar sin necesidad de piloto humano, gracias a un sistema de pilotaje autónomo. Estas aeronaves poseen sistemas que combinan información procedente de sistemas de posicionamiento como GPS, navegación mediante GIS, servomecanismos, con un tipo de carga útil en función de la misión a desarrollar (sensores de visión nocturna, sensores infrarrojos, radar, etc.).

Entre las aplicaciones de uso civil se destacan: detección de fuego y seguimiento de incendios forestales, detección de pesca ilegal, rescate, vigilancia y control de fronteras, conmutador emergente de comunicaciones, monitorización de autopistas y carreteras, estado del tiempo, monitorización de líneas férreas y eléctricas, operación en ambientes de alta toxicidad química y radiológicos. Entre las aplicaciones de vehículos aéreos de uso militar se destacan: vigilancia y reconocimiento, detección de objetivos, visión en tiempo real del campo de batalla, suministros logísticos, sensores para guerra química y bacteriológica, dispersión de humo para camuflaje, etc.

En la Universidad de Michigan han desarrollado un robot volador [COM-BAT, 2009] que vuela batiendo sus alas en lugar de usar hélices (figura 2.17). Este robot podría recargarse 
energéticamente en el futuro utilizando pequeñas placas solares o sistemas eólicos, lo cual le daría una autonomía en principio casi ilimitada. En principio transportaría sensores, micrófonos y cámaras para realizar labores de vigilancia y reconocimiento, actuando en un enjambre de estos robots voladores.

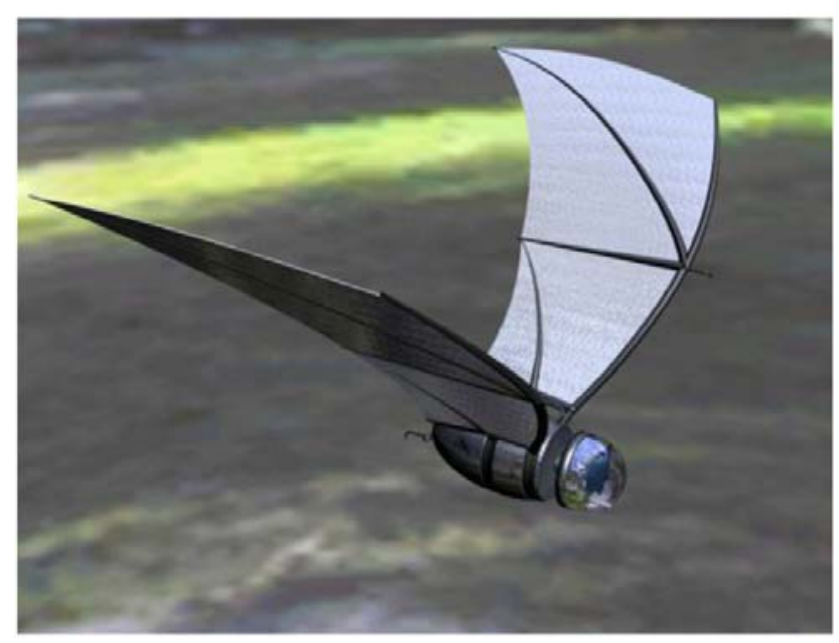

Figura 2.17 Robot volador universidad de Michigan

Existen tareas que un único robot no es capaz de realizar, requiriendo el trabajo en equipo o trabajo colectivo con otros robots. Este trabajo colectivo se basa en la inteligencia de enjambre, la que algunos investigadores la traducen al español como inteligencia colectiva. En el marco del comportamiento colectivo de los sistemas biológicos, particularmente insectos sociales, se realizaron importantes contribuciones en el contexto de comportamiento de hormigas o de enjambre [Dorigo, M., et al, 1999], siendo esta área fuente de inspiración en el contexto de la robótica colectiva. En este marco, los sistemas autónomos de robots realizan tareas colectivas o en conjunto para lograr una meta común. Trabajos precursores en esta área de la robótica, fueron los de Ronald Kube y colaboradores (1994, 2000), los que experimentaron con este fenómeno, realizando el comportamiento de empuje colectivo de una caja luminosa hacia una meta (destino de la caja), indicada por un foco de luz. La caja tiene un peso tal que un solo robot no la podría mover por sí solo. Roderich. Groß y Marco. Dorigo. (2009), simularon el comportamiento de un enjambre de robots destinados al transporte de objetos, a través de la agrupación física de unos con otros para empujar el objeto, organizándose en una estructura física colectiva para transportar el objeto a la locación indicada. 


\subsubsection{ROBOTS ACUÁTICOS}

Entre las aplicaciones de sistemas no tripulados marítimos se encuentran la inspección y mantenimiento preventivo de instalaciones submarinas, cables (fibra óptica submarina, Internet), tuberías (gas, combustible), entre otras aplicaciones.

Rory Doyle, científico investigador en la compañía de ingeniería BMT Group, que desarrolló el robot pez con investigadores de la Universidad de Essex, ha dicho que hay buenas razones para hacer un robot con forma de pez, en lugar de un minisubmarino convencional. "Utilizando un pez robótico estamos partiendo de un diseño creado por cientos de millones de años de evolución que es increíblemente eficiente energéticamente". La eficiencia es algo necesario para garantizar que los robots pez puedan navegar en el entorno submarino durante horas. El destino de estos robots es explorar las mayores profundidades del océano y lugares en los que el entorno es mortal para los seres humanos. El pez robot transmitirá la información a tierra. A diferencia de otros peces robot, que necesitan controles remotos, éste podrá navegar de forma independiente sin ninguna intervención humana.

En el campo experimental se trabaja inspirándose en diseños de la naturaleza, en peces robots nadadores, que se deslizan por el agua de forma tan grácil como sus homólogos biológicos. Estos peces robot autónomos, lo harán todo sin la intervención de los humanos. El grupo de peces robot actuará como un pez orgánico. Los peces robots utilizan aletas y cola en lugar de un propulsor de forma que sean más manejables y produzcan menos arrastre. Estos sistemas autónomos de peces robots maniobran con mayor facilidad en áreas donde los vehículos submarinos tradicionales no pueden llegar. Sería posible usar flotas de los nuevos robots para inspeccionar estructuras sumergidas, tales como la parte inferior del casco de barcos o tuberías de gas y petróleo; también para patrullar por puertos, lagos y ríos, y ayudar a detectar sustancias que contaminan el medio ambiente.

Debido a la robustez del pez robot, resultaría ideal como unidad de exploración y sondeo de larga duración. Sería viable mandar varios de estos a una misión, y debido a su bajo costo, aún cuando regresase sólo un pequeño porcentaje de ellos, no sería una pérdida económica terrible.

Los robots pez no son nuevos. En 1994, los ingenieros del MIT probaron a Robotuna, un pez robot de alrededor de un metro de largo. Pero mientras que Robotuna tenía 2.843 piezas, controladas por seis motores, el nuevo pez robot de la universidad de Essex, tiene menos de treinta centímetros de largo, es propulsado por un solo motor y contiene menos de diez componentes individuales, incluyendo un cuerpo flexible que alberga todos los componentes y los protege del entorno. El 
motor, colocado en la parte central del pez robot, genera un movimiento ondulatorio que se desplaza a lo largo del cuerpo flexible, propulsándolo hacia adelante.

Por sus características, estos nuevos peces robots son más maniobrables y más capaces de imitar el movimiento natatorio de peces reales, los cuales se autopropulsan mediante la contracción de los músculos a cada uno de los lados de sus cuerpos, generando un movimiento ondulatorio que viaja desde la cabeza hasta la cola. Los primeros prototipos de robot pez desarrollados por el equipo liderado por Huosheng $\mathrm{Hu}$ de la Universidad de Essex [Universidad de Essex, 2010], imitan la técnica natatoria de las truchas. Las últimas versiones del robot pez, de cerca de 20 centímetros de longitud, nadan como los atunes, los cuales están adaptados para nadar a mayores velocidades y distancias. Pese a ello, por ahora estos peces robóticos son todavía bastante más lentos que sus homólogos biológicos, aunque más veloces que las generaciones anteriores de robots pez [Huosheng Hu et al., 2006].

El robot, con aspecto de carpa, imita el movimiento de un pez real. Está equipado con sensores químicos para localizar contaminantes potencialmente peligrosos, como filtraciones de barcos o de tuberías subterráneas. Diversas universidades se encuentran desarrollando proyectos de pez robot entre estas la Universidad de Essex (figura 2.18 y 2.19), el MIT, la universidad de Osaka en Japón, otros esfuerzos se realizan en España con aplicaciones futuras del pez robot en la vigilancia medioambiental de puertos.

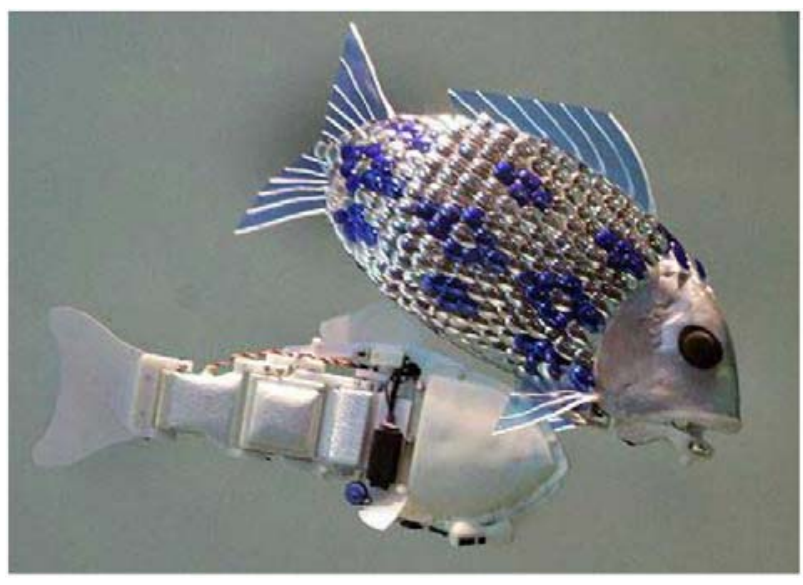

Figura 2.18 Pez Robot Universidad de Essex

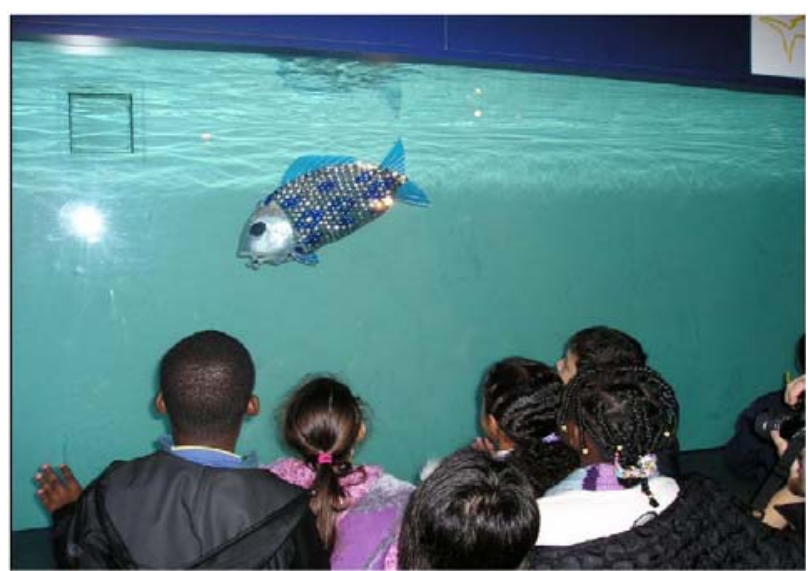

Figura 2.19 Pez Robot acuario de Londres

\subsubsection{ROBOTS TERRESTRES}

Los robots autónomos terrestres contribuyen con un importante número de aplicaciones, entre las más destacadas se encuentran la actuación en áreas peligrosas, la ejecución de misiones de reconocimiento (túneles, alcantarillas, edificios), observación remota en áreas restringidas con 
situaciones peligrosas (humo, calor, radiaciones), detección de explosivos, detección de intrusos, inspección de tanques de almacenamiento de gas, de tuberías, estructuras subterráneas, contribuir con el rescate de víctimas humanas atrapadas en escombros, entre otras aplicaciones que contribuyen y asisten al ser humano.

Se distinguen distintos tipos de robots móviles terrestres entre éstos podemos citar los robots con ruedas, orugas, bípedos, cuadrúpedos, hexápodos, serpientes entre otros. Si bien el propósito de este capítulo no es detallar ejemplos de cada uno, se discutirán sólo algunos de ellos en razón a la multiplicidad de tareas que éstos pueden desarrollar.

Esfuerzos importantes en materia de robots se centran en el desarrollo de diversos robots ofidios, en razón a que las serpientes son capaces de alcanzar lugares difícilmente accesibles para el hombre al ingresar éstas dentro de espacios muy pequeños. Gracias a su capacidad de arrastrarse y contornearse con enorme flexibilidad, éstos resultan muy útiles como robots al tener la capacidad de avanzar a través de las ruinas de edificios destruidos por un desastre natural como un terremoto, lo que permitiría la búsqueda de objetos, o lo que es más importante, encontrar a gente sepultada entre los escombros. También pueden aplicarse en tareas de inspecciones de alto riesgo, vigilancia y reconocimiento de campo.

Entre los robots serpientes encontramos a OmniTread, [Wright, C., et al ,2007] el que fue desarrollado en la facultad de Ingeniería de la Universidad de Michigan, (figura 2.20 a). Puede moverse rodando como un tronco, o alzando su cabeza o cola y empujándose hacia delante. El diseño único de sus superficies de apoyo evita que el robot se atasque en terrenos escabrosos. El ofidio robot está dividido en cinco segmentos conectados por el medio con una especie de columna vertebral que dirige los apoyos de todos los segmentos. Unos fuelles en las uniones que conectan las secciones se inflan y desinflan para hacer que el robot gire o eleve los segmentos. Los fuelles brindan la torsión suficiente para que el OmniTread pueda levantar los dos segmentos delanteros o traseros al escalar objetos.

Otro robot ofidio (serpiente robot) es el Moira 2 [Haraguchi, R., et al, 2005], desarrollado en la Universidad de Kobe Japón (figura 2.20 b). La Universidad Carnegie Mellon también está diseñando un robot con forma de serpiente para actuar como asistente médico capaz de llegar hasta una persona herida. El hecho de que tenga forma de serpiente le ayuda a desplazarse casi por cualquier sitio y llegar hasta personas situadas en zonas de difícil acceso y llevar hasta ellos materiales diversos de primeros auxilios.

En otro orden en materia de mini robots se distinguen el proyecto de I-SWARM (Intelligent SmallWorld Autonomous Robots for Micro-manipulation),[Seyfried, J., et al, 2005], [I-SWARM ,2009]. Este tipo de desarrollo de robots convoca a varios países que se interesan como Suecia, España, 
Alemania, Suiza e Italia, tras la idea de conformar procesos de miniaturización a fin de desarrollar máquinas cada vez más complejas y pequeñas, resolviendo diferentes tipos de problemas. Este proyecto busca crear robots pequeños y autónomos los que podrían ser utilizados en tareas tales como vigilancia y reconocimiento, medicina, limpieza, labores industriales de micro manufactura, entre otras. Para crear estos robots es necesario utilizar técnicas avanzadas que permiten construir el robot completo en una única placa de circuitos.

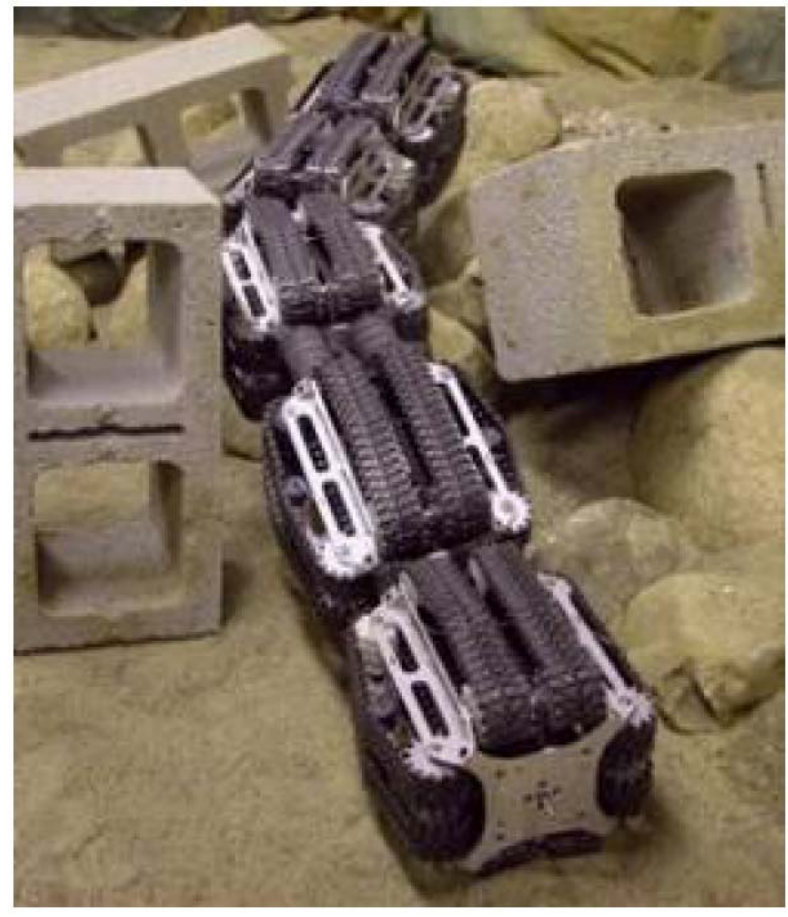

Figura 2.20.a OmniTread

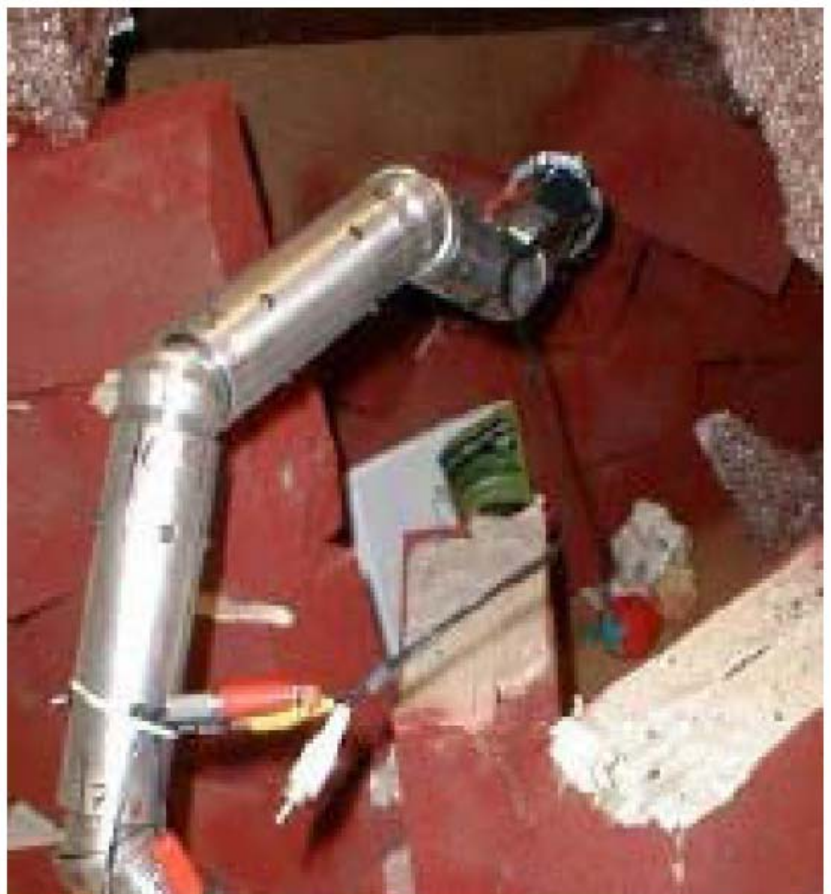

Figura 2.20.b Moira 2

Además se requiere una autonomía, asegurada por medio de la energía colectada a través de una celda solar que sería capaz de alimentar las patas del robot, el sensor que permite identificar objetos y otros robots, además del sistema de comunicación infrarroja. Ver Figura 2.21.

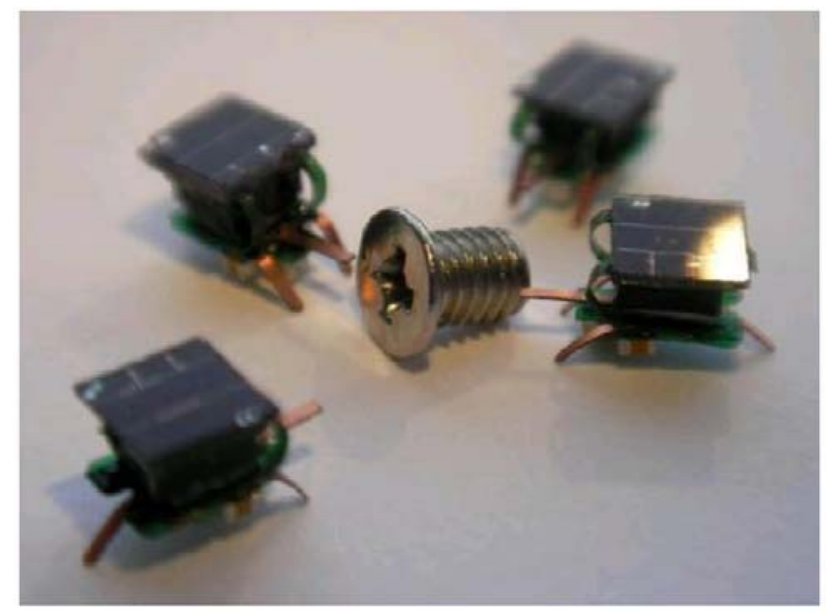

Figura 2.21. I-SWARM 


\subsubsection{ROBOTS DE EXPLORACIÓN EXTRATERRESTRE.}

La aplicación de robots en la exploración espacial, se realiza bajo las formas de teleoperación, donde se ordena a un vehículo explorador que realice ciertas tareas, y luego esperan a que éstas se realicen, con un alto grado de riesgo para el robot, si bien éste tiene preprogramada reglas para su conservación como por ejemplo evitar pendientes pronunciadas, conservar su estado de batería entre otras, el cambio de planes de acción del robot está limitado.

Sin embargo el paradigma de las exploraciones llevadas a cabo por robots en otros planetas está a punto de cambiar, [Fink, W., Tarbell, M. 2009]. Según Fink (ver Figura 2.22), en lugar de enviar un único vehículo espacial robótico dirigido desde la Tierra a planetas como Marte, en el futuro se enviarán múltiples robots de bajo coste, que se auto-dirigirán o que dirigirán a otros robots, los que se ubicarán en diversas localizaciones. El control de las misiones no se llevará a cabo desde la Tierra, sino que lo tendrán múltiples robots que trabajarán en conjunto, compartiendo entre ellos la información que cada uno de ellos recopile, de manera casi simultánea. Este tipo de exploraciones será aplicada algún día en misiones a Titán (satélite más grande del planeta Saturno), a Marte o a otros planetas.

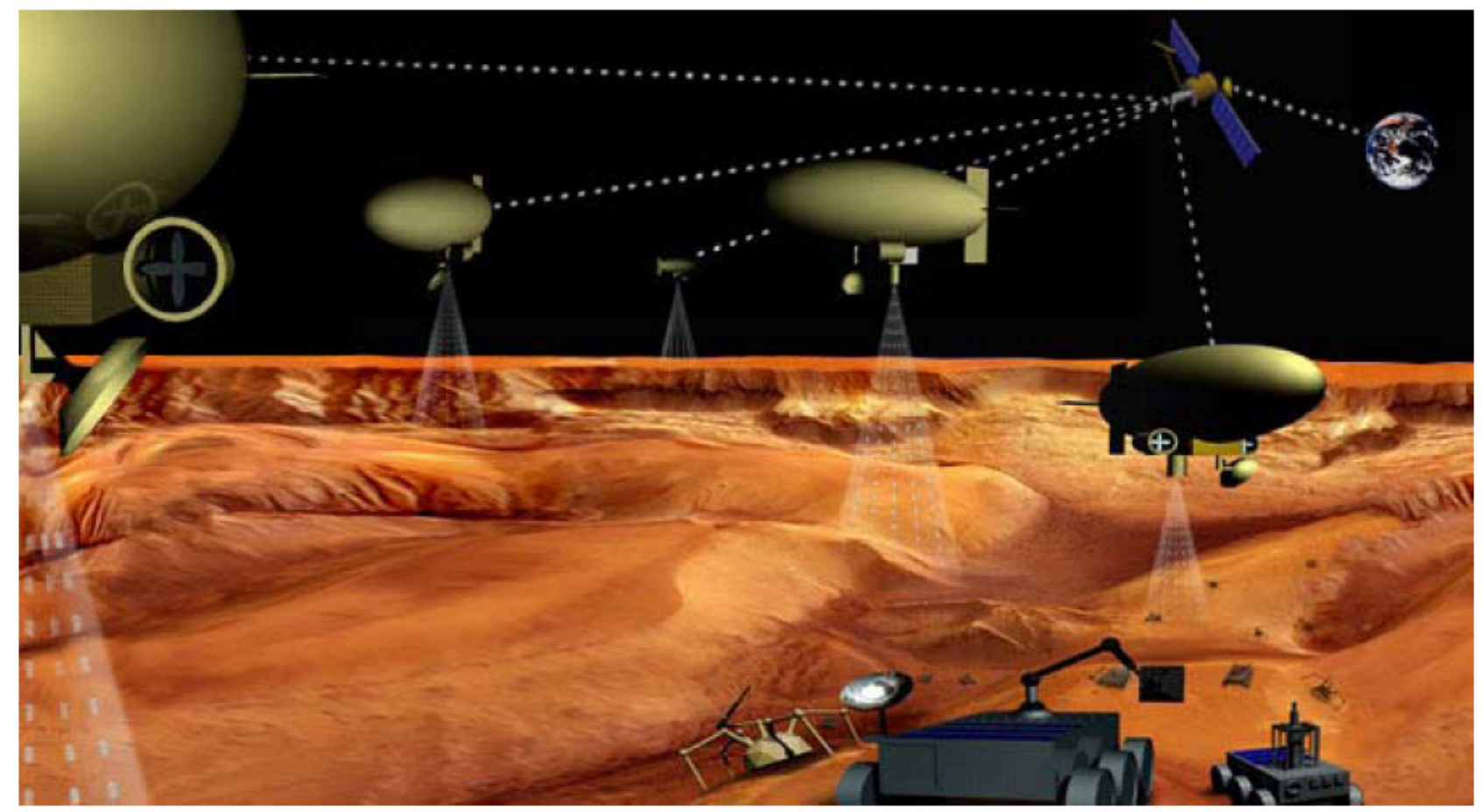

Figura 2.22. Robots de exploración autónomos JPL Nasa-Caltech 


\section{DESCRIPCIÓN DEL PROBLEMA}

En este capítulo se presenta: una introducción a la importancia del problema en el contexto de los sistemas autónomos (sección 3.1), la necesidad de contar con un ciclo de vida de aprendizaje de sistemas autónomos de robots (sección 3.2), la conveniencia de extender el trabajo de autores anteriores considerando la colaboración entre sistemas autónomos de robots ( sección 3.3), la importancia de contar con un modelo y arquitectura para múltiples sistemas autónomos de robots (sección 3.4), la experimentación de estadísticas de aprendizaje y métricas asociadas a la actuación del sistema autónomo de robots en relación a los métodos aplicados en sus arquitecturas (sección 3.5).

\subsection{INTRODUCCIÓN}

Los sistemas autónomos de robots deben ser capaces de generar teorías de cómo sus ambientes reaccionan a sus acciones, y cómo las acciones afectan al ambiente. Usualmente estas teorías de aprendizaje son parciales, incompletas e incorrectas, pero pueden ser usadas para modificar esas teorías o para crear nuevas y se enriquecen con la compartición de los conocimientos que los Sistemas Autónomos de Robots (SARs) cuentan en sus bases de conocimiento de teorías.

Según Fritz (1989) la inteligencia es la capacidad de adquirir nuevos conocimientos. Esto se manifiesta en los procesos de aprendizaje, que aceptan ser descritos en términos de asimilación e incorporación de información extraída del contexto. Una forma de adquirir conocimiento nuevo es el llamado "método del ensayo-error"; esta técnica permite descubrir leyes simples cuya verdad se deduce a partir de la experiencia.

La adquisición de conocimiento está centrada alrededor de la asimilación de experiencias, siendo las leyes empíricas las unidades de experiencia. De esta forma, un sistema inteligente autónomo puede definirse [García Martínez y Borrajo Millán, 1997], como aquél capaz de descubrir y registrar si una acción efectuada sobre una situación dada fue beneficiosa para lograr su objetivo.

Los Sistemas Inteligentes tienen objetivos, que consisten en acceder a una situación que les conviene. Están capacitados además para elegir sus acciones en función de sus objetivos y son capaces de aprender qué acción es útil efectuar en cada situación en relación a los objetivos y su situación en el ambiente de operación. 
La situación es el conjunto de los rasgos esenciales del estado de las cosas, en relación a los objetivos del sistema. Se elabora sobre la base de todas las entradas sensoriales del momento y sobre su conceptualización. Sobre la base de esta modelización se elige cada acción. Para lograr sus objetivos, los sistemas autónomos de robots en su actuación deben poder elegir acciones adecuadas, para lo cual deben contar con una memoria o base de conocimientos donde archivan sus experiencias

En este contexto una unidad de experiencia como se planteó en el capítulo anterior, se compone (por lo menos) de la situación vivida, la acción realizada, la situación resultante y el hecho de que las consecuencias de la acción hayan sido beneficiosas o no para lograr el objetivo. Este beneficio, o la falta del mismo, se traduce en utilidad resultante.

La decisión sobre la acción que conviene realizar se toma en función de las experiencias acumuladas, si es que están en relación con las circunstancias actuales (pueden ser tanto experiencias directas del sistema como también experiencias conocidas a través de lo que se verificó en otros).

Si en lo archivado como experiencia tal relación existe y la acción elegida en aquél entonces resultó beneficiosa, habrá una tendencia de elegir nuevamente esa misma acción o a optar por alternativas distintas si la acción resultó perjudicial.

Para aprender en un mundo real, un sistema necesita formular una teoría acerca de los efectos de las acciones sobre su entorno. Necesita construir planes, monitorizar la ejecución de esos planes para detectar expectativas violadas y diagnosticar y rectificar errores que los datos inconsistentes revelen.

En este orden los trabajos anteriores presentaron constantes mejoras en términos de rendimiento de un sistemas autónomo de robot (SAR), se distinguen las contribuciones en la materia realizadas por Fritz, W y colegas [1989], el que considera un sistema autónomo inteligente representado por un robot, con un planificador clásico o neutro (SARp neutro), al que García Martínez y Borrajo [1997; 2000], le incorpora la ponderación de planes y mutación de teorías similares (SARp- PM), luego Maceri y García Martínez [2001] ,García Martínez y colaboradores [2006], incorporan el intercambio de teorías [SARp- PMI]. Sin embargo resulta propicio explorar los mecanismos que mejoren la compartición de conocimiento en orden a la colaboración de un SAR que se encuentra en un estado de evolución superior a su SAR receptor, en este orden las teorías almacenadas por los sistemas autónomos propuestos por los autores anteriores (los que recogen la experiencia de actuación de estos), no distinguen el estado de evolución de los SARs y sus niveles de actuación diferenciados por el estado del SAR, como así tampoco escenarios calificados asociados a sus estados. Estos sistemas se encuentran sin un marco que contenga sus actuaciones y les permita la 
compartición de conocimientos entre sistemas que se encuentren en un mismo estado de evolución y entre sistemas que se encuentren en aptitud de brindar colaboración a otros sistemas receptores.

\subsection{SISTEMA AUTÓNOMO DE ROBOT}

El desarrollo de software para Sistemas Autónomos de Robots (SARs), plantea la necesidad de distinguir los niveles de actuación y evolución, producto de la interacción de los SARs con el ambiente y otros SARs, a través de un modelo que caracterice la evolución de estos, en el marco de un modelo de ciclo de vida.

En este orden para el modelo de ciclo de vida de aprendizaje de un SAR, se deberá explorar la definición de regiones y tareas asociadas a este ciclo, considerando las adecuaciones de este ciclo, observando que los sistemas autónomos de robots construyen conocimiento a través del descubrimiento de teorías de actuación que éste genera en su ambiente de operación.

Se deben considerar además de los conceptos de ciclo de vida, los de arquitecturas y modelos que caracterizarán al sistema autónomo de robot y su actuación en el ambiente de operación.

\subsection{COLABORACIÓN ENTRE SISTEMAS AUTÓNOMOS DE ROBOTS}

La colaboración entre sistemas autónomos de robots se debe considerar en comparación con los trabajos anteriores, comenzando con Fritz, W et al (1989) el que considera un sistema autónomo inteligente representado por un robot, con un planificador clásico, al que García Martínez, R y Borrajo, D. (2000), le incorpora la ponderación de planes y mutación de teorías similares, luego Maceri, D., Gracia Martínez, R, 2001 incorpora el intercambio de teorías. Sobre estas bases resulta conveniente considerar la extensión y experimentación de mecanismos de colaboración entre SARs en el marco de un ciclo de vida de aprendizaje, donde SARs más evolucionados colaboran con SARs receptores menos evolucionados.

En este contexto resulta conveniente estudiar los resultados obtenidos por el SAR que recibió colaboración, para lo cual se deben llevar a cabo experimentos orientados a verificar que los SARs tienen un mejor comportamiento utilizando colaboración que cuando no la usan. 


\subsection{MODELO Y ARQUITECTURA PARA MÚLTIPLES SISTEMAS AUTÓNOMOS DE ROBOTS}

Los trabajos anteriores no reparan en el desarrollo de un modelo de clases y una arquitectura en el marco de múltiples SARs, resultando conveniente para las integraciones de futuros sistemas autónomos de robots distribuidos contar con una propuesta inicial que permita integrar a estos robots en un ambiente de operación. En este orden se deberán considerar cada una de las actividades de cada uno de los módulos componentes, brindar al SAR un mayor detalle del ambiente de operación al reconsiderar la comparación de teorías efectuadas por autores anteriores que aplicaron un umbral fijo y global para todos los sensores, explorando la aplicación de un umbral variable por sensor y actuador, observar la interacción del planificador con el ambiente de operación del SAR, empleado por autores anteriores, el que denominamos SARp (Sistema Autónomo de Robot con planificador clásico), en busca de soluciones que permitan obtener un planificador de teorías que interactúe ciclo a ciclo con el ambiente, al que denominaremos SARr (Sistema Autónomo de Robot con planificador por ranking), permitiendo una mejor actuación del SAR en respuesta al ambiente de operación.

\subsection{ESTADÍSTICAS DE APRENDIZAJE Y MÉTRICAS ASOCIADAS A LA ACTUACIÓN DEL SISTEMA AUTÓNOMO DE ROBOTS}

Si bien en los trabajos de los autores anteriores García Martínez, R., y Borrajo, D. (2000), García Martínez, R., et al (2006) se consideran estadísticas para la evaluación del sistema, al incorporarse la colaboración, como así también mejoras en módulos que conforman la arquitectura del SAR, se requieren nuevas estadísticas que permitan sostener las métricas que faciliten la evaluación del SAR y de la colaboración. En otro orden resulta necesaria la elaboración de una taxonomía de tipos de SARs que participarán en función de las propuestas de autores anteriores y las nuevas capacidades esperadas en términos de colaboración y actuación del SAR en orden a sus métodos y bases de conocimientos asociadas. Se presentan a continuación las cuestiones relevantes en relación a la colaboración del SAR (sección 3.5.1), las cuestiones relevantes en relación a la Arquitectura del SAR (sección 3.5.2)

\subsubsection{CUESTIONES RELEVANTES EN RELACIÓN A LA COLABORACIÓN DEL SAR}

Considerando que existen propuestas anteriores enunciadas en el marco de sistemas autónomos de robots, resulta necesario la comparación entre éstas y la propuesta de colaboración, surgen así las 
siguientes cuestiones en términos de comparar el rendimiento del aprendizaje, al incorporar colaboración, en términos de cantidad de teorías, cantidad de planes exitosos, cantidad de ciclos exitosos, cantidad de teorías exitosas:

- ¿En qué medida la colaboración mejora el rendimiento del sistema autónomo de robots en comparación con las propuestas que aplican SAR neutro [Fritz, W., et al, 1989]? Se presentan los resultados en el primer grupo de experimentación (Sección 5.3.1.1 del Capítulo 5).

- ¿En qué medida la colaboración mejora el rendimiento del sistema autónomo de robot en comparación con la propuesta que aplica ponderación de planes y mutación [García Martínez, R. \& Borrajo Millán, D. 1996]? Se presentan los resultados en el primer grupo de experimentación (Sección 5.3.1.1 del Capítulo 5).

- ¿En qué medida la colaboración mejora el rendimiento del sistema autónomo de robot en comparación con la propuesta que aplica ponderación de planes, mutación e intercambio [García Martínez et al, 2006, Maceri, D., García Martínez, R., 2001]? Se presentan los resultados en el primer grupo de experimentación (Sección 5.3.1.1 del Capítulo 5).

- ¿En qué medida el método propuesto de colaboración en comparación con los métodos aplicados por el SARp individualmente, mejoran el rendimiento de un SARp? Considerando en este orden la comparación de un: SARp configurado por los métodos de ponderación y mutación, un SARp configurado con cooperación (intercambio), un SARp neutro y un SARp configurado con colaboración. Se presentan los resultados en el segundo grupo de experimentación (Sección 5.3.1.2 del Capítulo 5).

- ¿En qué medida la combinación de los métodos aplicados por el SARp, con el método propuesto de colaboración mejoran el rendimiento de un SARp? Considerando en este orden la comparación de las siguientes configuraciones de SARps: SARp neutro configurado con el método de colaboración, SARp configurado con la combinación de métodos de ponderación de planes, mutación y colaboración y SARp configurado con la combinación de métodos de cooperación (intercambio) y colaboración. Se presentan los resultados en el tercer grupo de experimentación (Sección 5.3.1.3 del Capítulo 5).

- ¿En qué medida el método propuesto de colaboración en comparación con los métodos aplicados por el SARr individualmente, mejoran el rendimiento de un SARr? Considerando en este orden la comparación de un: SARr neutro, SARr configurado con el método de mutación, SARr configurado con cooperación (intercambio) y SARr configurado con el método propuesto de colaboración Se presentan los resultados en el primer grupo de experimentación (Sección 5.3.2.1 del Capítulo 5). 
- ¿En qué medida la combinación de los métodos aplicados por el SARr, con el método propuesto de colaboración mejoran el rendimiento de un SARr? Considerando en este orden la comparación de las siguientes configuraciones de SARrs: SARr configurado con el método de cooperación (intercambio) y colaboración, un SARr configurado con la combinación de métodos de mutación y colaboración y un SARr configurado con la combinación de métodos de mutación, cooperación (intercambio) y colaboración. Se presentan los resultados en el segundo grupo de experimentación (Sección 5.3.2.2 del Capítulo 5).

\subsubsection{CUESTIONES RELEVANTES EN RELACIÓN A LA ARQUITECTURA DEL SAR}

Observando que ya existe un planificador de acciones del SARp, empleado por los sistemas autónomos de robots presentados por los autores de las propuestas anteriores, resulta necesario la comparación entre éste y la propuesta del planificador de acciones del SARr, surgen así las siguientes cuestiones (detalladas en la Sección 5.3.3 Capítulo 5):

- ¿En qué medida el planificador propuesto en comparación con el planificador clásico mejora el aprendizaje de un SAR neutro, en término de cantidad de ciclos exitosos?

- ¿ ¿En qué medida el planificador propuesto en comparación con el planificador clásico mejora el aprendizaje de un SAR que recibe colaboración, en término de cantidad de ciclos exitosos?

- ¿ ¿En qué medida el planificador propuesto en comparación con el planificador clásico mejora el aprendizaje de un SAR que aplica mutación y recibe colaboración, en término de cantidad de ciclos exitosos?

- ¿En qué medida el planificador propuesto en comparación con el planificador clásico mejora el aprendizaje de un SAR que aplica intercambio y recibe colaboración, en término de cantidad de ciclos exitosos?

- ¿ ¿En qué medida el planificador propuesto en comparación con el planificador clásico mejora el aprendizaje de un SAR que aplica mutación, intercambio y recibe colaboración, en término de cantidad de ciclos exitosos? 


\section{SOLUCIÓN PROPUESTA}

En este capítulo se presentan las características de un sistema autónomo de robots (sección 4.1), el ciclo de vida de aprendizaje de un sistema autónomo de robots (SARs) (sección 4.2), la arquitectura y el modelo MultiSARs (sección 4.3), se detalla cada uno de los componentes que integran el SAR propuesto (sección 4.4), se describen los escenarios aplicados (sección 4.5), se presentan las características generales del robot y simulador empleado (sección 4.6), finalmente se identifican los SARs en función de su configuración y tipo (sección 4.7).

\subsection{SISTEMA AUTÓNOMO DE ROBOT}

En esta sección se presenta la introducción con las consideraciones generales en materia de sistemas autónomos de robots en la subsección 4.1.1 y el modelo de teoría de un SAR en la subsección 4.1.2.

\subsubsection{INTRODUCCIÓN SISTEMA AUTÓNOMO DE ROBOTS}

Dados ambientes desconocidos, los sistemas autónomos de robots (SARs), deben generar teorías de cómo sus ambientes reaccionan a sus acciones, y cómo las acciones afectan al ambiente. Usualmente estas teorías de aprendizaje, son parciales, incompletas e incorrectas, pero pueden ser usadas para modificar esas teorías o para crear nuevas.

Uno de los principales objetivos de cada sistema autónomo de robot (SAR), es cómo los operadores que conforman las teorías, aprenden automáticamente modelos de acción, que predicen los efectos de acciones en el ambiente, por observación de las consecuencias de estas acciones. Para poder aprender estas descripciones, éste es capaz de lograr metas auto-definidas, ejecutar los planes, encontrar los comportamientos correctos o incorrectos, y aprender de la interacción con el ambiente y otros Sistemas Autónomos de Robots (SARs).

Cada Sistema Autónomo de Robot (SAR), recibe la percepción desde el ambiente, llamado situación y aprende de su interacción con el mundo externo (el ambiente y otros SAR). Al principio, el SAR percibe la situación inicial, y selecciona una acción al azar para ejecutar en el ambiente. Entonces, entra en un loop para la ejecución de una acción, percibiendo las situaciones resultantes y 
la utilidad de la acción, aprendiendo de la observación de los efectos de aplicar las acciones en el ambiente.

\subsubsection{MODELO DE TEORÍA}

En la teoría de sistemas inteligentes autónomos (SIA), planteada en [Fritz et al, 1989; 1990; García Martínez, 1992a] el aprendizaje está definido cada vez que el sistema adquiere la descripción de una nueva situación o de una nueva unidad de experiencia. En trabajos posteriores [García Martínez, 1991a; 1991b; 1992a; 1992b] se han explorado métodos de aprendizaje que contemplen el concepto de que la teoría utilizada con éxito debe ser reforzada, mientras que la teoría que es utilizada de forma infructuosa debe ser debilitada [Sutton, 1984,1990, 1992; Lespaérance, 1991].

El sistema puede ser descrito como un robot de exploración que percibe el entorno a través del sistema sensor, registra la situación, y arma una teoría local con la situación previa y la acción ejecutada [Falkenhainer y Rajamoney, 1988; Falkenhainer, 1990; Lin y Shoham, 1991]. Si la teoría local es igual a alguna teoría registrada, ésta se refuerza. Si es similar, se registra la teoría local, se pondera y se crean teorías mutantes [Eiter y Gottlob, 1992; Giunchicilia y Walsh, 1992].

El SAR encapsula su conocimiento a través de teorías. Una teoría es una tupla sobre la cual se almacena una instancia de conocimiento del SAR. Una teoría u operador se conforma por: la situación inicial, la acción tomada y la situación resultante, y sus parámetros de evaluación asociados, representados por P, K (ponderación de la teoría) y U (utilidad de la teoría).

El operador O (teoría), es una tupla $<$ Si,A,Sf,P,K,U $>$ [García Martínez y Borrajo, 2000] donde la teoría de un SAR se representa por: Situación inicial (Si) indica el estado en el que se encontraba el robot al querer ejecutar una acción. El estado está conformado por los valores de las lecturas de cada uno de los sensores del robot en un instante determinado. La acción (A), indica la acción que se realizó en función de la Situación inicial (una de las “n” acciones posibles a realizar por el SAR). La Situación final (Sf), indica el estado del robot luego de ejecutada la acción (A). El estado está conformado por la misma estructura de datos que la Situación inicial (Si).

El parámetro $\mathrm{P},(\mathrm{P})$ : cantidad de veces que teniendo la situación inicial $(\mathrm{Si})$, se ejecutó la acción $(\mathrm{A})$ y se obtuvo la situación final $(\mathrm{Sf})$. El parámetro $\mathrm{K},(\mathrm{K})$ : cantidad de veces que teniendo la situación inicial (Si), se ejecutó la acción A.

En la medida que las observaciones confirmen una teoría [Whitehead y Ballard, 1991; García Martínez, 1993], su P y K aumentan, aumentando también el $\mathrm{K}$ de las teorías complementarias (teorías con las mismas condiciones supuestas y las mismas acciones). Si se considera que el 
cociente $\mathrm{P} / \mathrm{K}$ es una medida de la confiabilidad de una teoría $(1=$ confiable, $0=$ no confiable $)$, cuanto más observaciones confirman una teoría, más confiable se vuelve ( $\mathrm{P} / \mathrm{K}$ aumenta) y menos confiables las teorías complementarias ( $\mathrm{P} / \mathrm{K}$ disminuye). Por otra parte, periódicamente podrían ser revisadas aquellas teorías con un valor de confiabilidad bajo ( $\mathrm{P} / \mathrm{K}$ muy pequeño) para ser eventualmente "olvidadas". En este contexto, son válidas las afirmaciones de Blaque [1986] que sostiene que la mente es un sistema ecológico donde las teorías que mejor explican lo que ocurre en el entorno sobreviven a las que no lo hacen.

Un SAR puede evaluar cuán útil (o inútil) puede ser realizar una acción para alcanzar sus objetivos. En este contexto, el modelo de teoría considera el concepto de utilidad de aplicar una acción (entendiendo por utilidad cuán beneficioso puede ser aplicar una acción en la situación vigente para alcanzar un determinado objetivo). El parámetro U, utilidad (U), indica la utilidad de la teoría en función de la tarea asociada al SAR. Se calcula con una fórmula, que indica si los resultados de la teoría fueron o no fructíferos para el robot.

Después de registrar la situación siguiente a la ejecución de una acción, el sistema está en condiciones de formular una teoría, donde las condiciones supuestas son la situación precedente o situación inicial, la acción es la acción ejecutada y los efectos predichos son la situación obtenida o situación final.

\subsection{CICLO DE VIDA DE APRENDIZAJE DE UN SISTEMA AUTÓNOMO DE ROBOT}

Sobre la base del modelo de ciclo de vida en espiral [Boehm, 1986, 1988] aplicado en el contexto de la ingeniería de software para la construcción de prototipos y versiones evolutivas de software, se inspira el modelo de Ciclo de Vida de Aprendizaje de Sistemas Autónomos de Robots [Ierache et al., 2008a; 2009b], que se propone en el presente trabajo como modelo de evolución del aprendizaje de un SAR.

En el modelo en espiral, el software se desarrolla en una serie de versiones incrementales, obteniendo versiones mucho más completas en las últimas versiones. El modelo en espiral se divide en un número de actividades estructurales, también llamadas regiones de tareas. Cada una de las regiones está poblada de una serie de tareas [Presman R, 1998].

El modelo de ciclo de vida de aprendizaje o LCC (Learning Life Cycle) propuesto se basa en tres layers (capas): [a] la layer de BIO (Built-In Operators) sobre la que se desarrolla el aprendizaje del SAR a partir de los operadores generados por el programa implantado por el programador o creador, [b] la layer TBO (Trained Base Operators) es la capa de aprendizaje en la que los 
operadores evolucionan en el contexto de entrenamiento del SAR sobre la base inicial de los operadores implantados previamente y [c] la layer WIO (World Interaction Operators) es la capa de aprendizaje en la que los operadores aprenden por la interacción con el mundo. El ciclo de vida propuesto para el aprendizaje del SAR se muestra en la Figura 4.1.

El ciclo de vida de aprendizaje (LLC) de un SAR, se conforma con siete regiones de tareas, tres layers (BIO, TBO, WIO) y los cuatro estados de evolución del SAR nacido (born), novato (newbie), entrenado (trained), maduro (mature), asociados al principio y fin de cada una de las layers. El SAR transita cada región de tareas en cada layer del LLC, durante una cantidad determinada de ciclos percepción-acción.

Los SARs actúan en un ambiente conformado por escenarios asociados a cada una de las layers del LCC. En este orden se distinguen los siguientes escenarios: BIO-Escenario (se corresponde con la layer que transita el SAR Born hasta alcanzar el estado de Newbie), TBO-Escenario (se corresponde con la layer que transita el SAR Newbie hasta alcanzar el estado de Trained), WIOEscenario (se corresponde con la layer que transita el SAR Trained hasta alcanzar el estado de Mature)

En la primera región de tareas del LLC, se registra la situación inicial o situación percibida por los sensores del SAR, en esta región se realizan las tareas de: [a]sensorización del ambiente por parte del SAR, al efectuar la lectura del ambiente a través de cada sensor, [b] se incorpora el conjunto de lecturas de los sensores del SAR para conformar la situación inicial de la teoría i del SAR, [c] se normalizan las lecturas de cada uno de los sensores del SAR.

En la segunda región de tareas del LLC, se ejecuta la acción del SAR, a través de las tareas asociadas al control de velocidad de cada uno de los efectores que conforman la actuación del SAR (para el caso del robot e-puck se considera el control de velocidad de la rueda izquierda y de la velocidad de la rueda derecha).

En la tercera región de tareas del LLC, se conforma la situación final o efectos predichos, registrados por los sensores del SAR, luego que éste ejecutó su acción, en esta región se realizan las tareas de: [a]sensorización del ambiente por parte del SAR, al efectuar la lectura del ambiente por parte de cada sensor, [b] se incorpora el conjunto de lecturas de los sensores del SAR para conformar la situación final de la teoría i del SAR, [c] se normalizan las lecturas de cada uno de los sensores del SAR.

En la cuarta región de tareas del LLC, se efectúa el cálculo de utilidad de la acción correspondiente a la teoría i del SAR.

En la quinta región de tareas del LLC, conforma el aprendizaje del SAR, en esta región se realizan las siguientes tareas: [a] ponderación de teorías (parámetros $\mathrm{P}$ y $\mathrm{K}$ ), [b] registro de la teoría 
conformada por la situación inicial (determinada en la primera región de tareas del LLC), la acción (determinada en la segunda región de tareas del LLC), la situación final (determinada en la tercera región de tareas del LLC), la estimación de parámetros $\mathrm{P}, \mathrm{K}$ y la utilidad U de la teoría (determinada esta ultima en la cuarta región del LLC).

En la sexta región de tareas del LLC, se realiza el registro de las estadísticas de aprendizaje del SAR (las que se detallan en la sección 4.4.9), correspondientes al Ciclo i de percepción - acción del $\mathrm{SAR}$, en este orden se realizan las siguientes tareas de registro de: [a] cantidad de situaciones, [b] cantidad de teorías nuevas, [c] cantidad de teorías acumuladas, [d] cantidad de teorías exitosas, [e]cantidad de ciclos exitosos, [f] cantidad de planes (planes exitosos y no exitosos), [g] cantidad de teorías por intervalo de utilidad, [h] cantidad de azares.

En la séptima región de tareas del LLC, se considera la evolución del SAR, a través de la tarea de evaluación del rendimiento del aprendizaje del SAR: [a] la cantidad de ciclos exitosos alcanzados por el SAR, la que tiende a crecer a medida que evoluciona el SAR. [b] la cantidad de teorías nuevas (propias), que el SAR genera en tiempo de ejecución, la que tiende a decrecer a medida que el SAR evoluciona, esto indica la representatividad de la base de conocimiento de teorías acumuladas (que el SAR aplica por colaboración) en el ambiente de actuación, [c] la cantidad de teorías vs situaciones,[d] la cantidad de planes exitosos, [e] la cantidad de teorías exitosas (teorías con utilidad:0,75<U $\leq 1$ ) acumuladas en su base de conocimiento. Finalmente se consideran como métricas primarias para la evolución del SAR la cantidad de ciclos exitosos del SAR y la cantidad de nuevas teorías, esta última se considera en el caso de que el SAR reciba colaboración.

Asociado a cada región se encuentran los estados de evolución que transita el SAR. El primer estado es el de born (nacido), este estado corresponde al inicio del layer BIO (Built-In Operators). El segundo estado en la evolución del SAR es el de newbie (novato), este estado es el que alcanza el SAR al finalizar el layer BIO y pasa al layer TBO (Trained Base Operators). El tercer estado de evolución que transita el SAR es el de trained (entrenado), este estado se alcanza cuando el SAR finaliza el layer TBO. El cuarto estado de evolución del SAR es el mature (maduro), este estado se alcanza cuando el SAR finaliza el layer WIO (World Interaction Operators).

La evolución de los estados asociados (born, newbie, trained, mature) del SAR se desarrolla a través de los Layers (BIO, BTO, WIO), como se puede observar en Figura 4.1 que representa el modelo de ciclo de vida.

Entre la región séptima y primera se representan las layer BIO, TBO, WIO que conforman las capas que transita el SAR en su LLC. En este marco se considera la Configuración del SAR que actuará en la layer, en este orden se contemplan en primer lugar la configuración de parámetros generales: [a] seleccionar ambiente en función de la layer en que actuará el SAR, [b] determinar la cantidad de 
ciclos del SAR en la layer, [c] seleccionar el método de comparación de teorías que aplicará el SAR, [d] si el SAR aplica base de conocimientos, seleccionar la misma en función de su estado de evolución, considerando la compartición de conocimientos con otras bases de conocimientos de SARs. La compartición de conocimiento se lleva a cabo a través de las siguientes tareas: [a] cooperación (obrar juntamente con otro u otros para un mismo fin, [RAE 2010a]) entre SARs (que se encuentran en el mismo layer), [b] colaboración (ayudar a otros al logro de algún fin, [RAE 2010 b] ) entre un SAR colaborador (que se encuentra en un layer superior) y un SAR receptor (que se encuentra en un layer inferior).

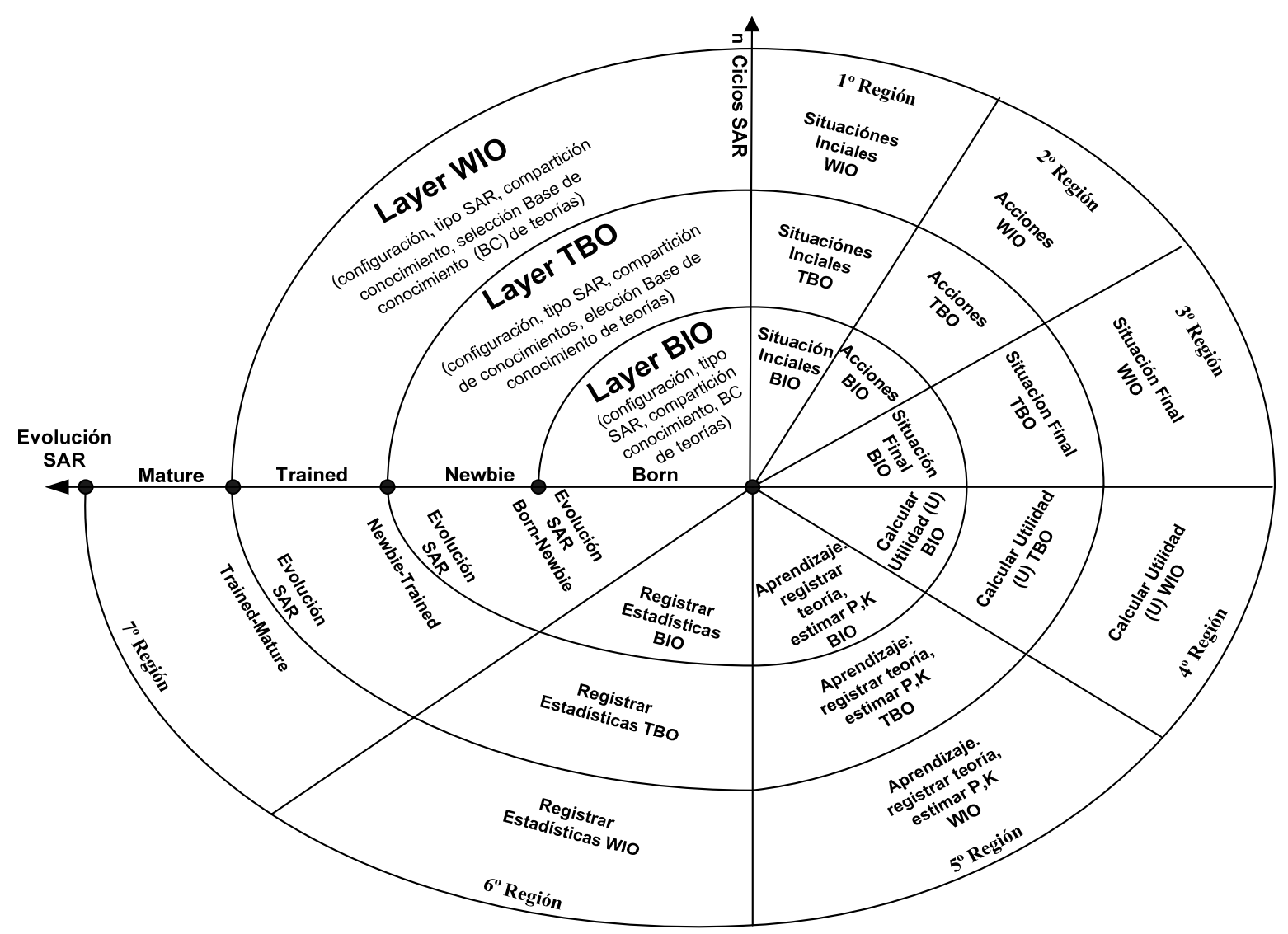

Figura 4.1 Modelo de Ciclo de vida del aprendizaje del SAR

En segundo lugar se considera la selección y configuración de estadísticas de aprendizaje del SAR (registradas en la sexta región de tareas del LLC). Esta configuración contempla: la selección del intervalo de muestra, el intervalo de distribución de utilidad de teorías y la elección de datos a registrar (las que se registran en la sexta región de tareas).

Finalmente se considera el tipo de SAR que actuará en la layer en función de la aplicación de planificador o no, la selección del tipo de planificador y métodos asociados que se seleccionen para la configuración del SAR. 
En el modelo de ciclo de vida de aprendizaje de un SAR, la amplitud del ciclo de vida se corresponde con la cantidad de ciclos percepción-acción que ejecutó el SAR, en este orden, la separación lateral entre layers contiguos indica la cantidad parcial de ciclos percepción-acción, realizados por el SAR mientras recorre un layer, ejecutando las tareas de cada una de las siete regiones del LLC. En este orden la Figura 4.2 muestra los n ciclos en raster que recorre el SAR a través de las regiones de tareas correspondientes a la actuación genérica de un SAR, en una layer (la que puede ser: BIO,TBO,WIO) del LLC. Se observan los $n$ ciclos percepción-acción, que el SAR realiza durante, su actuación, entre su estado inicial (el que puede ser: Born, Newbie, Trained) al inicio de la layer y la evolución de su estado (el que puede ser: Newbie, Trained, Mature), al final de su actuación en una layer en particular del LLC.

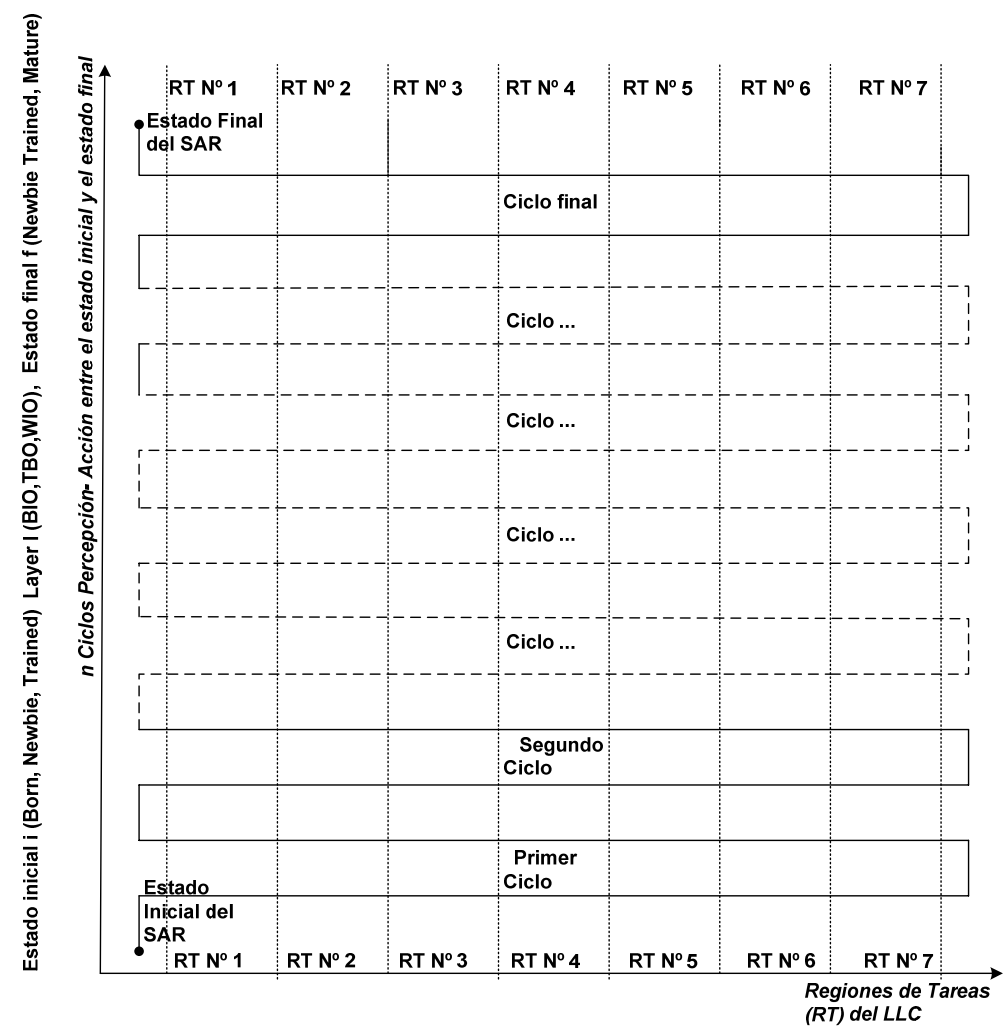

Figura 4.2 Modelo de Ciclo de vida del aprendizaje del SAR

El SAR a lo largo del eje correspondiente a los n ciclos percepción-acción entre el estado inicial y el estado final, ejecuta $n$ ciclos, por cada ciclo realiza las tareas asociadas a cada una de las siete regiones, a lo largo del eje de regiones de tareas del LLC como se puede observar en la Figura 4.1. Los conocimientos del SAR acumulados (bases de conocimiento de teorías) aportan una nueva dimensión al LLC propuesto, transformando éste, en un ciclo de vida en espiral cónico de tres dimensiones. Este modelo está basado, por una parte, en la idea de Spenger, retomada por Bartholomew, para mostrar los ciclos históricos de la geología terrestre y, por otra como fue 
expresado, en el modelo en espiral de Boehm. ( modelo en espiral en el plano x,y) [Gómez et al, 1997].

El problema es que el modelo en espiral en el plano, no da cuenta de la incorporación sistemática de los nuevos conocimientos que se producen por la propia interacción del SAR en su mundo. Estos nuevos conocimientos no pueden ser representados en el plano de la espiral de dos dimensiones. Por ello, se propone, tal y como se ve en las Figura 4.3 (visión lateral del LLC), una estructura en espiral cónica (espiral troncocónica) para la adición de nuevos conocimientos (teorías), a lo largo del eje Z durante el ciclo de vida del SAR.

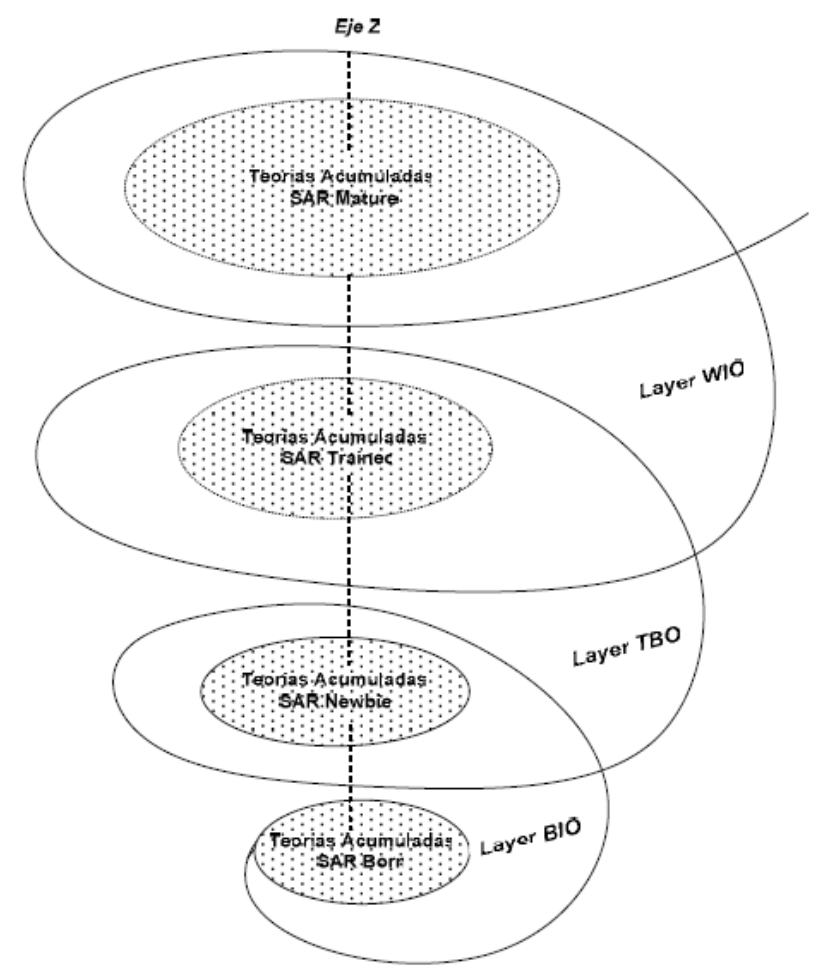

Figura 4.3 Visión Lateral del Ciclo de vida de aprendizaje

El eje $\mathrm{Z}$ indica la adquisición de conocimientos (teorías acumuladas) que crece con la cantidad de ciclos percepción-acción del SAR. La espiral troncocónica va de menor diámetro (menor cantidad de teorías acumuladas) a mayor diámetro (mayor cantidad de teorías acumuladas), asociado a la cantidad de teorías acumuladas en el LLC del SAR. Sin embargo si bien el SAR obtiene mayores cantidades de teorías acumuladas en su base de conocimiento, a medida que transita su layer, también refina su conocimiento por las tareas de cálculo de utilidad de teorías, que se realizan en la cuarta región de tareas y la ponderación de los parámetros $\mathrm{P}$ y $\mathrm{K}$ de la teoría en la quinta región de tareas del LLC. En función de la colaboración que reciba el SAR tendrá la necesidad de generar durante su actuación en el ambiente de operación, una menor cantidad de teorías nuevas para su actuación. 
Por otro lado el modelo de LLC propuesto contempla una visión concurrente [Davis y Sitaram, 1994], en el que se definen una serie de acontecimientos en función del aprendizaje del SAR, que permiten compartir el conocimiento entre SARs, correspondiente a la configuración del SAR que actuará en una layer en particular, a través de la cooperación y la colaboración.

La visión concurrente en el marco del LLC del SAR, se manifiesta por la acción de compartir conocimientos en forma concurrente entre SARs según se muestra en la Figura 4.4.

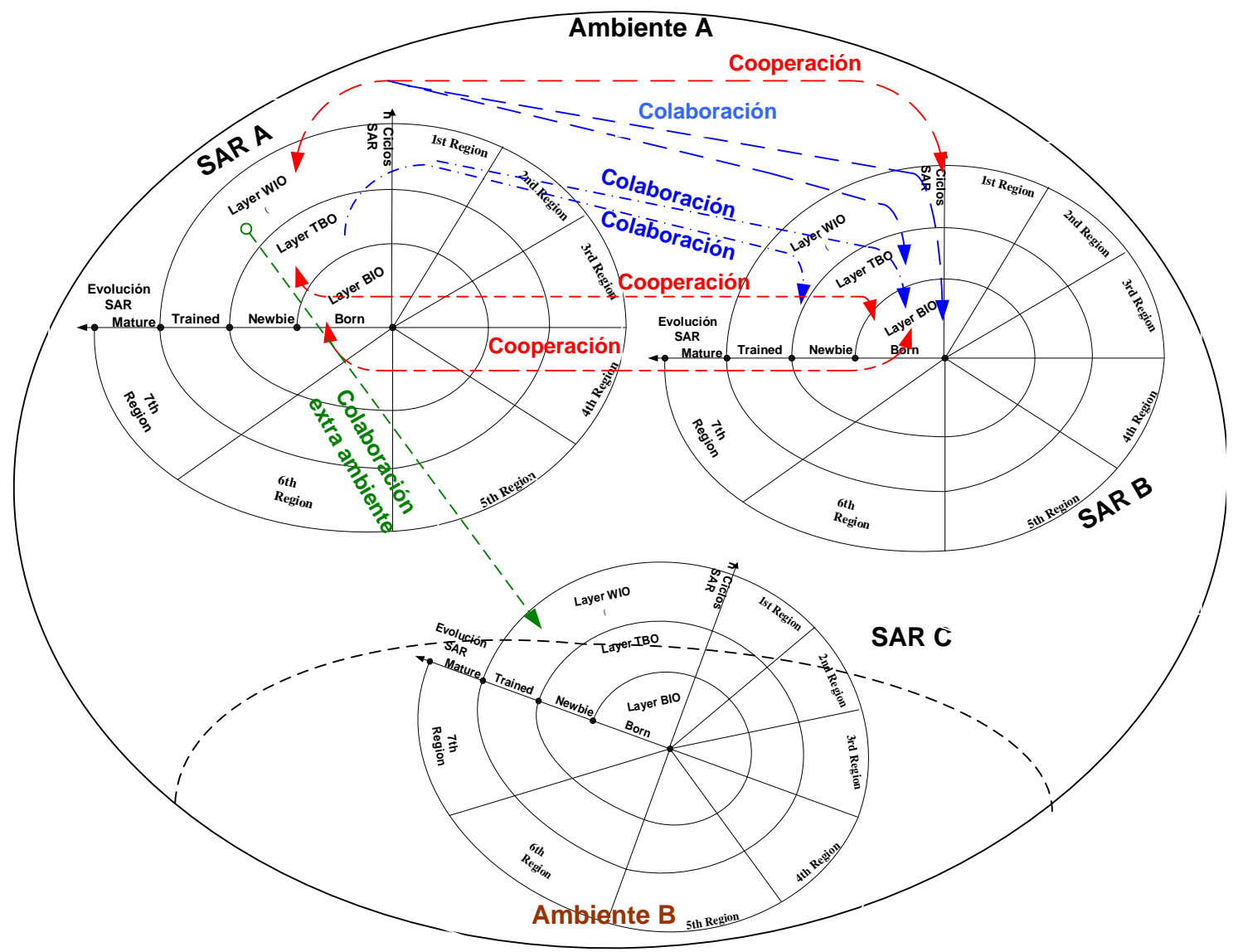

Figura 4.4 Concurrencia entre SARs en el marco del LLC

La acción de compartir conocimientos entre los SARs, se manifiesta en este contexto a través de la cooperación y la colaboración entre SARs. En este contexto el SAR A y el SAR B que se encuentran en un mismo ambiente de operación, recorriendo sus respectivos ciclos de vida de aprendizaje, cooperan entre sí, al mismo nivel de layer (escenario de actuación). El SAR A colabora con el SAR B desde layer de nivel superior. Los SARs que se encuentran en un layer superior en sus respectivos ciclos de vida de aprendizaje (LLC), colaboran con SARs que transitan un nivel inferior en sus LLCs, en un mismo ambiente. El SAR en su mundo de actuación, puede continuar sus actividades migrando a otro ambiente, en este contexto los mecanismos para compartir 
conocimientos (teorías) entre SARs que se originan en distintos ambientes de actuación, se reconocen como colaboración extra-ambiente, ésta se produce cuando un SAR transita de un ambiente a otro del mundo de actuación y recibe colaboración de un SAR (A) residente, que pertenece al ambiente, al cual el SAR (C) receptor migra.

\subsection{ARQUITECTURA Y MODELO MULTISAR.}

En esta sección, se describe la arquitectura para múltiples sistemas autónomos o MultiSAR en la subsección 4.3.1, el modelo conceptual en la subsección 4.3.2, la ontología preliminar del SAR en la subsección 4.3.3, esta última se presenta con la finalidad de extender el modelo conceptual, en futuras líneas de investigación.

\subsubsection{ARQUITECTURA MULTISAR}

Sobre la base de la arquitectura LOPE (Learning by Observation in Planning Environments) [García-Martínez y Borrajo, 2000; García-Martínez et al., 2006], y el LLC (Learning Life Cycle) [Ierache et al., 2008a] propuesto, se presenta en la Figura 4.5, el modelo conceptual de la arquitectura para múltiples sistemas autónomos de robots o MultiSAR, el que integra el ciclo de vida de aprendizaje propuesto con la arquitectura LOPE, reconocido como (LOPE-LLC).

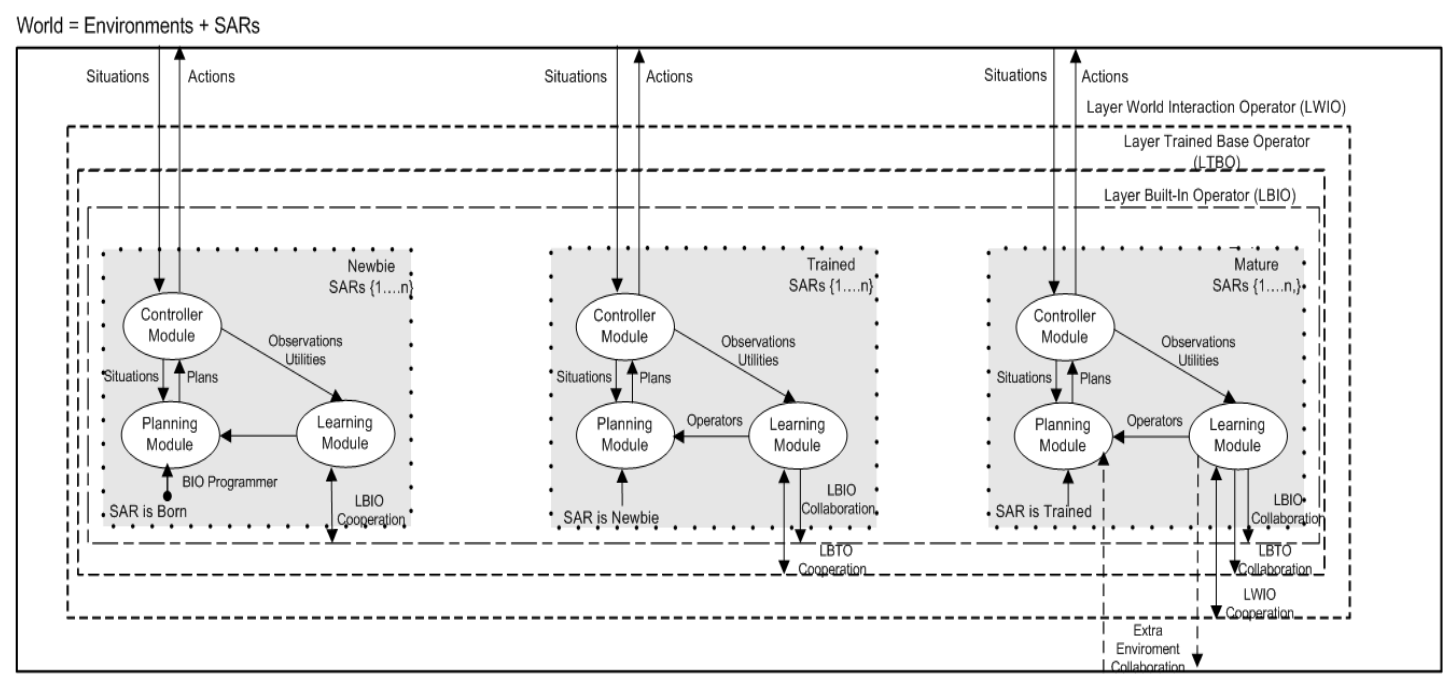

Figura. 4-5. Arquitectura MultiSAR 
En el contexto de la arquitectura propuesta los SARs pueden compartir sus teorías (operadores) a través de sus layers (LBIO, LBTO, LWIO) en su propio ambiente de operación, de acuerdo a su estado (born, newbie, trained, mature), donde se imponen los siguientes axiomas de compartición de teorías entre SARs: [a] un SAR puede cooperar (intercambiar operadores) con otros SARs que se encuentren en el mismo layer que éste, la cooperación se realiza sólo entre SARs que se encuentran con el mismo estado de evolución. [b] un SAR puede colaborar con otros SARs brindando sus teorías a un SAR receptor que se encuentra en un layer inferior a éste. La colaboración se presenta entre un SAR que se encuentra en un estado de evolución superior y un SAR receptor que se encuentra en un estado de evolución inferior, [c] un SAR mature (maduro) puede cooperar (intercambiar operadores de sus teorías) con otro SAR mature y puede colaborar (brindar los operadores de sus teorías a un SAR receptor ) con otros SARs receptores trained (entrenado), newbie (novato), born (nacido) [d] un SAR trained puede cooperar con otro SAR trained y puede colaborar con otros SARs receptores newbie, born [e] un SAR newbie puede cooperar con otro SAR newbie y puede colaborar con un SAR receptor born, [f] un SAR born puede cooperar con otro SAR born.

En el contexto de la arquitectura propuesta los SARs, fuera de su ambiente o extra ambiente de operación, pueden compartir conocimiento colaborando o recibiendo colaboración, a través de: [a] un SAR maduro, el que sólo puede colaborar con otro SAR maduro que migra a su ambiente, siendo este último el receptor de la colaboración, [b] un SAR maduro, que migra a otro ambiente sólo puede recibir colaboración de un SAR maduro que opera en ese ambiente.

La interacción de un SAR en su mundo de actuación (ambientes + SARs), se contempla en el ciclo percepción (situación) - acción del SAR con su ambiente de actuación, y en el intercambio de conocimientos (teorías) a través de: la cooperación (intercambio indicado con flujos entre SARs en ambos sentidos) entre SARs que se encuentran en el mismo layer en sus respectivos LLC, y la colaboración (indicada con flujos entre SARs en un solo sentido) entre un SAR que se encuentra en su LLC en un layer superior, en relación a un SARr receptor que se encuentra en un layer inferior. La colaboración de un SAR en su mundo compuesto por uno o más ambientes, se presentan escenarios intra ambiente (SARs que se encuentran en el mismo ambiente de operación) y extra ambientes, este último cuando el SAR migra a otro ambiente de operación y recibe colaboración de un SAR residente de ese ambiente. La colaboración extra ambiente se representa por una flecha en un solo sentido con su cuerpo en líneas de trazo, entre el ambiente de operación y el SAR mature (maduro), de igual forma cuando un SAR mature colabora con otro SAR mature que migra a su ambiente de operación. 


\subsubsection{MODELO MULTISAR}

Se representa en la Figura 4.6, el modelo conceptual genérico para un mundo en el que conviven múltiples SAR (MultiSAR), sobre la base del modelo de SAR propuesto por [Ierache et al., 2008d], considerando las ideas aportadas por modelo de arquitectura para el aprendizaje y compartición de conocimiento entre sistemas inteligentes autónomos distribuidos [Ierache et al., 2008a], se propone el modelo que incluye: [a] Mundo "World", [b] Sistema Autónomo de Robot "SAR" [c] Ambiente "Environment" especializado por Ambiente Real "Real Environment", Ambiente Virtual "Virtual Environment" y Ambiente Híbrido "Hybrid Environment", [d] Cuerpo de Conocimiento "Knowledge Body", compuesto por el grupo de operadores BIO,TBO,WIO, que conforman las teorías del SAR, [e] Arquitectura de Sensores "Sensors Architecture" compuesto (a modo de ejemplo), por visión, light, IR proximity, touch, microphone, accelerometer, [f]Arquitectura de Efectores "Effectors Architecture" compuesto (a modo de ejemplo) por speaker, right wheel, left wheel, [g] Arquitectura de Comunicación "Communications Architecture" compuesta por Bluetooth, IR receiver remote control, RS232.

El mundo (World) está compuesto por uno o más Sistemas Autónomos de Robots (SARs) y por uno o más ambientes (Environments), un SAR opera en un ambiente (Environment) el cual puede ser, real (RealEnvironment), virtual (VirtualEnvironment) o híbrido (HybridEnvironment).

Se representan los componentes de la clase arquitectura de sensores "Sensors Architecture" en el diagrama a través de una asociación por agregación, indicada por una línea entre el componente (visión, light, IR proximity, touch, microphone) y el todo (Sensors Architecture) con un rombo sin relleno que conforma el todo.

Los componentes de la arquitectura de efectores o actuadores se representa con la clase "Effectors Architecture", se simbolizan en el diagrama a través de una asociación por agregación, indicada por una línea entre el componente (speaker, right wheel, left wheel) y el todo (Effectors Architecture) con un rombo sin relleno que conforma el todo.

Los componentes de la arquitectura de comunicación se representa con la clase "Communications Architecture", se simbolizan en el diagrama a través de una asociación por agregación, indicada por una línea entre el componente (Bluetooth, IR receiver remote control, RS232) y el todo (Communications Architecture) con un rombo sin relleno que conforma el todo.

Se representa una jerarquía de herencias con la clase ambiente "Environment", donde el ambiente real se representa con la subclase "RealEnvironment", el ambiente virtual se representa con la subclase "VirtualEnvironment", el ambiente híbrido se representa con la subclase 
"HybridEnvironment", son tipos de ambientes "Environment", se indica en el diagrama a través de una línea entre cada clase subclase (subtipos de ambientes) y un triángulo sin relleno en la clase principal Environment.

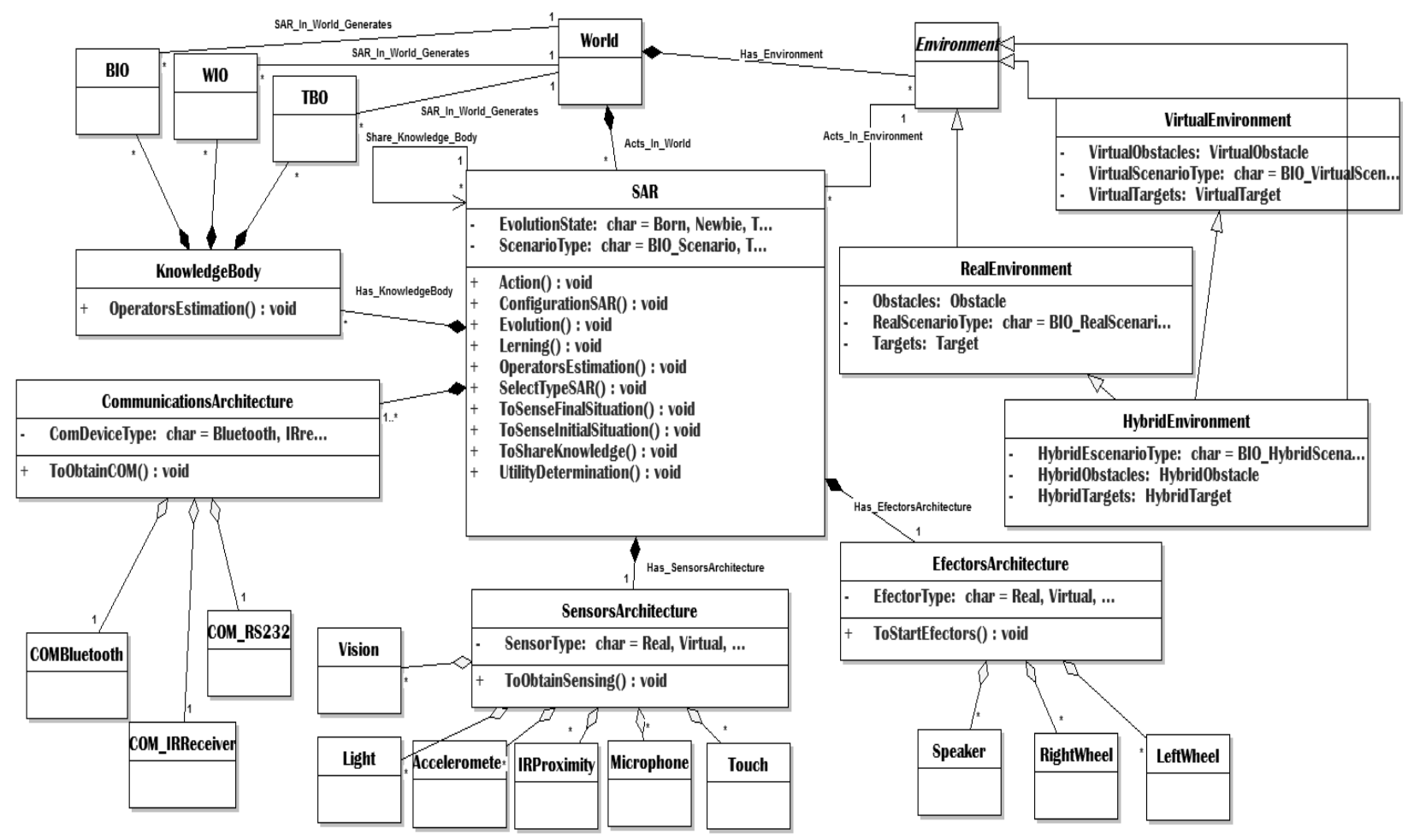

Figura 4.6. Modelo MultiSAR

La clase World se representa a través de una composición (un tipo de agregación), donde sus componentes son la clase SAR, y la clase Environment y pertenecen sólo a un todo que es World, se indica en el diagrama de modelado a través de una línea que parte de cada componente y se vincula con un rombo relleno en la clase World.

El SAR se representa a través de una composición, donde sus componentes son la clase cuerpo de conocimiento "KnowledgeBody", arquitectura de sensores "Sensors Architecture", arquitectura de efectores o actuadores "Effectors Architecture", arquitectura de comunicaciones "Communications Architecture", las que pertenecen a un todo que es SAR, se indica en el diagrama de modelado a través de una línea que parte de cada componente y se vincula con un rombo relleno con el SAR que vincula cada componente.

Se representa el cuerpo de conocimiento (base de conocimiento de teorías) "KnowledgeBody" a través de una composición, donde sus componentes son BIO, TBO, WIO y pertenecen a un todo que es cuerpo de conocimiento "KnowledgeBody", se indica en el diagrama de modelado a través de una línea que parte de cada componente y se vincula con un rombo relleno con la clase cuerpo de 
conocimiento "KnowledgeBody" que vincula cada componente. Se indica la multiplicidad de los componentes con un asterisco * sobre la línea que los vincula con la clase KnowledgeBody.

La compartición del conocimiento "Share- Knowledge-Body" entre un SAR y otros SAR, se representa a través de una asociación reflexiva, se indica en el diagrama de modelado con una línea desde la clase SAR hacia sí misma, indicando su multiplicidad de uno a muchos.

El SAR tiene un cuerpo de conocimiento (KnowledgeBody) el cual comparte con otros SARs e involucra cada una de las layers propuestas en el LLC (learning life cycle), con los estados asociados para un SAR: Born, Newbie, Trained y Mature. El SAR posee un cuerpo de conocimiento formado por las teorías, que inicialmente será reducido, pero nunca nulo. La clase cuerpo de conocimiento (KnowledgeBody) del SAR, realiza la estimación de los operadores a través del método "OperationEstimation": $\mathrm{P}, \mathrm{K}$ y la utilidad (U) de la teoría a través del método "UtilityDetermination".

El SAR pasará por distintos estados de evolución (EvolutionState), según el nivel de conocimientos adquiridos a lo largo de su vida. Estos estados van desde su nacimiento (born), pasando por un estado de novato (newbie), entrenado (trained), hasta alcanzar el nivel de madurez (mature). Los SARs actúan en el mundo (World), y puede haber muchos de ellos dentro de ese mundo. A su vez, dentro del mundo existen diferentes ambientes (Environments) que pueden ir a modo de ejemplo desde un ambiente conformado por un escenario con una baja densidad de obstáculos a otro con una alta densidad y diversidad de obstáculos en función del layer que transita el SAR. Los ambientes se caracterizan por escenarios "ScenarioType" que se identifican como: BIO-Scenario (se corresponde con la layer que transita el SAR Born hasta alcanzar el estado de Newbie), TBO-Scenario (se corresponde con la layer que transita el SAR Newbie hasta alcanzar es estado de Trained), WIOScenario (se corresponde con la layer que transita el SAR Trained hasta alcanzar el estado de Mature).

En el marco de las regiones de tareas establecidas en LLC (Learning Life Cycle) se presentan: [a] la situación inicial o situación percibida por los sensores del SAR, (correspondiente a la primera región de tareas del LLC) se obtiene con el método ToSenseInitialSituation, de la clase AIS (SAR), [b] la acción del SAR (correspondiente a la segunda región de tareas del LLC), se efectúa a través del método Action de la clase AIS (SAR), [c] la situación final o efectos predichos registrados por los sensores del SAR, luego que éste ejecutó su acción, (correspondiente a la tercera región del LLC) se obtiene a través del método ToSenseFinalSituation de la clase AIS (SAR), [d] el cálculo de utilidad de la acción que conforma la teoría i aplicada por el SAR (correspondiente a la cuarta región de tareas), se obtiene a través del método UtilyDetermination de la clase SAR, [e] el aprendizaje del SAR (correspondiente a la quinta región de tareas del LLC), a través del registro de 
teorías con la estimación de los parámetros $(\mathrm{P}, \mathrm{K})$ se realiza a través del método OperatorsEstimation de la clase SAR, [f] el registro de estadísticas de aprendizaje del SAR, (correspondiente a la sexta región de tareas del LLC), se lleva adelante a través del método Learning de la clase SAR, el que registra las estadísticas de aprendizaje y métricas del SAR, [g] la evolución del SAR (correspondiente a la séptima región de tareas del LLC) se lleva a cabo a través del método Evolution de la clase SAR, que realiza la evaluación del rendimiento del aprendizaje del SAR, sobre la base de las métricas correspondientes a cantidad de ciclos exitosos y cantidad de teorías nuevas (esta última se suma para SARs que reciben colaboración).

La configuración del SAR (cantidad de ciclos de la corrida, método de comparación de teorías, bases de conocimientos de teorías, configuración de estadísticas de aprendizaje del SAR) se realiza a través del método ConfigurationSAR.

La selección del tipo de SAR en función de su arquitectura (con planificador clásico, con planificador ranking, sin planificador o reactivo) y métodos asociados (mutación, ponderación de planes) se realiza a través del métodos SelectTypeSAR.

La compartición de conocimiento entre SARs, registrados en sus bases de conocimientos de teorías, se realiza a través del método ToShareKnowledge de la clase SAR, el que se lleva a cabo a través de la cooperación o intercambio entre SARs y colaboración entre un SAR colaborador y un SAR receptor.

El mundo (World: SARs + Environments), representa el mundo en el que los SARs pueden existir. Este mundo contiene a los SAR actuando dentro de él. A su vez el mundo (World) se divide en porciones más pequeñas llamadas ambientes (Environments).

Los SARs pueden actuar dentro de diferentes ambientes, pudiendo haber varios de ellos en cada uno, aunque un SAR, sólo pueden estar en un ambiente a la vez, en un momento determinado del tiempo. Sin embargo un SAR puede migrar de un ambiente a otro ambiente, el que inicialmente puede resultar no conocido para él.

Por otra parte, el ambiente está especializado en ambientes reales, virtuales e híbridos. Los ambientes reales tendrán obstáculos reales (como por ejemplo una pared, un cubo, etc.) y targets reales (como por ejemplo una carga de batería, fuente de energía, áreas con una determinada intensidad de luz, evitar colisiones, etc.). Los ambientes virtuales tendrán obstáculos virtuales (si bien no se aplican en la experimentación del presente trabajo), como por ejemplo un área de arena que dificulta la movilidad de un SAR, niebla que dificulta la visión del SAR, etc.) y targets reales (por ejemplo un sitio donde la intensidad de la luz es lo suficiente para que el SAR se sienta “feliz”). Los ambientes híbridos son una especialización de los ambientes reales y los virtuales, y 
contienen características de ambos (por ejemplo un laberinto real, obstáculos reales y la niebla virtual que limita la visión del SAR).

De este modo, los SARs pueden ir recorriendo diversos ambientes, que están dentro de su mundo. En estos ambientes los SARs se encontrarán con diversos obstáculos (obstacles), que se interpondrán con su objetivo, y que deberá sortear. También se encontrarán con targets, que representan beneficios para el SAR, y por lo tanto debe tratar de alcanzarlos siempre que le sea posible.

El ambiente del SAR se conforma por tipos de escenarios asociados a la layer que transita el SAR, estos escenarios crecen en su complejidad en función de los estados de evolución asociados en el inicio y final de cada layer. En este orden se reconocen los escenarios BIO-Scenario, TBO-Scenario WIO-Scenario.

Un SAR posee una arquitectura de sensores (SensorsArchitecture), que le permite conocer el ambiente en el que está inmerso, a través de la lectura de sus sensores y una arquitectura de efectores (EffectorsArchitecture), con la que realiza acciones dentro del ambiente, en respuesta a lo que ocurre a su alrededor.

La arquitectura de sensores del SAR es la que le permite percibir el ambiente en el que se encuentra, ejecutando el método ToObtainSensing. La arquitectura de sensores tiene tres tipos de sensores: reales, virtuales e híbridos. A su vez según el tipo de medición que realizan pueden existir sensores de visión, de sonido, de distancia, etc.Estos sensores pueden ser reales (por ejemplo: un sensor de luz real), virtuales (por ejemplo un sistema de cómputo externo simulado, un sensor de luz).

La arquitectura de efectores (EffectorsArchitecture) es la que le permite al SAR realizar acciones concretas en el escenario del ambiente en el que se encuentra, mediante el método ToStartEffectors. Del mismo modo que ocurría con la arquitectura de sensores, existen tres clases de efectores: reales virtuales e híbridos. Según el tipo de acción que realizan los efectores (actuadores) aplicados son: rueda derecha, rueda izquierda, speaker.

El SAR posee un cuerpo de conocimiento (KnowledgeBody), que inicialmente será reducido, pero nunca nulo. Los SARs pueden compartir entre ellos el conocimiento (KnowledgeBody) adquirido, contribuyendo de este modo al aprendizaje de otros SARs. Por lo tanto un SAR, sobre la base de conocimiento de teorías que conforma su cuerpo de conocimiento (KnowledgeBody), será capaz de aplicar teorías exitosas, que le permitan en función de la situación inicial realizar acciones en consecuencia a la lectura de sus sensores que conforman la situación, a fin de alcanzar un objetivo determinado (por ejemplo sortear los posibles obstáculos que puede encontrar en su camino). 


\subsubsection{ONTOLOGÍA PRELIMINAR DEL SISTEMA AUTÓNOMO DE ROBOT}

En esta subsección se presentan las bases preliminares para futuras líneas de investigación, que extiendan el modelo planteado en la subsección anterior y los trabajos previos en la materia [Ierache et al., 2008b], para brindar un marco para la compartición de teorías entre los SARs, sobre la base de una ontología. Según Grüber [1993], una ontología es la especificación formal de una conceptualización compartida y debe incluir un vocabulario de conceptos, relaciones y alguna especificación de su significado. En términos prácticos desarrollar una ontología incluye: definir las clases, organizar las clases en una jerarquía taxonómica (superclase/sub-clase), definir slots y describir valores permitidos para esos slots. En apoyo a las futuras líneas de investigación en la materia, se presentan los principales conceptos que integran la ontología preliminar en los Anexos A y el código obtenido al emplear la herramienta PROTÉGÉ en el Anexo N (Soporte digital). En el marco de la interoperabilidad semántica entre SARs, sobre la base del desarrollo de la futura ontología, para alcanzar la interoperabilidad semántica entre SARs, se rescata el trabajo de [Pulvermacher et al., 2004], éste presenta la integración semántica de sistemas de Comando y Control (C2), a través de M2M (Machine to Machine) en ambientes dinámicos.

\subsection{SISTEMA AUTÓNOMO DE ROBOT}

\subsubsection{INTRODUCCIÓN}

Se presenta una introducción al sistema implementado, describiendo la arquitectura y sus componentes (módulos que integran la arquitectura) sobre la plataforma de robot utilizada (subsección 4.4.2), la configuración del SAR (subsección 4.4.2.1), la selección del tipo de SAR (subsección 4.2.2.2), se detalla el método de utilidad de teorías empleado por el SAR en la subsección 4.4.3, el registro de teorías del SAR en su base de conocimiento de teorías en la subsección 4.4.4, el método de mutación de teorías en la subsección 4.4.5, el método de comparación de teorías en la subsección 4.4.6, el planificador de acciones del SAR en la subsección 4.4.7, el planificador clásico (subsección 4.4.7.1), el planificador por ranking de teorías (subsección 4.4.7.2), la compartición de teorías a través de la cooperación y de la colaboración entre SARs en la subsección 4.4.8, las estadísticas de aprendizaje del SAR en la subsección 4.4.9, finalmente la evolución del SAR en la subsección, 4.4.10. 


\subsubsection{SISTEMA AUTÓNOMO DE ROBOT PROPUESTO.}

Diversos robots, lenguajes y herramientas de simulación facilitan la implementación de un escenario de experimentación de sistemas autónomos de robots que interactúen y cumplan con sus objetivos [Ierache et al., 2009a], en este contexto el sistema inteligente autónomo (SIA) propuesto simula el comportamiento de un robot móvil (Sistema Autónomo de robot "SAR"), sobre la base del robot e-puck, empleando el simulador de robots móviles Webots 6 de Cyberbotics desarrollado en el Laboratorio de Micro Informática (LAMI) del Swiss Federal Institute of Technology, Lausanne, Switzerland (EPFL).El simulador Webots soporta la simulación del robot e-puck, en un mundo 3D, facilitando la lectura de los sensores y la actuación de los motores que controlan las ruedas del robot, actuado de interfase entre el robot y el sistema desarrollado, como puede observarse en la parte superior de la figura 4.7.

Se consideran dos tipos de creadores de SARs el primero sobre la base de una arquitectura con planificador (SARp) [García Martínez et al, 2000], [García Martínez et al., 2006, Maceri y García Martínez, 2001], el segundo (propuesto en este trabajo), sobre la base de una arquitectura de planificador por ranking de teorías (SARr). La implementación se llevó a cabo en el entorno Webots C++ [Webots, 2009], se adjunta documento con el código en la carpeta indicada como sección N-1 del Anexo N "Soporte Digital”.

La Figura 4.7 presenta el esquema de componentes del sistema y la forma en que éstos se integran en ambas arquitecturas con la plataforma e-puck a través de los siguientes módulos comunes: transformación de lectura de sensores, transformación de acciones, compartición de conocimiento de teorías entre SARs, cálculo de utilidad (U) de la acción de la teoría i, estimación de parámetros de teorías $(\mathrm{P}, \mathrm{K})$, controlador de acciones del SAR, aprendizaje (registro en teorías en la base de conocimiento del SAR), mutación de teorías, estadísticas de aprendizaje, evolución del SAR, configuración SAR, selección tipo SAR. Los módulos específicos para el SARp son el planificador clásico y el ponderador de planes. Para el SARr el módulo específico es el planificador por ranking de teorías.

Para que el sistema autónomo de robot interactúe con la plataforma e-puck, se desarrollan los módulos de transformación de lectura de sensores y el de transformación de acciones, el primer módulo que corresponde a la primera región de tareas del LLC, convierte las situaciones percibidas por la plataforma al formato utilizado por el sistema, y el segundo que corresponde a la segunda 
región de tareas del LLC, convierte las acciones correspondientes a las teorías que ejecuta el SAR, para que puedan ser aplicadas al simulador.

La situación final (efecto predicho) es transformada por el módulo de tratamiento de lectura de sensores, que corresponde a la tercera región de tareas del LLC, el cálculo de utilidad de la acción de la teoría i que corresponde a la cuarta región de tareas del LLC, lo realiza el módulo cálculo de utilidad. Un diagrama de integración entre el robot e-puck y el sistema desarrollado es presentado a nivel conceptual en el Anexo O.

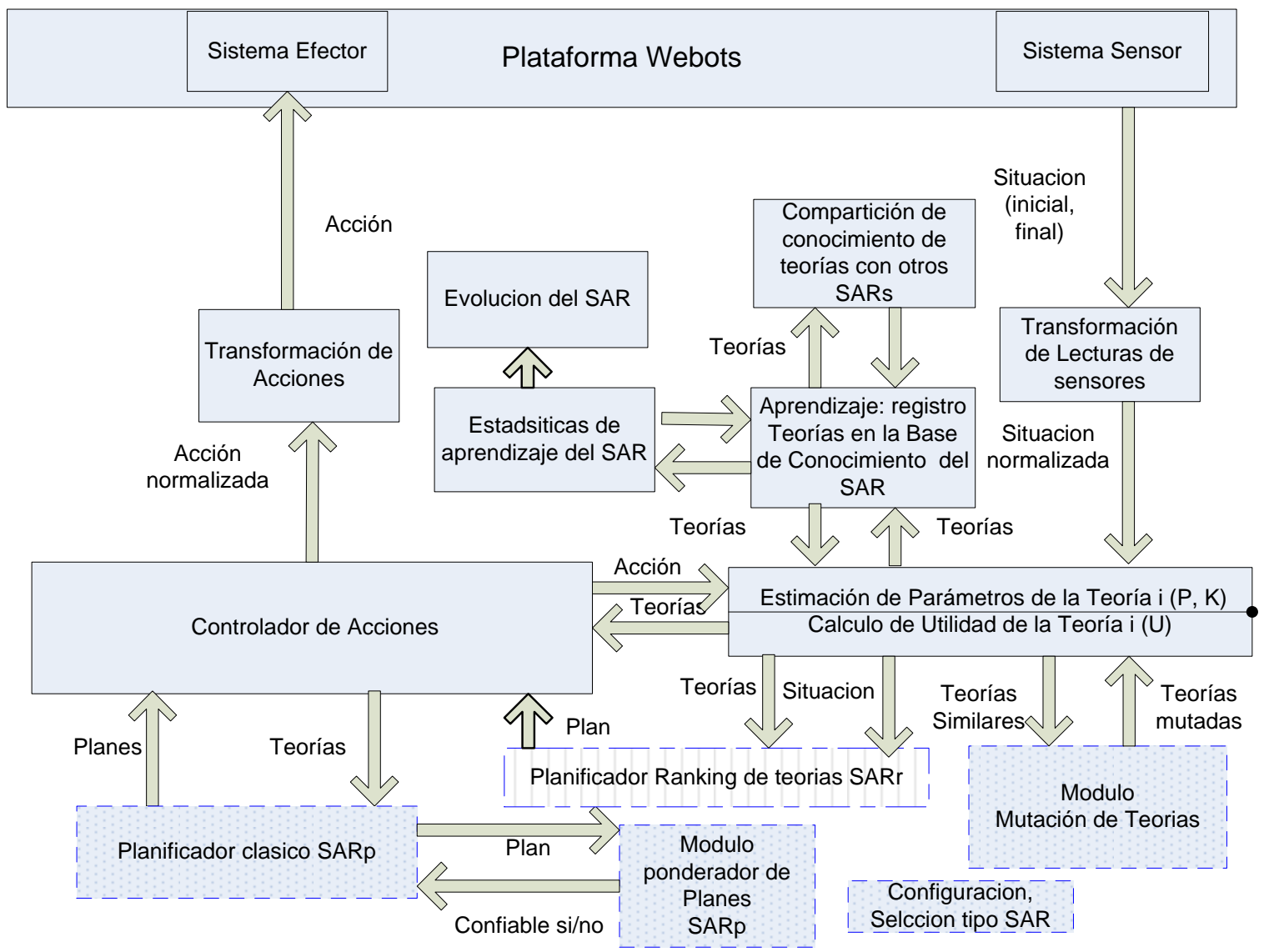

Figura. 4.7. Componentes del SAR implementado en el robot e-puck

La lectura de los sensores y su acciones conforman la teoría del SAR, la que se registra en la base de conocimientos del SAR a través del módulo de Aprendizaje, con la estimación de $\mathrm{P}$, K de la teoría i, que se lleva a cabo en el módulo Estimación de Parámetros $(\mathrm{P}, \mathrm{K})$, estos módulos se corresponden con la quinta región de tareas del LLC del SAR.

El registro de las estadísticas de aprendizaje (que se corresponde con la sexta región de tareas del LLC del SAR) es llevado a cabo por el módulo de Estadísticas de Aprendizaje del SAR. En función del intervalo entre los ciclos de percepción - acción del SAR (seleccionado en la configuración), se registran en el módulo de estadísticas de aprendizaje (sexta región de tareas del LLC del SAR), las estadísticas correspondientes a la actuación del SAR, considerando: el ciclo de ejecución, la 
cantidad de situaciones, la cantidad de teorías nuevas, la cantidad de teorías acumuladas, la cantidad de teorías exitosas, la cantidad de ciclos exitosos, el porcentaje de ciclos exitosos, la cantidad de planes exitosos, cantidad de planes, cantidad de planes fallidos, cantidad de acciones al azar. La evolución de estados del SAR (séptima región de tareas del LLC del SAR) es considerada por el módulo Evolución del SAR.

En función de los resultados observados de las estadísticas del SAR registradas, en el módulo de evolución, se considera la evolución del SAR, a través de la tarea de evaluación del rendimiento del aprendizaje del SAR sobre las métricas representadas por la cantidad de ciclos exitosos, la cantidad de teorías nuevas (esta última se suma a los SARs que reciben colaboración).

La compartición de conocimiento (cooperación, colaboración entre SARs) se lleva a cabo en un proceso independiente, a través del módulo de Compartición de Conocimiento de Teorías, que actúa sobre las bases de conocimiento de teorías de los SARs. La configuración y selección de tipo de SAR se lleva a cabo por el módulo de Configuración y Selección tipo SAR. Los módulos de transformación de lecturas de los sensores, actúan en la primera y en la tercera región de tareas del LLC, realizan las tareas de sensorización del ambiente por parte del SAR, al efectuar la lectura del ambiente por parte de cada sensor, normalizan los valores de cada uno de los sensores, e incorporan el conjunto de lecturas para conformar la situación (inicial, final) de la teoría i del SAR. El módulo de transformación de acciones, que actúa en la segunda región de tareas del LLC, realiza las tareas asociadas a la normalización de valores para el control de velocidad de cada una de las ruedas del robot e-puck.

Para la arquitectura de sistema autónomo de robot con planificador SARp que se muestra en la Figura 4.7, el sistema controlador de acciones en ejecución está encargado de verificar que las predicciones de los planes se hayan cumplido y en caso de necesitarlo le pide al subsistema planificador que cree nuevos planes, quien mediante el subsistema ponderador de planes decide si una plan es confiable o no. Luego de este proceso el sistema controlador de acciones puede enviarle al robot la próxima acción a ejecutar.

Para la arquitectura del sistema autónomo de robot con ranking SARr que se muestra en la Figura 4.7, el subsistema de ranking de teorías del SARr, consta de: un módulo dedicado a armar el ranking de teorías en función de su utilidad y del valor de $\mathrm{P}, \mathrm{K}$ de éstas. Este módulo de planificación por ranking, selecciona la teoría sobre la base de la situación percibida actual y la base de teorías ordenadas por el módulo de ranking, el que sobre la base de la teoría seleccionada, envía la acción al módulo controlador de acciones, quien la envía al robot, como la próxima acción a ejecutar. 
El diagrama de actividades que representa el flujo general de actividades realizadas por los diferentes módulos del SAR puede verse en la Figura 4.8. A continuación se detalla el proceso de ejecución del SAR durante la corrida de $n$ ciclos del robot.

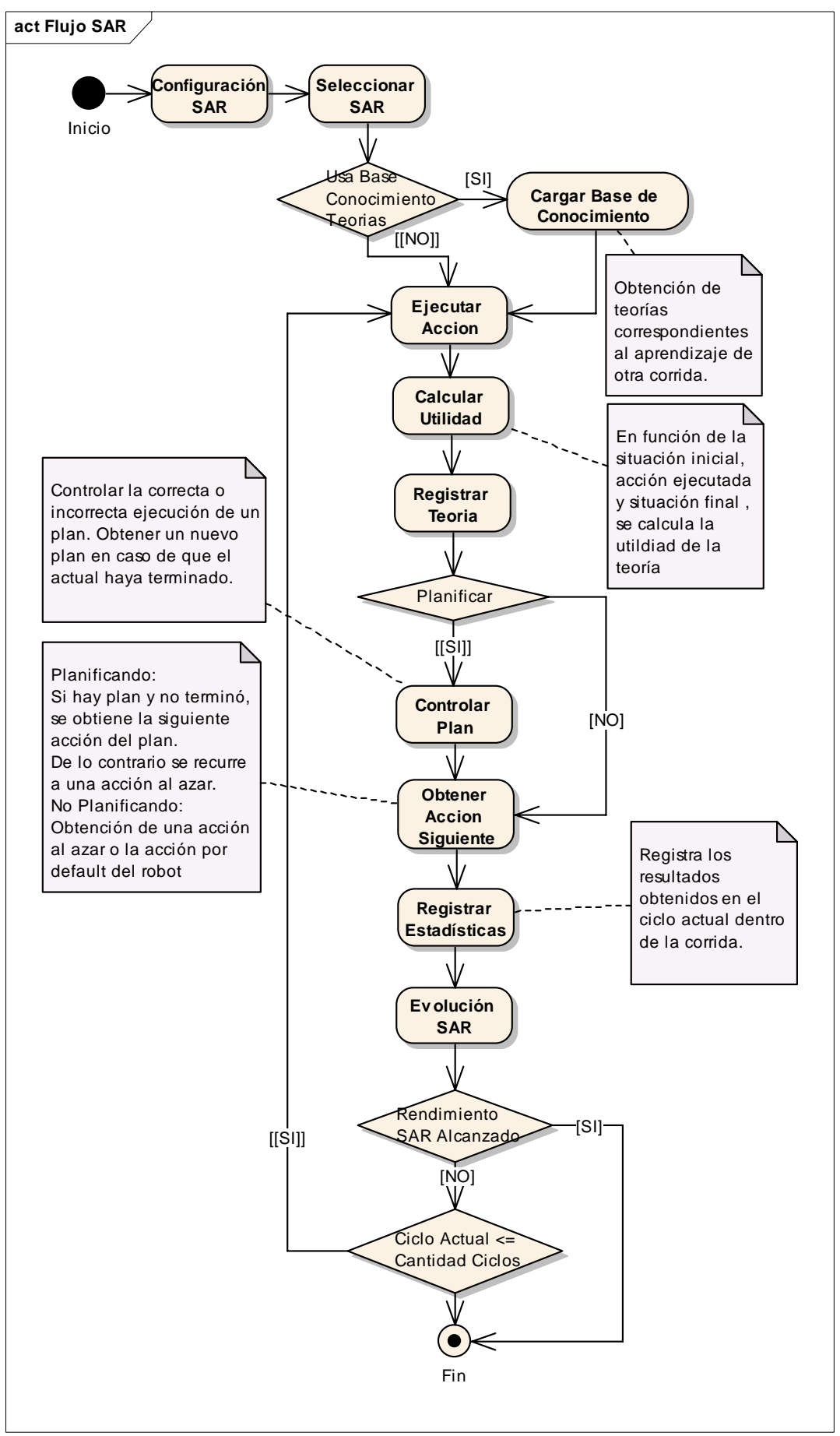

Figura. 4.8. Diagrama de actividades realizadas por los diferentes módulos del SAR

En primer lugar se realiza la actividad correspondiente a la "Configuración del SAR" en este contexto se realiza la selección del ambiente de operación del SAR, la configuración de parámetros 
generales y la configuración de estadísticas de aprendizaje del SAR. Se detallan las actividades correspondientes a la configuración del SAR en la subsección 4.4.2.1.

En segundo lugar se realiza la actividad correspondiente a la "Selección del tipo SAR" y sus métodos asociados. En este orden se presentan SARp neutro o SARp clásico, SARp con ponderación de planes y mutación (SARp P,M), SARr neutro, SARr con mutación de teorías (SARr M), SAR reactivo, este último no tiene métodos asociados y se aplica para generar las teorías iniciales en la base de conocimiento de un SAR nacido o born. Se detallan las actividades correspondientes a la selección del tipo de SAR y sus métodos asociados en la subsección 4.4.2.2.

Antes de empezar a correr el primer ciclo, si la configuración lo indica se efectúa la carga de la base de conocimiento de teorías, desde el archivo correspondiente al SAR que comparte sus teorías.

Inicialmente se obtiene la situación actual del robot (es decir, se obtienen los valores de cada uno de sus sensores), correspondiente a la primera región de tareas del LLC del SAR, realizando una acción al azar y comenzando el primer ciclo percepción-acción del SAR. Cada uno de los ciclos que ejecuta el SAR, se lleva a cabo mediante los siguientes pasos: [a] la ejecución de la "acción" correspondiente a la segunda región de tareas del LLC del SAR. En el caso de nuestro robot epuck, esto se corresponde con establecer (setear) los valores de velocidad de cada una de las dos ruedas, determinados en la acción, [b] la obtención de la "situación final" como producto de la ejecución de la acción establecida correspondiente a la tercera región de tareas del LLC del SAR, teniendo en cuenta la situación inicial y la acción ejecutada por el robot se calcula la utilidad resultante, correspondiente a la cuarta región de tareas del LLC del SAR. Se detalla el método de cálculo de utilidad basado en la situación en la subsección 4.4.3.1 y el método de cálculo de utilidad basado en la acción en la subsección 4.4.3.2, este último, es el método aplicado en el presente trabajo [c] el "registro de las teorías" obtenidas, (correspondiente al aprendizaje del SAR que se desarrolla en quinta región de tareas del LLC del SAR), sobre la base de conocimiento de teorías, en función de la situación inicial, la acción, la situación final resultante, incorporando la estimación de sus parámetros $\mathrm{P}$ y K. Se detalla el registro de la teoría en la subsección 4.4.4, así mismo se detalla la estimación de parámetros $\mathrm{P}$ y $\mathrm{K}$ con la aplicación del método de mutación de teorías similares en la subsección 4.4.5, [d] la "planificación de las acciones" del SAR (se lleva a cabo en la elección de la acción del SAR, correspondiente a la tercera región de tareas del LLC), se presentan tres métodos, el primero planificador clásico [Fritz et al ,1990] que identificamos como SARp neutro (clásico) o simplemente SARp, el segundo planificador con ponderación que aplica los métodos de ponderador de planes y mutación [Maceri et al ,2006] que forma parte del SARp que identificaremos con las siglas, SARp P M (SARp con ponderación de planes y mutación de teorías), el tercero correspondiente al SAR con planificador por ranking (propuesto) que identificaremos con 
las siglas SARr, el que se reconoce como neutro y SARr M si aplica el método de mutación de teorías. El planificador le permite al SAR obtener la acción a ejecutar, en caso de que haya un plan válido, de lo contrario el planificador recurre a una acción al azar (selección de una teoría de la base de conocimiento). La planificación de acciones del SAR, se detalla en la subsección 4.4.7. En el caso en que el SAR no utilice planificador, el SAR por defecto actúa como reactivo y se lo identifica como SAR reactivo, [e] la "comparación de teorías" (empleado en el proceso de registro de teorías y en la planificación de acciones) se distinguen tres métodos de comparación: exacto, umbral fijo, umbral variable, este último es el que se aplica en el presente trabajo, se presentan los mencionados métodos en la sección 4.4.6 [f] la "compartición de teorías" a través de la cooperación y la colaboración entre SARs se detalla en la subsección 4.4.8, [g] el "registro de las estadísticas" de aprendizaje (correspondientes a la sexta región de tareas del LLC) en función del ciclo i ejecutado por el SAR: cantidad de situaciones, cantidad de teorías (teorías acumuladas en la base de conocimiento), cantidad de teorías exitosas (teorías con utilidad:0,75<U $\leq 1$ ), cantidad de teorías nuevas (generadas en la actuación),cantidad de planes exitosos, cantidad de ciclos exitosos, porcentaje de ciclos exitosos, relación $\mathrm{P} / \mathrm{K}$ de las teorías, se detalla en el diagrama de actividad correspondiente a la configuración del SAR, las estadísticas registradas por el SAR ( subsección 4.4.2.1).En la subsección 4.4.9 se detalla el registro y las estadísticas de aprendizaje del SAR, [h] el rendimiento de aprendizaje del SAR (correspondiente a la séptima región de tareas del LLC), se evalúa sobre la base de la cantidad de los ciclos exitosos y la cantidad de teorías nuevas (esta última sólo para SARs que recibieron colaboración), la evolución de estado del SAR, se describe en la subsección 4.4.10. En el Anexo O se presentan mayores detalles de la interfase entre el robot e-puck y el sistema desarrollado.

\subsubsection{Configuración del sistema autónomo de robot}

Se detalla el diagrama de actividad correspondiente a la configuración del SAR en la Figura 4.9. En este contexto se realizan las siguientes actividades:[a] la selección del ambiente de operación del SAR, éstos se clasifican en escenarios asociados a los estados de evolución y los layers que los comprenden, éstos son, escenario Born-Newbie asociado al layer BIO, escenario Newbie-Trained asociado al layer TBO, escenario Trained-Mature asociado al layer WIO, [b] configuración de parámetros generales que corresponden a la cantidad de ciclos que se ejecutarán, el método de comparación de teorías que se aplicará (exacto, umbral fijo, umbral variable) y la selección de la base de conocimiento del SAR, [c] la configuración de estadísticas, que comprende la 
determinación del intervalo de muestras del estado de ejecución del SAR, la determinación del intervalo de distribución de utilidad de teorías y la elección de los datos a registrar (Ciclos, Cantidad de Situaciones, Cantidad de Teorías Acumuladas, Cantidad de Teorías Nuevas, Cantidad de Teorías Exitosas, Cantidad de Teorías por intervalo de utilidad, Cantidad de Ciclos Exitosos, Cantidad de Planes Exitosos, Cantidad de planes, Cantidad de planes sin éxito, Cantidad de Azares) que conformarán la estadística del comportamiento del SAR,[d] rendimiento de aprendizaje en función del porcentaje de ciclos exitosos y el porcentaje de teorías nuevas.

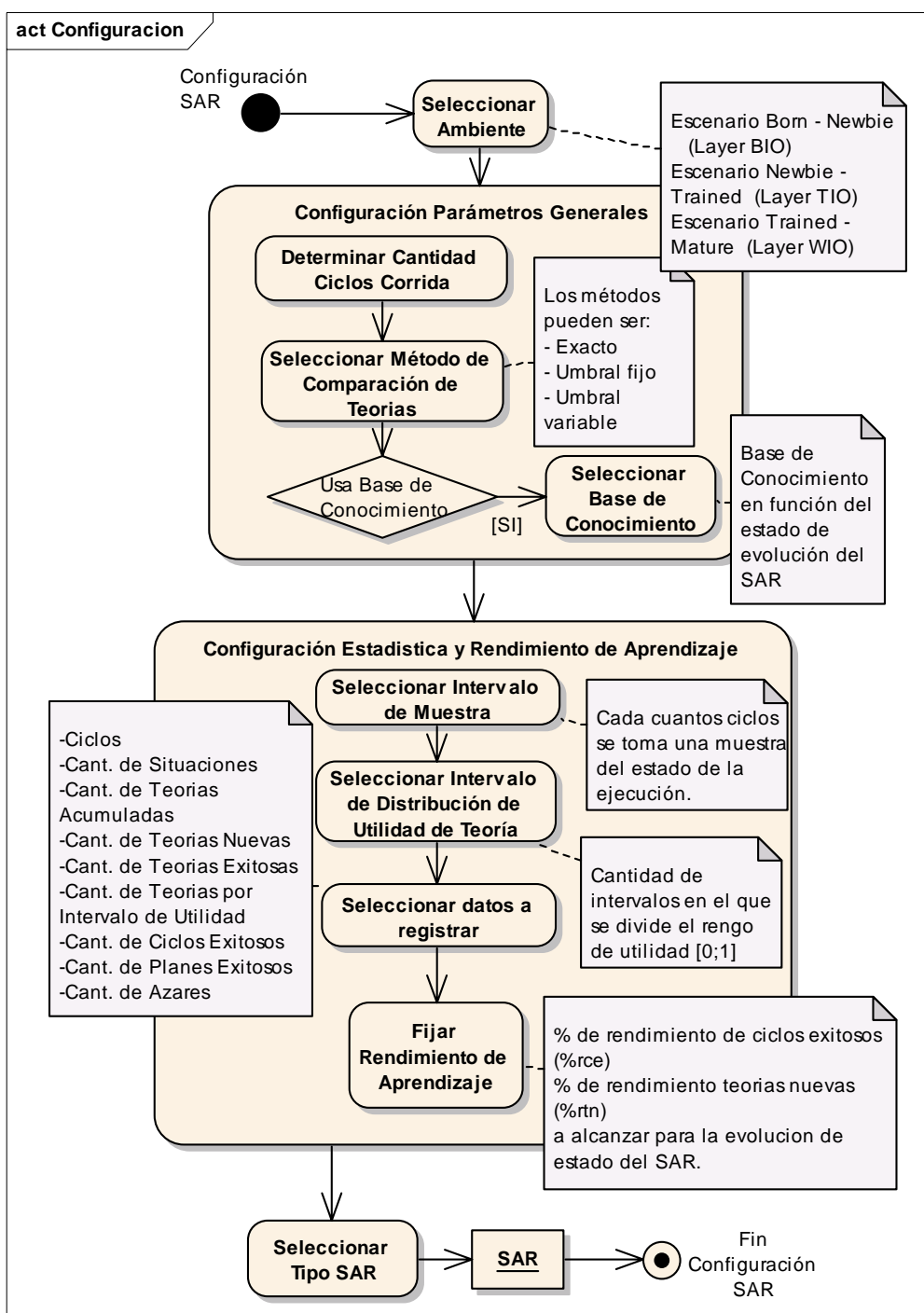

Figura 4.9.Diagrama de actividades correspondientes a la configuración del SAR 


\subsubsection{Selección del sistema autónomo de robot y sus métodos asociados.}

Se presenta en la Figura 4.10, el diagrama de actividad correspondiente a la selección del tipo de SAR y sus métodos asociados, en este orden se presenta en primer lugar la selección del SAR con planificador para la determinación de las acciones del SAR, o aplicar un SAR reactivo que no aplica planificador y se emplea para generar una base de conocimiento de teorías iniciales. En segundo lugar en el contexto de SAR con planificador, las actividades que se realizan en el marco de su elección son:[a] seleccionar el método que se aplicará para determinar la utilidad (clásica basada en la situación, coeficientes, basado en la acción) de las teorías que aplica el SAR ,[b] selección del planificador a emplear, en este orden se presentan el planificador clásico (SARp) o el SARr con planificador por ranking de teorías (propuesto), [c] para ambos casos la selección de aplicar o no mutación de teorías resultando de aplicar mutación en el SARr la configuración final SARr con mutación (SARr M),y de no aplicarla SARr neutro,[d] para el caso del SARp de aplicar mutación y no aplicar ponderador de planes, se presenta la configuración final del SARp con mutación (SARp M) y de aplicar ponderador se presenta la configuración final SARp con ponderador y mutación (SARp P, M),[e] Para el SARp que no aplica mutación pero aplica ponderador de planes, resulta la configuración de SARp con ponderador (SARp P), de no aplicar ponderador de planes ni mutación, resulta la configuración de SARp neutro.

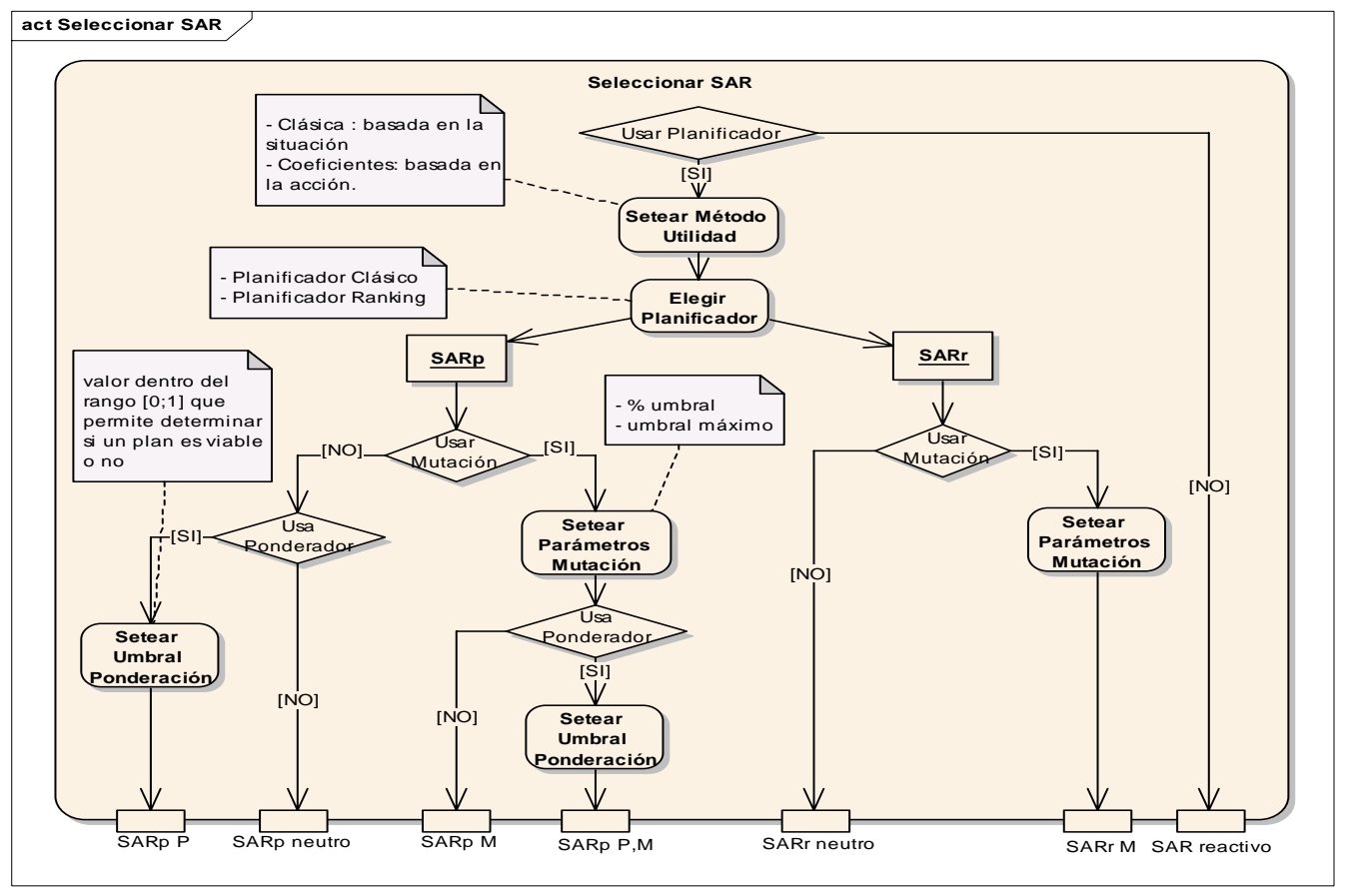

Figura. 4.10. Diagrama de actividades selección del SAR y sus métodos asociados 
La mutación requiere establecer (setear) parámetros correspondientes al porcentaje de umbral de teorías a mutar y el umbral máximo de teorías a mutar. La ponderación requiere establecer un valor de ponderación de plan, para determinar la viabilidad del plan.

En función de la compartición de conocimiento entre SARs, detallada en la subsección 4.4.8, se extienden los tipos de SARs al considerar la base de conocimiento asociada, se presenta en la subsección 4.7.1 para el SAR con planificador clásico (SARp) las extensiones de SARps que se aplican en el Capítulo 5 experimentación y en la subsección 4.7.2 se presenta para el SAR con planificador por ranking de teorías (SARr), las extensiones de SARrs que se aplican en el Capítulo 5 experimentación.

Se presenta en el Anexo K un ejemplo de un archivo que contiene los parámetros de configuración, tipo de SAR y métodos asociados.

\subsubsection{UTILIDAD DE UNA TEORÍA.}

Se presentan dos métodos de cálculo de utilidad, el primero basado en la situación (4.4.3.1) y el segundo, basado en la acción (4.4.3.2), este último método es el que se aplica en el presente trabajo.

\subsubsection{Utilidad basada en la Situación}

Este método de utilidad, se basa en la situación percibida por el robot, a partir de la información de distancia a los obstáculos que le brindan sus sensores de proximidad [García Martínez et al., 2000], [García Martínez et al., 2006, Maceri y García Martínez, 2001], el rango de cada sensor es [0 a 1023]. El robot obtiene la mayor utilidad "U”, cuando se encuentra a mayor distancia de una pared u obstáculo.. En este método, se transforma (normaliza) la utilidad final de la teoría al rango de valores $[-1 \mathrm{a}+1]$. El robot estará más cerca de un obstáculo cuanto más cercano a 1023 estén los valores de sus sensores (utilidad: -1), cuanto más alto sea el valor de la suma de valores de cada sensor, la utilidad se acercará a -1 (más cerca del obstáculo). Cuanto más bajo sea el valor de la suma de los valores obtenidos de los sensores, más lejos se encuentra el obstáculo, la utilidad se acercará a uno $(+1)$.

Este método maximiza cuán lejos se encuentra un SAR de un obstáculo. En el método de cálculo se suman los valores de todos los sensores de detección del robot (sumaSensores), en el caso del robot e-puck, se suman los ocho sensores de proximidad, el máximo rango es MAX_RANGE = 1023* 8, 
sobre éste se determina el valor de AUX que se aplicará en la normalización, resultando AUX= MAX_RANGE/2, AUX=4092.

Luego se determina la Utilidad Auxiliar como UtilidadAux= AUX - SumaSensores (valor acumulado por la suma de las lecturas de los sensores). Cuanto más grande sea el valor de SumaSensores correspondiente a la suma de las lecturas de los sensores, más cerca de un obstáculo está el robot, con lo cuál, la utilidad se acercará a -1 , caso contrario se acercará a +1 .Finalmente, el valor UtilidadAux se divide por el valor de AUX, (4092) para llevarlo al rango [-1; 1], que indica el valor de utilidad (U) de la teoría. Habrá mayor Utilidad cuanto más lejos esté de una pared el robot. Se muestra en la Figura 4.11 el diagrama del módulo de utilidad basado en la situación o utilidad original. Asimismo se detalla en el algoritmo 4.1, el código del método de utilidad basado en la situación final.

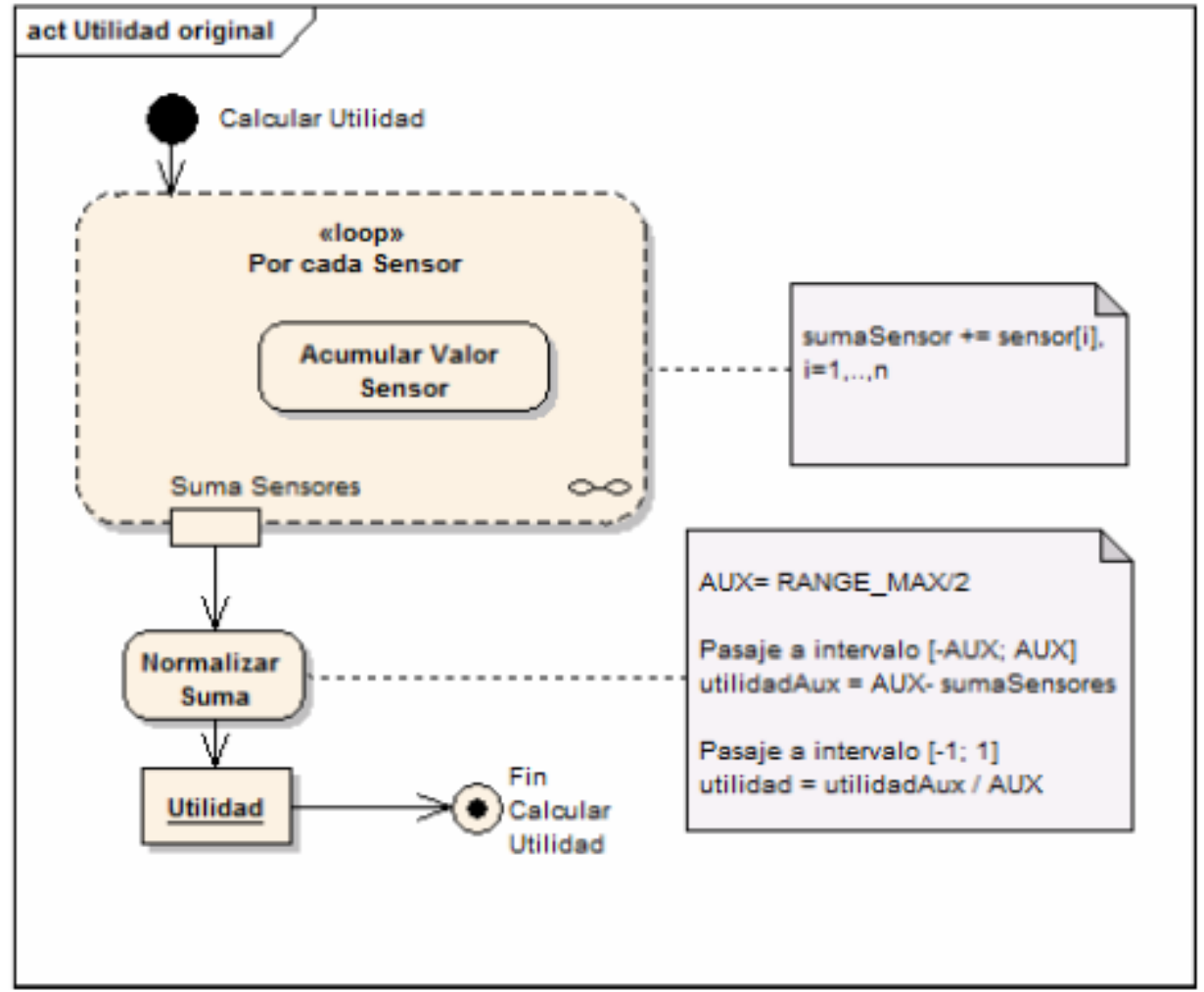

Figura. 4.11. Diagrama de actividad del Módulo de utilidad basada en la situación 


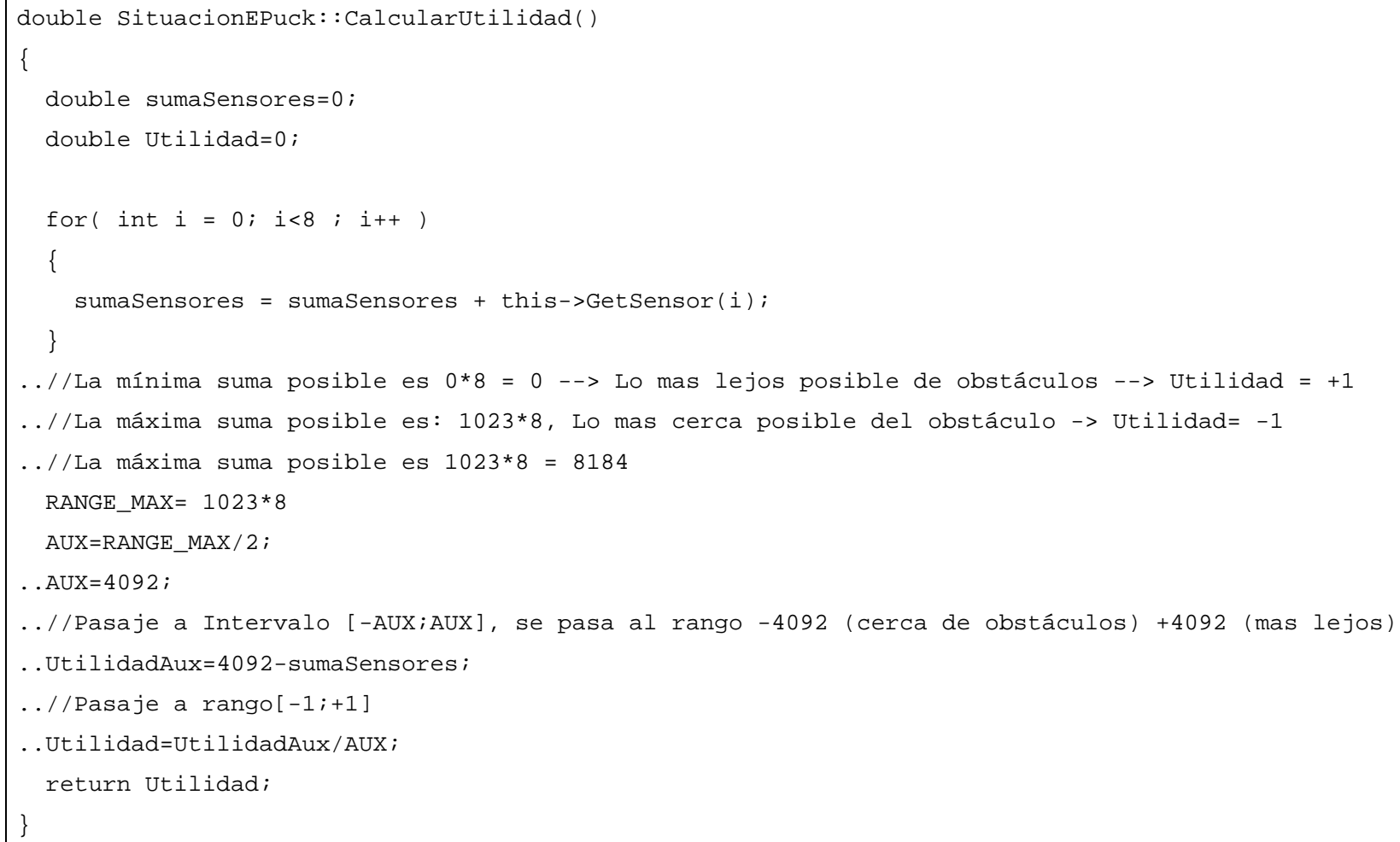

Algoritmo 4.1. Método de Utilidad basado en la situación

\subsubsection{Utilidad con coeficientes o basada en la acción}

El segundo método de utilidad se basa en la acción realizada por el robot (velocidades aplicadas a cada una de las ruedas del robot), la que se determina sobre la base de la velocidad diferencial (VELOCIDAD_BRAITENBERG), aplicando los coeficientes de Braitenberg [Braitenberg, V., 1984], método aplicado por el simulador Webots para la determinación de velocidad del robot e-puck. La utilidad de la teoría i se determina a través de la comparación entre las velocidades que indica la acción de la teoría i (VELOCIDAD _ TEORÍA) de la base de conocimiento que aplica el SAR y la acción determinada con los coeficientes de Braitenberg para sus ruedas izquierda y derecha. Cuanto más cerca esté la acción de la teoría i en cuanto a las velocidades aplicadas (VT) por el robot, en relación a la velocidades (VB) determinadas con los coeficientes de Braitenberg, mayor utilidad tendrá la acción tomada por el SAR (más cerca de uno), cuanto más lejos se encuentre la acción de la teoría, menor utilidad tendrá (cerca de menos uno). Para contabilizar las teorías exitosas, se adoptó como criterio el rango valores de utilidad " $U$ ": $0,75<\mathrm{U} \leq 1$. Se muestra en la Figura 4.12 el 
módulo de utilidad basado en la acción. La interfase entre el robot e-puck y el sistema desarrollado se presenta a nivel conceptual en el Anexo O. La VELOCIDAD_BRAITENBERG se determina para cada rueda del robot e-puck, en función del valor obtenido por la lectura de cada uno de los sensores de proximidad del robot y cada coeficiente de la matriz de Braitemberg. Dicha matriz es de $\mathrm{N}$ x M, donde $\mathrm{N}$ es la cantidad de sensores (ocho), y M es la cantidad de ruedas (dos).Se normaliza el Sensor [i] como (1-Sensor [i] / 1024), en el rango de [0,1].

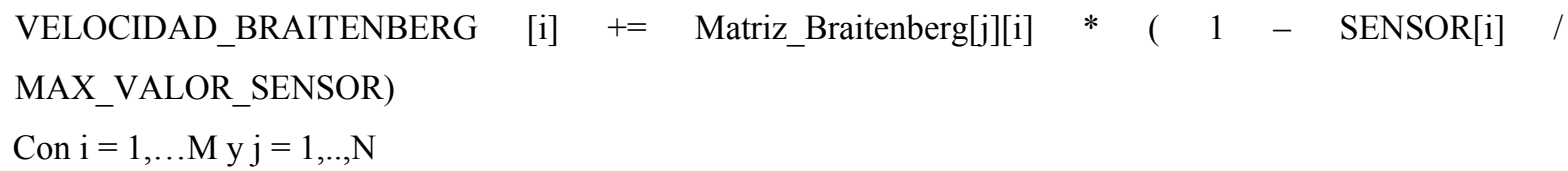

Luego se calcula la utilidad a partir de la diferencia absoluta entre la Velocidad obtenida de la Acción de la teoría (VELOCIDAD_TEORIA) seleccionada de la base de la teoría aplicada y la VELOCIDAD_BRAITENBERG (VELOCIDAD_CALCULADA) y se normaliza dicho valor de utilidad para llevarlo al rango $[-1 ; 1]$.

$$
\begin{aligned}
& \mathrm{V}[\mathrm{i}]=\mid \text { VELOCIDAD_BRAITENBERG }[\mathrm{i}]-\text { VELOCIDAD_TEORIA }[\mathrm{i}] \mid \\
& \mathrm{V}[\mathrm{i}]=\mathrm{V}[\mathrm{i}] / \text { VALOR_NORMALIZACION }
\end{aligned}
$$

Donde el VALOR_NORMALIZACION es la amplitud del rango de velocidad que toman las ruedas del robot (1600).El algoritmo utilizado para obtener el valor de las velocidades en cada paso del robot se detalla en el algoritmo 4.3 "Método de cálculo de la velocidad de las ruedas", donde speed [i] es el vector con las velocidades resultantes para el paso actual y s->GetSensor(j) es el valor del sensor “j” en el paso actual.

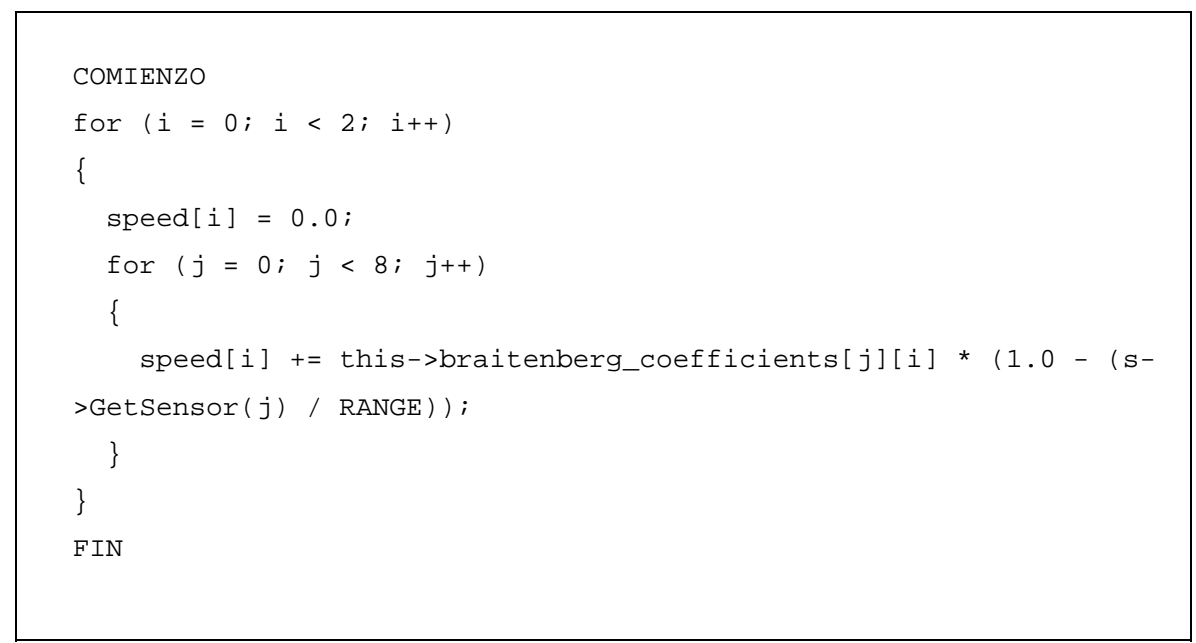

Algoritmo 4-3 Método de cálculo de la velocidad de las ruedas del SAR 
Los coeficientes de Braitenberg se almacenan en una matriz de 8x2 que se detalla en la tabla 4.1. Se detalla en el Anexo B, un ejemplo del método de cálculo de utilidad basado en la acción. En el Anexo N, se presentan mayores detalles en cuanto a la obtención de la velocidad a partir de los valores obtenidos de los sensores de proximidad del robot.

Cuanto más cercana esté la acción tomada de lo que se hubiera calculado con los coeficientes Braitenberg, mayor utilidad (U) habrá (más cerca de +1 ). Cuanto más lejos, menor utilidad (U) habrá (cerca de -1).

El pseudo-código del algoritmo para el método de utilidad se detalla en el algoritmo 4-2 "Método de utilidad basado en la acción". Con relación a los trabajos de Braitenberg se presenta en el Anexo $\mathrm{P}$, un resumen general de los vehículos robots propuestos por Valentino Braitenberg.

\begin{tabular}{|c|}
\hline braitenberg_coefficients $[0][0]=150$; \\
\hline braitenberg_coefficients $[0][1]=-35$; \\
\hline braitenberg_coefficients $[1][0]=100 ;$ \\
\hline braitenberg_coefficients[1][1] $=-15$; \\
\hline braitenberg_coefficients[2][0] $=80$ \\
\hline braitenberg_coefficients[2][1] $=-10$; \\
\hline braitenberg_coefficients[3][0] $=-10$; \\
\hline braitenberg_coefficients[3][1] $=-10$; \\
\hline braitenberg_coefficients[4][0] $=-10$; \\
\hline braitenberg_coefficients[4][1] $=-10$; \\
\hline braitenberg_coefficients[5][0] $=-10$ \\
\hline braitenberg_coefficients[5][1] = 80; \\
\hline braitenberg_coefficients $[6][0]=-30$; \\
\hline braitenberg_coefficients[6][1] $=100$; \\
\hline braitenberg_coefficients[7][0] $=-20$ \\
\hline braitenberg_coefficients[7][1] $=150$ \\
\hline
\end{tabular}

Tabla 4-1 Matriz de Coeficientes de Braitenberg

ENTRADA: SituacionInicial, AccionTomada

SALIDA: Utilidad

Se obtiene VELOCIDAD_ $\odot$ y VELOCIDAD_1 que se hubiera obtenido con los Coeficientes Se determina diferencia (delta velocidad rueda $\odot$ ) DO entre VELOCIDAD_@ y AccionTomada->Velocidad $(\odot)$

Se determina diferencia (delta velocidad rueda 1) D1 entre VELOCIDAD_1 y AccionTomada->Velocidad(1)

Se normaliza D $\odot$ y $D 1$ a valores entre $\odot$ y 1

Utilidad previa $=\mathrm{D} \odot+\mathrm{D} 1$ (valor entre $\odot$ y 2 )

Se normaliza Utilidad (U) al rango $[-1 ;+1]$, (U= U previa-1)

Se devuelve Utilidad (U)

FIN

Algoritmo 4-2 Método de utilidad basado en la acción 
Se implementó el método de utilidad, basado en la acción, sobre un e-puck reactivo. El robot reactivo aplica los coeficientes de Braitemberg (utilizados por el simulador Webots) junto a la situación obtenida por la lectura de sus ocho sensores de proximidad en cada ciclo, para determinar el valor que corresponde para las velocidades de las ruedas izquierdas y derechas.

De esta manera el SAR born, reactivo (implementado en un robot e-puck), logra moverse lo mejor posible en el escenario, sin necesidad de adquirir más conocimientos que los que le brinda su creador (programador). Se muestra en la Figura 4.12 el diagrama de actividad del módulo de utilidad de coeficientes o basado en la acción (velocidad de las ruedas)

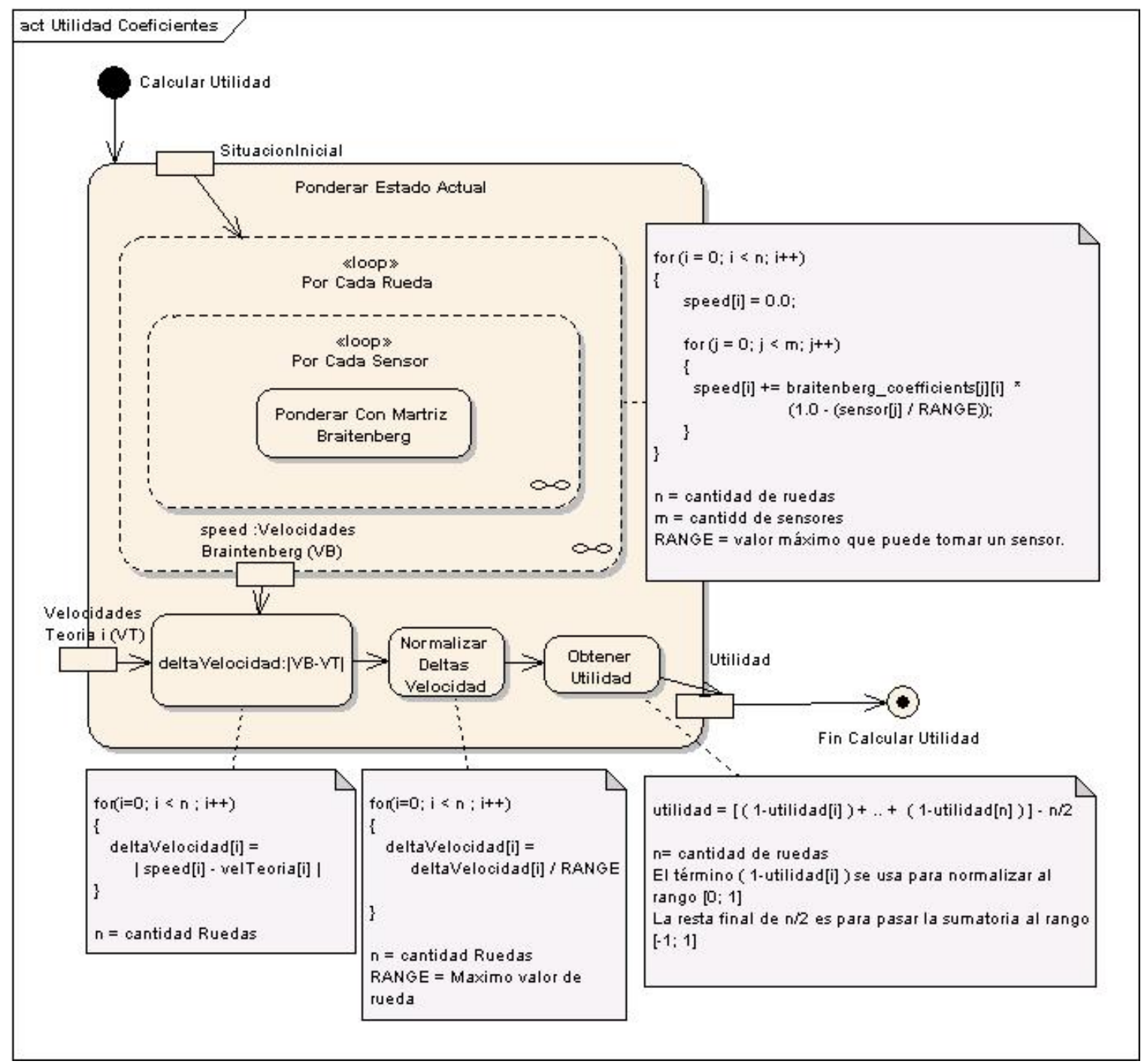

Figura. 4.12 Diagrama de actividad del módulo de utilidad basada en la acción 


\subsubsection{REGISTRO DE TEORÍAS}

El registro de una teoría de un SAR en la base de conocimiento de teorías constituye el proceso de aprendizaje del SAR al estimar sus parámetros $\mathrm{P}$ y K asociados. La teoría se conforma por: la situación inicial (determinada en la primera región de tareas del LLC), la acción (determinada en la segunda región de tareas del LLC), la situación final (determinada en la tercera región de tareas del LLC), el cálculo de la utilidad U de la teoría (determinado en la cuarta región de tareas del LLC), el proceso de registro de la teoría, se lleva a cabo en la quinta región de tareas del ciclo de vida de aprendizaje (LLC) del SAR, en esta región se lleva a cabo también la estimación de los parámetros P y K de la teoría. En la Figura 4.13, se muestra el diagrama de actividades del módulo de registro de teoría.

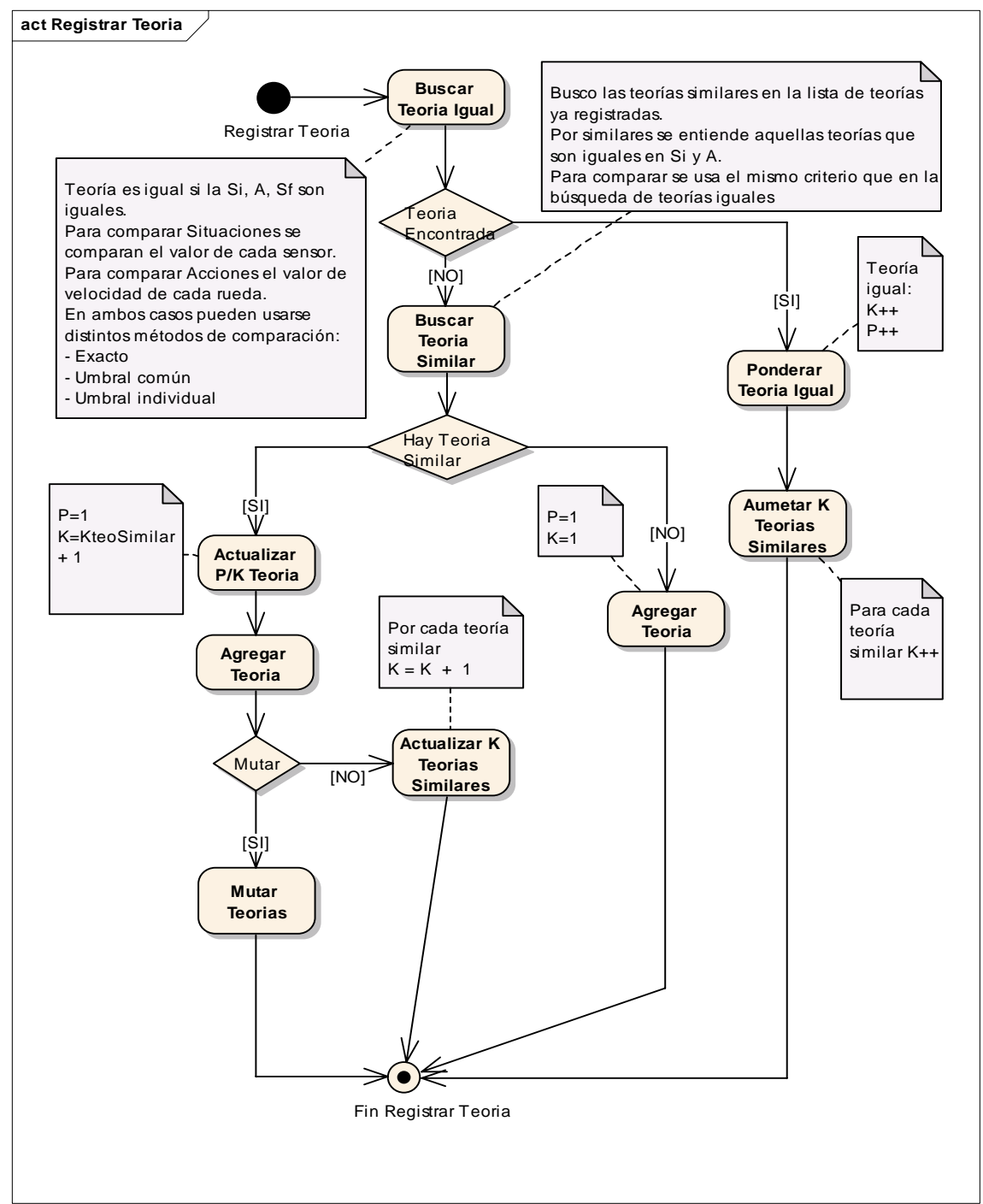

Figura 4.13 Diagrama de actividad del módulo de registro de teorías 
El método empleado contempla el concepto de que la teoría que es utilizada con éxito debe ser reforzada incrementando su $\mathrm{P}$ y su $\mathrm{K}$ y que la teoría que es utilizada de forma infructuosa debe ser debilitada incrementando su K, sin incrementar su P. En caso de que se encuentre una teoría igual, se actualizan los $\mathrm{P}$ y $\mathrm{K}$ de la misma y se actualizan los $\mathrm{K}$ de las teorías similares (una teoría es similar si posee la misma situación inicial y la misma acción que la otra). En caso de que no haya una teoría igual se buscan las teorías similares. Si no existen teorías similares, se agrega la teoría como una teoría nueva con $\mathrm{P}=1$ y $\mathrm{K}=1$.

En caso de que existan teorías similares, se actualiza el P y K de la teoría, estableciendo (seteando) $\mathrm{P}=1$ y $\mathrm{K}=$ Ksimilar +1 y se agrega la teoría a la base de conocimiento de teorías del SAR. Si la mutación está habilitada, entra en juego el módulo de mutación para $\mathrm{n}$ teorías. La cantidad de teorías a mutar (n) se calcula sobre la base del porcentaje de mutación que se aplica sobre la cantidad de teorías similares encontradas o bien, si dicha cantidad calculada supera un umbral (valor máximo de teorías mutadas), la cantidad de teorías a mutar adopta el valor del umbral.

De lo contrario, si no se aplica mutación, se actualiza el $\mathrm{K}$ de todas las teorías similares como $\mathrm{K}=\mathrm{K}+1$. El proceso de mutación de teorías aplicado a las teorías similares se desarrolla en la subsección 4.4.5

Las teorías se registran en un archivo XML, se presenta en el Anexo C un ejemplo del registro de teorías del SAR.

\subsubsection{MUTACIÓN DE TEORÍAS}

El método de mutación que se aplica a las teorías similares, se selecciona en la configuración del $\mathrm{SAR}$, en el marco de los métodos de aceleración del aprendizaje. Este método genera teorías mutadas sobre la base de las teorías similares, incrementando la base de conocimiento de teorías del SAR.

Se detalla en el Anexo D, un ejemplo del método de mutación de teorías, sobre la base de un conjunto inicial de teorías. En la Figura 4.14 se presenta el diagrama de actividades del método de mutación de teorías, inicialmente se actualiza el valor de $\mathrm{K}$ de la teoría similar en 1 (uno).A continuación se genera una teoría mutada de la siguiente manera: se crea una situación mutada, luego se comparan entre sí los valores de lectura registrados en la situación de la teoría similar y en la situación de la teoría actual, correspondientes a cada uno de los ocho sensores del robot e-puck que registran la situación. Si los valores de sensores son iguales, se copia dicho valor al sensor correspondiente de la situación mutada. De lo contrario, el sensor correspondiente de la situación 
mutada toma un valor generado al azar. Las características del método de comparación entre situaciones de teorías se describen en la subsección 4.4.6. Se instancia la teoría mutante que toma los valores de la teoría actual, pero su situación pasa a ser la situación mutada previamente calculada. Con estos valores que conforman la teoría mutada, se calcula la utilidad de la teoría mutada.

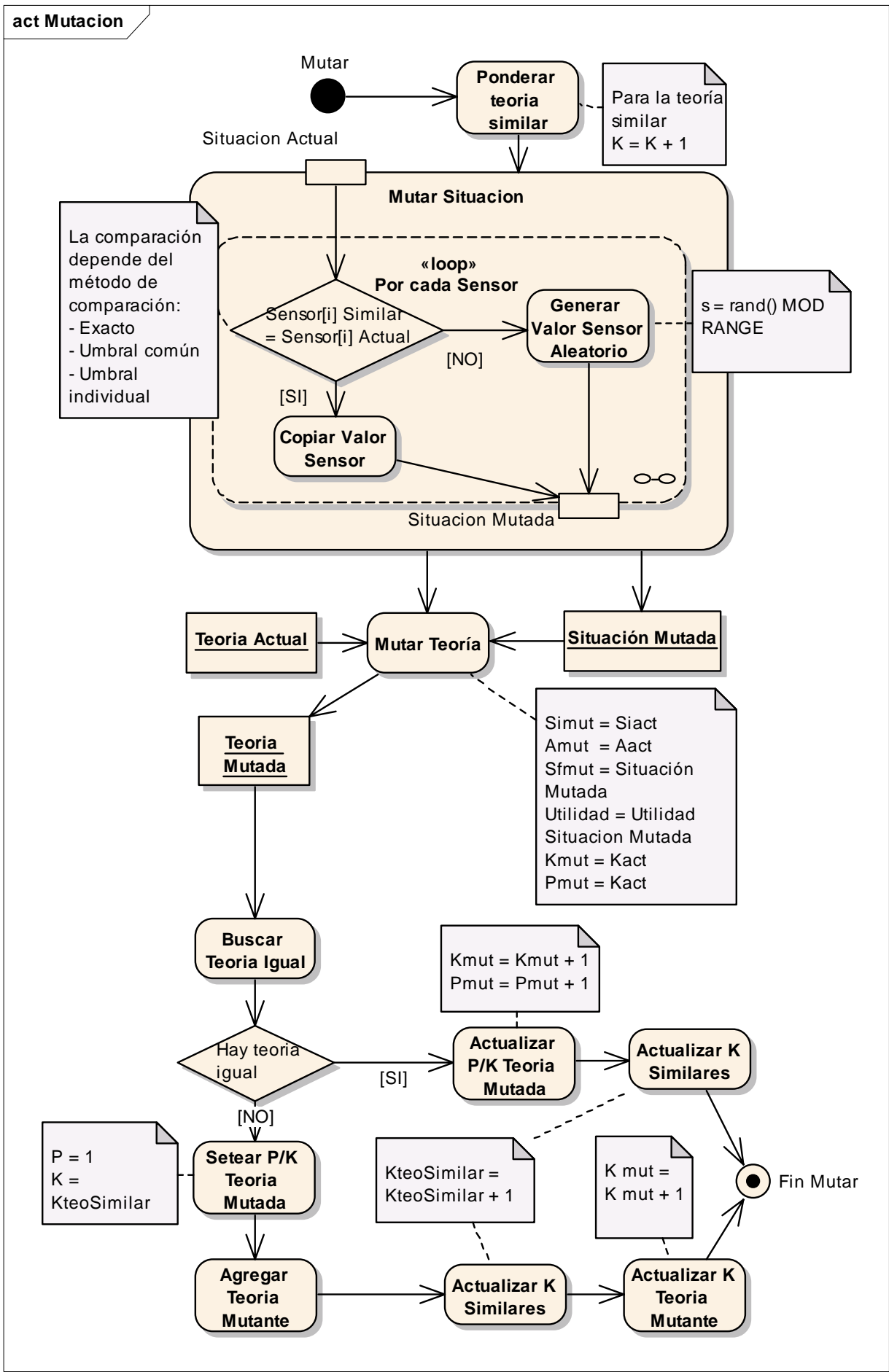

Figura 4.14. Diagrama de actividades del módulo de mutación 
Posteriormente se busca en la base de conocimientos que aplica el SAR una teoría igual a la teoría mutante recientemente generada, si existe, se aumenta el P y K de la teoría mutante en 1 (uno) y además se aumentan los $\mathrm{K}$ de las teorías similares.

Si no existe en la base de conocimientos del SAR un teoría igual a la teoría mutante, se establece para la teoría mutante $\mathrm{P}=1$ y $\mathrm{K}=$ KteoriaSimilar y se agrega la teoría mutante a la lista. Luego se prosigue a aumentar el $\mathrm{K}$ de las teorías similares a la mutante y actualizar el $\mathrm{K}$ de la teoría mutante. El método de mutación se implementó sobre la base del trabajo de García-Martínez, R., Borrajo, P, Britos, y Maceri, D (2006), incorporando parámetros de configuración de la mutación que aplica el SAR, estos parámetros propuestos actúan sobre la base un máximo de teorías agregadas por mutación en cada paso definidas por configuración del SAR, esto se realizó para evitar un crecimiento exponencial de teorías, con la actuación del método de mutación, debido a que, de un ciclo a otro podría haber una gran cantidad " $\mathrm{N}$ " de teorías similares, lo cual generaba "N" teorías mutantes, aumentando la curva de teorías exponencialmente con la mutación.

En este caso no podrán crearse más de " $X$ " nuevas teorías de un ciclo al otro con mutación. Donde "X" es un valor obtenido según una proporción de teorías a mutar, teniendo en cuenta el total de teorías similares. Si esa proporción supera a la cota máxima "C", el valor "X", adoptará el valor de “C”. Para esto se ingresan por configuración los siguientes parámetros: "Límite de Mutación”(C) y "Proporción de Mutación” (P), donde X es igual a N*P. La mutación es llamada por el método RegistrarTeoría( ) del Módulo de "Aprendizaje", cuando una nueva teoría (Tn) se va a almacenar en la lista y esta teoría es "Similar" a otra/s teorías de la base de conocimientos del SAR (Tsi). Se genera una nueva teoría mutante, de acuerdo con el pseudocódigo detallado en el algoritmo 4.4.

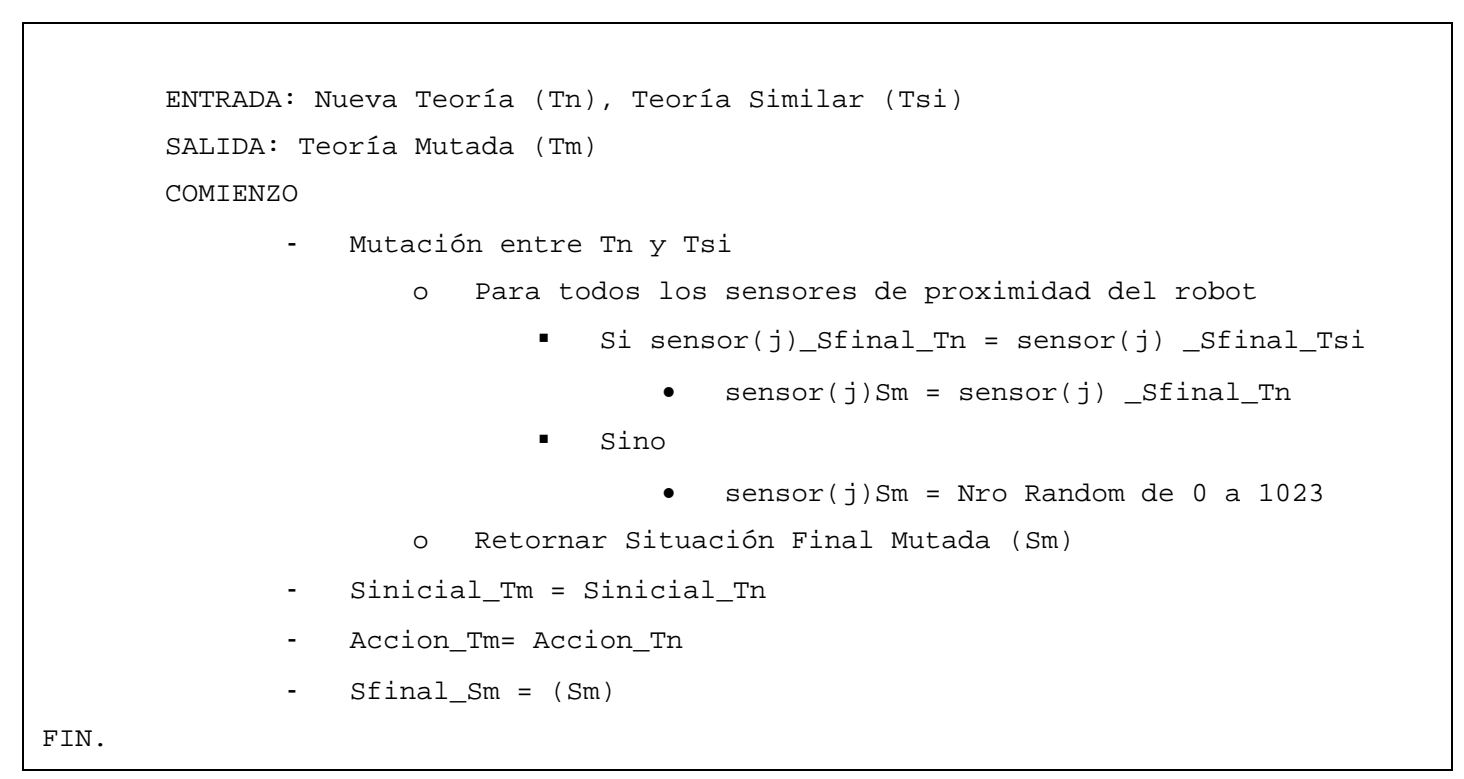

Algoritmo 4.4 Pseudos-código del método de mutación de teorías 


\subsubsection{COMPARACIÓN DE TEORÍAS}

Para la comparación entre valores de lectura de situaciones se distinguen en el presente trabajo tres métodos, éstos son: [a]comparación de valores de sensores exacta, donde los valores de lectura de los sensores del SAR se comparan con los valores de la situación. La condición de igualdad de situaciones, exige que los valores de lectura de cada uno de los sensores que conforman las situaciones comparadas sean exactamente iguales unos a otros, [b] comparación de valores de lectura de sensores por un umbral común (igual) y fijo para todos las lecturas de los sensores que conforman la situación, se presenta este método en la subsección 4.4.6.1,[c] comparación de valores de lectura de sensores a través de un umbral individual y variable por cada sensor y actuador o efector (ruedas del robot), determinado por el desvío estándar de los valores acumulados de lecturas anteriores, se presenta en la subsección 4.4.6.2, este último es el empleado en el presente trabajo.

\subsubsection{Comparación de valores por umbral común}

La comparación se realiza sobre la base del rango de valores del sensor, las lecturas del sensor de proximidad o cercanía a un objeto se realizan en el rango entre 0 y 1023, por cada uno de los ocho sensores que conforman la situación del SAR, la presencia de un obstáculo se determina en función del valor de umbral fijo. En trabajos anteriores [García Martínez, R., et al. 2006, Maceri, D., García Martínez, R., 2001.], se considera al valor máximo del rango de lectura 1023, lo que significa que un objeto está muy cerca del SAR y el mínimo valor de lectura cero (0), lo que significa que ningún objeto es percibido por el SAR. Cada valor de lectura de cada uno de los ocho sensores es convertido a 1 (uno) o a un 0 (cero), para representar la presencia o ausencia de un obstáculo frente a cada sensor del SAR, en función al umbral seleccionado, para realizar la conversión. En los trabajos anteriores mencionados se selecciona un umbral de 750, en este caso un sensor indica la presencia de un obstáculo (con un bit en uno) frente a él, si el valor de lectura se encuentra entre 750 y 1023 . La ausencia de un objeto se indica con un bit que representa al sensor en 0 (cero) el que se producirá cuando el valor del sensor es menor de 750 . 


\subsubsection{Comparación de valores por umbral individual}

Este método de comparación propuesto (aplicado en el presente trabajo), asegura una mayor diversidad de valores de umbrales, independientes para cada uno de los ocho sensores de proximidad distribuidos en el robot e-puck, como se indica figura 4.15, a diferencia del método anterior que aplica un umbral fijo para todos los sensores. Se detalla en el Anexo E, un caso de ejemplo para el umbral de comparación entre situaciones y acciones entre teorías.

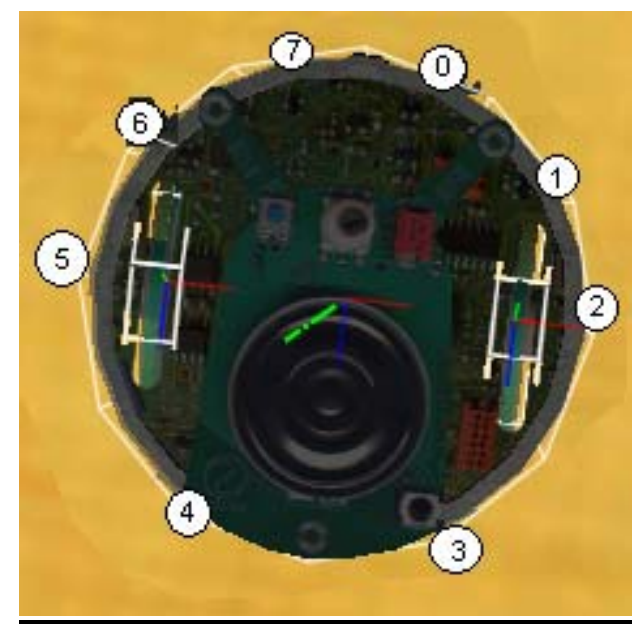

Figura 4.15 Distribución de sensores de proximidad del robot e-puck

Los umbrales de aplicación se determinan a partir del cálculo del desvío estándar de lecturas anteriores de los sensores y de los registros anteriores de los actuadores del SAR. Se seleccionó el desvío estándar para la determinación de cada umbral en forma independiente, en razón de que esta medida representa el promedio de desviación de las lecturas de sensores y registros de acciones del SAR con respecto a la media respectiva para el Sensor i y para el actuador o efector i (rueda).

Con esta medida se obtiene para cada Sensor - Actuador, cuánto se desvía en promedio de la media el conjunto de lecturas de un sensor $\mathrm{i}$ en particular y las acciones registradas en un actuador $\mathrm{i}$ en particular, al operar en un ambiente durante una cantidad de ciclos de percepción-acción .

Para el SAR (robot e-puck) cada sensor tiene 1024 valores posibles (en el rango de 0 a 1023) y cada actuador (rueda) cuenta con 1600 valores posibles (en el rango de -800 a 800) que pueden adoptar en forma independiente cada una de las ruedas.

El umbral de cada sensor surge en forma independiente del desvío estándar calculado para cada uno de los ocho sensores, calculado sobre la base de ciclos de percepción - acción que realiza un SAR (robot e-puck) con comportamiento reactivo.

A diferencia del método anterior este método contempla la acción del SAR a través del control de sus actuadores o efectores, en este caso sus ruedas, incorporando un umbral para cada una de sus 
dos ruedas, sobre la base del desvío estándar calculado a partir de las velocidades registradas para cada rueda, durante los ciclos de percepción-acción que ejecuta el SAR en su escenario tipo.

El umbral de comparación de situaciones de teorías, se determina sobre la base del desvío estándar, calculado a partir de las lecturas de cada sensor (sensor 0..sensor 7) que conforman la situación del SAR. El cálculo de desvío estándar se efectúa sobre la base de 600 muestras correspondientes a 600 ciclos de percepción-acción de un SAR born inicial, que comienza como reactivo con 400 ciclos. El umbral de comparación de acciones de teorías se determina, sobre la base del desvío estándar, calculado a partir de las lecturas de velocidad de cada rueda (Rueda 1, Rueda 2) que conforman la acción del SAR. Para la determinación de los valores de umbrales de comparación de situación (sensor $0 \ldots$ sensor 7) y de acción (velocidad- rueda 1, velocidad rueda 2), se aplicó un escenario de experimentación correspondiente a la layer BIO, como se puede observar en la Figura 4.16.

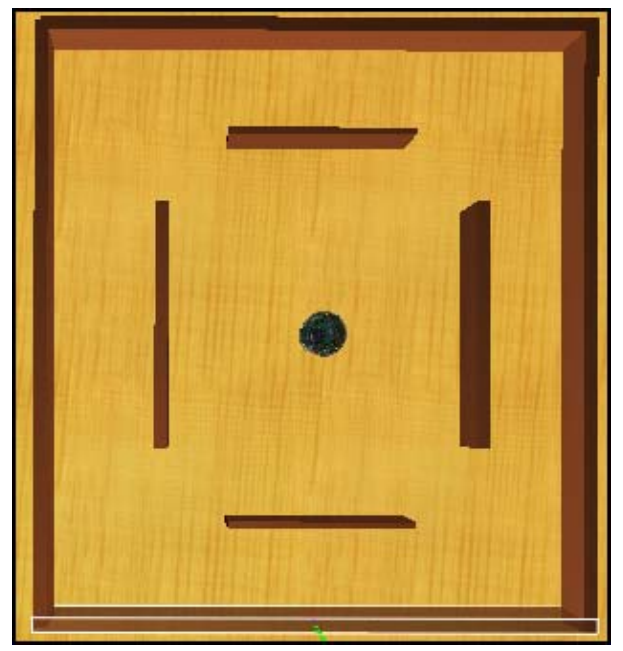

Figura 4.16 Escenario tipo aplicado

El método de comparación de situaciones determina para cada sensor i $(0 \ldots 7)$ de cada una de las situaciones comparadas (situación 1, situación 2), el valor absoluto de la diferencia entre ambos sensores i, si este valor es inferior o igual al umbral (desvío estándar) calculado para el sensor i, entonces se considera que las lecturas de ambos sensores i, de ambas situaciones son iguales. Si todas las diferencias absolutas de lecturas de sensores de ambas situaciones, no superan el umbral calculado para cada sensor i, entonces se considera que ambas situaciones son iguales, caso contrario si al menos una diferencia absoluta entre sensores i de las situaciones comparadas supera el umbral calculado, se considera a las situaciones comparadas como diferentes.

De igual forma el método de comparación de acciones determina para cada actuador i (rueda uno, rueda dos) de cada una de las acciones comparadas (acción 1, acción 2), el valor absoluto de la diferencia entre ambos actuadores i, si este valor es inferior o igual al umbral (desvío estándar) 
calculado para el actuador $\mathrm{i}$, entonces se considera que las lecturas de ambos actuadores $\mathrm{i}$, de ambas acciones son iguales. Si todas las diferencias absolutas registradas de actuadores de ambas acciones, no superan el umbral calculado para cada actuador i, entonces se considera que ambas acciones son iguales, caso contrario si al menos una diferencia absoluta entre actuadores i de las acciones comparadas supera el umbral calculado, se considera a las acciones comparadas como diferentes.

\subsubsection{PLANIFICACIÓN DE ACCIONES DEL SISTEMA AUTÓNOMO DE ROBOT}

El planificador de acciones del SAR se encarga de construir planes (conjunto de acciones ordenadas a ser ejecutadas), que le permiten al sistema transformar su situación actual en una situación objetivo.

El objetivo está implícito en la naturaleza del SAR y se corresponde con la función de utilidad con la cual se evalúe el comportamiento de éste, en este orden el planificador selecciona teorías que transformen la situación actual en la situación asociada a la teorías con mayor utilidad que le permitan al SAR alcanzar la situación deseada con la mayor utilidad.

De las teorías presentes en la base de conocimientos del SAR, se elige aquella cuya utilidad sea máxima y si se puede construir un plan que lleve al SAR de la situación actual hasta ella, esta situación se convierte en situación deseada o situación objetivo. El planificador consta de un módulo controlador del plan, encargado del seguimiento y control del plan y de los planificadores propiamente dichos.

El controlador de plan básicamente se encarga de seguir el plan en caso de que se esté ejecutando, o bien de obtener un nuevo plan. Se muestra el diagrama de actividades del módulo controlador de plan en la Figura 4.17.

El controlador de plan evalúa la situación en la que se encuentra un robot, luego de haber ejecutado una acción, se compara si la situación alcanzada es igual a la situación esperada por el plan. En caso afirmativo, se actualiza el contador de acciones exitosas en el plan y se sigue con el mismo. De lo contrario, se aborta el plan y se actualiza la cantidad de planes sin éxito. 


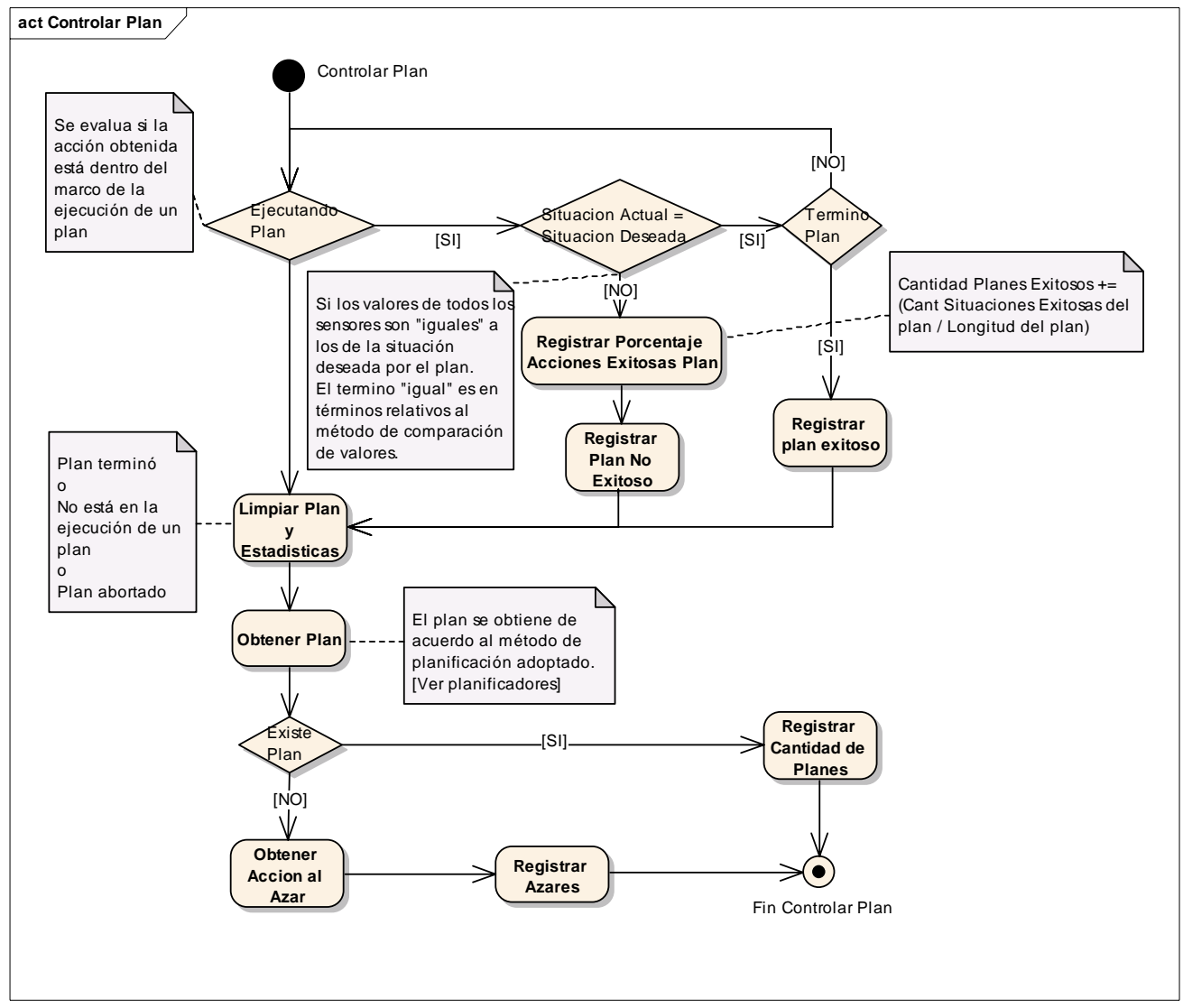

Figura 4.17. Diagrama de actividades del módulo controlador del plan

La cantidad de planes exitosos indica la cantidad de planes que llegaron a su fin habiendo pasado por todos los eslabones de la cadena del plan. Este valor puede ser un número racional, ya que cuando un plan no tiene éxito, se toma el éxito parcial del mismo (es decir, si el plan era de 10 pasos y 5 fueron exitosos, este valor será 0.5). Este valor se calcula como la cantidad de acciones del plan que obtuvieron una situación esperada sobre la cantidad total de acciones del plan.

Si el plan efectúa todas las acciones previstas exitosamente, se actualiza la cantidad de planes exitosos. En caso de que el plan haya abortado o terminado, o bien no exista el plan, se obtiene un nuevo plan. Si éste es viable, se actualiza el contador de planes. De lo contrario, se obtiene una teoría de la base de conocimientos a través de una selección al azar y se actualiza el contador de azares.

A continuación se van a describir los distintos métodos de obtención de planes, en la subsección 4.4.7.1 se describe el método de planificación con ponderación de planes [García Martínez et al. 2006, Maceri y García Martínez, 2001] y en la subsección 4.4.7.2 se describe el método de planificación propuesto a través del ranking de teorías de la bases de conocimiento que emplea el SAR. 


\subsubsection{Planificador y ponderador de planes}

El planificador recibe el conjunto de teorías y situación actual, debiendo retornar un conjunto de planes (pudiendo no devolver un plan, en el caso de que a partir de las teorías aprendidas por el SAR, no se pueda armar un plan), que aplicado a la situación presente logre alcanzar la situación deseada o situación objetivo que se puede alcanzar con la utilidad máxima El método de planificación intenta armar un plan que mediante su ejecución permita llegar de la situación actual a la situación registrada con mayor utilidad en la menor cantidad de pasos, inicialmente se arma un grafo de teorías (Figura 4.18) en donde cada nodo es una situación y cada arco representa una teoría. Por ejemplo S1 $\rightarrow$ S4 representa la teoría cuya situación inicial es S1 y mediante la acción 2, llegó a la situación final $\mathrm{S} 4$ con $\mathrm{P}=2, \mathrm{~K}=3$ y una utilidad de $\mathrm{U}=3 / 4$

En base a este grafo, se arma una pila de Situaciones deseables ordenada por utilidad descendiente, cuya utilidad se toma del arco que entra al nodo. Una vez generada la pila, se empieza a desapilar (sacar del tope de la pila de situaciones) hasta que se encuentre un plan viable o bien no haya más elementos en la misma.

La situación desapilada se toma como raíz del árbol y sus hijos se determinan por los arcos entrantes a cada nodo. Suponiendo que la situación desapilada es la S3, según el grafo de situaciones previamente diagramado se obtendría el siguiente árbol, indicado en la Figura 4.19.

Se busca dentro de los nodos del árbol la situación actual y se busca el camino mínimo de dicho nodo al nodo raíz, determinando cada terna Nodo-Arco-Nodo, una teoría registrada en la lista de teorías del SAR. Si no se encuentra la situación actual dentro del árbol, el plan no existe y se prosigue a desapilar el siguiente elemento de la pila de situaciones deseables.

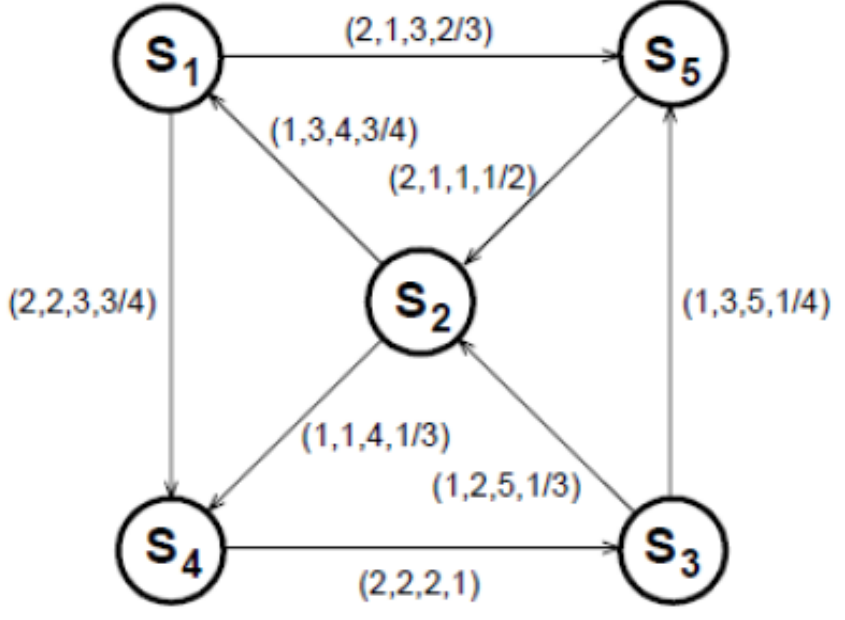

Figura 4.18 Grafo de teorías

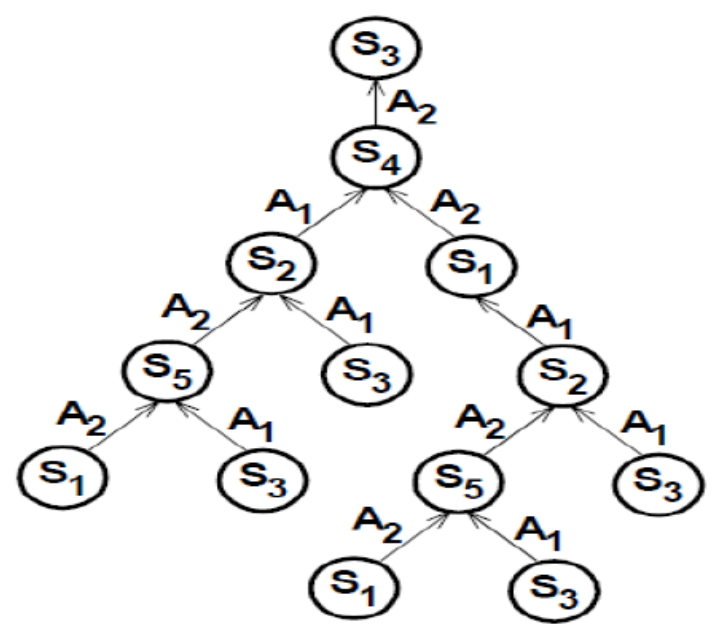

Figura 4.19 Árbol de Situaciones-Acciones 
Si existe un camino mínimo, y se encuentra activa la ponderación de planes, éste se pondera mediante el módulo de ponderación, y si el resultado obtenido es mayor a un valor umbral determinado en la configuración del SAR, el plan es viable y queda conformado por las teorías que conforman el camino mínimo. Si la ponderación no supera el valor umbral, el plan no es válido y se prosigue a desapilar el siguiente elemento de la pila de situaciones deseables. Se muestra en la Figura 4.20 el diagrama de actividad del módulo de planificación, el que también es llamado como planificador clásico.

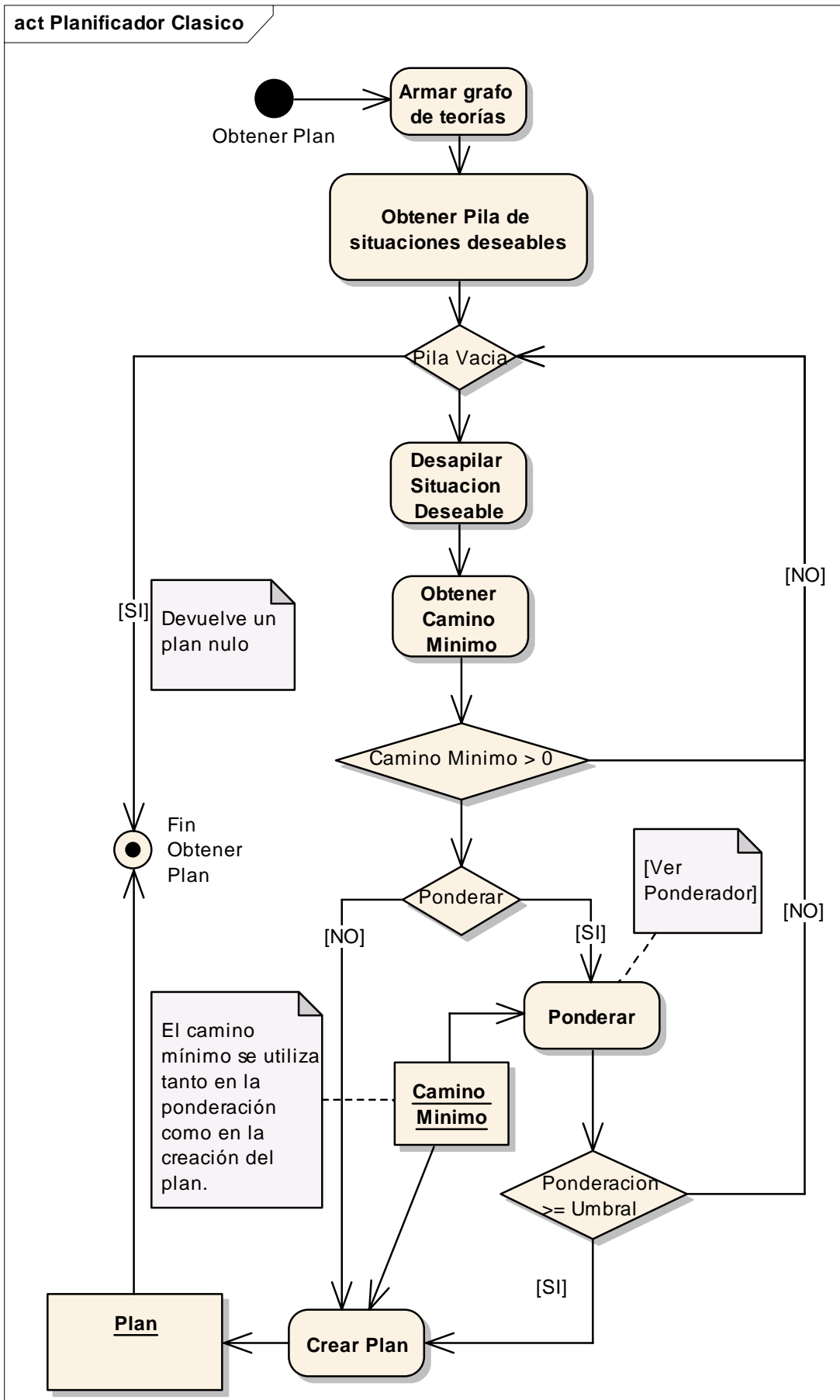

Figura 4.20. Diagrama de actividades del módulo de planificación 
En el algoritmo 4.5 se presenta el pseudo código del planificador clásico, en el algoritmo 4-6 se presenta el pseudo-código del ponderador de planes. Se presentan en el Anexo F y en la sección N-6 del Anexo Soporte Digital, mayores detalles del planificador clásico con ponderador de planes aplicado por [García-Martínez et al., 2006]

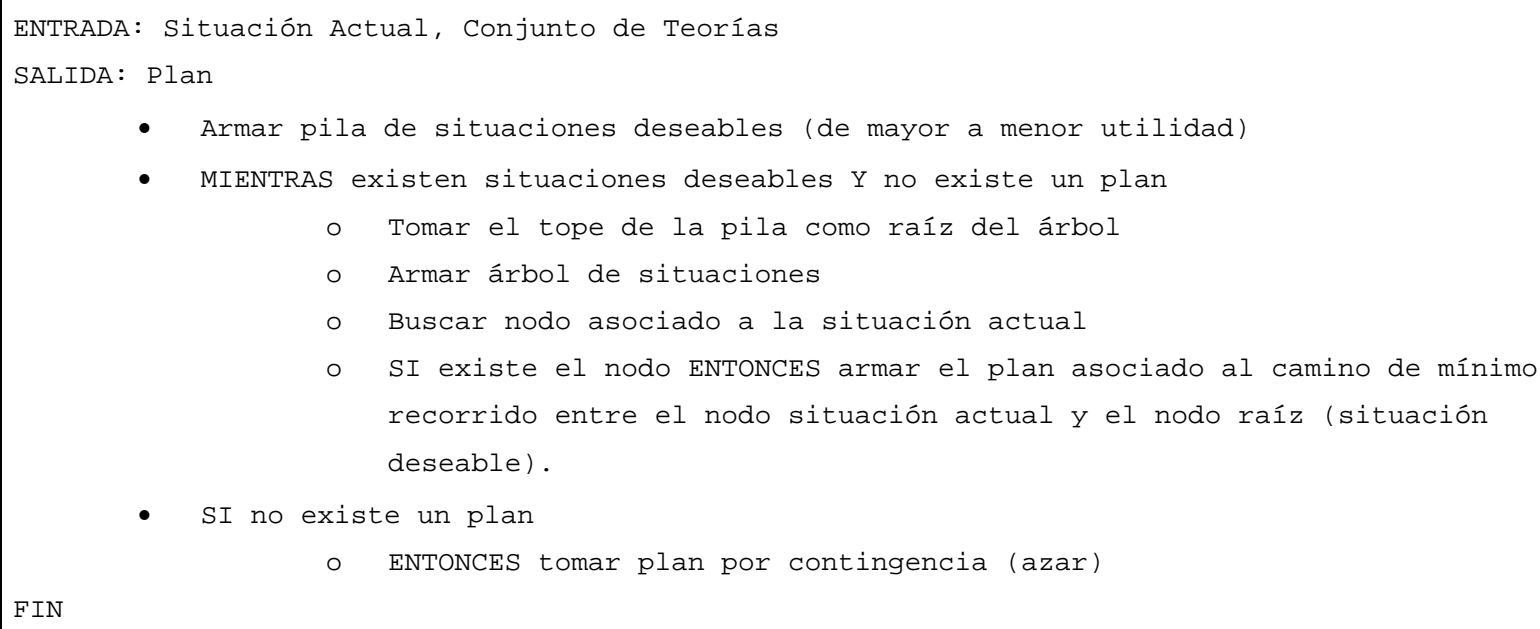

Algoritmo 4.5 Pseudocódigo del planificador clásico

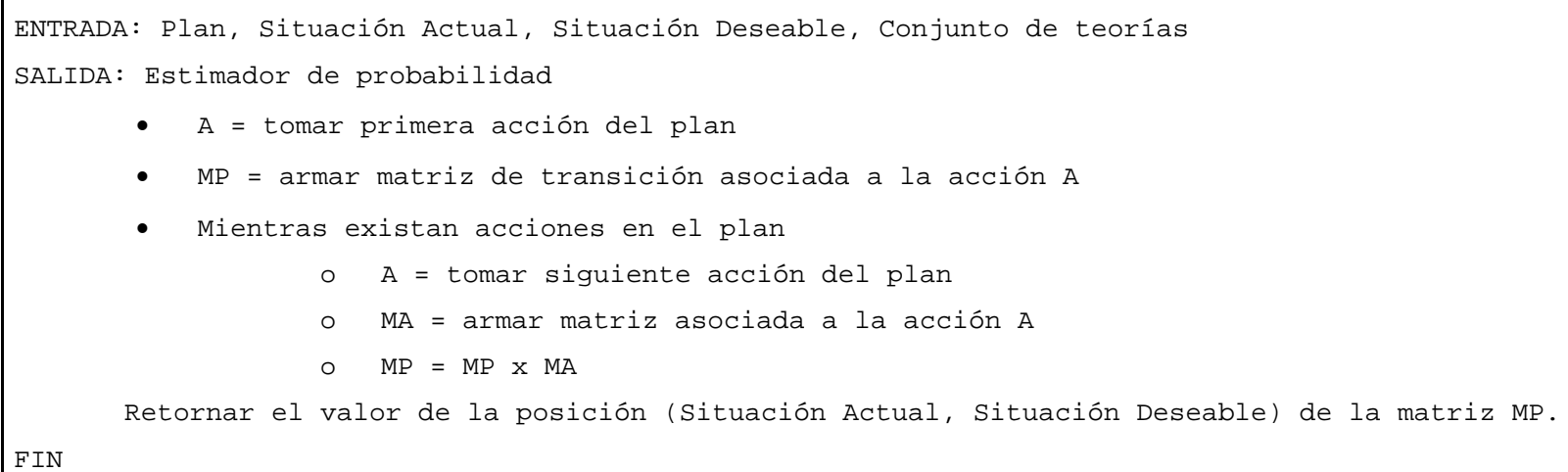

Algoritmo 4.6 Pseudo-código del ponderador de planes

\subsubsection{Planificador Ranking de Teorías}

Este método de planificación propuesto ordena la lista de teorías corrientes por utilidad y luego por P y K. Luego se seleccionan las teorías de la lista ordenada que tengan como Situación Inicial a la Situación Actual, la acción de la teoría seleccionada conforma el plan del SAR. 
Se observó en el planificador clásico una mayor recurrencia de azares y menor cantidad de planes exitosos, razón por la cual se exploraron nuevas soluciones, generando un planificador basado en selección de teorías en función de la situación registrada por los sensores del SAR paso a paso, generando un ranking de teorías en función de la utilidad y del valor de P y K (la probabilidad de ocurrencia del efecto deseado o situación final (Sf) al aplicar la acción A de la teoría Ti), generando un plan paso a paso o ciclo a ciclo de ejecución.

Se presenta en la Figura 4.21 el diagrama de actividades del planificador basado en ranking de teorías. El SAR obtiene el plan en función de su base de conocimiento de teorías ordenada en primer lugar por la mayor utilidad " $U$ ", en segundo lugar ante teorías con igual utilidad, se ordenan por mayor valor de $\mathrm{P}$, en tercer lugar ante igual $\mathrm{U}$ y $\mathrm{P}$ de las teorías se ordenan estas por el menor K. Sobre esta base de teorías ordenadas, el SAR selecciona las teorías en las que la situación actual registrada por los sensores de proximidad sea igual a la situación inicial de la teoría.

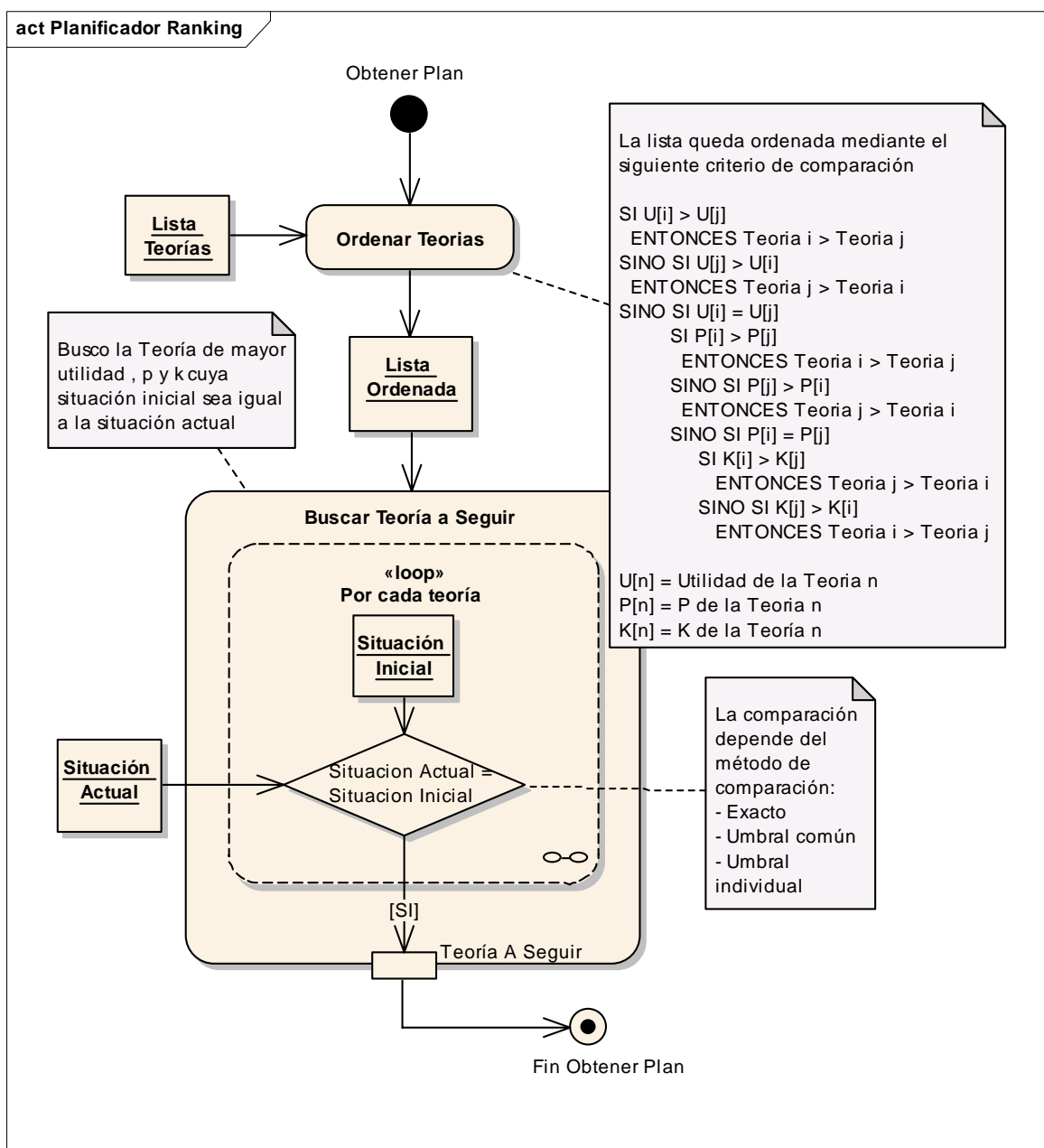

Figura 4.21. Diagrama de actividades del planificador basado en ranking de teorías 
La comparación de teorías depende del método aplicado para determinar la igualdad de situación actual registrada por los sensores y la situación inicial de la teoría. En este orden los métodos aplicados se describen en la sección 4.4.6

El método propuesto se orienta a observar el escenario para crear los planes, es decir, analizar la Situación Actual en cada paso que da el robot. Para ello se dejaron de crear Planes a largo plazo como lo realiza el planificador clásico. Este Planificador crea un Plan por paso de longitud igual a una sola acción.

Esto permite trabajar en el corto plazo y facilita un mejor comportamiento del SAR, al tener una situación del ambiente ciclo a ciclo de ejecución o paso a paso, a través de sus sensores de proximidad sobre el ambiente de operación en un instante dado. Se podría decir que sería como replanificar en cada paso con el Planificador clásico del SAR, con la siguiente diferencia: la planificación en Ranking trae un muy bajo costo de procesamiento a diferencia de Planificador SAR.

Este Planificador toma en cada paso la Situación Actual y lo que hace es buscar en la Base de Teorías, cuál es la Teoría con mayor Utilidad (U), cuya Situación Inicial (Si) coincida con la Situación Actual.

Si se presentan más de una teoría con la misma utilidad se selecciona la de mayor valor de $\mathrm{P}$ y si se mantiene más de una teoría con igual utilidad y valor de $\mathrm{P}$, se selecciona la de menor valor de $\mathrm{K}$. Esto le asegura al SAR poder realizar una acción con sentido en cada paso o ciclo de ejecución, ya que se analiza la acción correspondiente a la teoría con mayor utilidad y mejor posibilidad en función de los conocimientos que el SAR tiene en su Base de Conocimientos de Teorías aprendidas. Este método de Planificación brinda una gran rapidez en el armado de los planes por el SAR. En este caso los planes son siempre de una sola Teoría. Para armarlos ordena la Base de conocimiento de teorías por Utilidad decreciente y por mayor valor de $\mathrm{P}$ y menor de $\mathrm{K}$, busca la teoría cuya SituacionInicial coincide con la SituacionActual del robot. Esa Teoría será utilizada por el SAR como Plan a seguir en ese ciclo.

Este método de Planificación arroja sus mejores resultados utilizando la nueva función de Utilidad basada en los Coeficientes de Braitemberg.

Se detalla en el algoritmo 4.7 el pseudo-código del método de planificación por ranking. Se presenta en el Anexo G, un ejemplo de aplicación del método de planificación por ranking propuesto. Este planificador no resulta costoso, considerando que trabaja sobre la base de conocimientos del SAR, seleccionando una teoría en función de la situación, priorizando éstas por utilidad y la relación $\mathrm{P} / \mathrm{K}$. Este planificador resulta oportuno en el contexto del modelo de ciclo de vida propuesto, el que actúa en forma independiente del tipo de planificador empleado por el SAR. 


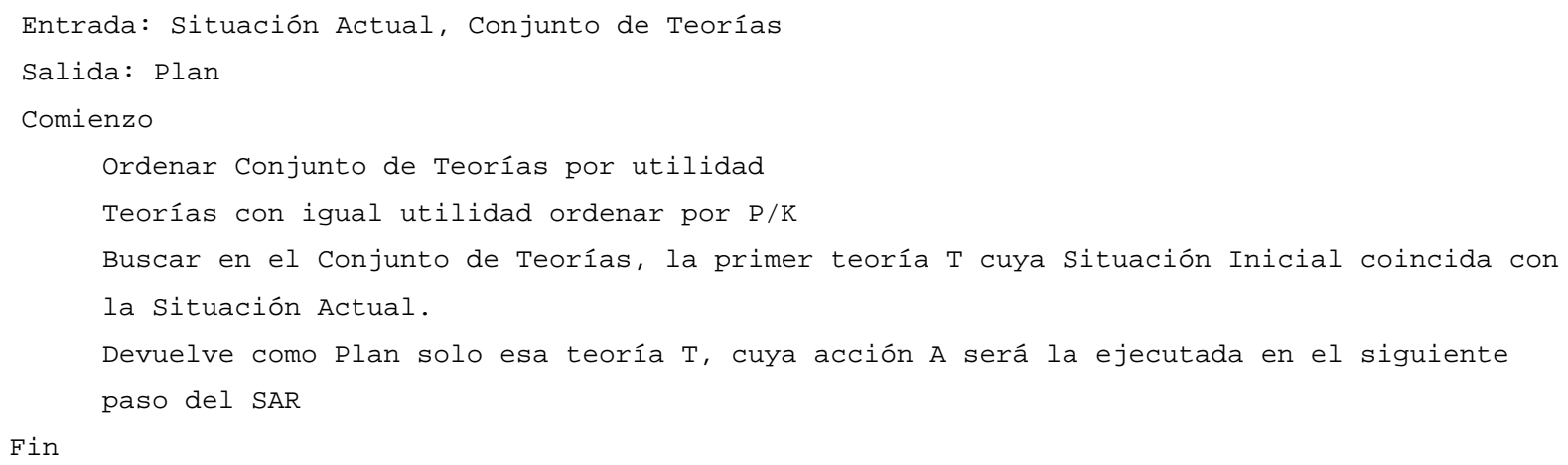

Algoritmo 4.7 Pseudo código del método de planificación por ranking

\subsubsection{COMPARTICIÓN DE CONOCIMIENTO}

La compartición de conocimientos entre SAR se presenta a través del intercambio de teorías entre SARs que se encuentran en el mismo estado de evolución recorriendo el mismo layer en sus respectivos ciclo de vida de aprendizaje, se detalla el método de intercambio o cooperación entre SAR en la subsección 4.4.8.1. La colaboración entre SAR se produce a través de un SAR colaborador que alcanzó un estado de evolución en sus conocimientos superior al SAR receptor que se encuentra en un estado inferior, se detalla el método de colaboración en la subsección 4.4.8.2.

\subsubsection{Intercambio de teorías (cooperación)}

La cooperación (intercambio) entre SARs, le permite a ambos SARs cruzar sus bases de conocimiento previo a la corrida y dan lugar a una nueva base de conocimiento de teorías que podrán utilizar ambos.

Los SARs se benefician con este intercambio, incrementando la cantidad y calidad de conocimientos. Estos conocimientos ingresarán gracias a las experiencias de otros SARs. El módulo de intercambio de Teorías crea una Base de Conocimientos o Lista de Teorías a partir de las bases de conocimiento individuales de los SARs. Se detalla en algoritmo 4-9 el pseudo-código del método de intercambio entre SARs, sobre la base del trabajo [García-Martínez et al., 2006]. 
ENTRADA: Base de Conocimientos Robot A (BCRA), Base de. Conocimientos Robot B (BCRB)

SALIDA: Base de Conocimiento Cooperación Robots A-B (BCCRAB)

COMIENZO:

- Se recorren todas las Teorías de la BCRA

- Para cada teoría de la BCRA:

o Si existe una teoría igual en la BCRB

- $\mathrm{K}=$ Kteoria RB + Kteoria RA

- $\mathrm{P}=$ Pteoria RB + Pteoria RA

- Se agrega esta teoría con los nuevos $\mathrm{P}$ y $\mathrm{K}$ a la BCCRAB

o Si no existe una teoría igual en la BCRB

- Se Buscan teorías similares

- $\quad$ Si existen teorías similares

o $\quad \mathrm{K}=$ Kteoria RB + KTeoria RA

o $\quad P=$ Pteoria RA

o Se agrega estas teorías con los nuevos $\mathrm{P}$ y $\mathrm{K}$ a la BCCRAB

- Si no existen teorías similares

o $\mathrm{K}=$ Kteoria RA

o $\quad \mathrm{P}=$ Pteoria RA

o Se agrega esta teoría con los mismos $\mathrm{P}$ y $\mathrm{K}$ a la BCCRAB

- Luego se recorre la BCRB

- Para cada Teoría en la BCRB:

o Si existe una Teoría Igual en la BCRA

- Se pasa a la siguiente teoría

o Si no existe una Teoría Igual en la BCRA

- Si existe una teoría Similar en la BCRA

- $\mathrm{K}=\mathrm{KTeoria} \mathrm{RA}+\mathrm{KTeoria} \mathrm{RB}$

- $\quad \mathrm{P}=$ PTeoria RB

- Se agrega esta teoría con los nuevos $\mathrm{P}$ y $\mathrm{K}$ a la BCCRAB

- Si no existe una teoría Similar en la BCRA

- Se agrega esta teoría con los mismos $\mathrm{P}$ y $\mathrm{K}$ de la Teoría de RB a la BCCRAB

Una vez que se finalizan ambos recorridos, se asigna la BCCRAB para ser aplicada por RA y RB

FIN.

Algoritmo 4.9 Pseudo-código del método cooperación entre SARs

Se presenta en la Figura 4.22 el diagrama de actividades del método de cooperación entre sistemas autónomos de robots, identificados como robot A (RA) y robot B (RB)

Se presenta en el Anexo $\mathrm{H}$ un ejemplo entre dos sistemas autónomos que cooperan entre sí, intercambiando sus teorías y generando como consecuencia la base de conocimiento de cooperación entre ambos SAR. Independientemente cada uno de estos SARs puede hacer uso de la nueva base de conocimiento de teorías que surge como producto de la cooperación entre ambos SARs. 


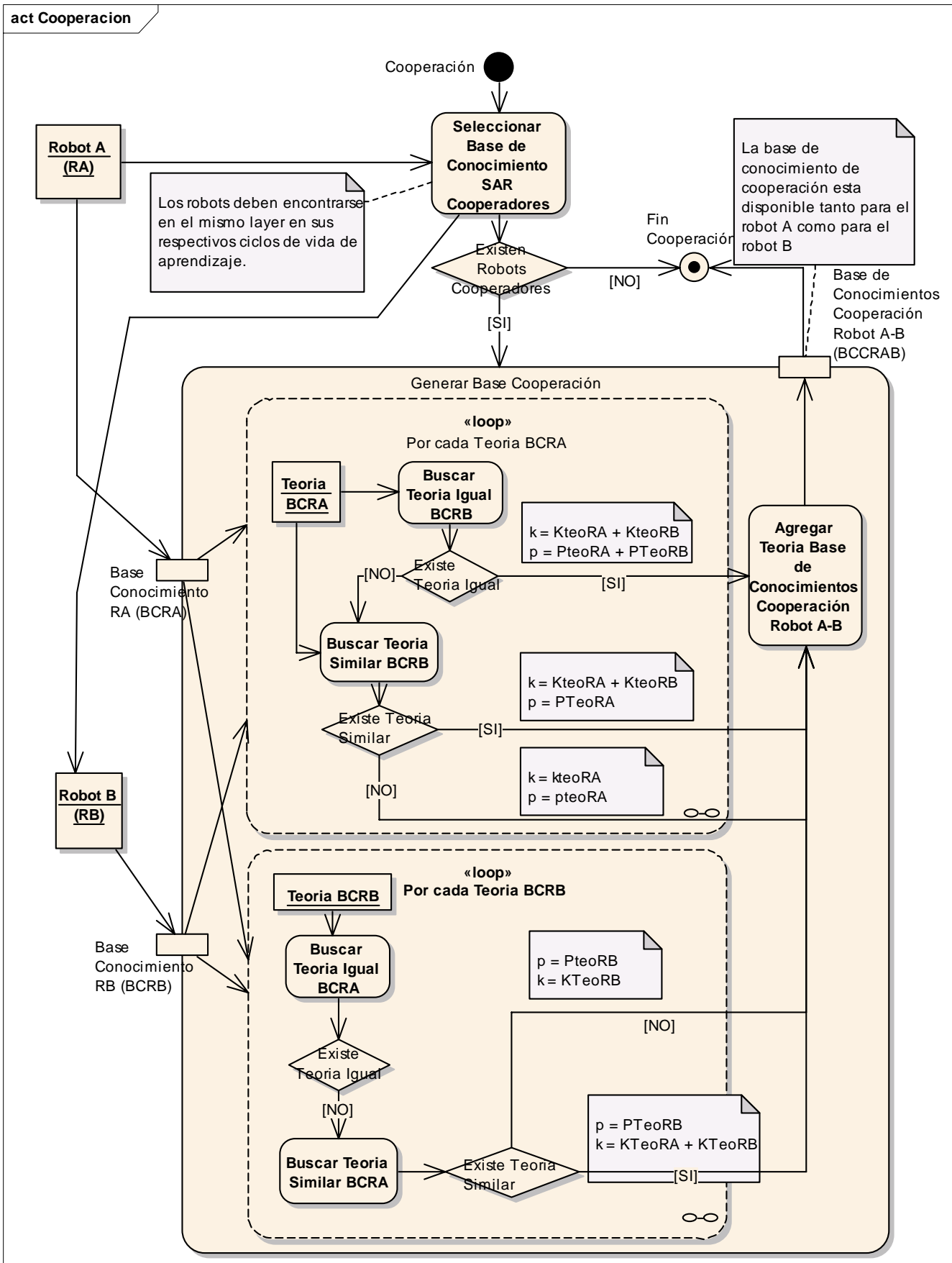

Figura 4.22 Diagrama de Actividades módulo cooperación

En la Figura 4.23 se muestra el diagrama de actividades correspondiente al proceso de selección de los robots, que cooperarán intercambiando sus bases de conocimientos. En la actividad seleccionar bases de conocimientos de los SARs o robots (RA y RB), la condición necesaria para que la cooperación pueda aplicarse, es que ambos robots esté en un mismo estado de evolución. Caso contrario, la cooperación entre SARs no es posible. Hay que seleccionar otra base de conocimiento u otro SAR, hasta que se cumpla con la condición indicada. 


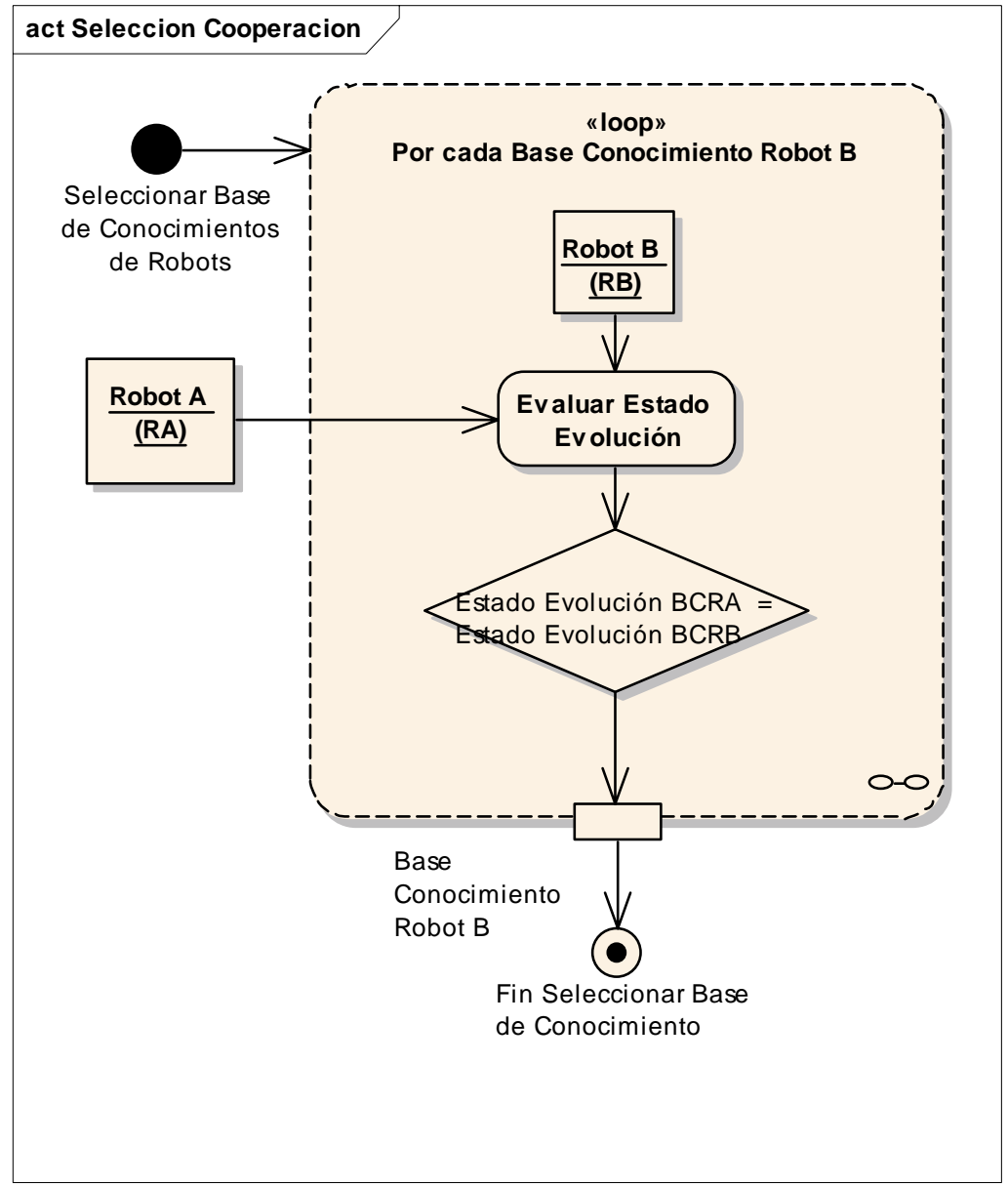

Figura 4.23 Diagrama de Actividades del módulo seleccionar SARs cooperadores

\subsubsection{Colaboración}

Se presenta en esta subsección la descripción del método de colaboración entre un SAR que alcanzó un estado de evolución superior y un SAR receptor que se encuentra en un estado de evolución inferior. El mecanismo propuesto considera la ponderación de teorías y la inclusión de nuevas teorías en la base de conocimiento del SAR receptor, aportadas por el SAR colaborador.

La Figura 4.24 muestra un esquema del modelo orientado a colaboración, sobre la base del LLC (Learning Life Cycle). En el marco del LLC de un SAR, se presentan tres layers de aprendizaje: [a] Layer BIO (Built-In Operators) es el layer donde los operadores son implantados al SAR "Born" por su creador, [b] Layer TBO (Trained Base Operations) es el layer donde los operadores son aprendidos por el SAR "Newbie", en el escenario de simulación (previamente diseñado) y por técnicas de aprendizaje evolutivo, [c] Layer WIO (World Interaction Operators) es el layer donde los operadores son aprendidos por la interacción del SAR "Trained" con la parte del mundo que 
representa su ambiente de operación y con la presencia de otros SARs, para convertirse en un SAR "Mature".

El objetivo del SAR es aprender automáticamente operadores (modelos de acción), que predigan los efectos de las acciones en el ambiente, por observación de las consecuencias de estas acciones y avanzar en su estado de evolución (Born, Newbie, Trained, Mature).

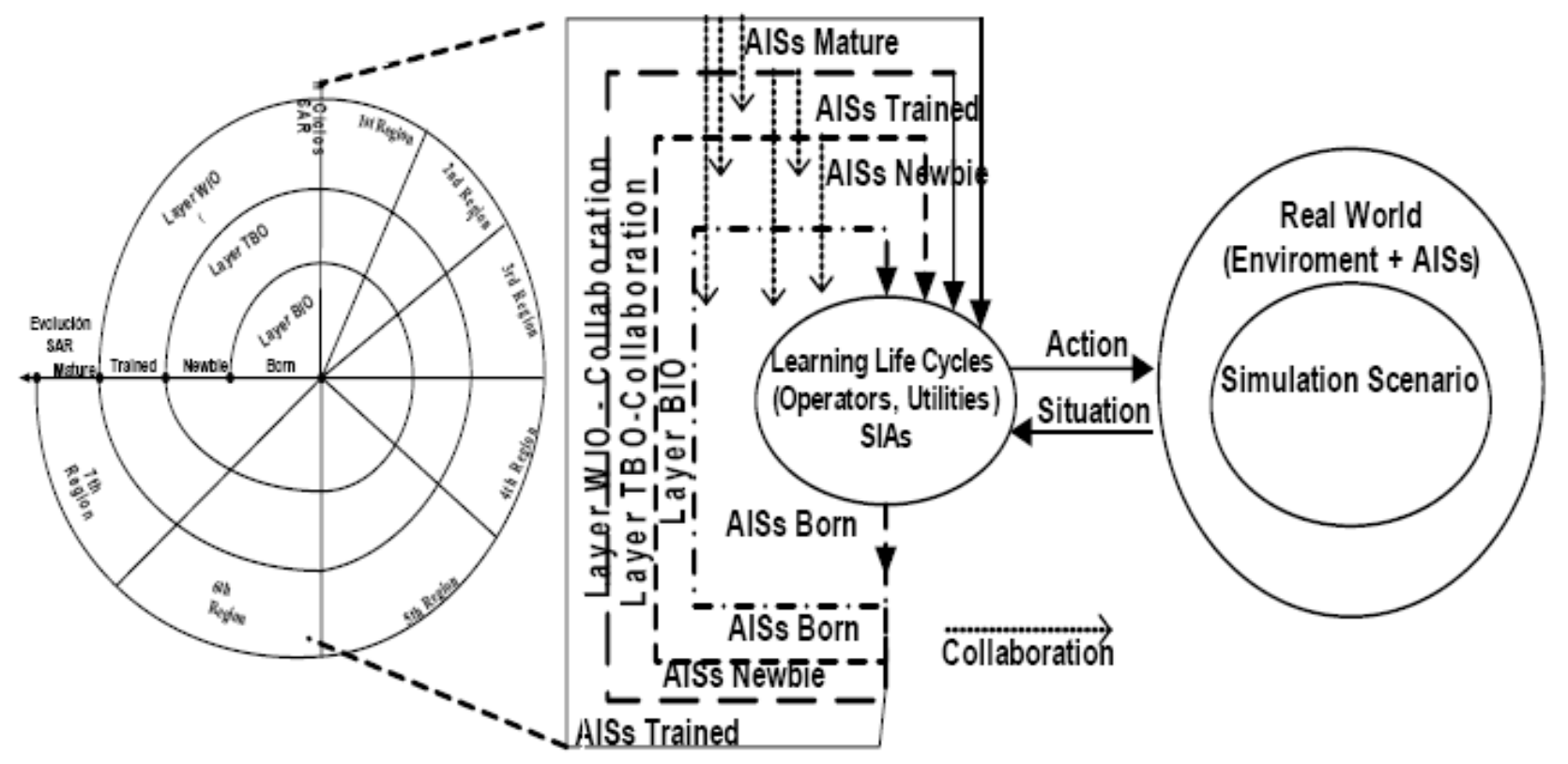

Figura 4.24. Modelo de colaboración propuesto

La colaboración permite que un SAR pueda recibir conocimiento previamente adquirido por un SAR que se encuentra en un estado de evolución superior en el marco del LLC. (Learning Life Cycle).

Se presenta en la Figura 4.24 al SAR en forma genérica como un AIS(Autonomous Intelligent Systems), se pueden observar los niveles de colaboración posibles entre:[a] un SAR Mature que finalizó el layer WIO con un SAR Trained que se encuentra en el inicio del layer WIO o con un SAR Newbie que se encuentra en el inicio de layer TBO, o con un SAR Born que se encuentra al final del layer BIO.[b] un SAR Trained que finalizó el layer TBO con un SAR Newbie que finalizó el Layer BIO o un SAR Born que inicia el layer BIO. [c] un SAR Newbie que finalizó el Layer BIO con un SAR Born que inicia el layer BIO.

Cuando un SAR colabora, comparte su experiencia acumulada producto tanto de sus errores como de sus aciertos. Por lo tanto siguiendo el modelo de teoría y su método de ponderación, es necesario al colaborar con operadores, reflejar este conocimiento en el SAR receptor, manteniendo la consistencia del conjunto de teorías de este. 
El método empleado contempla el concepto de que la teoría que es utilizada con éxito debe ser reforzada incrementando su $\mathrm{P}$ y su $\mathrm{K}$ y que la teoría que es utilizada de forma infructuosa debe ser debilitada incrementando su K, sin incrementar su P.

En el proceso de colaboración, si una teoría del SAR colaborador existe en el SAR receptor ésta se refuerza sumando sus $\mathrm{P}$ y sus $\mathrm{K}$, por otro lado si una teoría del SAR colaborador no existe en el SAR receptor, pero sí existe en este último una teoría similar, se debilita esta teoría, dejándole el mismo P y sumando a su K el K del SAR colaborador.

Por otro lado aquellas teorías del SAR colaborador que no estén en el SAR receptor, ni sean similar, ni iguales, no presentan cambios, sólo se transfieren al SAR receptor con sus valores de P y K. Para mantener la consistencia del método de ponderación de teorías se verifica que luego de la colaboración la suma de los $\mathrm{P}$ de las teorías similares en el SAR receptor es igual al K de cualquiera de ellas.

Se presenta en el Anexo I, un ejemplo entre un sistema autónomo de robot que colabora con otro sistema autónomo de robot receptor brindando a este último sus teorías y generando como consecuencia la base de conocimiento de colaboración para ser explotada por el sistema autónomo de robot receptor.

Para iniciar la colaboración, se debe realizar un proceso de verificación de estados evolutivos de los robots, en este orden, el estado de evolución del Robot Colaborador (RC) debe ser superior al estado de evolución del Robot Receptor (RR), caso contrario, la colaboración de RC hacia el RR no es posible y se debe continuar con el proceso de selección del RC.

Si bien el proceso de compartición de teorías para la cooperación y colaboración es el mismo, se presentan diferencias en el proceso de selección de las bases de conocimientos y en los actores que explotan la base de conocimiento de teorías, por esta razón se presenta el proceso de colaboración a continuación

Se muestra en la Figura 4.25 el diagrama de actividades correspondiente a la colaboración de un SAR colaborador representado por el Robot Colaborador (RC) a un SAR receptor representado por el Robot Receptor (RR) de la colaboración.

Se presenta en el algoritmo 4.10 el pseudocódigo correspondiente al proceso de colaboración entre un SAR Colaborador (RC) y un SAR receptor (RE). 


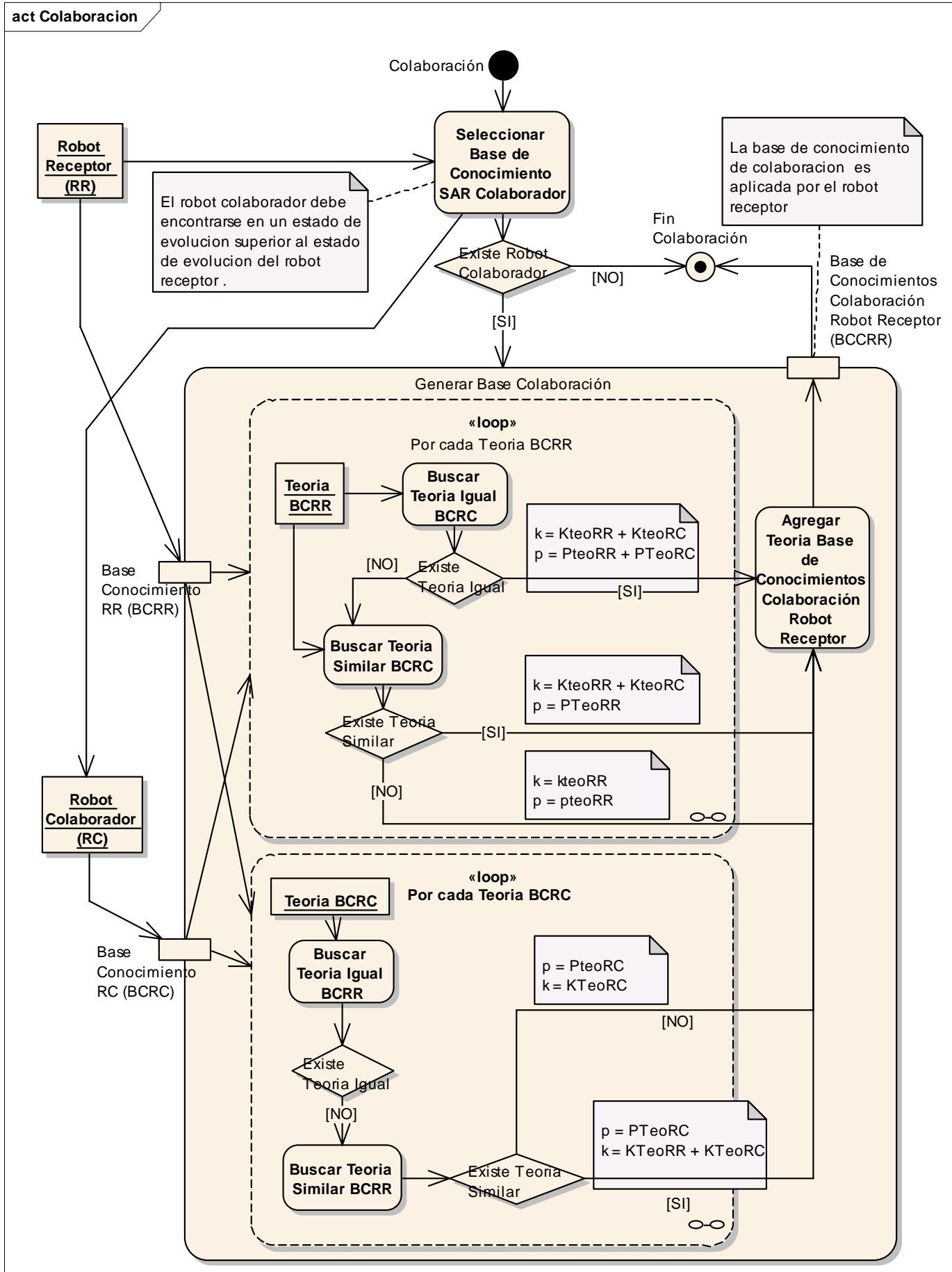

Figura 4.25 Diagrama de Actividades módulo colaboración

En la Figura 4.26 se muestra el diagrama de actividades correspondiente al proceso de selección del robot que colaborará con el robot receptor. En la actividad seleccionar base de conocimiento SAR colaborador o robot colaborador (RC) que va a colaborar con el robot receptor (RA), la condición necesaria para que la colaboración pueda aplicarse, es que el robot colaborador esté en un layer superior (lo que implica un estado de evolución también superior) al del robot receptor (RE). 


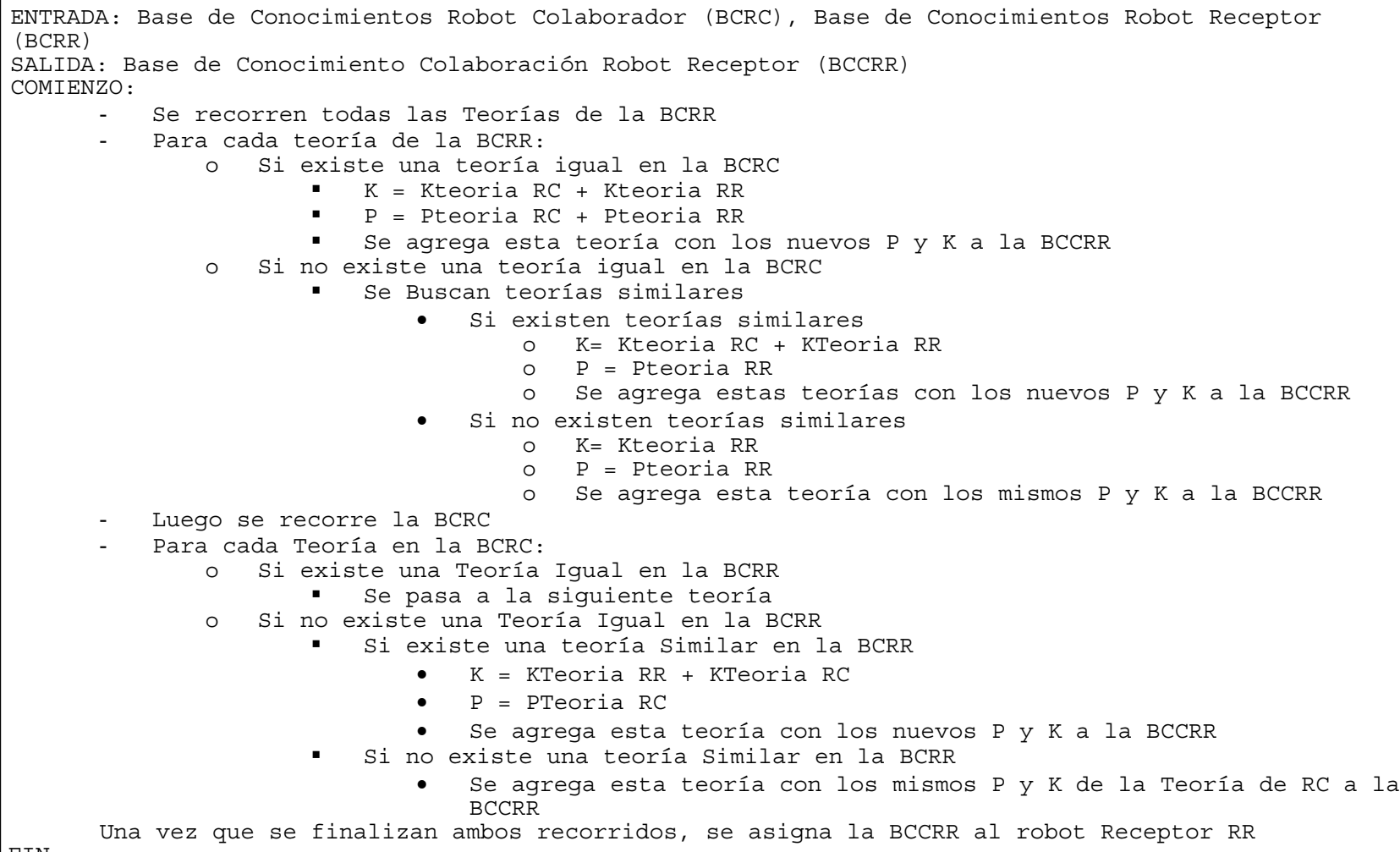

Algoritmo 4.10 Pseudocódigo del método de colaboración entre SARs

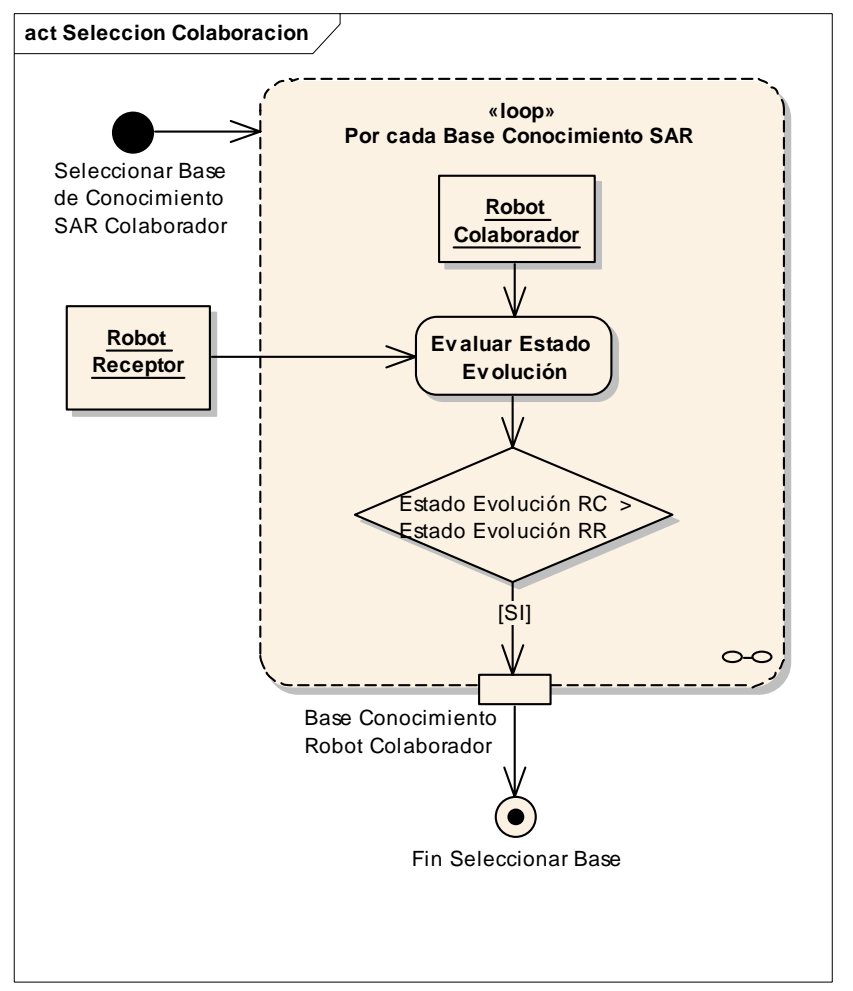

Figura 4.26 Diagrama de Actividades del módulo seleccionar SAR colaborador 
Para verificarlo al momento de iniciar la colaboración, se debe realizar un proceso de verificación de estados evolutivos de los robots, representado éste por sus bases de conocimientos de teorías. En este orden si el estado de evolución de la base de conocimientos del robot colaborador es superior al estado de evolución del robot receptor, se puede realizar la colaboración. Caso contrario, la colaboración no es posible. Hay que seleccionar otra base de conocimiento del SAR colaborador $\mathrm{u}$ otro SAR colaborador hasta que se cumpla con la condición indicada.

\subsubsection{REGISTRO DE ESTADÍSTICAS DE APRENDIZAJE DEL SISTEMA AUTÓNOMO DE ROBOT}

El registro de estadísticas de aprendizaje del SAR se realiza en función del intervalo de n ciclos, seleccionado en la configuración del SAR (subsección 4.2.2.1). Se describen a continuación las estadísticas registradas por el SAR (sobre la base del intervalo de n ciclos) de: Cantidad situaciones; teorías acumuladas; utilidad teorías [0-0.25]; utilidad teorías [ $>0.25-0.5]$; utilidad teorías [ $>0.5-$ 0.75]; utilidad teorías [ $>0.75-1$ ]; cantidad de planes; cantidad de planes exitosos; cantidad de planes sin éxito, cantidad de azares; relación $\mathrm{P} / \mathrm{K}_{1}$ [0-0.25]; $\mathrm{P} / \mathrm{K}_{2}$ relación [ $\left.>0.25-0.5\right]$; relación $\mathrm{P} / \mathrm{K}_{3}[>0.5$ 0.75]; relación $\mathrm{P} / \mathrm{K}_{4}[>0.75-1]$; relación $\mathrm{P} / \mathrm{K}$ general; cantidad de ciclos exitosos .

Para el registro de la estadística de "Cantidad Ciclos Exitosos", que representa la cantidad de ciclos que finalizaron con la aplicación de una teoría cuya utilidad (U), resultó superior a 0,75 , se debe considerar que es un valor que se acumula solamente durante la actuación del SAR. Se inicia en cero (0) y aumenta en 1 cada vez que el robot realizó un ciclo percepción- acción, en el cual finaliza con una teoría cuya utilidad (U), resulta mayor a 0.75 . Se detalla un ejemplo en la tabla 4.2.

Para el registro de las estadísticas de "Planes Exitosos" (en función de la subsección 4.4.7), se consideran: [a] cantidad planes (construidos), ésta es la cantidad de planes que se pudieron construir a lo largo de la ejecución, [b] la cantidad de planes exitosos, es la cantidad de planes que llegaron a su fin habiendo pasado por todos los eslabones de la cadena del plan. [c] la cantidad de planes sin éxito. Luego, se puede obtener el porcentaje de planes exitosos de la relación entre la "Cantidad de Planes Exitosos" y "Cantidad Planes Construidos (cantidad de planes exitosos más cantidad de planes sin éxito). Finalmente se debe considerar que esta estadística es útil para el planificador clásico (SARp) y sus métodos asociados, excepto para el planificador ranking (SARr) ya que éste último sólo realiza planes de longitud igual a uno. 


\author{
Inicio corrida del SAR \\ - $\quad$ El robot inicia la simulación obteniendo "Situación Inicial" (Si) de la lectura de sus sensores \\ inicial \\ - $\quad \mid$ CICLO $0 \mid$ Cantidad. Ciclos Exitosos $=0$ \\ - El robot finaliza el CICLO 0 habiendo ejecutado la Acción "A" y obteniendo la "Situación Final" \\ (Sf) de la lectura de sus sensores final \\ - $\quad$ El sistema arma la teoría local $\mathrm{TL}=(\mathrm{Si} ; \mathrm{A} ; \mathrm{Sf})$ cuya utilidad es $=0,89$ \\ - Como 0,89 es $>=0,75$, se aumenta en 1 la "Cantidad. Ciclos Exitosos" \\ - $\quad \mid$ CICLO $1 \mid$ Cantidad. Ciclos Exitosos = 1 \\ - El robot inicia el CICLO 1 obteniendo una nueva "Situación Inicial" (Si) de la lectura de sus \\ sensores inicial (es igual a la Sf anterior) \\ - El robot finaliza el CICLO 1 habiendo ejecutado la Acción "A" y obteniendo la "Situación Final" \\ (Sf) de la lectura de sus sensores final \\ - $\quad$ El sistema nuevamente arma la teoría local TL $=(\mathrm{Si} ; \mathrm{A} ; \mathrm{Sf})$ cuya utilidad es $=0,53$ \\ - Como 0,53 es $<0,75$, no se aumenta la "Cantidad. Ciclos Exitosos" \\ - $\quad \mid$ CICLO $2 \mid$ Cantidad. Ciclos Exitosos $=1$ \\ Y así sucesivamente durante los n ciclos restante se evalúa la utilidad de la teoría \\ Fin
}

Tabla 4.2 Ejemplo Cantidad de Ciclos Exitoso del SAR

El registro de la estadística de "Cantidad de Acciones al Azar", se obtiene de contabilizar la cantidad de planes que recurren a acciones al azar, debido a que el SAR tuvo que ejecutar una acción al azar, dado que no pudo obtener un plan que se pudiera utilizar.

El registro de "Cantidad de Teorías Exitosas" se contabilizará sobre la base de las teorías acumuladas más las que se originan en la actuación del SAR, cuya utilidad es superior a 0,75. Se calcula igual tanto para un SARr y como para un SARp. Para determinar la cantidad teorías exitosas que se obtienen durante la actuación del SAR, se considera la acumulación de éstas solamente durante la simulación, se inicia en cero (0) y aumenta en uno (1), cada vez que el SAR realiza un ciclo en el cual finaliza con una Teoría con utilidad (U) mayor a 0,75. Se presenta un ejemplo en la tabla 4-3. 


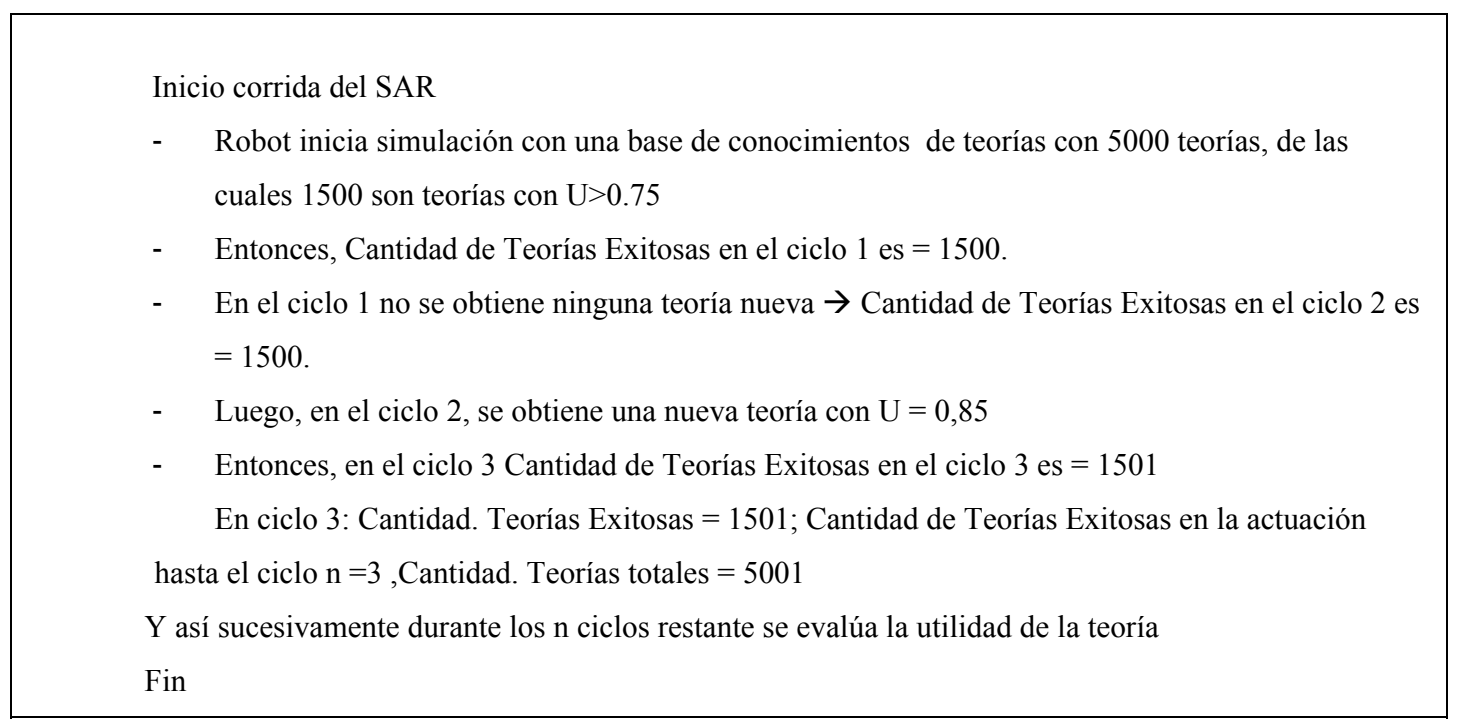

Tabla 4.3 Ejemplo Cantidad de Teorías Exitosas del SAR

El registro de la "Cantidad de Teorías por Intervalos de Utilidad", se desarrolla sobre la base de la cantidad de intervalos de distribución de utilidad seleccionados. El intervalo de distribución de utilidad que se establece en la actividad de configuración de estadísticas en el marco de la configuración del SAR, determina los umbrales que se generarán para catalogar las teorías por utilidad (U). La cantidad de intervalos en los que se divide el rango de utilidad (U) de una teoría, es entre cero (0) y uno (1).En este orden si se seleccionan dos (2) intervalos, resultaran las teorías agrupadas por utilidad (U) donde el primer intervalo se corresponde con las teorías cuya utilidad (U): $0,01<\mathrm{U}<=0,50$ y el segundo intervalo se corresponde con las teorías cuya utilidad (U): $0,50<$ $\mathrm{U}<=1$. Por defecto se seleccionan cuatro intervalos (4), en donde el primer intervalo se corresponde con las teorías cuya utilidad $(\mathrm{U}): 0,01<\mathrm{U}<=0,25$ el segundo intervalo se corresponde con las teorías cuya utilidad (U): $0,25<\mathrm{U}<=0,50$, el tercer intervalo se corresponde con las teorías cuya utilidad (U): $0,50<\mathrm{U}<=0,75$, el cuarto intervalo se corresponde con las teorías cuya utilidad (U): $0,75<\mathrm{U}<=1$. De esta forma se pueden registrar la cantidad de teorías distribuidas por rango de utilidad.

Se consideran teorías exitosas aquellas teorías que pertenecen al cuarto rango, cuya utilidad (U), se encuentra entre: $0,75<\mathrm{U}<=1$.

Independientemente de la configuración de estadísticas a registrar por el SAR, se registran en el archivo de estadísticas la relación entre la cantidad acumulada de $\mathrm{P} / \mathrm{K}$ y la cantidad de teorías de acuerdo a los siguientes rangos: $\mathrm{P} / \mathrm{K}_{1}[0-0.25] ; \mathrm{P} / \mathrm{K}_{2}$ relación $[>0.25-0.5] ; \mathrm{P} / \mathrm{K}_{3}[>0.5-0.75] ; \mathrm{P} / \mathrm{K}_{4}$ [>0.75-1]; y la relación $\mathrm{P} / \mathrm{K}$ general, producto de la suma de los valores obtenidos en cada rango. Se presenta un ejemplo en la tabla 4-4 
Relación P/K

Parámetro P (P): Cantidad de veces que teniendo la situación inicial Sinicial, se ejecutó la acción A y se obtuvo la situación final Sfinal.

Parámetro K (K):Cantidad de veces que teniendo la situación inicial Sinicial, se ejecutó la acción A

- Para las teorías dentro de un rango de Utilidad específico se va sumando el cociente P/K de las nuevas teorías que vayan apareciendo en ese rango.

- En el archivo de estadísticas se imprime el acumulado para el rango específico dividido por la cantidad de Teorías dentro de ese rango. De esta manera el valor siempre estará entre 0 y 1 ( $0 \%$ у $100 \%)$.

Por ejemplo:

Ciclo 1: Se agrega Teoría 1 con $\mathrm{P}=1$ y $\mathrm{K}=1 \mathrm{U}=0,2$

Ciclo 2: Se agrega Teoría 2 con $\mathrm{P}=1$ y $\mathrm{K}=1 \mathrm{U}=0,15$

Ciclo 3: Se agrega Teoría 3 SIMILAR a Teoría 2 con $\mathrm{P}=1$ y $\mathrm{K}=2 \mathrm{U}=0,23$ (Teoría 2 queda con $\mathrm{P}=1$ y $\mathrm{K}=2$ )

En el Ciclo 3, el P/K para el rango de Utilidad $[0 ; 0,25]$ será 0,67 (67\%) y se calcula de la siguiente manera:

- $\quad \sum$ ProbabilidadTotal $=\mathrm{P} / \mathrm{K}(\mathrm{T} 1)+\mathrm{P} / \mathrm{K}(\mathrm{T} 2)+\mathrm{P} / \mathrm{K}(\mathrm{T} 3)=$

$1+1 / 2+1 / 2=2$

- $\quad \mathrm{P} / \mathrm{K}$ para el Rango $[0 ; 0,25]=\sum$ ProbabilidadTotal $/$ CantTeoriasRango $[0 ; 0,25]=2 / 3=0,67$

Tabla 4.4 Ejemplo Cantidad de Teorías Exitosas del SAR

El registro de estadística de aprendizaje del SAR "Cantidad de teorías Acumuladas" considera la totalidad de teorías que el SAR tiene en su base de conocimiento con independencia del rango de utilidad y de las teorías anteriores a la actuación del SAR

Para el registro de "Cantidad de Situaciones" se considera la cantidad de situaciones diferentes generadas por el SAR a lo largo de su actuación, contabilizado en función del intervalo de $\mathrm{n}$ ciclos determinado para el registro de estadísticas del SAR.

Para la determinación de "Cantidad de Teorías Nuevas" se considera el total de teorías acumuladas que surgen de la diferencia entre el intervalo de estadística $n+1$ y el intervalo $n$, de esta forma se obtiene la cantidad de teorías generadas en la actuación del SAR en función del intervalo de estadística de n ciclos seleccionado en la configuración. Finalmente se presenta en la Figura 4.27 el diagrama de actividad del módulo de estadística del SAR. 


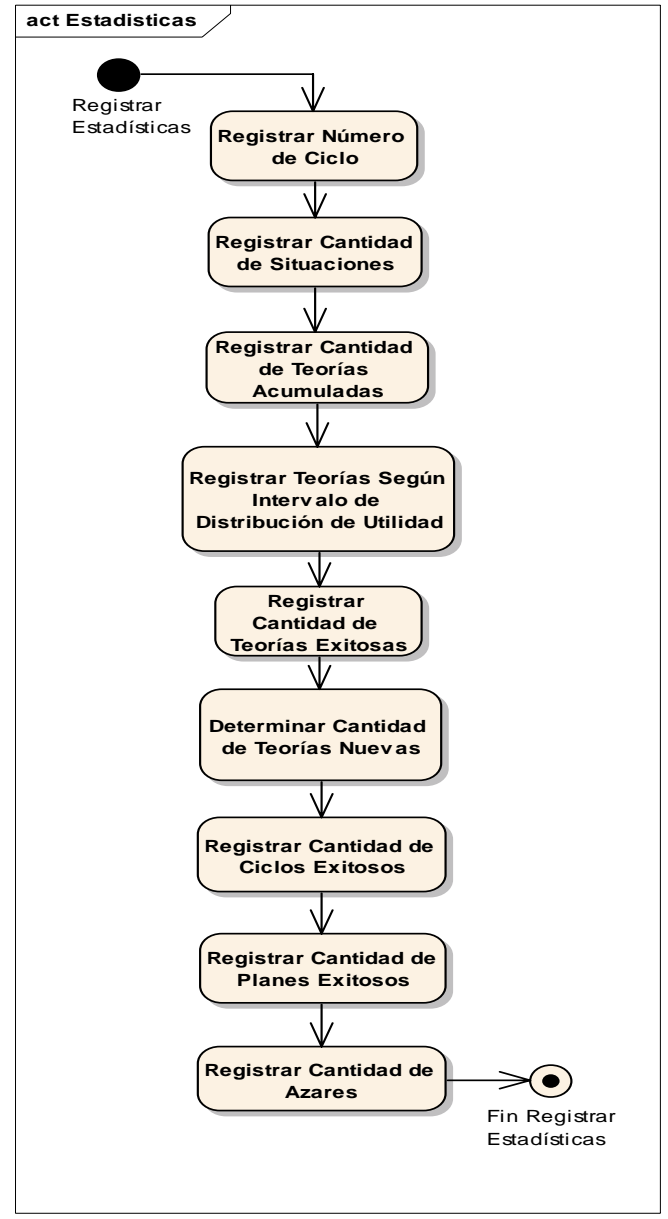

Figura 4.27 Diagrama de Actividades del módulo estadísticas del SAR

En el Anexo J, se detalla un ejemplo del archivo de estadísticas registradas por el SAR durante su actuación durante $n$ ciclos de percepción acción.

\subsubsection{EVOLUCIÓN DEL SISTEMA AUTÓNOMO DE ROBOT}

En el marco de la evolución de un SAR, se consideran distintos estados de evolución, en este orden, el primer estado es SAR- Born (nacido), SAR-Newbie (novato), SAR-Trained (trained), SARMature (maduro). En función de la configuración del SAR se evalúa el rendimiento de aprendizaje de éste para promover su estado de evolución. La evolución de un SAR en particular se caracteriza por los métodos y las bases de conocimiento que éste aplique, a fin de considerar luego de su actuación en el escenario el rendimiento que obtuvo. En este orden la cantidad de ciclos exitosos es la primera métrica general que se observa para todos los SARs, para los SARs que aplican colaboración se considera además la cantidad de teorías nuevas que el SAR generó en su actuación. Se muestra en la Figura 4.28 el diagrama de actividades correspondiente a la evolución de un SAR $\underline{\text { que recibió colaboración, sobre la base del rendimiento de aprendizaje del SAR, obtenido en }}$ 
función del porcentaje de ciclos exitosos alcanzados (\% CEA) y el porcentaje de teorías nuevas alcanzadas (\% TNA) en su actuación en el ambiente de operación.

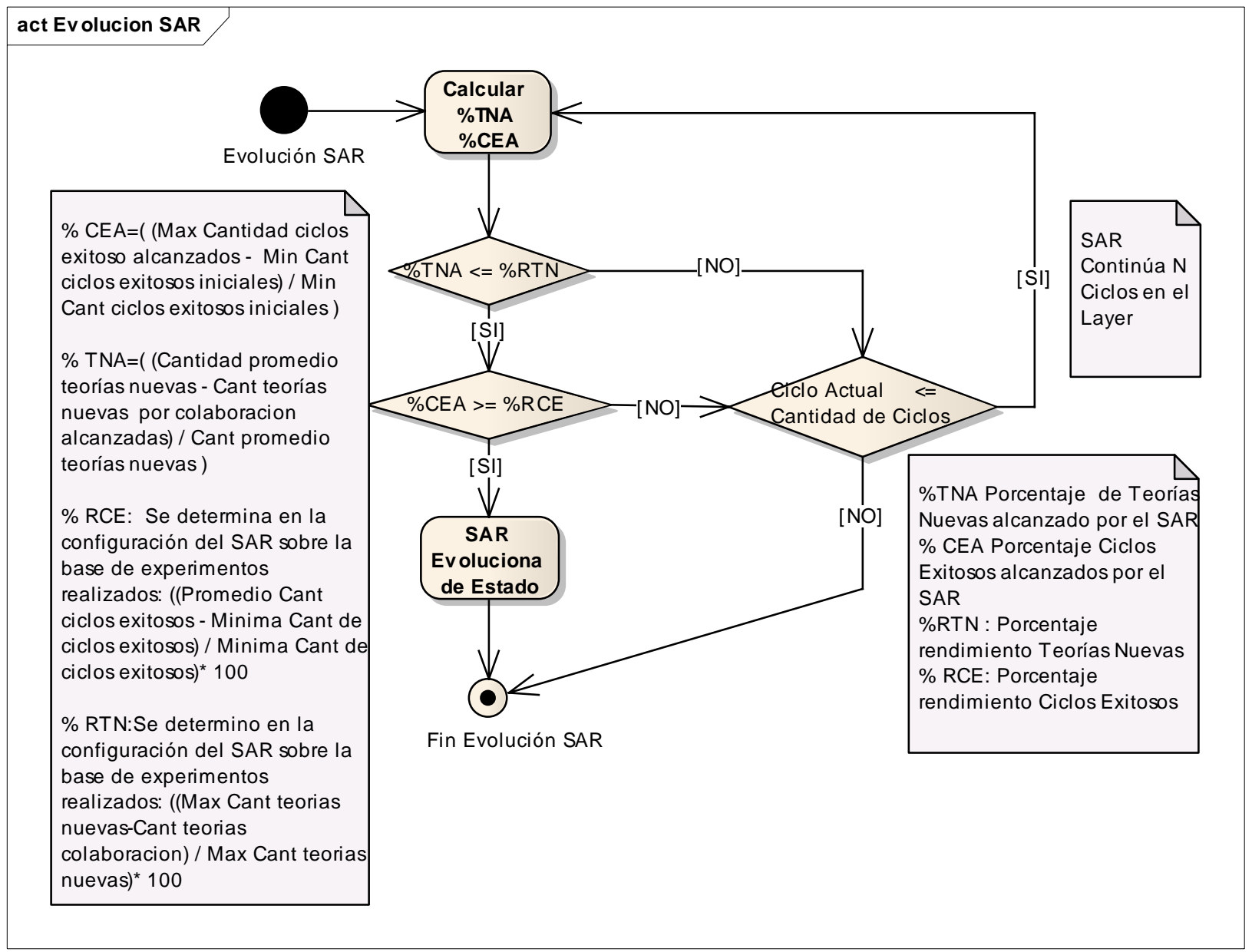

Figura 4.28 Diagrama de Actividades del módulo de evolución del SAR

En este contexto el rendimiento del SAR se considera sobre la base de los parámetros establecidos en la actividad estadística y rendimiento de aprendizaje correspondiente al módulo de configuración del SAR (subsección 4.4.2.1), a través del porcentaje de rendimiento de ciclos exitosos (\% RCE) y el porcentaje de teorías nuevas (\% RTN), estos porcentajes fueron definidos empíricamente para cada una de las arquitecturas, aplicando los mismos valores en todos los casos de experimentación. La determinación de los porcentajes para ciclos exitosos y teorías nuevas alcanzados (\% CEA, \% TNA) y los porcentajes de rendimientos (\% RCE y \% RTN) aplicados en la experimentación se presentan en la sección L-3 del Anexo L. Para evaluar la evolución del SAR en condiciones más restrictivas en términos de evolución, se consideró la cooperación entre SARs que cooperan en la layer BIO, entre SARs nacidos que transitan esta layer para alcanzar el estado de evolución de novato. Se consideró la colaboración desde un SAR que está en la layer TBO (de un SAR novato que transita este layer para alcanzar el estado de evolución de entrenado), a un SAR receptor que se 
encuentra en el layer BIO. En el módulo de evolución se calcula el porcentaje de teorías nuevas alcanzadas (\% TNA) y el porcentaje de ciclos exitosos alcanzados (\% CEA) por el SAR durante el ciclo i de percepción - acción de SAR. Si el SAR (recibió colaboración) en su actuación, en el ambiente de operación genera una menor cantidad de teorías nuevas, que es lo esperado en el proceso de aprendizaje, resultando el \% TNA menor o igual al parámetro de rendimiento de teorías nuevas correspondiente al porcentaje de rendimiento de teorías nuevas ( $\% \mathrm{RTN})$ y el SAR aumenta su cantidad de ciclos exitosos en su actuación en el ambiente de operación, que es lo esperado en el proceso de aprendizaje, resultando el (\% CEA) mayor o igual al parámetro de rendimiento de ciclos exitosos correspondiente al porcentaje de rendimiento de ciclos exitosos (\% RCE), entonces el SAR alcanza un nuevo estado de evolución, de otra manera el SAR continúa en su layer de actuación, durante $\mathrm{n}$ ciclos, hasta alcanzar la cantidad de ciclos de percepción - acción correspondiente a su actuación en el ambiente de operación o cumplir con las condiciones de evolución.

\subsection{ESCENARIOS DEL SISTEMA AUTÓNOMO DE ROBOT}

En esta sección se presentan escenarios, cada uno de ellos con diferente complejidad, correspondientes a las distintas layers que el SAR puede aplicar en su LLC en función de su estado de evolución, durante su actuación en el ambiente de operación. Se presenta el escenario para la layer BIO en la subsección 4.5.1, para la layer TBO en la subsección 4.5.2 y para la layer WIO en la subsección 4.5 .3

\subsubsection{ESCENARIO LAYER BIO}

Este escenario se corresponde con la actuación de SARs que inician su tránsito en la layer BIO con el estado de evolución Born y finalizan su tránsito con el estado de evolución Newbie. Este escenario inicial en el ciclo de vida del SAR se compone de cuatro paredes unidas que cercan los límites exteriores del escenario y cuatro paredes más pequeñas y separadas en el interior que aparecen a modo de obstáculos según se muestra en la Figura 4.29. En la carpeta denominada subsección N-2.1 de la sección N-2 del Anexo N “Soporte Digital” se puede observar un video del robot en el escenario de la layer BIO, recreado en el ambiente del simulador Webots. 


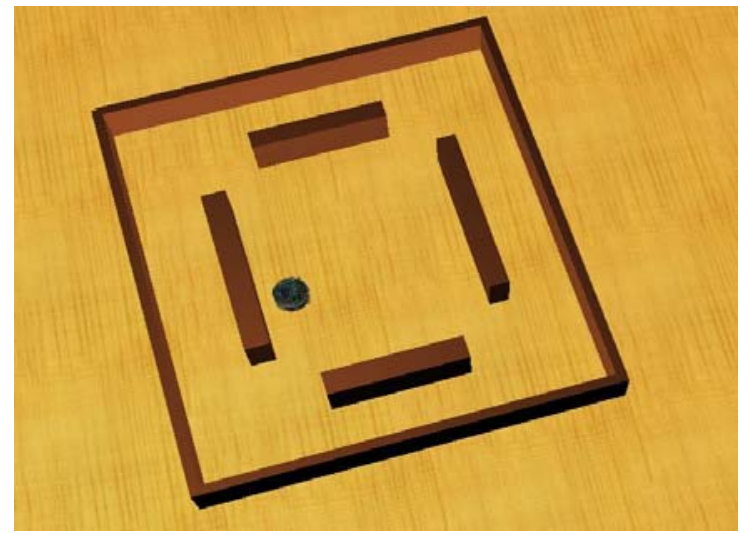

Figura 4.29 Escenario Layer BIO

\subsubsection{ESCENARIO LAYER TBO}

Este escenario se corresponde con la actuación de SARs que inician su tránsito en la layer TBO con el estado de evolución Newbie y finalizan su tránsito con el estado de evolución Trained. Este escenario en el ciclo de vida del SAR es del tipo laberinto y se compone de cuatro paredes unidas que cercan los límites exteriores del escenario y por dentro por cuatro paredes más pequeñas separadas que contiene en su interior cubos según se muestra en la Figura 4.30. Este escenario se caracteriza por dos tipos de obstáculos (pared y cubo). Se observa en la parte inferior derecha del escenario una vista de la cámara virtual del robot. En la carpeta denominada subsección N-2.2 de la sección N-2 del Anexo N "Soporte Digital” se puede observar un video del robot en el escenario de la layer TBO, recreado en el ambiente del simulador Webots.

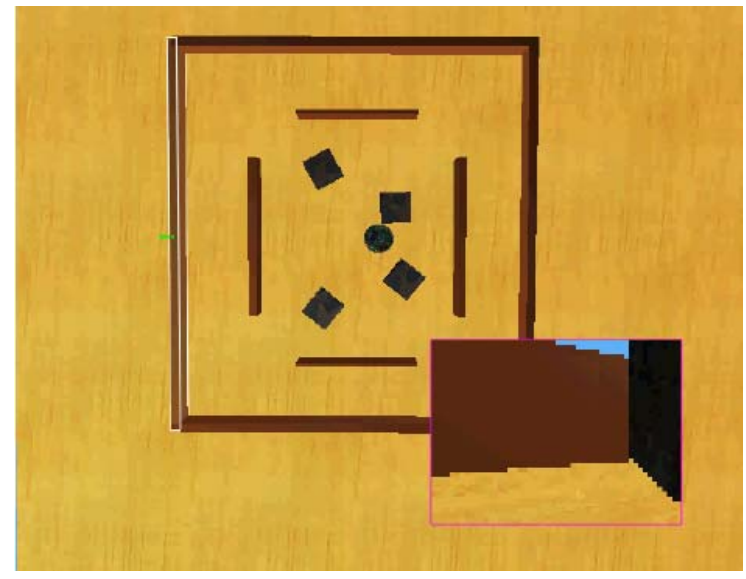

Figura 4.30 Escenario Layer TBO 


\subsubsection{ESCENARIO LAYER WIO}

Este escenario se corresponde con la actuación de SARs que inician su tránsito en la layer WIO con el estado de evolución Trained y finalizan su tránsito con el estado de evolución Mature. Este escenario real en el ciclo de vida del SAR, se compone de una base sobre la que se cuenta con cuatro paredes separadas en los límites exteriores del escenario y por dentro con un conjunto de cubos. Este escenario se caracteriza por dos tipos de obstáculos, paredes y cubos.

Se muestra en la Figura 4.31 el escenario real para la layer WIO, donde se puede observar al SAR trained. Se observa en la parte inferior derecha del escenario una vista de la cámara del robot. En la carpeta denominada subsección N-2.3 de la sección N-2 del Anexo N "Soporte Digital" se puede observar un video del robot corriendo en el escenario (real) de la layer WIO.

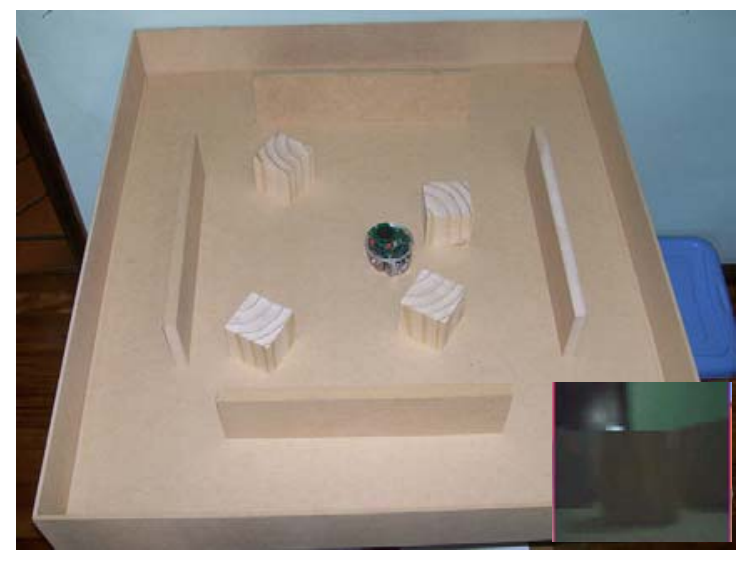

Figura 4.31 Escenario Layer WIO

\subsection{CARACTERÍSTICAS DEL ROBOT Y SIMULADOR EMPLEADO}

En esta sección se presentan las características generales del mini robot e-puck en la subsección 4.6.1 y las características generales del simulador Webots un CAD robots software en la subsección 4.6.2. El contenido de esta sección se desarrolló sobre la base del documento Cyberbotics Robot Curriculum [Cyberbotics Ltd., Olivier Michel, Fabien Rohrer, Nicolas Heiniger and wikibooks, 2009]. 


\subsubsection{CARACTERÍSTICAS GENERALES DEL MINI ROBOT E-PUCK}

El robot e-puck fue diseñado por el Dr. Francesco Mondada y Michael Bonani en 2006 en la EPFL, el Instituto Federal Suizo de Tecnología en Lausanne (Figura 4.32).con el propósito de ser un instrumento para la educación universitaria y el campo de la investigación. El robot (e-puck) cumple una serie de requisitos, entre ellos se destacan el diseño de una estructura simple que le permite la integración de diversos sensores, el software de simulación del robot e-puck (webots), brinda una fácil programación, simulación y control remoto del robot con Bluetooth. El robot e-puck ha sido utilizado en una amplia gama de aplicaciones en: robótica móvil, comunicación entre robots, robótica evolutiva (robots autónomos que pueden sobrevivir en los entornos en los que se encuentran, siempre con la menor intervención humana posible), robótica colectiva (trabajo de robots en equipo), robótica bio-inspirada (diseño de robots inspirados en animales, insectos).

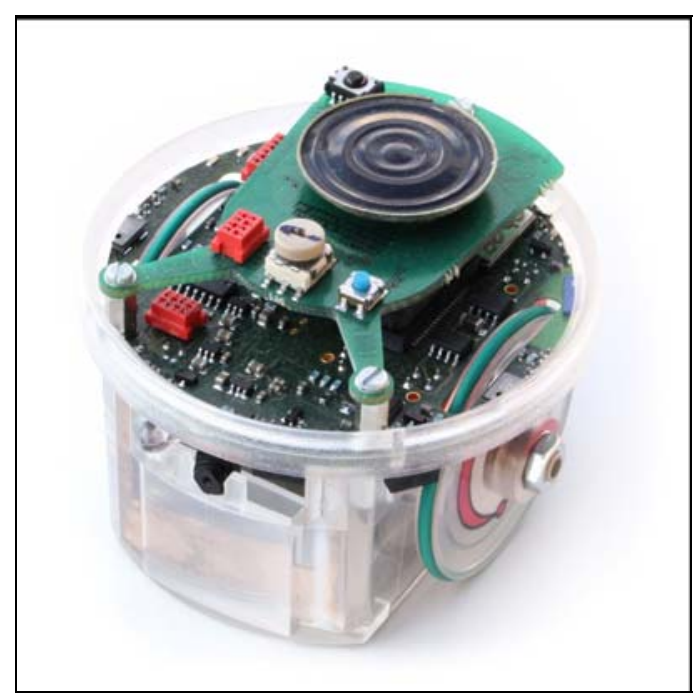

Figura 4.32 Robot móvil e-puck

El e-robot (e-puck) tiene un procesador dsPIC (Digital Signal Programmable Integrated Circuit) de Microchip. El robot e-puck también cuenta con un gran número de sensores y actuadores como se muestra en la Figura 4.33, los que se detallan en la tabla 4-5. Los aspectos generales de movilidad y sensorística empleados en el sistema desarrollado se presentan en el Anexo N. 


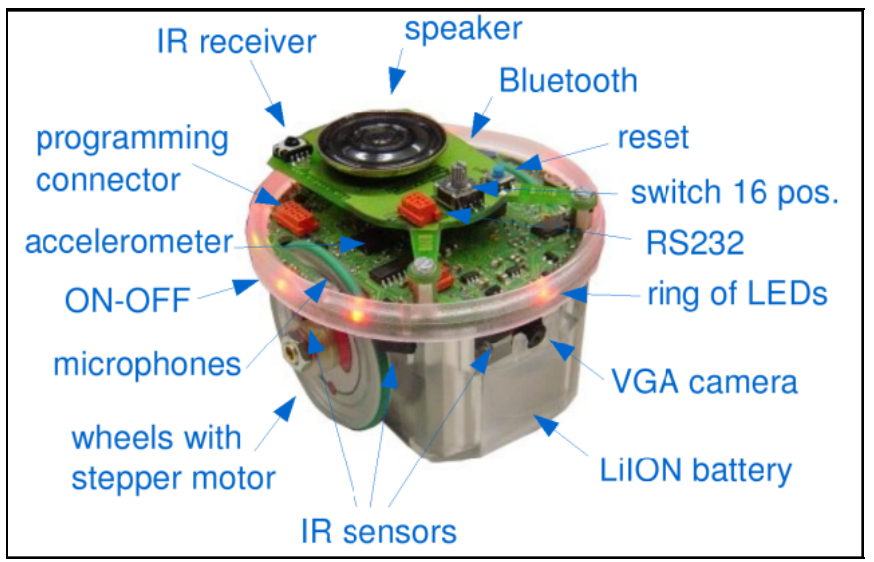

Figura 4.33 Sensores y actuadores del robot e-puck

\begin{tabular}{|c|c|}
\hline Características & Detalle \\
\hline Dimensiones & Altura $70 \mathrm{~mm}$ diametro, $55 \mathrm{~mm}$, peso $150 \mathrm{~g}$ \\
\hline Autonomía Batería & Batería recargable y renovable ( $5 \mathrm{Wh}$ LiION), provee tres $(3)$ horas de autonomía \\
\hline Procesador & dsPIC 30F6014A@60 Mhz ( 15 MIPS) 16 bit microcontroller con DSP core \\
\hline Memoria & RAM: 8 KB; FLASH: 144 KB \\
\hline Motores & $\begin{array}{l}2 \text { motores paso a paso con una reducción de 50:1,resolución: } 0.13 \mathrm{~mm} \text {, velocidad } \\
\text { máxima: } 15 \mathrm{~cm} / \mathrm{s}\end{array}$ \\
\hline Estructura Mecánica & Cuerpo de plástico transparente que soporta PCBs, la batería y los motores \\
\hline Sensores IR & 8 sensores infra-red miden la luz ambiente y la proximidad los objetos hasta $6 \mathrm{~cm}$ \\
\hline Cámara VGA & Cámara color con una resolución of 480 x 640 (típico uso: $52 \times 39$ or $480 \times 1$ ) \\
\hline Micrófonos & 3 micrófonos omni-direccionales para la localización de sonidos \\
\hline Acelerómetro & 3D acelerómetro a lo largo de los ejes $\mathrm{X}, \mathrm{Y}$ and $\mathrm{Z}$ \\
\hline LEDs & $\begin{array}{l}8 \text { LEDs independientes color rojo sobre el anillo del cuerpo del robot, un LED verde } \\
\text { sobre el cuerpo del robot y un LED rojo fuerte en el frente del robot }\end{array}$ \\
\hline Parlante & Parlante incorporado en el robot, capaz de reproducir sonidos y tonos WAV \\
\hline Switch & Switch de rotación de 16 posiciones, ubicado en la parte superior del robot \\
\hline Conexión PC & Port serie standard, velocidad hasta $115 \mathrm{Kbps}$ \\
\hline Wireless Bluetooth & $\begin{array}{l}\text { Para la comunicación inalámbrica entre robot y computadora y la comunicación } \\
\text { inalámbrica entre robots }\end{array}$ \\
\hline Control Remoto & Receptor Infra-rojo, para comandos de control remoto standard \\
\hline Bus de expansión & bus de expansión diseñado para añadir nuevas capacidades \\
\hline Programación: & C programming con free GNU GCC compiler \\
\hline Ambiente Grafico IDE & $\begin{array}{l}\text { Ambiente de desarrollo integrado IDE (integrated development environment) } \\
\text { provisto por el simulador Webots }\end{array}$ \\
\hline $\begin{array}{l}\text { Facilidades con } \\
\text { Webots }\end{array}$ & $\begin{array}{l}\text { El uso robot e-puck robot: con simulación, control remoto y ambiente grafico } \\
\text { gráficos y la programación del robot en } \mathrm{C}\end{array}$ \\
\hline
\end{tabular}

Tabla 4.5 Características del robot e-puck 


\subsubsection{CARACTERÍSTICAS DEL SIMULADOR WEBOTS}

Webots es un software de prototipado y simulación para robots móviles [Webots, 2009]., en la actualidad es empleado por más de 700 universidades en el mundo, Se ha desarrollado desde 1996 y fue diseñado originalmente por el Dr. Olivier Michel de la EPFL, del Instituto Federal Suizo de Tecnología de Lausana, Suiza. Es utilizado principalmente para la investigación y la educación en la robótica. Además de la universidad, Webots también es utilizado por organizaciones de investigación y de centros de investigación de las empresas, incluyendo Toyota, Honda, Sony, Panasonic, Pioneer, NTT, Samsung, La NASA, Stanford Research Institute, la investigación Tanner, BAE Systems, Vorverk, etc.

Webots es un software para prototipado rápido y simulación de robots móviles, permite visualizar rápidamente el comportamiento del robot y comprobar si cumplen los requisitos esperados, en el contexto de un control inteligente del robot y finalmente permite la transferencia de los resultados de la simulación a un robot real. Webots permite realizar las cuatro etapas básicas en el desarrollo de un proyecto de robótica como se muestra en la Figura 4.34.

La primera etapa, consiste en el diseño del cuerpo físico de los robots, incluyendo sus sensores y actuadores (color, forma, características técnicas de los sensores y actuadores, etc.) así como el modelo físico del ambiente de actuación del robot con sus propiedades. De esta manera, cualquier tipo de robot puede ser creado, incluyendo los robots de ruedas, robots de cuatro patas, robots humanoides. El entorno de los robots se crea poblando el espacio con objetos como paredes, puertas, escaleras, pelotas, obstáculos, etc.

Los parámetros físicos del objeto pueden ser definidos, como la distribución de la masa, los objetos de delimitación, la fricción, los parámetros de rebote, etc., para que el motor de simulación en Webots pueda simular su física

La Figura 4.35 muestra el modelo de la simulación del robot e-puck en exploración de un entorno con obstáculos. Una vez creados los robots virtuales y entornos virtuales, puede pasar a la segunda etapa. 


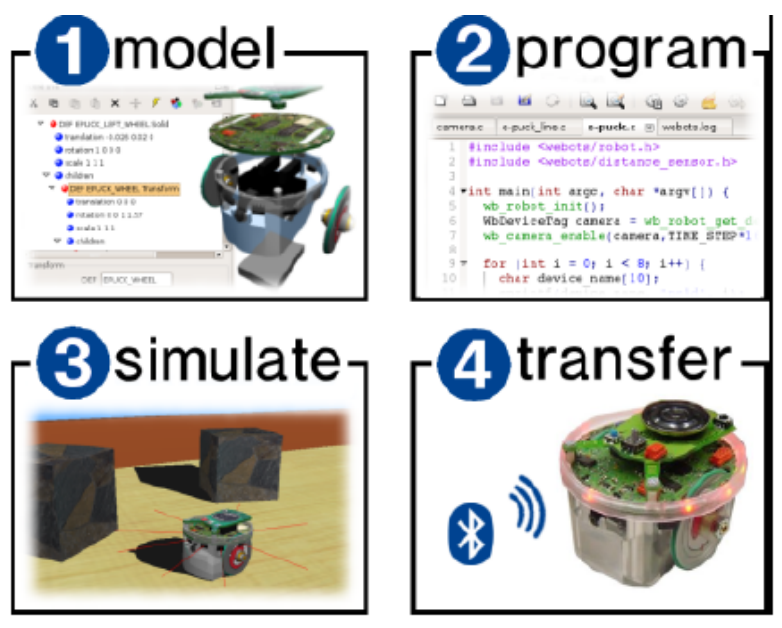

Figura 4.34 Etapas de desarrollo con Webots

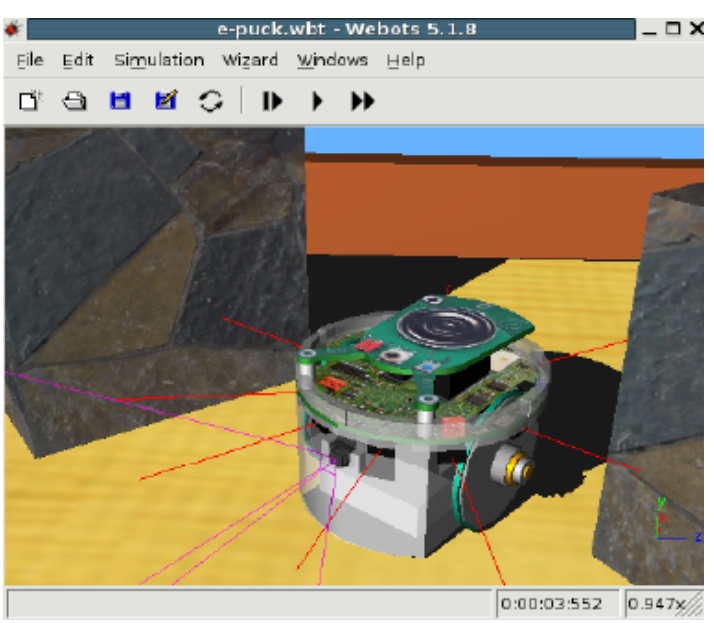

Figura 4.35. Modelo de un e-puck in Webots

En la segunda etapa se realiza la programación del comportamiento del robot. Webots incluye herramientas de programación gráfica que son fáciles de utilizar para los principiantes y los lenguajes de programación (como $\mathrm{C}, \mathrm{C}++$ o Java), que son más poderosos y permiten el desarrollo de comportamientos más complejos.

El programa de control de un robot es generalmente un bucle sin fin que se divide en tres partes: (1) leer los valores medidos por los sensores del robot, (2) calcular cuál debe ser la acción siguiente del robot y (3) enviar comandos a los actuadores que llevan a cabo estas acciones. La parte más fácil son las partes (1) y (3). La más difícil es la parte (2), ya que es aquí donde se encuentra toda la inteligencia del robot. La parte (2) puede ser dividida en sub-partes, como el procesamiento de datos de sensores, el aprendizaje, la generación de las acciones.

En la tercera etapa se aplica la simulación, ésta permite probar si el programa se comporta correctamente. Mediante la ejecución de la simulación, se puede ver el comportamiento del robot, pudiendo interactuar con el robot en forma interactiva, moviendo los obstáculos o el robot con el Mouse. También se pueden visualizar los valores medidos por los sensores, los resultados de la transformación del programa, etc. Por último, la cuarta etapa es la transferencia del programa de control a un robot real, que actúa en el mundo real.

En la Figura 4.36 se muestran dos ventanas, la ventana de la izquierda muestra la interfase de epuck con los valores de los sensores y actuadores del robot, esta ventan permite la transferencia desde la simulación al robot real, a la derecha de esta ventana, se puede ver el punto de vista de la cámara del robot simulado e-puck. En la ventana derecha, se puede ver el punto de vista de la cámara real del robot y el valor de los sensores del robot. 

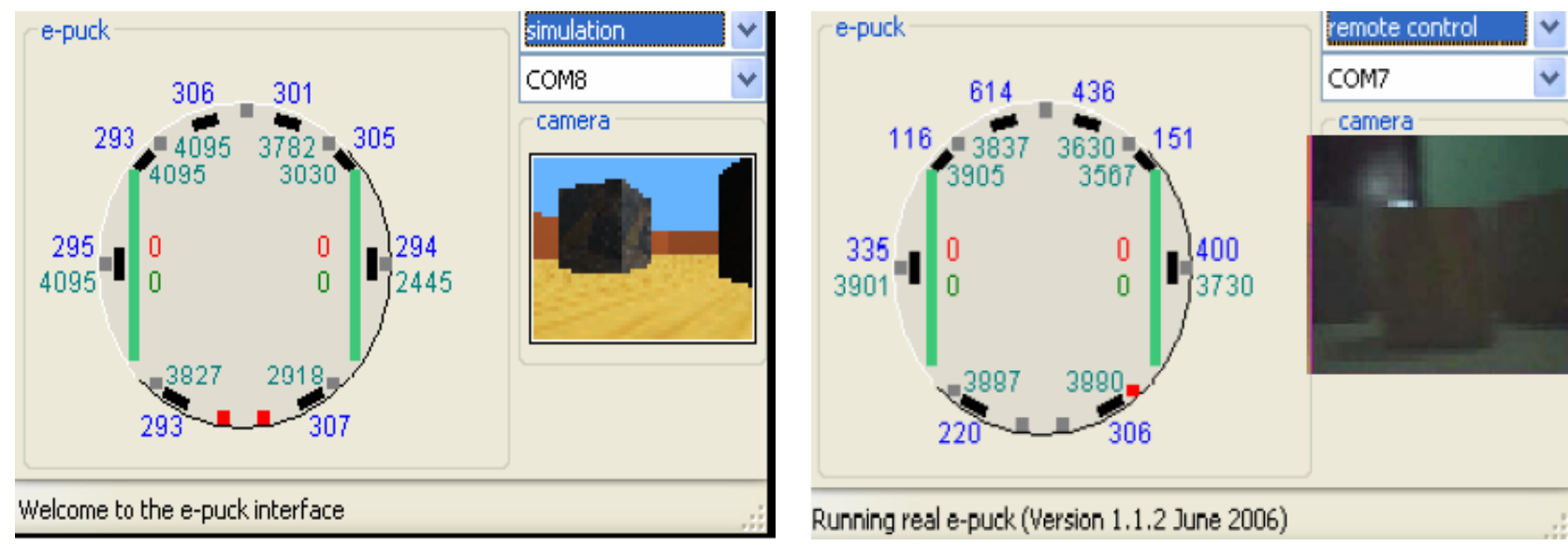

Figura 4.36 Transferencia desde el simulador al robot real

Se muestra en la Figura 4.36 la visualización de los dispositivos (sensores y actuadores) del robot. las mediciones de distancia se muestran en azul, fuera del cuerpo del robot. Las mediciones de luz se muestran en color verde, en el interior del cuerpo. Los LEDs se muestran en gris cuando está apagado y rojo cuando está conectado. Las velocidades del motor se muestran en rojo, y la posición del motor se muestra en verde justo debajo de la velocidad de cada motor. La imagen de la cámara (si está presente) se muestra en la parte derecha de la ventana. Los valores de los sensores de piso (si se encuentran instalados) se muestran en la parte superior del cuerpo.

\subsection{CONFIGURACIÓN Y TIPOS DE SARS}

En función de la configuración del SAR (específicamente en la selección de sus métodos, base de conocimientos y del tipo de planificador), surgen las distintas combinaciones. En este orden los SARs que aplican compartición de conocimientos a través de intercambio de teorías (cooperación) y colaboración, dan lugar a una extensión de identificación del tipo de SAR, no solamente por sus métodos asociados, sino también por la aplicación de la compartición de conocimiento a través del empleo de sus bases de conocimiento.

Se presenta en la subsección 4.7.1 para el SAR con planificador clásico (SARp) las extensiones que se aplican en el Capítulo 5 experimentación, en la subsección 4.7.2 se presenta para el SAR con planificador por ranking de teorías (SARr), las extensiones que se aplican en el Capítulo 5 experimentación, en la subsección 4.7.3 se presenta un taxonomía de las extensiones de tipos de SARs empleados en el presente trabajo. 


\subsubsection{IDENTIFICACIÓN DE SARP EN FUNCIÓN DE LA CONFIGURACIÓN Y TIPO}

En este orden se presentan, en función de los experimentos considerados en el Capítulo 5, los siguientes SARps: [a] SARp, que no tiene métodos asociados, se reconoce también como SARp Neutro "SN", [b] SARp, que no tiene métodos asociados y emplea la base de conocimiento de intercambio o cooperación generada con otro SAR que se encuentra en el mismo nivel de layer, se reconoce como "SI", [c] SARp, que no tiene métodos asociados y emplea la base de conocimiento producto de la colaboración recibida de un SAR que se encuentra en un layer superior, se reconoce como "SC", [d] SARp que no tiene métodos asociados y emplea la base de conocimiento de intercambio (cooperación) generada con otro SAR y la colaboración sobre esta base de intercambio, recibida por un SAR que se encuentra en un layer superior, se reconoce como "SIC", [e] SARp, que aplica el método de ponderación de planes y mutación se reconoce como "SPM", [f] SARp que aplica el método de ponderación de planes, mutación y emplea la base de conocimiento de intercambio o cooperación que generó con otro SAR que se encuentra en el mismo nivel de layer, se reconoce como "SPMI", [g] SARp, que aplica el método de ponderación de planes, mutación y emplea la base de conocimiento, producto de la colaboración recibida por un SAR que se encuentra en un layer superior, se reconoce como "SPMC", [h] SARp, que aplica el método de ponderación de planes, mutación y emplea la base de conocimiento de intercambio (cooperación) que generó con otro SAR y la colaboración sobre la base de cooperación, recibida por un SAR que se encuentra en un layer superior, se reconoce como "SPMIC".

\subsubsection{IDENTIFICACIÓN DE SARR EN FUNCIÓN DE LA CONFIGURACIÓN Y TIPO}

En el marco de los experimentos que se consideran en el Capítulo 5, se distinguen los siguientes SARrs que aplican planificador por ranking: [a] SARr o SARr neutro que no tiene métodos asociados, se reconoce como "SNr, [b] SARr que aplica el método de mutación se reconoce como "SMr", [c] SARr, que no tiene métodos asociados y emplea la base de conocimiento de intercambio o cooperación generada con otro SAR que se encuentra en el mismo layer, se reconoce como "SIr", [d] SARr, que no tiene métodos asociados y emplea la base de conocimiento producto de la colaboración recibida de un SAR que se encuentra en un layer superior, se reconoce como "SCr", [e] SARr, que no tiene métodos asociados y emplea la base de conocimiento de intercambio 
(cooperación) que generó con otro SAR y sobre esta base la colaboración recibida por un SAR que se encuentra en un layer superior, se reconoce como "SICr", [f] SARr que aplica el método de mutación y emplea la base de conocimientos producto de la colaboración recibida por un SAR que se encuentra en un layer superior, se reconoce como "SMCr", [g] SARr que aplica el método de mutación y emplea la base de conocimiento de intercambio (cooperación) que generó con otro SAR y sobre esta base, la colaboración recibida por un SAR que se encuentra en un layer superior, se reconoce como "SMICr".

\subsubsection{TAXONOMÍA DE LAS EXTENSIONES DE SARS APLICADAS}

Se presenta en la Figura 4.37 la taxonomía de SARs que se emplean en el presente trabajo, en este orden se distinguen la conformación de grupos que: [a] combinan métodos y compartición de conocimientos, [b] sólo aplican compartición de conocimientos sin métodos asociados, [c] neutros, no aplican compartición de conocimientos ni métodos asociados, [d] sólo aplican métodos asociados y no aplican compartición de conocimientos.

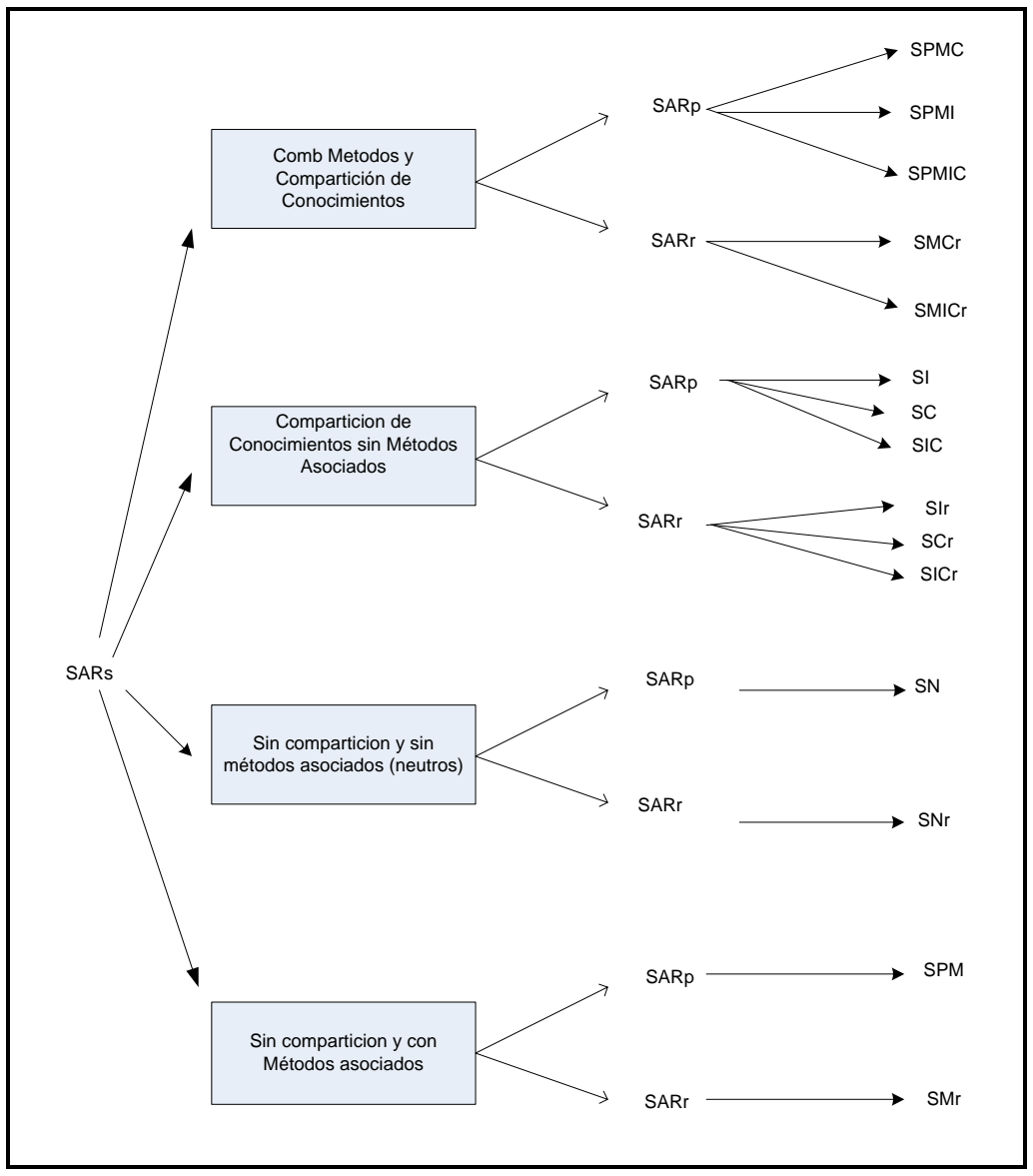

Figura 4.37 taxonomia de SARs empleados 


\section{EXPERIMENTOS}

En este Capítulo se presentan los resultados experimentales del comportamiento de un Sistema Autónomo de Robot (SAR) que recibe colaboración. El SAR fue implementado sobre la base de una plataforma e-puck, se experimentaron dos tipos de arquitecturas de SAR, la primera con planificador clásico (SARp) y la segunda con planificador de acciones por ranking (SARr).En la sección 5.1 se realiza una introducción de la experimentación, en la sección 5.2 se describe el diseño experimental, en la sección 5.3 se presentan gráficamente los resultados obtenidos, su interpretación y la comparación de los resultados obtenidos en la experimentación entre la arquitectura de SARp y la arquitectura propuesta de SARr.

\subsection{INTRODUCCIÓN.}

Se realiza la simulación del SAR sobre la base del robot e-puck, empleando el simulador de robots móviles Webots 6 de Cyberbotics [Webots, 2009] desarrollado en el Laboratorio de Micro Informática (LAMI) del Swiss Federal Institute of Technology, Lausanne, Switzerland (EPFL). Para cada tipo de arquitectura de SAR se desarrolló la experimentación sobre la base de exploración del SAR en un escenario con obstáculos, aprendiendo los efectos de aplicar determinadas acciones a determinadas situaciones.

\subsection{DISEÑO EXPERIMENTAL}

En esta sección se presentan el diseño de los experimentos, a través de la subsección 5.2.1 se detallan las variables independientes y en la subsección 5.2.2 las variables dependientes que se consideran en la experimentación de los SARs. Se presentan en la subsección 5.2.3, las arquitecturas de SAR con sus métodos particulares de configuración considerados en la experimentación. En la subsección 5.2.4 se detallan cada uno de los grupos de experimentos realizados para estudiar los efectos de la aplicación de la colaboración en cada una de las arquitecturas de SARs. El procedimiento aplicado en cada uno de los experimentos, se realizó sobre la base de la simulación del SAR durante 600 ciclos (ciclo=percepción/acción) para todos los experimentos, considerando la posición de inicio del SAR en forma aleatoria en el escenario 
de experimentación. Cada 20 ciclos se efectuó la generación de un informe sobre el estado de las variables del SAR según se muestra a modo de ejemplo en la tabla 5.1, generando la fila I de la matriz que contiene las variables del SAR generada en el ciclo I*20.

El procedimiento experimental general correspondiente a cada instancia experimental, considerado para cada caso fue: la ejecución de diez experimentaciones ( equivalente a 6000 ciclos percepción acción) para cada una de las configuraciones de SARs, considerando en todos los casos, los valores por defecto indicados para las variables independientes, a partir de los cuales se realiza la construcción de una matriz promedio resultante de las matrices en función de las variables dependientes seleccionadas en la configuración del SAR. Se presentan las correspondientes tablas en el Anexo L. La generación de las gráficas de comportamiento correspondientes a cada SAR, se realizan sobre la base de la información de cada matriz promedio, acompañado de la interpretación de los resultados obtenidos.

\begin{tabular}{|c|c|c|c|c|c|c|c|}
\hline & $\begin{array}{c}\text { Cantidad } \\
\text { de } \\
\text { Ciclo }\end{array}$ & $\begin{array}{c}\text { Cantidad } \\
\text { de } \\
\text { Teorías } \\
\text { acumuladas }\end{array}$ & $\begin{array}{c}\text { Cantidad } \\
\text { de } \\
\text { Teorías } \\
\text { nuevas }\end{array}$ & $\begin{array}{c}\text { Cantidad } \\
\text { de } \\
\text { Teorías } \\
\text { exitosas }\end{array}$ & $\begin{array}{c}\text { Cantidad } \\
\text { de } \\
\text { Planes } \\
\text { Exitosos }\end{array}$ & $\begin{array}{c}\text { Cantidad } \\
\text { de } \\
\text { Ciclos } \\
\text { Exitosos }\end{array}$ & $\begin{array}{c}\text { Exiclos } \\
\text { Exitosos }\end{array}$ \\
\hline 1,00 & 1,00 & 87,00 & 0 & 56,00 & 0,00 & 0,00 & 0,00 \\
\hline 20,00 & 2,00 & 87,00 & 0 & 56,00 & 7,67 & 9,00 & 0,45 \\
\hline 40,00 & 5,67 & 91,67 & 4,67 & 57,67 & 23,33 & 22,67 & 0,57 \\
\hline$\cdots$ & $\cdots$ & $\cdots$ & $\cdots$ & $\cdots$ & $\cdots$ & $\cdots$ & $\cdots$ \\
\hline$\ldots$ & $\cdots$ & $\cdots$ & $\cdots$ & $\cdots$ & $\cdots$ & $\cdots$ & $\cdots$ \\
\hline 600,00 & 127,67 & 609,33 & 522,33 & 111,00 & 59,67 & 130,00 & 0,22 \\
\hline
\end{tabular}

Tabla 5.1. Estructura del informe del promedio de las variables del SAR

Los sistemas autónomos de robots (SARs), durante la experimentación han formulado un conjunto de teorías que les permite predecir "a priori” el efecto de sus acciones. Sobre esta base de experimentación del intercambio (cooperación) se realizó entre SARs borns que se encuentran en el layer BIO y la colaboración desde un SAR Newbie que se encuentra en el layer TBO, a un SAR receptor born que se encuentra en el layer BIO del LLC (Learning Life Cycle).

Se asume como criterio más restrictivo para la experimentación de la colaboración entre SARs, la selección de bases de conocimiento de teorías de SARs que se encuentren próximos en su estado de evolución, en este orden se aplicaron para la experimentación, la bases de conocimiento de teorías de tres SARs que son representados por: el robot A (born con 600 ciclos de simulación, que se encuentra iniciando layer $\mathrm{BIO}$ ), el robot $\mathrm{B}_{\mathrm{b}}$ (born con 3000 ciclos de 
simulación, recorriendo el Layer BIO), el robot $\mathrm{B}_{\mathrm{n}}$ (newbie con 6000 ciclos de simulación iniciando el layer TBO).

Sobre estas bases de teorías generadas se realizó el intercambio a nivel de born en el layer BIO, entre el robot A (born, que se encuentra al inicio del layer BIO) y el robot $\mathrm{B}_{\mathrm{b}}$ (born, que se encuentra transitando la mitad del layer BIO), generando la base de teorías de intercambio robot A-B. La colaboración se realizó entre el robot $B_{n}$ (newbie que se encuentra iniciando el layer TBO) al robot A (born que se encuentra al inicio del layer BIO) receptor. El intercambio y colaboración se realizó entre la base de teorías de intercambio robot A-B borns y la base de teorías del robot $\mathrm{B}_{\mathrm{n}}$ newbie.

Las bases de teorías enunciadas fueron empleadas por el robot E (robot de experimentación), sobre el que se realizaron los experimentos con la aplicación de los métodos de ponderación de planes y mutación. El SAR neutro se desarrolló sobre la base de un robot born que corrió 600 ciclos (robot A). Los robots A y B se iniciaron con su creador (programador), corriendo 400 ciclos para generar su base inicial de teorías a través de un comportamiento inicial reactivo. Las bases de teorías de los distintos robots se almacenaron en XML, se adjuntan las bases de conocimiento en la carpeta indicada como Sección N-3 del Anexo N, "Soporte Digital”.

Independientemente de la arquitectura del SAR, las teorías que se generan, tienen la misma estructura de datos, la que se detalla en el Anexo C, acompañada por un ejemplo.

En el Anexo M, se presenta la características de las bases de teorías empleadas por los SARs (Reactivo, Born, Newbie, SAR cooperación, SAR colaboración), utilizados como base en la experimentación.

\subsubsection{VARIABLES INDEPENDIENTES}

Se consideran las siguientes variables independientes:

Cantidad de Intervalos: Es una variable cuantitativa cuyo valor pertenece al intervalo [0,1] Determina la cantidad de intervalos en los que se divide el rango de utilidad " $U$ ” y el rango de valores de la relación “ $P / K$ ”, por defecto el valor es 0,25 , con el que se generan cuatro intervalos. Por defecto se seleccionan cuatro intervalos (4), en donde el primer intervalo se corresponde a valores comprendidos entre: $0,01<\mathrm{V}<=0,25$, el segundo intervalo se corresponde con los valores comprendidos entre: $0,25<\mathrm{U}$ $<=0,50$. el tercer intervalo se corresponde con los valores comprendidos 
entre: $0,50<U<=0,75$, el cuarto intervalo se corresponde con los valores comprendidos entre: $0,75<U<=1$. De esta forma se registra la cantidad de teorías y los valores de relación $\mathrm{P} / \mathrm{K}$ distribuidos por rangos, el rango más restrictivo que exige mejores resultados es el último correspondiente a $0,75<U<=1$, sobre el cuál se trabajó en forma constante en toda la experimentación. Si bien el rango de utilidad es determinado en 4.4.3.2 entre [-1,1] a los efectos de la experimentación se consideró sólo el rango de utilidad entre [0,1], descartando de la clasificación la utilidad negativa.

Colaboración: Esta variable cualitativa adopta el valor: 1 (UNO) si se emplea colaboración entre SARs y 0 (CERO), si no se emplea. Indica si el método propuesto de colaboración se emplea en la generación y valoración de teorías entre un SAR colaborador y un SAR receptor que se encuentra en un nivel inferior de evolución en el marco del ciclo de vida propuesto para un SAR.

Intercambio: Esta variable cualitativa, adopta el valor: 1 (UNO), si se emplea intercambio (cooperación) entre SARs y 0 (CERO) si no se emplea. Indica si el método de intercambio [García Martínez, R., et al. 2006, Maceri, D., García Martínez, R., 2001], se emplea en la generación y valoración de teorías entre SARs del mismo nivel de evolución.

Intervalo de muestras: Es una variable cuantitativa cuyo valor pertenece al intervalo $[0,100]$ que se aplica sobre el tiempo o cantidad de ciclos definidos. Representa el intervalo de muestra, sobre el cual, cada n ciclos se toma una muestra para el registro de las estadísticas correspondientes a las variables dependientes seleccionadas en la configuración. Por defecto se emplea el intervalo de muestra cada veinte (20) ciclos.

Mutación: Es una variable cualitativa que adopta el valor 1 (UNO) si el método de mutación se encuentra activo y 0 (CERO) si no se encuentra activo. Con mutación activa se generan nuevas teorías a partir de las teorías similares. Se asocian al método de mutación dos variables independientes para el control del mismo, éstas son el Porcentaje de Teorías que se Mutan, ésta es una variable cuantitativa cuyo valor pertenece al intervalo entre 0-100 \%, por defecto se adopta el valor de 50\% de las teorías. La otra 
variable asociada es el Límite Teorías que participan de la mutación, ésta es una variable cuantitativa cuyo valor pertenece al intervalo [0100] teorías, por defecto esta variable adopta el valor de 3 teorías. La cantidad de teorías que surjan del porcentaje de teorías a mutar no podrá superar al límite de teorías a mutar. Según se detalla en la subsección 4.4.5 “Mutación de Teorías” del Capítulo 4.

Neutro: Esta variable cualitativa adopta el valor: 1 (UNO) si se emplea un SAR neutro (no aplica ninguno de los métodos indicados como: colaboración, intercambio, ponderación, mutación) y 0 (CERO), si se emplea un SAR que aplica uno o más de los métodos indicados. Por defecto esta variable está siempre en uno 1 (UNO) y pasa automáticamente a 0 (CERO), si se selecciona alguno de los métodos indicados.

Planificador: Es una variable cualitativa, adopta el valor 1 (UNO) si se emplea un SAR con planificador y 0 (CERO) si se emplea un SAR reactivo.

Ponderador de planes: Esta variable cualitativa, adopta el valor de 1 (UNO), si se emplea ponderación y de 0 (CERO) si no se emplea, indica si el comportamiento de ponderación de planes [García Martínez, R., et al. 2000], se emplea en los planes a ejecutar por el SAR. Es aplicable sólo para la arquitectura de SARp con planificador. Si se encuentra activo el ponderador, se define el Umbral de Aceptación del plan entre 0 y 1, por defecto se aplica el valor de umbral de 0,5 .

Porcentaje de rendimiento de ciclos exitosos: Es una variable cuantitativa cuyo valor pertenece al intervalo [0,100], determina el valor del umbral del porcentaje de rendimiento de la cantidad de ciclos éxitos (\% RCE), que se aplicará al SAR como métrica para evaluar su evolución de estado. En este orden el valor por defecto para el porcentaje de rendimiento de ciclos exitosos seleccionado es de RCE $=40 \%$.

Porcentaje de rendimiento de nuevas teorías: Es una variable cuantitativa cuyo valor pertenece al intervalo [0,100], determina el valor del umbral del porcentaje de rendimiento de cantidad de teorías nuevas (\% RTN), que se aplicará al SAR como métrica para evaluar su evolución de estado. Este porcentaje de rendimiento sólo se aplica para los SARs que recibieron colaboración. Se seleccionaron los siguientes valores por defecto para el 
porcentaje de rendimiento de teorías nuevas: para el SARp, el valor de $\mathrm{RTN}=25 \%$ y para SARr el valor de $\mathrm{RTN}=30 \%$.

Tiempo: los experimentos se desarrollan sobre la base de esta variable independiente, se considera una unidad de tiempo como el lapso transcurrido entre una percepción del entorno y otra. Es una variable cuantitativa cuyo valor pertenece al intervalo [0,600], representando los n ciclos de percepciónacción del robot. La duración de cada ciclo se determina en la configuración del SAR-N por el TIME-STEP en milisegundos.

Tipo Planificador: Es una variable cualitativa, adopta el valor 0 (CERO) si se emplea un sistema autónomo de robot con planificador clásico (SARp) y 1 (UNO) si se aplica un sistema autónomo de robot con planificador por ranking (SARr).

Umbrales de comparación de los valores para cada actuador o efector (ruedas) del SAR: es un conjunto de variables cuantitativas que pertenece al rango [-999,999], para cada una de las dos ruedas, a partir del cual se comparan las lecturas de las acciones (velocidades aplicadas) a lo largo del tiempo, en forma independiente para cada una de las rueda del SAR que componen la acción ejecutada. Los valores de umbrales, se consideran de acuerdo al método de umbral variable, para cada una de los dos (2) actuadores (ruedas) del robot, según se detalla en la subsección 4.4.6.2 del Capítulo 4.

Umbrales de lecturas de sensores: la comparación de lecturas para cada uno de los ocho sensores IR de proximidad del AIS: (robot e-puck), es un conjunto de variables cuantitativas [0,999], para cada uno de los ocho sensores del AIS, a partir del cual se comparan las lecturas de las situaciones percibidas a lo largo del tiempo. Los valores de umbral, se consideran de acuerdo al método de comparación de teorías de umbral variable, para cada uno de los ocho (8) sensores de proximidad, según se detalla en la subsección 4.4.6.2 del Capítulo 4. 


\subsubsection{VARIABLES DEPENDIENTES}

Se consideran las siguientes variables dependientes:

Cantidad ciclos exitosos: Es una variable cuantitativa, cuyo valor pertenece al intervalo [0,600], es un valor que se acumula durante la simulación, se inicia en 0 (CERO) y aumenta en 1 (UNO), cada vez que el robot realizó un ciclo en el cual finalizó con una teoría de utilidad $\mathrm{U}: 0,75<\mathrm{U}<1$. Sobre la base de esta variable dependiente se calcula el Porcentaje de ciclos exitosos: Es una variable cuantitativa, cuyo valor pertenece al intervalo [0,100],indica el porcentaje de ciclos que resultaron exitosos en función de la variable tiempo. Esta variable indica el porcentaje de Ciclos que finalizaron con una teoría con utilidad mayor o igual a 0.75 en un instante dado de la simulación del robot.

Cantidad de azares: Es una variable cuantitativa cuyo valor pertenece al intervalo [0,600], indica la cantidad de azares, que han sido generados por el SAR en función de la variable tiempo.

Cantidad de planes exitosos: Es una variable cuantitativa, cuyo valor pertenece al intervalo [0,600].Esta variable indica la cantidad de planes exitosos que han sido generados por el sistema en el intervalo de tiempo: [0 , tiempo]. Es la cantidad de planes que llegaron a su fin habiendo pasado por todos los eslabones de la cadena del plan. Este valor puede ser un número racional, ya que cuando un plan no tiene éxito, se toma el éxito parcial del mismo (es decir, si el plan era de 10 pasos y 5 fueron exitosos, este valor será 0.5). Este valor se calcula como la cantidad de acciones del plan que obtuvieron una situación esperada sobre la cantidad total de acciones del plan. Esta variable para arquitectura de SARr con planificador por "Ranking”, sólo considera planes de una acción.

Cantidad de situaciones: Es una variable cuantitativa cuyo valor pertenece al intervalo [0,200], indica el promedio de la cantidad de situaciones diferentes que han sido generadas por el SAR en función de la variable tiempo. 
Cantidad de teorías acumuladas: Es una variable cuantitativa cuyo valor pertenece al intervalo [0,99999], indica la cantidad de teorías acumuladas, que el SAR cuenta en su base de conocimiento y las que se incorporan en función de la variable tiempo.

Cantidad de teorías exitosas: Es una variable cuantitativa, cuyo valor pertenece al intervalo [0,600], indica la cantidad de teorías exitosas generadas por el SAR en función de la variable tiempo. Considerándose estas teorías como exitosas a aquellas que su utilidad supera el umbral de 0,75.

Cantidad de teorías nuevas: Es una variable cuantitativa cuyo valor pertenece al intervalo [0,600], indica la cantidad de teorías nuevas, que han sido generadas por el SAR en función de la variable tiempo.

Cantidad de teorías por intervalo de utilidad: Es una variable cuantitativa, cuyo valor pertenece al intervalo [0,600], indica la cantidad de teorías generadas por el SAR en función de la variable tiempo, correspondiente a cada intervalo de utilidad comprendido entre los rangos de valores determinados en función de la variable independiente “cantidad de intervalos”.

\subsubsection{ARQUITECTURA DE SISTEMA AUTÓNOMO DE ROBOT (SAR)}

\subsubsection{Arquitectura de Sistema Autónomo Robot con planificador clásico (SARp).}

Para la arquitectura de un SARp, se consideraron los métodos de ponderador de planes, mutación y los que se aplican sobre las bases de teorías, conformados por intercambio entre SARps, colaboración entre SARps, e intercambio y colaboración entre SARps. Se generan las distintas configuraciones para la arquitectura del SARp en función de la combinación de valores de las variables independientes (ponderador de planes, mutación, intercambio, colaboración) del SAR. El SARp que no incorpora métodos se lo denomina SARp neutro o SARp. Las configuraciones de base para la arquitectura de un SARp sin combinación entre los métodos son:

- SARp (neutro)

- SARp- Ponderador de planes.

- SARp- Mutación.

- SARp- Cooperación (intercambio). 
- SARp- Colaboración.

Las configuraciones para la arquitectura de SARp, se efectuaron en función de la taxonomía de extensiones de SARs propuestas en la subsección 4.7.3 del Capítulo 4. Se presentan en la sección 5.2.4 los grupos de experimentos correspondientes a la arquitectura de SARp.

\subsubsection{Arquitectura de Sistema Autónomo Inteligente con Ranking (SARr)}

Para la arquitectura de un SARr, se consideraron el método de mutación y los métodos que se aplican sobre las bases de teorías de SARrs, conformados por intercambio entre SARrs, colaboración entre SARrs, e intercambio y colaboración entre SARrs. Se generan las distintas configuraciones para la arquitectura del SARr en función de la combinación de valores de las variables independientes (mutación, intercambio, colaboración) del SAR. El SARr que no incorpora métodos se lo denomina SARr neutro o SARr. Las configuraciones de base para la arquitectura de un SARr sin combinación entre los métodos son:

- SARr (neutro)

- SARr -Mutación

- SARr- Cooperación (intercambio)

- SARr- Colaboración

Las configuraciones para la arquitectura de SARr, se efectuaron en función de la taxonomía de extensiones de SARs propuestas en la subsección 4.7.3 del Capítulo 4. Se presentan en la sección 5.2.4 los grupos de experimentos correspondientes a la arquitectura de SARr.

\subsubsection{GRUPO DE EXPERIMENTOS}

Se distinguen cinco grupos de experimentos, distribuidos en tres grupos de experimentos para la arquitectura de SARp y dos grupos de experimentos para la arquitectura de SARr:

Primer grupo de experimentos para el SARp, se enfoca en la comparación de las combinaciones de métodos aplicados por los autores de propuestas anteriores: SARp neutro [Fritz, W., 1989], SARp ponderación, mutación [García Martínez, R., et al. 2000], SARp ponderación, mutación e intercambio (cooperación) [García Martínez, R., et al. 2006; Maceri, D., García Martínez, R., 2001] y la combinación de este último con colaboración. 
Segundo grupo de experimentos para el SARp, se enfoca en la comparación individual de los métodos aplicados por el SARp, con el método propuesto de colaboración, sobre la base de un: SARp configurado por los métodos de ponderación y mutación, un SARp configurado con cooperación (intercambio), un SARp neutro y un SARp configurado con colaboración.

Tercer grupo de experimentos para el SARp, se enfoca en la comparación de la combinación de los métodos aplicados por el SARp, con el método propuesto de colaboración, sobre la base de: un SARp neutro configurado con el método de colaboración, un SARp configurado con la combinación de métodos de ponderación de planes, mutación y colaboración y un SARp configurado con la combinación de métodos de cooperación (intercambio) y colaboración.

Primer grupo de experimentos para el SARr se enfoca en la comparación individual, entre: un SARr neutro, un SARr configurado con el método de mutación, un SARr configurado con cooperación (intercambio) y un SARr configurado con el método propuesto de colaboración.

Segundo grupo de experimentos para el SARr, se enfoca en la comparación de la combinación de los métodos aplicados por el SARr, con el método propuesto de colaboración, sobre la base de un: SARr configurado con el método de cooperación (intercambio) y colaboración, un SARr configurado con la combinación de métodos de mutación y colaboración y un SARr configurado con la combinación de métodos de mutación, cooperación (intercambio) y colaboración.

\subsection{GRÁFICAS Y SU INTERPRETACIÓN}

Se presentan los resultados obtenidos para la arquitectura de Sistema Autónomo de Robot con planificador (SARp) en 5.3.1 y para la arquitectura de Sistema Autónomo de Robot con ranking (SARr) en 5.3.2, en 5.3.3 se realiza una comparación de los resultados obtenidos en función de la cantidad de ciclos exitosos de ambas arquitecturas de Sistemas Autónomos de Robots (SARs), finalmente en 5.3.4 se presenta la relación entre cantidad de teorías, cantidad de planes y cantidad de ciclos cuando éstos son exitosos.

\subsubsection{GRÁFICAS DEL SISTEMA AUTÓNOMO DE ROBOT CON PLANIFICADOR Y SU INTERPRETACIÓN}

Para analizar el comportamiento del Sistema Autónomo de Robot con planificador (SARp), se han desarrollado doce (12) experimentos que surgen de aplicar los distintos métodos y las combinaciones entre ellos, sobre la base de los resultados publicados por Ierache, J., et al 2010. 
Los experimentos se desarrollaron sobre la base de las variables independientes y dependientes enunciadas, se estructuraron en grupos de experimentos como se detalló en la sección 5.2.4, en este orden el primer grupo de experimentos del SARp, se detalla en la sección 5.3.1.1, el segundo grupo de experimentos del SARp, se detalla en la sección 5.3.1.2, el tercer grupo de experimentos del SARp, se detalla en la sección 5.3.1.3.

\subsubsection{Primer Grupo de Experimentos del SARp}

Los experimentos de este grupo se enfocan en la comparación de los SARp configurados con las siguientes combinaciones de métodos: Ponderador de planes y mutación e Intercambio, sumando el método propuesto de colaboración (SPMIC), Ponderador de planes, Mutación, e Intercambio (SPMI) [García Martínez, R., et al. 2006; Maceri, D., García Martínez, R., 2001], Ponderador Planes y Mutación (SPM) [García Martínez, R., et al. 2000] y finalmente el SARp Neutro (SN) [Fritz, W., 1989] que no aplica métodos de aceleración de aprendizaje.

Para la comparación de las configuraciones de SARp de este grupo, se realizaron cuatro experimentos. Se presentan los resultados en seis gráficos, correspondientes a las variables dependientes: cantidad de situaciones versus cantidad de teorías en la subsección 5.3.1.1.1, cantidad de teorías nuevas en la subsección 5.3.1.1.2, cantidad de planes exitosos en la subsección 5.3.1.1.3, cantidad de teorías exitosas en la subsección 5.3.1.1.4, cantidad de ciclos exitosos a lo largo del tiempo y el porcentaje de ciclos exitoso en la subsección 5.3.1.1.5.

Finalmente se presenta la discusión de los resultados del primer grupo de experimentación en la subsección 5.3.1.1.6.

\subsection{Cantidad de situaciones y cantidad de teorías a lo largo del tiempo}

En esta subsección se presenta en la gráfica 5.1, la cantidad de situaciones promedio y cantidad promedio de teorías para el SARp, configurado con los métodos de ponderación de planes, mutación, intercambio y el método propuesto de colaboración (SPMIC). Se observa en la gráfica 5.1, que la cantidad de teorías aumenta más rápido que la cantidad de situaciones (condiciones supuestas o efectos predichos). Esto sostiene la hipótesis de que el sistema descubre nuevas relaciones entre situaciones aplicando colaboración, aún después que tiende a estabilizarse el número de situaciones. 


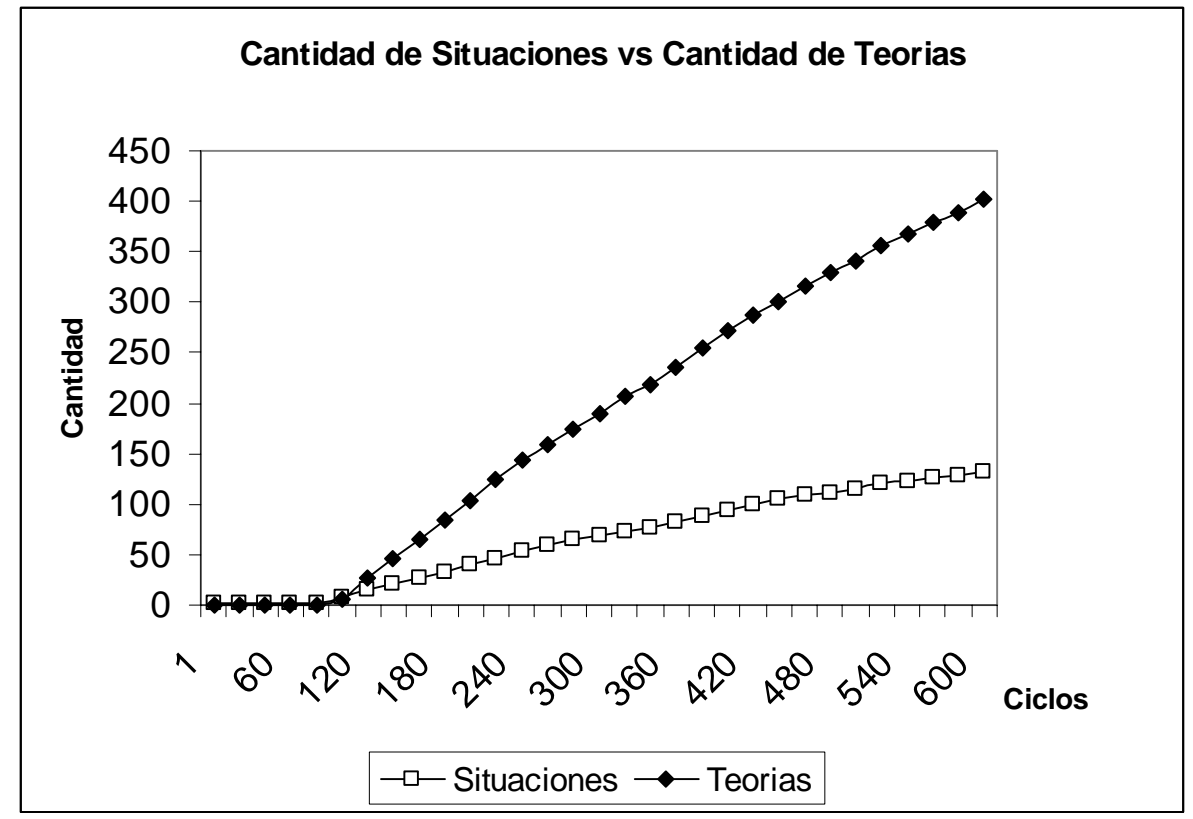

Gráfica 5.1 Cantidad de situaciones y teorías para la configuración de SARp SPMIC

\subsection{Cantidad de teorías nuevas a lo largo del tiempo}

En esta subsección se analizará la cantidad promedio de teorías nuevas generadas por los SARps a lo largo del tiempo, al aplicar las configuraciones de métodos, en este orden se presentan los resultados para: un SARp configurado con ponderación de planes, mutación (SPM), un SARp configurado con ponderación de planes, mutación e intercambio (SPMI), un SARp configurado con ponderación de planes, mutación, intercambio y colaboración (SPMIC) y un SARp neutro (SN), indicadas en la sección 5.3.1.1, correspondiente al primer grupo de experimentos del SARp. Se observa en la gráfica 5.2 “Cantidad de teorías nuevas”, que la mayor cantidad promedio generada de teorías nuevas a lo largo del tiempo le corresponden al SARp neutro (SN) y la menor al SARp que aplica colaboración (SPMIC).

La base de conocimiento de teorías acumuladas del SARp neutro, es menos representativa en materia de teorías exitosas (experiencia), que la del SARp que recibió colaboración, razón por la cual al contar con más experiencia en el ambiente de operación (mayor cantidad de teorías exitosas, según se muestra en la gráfica 5.4) el SARp que recibió colaboración generó la menor cantidad de teorías nuevas, en comparación con el resto de los métodos.

Esto sostiene la hipótesis que la colaboración contribuye al crecimiento de la base de conocimientos de teorías que el SAR emplea para su actuación. 


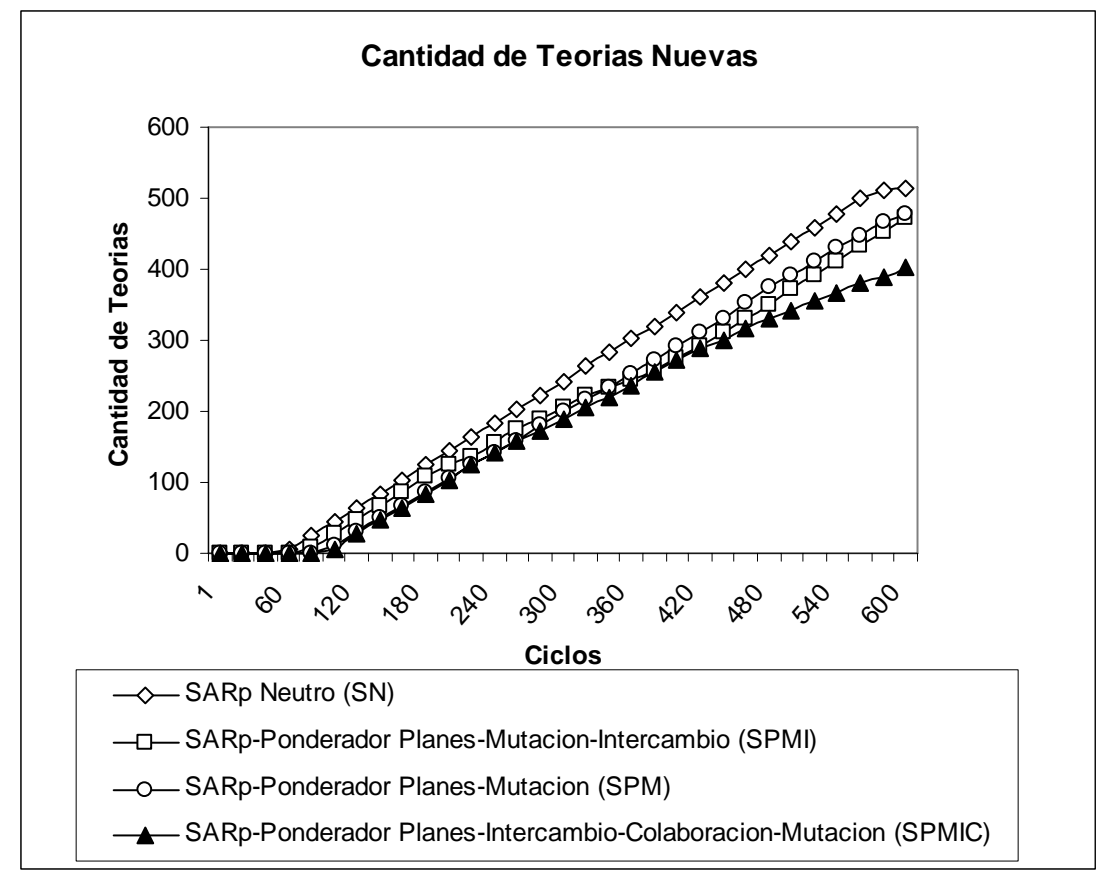

Gráfica 5.2 Cantidad de teorías nuevas generadas por los SARp: SN, SPM, SPMI, SPMIC

\subsection{Cantidad de Planes exitosos a lo largo del tiempo}

En esta subsección se analizará la cantidad promedio de planes exitosos generados por los SARps a lo largo del tiempo al aplicar las configuraciones de métodos, en este orden se presentan los resultados para: un SARp configurado con ponderación de planes, mutación (SPM), un SARp configurado con ponderación de planes, mutación e intercambio (SPMI), un SARp configurado con ponderación de planes, mutación, intercambio y colaboración (SPMIC) y un SARp neutro (SN), indicadas en la sección 5.3.1.1,correspondiente al primer grupo de experimentos del SARp.

Se observa en la gráfica 5.3 “Cantidad de Planes Exitosos”, que la mayor cantidad promedio de planes exitosos a lo largo del tiempo, le corresponden al SARp que aplica colaboración (SPMIC), seguido en la primera mitad de la experimentación por el SARp SPM, siendo superado este último por el SARp SPMI en la segunda mitad de la experimentación. El SARp neutro (SN) obtuvo la menor cantidad de planes exitosos. Los SARps SPM y SN muestran un ligero ascenso en la cantidad de planes exitosos al final de la experimentación, en comparación con el SARp SPMI, finalmente el SARp SPMIC continúa con su ascenso en materia de cantidad de planes exitosos. Esto sostiene la hipótesis de que un SARp que recibe colaboración, genera una mayor cantidad de planes exitosos, sobre la base de que dispone de una mayor cantidad de teorías exitosas como se puede observar en la gráfica 5.4. 


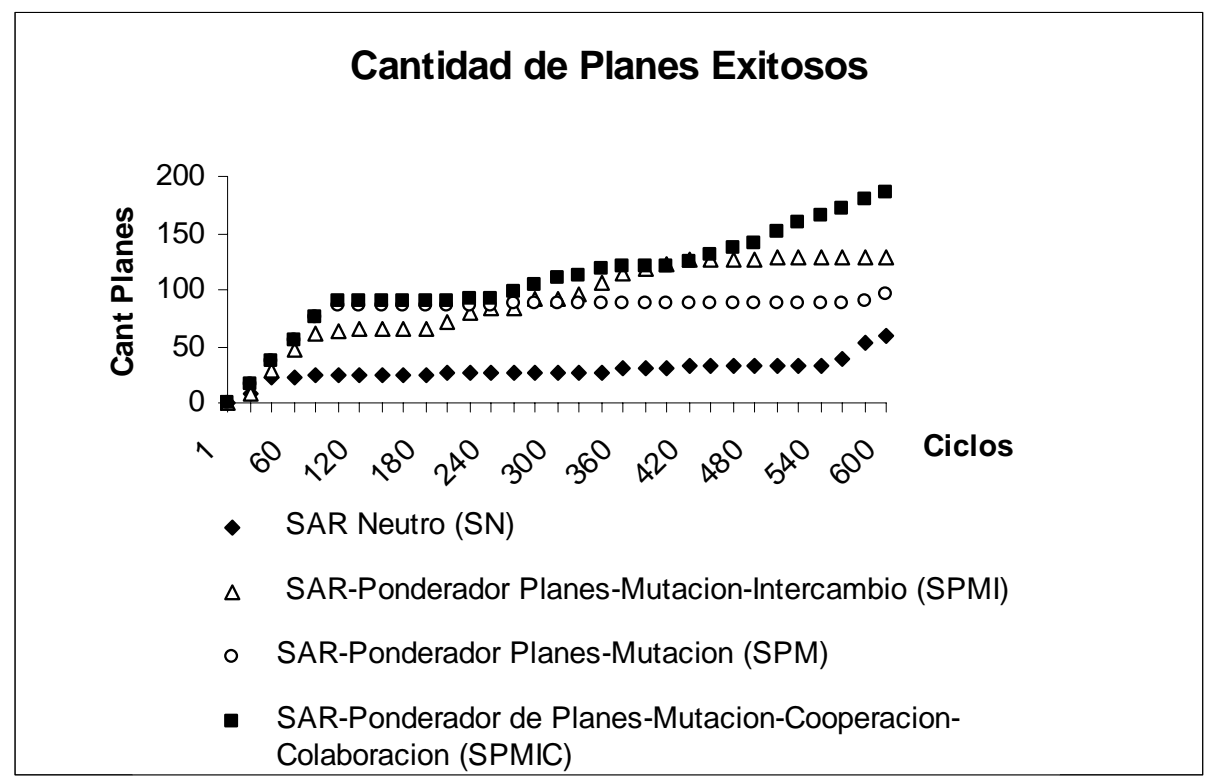

Gráfica 5.3 Cantidad de planes exitosos para los SARp: SN, SPM, SPMI, SPMIC

\subsection{Cantidad de teorías exitosas a lo largo del tiempo}

En esta subsección se analizará la cantidad promedio de teorías exitosas generadas por el SARps a lo largo del tiempo, al aplicar las configuraciones de métodos, en este orden se presentan los resultados para: un SARp configurado con ponderación de planes, mutación (SPM), un SARp configurado con ponderación de planes, mutación e intercambio (SPMI), un SARp configurado con ponderación de planes, mutación, intercambio y colaboración (SPMIC) y un SARp neutro (SN), indicadas en la sección 5.3.1.1,correspondiente al primer grupo de experimentos del SARp. Se observa en la gráfica 5.4 "Cantidad de teorías exitosas”, que el SARp que recibió colaboración (SPMIC) cuenta con la mayor cantidad promedio de teorías exitosas, seguido por el SARp (SPMI) y por los SARps (SPM) y (SN) estos últimos con resultados similares.

Estos resultados sostienen la hipótesis, que la colaboración contribuye al crecimiento de la base de conocimientos de teorías del Sistema Autónomo de Robot (SAR). 


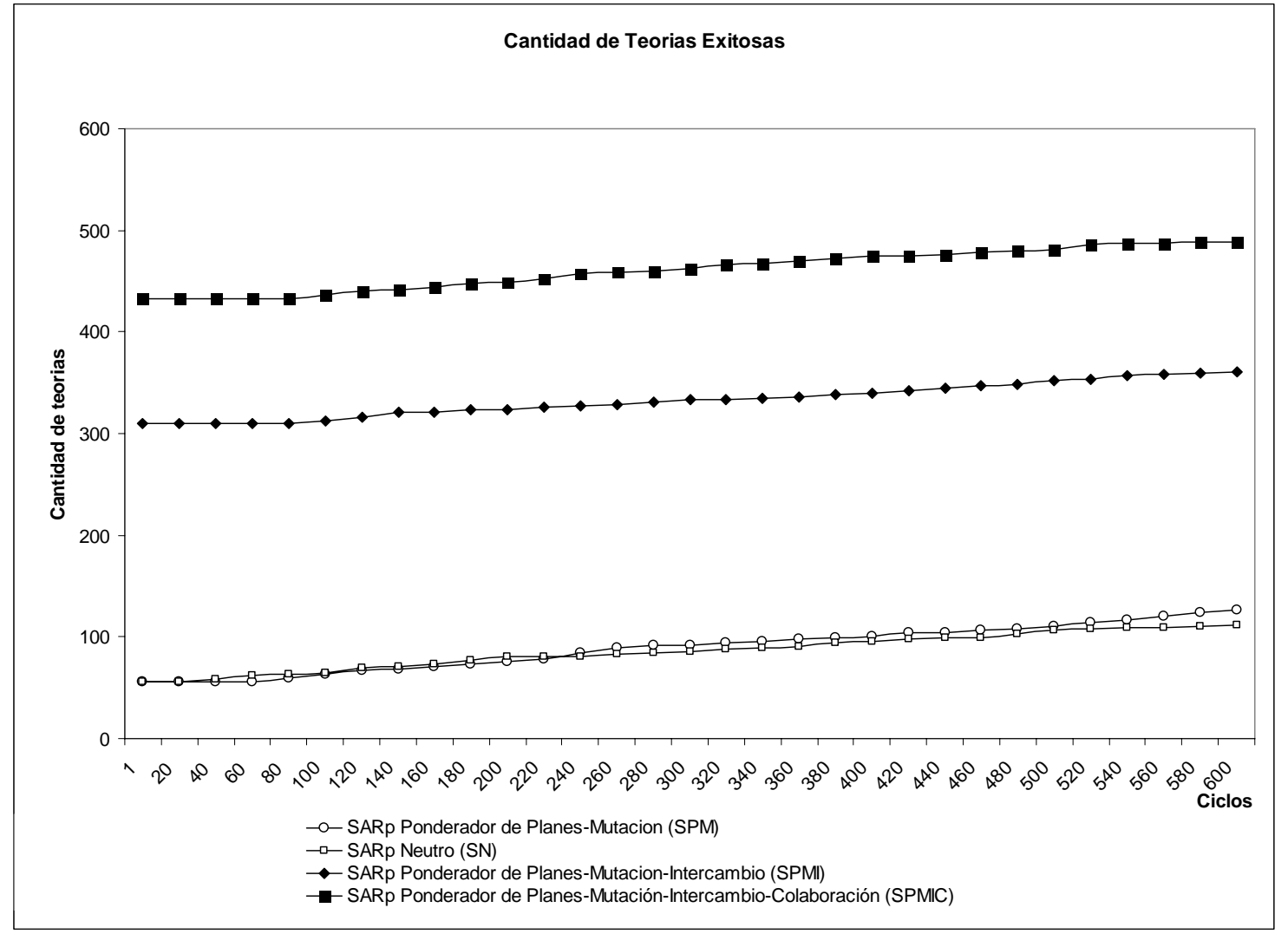

Gráfica 5.4 Cantidad de teorías exitosas para los SARp: SN, SPM, SPMI, SPMIC

\subsection{Ciclos exitosos a lo largo del tiempo}

En esta sub sección se analizará el resultado promedio de ciclos exitosos alcanzado por los SARp a lo largo del tiempo en este orden se presentan los resultados para : un SARp configurado con ponderación de planes, mutación (SPM), un SARp configurado con ponderación de planes, mutación e intercambio (SPMI), un SARp configurado con ponderación de planes, mutación, intercambio y colaboración (SPMIC) y un SARp neutro (SN), indicadas en la sección 5.3.1.1,correspondiente al primer grupo de experimentos del SARp.

Se observa en la gráfica 5.5 a “Cantidad de ciclos exitosos”, que la configuración SPMIC correspondiente al SARp que incorpora la colaboración, obtiene la mayor cantidad promedio de ciclos exitosos, incrementado la aceleración de ciclos exitosos en la segunda mitad de la simulación en comparación con el SARp SPMI, y el SARp SPM. El SARp neutro (SN) obtuvo la menor cantidad de ciclos exitosos, sin embargo se observa al final de la experimentación una aceleración de ciclos exitosos. Se observa en la gráfica 5.5 b "Porcentaje de Ciclos Exitosos" que el mayor porcentaje promedio de ciclos exitosos a lo largo del tiempo le corresponden al SARp que aplica colaboración (SPMIC), seguido por el SARp SPM con resultados similares, sin 
mientras el SARp SPMIC tiende a mantener el porcentaje de ciclos exitosos. El SARp SPM finaliza con resultados similares al SARp SN, sin embargo este último tiende a incrementar el porcentaje de ciclos exitosos en la etapa final de la experimentación.

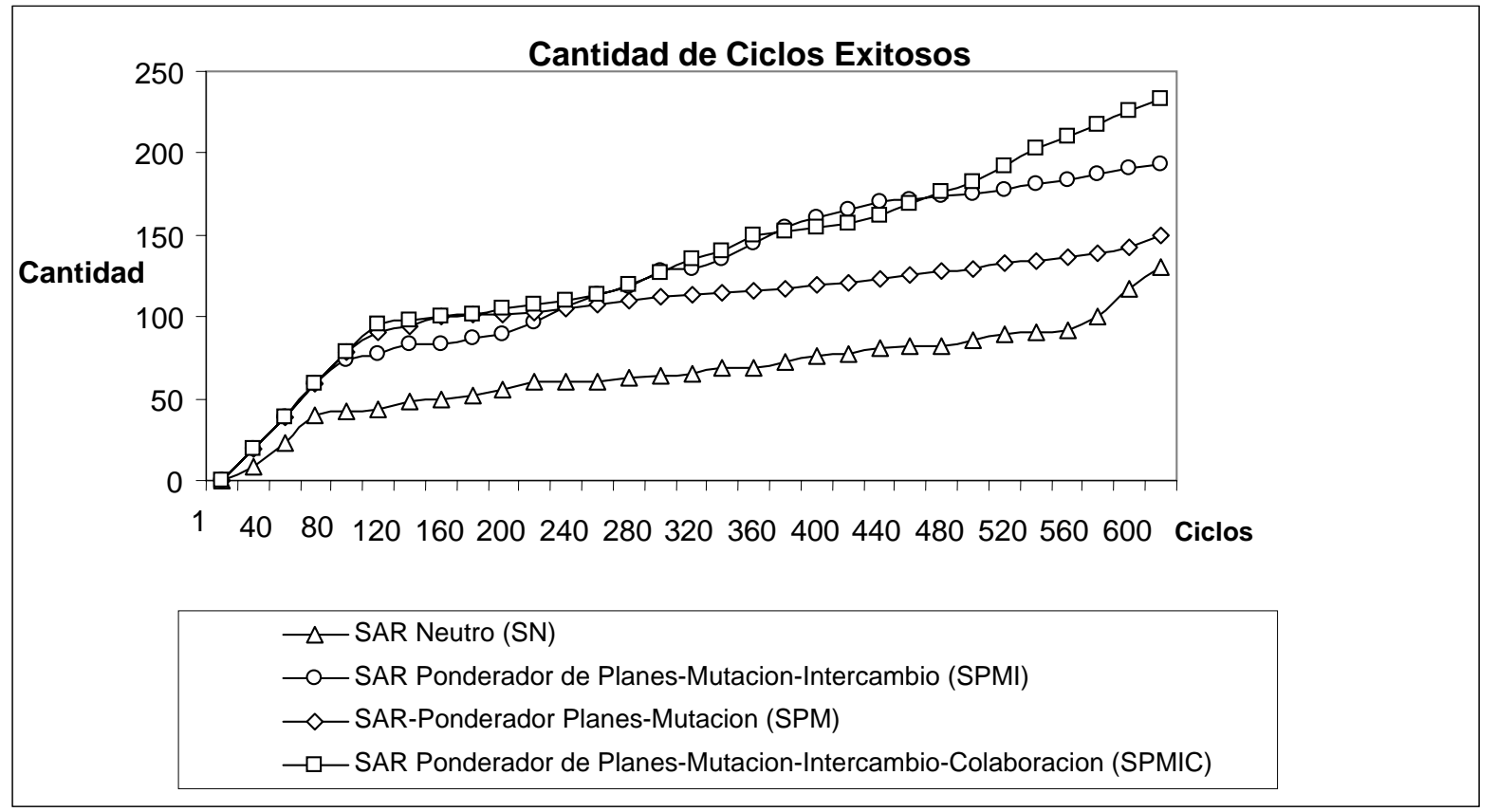

Grafico 5.5.a Porcentaje de Ciclos Exitosos para los SARp: SN, SPM, SPMI, SPMIC

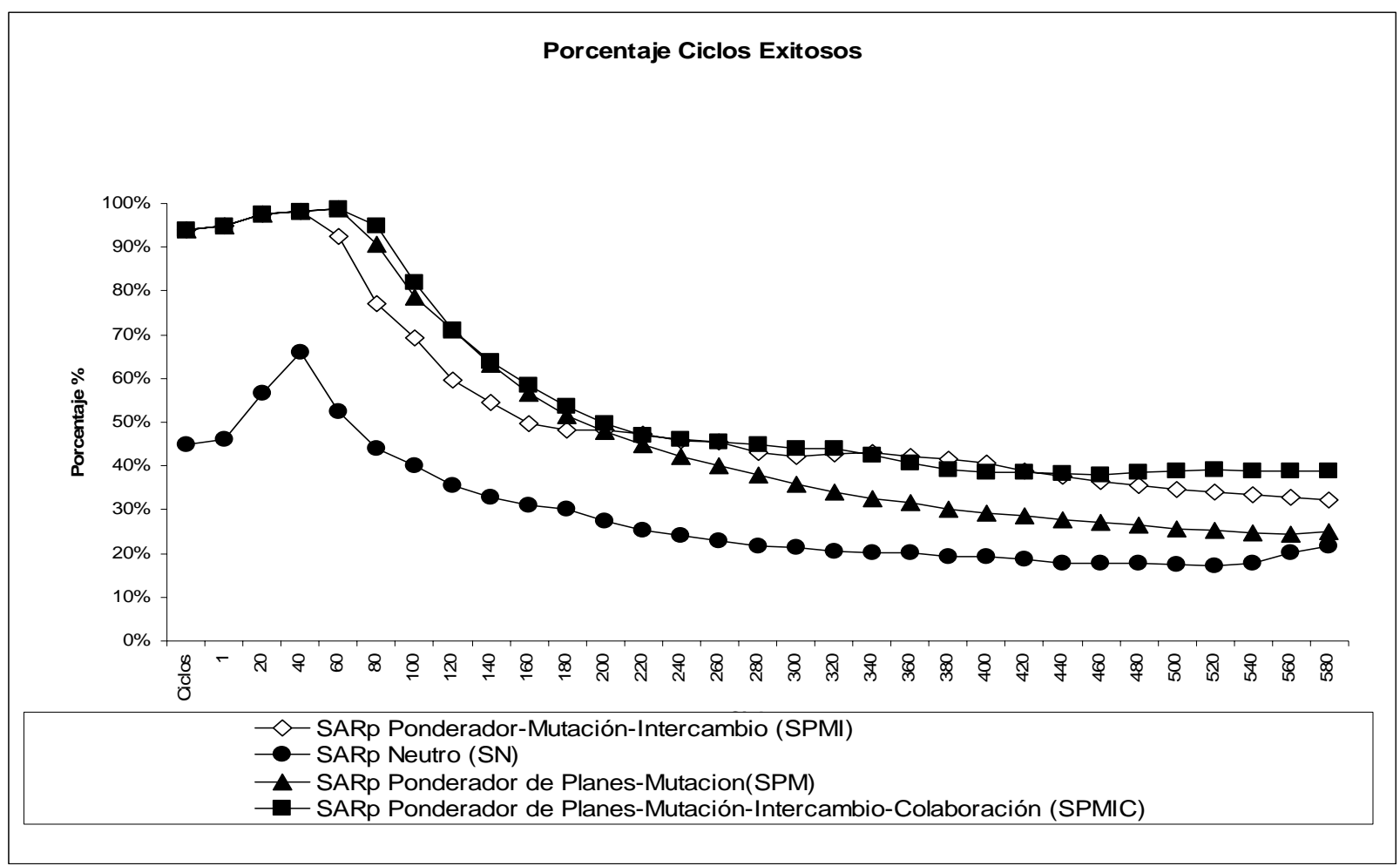

Grafico 5.5.b Porcentaje de Ciclos Exitosos para los SARp : SN, SPM, SPMI, SPMIC 
Finalmente estos resultados sostienen la hipótesis de que un SARp que recibe colaboración obtiene una mayor cantidad y porcentaje de ciclos exitosos, sobre la base de que dispone de una mayor cantidad de teorías exitosas como se puede observar en la gráfica 5.4.

\subsection{Discusión de los resultados del primer grupo de experimentación del SARp}

De los resultados obtenidos del primer grupo de experimentación se concluye que el SARp configurado con las siguientes combinaciones de métodos: ponderador de planes, mutación e Intercambio, sumando el método propuesto de colaboración (SPMIC), produce una mayor aceleración del aprendizaje en comparación con las propuestas anteriores, en términos de cantidad de planes exitosos, cantidad de teorías exitosas, cantidad y porcentaje de ciclos exitosos.

Asimismo el SARp SPMIC, receptor de la colaboración, generó una menor cantidad de teorías nuevas en virtud de contar con una base de teorías exitosas más representativa que las de los otros SARp comparados, producto de la colaboración que el SARp A (born, que se encuentra iniciando el layer BIO) recibió del SARp B (newbie, que se encuentra iniciando el layer TBO), generando la base de teorías de colaboración entre SARp A-B (born -newbie).

El SARp (SPMIC), generó una menor cantidad de teorías nuevas, en virtud de contar con una base de teorías exitosas más representativa que las aplicadas por las restantes combinaciones de métodos de los otros SARp comparados.

La base de teorías del SARp (SPMIC) es producto de la base de teorías que inicialmente se origina en el SARp A receptor, (born, al inicio del layer BIO) que efectuó intercambio con el SARp B (born en tránsito por el layer BIO), generando la base de teorías de intercambio (cooperación) entre SARp A-B (borns), sobre la cual el SARp B (newbie Layer TBO), aplicó colaboración, generando la base de teorías de intercambio-colaboración SARp A (born) - B (newbie), la que fue empleada durante la experimentación por el SARp E, (SPMIC), aplicando el método de ponderación de planes para sus acciones y el método de mutación sobre las teorías similares, sumando por acción de este último método nuevas teorías a la base de teorías del SARp E, (SPMIC).

Finalmente el SARp SPMIC descubrió nuevas relaciones entre situaciones aplicando colaboración, aún después que tiende a estabilizarse el número de situaciones, continuó aumentando el número de teorías más rápido que la cantidad de situaciones, como se muestra en la figura 5.1. 


\subsubsection{Segundo grupo de experimentación del SARp.}

En este grupo se presentan los resultados de cuatro (4) experimentos, que se enfocan en la comparación individual de métodos aplicados por los SARps, sobre la base de un: SARp configurado por los métodos de ponderación y mutación (SPM), un SARp configurado con intercambio (SI), un SARp configurado con colaboración (SC) y finalmente un SARp neutro $(\mathrm{SN})$.

Se presentan los resultados obtenidos en este grupo en seis gráficos, que se desarrollan en función de las siguientes variables dependientes: cantidad de situaciones versus cantidad de teorías en la subsección 5.3.1.2.1, cantidad de teorías nuevas en la subsección 5.3.1.2.2, cantidad de planes exitosos en la subsección 5.3.1.2.3, cantidad de teorías exitosas en la subsección 5.3.1.2.4, cantidad de ciclos exitosos a lo largo del tiempo y el porcentaje de ciclos exitoso en la subsección 5.3.1.2.5.

Finalmente se presenta la discusión de los resultados del segundo grupo de experimentos en la subsección 5.3.1.2.6.

\subsection{Cantidad de situaciones y cantidad de teorías a lo largo del tiempo}

En esta subsección se presenta en la gráfica 5.6, la cantidad promedio de situaciones y cantidad promedio de teorías para el SARp, configurado sobre la base de un SARp neutro con el método propuesto de colaboración (SC). Se observa en la gráfica 5.6, que la cantidad de teorías aumenta más rápido que la cantidad de situaciones (condiciones supuestas o efectos predichos). Esto sostiene la hipótesis de que el sistema descubre nuevas relaciones entre situaciones aplicando colaboración, aún después que tiende a estabilizarse el número de situaciones. 


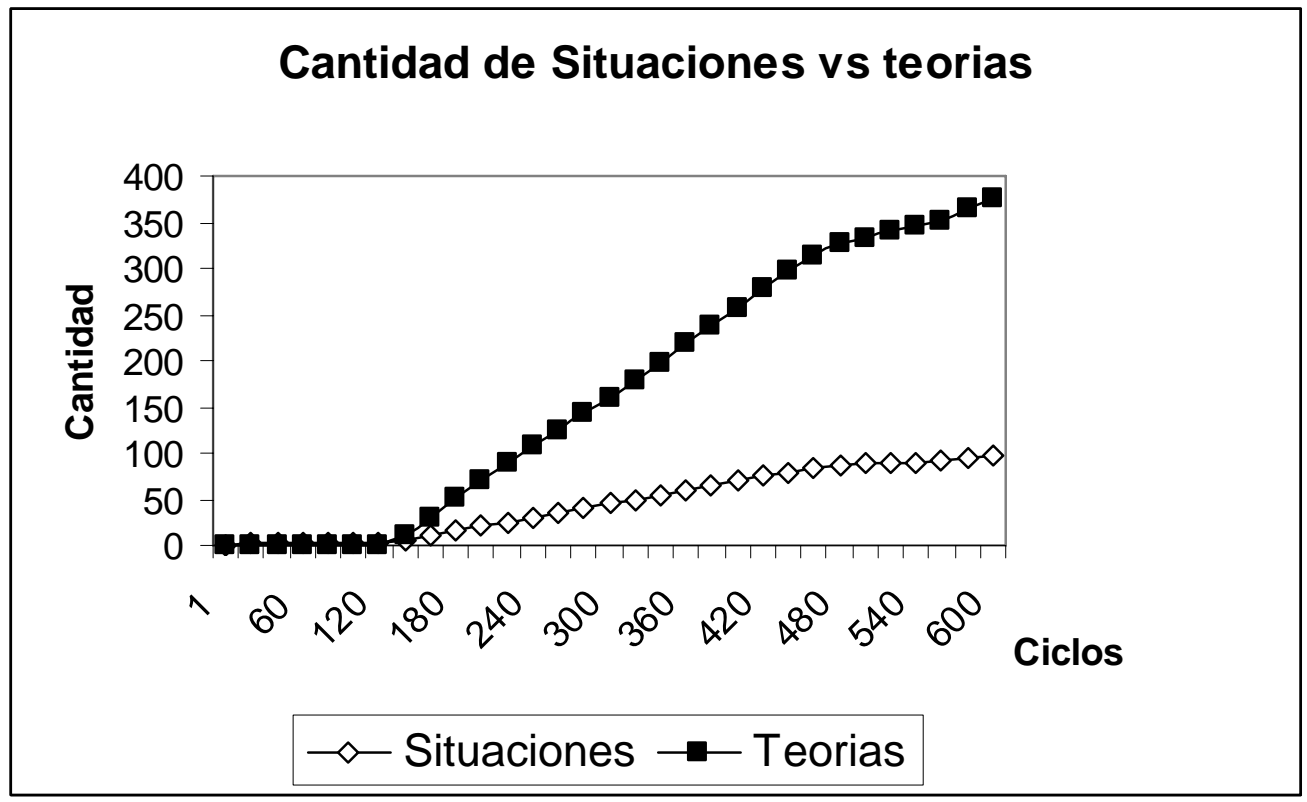

Gráfica 5.6 Cantidad de Situaciones vs teorías para la configuración de SARp: SC

\subsection{Cantidad de teorías nuevas a lo largo del tiempo}

En esta subsección se analizará la cantidad promedio de teorías nuevas generadas por los SARps a lo largo del tiempo al aplicar las configuraciones de métodos, sobre la base de: un SARp configurado por los métodos de ponderación y mutación (SPM), un SARp configurado con intercambio (SI), un SARp configurado con colaboración (SC) y finalmente un SARp neutro (SN), indicados en la sección 5.3.1.2, correspondiente al segundo grupo de experimentos del SARp .Se observa en la gráfica 5.7 "Cantidad de teorías nuevas”, que la mayor cantidad promedio generada de teorías nuevas a lo largo del tiempo le corresponden al SARp neutro (SN), seguida por el SARp que aplica ponderación y mutación (SPM), la menor cantidad de teorías nuevas generadas durante la experimentación, les corresponde con resultados similares al SARp que aplica colaboración (SC) y al SARp que aplica intercambio (SI), resultando la menor cantidad al término de la experimentación para el SARp que aplica colaboración (SC).

La base de conocimiento de teorías acumuladas del SARp neutro, es menos representativa en materia de teorías exitosas (experiencia), que la del SARp que recibió colaboración, razón por la cual, al contar con más experiencia en el ambiente de operación (mayor cantidad de teorías exitosas, según se muestra en la gráfica 5.9), el SARp que recibió colaboración generó la menor cantidad de teorías nuevas, en comparación con el resto de los métodos.

Esto sostiene la hipótesis que la colaboración contribuye al crecimiento de la base de conocimientos de teorías que el SAR emplea para su actuación. 


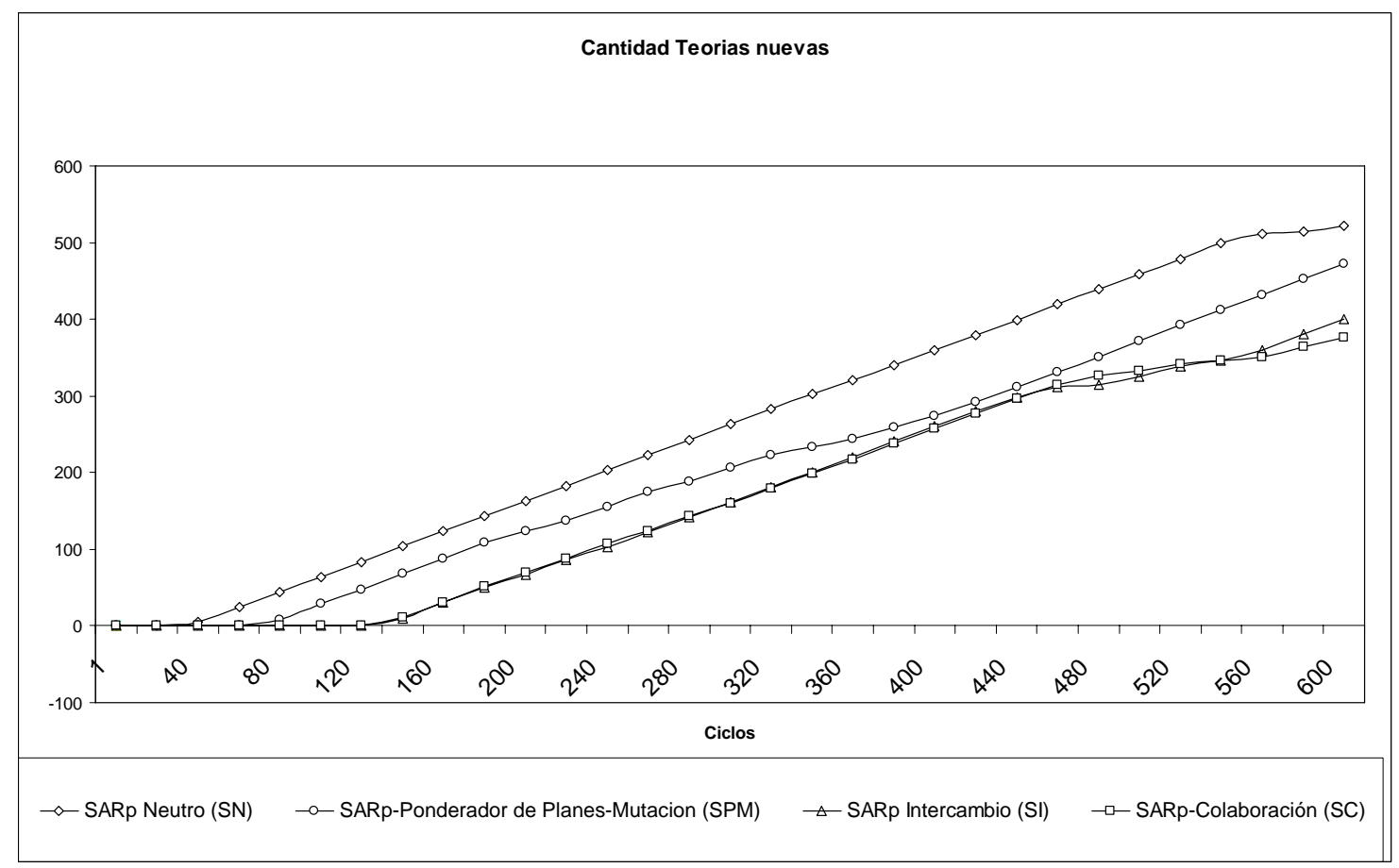

Gráfica 5.7 Cantidad de Teorías nuevas para las configuraciones de SARp: SN, SPM,SI, SC

\subsection{Cantidad de planes exitosos a lo largo del tiempo.}

En esta subsección se analizará la cantidad promedio de planes exitosos generados por los SARps a lo largo del tiempo al aplicar la configuración de métodos, sobre la base de: un SARp configurado por los métodos de ponderación y mutación (SPM), un SARp configurado con intercambio (SI), un SARp configurado con colaboración (SC) y finalmente un SARp neutro (SN), indicadas en la sección 5.3.1.2, correspondiente al segundo grupo de experimentos del SARp. Se observa en la gráfica 5.8 "Cantidad de Planes Exitosos”, que la mayor cantidad promedio de planes exitosos a lo largo del tiempo, le corresponden al SARp que aplica colaboración (SC), seguido en la primera mitad de la experimentación por el SARp SI, siendo superado este último por el SARp SC en la segunda mitad de la experimentación. Seguidos estos por SARp que aplica ponderación y mutación (SPM) y el SARp neutro (SN), el que obtuvo la menor cantidad de planes exitosos, sin embargo este último muestra un ascenso en la cantidad de planes exitosos al final de la experimentación, en comparación con el SARp SPM que se ameseta. El SARp SC luego de amesetarse continúa con su ascenso en materia de cantidad de planes exitosos.Esto sostiene la hipótesis de que SARp que recibe colaboración genere una mayor cantidad de planes exitosos, sobre la base de que dispone de una mayor cantidad de teorías exitosas como se puede observar en la gráfica 5.9 


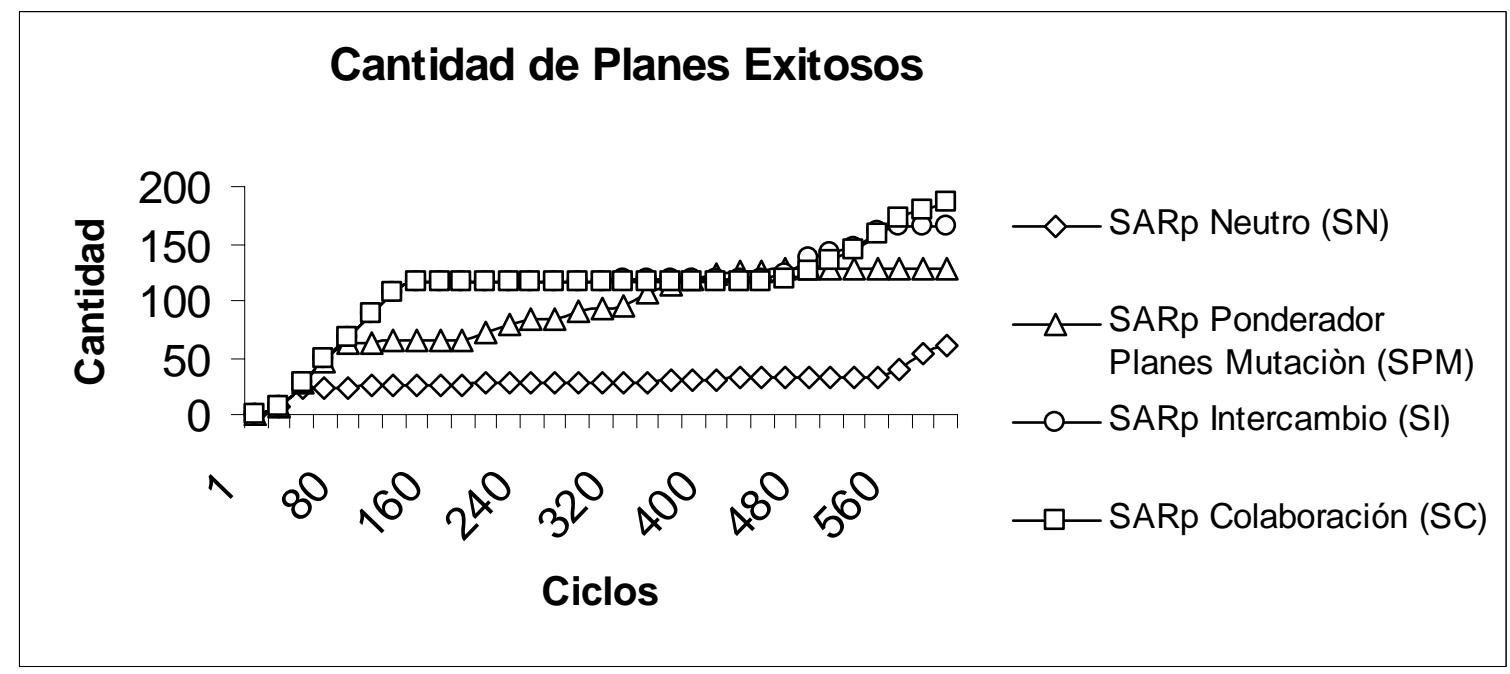

Gráfica 5.8 Cantidad de Planes Exitosos para las configuraciones de SARp: SN, SPM,SI, SC

\subsection{Cantidad de teorías exitosas a lo largo del tiempo}

En esta subsección se analizará la cantidad promedio de teorías exitosas generadas por el SARps a lo largo del tiempo al aplicar las configuraciones de métodos, sobre la base de: un SARp configurado por los métodos de ponderación y mutación (SPM), un SARp configurado con intercambio (SI), un SARp configurado con colaboración (SC) y finalmente un SARp neutro (SN), indicadas en la sección 5.3.1.2,correspondiente al segundo grupo de experimentación.

Se observa en la gráfica 5.9 “Cantidad de teorías exitosas”, que el SARp que recibió colaboración (SC) cuenta con la mayor cantidad promedio de teorías exitosas (teorías cuya utilidad U: 0,75<U $<1$ ), seguido por el SARp (SI) y por los SARps (SPM) y (SN), estos últimos con resultados similares.

Estos resultados sostienen la hipótesis, que la colaboración contribuye al crecimiento de la base de conocimientos de teorías exitosas del Sistema Autónomo de Robot (SAR). 


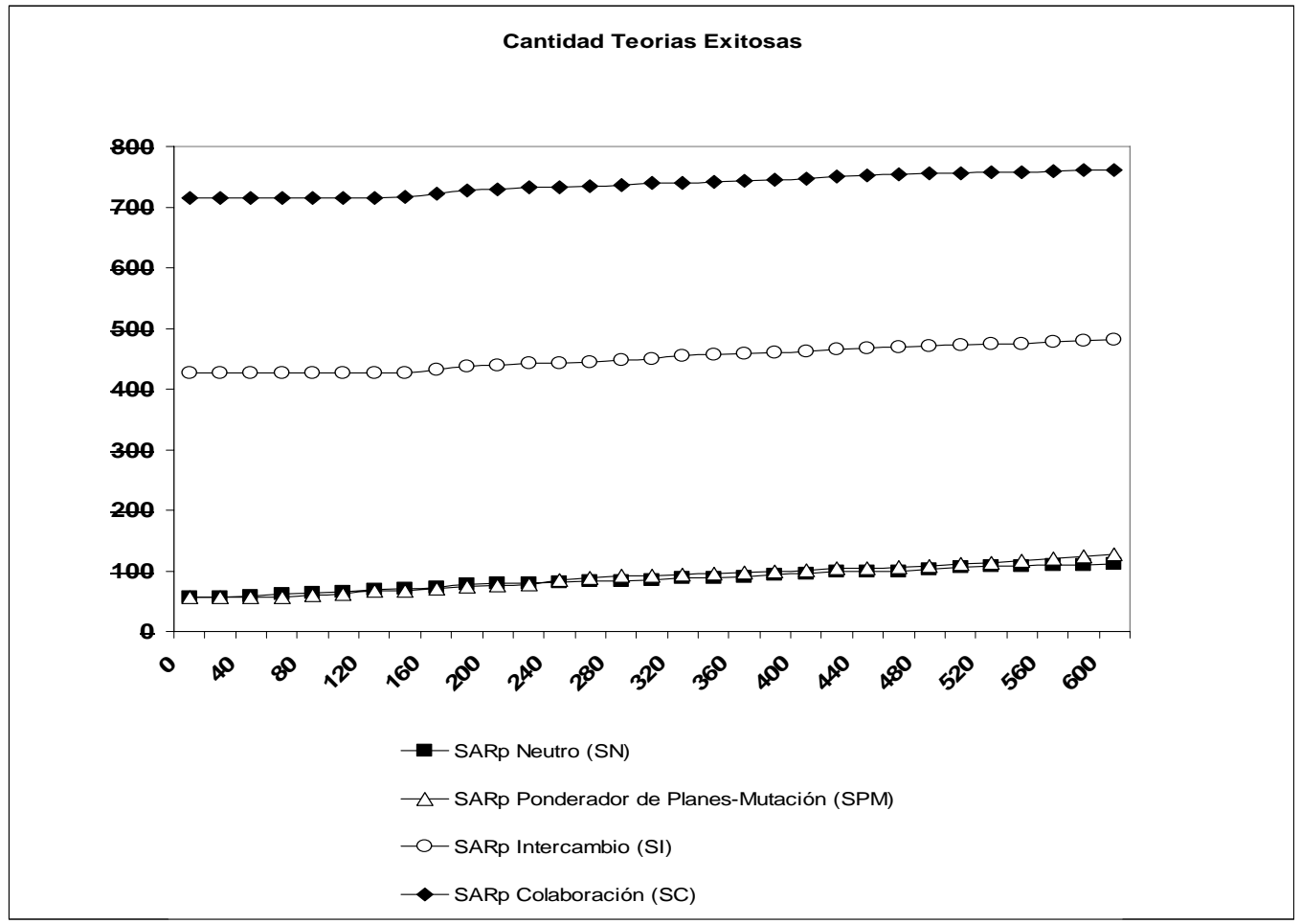

Gráfica 5.9 Cantidad de Teorías Exitosas para las configuraciones de SARp: SN, SPM, SI, SC

\subsection{Ciclos exitosos a lo largo del tiempo}

En esta sub sección se analizará el resultado de los ciclos exitosos promedio alcanzado por los SARp a lo largo del tiempo, al aplicar las configuraciones de métodos, sobre la base de: un SARp configurado por los métodos de ponderación y mutación (SPM), un SARp configurado con intercambio (SI), un SARp configurado con colaboración (SC) y finalmente un SARp neutro (SN), indicadas en la sección 5.3.1.2,correspondiente al segundo grupo de experimentación.

Se observa en la gráfica 5.10. a "Cantidad de ciclos exitosos", que el SARp que aplica colaboración (SC) genera la mayor cantidad promedio de ciclos exitosos a lo largo del tiempo, obteniendo resultados similares con el SARp que aplica intercambio (SI), si bien la tendencia final es en aumento para el SARp que aplica colaboración. Sin embargo en el último cuarto de la experimentación, el SARp que aplica colaboración (SC) mantiene su tendencia de crecimiento en la cantidad de ciclos exitosos promedio y el SARp que aplica intercambio (SI) muestra una tendencia en decrecimiento de la cantidad de ciclos exitosos promedio. Finalmente en orden a la cantidad de ciclos exitosos promedio, siguieron el SARp que aplicó ponderación de planes y mutación (SPM), y el SARp neutro (SN), este último muestra en el último cuarto de la experimentación un crecimiento de la cantidad de ciclos exitosos. 
Se observa en la gráfica 5.10. b "Porcentaje de Ciclos Exitosos” que el SARp que aplica colaboración (SC), obtiene el mayor resultado en materia de porcentaje promedio de ciclos exitosos, sus resultados generales son similares al SARp que aplica intercambio (SI), sin embargo este último muestra una tendencia a desacelerar el porcentaje de ciclos exitosos, próximos a finalizar la experimentación. El SARp SPM obtuvo mejores resultados que el SARp SN que obtuvo el menor porcentaje promedio de ciclos exitosos a lo largo del tiempo de experimentación, sin embargo en el último cuarto de la experimentación se observa que SN tiende a un crecimiento del porcentaje de ciclos exitosos.

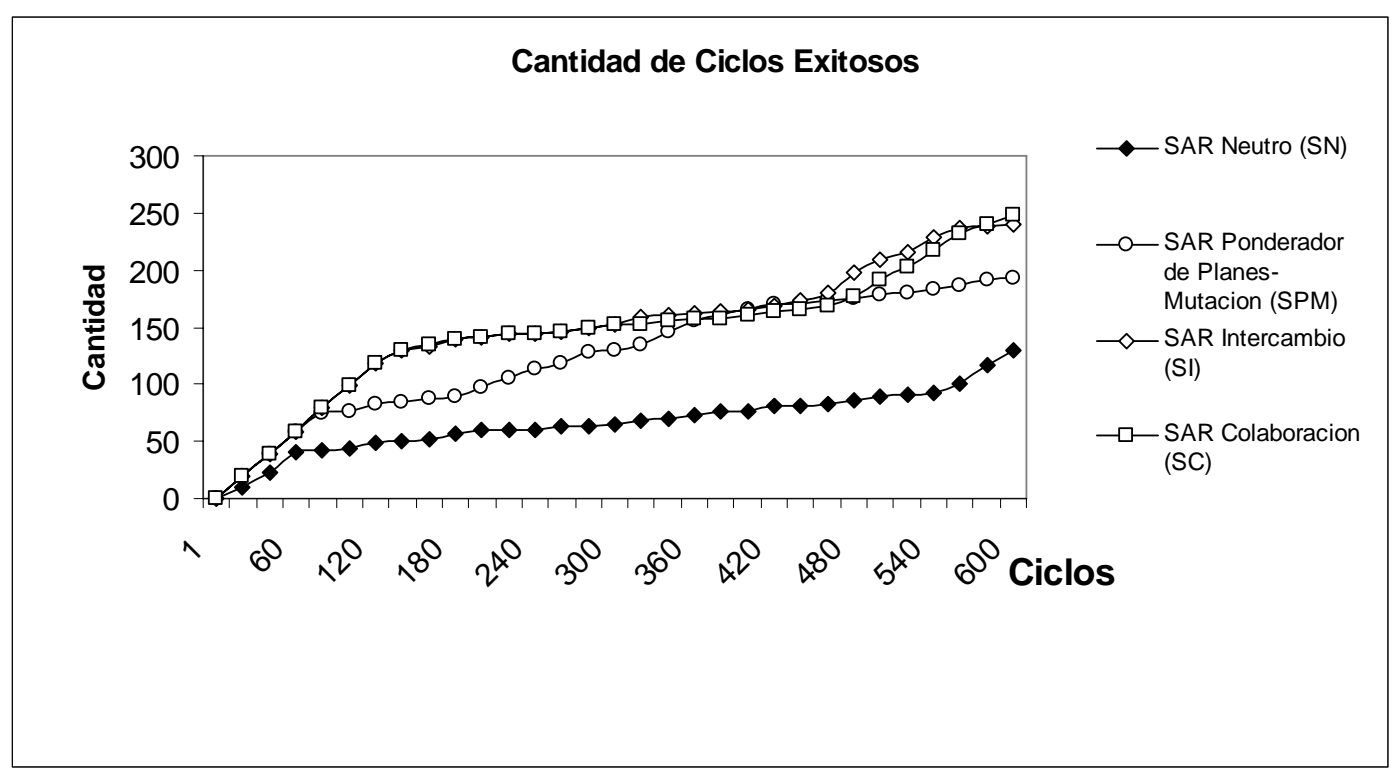

Gráfica 5.10.a Cantidad de Ciclos Exitosos para las configuraciones de SARp: SN, SPM,SI, SC

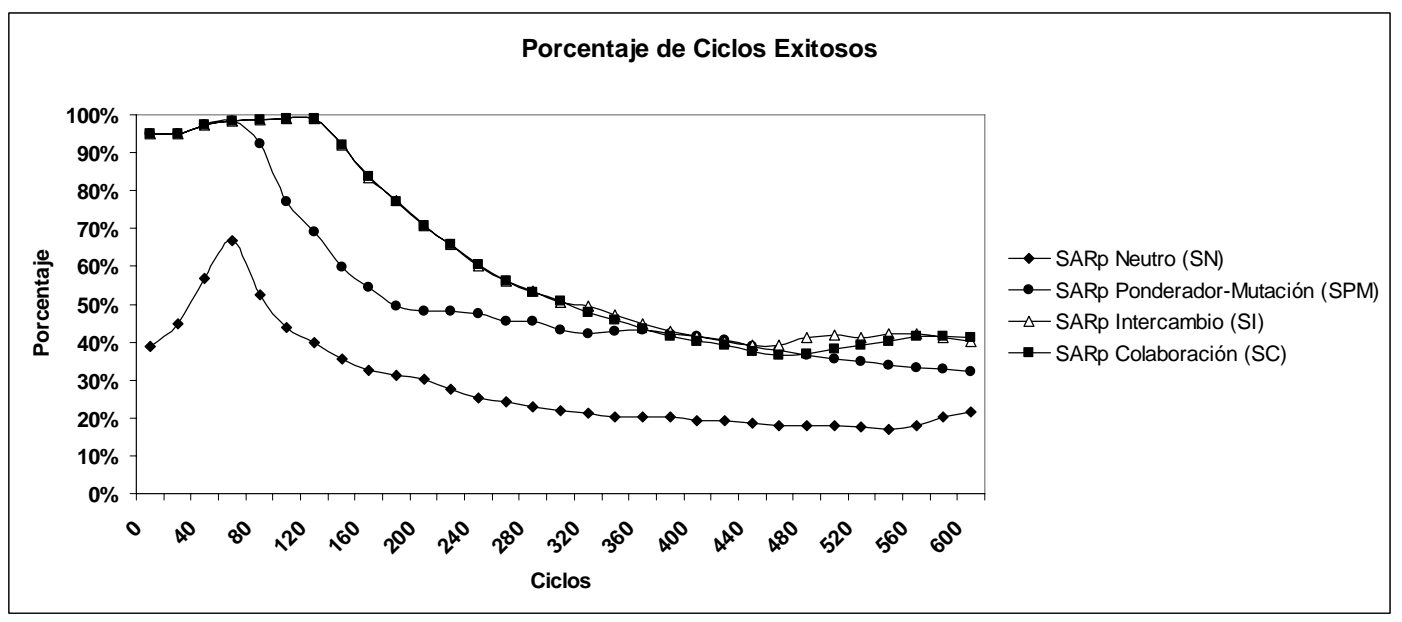

Gráfica 5.10.b Porcentaje de Ciclos Exitosos para las configuraciones de SARp: SN, SPM,SI, SC

Esto sostiene la hipótesis de que un SARp que recibe colaboración obtiene un mayor porcentaje y una mayor cantidad de ciclos exitosos, sobre la base de que dispone de una mayor cantidad de teorías exitosas como se puede observar en la gráficas 5.10 a y 5.10 b respectivamente. 


\subsection{Discusión de los resultados del segundo grupo de experimentación del SARp}

De los resultados obtenidos del segundo grupo de experimentación se concluye que la colaboración aplicada a un SARp, en comparación con las configuraciones experimentadas en este grupo, produce una mayor aceleración en el aprendizaje de un SARp, aumentando el SAR receptor que aplicó colaboración (SC) la cantidad de: planes exitosos, teorías exitosas, ciclos exitosos, y el porcentaje de ciclos exitosos.

Asimismo el SARp receptor que recibió colaboración, generó una menor cantidad de teorías nuevas en virtud de contar con una base de teorías exitosas más representativa que las de los otros SARp comparados, producto de la colaboración que el SARp A (born, que se encuentra iniciando el layer BIO) recibió del SARp B (newbie, que se encuentra iniciando el layer TBO),generando la base de teorías de colaboración entre SARp A-B (born -newbie) .

También se observó que, si bien la cantidad de situaciones tiende a estabilizarse, el SARp que aplica colaboración continúa descubriendo nuevas relaciones entre situaciones (condiciones supuestas o efectos predichos), generando nuevas teorías, como se muestra en la gráfica 5.6.

\subsubsection{Tercer grupo de experimentación del SARp.}

En este grupo se realizan cuatro experimentos que se enfocan en la comparación de la combinación de métodos sobre la base de un: SARp neutro configurado con el método de colaboración (SC), SARp configurado con la combinación de métodos de ponderación de planes, mutación y colaboración (SPMC) y un SARp configurado con la combinación de métodos de intercambio y colaboración (SIC).

Se presentan los resultados obtenidos en este grupo en seis gráficos, que se desarrollan en función de las siguientes variables dependientes: cantidad de situaciones versus cantidad de teorías en la subsección 5.3.1.3.1, cantidad de teorías nuevas en la subsección 5.3.1.3.2, cantidad de planes exitosos en la subsección 5.3.1.2.3, cantidad de teorías exitosas en la subsección 5.3.1.3.4, cantidad de ciclos exitosos a lo largo del tiempo y el porcentaje de ciclos exitosos en la subsección 5.3.1.3.5.

Finalmente se presenta la discusión de los resultados del tercer grupo de experimentos en la subsección 5.3.1.3.6. 


\subsection{Cantidad de situaciones y cantidad de teorías a lo largo del tiempo}

En esta subsección se presenta en la gráfica 5.11, la cantidad de situaciones y cantidad de teorías para el SARp, configurado con la combinación de Intercambio y colaboración (SIC). Se observa en la gráfica 5.11, que el promedio de la cantidad de teorías aumenta más rápido que el promedio de la cantidad de situaciones (condiciones supuestas o efectos predichos). Esto sostiene la hipótesis de que el sistema descubre nuevas relaciones entre situaciones sumando al intercambio, colaboración, aún después que tiende a estabilizarse el número de situaciones.

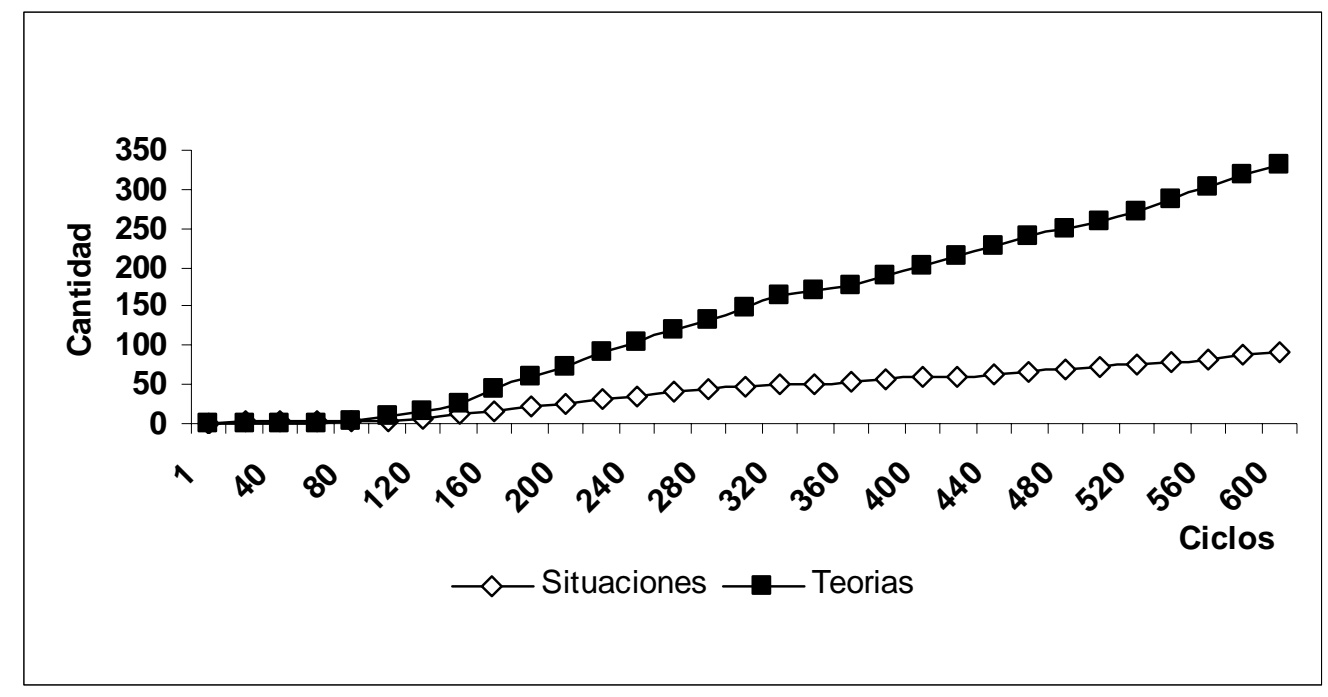

Gráfica 5.11 Cantidad de situaciones vs teorías para la configuración de SARp: SIC

\subsection{Cantidad de teorías nuevas a lo largo del tiempo}

En esta subsección se analizará la cantidad promedio de teorías nuevas generadas por los SARps a lo largo del tiempo al aplicar las configuraciones de métodos, sobre la base de: un SARp configurado por los métodos de ponderación de planes, mutación, colaboración (SPMC), un SARp configurado con intercambio y colaboración (SIC), un SARp clásico configurado con colaboración (SC), indicadas en la sección 5.3.1.3,correspondiente al tercer grupo de experimentación. Se observa en la gráfica 5.12 “Cantidad de teorías nuevas”, que la mayor cantidad promedio generada de teorías nuevas a lo largo del tiempo le corresponden al SARp que aplicó ponderación, mutación y colaboración (SPMC), seguido por el SARp que aplicó colaboración (SC) y el SARp que aplicó intercambio y colaboración (SIC). 
El SARp que realizó intercambio y recibió colaboración (SIC), cuenta con más experiencia en el ambiente de operación (mayor cantidad de teorías exitosas en su base de conocimiento, como se puede observar en la gráfica 5.14), requiriendo generar una menor cantidad de teorías nuevas en comparación con el resto de los SARps (SPMC y SC).

El SARp SPMC al aplicar mutación sobre las teorías similares en su base de conocimiento, genera una mayor cantidad de teorías nuevas en comparación con el SARp SC. La base de conocimiento de teorías que combina intercambio y colaboración (SIC), es más representativa en materia de teorías exitosas (experiencia), para la actuación del SARp, que el resto de las configuraciones comparadas.

Esto sostiene la hipótesis que un SARp que actúa con una base de conocimiento de teorías exitosas mayor por acción de la colaboración en combinación con el intercambio, requiere generar menor cantidad de teorías nuevas para su actuación.

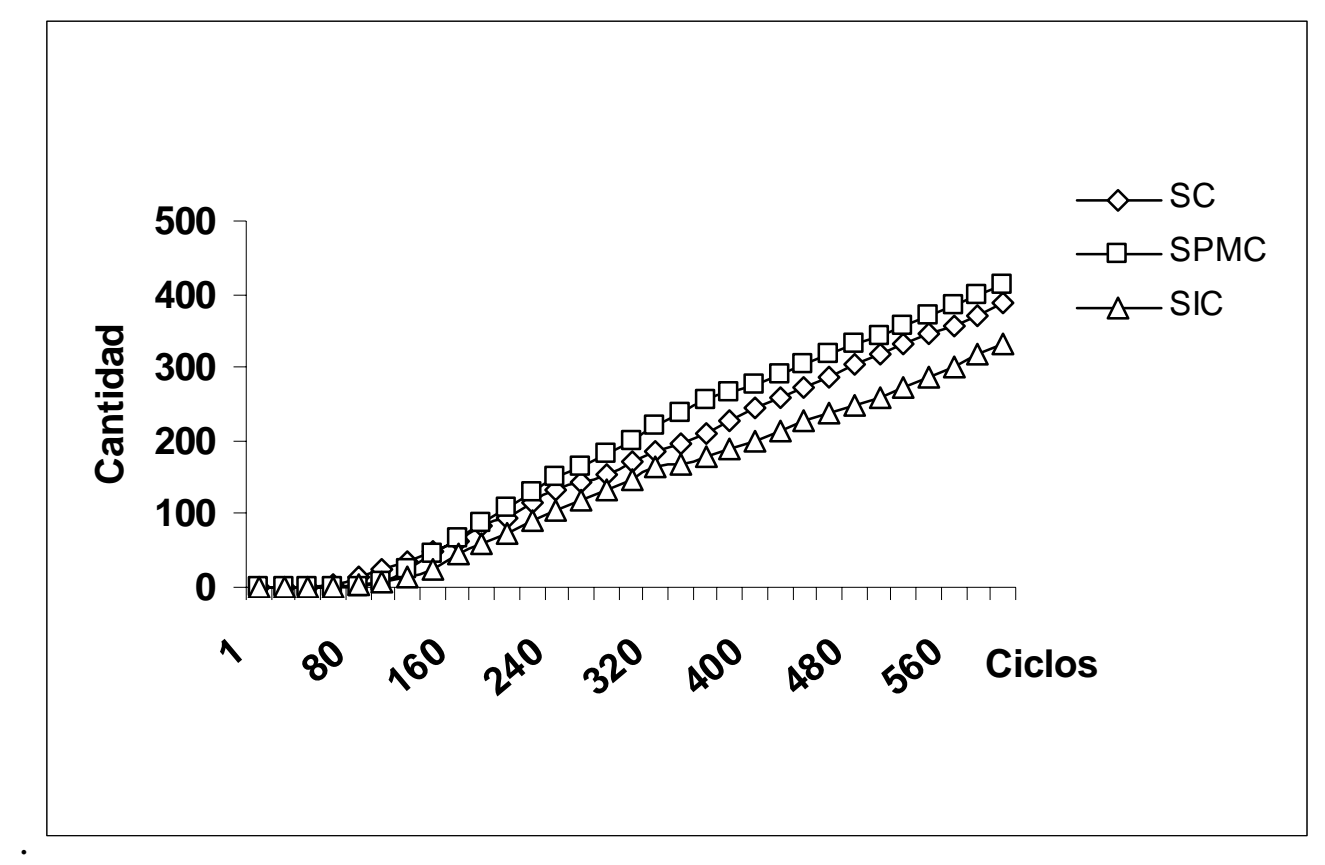

Gráfica 5.12 Cantidad de teorías nuevas para las configuraciones de SARp: SC, SPMC, SIC

\subsection{Cantidad de planes exitosos a lo largo del tiempo.}

En esta subsección se analizará la cantidad de planes exitosos promedio generados por los SARps a lo largo del tiempo al aplicar las configuraciones de métodos, sobre la base de: un SARp configurado por los métodos de ponderación de planes, mutación, colaboración (SPMC), un SARp configurado con intercambio (SI), un SARp configurado con colaboración (SC), indicadas en la sección 5.3.1.3, correspondiente al tercer grupo de experimentación . 
Se observa en la gráfica 5.13 "Cantidad de Planes Exitosos”, que la cantidad promedio de planes a lo largo del tiempo del SARp que aplica intercambio y colaboración (SIC), supera al SARp que aplicó ponderación de planes, mutación, colaboración (SPMC), y ambos al SARp que aplicó colaboración (SC).

La generación de planes exitosos para el SARp (SIC) en la etapa final de la simulación tiende a amesetarse y el SARp (SPMC) continúa con su crecimiento en materia de planes exitosos, producto de la actuación del método de ponderación en la construcción de planes y del método de mutación, que actúa sobre las teorías similares. Finalmente el SARp SPMC y el SARp SIC obtienen resultados similares.

Esto sostiene la hipótesis de que SARp que actúa con una base de conocimiento de teorías exitosas mayor por acción de la colaboración en combinación con el intercambio, genera una mayor cantidad de planes exitosos.

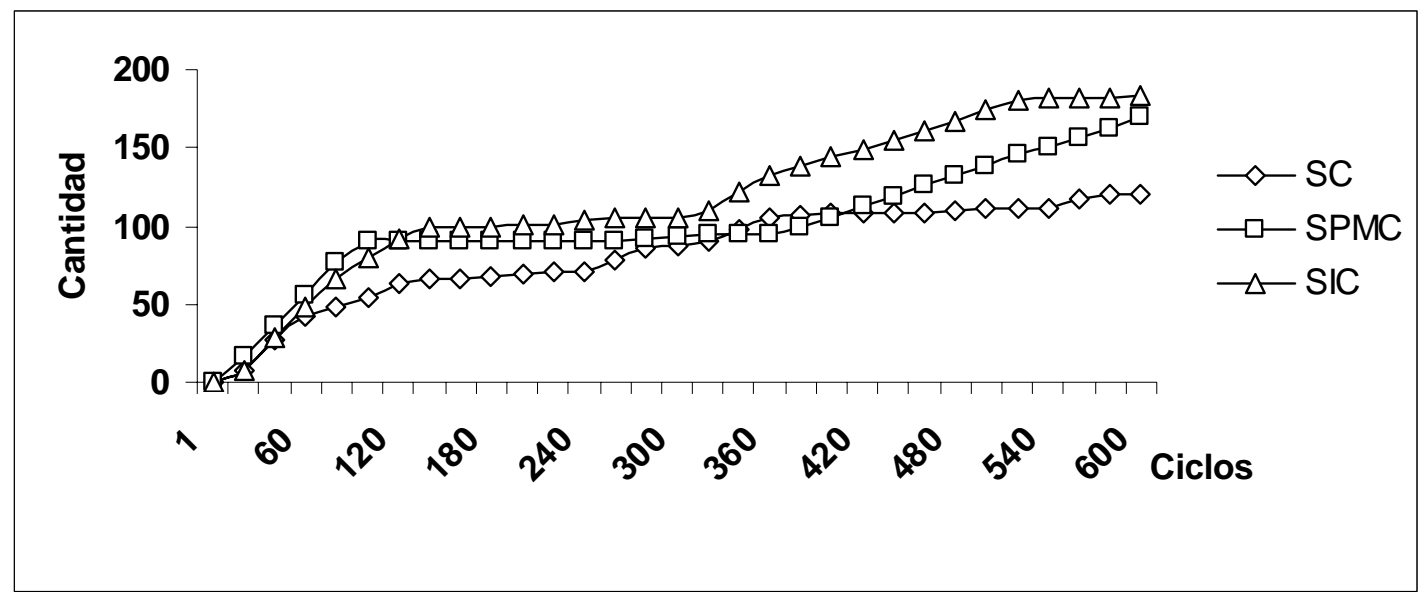

Gráfica 5.13 Cantidad de Planes Exitosos para las configuraciones de SARp: SC, SPMC, SIC

\subsection{Cantidad de teorías exitosas a lo largo del tiempo}

En esta subsección se analizará la cantidad de teorías exitosas promedio generadas por los SARps a lo largo del tiempo al aplicar las configuraciones de métodos, sobre la base de: un SARp configurado por los métodos de ponderación de planes, mutación, colaboración (SPMC), un SARp configurado con intercambio (SI), un SARp configurado con colaboración (SC), indicadas en la sección 5.3.1.3, correspondiente al tercer grupo de experimentación.

Se observa en la gráfica 5.14 “Cantidad de teorías exitosas”, que el SARp (SIC) obtuvo la mayor cantidad de teorías exitosas, seguido con un resultado similar por el SARp (SPMC), superando ambos al SARp (SC).El SARp (SPMC) y el SARp (SIC), aplican colaboración y obtienen una 
cantidad similar de teorías exitosas a lo largo del tiempo. El SARp SPMC que aplica mutación, genera más teorías (sobre la base de teorías similares presentes en la base de conocimiento de teorías), y el SARp SIC, incrementa la cantidad de teorías exitosas, por la acción del intercambio entre SARps .

Esto sostiene la hipótesis de que la colaboración en combinación con métodos de intercambio, mutación contribuye al crecimiento de la base de conocimientos de teorías del SARp.

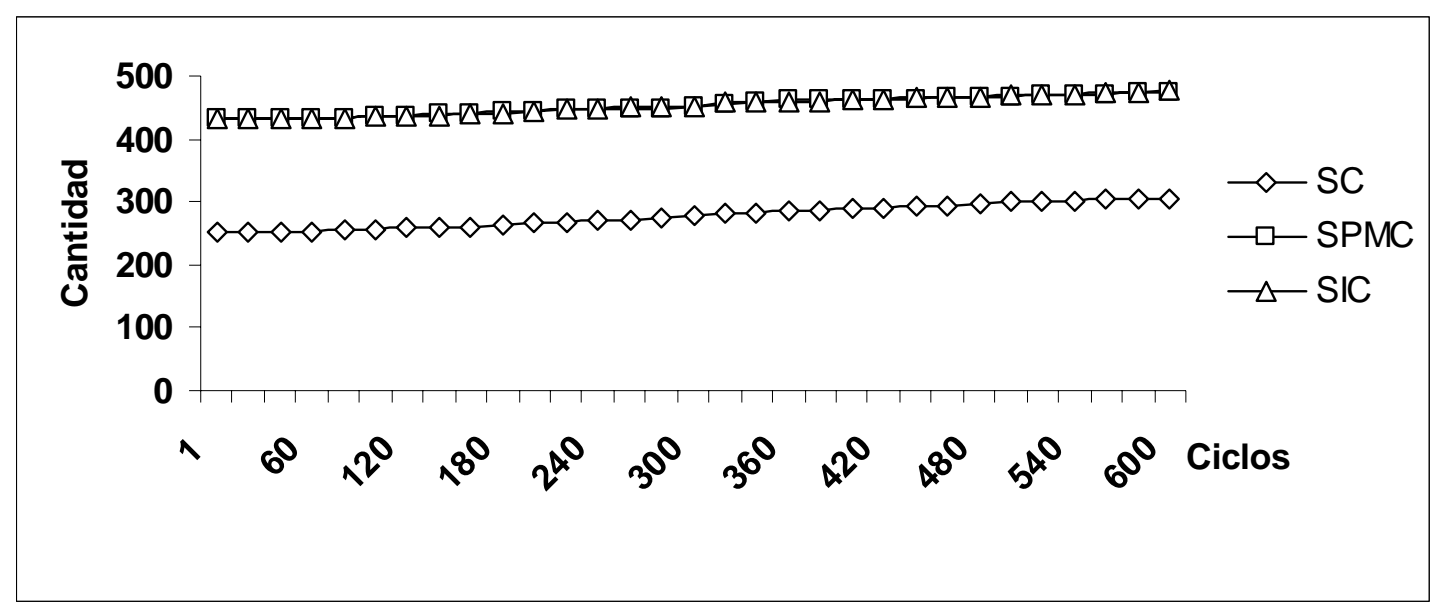

Gráfica 5.14 Cantidad de Teorías Exitosas para las configuraciones de SARp: SC, SPMC, SIC

\subsection{Ciclos exitosos a lo largo del tiempo}

En esta subsección se analizará el resultado promedio de ciclos exitosos alcanzado por los SARp a lo largo del tiempo, al aplicar las configuraciones de métodos, sobre la base de: un SARp configurado por los métodos de ponderación de planes, mutación, colaboración (SPMC), un SARp configurado con intercambio (SI), un SARp configurado con colaboración (SC), indicadas en la sección 5.3.1.3, correspondiente al tercer grupo de experimentación.

Se observa en la gráfica 5.15.a "Cantidad de ciclos exitosos", que el SARp que combina intercambio y colaboración (SIC), obtuvo la mayor cantidad promedio de ciclos exitosos a lo largo del tiempo, seguido en una primera etapa por el SARp (SPMC) que aplica ponderación, mutación, colaboración y el SARp (SC) que aplica sólo colaboración.

En la primera parte de la segunda mitad de la experimentación se observa que el SARp SC supera al SARp SPMC, sin embargo en el cuarto final de la experimentación el SARp SPMC aumenta su aceleración generando una mayor cantidad promedio de ciclos exitosos superando al SARp SC. El SARp SPMC al aplicar el método de mutación (a teorías similares) genera nuevas teorías que incrementa la cantidad de ciclos exitosos del SARp (SPMC). 
De igual forma se observa en la gráfica 5.15. b "Porcentaje de ciclos exitosos", que el mejor porcentaje promedio a lo largo del tiempo lo obtiene el SAR que aplica intercambio y colaboración (SIC), en relación a los otros métodos comparados.

En la primera mitad de la simulación se observa que el SARp SPMC supera al SARp SC, en la segunda parte el SARp SC supera al SARp SPMC, sin embargo en el cuarto final el SARp SPMC tiene una tendencia a generar un mayor porcentaje de ciclos exitosos producto de la aplicación del método de mutación que actúa sobre las teorías similares generando nuevas teorías que facilitan el incremento del porcentaje de ciclos exitosos, al presentarse teorías exitosas, tendiendo a superar al SARp SC en término de porcentaje de ciclos exitosos.

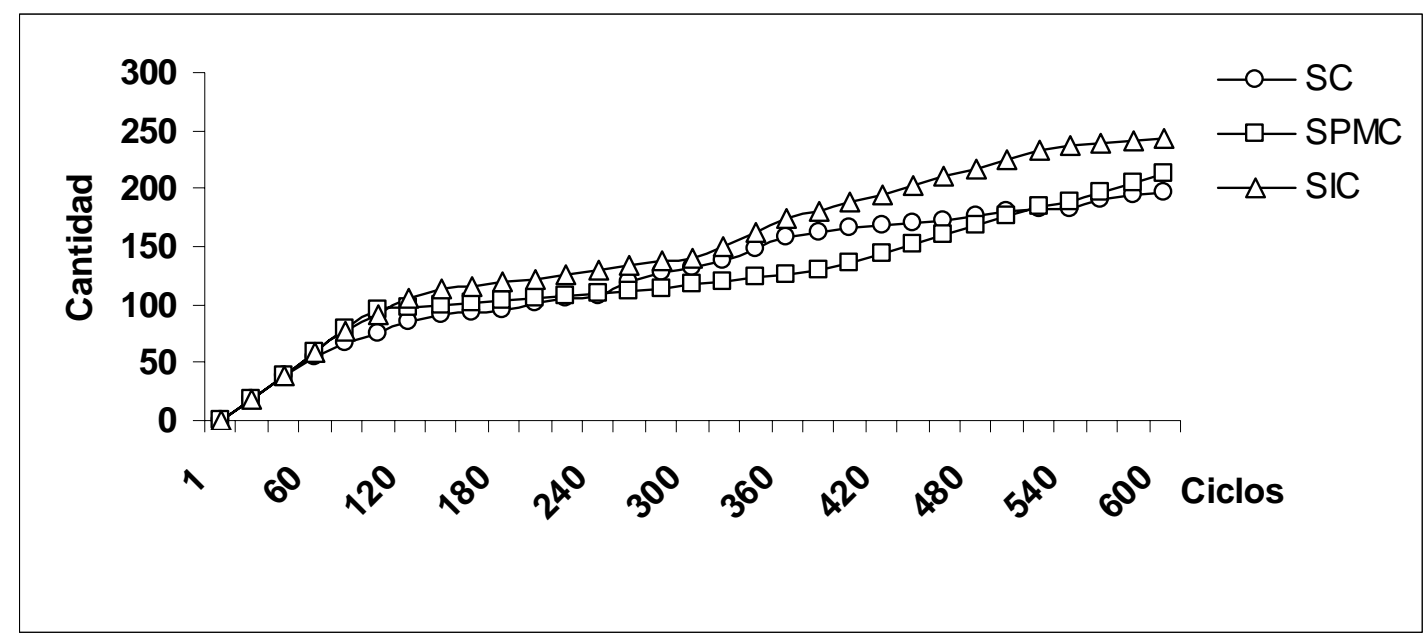

Gráfica 5.15.a Cantidad de ciclos exitosos para las configuraciones de SARp: SC, SPMC, SIC

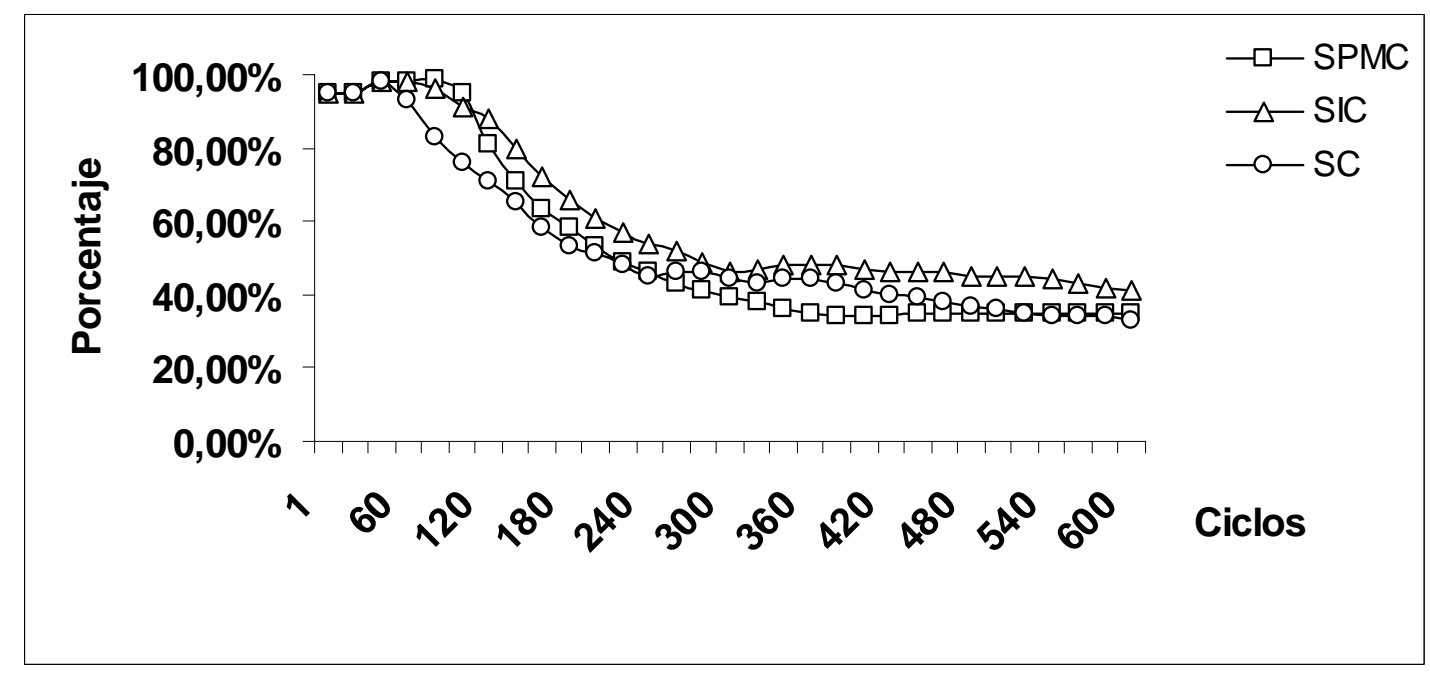

Gráfica 5.15.b Porcentaje de ciclos exitosos para las configuraciones de SARp: SC, SPMC, SIC

Esto sostiene la hipótesis que la colaboración en combinación con intercambio contribuye al incremento de ciclos exitosos del SARp. 


\subsection{Discusión de los resultados del tercer grupo de experimentación del SARp}

De los resultados obtenidos del tercer grupo de experimentación se concluye que el SARp que aplicó la combinación de la colaboración y el intercambio (SIC), en comparación con las otras combinaciones de configuraciones experimentadas en este grupo, produce una mayor aceleración en el aprendizaje de un SARp, aumentando el SAR receptor que aplicó la combinación de colaboración e intercambio, la cantidad de: planes exitosos, teorías exitosas, ciclos exitosos, y el porcentaje de ciclos exitosos.

Asimismo el SARp (SIC), receptor generó una menor cantidad de teorías nuevas, en virtud de contar con una base de teorías exitosas más representativa que las aplicadas por las restantes combinaciones de métodos de los otros SARp comparados.

La base de teorías del SARp (SIC), inicialmente se origina en el SARp A receptor, (born, al inicio del layer BIO) que efectuó intercambio con el SARp B (born en tránsito por el layer BIO), generando la base de teorías de intercambio entre SARp A-B (borns), sobre la cual el SARp B (newbie Layer TBO), aplicó colaboración, generando la base de teorías de intercambiocolaboración SARp A (born)-B (newbie), la que fue empleada durante la experimentación por el SAR E, (SIC).

Finalmente, si bien la cantidad de situaciones tiende a estabilizarse para el SARp para el SARp que combina intercambio con colaboración (SIC), éste continúa descubriendo nuevas relaciones entre situaciones (condiciones supuestas o efectos predichos), generando nuevas teorías, como se muestra en la gráfica 5.11 .

\subsubsection{GRÁFICAS DEL SISTEMA AUTÓNOMO DE ROBOT CON RANKING}

Para analizar el comportamiento del Sistema Autónomo de Robot con ranking (SARr), se han desarrollado ocho experimentos que surgen de aplicar los distintos métodos y las combinaciones entre ellos. Los experimentos se desarrollaron sobre la base de las variables independientes y dependientes enunciadas, se estructuraron en grupos de experimentos como se detalló en la sección 5.2.4, el primer grupo de experimentos del SARr, se detalla en la sección 5.3.2.1, el segundo grupo de experimentos del SARp, se detalla en la sección 5.3.2.2. 


\subsubsection{Primer grupo de experimentos del SARr}

En este grupo se presentan los resultados de cuatro experimentos, que se enfocan en la comparación individual de métodos aplicados por los SARrs, sobre la base de un: SARr configurado por el método de mutación (SMr), un SARr configurado con intercambio (SIr), un SARr configurado con colaboración (SCr) y finalmente un SARr neutro (SNr).

Se presentan los resultados de los experimentos del grupo en seis (6) gráficos, correspondientes a las variables dependientes: cantidad de situaciones versus cantidad de teorías en la subsección 5.3.2.1.1, cantidad de teorías nuevas en la subsección 5.3.2.1.2, cantidad de planes exitosos en la subsección 5.3.2.1.3, cantidad de teorías exitosas en la subsección 5.3.2.1.4, cantidad de ciclos exitosos a lo largo del tiempo y el porcentaje de ciclos exitosos en la subsección 5.3.2.1.5.

Finalmente se presenta la discusión de los resultados del primer grupo de experimentación en la subsección 5.3.2.1.6.

\subsection{Cantidad de situaciones y cantidad de teorías a lo largo del tiempo}

En esta subsección se presenta en la gráfica 5.16, la cantidad de situaciones y cantidad de teorías promedio para el SARr, configurado sobre la base de un SARr neutro con el método propuesto de colaboración (SCr). Se observa en la gráfica 5.16, que la cantidad de teorías en la segunda mitad de la experimentación, aumenta más rápido que la cantidad de situaciones (condiciones supuestas o efectos predichos). Esto sostiene la hipótesis de que el sistema descubre nuevas relaciones entre situaciones aplicando colaboración.

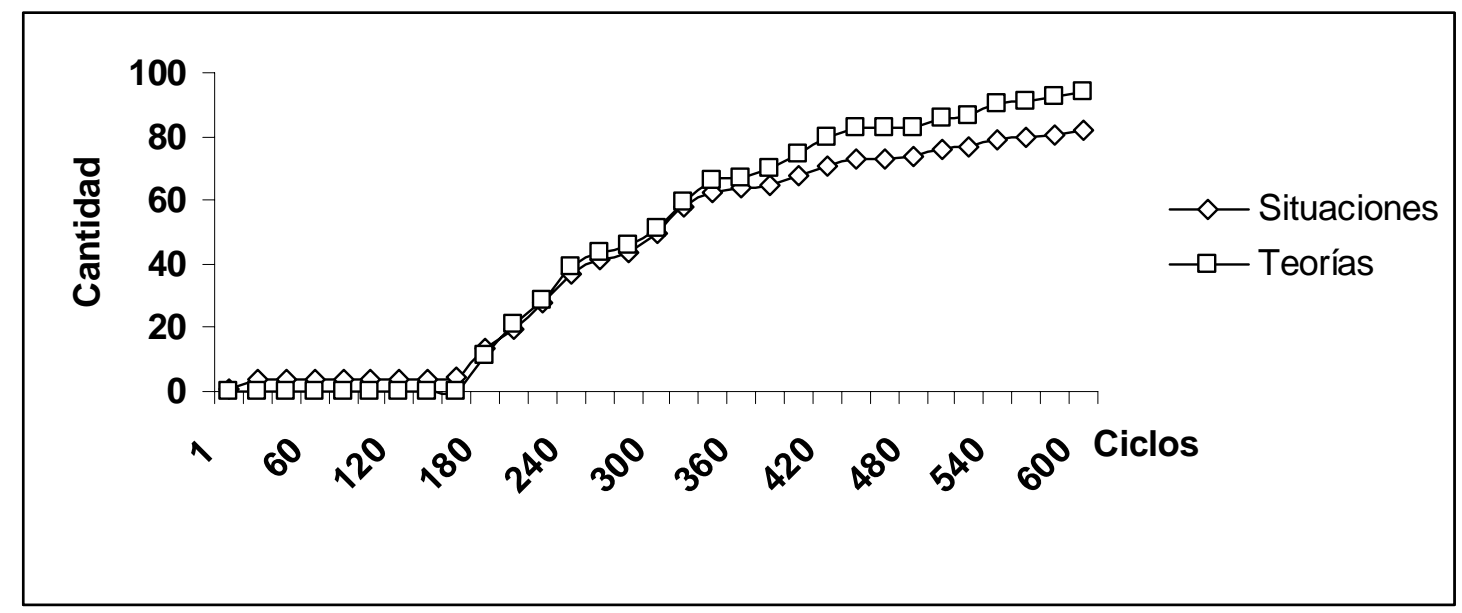

Gráfica 5.16 Cantidad de Situaciones vs teorías para la configuración de SARr: SCr 


\subsection{Cantidad de teorías nuevas a lo largo del tiempo}

En esta subsección se analizará la cantidad promedio de teorías nuevas generadas por los SARrs a lo largo del tiempo al aplicar las configuraciones de métodos, sobre la base de: un SARr configurado con el método de mutación (SMr), un SARr configurado con intercambio (SIr) y un SARr configurado con colaboración (SCr) y finalmente un SARr neutro (SNr), indicadas en la sección 5.3.2.1,correspondiente al primer grupo de experimentación de SARr.

Se observa en la gráfica 5.17 “Cantidad de teorías nuevas”, que la mayor cantidad promedio generada de teorías nuevas a lo largo del tiempo le corresponden al SARr neutro (SNr), seguido del SARr que aplicó el método de mutación (SMr) y por el SARr configurado con intercambio (SIr), finalmente con la menor cantidad de teorías nuevas generadas durante la experimentación, se presenta el SARr que aplica colaboración (SCr).

Durante la experimentación el SARr SCr y el SARr SIr superan al SARr SNr, sin embargo en el último cuarto el SARr SCr y el SARr SCr tiende a decrecer la cantidad de teorías nuevas y son superados por el SARr SNr, el que continúa con una tendencia en crecimiento, superior al resto de tendencias de los otros SARrs.

El SARr SCr tiene más experiencia (mayor cantidad de teorías exitosas en su base de conocimiento de teorías acumuladas, según se muestra en la gráfica 5.19), al contar con más teorías exitosas que el resto de los SARr comparados, razón por la cual, al contar con más experiencia en el ambiente de operación el SARr que recibió colaboración generó la menor cantidad de teorías nuevas, en comparación con el resto de los métodos.

Esto sostiene la hipótesis que la colaboración contribuye al crecimiento de la base de conocimientos de teorías que el SAR emplea para su actuación.

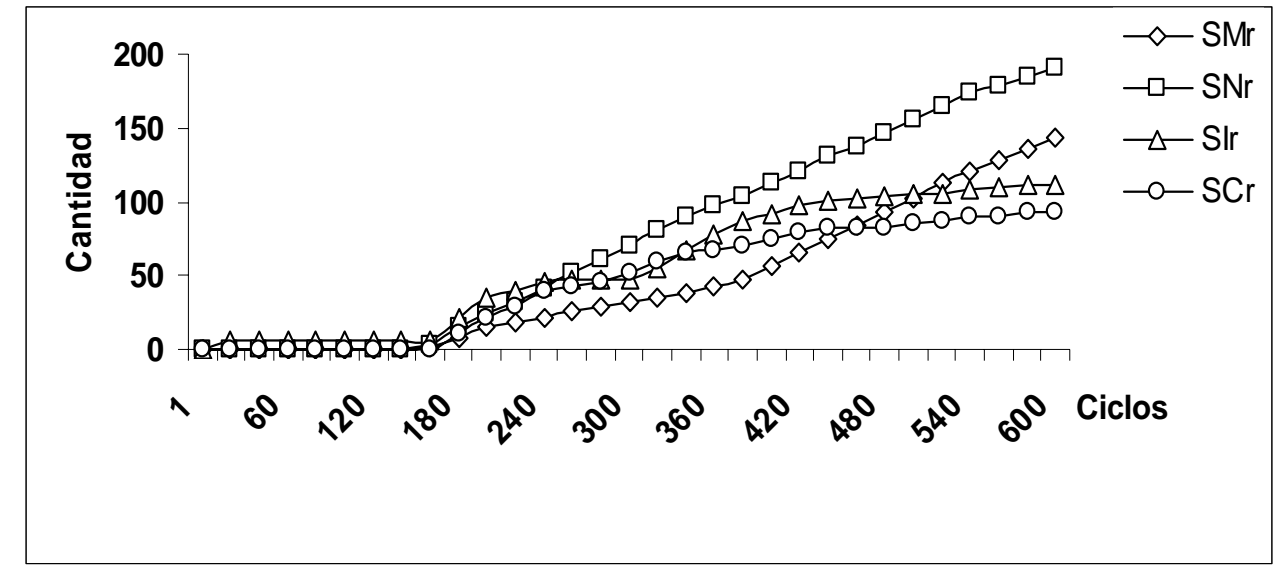

Gráfica 5.17 Cantidad de teorías nuevas para la configuración de SARr: SNr, SMr, SIr,SCr 


\subsection{Cantidad de planes exitosos a lo largo del tiempo}

En esta subsección se analizará la cantidad promedio de planes exitosos generadas por los SARrs a lo largo del tiempo al aplicar las configuraciones de métodos, sobre la base de: un SARp configurado con el método de mutación (SMr), un SARr configurado con intercambio (SIr) y un SARr configurado con colaboración (SCr) y finalmente un SARr neutro (SNr), indicadas en la sección 5.3.2.1, correspondiente al primer grupo de experimentación de SARr.

Se observa en la gráfica 5.18 "Cantidad de planes exitosos”, que la mayor cantidad promedio de planes exitosos a lo largo del tiempo le corresponden al SARr que aplicó el método de colaboración (SCr), seguido por el SARr configurado con intercambio (SIr), el SARr que aplica el método de mutación (SMr) y finalmente con la menor cantidad de planes exitosos, se encuentra el SARr neutro (SNr).

Finalmente se observa que la tendencia a lo largo del tiempo para todos los métodos es la misma, en razón que la arquitectura de ranking sólo planifica la acción del instante siguiente, un solo paso, a diferencia de las arquitectura con planificación clásica. Sin embargo el SARr que aplica colaboración (SCr) conserva la tendencia de mayor crecimiento de planes exitosos en comparación con el resto de los SARr.

Esto sostiene la hipótesis de que SARr que actúa con una base de conocimiento de teorías exitosas mayor por acción de la colaboración en combinación con el intercambio, genera una mayor cantidad de planes exitosos.

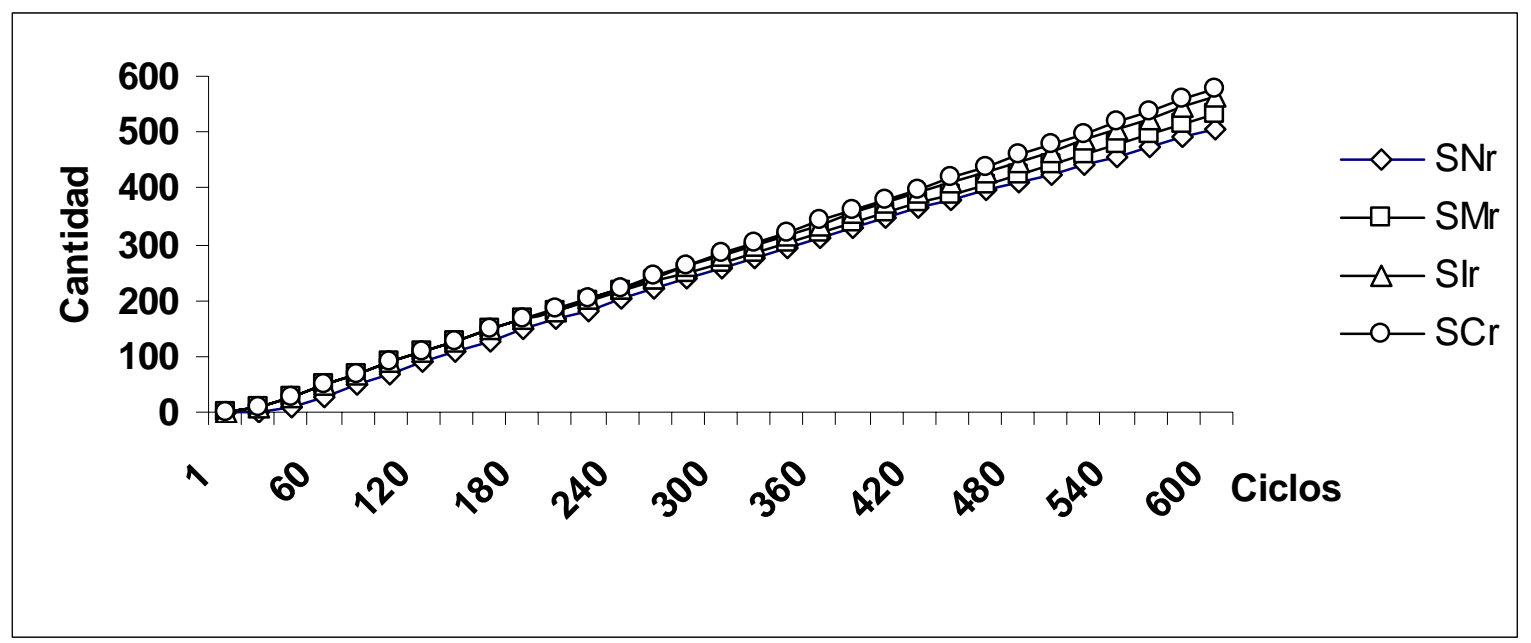

Gráfica 5.18 Cantidad de planes exitosos para la configuración de SARr: SNr, SMr, SIr,SCr 


\subsection{Cantidad de teorías exitosas a lo largo del tiempo}

En esta subsección se analizará la cantidad promedio de teorías exitosas generadas por los SARrs a lo largo del tiempo al aplicar las configuraciones de métodos, sobre la base de: un SARp configurado con el método de mutación (SMr), un SARr configurado con intercambio (SIr) y un SARr configurado con colaboración (SCr) y finalmente un SARr neutro (SNr), indicadas en la sección 5.3.2.1, correspondiente al primer grupo de experimentación de SARr.

Se observa en la gráfica 5.19 "Cantidad de teorías exitosas”, que el SARr que aplicó colaboración (SCr) obtuvo la mayor cantidad de teorías exitosas, seguido con un resultado similar durante el primer cuarto de la experimentación por el SARr que aplicó intercambio (SIr), el resto de la experimentación el SARr SCr incrementa la cantidad de teorías exitosas por sobre el SARr SIr, ambos SARs superan en cantidad de teorías exitosas al SARp que aplicó mutación (SMr) y al SARr neutro (SNr).El SARr neutro (SNr), es superado por el SARr que aplica mutación (SMr), la aplicación del método de mutación sobre las teorías similares de la base de conocimiento de teorías del SARr, genera una mayor cantidad de teorías exitosas.

Estos resultados sostienen la hipótesis que la colaboración contribuye al crecimiento de la base de conocimientos de teorías del SARr, facilitando una mayor cantidad de teorías exitosas.

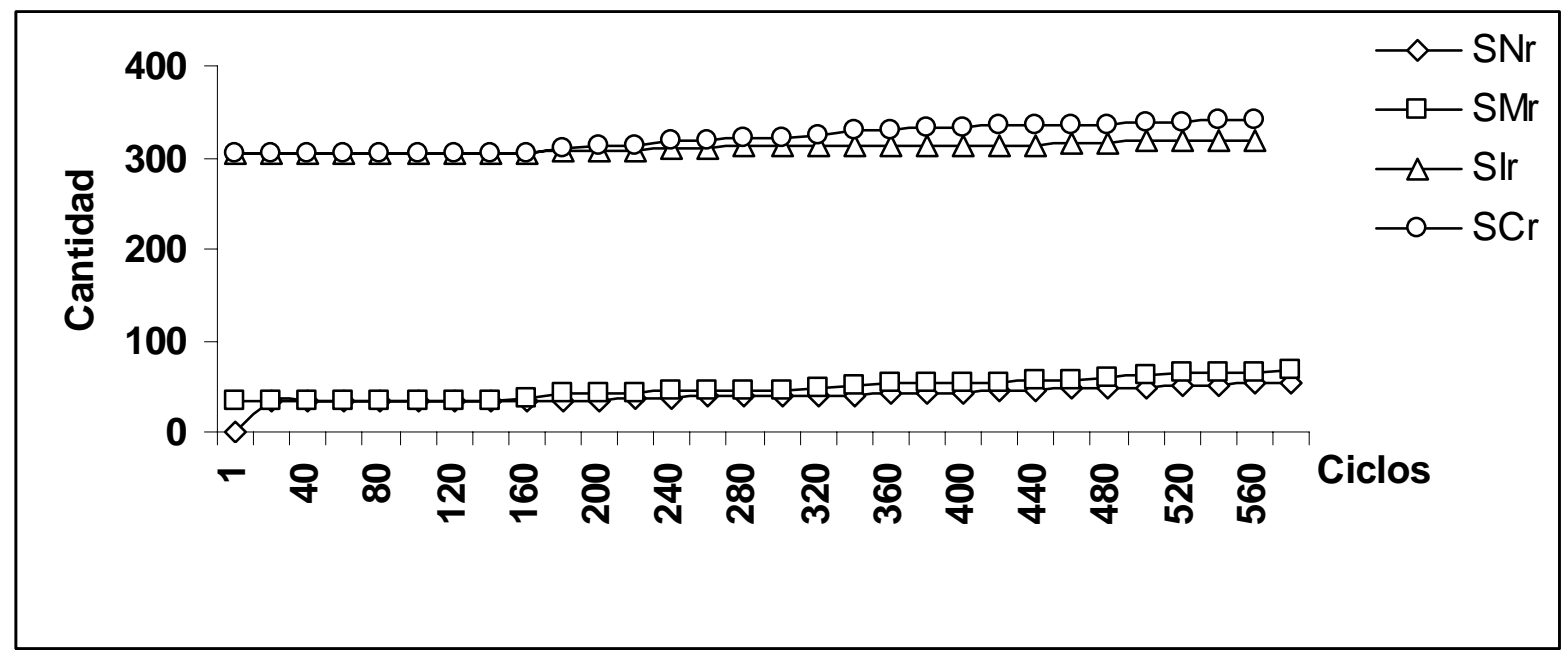

Gráfica 5.19 Cantidad de teorías exitosas para la configuración de SARr: SNr, SMr, SIr,SCr 


\subsection{Ciclos exitosos a lo largo del tiempo}

En esta subsección se analizará el resultado de ciclos exitosos promedio generados por los SARrs a lo largo del tiempo al aplicar las configuraciones de métodos, sobre la base de: un SARp configurado con el método de mutación (SMr), un SARr configurado con intercambio (SIr) y un SARr configurado con colaboración (SCr) y finalmente un SARr neutro (SNr), indicadas en la sección 5.3.2.1, correspondiente al primer grupo de experimentación de SARr.

Se observa en la gráfica 5.20. a "Cantidad de ciclos exitosos”, que en el primer cuarto de la experimentación los SARrs obtienen resultados similares, luego el SARr que aplica colaboración (SCr) genera la mayor cantidad promedio de ciclos exitosos, seguido con resultados similares por el SARr que aplica intercambio (SIr), superando ambos al SARr que aplica mutación (SMr) y al SARr neutro (SNr), sin embargo este último muestra en el cuarto final de la experimentación, una tendencia a decrecer su cantidad de ciclos exitosos en comparación con los otros métodos que mantienen su tendencia de crecimiento en cantidad de ciclos exitosos.

Se observa en la gráfica 5.20. b "Porcentaje de Ciclos Exitosos" que en el primer cuarto de la experimentación los SARrs obtienen resultados similares con un alto porcentaje de ciclos exitosos, en el resto de la experimentación el SARr que aplica colaboración (SCr), obtiene el mayor resultado en materia de porcentaje promedio de ciclos exitosos, seguido por el SARr que aplica intercambio (SIr) y el SAR neutro el que mantiene una tendencia decreciente, siendo superado éste, en el último cuarto de la experimentación por el SARr que aplica mutación (SMr). EL SARr SCr y el SARr SIr mantienen la tendencia de porcentajes de ciclos exitosos, al igual que el SARr SMr.

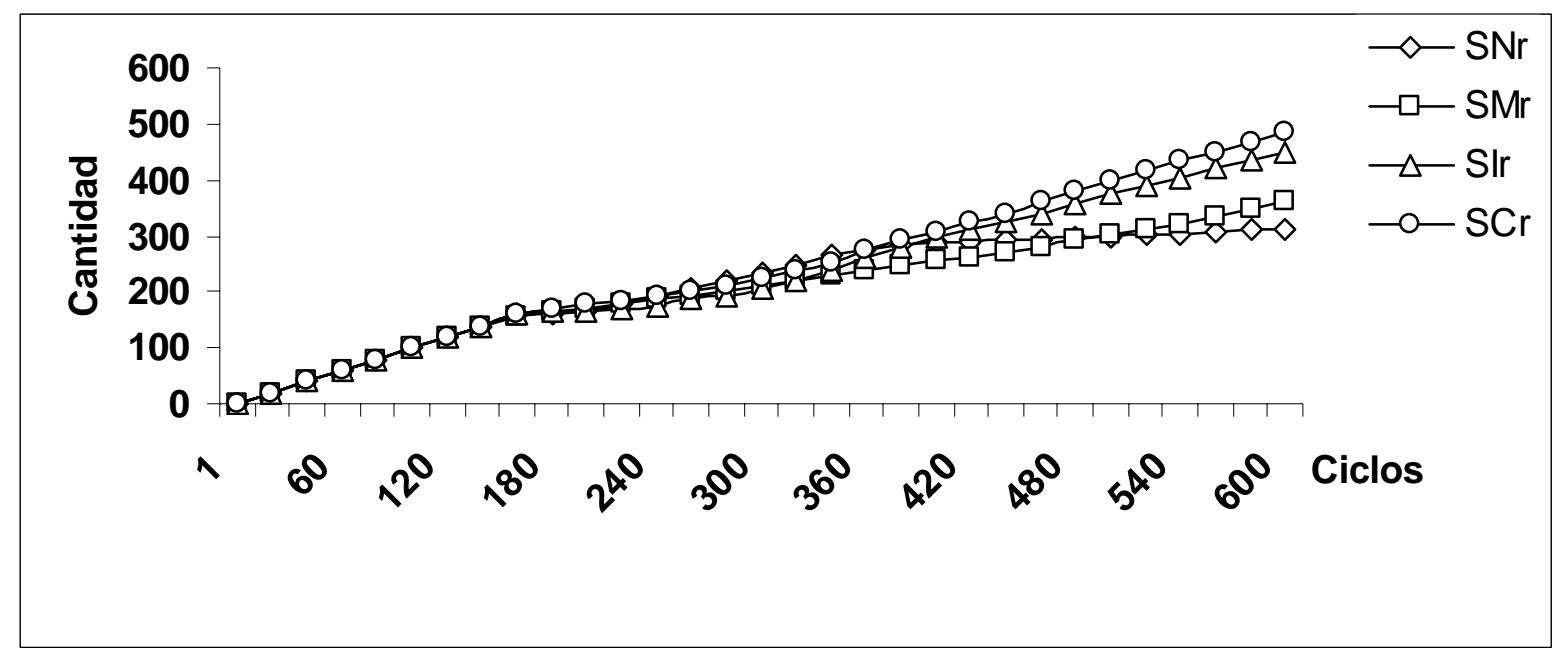

Gráfica 5.20.a Cantidad de Ciclos Exitosos para las configuraciones de SARr: SNr, SMr, SIr,SCr 


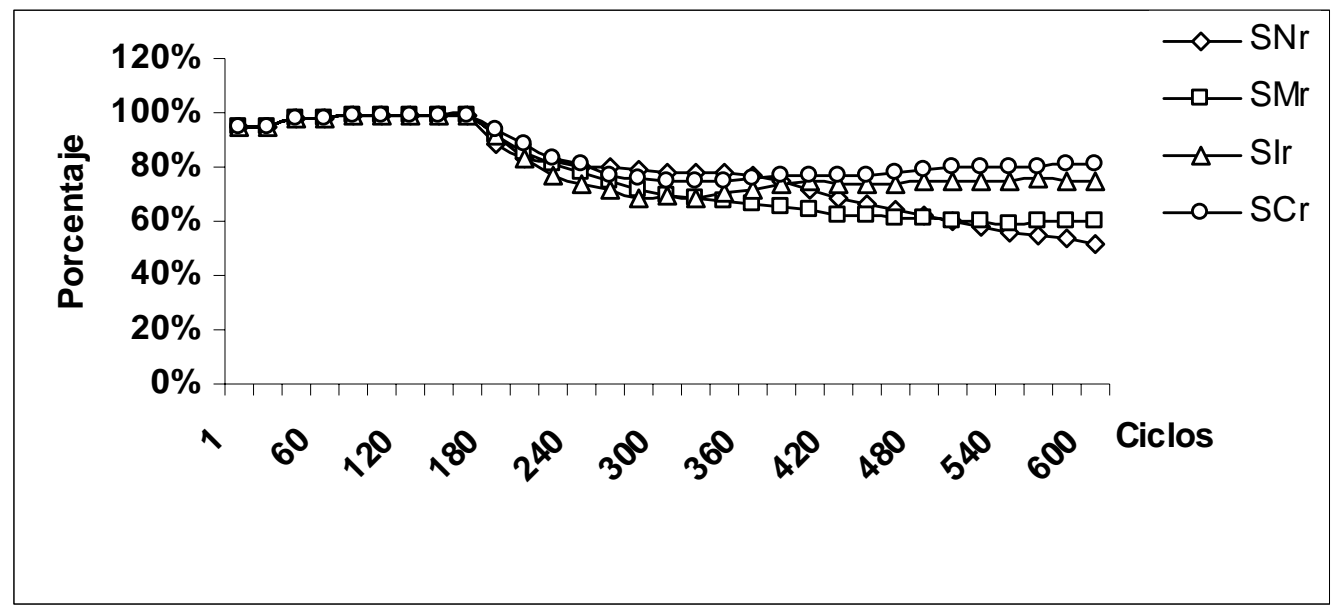

Gráfica 5.20.b Porcentaje de Ciclos Exitosos para las configuraciones de SARr: SNr, SMr, SIr,SCr

Esto sostiene la hipótesis de que un SARr que recibe colaboración obtiene un mayor porcentaje y una mayor cantidad de ciclos exitosos, sobre la base de que dispone de una mayor cantidad de teorías exitosas.

\subsection{Discusión de los resultados del primer grupo de experimentación del SARr.}

De los resultados obtenidos del primer grupo de experimentación se concluye que la colaboración aplicada a un SARr, en comparación con las configuraciones experimentadas en este grupo, produce una mayor aceleración en el aprendizaje de un SARr, aumentando el SAR receptor que aplicó colaboración (SCr) la cantidad de: planes exitosos, teorías exitosas, ciclos exitosos, y el porcentaje de ciclos exitosos.

Asimismo el SARr receptor generó una menor cantidad de teorías nuevas en virtud de contar con una base de teorías exitosas más representativa, que las de los otros SARr comparados, producto de la colaboración que el SARr A (born, que se encuentra iniciando el layer BIO) recibió del SARr B (newbie, que se encuentra iniciando el layer TBO), generando la base de teorías de colaboración entre SARr A-B (born -newbie) la que fue empleada durante la experimentación por el SARr E, (SCr).

También se observó que, si bien la cantidad de situaciones tiende a estabilizarse, el SARr que aplica colaboración (SCr) continúa descubriendo nuevas relaciones entre situaciones (condiciones supuestas o efectos predichos), generando nuevas teorías, como se muestra en la gráfica 5.16. 


\subsubsection{Segundo grupo de experimentos del SARr}

En este grupo se presentan los resultados de cuatro experimentos, que se enfocan en la comparación de los resultados de combinar métodos aplicados por los SARrs, sobre la base de un: SARr configurado por el método de mutación y colaboración (SMCr), un SARr configurado con intercambio y colaboración (SICr), un SARr configurado con mutación, intercambio y colaboración (SMICr).

Se presentan los resultados de los experimentos del grupo en seis gráficos, correspondientes a las variables dependientes: cantidad de situaciones versus cantidad de teorías en la subsección 5.3.2.2.1, cantidad de teorías nuevas en la subsección 5.3.2.2.2, cantidad de planes exitosos en la subsección 5.3.2.2.3, cantidad de teorías exitosas en la subsección 5.3.2.2.4, cantidad de ciclos exitosos a lo largo del tiempo y el porcentaje de ciclos exitosos en la subsección 5.3.2.2.5.

Finalmente se presenta la discusión de los resultados del primer grupo de experimentación en la subsección 5.3.2.2.6.

\subsection{Cantidad de situaciones y cantidad de teorías a lo largo del tiempo}

En esta subsección se presenta en la gráfica 5.21, la cantidad de situaciones y cantidad de teorías promedio para el SARr, configurado sobre la base de un SARr con la combinación de métodos de mutación, intercambio y colaboración (SMICr). Se observa en la gráfica 5.21, que la cantidad de teorías en la segunda mitad de la experimentación, aumenta más rápido que la cantidad de situaciones (condiciones supuestas o efectos predichos). Esto sostiene la hipótesis de que el sistema descubre nuevas relaciones entre situaciones aplicando colaboración, aún después que tiende a estabilizarse el número de situaciones.

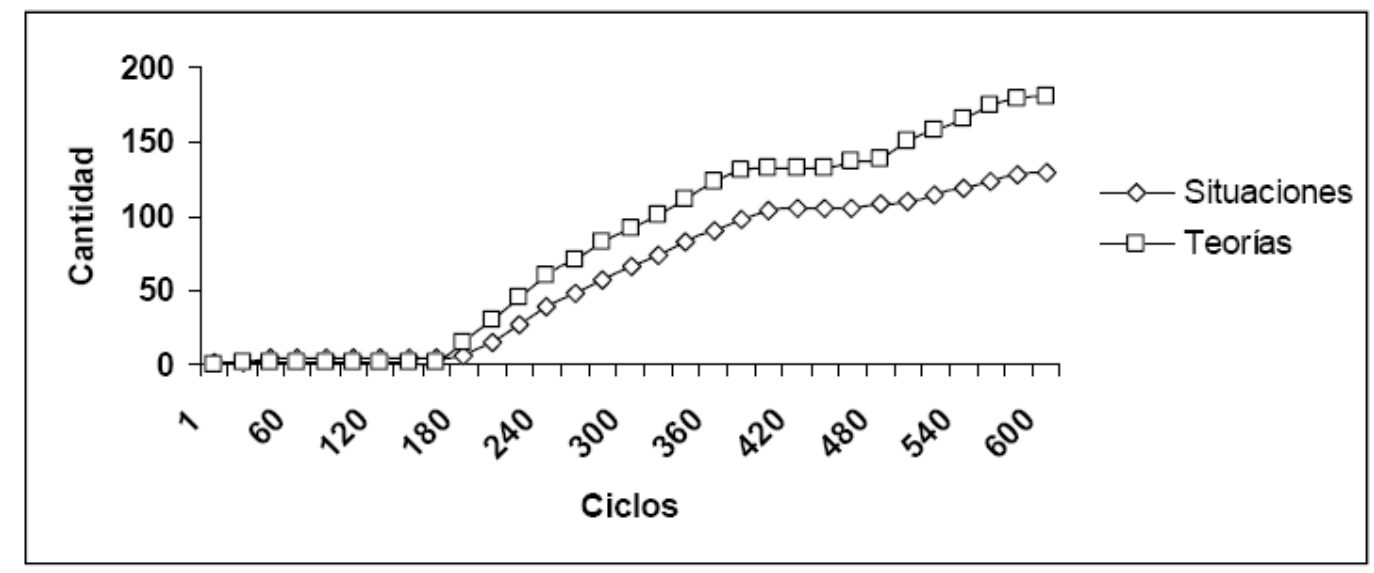

Gráfica 5.21 Cantidad de Situaciones vs teorías para la configuración de SARr: SMICr 


\subsection{Cantidad de teorías nuevas a lo largo del tiempo}

En esta subsección se analizará la cantidad promedio de teorías nuevas generadas por los SARrs a lo largo del tiempo al aplicar las combinaciones de métodos, sobre la base de: un SARr configurado con los métodos de mutación, intercambio y colaboración (SMICr), un SARr configurado con mutación y colaboración (SMCr) y un SARr configurado con intercambio y colaboración (SICr), indicadas en la sección 5.3.2.2, segundo grupo de experimentación SARr.

Se observa en la gráfica 5.22 "Cantidad de teorías nuevas", que la mayor cantidad promedio generada de teorías nuevas a lo largo del tiempo le corresponden al SARr que aplicó mutación y colaboración (SMCr), seguido por el SARr que aplicó la combinación de intercambio y colaboración (SICr) y el SARr que aplicó la combinación de mutación, intercambio y colaboración (SMICr).

El SARr que realizó mutación intercambio y recibió colaboración (SMICr), cuenta con más experiencia en el ambiente de operación (mayor cantidad de teorías exitosas en su base de conocimiento, como se puede observar en la gráfica 5.24), requiriendo generar una menor cantidad de teorías nuevas en comparación con el resto de los SARps (SICr y SMCr).

Esto sostiene la hipótesis que un SARr que actúa con una base de conocimiento de teorías exitosas mayor, por acción de la colaboración en combinación el intercambio y mutación, requiere generar menor cantidad de teorías nuevas para su actuación.

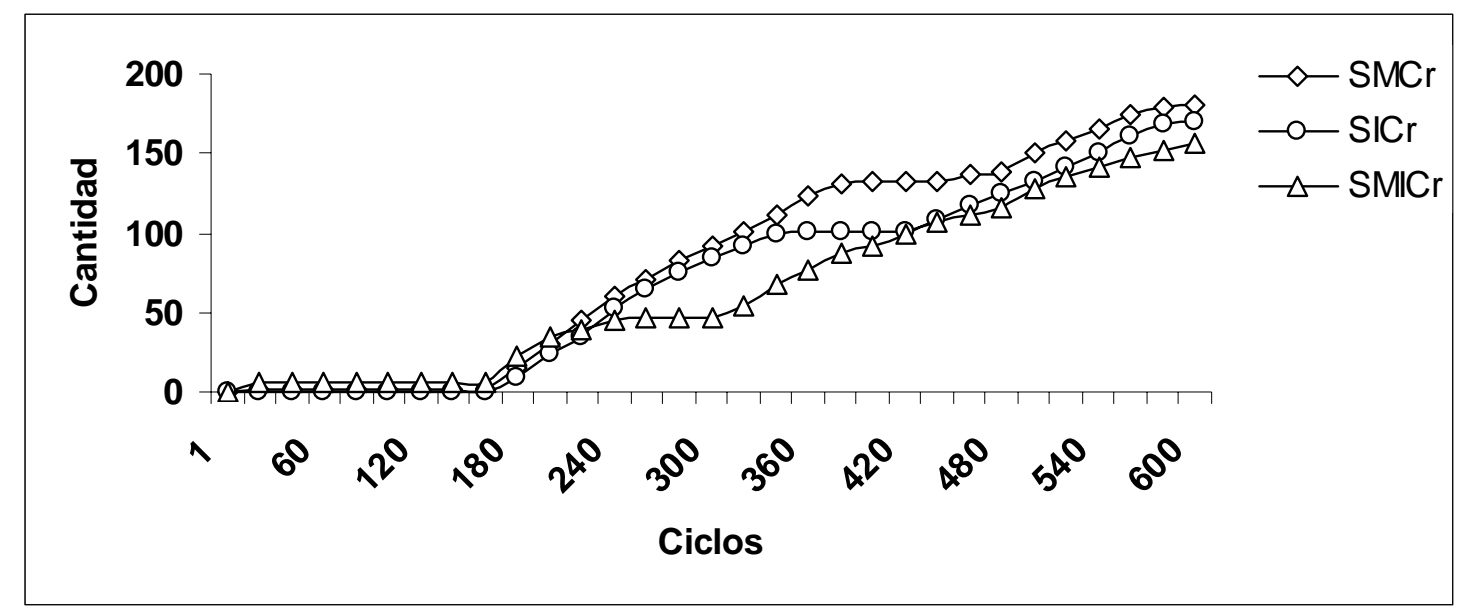

Gráfica 5.22 Cantidad de teorías nuevas para la configuración de SARr: SMICr, SMCr,SICr 


\subsection{Cantidad de planes exitosos a lo largo del tiempo}

En esta subsección se analizará la cantidad promedio de planes exitosos generados por los SARrs a lo largo del tiempo al aplicar las combinaciones de métodos, sobre la base de: un SARr configurado con los métodos de mutación, intercambio y colaboración (SMICr), un SARr configurado con mutación y colaboración (SMCr) y un SARr configurado con intercambio y colaboración (SICr), indicadas en la sección 5.3.2.2, segundo grupo de experimentación SARr.

Se observa en la gráfica 5.23 “Cantidad de planes exitosos”, que si bien la mayor cantidad promedio de planes exitosos a lo largo del tiempo le corresponden al SARr que aplicó el método de intercambio y colaboración (SICr), los resultados obtenidos para el resto de las combinaciones de métodos son similares al del SICr. Todos los SARrs conservan la tendencia ascendente en el crecimiento de planes exitosos.

Los SARrs con las combinaciones de SMCr y SMICr generan una cantidad muy similar de planes a los generados por la combinación SICr, por la acción de la mutación que se aplica sobre las teorías similares en la base de conocimiento. La combinación de métodos SICr facilita al SARr receptor contar con una base de teorías mayor producto del intercambio y de la colaboración recibida, esto le facilita a éste último una mayor generación de planes exitosos.

Finalmente se observa que la tendencia a lo largo del tiempo para todas las combinaciones de métodos es la misma, en razón que la arquitectura de ranking sólo planifica la acción del instante siguiente (un solo paso).

Esto sostiene la hipótesis de que SARr que actúa con una base de conocimiento de teorías exitosas mayor por acción de la colaboración en combinación con el intercambio, genera una mayor cantidad de planes exitosos.

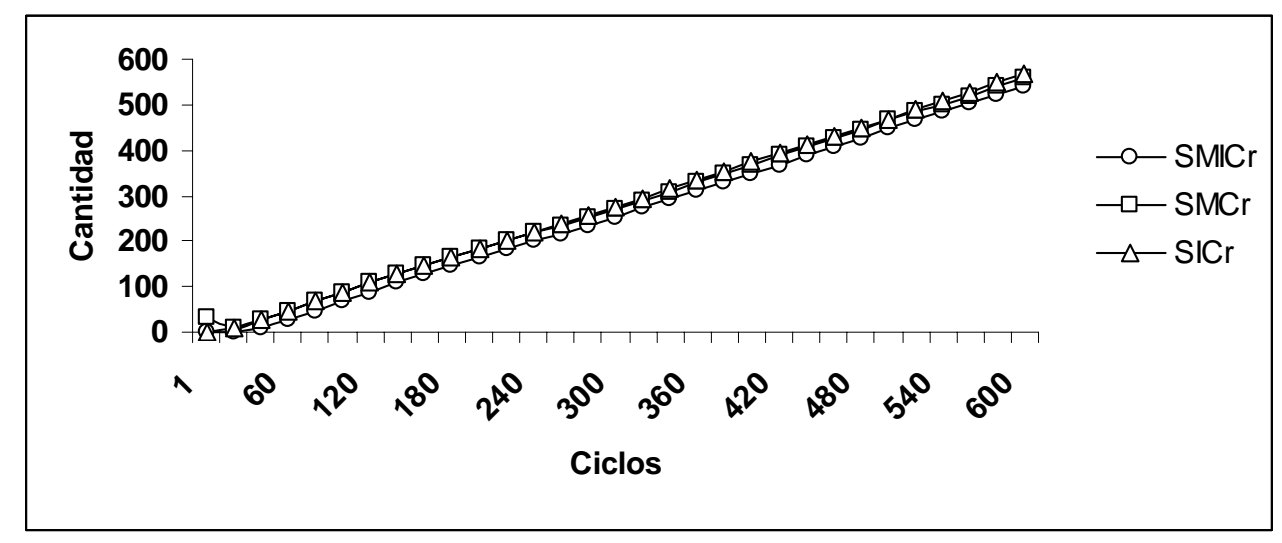

Gráfica 5.23 Cantidad de planes exitosos para la configuración de SARr: SMICr, SMCr,SICr 


\subsection{Cantidad de teorías exitosas a lo largo del tiempo}

En esta subsección se analizará la cantidad promedio de teorías exitosas generadas por los SARrs a lo largo del tiempo al aplicar las combinaciones de métodos, sobre la base de: un SARr configurado con los métodos de mutación, intercambio y colaboración (SMICr), un SARr configurado con mutación y colaboración (SMCr) y un SARr configurado con intercambio y colaboración (SICr), indicadas en la sección 5.3.2.2, segundo grupo de experimentación SARr.

Se observa en la gráfica 5.24 "Cantidad de teorías exitosas”, que el SARr que aplicó la combinación de métodos de mutación, intercambio y colaboración (SMICr) obtuvo la mayor cantidad de teorías exitosas, seguido por el SARp que aplicó intercambio y colaboración (SICr) y finalmente por el SARr que aplicó mutación y colaboración (SMCr).

Esto sostiene la hipótesis que la colaboración en combinación con el intercambio y la mutación, contribuye al crecimiento de la base de conocimientos de teorías del SARr, facilitando una mayor cantidad de teorías exitosas.

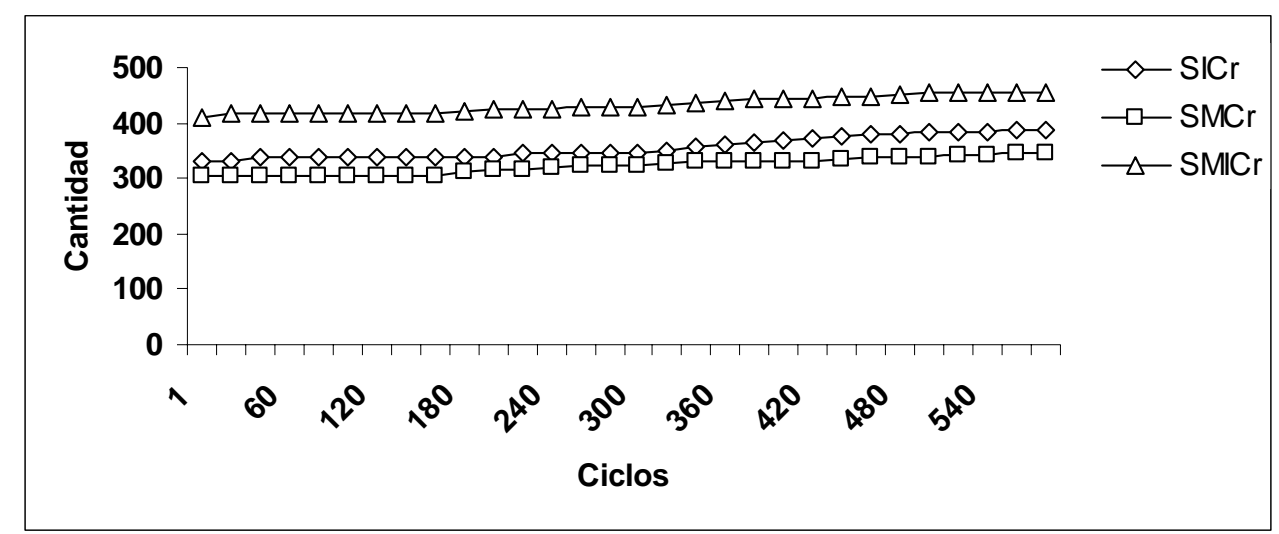

Gráfica 5.24 Cantidad de teorías exitosas para la configuración de SARr: SMICr, SMCr,SICr

\subsection{Ciclos exitosos a lo largo del tiempo}

En esta subsección se analizará el resultado de ciclos exitosos promedio generados por los SARrs a lo largo del tiempo al aplicar las configuraciones de métodos, sobre la base de: un SARr configurado con los métodos de mutación, intercambio y colaboración (SMICr), un SARr configurado con mutación y colaboración (SMCr) y un SARr configurado con intercambio y colaboración (SICr), indicadas en la sección 5.3.2.2, segundo grupo de experimentación SARr. 
Se observa en la gráfica 5.25. a "Cantidad de ciclos exitosos", que en la primera mitad de la experimentación los SARrs obtiene resultados similares, luego el SARr que aplica mutación, intercambio y colaboración (SMICr) genera la mayor cantidad promedio de ciclos exitosos, seguido con resultados similares por el SARr que aplica mutación y colaboración (SMCr), el que es superado en el último cuarto de la experimentación por el SARr que aplica intercambio y colaboración (SICr).El SARr que aplica mutación y colaboración (SMCr) en el cuarto final de la experimentación, muestra una tendencia a decrecer su cantidad de ciclos exitosos en comparación con los otros métodos que mantienen su tendencia de crecimiento en materia de cantidad de ciclos exitosos.

Se observa en la gráfica 5.25. b "Porcentaje de Ciclos Exitosos" que en la primer mitad de la experimentación los SARrs obtiene resultados similares, con un alto porcentaje promedio de ciclos exitosos, en el resto de la experimentación el SARr que aplica mutación, intercambio y colaboración (SMICr) obtiene el mayor porcentaje promedio, seguido durante el tercer cuarto de la experimentación por el SARr que aplica mutación y colaboración (SMCr) y con valores similares a éste último por el SARr que aplica intercambio y colaboración (SICr), el que en el último cuarto de la experimentación supera al SARr que aplica mutación y colaboración (SMCr). Finalmente se observa que los SARrs SMICr y SICr mantienen la tendencia del porcentaje de ciclos exitosos y el SARr SMCr, tiende a disminuir la tendencia del crecimiento del porcentaje de ciclos exitosos.

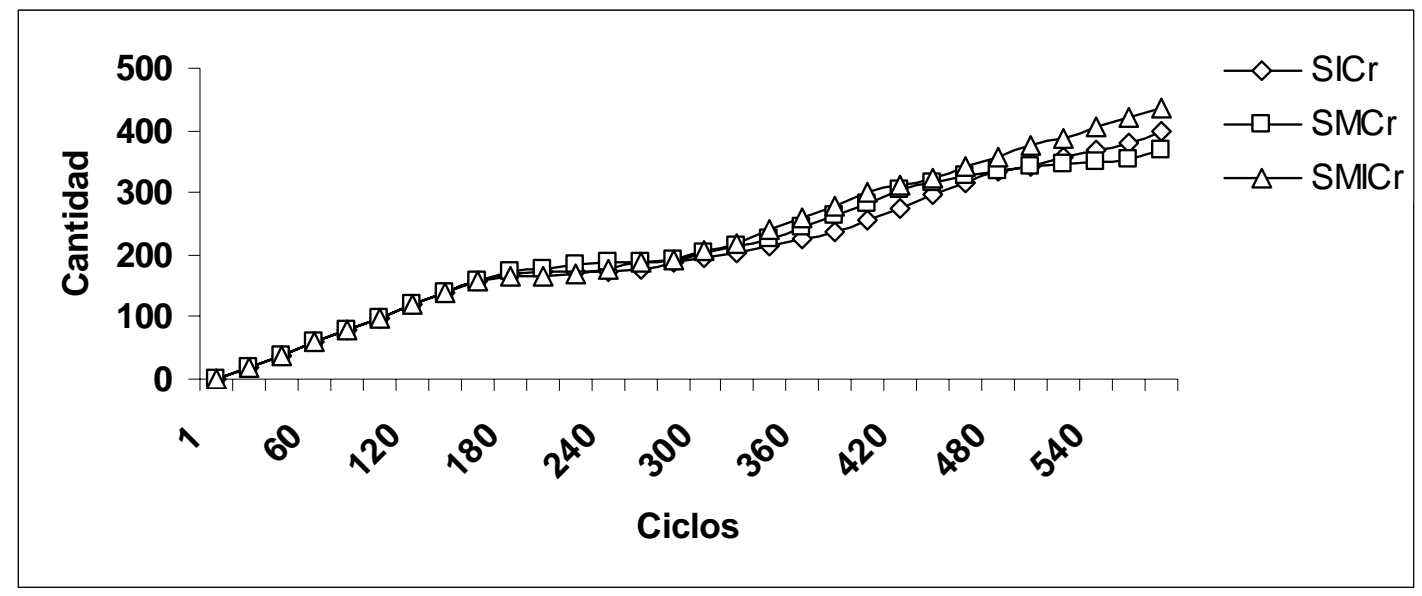

Gráfica 5.25a Cantidad de ciclos exitosos para la configuración de SARr: SMICr, SMCr,SICr 


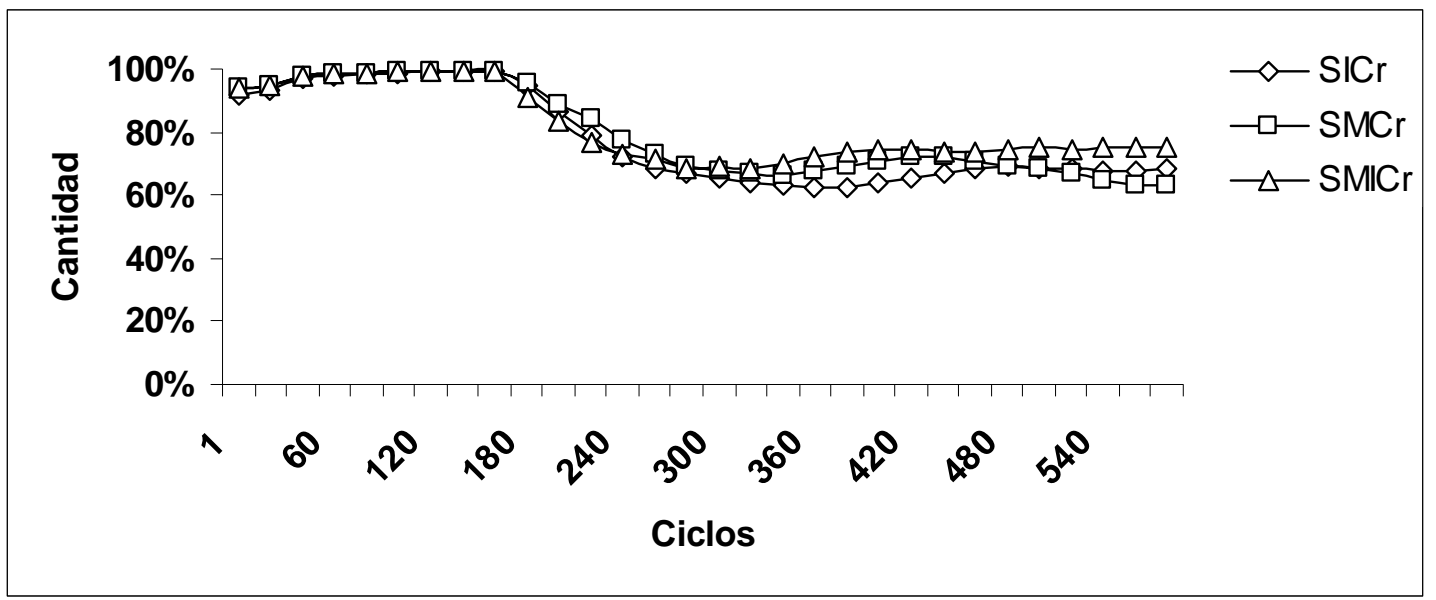

Gráfica 5.25b Porcentaje de ciclos exitosos para la configuración de SARr: SMICr, SMCr,SICr

Esto sostiene la hipótesis de que un SARr que combina colaboración, intercambio y mutación, obtiene un mayor porcentaje y una mayor cantidad de ciclos exitosos, sobre la base de que dispone de una mayor cantidad de teorías exitosas como se puede observar en las gráficas 6-25 a y 6-25 b respectivamente.

\subsection{Discusión de los resultados del segundo grupo de experimentación del SARr.}

De los resultados obtenidos del segundo grupo de experimentación se concluye que el SARr (SMICr) que aplicó la combinación de los métodos de intercambio, colaboración y mutación, en comparación con las configuraciones experimentadas en este grupo, produce una mayor aceleración en el aprendizaje de un SARr, aumentando el SAR receptor que aplicó colaboración combinado con mutación e intercambio (SMICr), la cantidad de: planes exitosos (similar en todos los casos), teorías exitosas, ciclos exitosos, y el porcentaje de ciclos exitosos.

Asimismo el SARr (SMICr), receptor generó una menor cantidad de teorías nuevas, en virtud de contar con una base de teorías exitosas más representativa que las aplicadas por las restantes combinaciones de métodos de los otros SARr comparados. La base de teorías del SARr (SMICr) es producto de la base de teorías del SARr SMICr que inicialmente se origina en el SARr A receptor, (born, al inicio del layer BIO) que efectuó intercambio con el SARr B (born en tránsito por el layer BIO), generando la base de teorías de intercambio entre SARr A-B (borns), sobre la cual el SARp B (newbie Layer TBO), aplicó colaboración, generando la base de teorías de intercambio-colaboración SARr A(born) - B(newbie), la que fue empleada durante la experimentación por el SARr E, (SMICr), aplicando el método de mutación sobre las teorías similares, sumando nuevas teorías a la base de teorías del SARr E, (SMICr). 
Finalmente se observó que, si bien la cantidad de situaciones tiende a estabilizarse, el SARr que combina colaboración con los métodos de mutación e intercambio (SMICr) continúa descubriendo nuevas relaciones entre situaciones (condiciones supuestas o efectos predichos), generando nuevas teorías, como se muestra en la gráfica 5.21.

\subsubsection{COMPARACIÓN DE LOS RESULTADOS OBTENIDOS POR AMBAS ARQUITECTURAS DE SISTEMAS AUTÓNOMOS DE ROBOTS (SARS)}

En esta sección se presenta la comparación entre las arquitecturas experimentadas de Sistema Autónomo de Robot con planificador (SARp) y la arquitectura de sistema autónomo de robot con ranking (SARr). La comparación entre ambas arquitecturas de sistemas autónomos de robots (SARs), se efectúa sobre la base del rendimiento obtenido en materia de cantidad promedio de ciclos exitosos ejecutados por cada SARs .

Se presentan los resultados de las comparaciones entre las arquitecturas en cinco gráficos, correspondientes a las siguientes variables independientes aplicadas por cada SAR: neutro en la subsección 5.3.3.1, colaboración en la subsección 5.3.2.2, mutación y colaboración en la subsección 5.3.2.3, intercambio, y colaboración en la subsección 5.3.2.4, mutación, intercambio y colaboración en la subsección 5.3.2.5.

Finalmente se presenta la discusión de los resultados de la comparación de rendimiento de ambas arquitecturas en la subsección 5.3.2.6.

\subsubsection{Cantidad de ciclos exitosos para SARs neutros.}

En esta subsección se analizará los resultados de ciclos exitosos promedio generados por el SARp neutro y el SARr neutro a lo largo del tiempo.

Se observa en la gráfica 5.26 “Cantidad de ciclos exitosos”, que el SARr, generó una mayor cantidad promedio de ciclos exitosos en comparación con el SARp. En el cuarto final de la experimentación, se observa que el SARr muestra una tendencia a amesetar el crecimiento de ciclos exitosos, a diferencia del SARp que muestra una tendencia de crecimiento. 


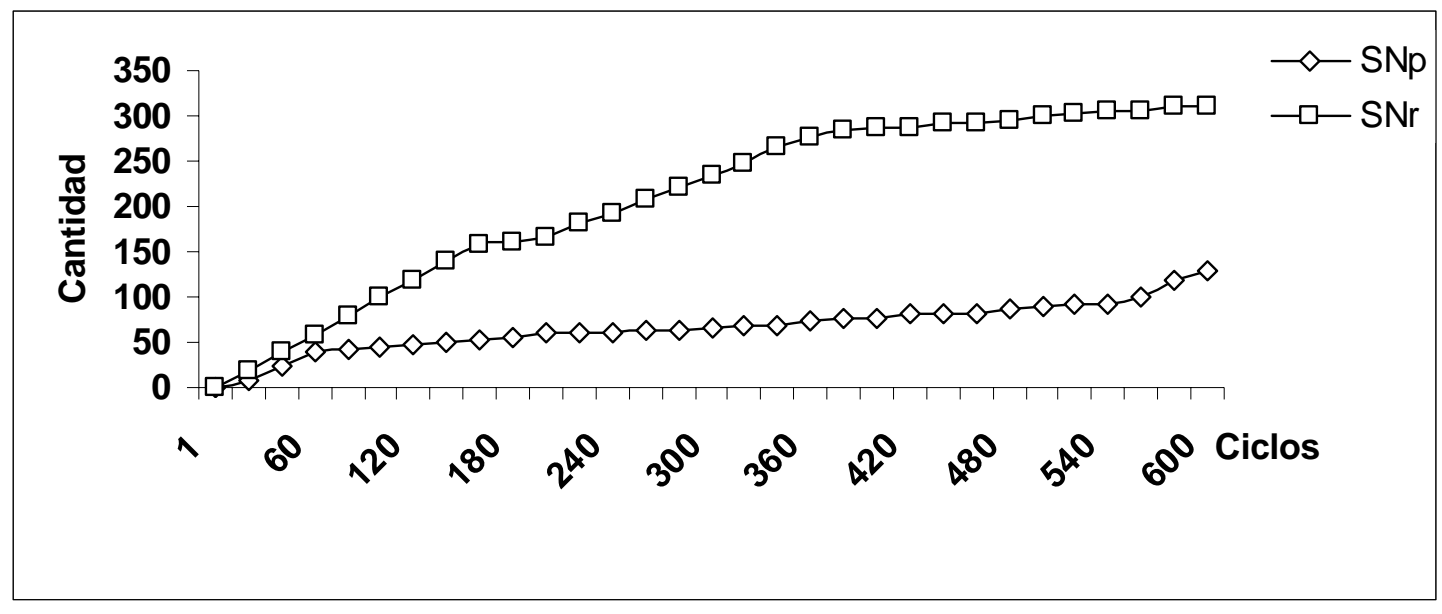

Gráfica 5.26 Cantidad de ciclos exitosos para la configuraciones de SARs: SNp y SNr

\subsubsection{Cantidad de ciclos exitosos para SARs que aplican colaboración.}

En esta subsección se analizará los resultados de ciclos exitosos promedio generados por el SARp y el SARr que aplican el método de colaboración a lo largo del tiempo.

Se observa en la gráfica 5.27 “Cantidad de ciclos exitosos”, que el SARr, generó una mayor cantidad promedio de ciclos exitosos en comparación con el SARp. En el cuarto final de la experimentación, se observa que el SARp muestra una tendencia a amesetar el crecimiento de ciclos exitosos, a diferencia del SARr que muestra una tendencia de crecimiento a lo largo del tiempo.

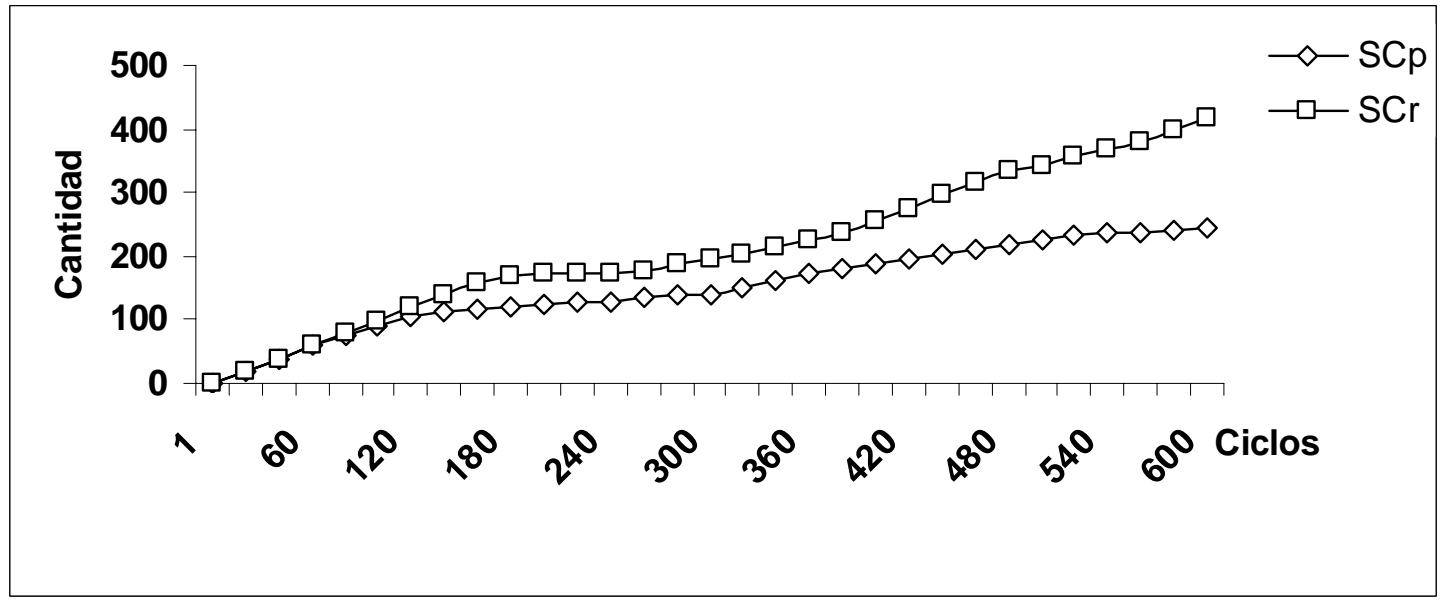

Gráfica 5.27 Cantidad de ciclos exitosos para la configuraciones de SARs: SCp y SCr 


\subsubsection{Cantidad de ciclos exitosos para SARs que aplican mutación y colaboración.}

En esta subsección se analizará los resultados de ciclos exitosos promedio generados a lo largo tiempo, por el SARp configurado con la combinación de métodos de ponderación de planes, mutación y colaboración (SPMC) y el SARr configurado con la combinación de los métodos de mutación y colaboración (SMCr).

Se observa en la gráfica 5.28 "Cantidad de ciclos exitosos”, que el SARr (SMCr), generó una mayor cantidad promedio de ciclos exitosos en comparación con el SARp (SPMCp). Ambos SARs sostienen su tendencia de crecimiento de ciclos exitosos a lo largo de la experimentación .

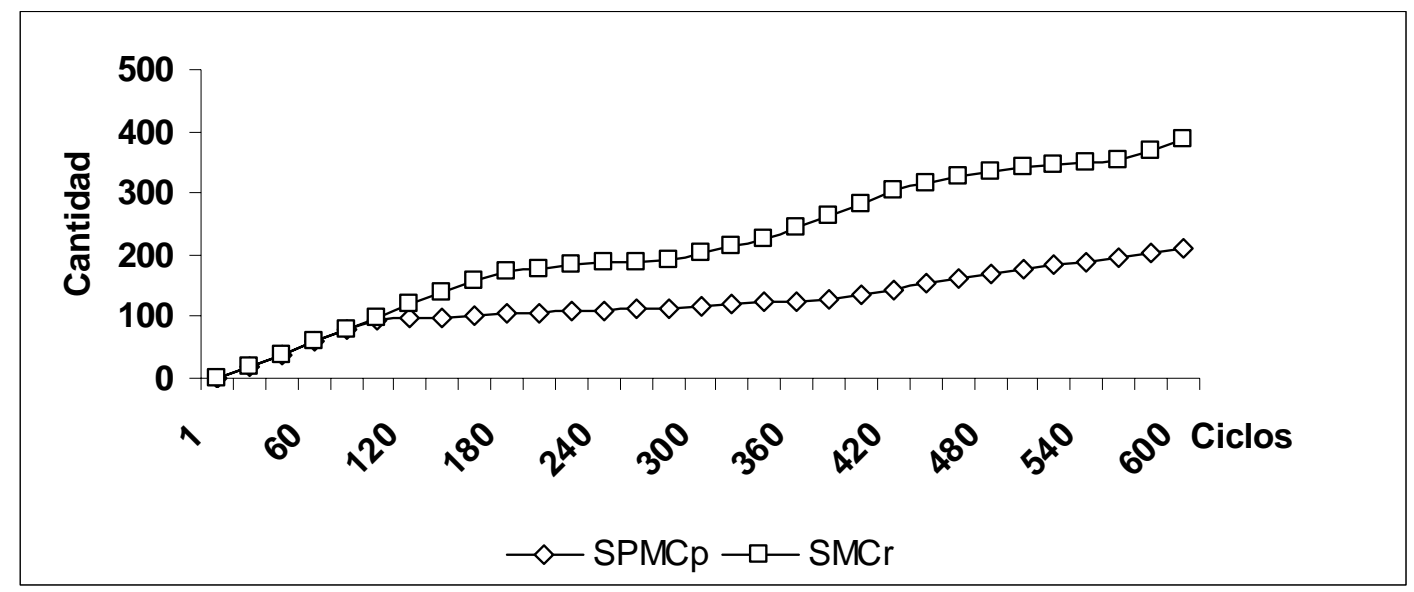

Gráfica 5.28 Cantidad de ciclos exitosos para la configuraciones de SARs: SPMCp y SMCr

\subsubsection{Cantidad de ciclos exitosos para SARs que aplican intercambio y colaboración.}

En esta subsección se analizarán los resultados de ciclos exitosos promedio generados a lo largo tiempo, por el SARp configurado con la combinación de métodos intercambio y colaboración (SICp) y el SARr, configurado con la combinación de los métodos de intercambio y colaboración (SICr).

Se observa en la gráfica 5.29 "Cantidad de ciclos exitosos”, que el SARr (SICr), generó una mayor cantidad promedio de ciclos exitosos en comparación con el SARp (SICp). En el cuarto final de la experimentación, se observa que el SARp muestra una tendencia a amesetar el crecimiento de ciclos exitosos, a diferencia del SARr que muestra una tendencia de crecimiento a lo largo del tiempo. 


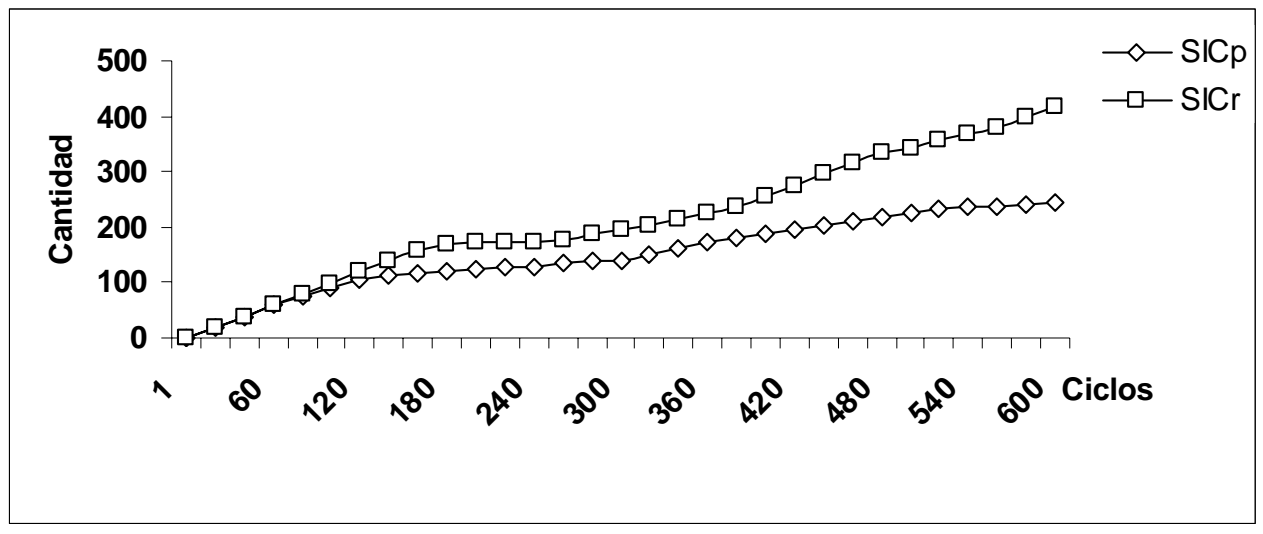

Gráfica 5.29 Cantidad de ciclos exitosos para la configuraciones de SARs: SICp y SICr

\subsubsection{Cantidad de ciclos exitosos para SARs que aplican mutación, intercambio y colaboración}

En esta subsección se analizarán los resultado de ciclos exitosos promedio generados a lo largo tiempo, por el SARp configurado con la combinación de métodos de ponderador, mutación, intercambio y colaboración (SPMICp) y el SARr configurado con la combinación de los métodos de mutación, intercambio y colaboración (SMICr).

Se observa en la gráfica 5.30 “Cantidad de ciclos exitosos”, que el SARr (SMICr), generó una mayor cantidad promedio de ciclos exitosos en comparación con el SARp (SPMICp). Ambos SARs sostienen su tendencia de crecimiento de ciclos exitosos a lo largo de la experimentación.

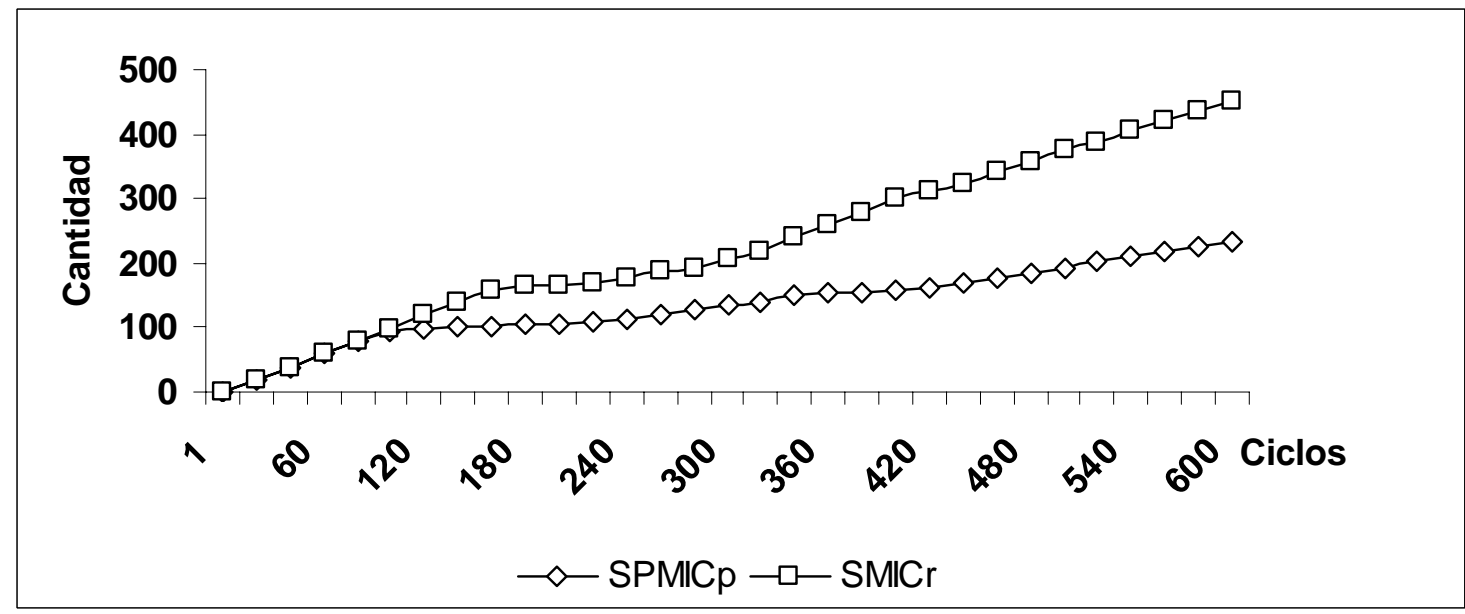

Gráfica 5.30 Cantidad de ciclos exitosos para la configuraciones de SARs: SPMICp y SMICr 


\subsubsection{Discusión de los resultados de la comparación de rendimiento de ambas arquitecturas (SARp y SARr)}

De los resultados obtenidos de la comparación de rendimiento sobre la base de la cantidad promedio de ciclos exitosos obtenidos a lo largo del tiempo de experimentación por parte del sistema autónomo de robot con planificador (SARp) y del sistema autónomo de robot con ranking (SARr), se concluye que el SARr obtuvo el mayor rendimiento en todas las configuraciones de métodos experimentadas.

Se observa que en ambas arquitecturas aplicando colaboración se obtiene una mayor cantidad de ciclos exitosos en comparación con la base de un SARp o SARr neutros, sin embargo la combinación de mutación y colaboración sostiene el crecimiento de la cantidad de ciclos exitosos a lo largo del tiempo en ambas arquitecturas evitando las tendencias de amesetamiento de ciclos exitosos. Finalmente los mejores resultados para ambas arquitectura surgen de la combinación de la colaboración con el intercambio y la mutación.

Esto sostiene la hipótesis de que con independencia de la arquitectura empleada la colaboración produce una mayor aceleración en el aprendizaje de un SAR, aumentando el SAR receptor su rendimiento en materia de cantidad de ciclos exitosos a lo largo del tiempo.

También se sostiene la hipótesis que la colaboración en combinación con los métodos de mutación e intercambio produce la mayor aceleración en el aprendizaje de un SAR, aumentando el SAR receptor su rendimiento en materia de cantidad de ciclos exitosos a lo largo del tiempo.

\subsubsection{RELACIÓN ENTRE CANTIDAD DE TEORÍAS, CANTIDAD DE PLANES Y CANTIDAD DE CICLOS CUANDO ÉSTOS SON EXITOSOS}

Se presentan para un SARp configurado con los métodos de SPMIC, los resultados alcanzados en materia de correlación (aplicando un análisis parametrito con coeficiente de correlación de Pearson) entre cantidad de planes exitosos (CPE) y cantidad de teorías exitosas (CTE) en la subsección 5.3.4.1, entre cantidad de ciclos exitosos (CCE) y cantidad teorías exitosas (CTE) en la subsección 5.3.4.2 y entre cantidad de planes exitosos (CPE) y cantidad de ciclos exitosos (CCE) en la subsección 5.3.4.3. Se presentan para un SARr configurado con los métodos de SMIC, los resultados alcanzados en materia de correlación entre cantidad de planes exitosos (CPE) y cantidad de teorías exitosas (CTE) en la subsección 5.3.4.4, entre cantidad de ciclos exitosos (CCE) y cantidad teorías exitosas (CTE) en la subsección 5.3.4.5 y entre cantidad de planes exitosos (CPE) y cantidad de ciclos exitosos (CCE) en la subsección 5.3.4.6, en la sección 5.3.4.7 se presenta un análisis complementario no paramétrico aplicando Spearman. 
Para ambos tipos de SARs se optó por la configuración más completa de métodos a fin de observar los resultados de la correlación en presencia de una mayor diversidad de métodos aplicados por el SAR. En este orden se realizó un análisis paramétrico bajo las pruebas estadísticas aplicando el coeficiente de correlación de Pearson " $r$ ” (prueba estadística para analizar la relación entre dos variables medidas en un nivel por intervalos o razón). Se aplicó este análisis en la relación entre los valores promedio de dos variables (CPE-CTE, CCE-CTE, CPE-CCE) medidas en intervalos de veinte ciclos. En todos los casos el coeficiente es significativo en 0,05 (95 \% de confianza en que la correlación es verdadera y $5 \%$ de probabilidad de error).Finalmente se determinó la varianza de factores comunes $\left(\boldsymbol{r}^{2}\right)$ con el objetivo de determinar el porcentaje de variación de una variable debido a la variación de la otra y viceversa. Para obtener los resultados de $\boldsymbol{r}$ y $\boldsymbol{r}^{2}$ se aplicó la herramienta XLSTAT 2010.5.02.

\subsubsection{Cantidad de Planes Exitosos (CPE) y Cantidad de Teorías Exitosas (CTE) para un SARp.}

El resultado de la correlación entre cantidad de planes exitosos (CPE) y cantidad de teorías exitosas (CTE) arrojó un valor del coeficiente de Pearson $\boldsymbol{r}=0,930$ lo que indica una correlación positiva muy fuerte entre CTE y CPE. El coeficiente es significativo al nivel de 0,05. El valor de la varianza de factores comunes es $\boldsymbol{r}^{2}=0,865$ (\% de variación de una variable debido a la variación de la otra variable y viceversa), la CTE constituye el 86\% de la variación de la CPE y viceversa. Se presenta en la gráfica 5-31 la representación obtenida a partir de ambas variables. Los resultados, sin considerar los pares de valores donde CTE se mantiene constante, son: Pearson $\boldsymbol{r}=0,933$ y $\boldsymbol{r}^{2}=0,870$, por lo que no se observan mayores diferencias. En la sección N8.1 del Anexo N “Soporte Digital” se adjuntan los resultados obtenidos.

Correlacion CPE-CTE

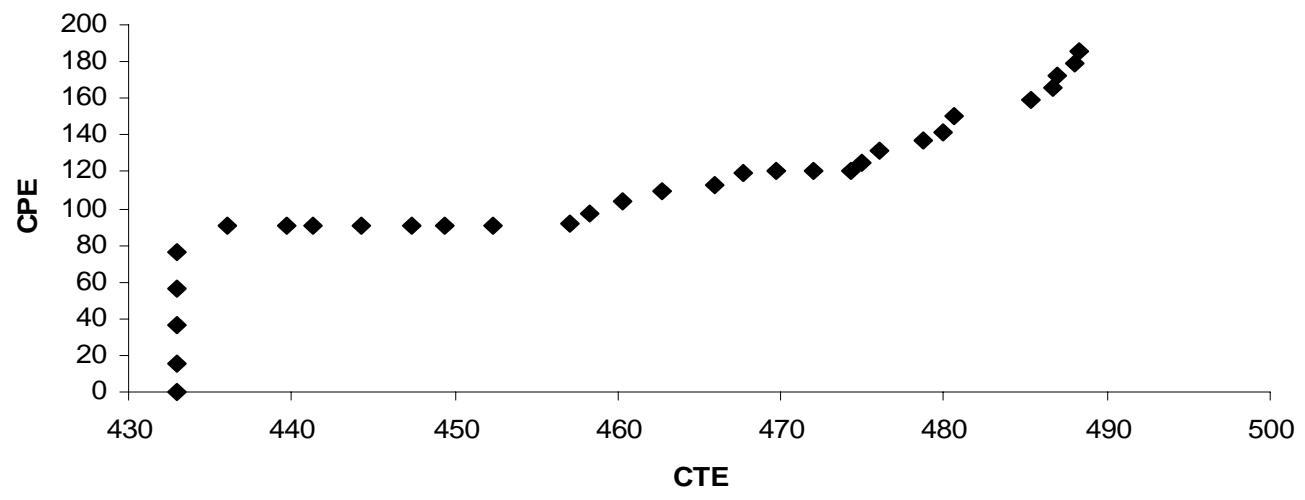

Gráfica 5.31 Relación entre cantidad de planes exitoso y cantidad de teorías exitosas. 


\subsubsection{Cantidad de Ciclos Exitosos (CCE) y Cantidad de Teorías Exitosas (CTE) para un SARp.}

El resultado de la correlación entre cantidad de ciclos exitosos (CCE) y cantidad de teorías exitosas (CTE) arrojó un valor del coeficiente de Pearson $\boldsymbol{r}=0,963$ lo que indica una correlación positiva muy fuerte entre CCE y CTE. El coeficiente es significativo al nivel de 0,05. El valor de la varianza de factores comunes es $r^{2}=0,927369$ (\% de variación de una variable debido a la variación de la otra variable y viceversa), la CTE constituye el 93\% de la variación de la CCE y viceversa. Se presenta en la gráfica 5-32 la representación obtenida a partir de ambas variables. Los resultados, sin considerar los pares de valores donde CTE se mantiene constante, son: Pearson $\boldsymbol{r}=0,965$ y $\boldsymbol{r}^{2}=0,932$, por lo que no se observan mayores diferencias. En la sección N8.2 del Anexo N “Soporte Digital” se adjuntan los resultados obtenidos.

Correlacion CCE-CTE

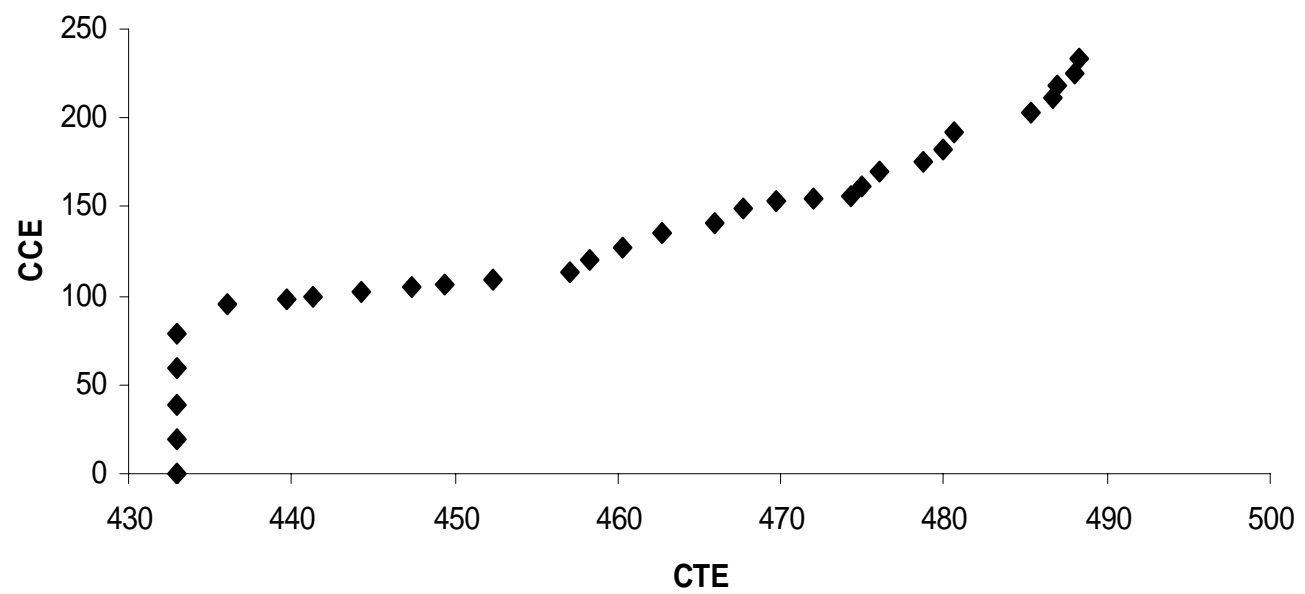

Gráfica 5.32 Relación entre cantidad de ciclos exitoso y cantidad de teorías exitosas

\subsubsection{Cantidad de Planes Exitosos (CPE) y Cantidad de Ciclos Exitosos (CCE) para un SARp.}

El resultado de la correlación entre cantidad de ciclos exitosos (CCE) y cantidad de planes exitosos (CPE) arrojó un valor del coeficiente de Pearson $\boldsymbol{r}=0,994$ lo que indica una correlación positiva muy fuerte entre CCE y CPE. El coeficiente es significativo al nivel de 0,05. El valor de la varianza de factores comunes es $\boldsymbol{r}^{2}=0,988036$ (\% de variación de una variable debido a la variación de la otra variable y viceversa), la CCE constituye el 99\% de la variación de la CPE y 
viceversa. Se presenta en la gráfica 5-33, la representación obtenida a partir de ambas variables. En la sección N-8.3 del Anexo N “Soporte Digital” se adjuntan los resultados obtenidos.

Correlación CPE-CCE

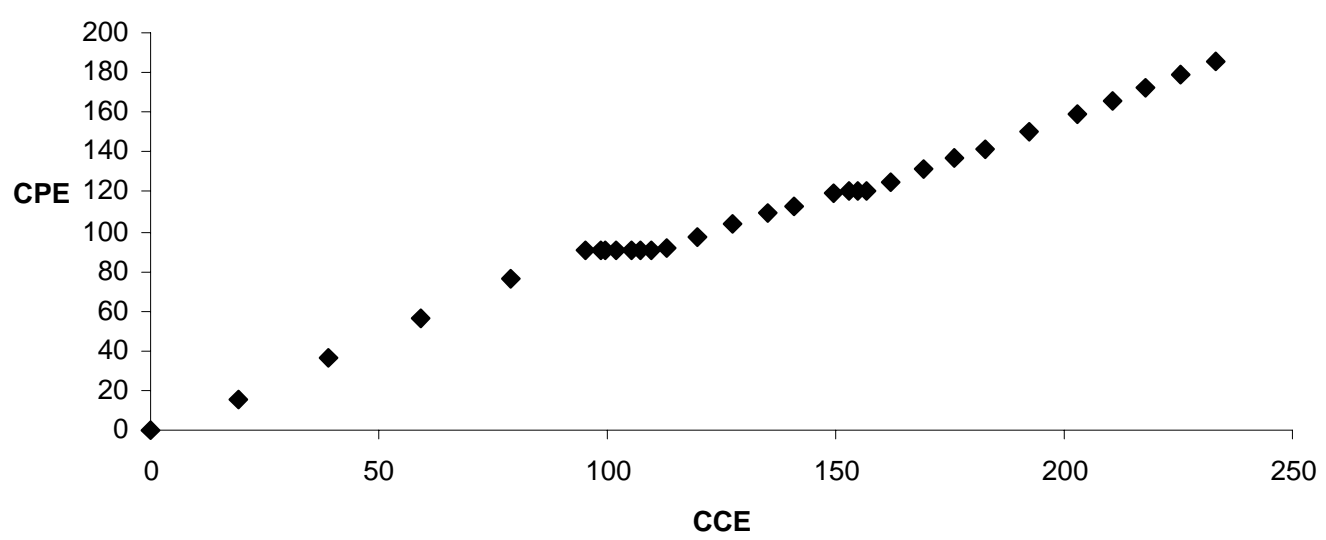

Gráfica 5.33 Relación entre cantidad de cantidad de planes exitosos y ciclos exitosos.

\subsubsection{Cantidad de Planes Exitosos (CPE) y de Cantidad Teorías Exitosas (CTE) para un SARr.}

El resultado de la correlación entre cantidad de planes exitosos (CPE) y cantidad de teorías exitosas (CTE) arrojó un valor del coeficiente de Pearson $\boldsymbol{r}=0,981$ lo que indica una correlación positiva muy fuerte entre CTE y CCE. El coeficiente es significativo al nivel de 0,05. El valor de la varianza de factores comunes es $\boldsymbol{r}^{2}=0,962361$ (\% de variación de una variable debido a la variación de la otra variable y viceversa), la CTE constituye el 96\% de la variación de la CPE y viceversa. Se presenta en la gráfica 5-34, la representación obtenida a partir de ambas variables. Los resultados, sin considerar los pares de valores donde CTE se mantiene constante, son: Pearson $\boldsymbol{r}=0,991$ y $\boldsymbol{r}^{2}=0,982$, por lo que no se observan mayores diferencias. En la sección N8.4 del Anexo N “Soporte Digital” se adjuntan los resultados obtenidos. 
Correlacion CTE-CPE

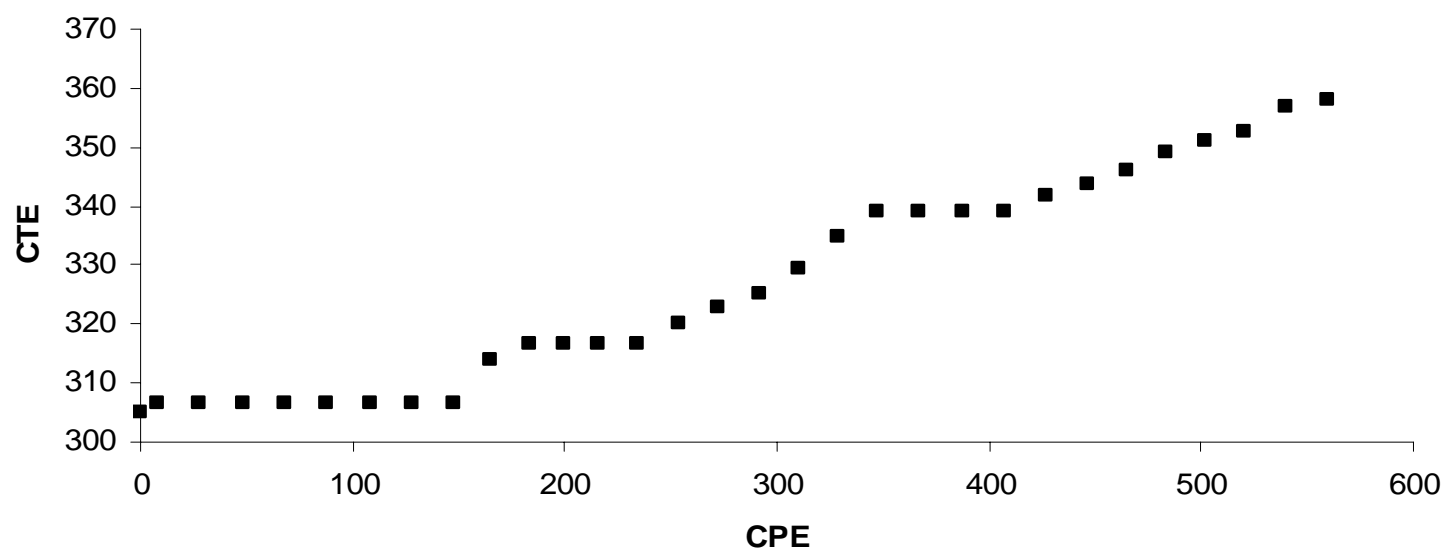

Gráfica 5.34 Relación entre cantidad de teorías exitosas y cantidad de planes exitosos.

\subsubsection{Cantidad de Ciclos Exitosos (CCE) y Cantidad de Teorías Exitosas (CTE) para un SARr.}

El resultado de la correlación entre cantidad de ciclos exitosos (CCE) y cantidad de teorías exitosas (CTE) arrojó un valor del coeficiente de Pearson $\boldsymbol{r}=0,957$ lo que indica una correlación positiva muy fuerte entre CTE y CCE. El coeficiente es significativo al nivel de 0,05. El valor de la varianza de factores comunes es $\boldsymbol{r}^{2}=0,915849$ (\% de variación de una variable debido a la variación de la otra variable y viceversa), la CTE constituye el 91\% de la variación de la CCE y viceversa. Se presenta en la gráfica 5-35, la representación obtenida a partir de ambas variables. Los resultados, sin considerar los pares de valores donde CTE se mantiene constante, son: Pearson $\boldsymbol{r}=0,964$ y $\boldsymbol{r}^{2}=0,929$, por lo que no se observan mayores diferencias. En la sección N8.5 del Anexo N “Soporte Digital” se adjuntan los resultados obtenidos.

\section{Correlacion CTE-CCE}

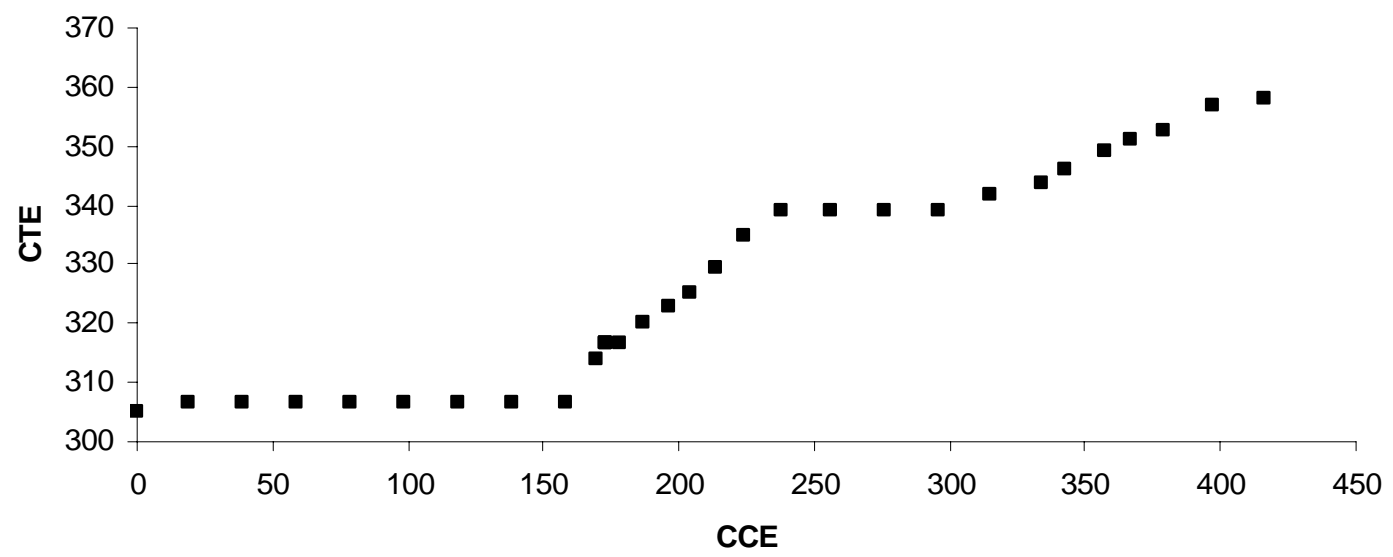

Gráfica 5.35 Relación entre cantidad de teorías exitosas y cantidad de ciclos exitosos 


\subsubsection{Cantidad de Planes Exitosos (CPE) y Cantidad de Ciclos Exitosos (CCE) para un SARr.}

El resultado de la correlación entre cantidad de ciclos exitosos (CCE) y cantidad de planes exitosos (CPE) arrojó un valor del coeficiente de Pearson $\boldsymbol{r}=0,99$ lo que indica una correlación positiva muy entre CCE y CPE. El coeficiente es significativo al nivel de 0,05. El valor de la varianza de factores comunes es $\boldsymbol{r}^{2}=0,9801$ (\% de variación de una variable debido a la variación de la otra variable y viceversa), la CCE constituye el 98\% de la variación de la CPE y viceversa. Se presenta en la gráfica 5-36, la representación obtenida a partir de ambas variables. En la sección N-8.6 del Anexo N “Soporte Digital” se adjuntan los resultados detallados obtenidos en las prueba de correlación aplicando la herramienta XLSTAT 2010.5.02.

\section{Correlación CCE-CPE}

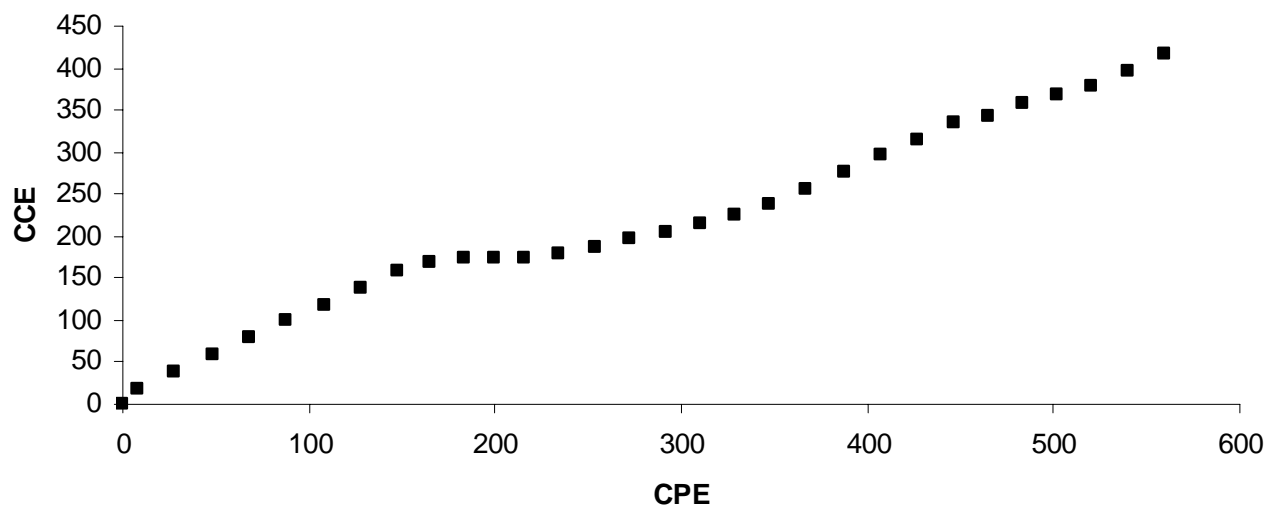

Gráfica 5.36 Relación entre cantidad de planes exitosos y cantidad de ciclos exitoso

\subsubsection{Pruebas complementarias}

En la sección N-8.7 del Anexo N "Soporte Digital” se adjuntan los resultados detallados obtenidos a través de un análisis no paramétrico aplicando la correlación de Spearman considerando las tres variables simultáneamente CTE-CPE-CCE. En comparación se obtuvieron resultados similares, si bien este último método arrojó valores ligeramente superiores para ambos SARs (Tabla 5.2 y Tabla 5.3), para una significación de alfa = 0,05.

\begin{tabular}{|c|c|c|c|c|c|c|c|}
\hline Variables & CTE & CPE & CCE & Variables & CTE & CPE & CCE \\
\hline CTE & 1 & 0,994 & 0,998 & CTE & 1 & 0,989 & 0,990 \\
\hline CPE & 0,994 & 1 & 0,996 & CPE & 0,989 & 1 & 1,000 \\
\hline CCE & 0,998 & 0,996 & 1 & CCE & 0,990 & 1,000 & 1 \\
\hline
\end{tabular}




\section{CONCLUSIONES}

En este capítulo se presentan las conclusiones del presente trabajo, destacándose los aportes de la propuesta de un modelo de ciclo de vida para el aprendizaje de Sistemas Autónomos de Robots, en la sección 6.1 y la propuesta de Sistema Autónomo de Robot en la sección 6.2. Finalmente se presentan las futuras líneas de investigación en la sección 6.3.

\subsection{PROPUESTA DE MODELO DE CICLO DE VIDA PARA EL APRENDIZAJE DE SISTEMAS AUTÓNOMOS DE ROBOTS}

En el marco del aporte que realiza la presente tesis en relación al modelo de ciclo de vida para sistemas autónomos de robots, se alcanzaron resultados que permitieron realizar:

(i) La presentación de un modelo de ciclo de vida de aprendizaje en el contexto de los Sistemas Autónomos de Robots, sobre la base del modelo de clásico de ciclo de vida en espiral de Bohem, B., (1988) y el modelo en espiral troncocónico de Alonso y colegas (1995) [Gómez, A., et al, 1997], incorporando la dimensión Z que representa, la evolución del conocimiento del Sistema Autónomo de Robot, en un modelo de ciclo de vida 3D.

(ii) La propuestas de estados de evolución del Sistema Autónomo de Robot (SAR), conformado por SAR born (nacido), SAR newbie (novato), SAR trained (entrenado), SAR mature (maduro), en función del rendimiento obtenido por el SAR en su actuación en el escenario del layer del ciclo de vida de aprendizaje que transita.

(iii) La determinación de las regiones y tareas asociadas en el marco del modelo de ciclo de vida de un Sistema Autónomo de Robot.

(iv) La determinación de estadísticas de aprendizaje y métricas asociadas del Sistema Autónomo de Robot en el marco del modelo de ciclo de vida de aprendizaje propuesto.

(v) La propuesta de un modelo y arquitectura para la actuación de múltiples Sistemas Autónomos de Robots (MultiSAR).

(vi) La extensión de los mecanismos de compartición de conocimientos propuesto por García Martínez et al, a la colaboración entre Sistemas Autónomos de Robots, incorporando la 
figura del SAR receptor y del SAR colaborador en el marco del ciclo de vida de aprendizaje propuesto, observando el nivel de evolución de SAR.

\subsection{PROPUESTA DE SISTEMA AUTÓNOMO DE ROBOT}

En el marco del aporte que realiza la presente tesis en relación a los Sistemas Autónomos de Robots (SARs), se alcanzaron resultados que permitieron realizar:

(i) La propuesta de una arquitectura de implementación del Sistema Autónomo de Robot aplicado en la plataforma de robot e-puck.

(ii) La propuesta y experimentación de un planificador por ranking de teorías aplicado para la actuación del Sistema Autónomo de Robot.

(iii) La propuesta y experimentación del método de utilidad de las teorías del Sistema Autónomo sobre la base de la acción del SAR o basado en coeficientes.

(iv) La propuesta y experimentación de un método de comparación de teorías, sobre la base de la comparación individual de cada uno de los sensores (IR-proximidad) y actuadores (ruedas) con un umbral individual determinado en el escenario de actuación, a diferencia de los métodos aplicados por autores anteriores en la presente línea de trabajo, que aplican un umbral fijo y general para todos los sensores.

(v) La ratificación experimental de que los Sistemas Autónomos de Robots (SARs) obtienen mejores resultados en su aprendizaje a través de la colaboración, considerando la comparación de resultados de experimentación del método de planificación clásica aplicada por los autores anteriores y el método propuesto basado en el ranking de teorías, a través del desarrollo de cinco grupos de experimentos, distribuidos en tres grupos de experimentos para la arquitectura que aplica el SARp y dos grupos de experimentos para la arquitectura que aplica el SARr.

(vi) La ratificación experimental del rendimiento de las arquitecturas de Sistemas Autónomos de Robots (SARs), en respuesta a las cuestiones planteadas en la subsección 3.5.2 del Capítulo 3 “Descripción del Problema”, a través de la comparación de los resultados obtenidos por el Sistema Autónomo de Robot con planificador clásico (SARp) y el Sistema Autónomo de Robot con planificador por ranking de teorías (SARr) en el marco del ciclo de vida de aprendizaje, permite concluir al respecto del rendimiento comparado que: 
(vi.a) El Sistema Autónomo de Robot con planificador por ranking (SARr), obtuvo el mayor rendimiento en función de la cantidad promedio de ciclos exitosos obtenidos a lo largo del tiempo de experimentación en todas las configuraciones de métodos experimentadas, en comparación con el Sistema Autónomo de Robot con planificador (SARp).

(vi.b) En ambas arquitecturas aplicando colaboración se obtiene una mayor cantidad de ciclos exitosos en comparación con la base de un SARp o SARr neutros, sin embargo la combinación de mutación y colaboración sostiene el crecimiento de la cantidad de ciclos exitosos a lo largo del tiempo en ambas arquitecturas evitando las tendencias de amesetamiento de ciclos exitosos.

(vi.c) Finalmente los mejores resultados para ambas arquitecturas surgen de la combinación de la colaboración con el intercambio y la mutación. Esto sostiene la hipótesis de que, con independencia de la arquitectura empleada, la colaboración produce una mayor aceleración en el aprendizaje de un Sistema Autónomo de Robot (SAR), aumentando el SAR receptor su rendimiento en materia de cantidad de ciclos exitosos a lo largo del tiempo.

A modo de ejemplo, las futuras aplicaciones reales de estos sistemas autónomos de robots permitirán que éstos eviten obstáculos en situaciones de rescate de víctimas de terremotos, compartiendo éstos sus teorías exitosas o recibiendo colaboración de un robot que se encuentra en un nivel superior en cuanto a su aprendizaje en la operación en este tipo de escenarios.

\subsection{FUTURAS LÍNEAS DE INVESTIGACIÓN}

Sobre la base de los resultados obtenidos, se plantean como líneas de trabajo de investigación:

(i) Extender los trabajos de la presente tesis en: el marco de la colaboración extra ambiente entre SARs, determinar los coeficientes de Braitenberg sobre la base de algoritmos genéticos en orden a la función de utilidad que aplica un SAR en un ambiente de operación y refinar las métricas orientadas a la evaluación de la evolución del SAR.

(ii) Continuar con las funcionalidades del framework para el intercambio de operadores (teorías), en el contexto del ciclo de vida de aprendizaje de Sistemas Autónomos, el que se implementó durante el proceso final de la presente tesis, en el marco del trabajo 
profesional de Milton Berman, Fernando Torres y Leonardo Yagi, dirigido por Jorge Ierache, 2009.

(iii) En función del modelo MultiSAR, explorar la compartición de conocimiento sobre un ambiente de web semántica, con la modelización de conocimiento a través de una ontología que represente al SAR en su actuación, aprendizaje y compartición de conocimientos, observando las propuestas preliminares de Ierache et al (2008 d), con el objeto de facilitar la búsqueda y el intercambio de teorías de actuación distribuidas de distintos SARs a través de Internet.

(iv) La valoración del comportamiento del Sistemas Autónomos de Robots (SAR) a través de bioseñales del observador humano [Ierache et al., 2009c], incorporadas en la estructura de las teorías de conocimiento del Sistema Autónomo de Robot.

(v) Aplicar las bases de la compartición de conocimiento entre Sistemas Autónomos de Robots (SAR), en un contexto de robótica colectiva, sobre la base de los trabajos de Marco Dorigo en materia de SWARM.BOTS, [Dorigo, M., et al , 2005)], [Trianniy, V., Dorigo, M., et al (2004).], [Tuci, E., Dorigo, M., et al (2005)].En estos trabajos, grupos de robots móviles pequeños llamados s-bots tienen la capacidad de organizarse unos con otros a través de la cooperación y coordinación en forma autónoma para la ejecución de tareas tales como el transporte de un objeto, decidiendo los robots cuándo necesitan o no ensamblarse unos con otros. Esta línea propone la compartición de teorías grupales para la movilidad y la habilidad de un robot para conectarse o agruparse físicamente y desconectarse con otro robot en un entorno de actuación de robótica colectiva. Se detalla en la Sección 4.2 del Anexo $\mathrm{N}$ un resumen de los trabajos de Marco Dorigo y colaboradores en materia de robótica colectiva basada en comportamiento de enjambre.

(vi) Aplicación de métodos difusos (Fuzzy) para la comparación de situaciones y acciones que conforman las teorías de los Sistemas Autónomos de Robots y la determinación de utilidad de la teoría que aplica un Sistema Autónomo de Robot, en su actuación en un escenario en particular. Esto aportaría una categorización de conjuntos borrosos para los sensores así también como para los motores de las ruedas y la utilidad de las teorías, tratando de rescatar teorías o reglas en el contexto del control borroso del robot. Se detalla en la sección 4.3 de Anexo N mayor información de la aplicación de lógica difusa.

(vii) Implementar la comunicación entre bases de conocimiento de Sistemas Autónomos de Robots (SAR) con el empleo de protocolos de aplicación estándar, tales como FIPA (Foundation for Intelligent Physical Agents) [FIPA., 2004]. 


\section{REFERENCIAS}

Bioloid (2009). “Bioloid Comprensive kit”, publicado en http://www.crustcrawler.com/products/ bioloid/index.php?prod=59, vigente marzo 2010.

Blaque, J., (1986). “La Mente como un Sistema Ecológico”. Mundo Informático. Vol 5 Número 122, pp 12-13, Bs. As. 1986.

Boehm B, (1986) "A Spiral Model of Software Development and Enhancement", ACM SIGSOFT Software Engineering Notes", "ACM", 11(4):14-24, August 1986.

Boehm B, (1988) "A Spiral Model of Software Development and Enhancement", Computer, volumen 21, $\mathrm{N}^{\circ}$ 5, pp 61-72.

Braitenberg, V. (1984). “Vehicles: Experiments in Synthetic Psychology”, MIT Press,Cambridge, MA.

Brooks, R.A. (1986). “Achieving Artificial Intelligence through Building Robots”, A.I Memo 898, MIT, AI Lab.

Brooks, R.A. (1987). "Planning is Just a Way of Avoiding Figuring Out What to Do Next", Working Paper 303, MIT AI Laboratory.

Brooks, R.A. (1990). “Elephants don't Play Chess”, In Designing Autonomous Agents: Theory and Practice form Biology to Engineering and Back, Patti Maes (Ed.), MIT Press, pp 3-15.

Brooks, R.A. (1991 a). “Intelligence without Representation, Artificial Intelligence”, Vol. 47, pp. 3-15.

Brooks, R.A. (1991 b). “ New Approaches to Robotics”, Science, Vol 253, pp 1227-1231.

CAFR 09. (2009) “Campeonato Argentino de Fútbol Robots”, publicado en http://www.cafr2009.com.ar/, vigente a marzo 2010. 
Cliff, D., Harvey, I., and Husbands, P., (1992). "Incremental Evolution of Neural Network Architectures for Adaptive Behaviour”, Tech. Rep. No. CSRP256, Brighton, School of Cognitive and Computing Sciences, University of Sussex, UK.

COM-BAT http://www.ns.umich.edu/htdocs/releases/story.php?id=6409,vigente a marzo 2010.

Cyberbotics Ltd., Olivier Michel, Fabien Rohrer, Nicolas Heiniger and wikibooks (2009) “Contributors”, vigente marzo 2010, publicado en: http://en.wikibooks.org/wiki/ Image:Cyberbotics'_Robot_Curriculum.pdf.

Davis, A., y Sitaram, P., (1994). “A Concurrent Process Model for Software Development”, software engineering notes, ACM Press, Volumen 19, N² 2, pp 38-51, 1994.

Dorigo., M (2010). Publicado en http://www.swarm-bots.org/ y en http://iridia.ulb.ac.be/ mdorigo/HomePageDorigo/publicationsbyyear.php , vigente a septiembre 2010.

Dorigo., M., (2005). “Swarm-bot: an experiment in swarm robotics” IRIDIA Universit_e Libre de Bruxelles, Bruxelles, Belgium. Institute of Cognitive Sciences and Technologies - CNR, Roma, Italy.

Eiter, T., Gottlob, G., (1992). “On The Complexity of Propositional Knowledge Base Revision, Updates and Counterfactuals”. Volumen 57.pp 227-270. Elseiver. 1992.

E-Puck, (2010) “Robot e-puck”, publicado en web: http://www.e-puck.org/ página vigente al 01/04/2010.

Falkenhaimer, B., (1990). “A Unified Approach to Explanation and Theory Formation”. En Computational Models of Scientific Discovery and Theory Formation. Shrager, J.Y Langley, P. (Editores). Morgan Kaufman. 1990.

Falkenhaimer, B., Rajamoney, S., (1988). “The interdependencies of Theory Formation, Revision, and Experimentation”. Fifth International Conference on Machine Learning. Ann Harbour. 1988.

Farid Fleifel Tapia, (2002). “Robots Autónomos y Aprendizaje por Refuerzo” publicado en http://www.fleifel.net/ia/robotsyaprendizaje.php, página vigente al 01/04/2010. 
Fink, W., Tarbell, M., "Multi-rover testbed for teleconducted and autonomous surveillance, reconnaissance, and exploration”. Proceedings of Space Exploration Technologies II, Volume: 7331, ISBN: 9780819475978, 2009.

FIRA. (2010). "Federation of International Robot-Soccer Association" publicado en http://www.fira.net/, vigente a marzo 2010.

FIPA. (2004). “Foundation for Intelligent Physical Agents” publicado en http://www.fipa.org vigente a septiembre 2010.

Floreano. D., Mondada, F., (1998). “Evolutionary Neurocontrollers for Autonomous Mobile Robots”, Neural Networks, Vol. 11, pp 1461-1478.

Fritz, W. (1984). “The Intelligent System.” SIGART Newsletter, 90: 34-38. ISSN 0163-5719.

Fritz, W. (1992). “World view and learning systems”. Robotics and Autonomous Systems 10(1): 17. ISSN 0921-8890.

Fritz, W., García Martínez, R., Marsiglio, A (1990). “Sistemas Inteligentes Artificiales”, C.E.I.L.P. La Plata, 1990.

Fritz, W., García Martínez, R., Rama, A., Blanqué, J., Adobatti, R. y Sarno, M.(1989). “The Autonomous Intelligent System”. Robotics and Autonomous Systems, 5(2):109-125. ISSN 0921-8890.

García Martínez, R. (1991a) “Un método de Aprendizaje por ajuste de Coeficientes en Sistemas Inteligentes Artificiales”. Anales del II Simposio de Inteligencia Artificial y Robótica. Buenos Aires. 1991.

García Martínez, R. (1991b). “Heurísticas de Ajustes de Unidades de Experiencia para Sistemas Inteligentes Artificiales”. Producción Científica del Programa IDEIA, pp 20-29. Departamento de Ciencias y Técnica. Universidad de Luján. 1991.

García Martínez, R. (1992a). “Aprendizaje Automático no Supervisado”. Cuaderno № 4. Secretaría de Ciencias y Técnica. Universidad de Luján. 1992.

García Martínez, R. (1992b). “Aprendizaje Automático por interacción con el entorno”. Cuaderno No 4.Anales de las II Jornadas de Pesquisa de USFM. Pagina 594. Universidad Federal de Santa María. Río Grande do Sul. Brasil. 1992 
García Martínez, R. (1993a). “Aprendizaje Automático basado en Método Heurístico de Formación y Ponderación de Teorías”. Revista Tecnológica. Brasil. Volumen 15, pp 159-182. 1993.

García Martínez, R. (1993b). “Ponderación de Planes a partir de Teorías del efecto de las acciones”. Anales del Primer Congreso Internacional de Informática, Computación y Teleinformática, pp 164-170. Editorial Excelencia. Mendoza. 1993.

García Martínez, R. y Borrajo, D. (1997). “Planning, Learning and Executing in Autonomous Systems”. Lecture Notes in Artificial Intelligence 1348: 208-210. ISBN 978-3-54063912-1.

García Martínez, R. y Borrajo, D. (2000). “An Integrated Approach of Learning, Planning and Executing”. Journal of Intelligent and Robotic Systems 29(1): 47-78. ISSN 0921-0296.

García-Martínez, R., Borrajo, D., Britos, P. y Maceri, P. (2006). “Learning by Knowledge Sharing in Autonomous Intelligent Systems”. Lecture Notes in Artificial Intelligence, 4140: 128-137. ISBN 978-3-540-45462-5.

Giunchicilia, F., Walsh, T., (1992). “A Theory of Abstraction”. Volumen 57 , pp 323-389. Elseiver. 1992.

Gómez, A., Jurista, N., Montes, C., Pazos, J., (1997) “Ingeniería del Conocimiento”, pp 26-31, Editorial Centro de Altos Estudios Ramón Areces, S.A, Madrid, ISBN 84-8004-269-9, 1997.

R. Groß and M. Dorigo. “Towards Group Transport by Swarms of Robots”. International Journal of Bio-Inspired Computation, 1(1-2):1-13, 2009.

Gruber T. R. (1993). “A Translation Approach to Portable Ontology Specifications”. Knowledge Acquisition, 5:199-220.

Haas, H., Brown, A., (2004). “Web Services Glossary”, Disponible en: http://www.w3.org/TR/wsgloss/, vigente 01/04/2010

Haraguchi, R., Osuka, K., Makita, S., Tadokoro, S., (2005) “The Development of the Mobile Inspection Robot for Rescue Activity”, MOIRA2 Advanced Robotics,. ICAR '05. Proceedings, 12th International Conference on, 2005. 
Hayes-Roth, F. (1983), Using Proofs and Refutations to Learn from Experience. En Machine Learning: The Artificial Intelligence Approach Volumen I editado por Carbonell J., Michalski R. \& Mitcehll T. Morgan Kaufmann. 1983.

Hiton, G., Nowlan, S. (1987) “How Learning can Guide Evolution”, Complex Systems, Vol. 1 ,pp. 495-502.

Huosheng Hu, Jindong Liu, Ian Dukes and George Francis (2006) . “Design of 3D Swim Patterns for Autonomous Robotic Fish”. Proceedings of the 2006 IEEE/RSJ International Conference on Intelligent Robots and Systems October 9 - 15, 2006, Beijing, China

Husbands, P., Harvey, I., Cliff, D. and Miller, G. (1994), “The Use of Genetic Algorithms for the Development of Sensorimotor Control Systems”, P Gaussier and J-D, Nicoud (Eds.), From Perception to Action, IEEE Computer Society Press, los Alamitos CA, pp 110121.

Ierache, J., García-Martínez, R., De Giusti, A. (2008a), “Learning Life-Cycle in Autonomous Intelligent Systems”. Artificial Intelligence in Theory and Practice II, ed. M. Bramer, (Boston: Springer), pp 451- 455, ISSN 1571-5736.

Ierache, J., Naiouf, M., García Martínez, R., De Giusti, A. (2008b). “Un Modelo de Arquitectura para el Aprendizaje y Compartición de Conocimiento entre Sistemas Inteligentes Autónomos Distribuidos”. Proceedings VII Jornadas Iberoamericanas de Ingeniería de Software e Ingeniería del Conocimiento. Pág. 179-187. ISSN 1390-292X.

Ierache, J., Dittler, M. (2008c). “Sistemas Autónomos de Programación Abierta a partir de Juguetes Bípedos en el contexto de Fútbol de Robots”, Anales del V Workshop de Inteligencia Artificial aplicada a la robótica móvil, Universidad Nacional del Comahue, Pág 105-111, ISBN: 978-987-604-100-3.

Ierache, J., Bruno, M García-Martínez, R. (2008d). “Ontología para el aprendizaje y compartición de conocimientos entre sistemas autónomos”. XIV Congreso Argentino de Ciencias de la Computación 6 al 10 octubre CACIC 2008, Universidad Nacional de Chilecito, ISBN 978.987-24511-0-2

Ierache, J., García-Martínez, R., De Giusti, A. (2009a). “A Proposal of Autonomous Robotic Systems Educative Environment”. Communications in Computer and Information 
Science 44: 224-231. Springer-Verlag Berlin Heidelberg. ISSN 1865-0929 / ISBN: 978-3-642-03985-0.

Ierache, J., García Martínez, R. (2009b). “Aprendizaje y Compartición de Conocimientos entre Sistemas Inteligentes Autónomos”. Proceedings XI Workshop de Investigadores en Ciencias de la Computación. Pág. 580-583. ISBN 978-950-605-570-7.

Ierache, J., Dittler M., Pereira G., García Martínez R.(2009c). “Robot Control on the basis of Bioelectrical Signals”. XVI Congreso Argentino de Ciencias de la Computación 5 al 9 octubre CACIC 2009, Universidad Nacional de Jujuy, Facultad de Ingeniería, ISBN 978-897-24068-3-9 ,pag 30.

Ierache, J., García-Martínez, R., De Giusti, A. (2010), Learning by Collaboration in Intelligent Autonomous Systems”. IFIP Advances in Information and Communication Technology, Artificial Intelligence in Theory and Practice III, ed. M. Bramer, (Boston: Springer), Volume 331/2010, 143-152, DOI: 10.1007/978-3-642-15286-3_14

I-SWARM, (2009). “Intelligent Small-World Autonomous Robots for Micro-manipulation”, (ISWARM), publicado en: http://www.i-swarm.org vigente a marzo 2010.

Khepera III, 2010. “Robot khepera-III”, publicado en: http://www.k-team.com/mobile-roboticsproducts/khepera-iii, vigente marzo 2010.

Kodjabachian, J., Meyer, J-A., (1995). “Evolution and Development of Control Architectures in Animats”, Robotics and Autonomous Systems, Vol 16, pp. 161-182.

Kube, C.R., Zhang., H., (2004). “Collective Robotics: From Social Insects to Robots”, Adaptive Behavior, Vol. 2, 189-218

Kube, C.R. , Bonadeau, E. (2000), “ Cooperative Transport by Ants and Robots”, Robotics and Autonomous Systems, Vol. 30. 85-101.

Lespérance, Y., (1991). “A Formal Theory of Indexical Knowledge and Action”. Technical Report CSRI-248. Computer Systems Research Institute. Universidad de Toronto. 1991

Lin, F., y Shoham, Y., (1991). “Probably Correct Theories of Action”. Proceedings Ninth National Conference on Artificial Intelligence, pp 349-354. AAAI Press. Menlo Park. 1991. 
Maceri, P. y García Martínez, R.2001. “Learning Planning Operators in Autonomous Intelligent Systems”. Proceedings del VII Congreso Internacional de Ingeniería Informática. Pág. 611-620. ISBN 987-98197-0-5.

Mataric, M. J. (1992). “Behavior-Based Systems: Main Properties and Implications”, Proceedings of IEEE International Conference on Robotics and Automation, Workshop on Architectures for Intelligent Control Systems, Nice, France, pp. 46-54.

Minsky, M., (1986). “Society of Mind”, New York: Simon and Schuster, 1986.

Mondada, F., Bonani, M., Raemy, X., Pugh, J., Cianci, C., Klaptocz, A., Magnenat, S., Zufferey, J.C., Floreano, D. and Martinoli, A. (2009) “The e-puck, a Robot Designed for Education in Engineering”. Proceedings of the 9th Conference on Autonomous Robot Systems and Competitions, 1(1) pp. 59-65

NXT MINDSTORMS,(2010). “Lego Mindstorms NXT”, publicado en http://mindstorms.lego. com/en-us/Default.aspx, vigente marzo 2010.

Protégé, (2010), “The Protégé Project”., Diponible en Web: http://protege.stanford.edu. Página vigente al 01/04/10.

Pulvermacher M., Stoutenburg S., Semy, S. (2004). "Netcentric Semantic Linking: An Approach for Enterprise Semantic Interoperability”, MITRE Technical Report.

RAE,(2010a).http://buscon.rae.es/draeI/SrvltConsulta?TIPO_BUS=3\&LEMA=cooperación, vigente a marzo de 2010

RAE,(2010b).http://buscon.rae.es/draeI/SrvltConsulta?TIPO_BUS=3\&LEMA=colaboración ,vigente a marzo de 2010

RCX MINDSTORMS,(2010). “Lego Mindstorms RCX”, publicado en http:/www.lego.com/ eng/education/mindstorms/home.asp?pagename=rcx, vigente a marzo 2010.

RoboCup. 2010 "RoboCup World Championship and Conference" publicado en http://www.robocup.org/, vigente marzo 2010

Russell, S., Wefald, E., (1991), “Do the Right Thing”, Cambridge, MA: MIT Press, 1991. 
Santos, J., Richard J. Duro.(2005). “Evolución Artificial y Robótica Autónoma”, pp 2-36, Edición Original publicada por RA-MA Editorial MADRID, España Alfaomega. Grupo Editor, México, 2005, .ISBN 84-7897-631-0.

Seyfried, J., Szymanski, M., Bender, N., Estaña, R., Thiel, M., and Wörn, H., (2005) “The ISWARM Project”: Intelligent Small World Autonomous Robots for Micro-manipulation, pp 70-83 Swarm Robotics, Lecture Notes in Computer Science, Volume 3342/2005, Springer Berlin / Heidelberg, ISBN 978-3-540-24296-3

Shen, W. (1989). "Learning from the Environment Based on Actions and Percepts". Tesis Doctoral. Universidad Carnegie Mellon. 1989.

Shen, W., Simon, H. (1989) "Rule Creation and Rule Learning Through Environmental Exploration”. Proceedings of the Eleventh International Joint Conference on Artificial Intelligence. Pág. 675-680. Morgan Kauffman. 1989

Simon, H., (1969) The sciences of the artificial ( $1^{\text {st }}$ ed). Cambridge, MA: MIT Press.

STARMAC, (2008). "Stanford Testbed of Autonomous Rotorcraft for Multi-Agent”, publicado en http://www.wired.com/dangerroom/2008/07/video-unmanned/, vigente a marzo 2010.

Suton, R., (1984). “Temporal Credit Assignment in Reinforcement Learning”. Ph. D. Dissertation. Graduate School of the University of Massachusetts. 1984.

Suton, R., (1990). “Integrated Architecture for Learning, Planning, and Reacting Based”. Proceedings of the Seventh International Conference on Machine Learning pp 214-224. Kaufman. 1990.

Suton, R., (1992). “Machine Learning: Special Issue on Reinforcement Learning”. Volumen 9. Números 3/4. Kluwer Academic Publishers. 1992.

Trianniy,V.,.Nol, S., Dorigo., M., (2004). “Cooperative Hole Avoidance in a Swarm-bot” IRIDIA Universit_e Libre de Bruxelles, Bruxelles, Belgium. Institute of Cognitive Sciences and Technologies - CNR, Roma, Italy.

Tuci, E., Roderich, G., Trianni, V., Mondada, F., Bonani, M., and Dorigo, M., Trianniy, V., Nol., S., (2005). "Cooperation through self-assembling in multi-robot systems" IRIDIA 
Universit_e Libre de Bruxelles, Bruxelles, Belgium. Institute of Cognitive Sciences and Technologies - CNR, Roma, Italy.

University of Essex (2010). “Department of Computer Science”, University of Essex, publicado en: http://cswww.essex.ac.uk/staff/hhu/HCR-Group.html, vigente a marzo 2010

W3C, (2010). "Web Ontology working group”, publicado en web: http://www.w3.org/ 2001/sw/WebOnt/, página vigente a abril 2010.

Walter, G., (1953). “The Living Brain”, Norton, New York.

Webots, (2009). “Simulador Webots”, publicado en: http://www.cyberbotics.com/, vigente marzo 2009.

Whitehead, S., Ballard, D (1991). “Learning to Perceive and Act by Trial and Error”. Machine Learning. Volumen 7. pp 45-83. Kluwer Academic Publishers. 1991.

Wright, C., Johnson, A., Peck,A., McCord, Z., Naaktgeboren,A., Gianfortoni, P., González-Rivero, M., Hatton, R., and Choset, H., (2007). "Design of a Modular Snake Robot" Proceedings of the 2007 IEEE/RSJ International Conference on Intelligent Robots and Systems San Diego, CA, USA, 2007

Zamo L, Ierache J, (2009). “Prototipo de Robot Cuadrúpedo, Descripción y Aplicaciones”, pp 3441. Anales del VII Campeonato de Fútbol de Robots y Workshop de Sistemas Autónomos de Robots. CAFR-2009 ISBN: 978-950-9474-45-1, 2009- Universidad de Morón, FICCTE 


\section{ANEXO A: ONTOLOGÍA DEL SAR}

La modelización preliminar de la Ontología del SAR que representa a un sistema autónomo inteligente (AIS), se detalla en la sección A-1, sobre la base de los principales conceptos World, SARs, este último se representa a través de: AISs, Environment, KnowledgeBody, SensorsArchitecture, EffectorsArchitecture, discutidos en la subsección 4.3.2 del Capítulo 4. Se presenta en esta sección una breve descripción de las distintas herramientas en el contexto de PROTEGE, [Protégé, 2010], las que se aplicaron para la modelización de la ontología del Sistema Autónomo Inteligente (AIS), representado por sistemas autónomos de robots (SAR). En la sección A-2, se efectúan consideraciones generales en el marco de un Semantic Web Services, [W3C, 2010], para la interoperabilidad semántica entre SARs, en apoyo a futuras líneas de investigación, en la Sección N-5 del Anexo N "Soporte Digital" se presentan los códigos obtenidos con la herramienta PROTÉGÉ sobre la base de la ontología preliminar propuesta en la subsección 4.3.3 del Capítulo 4.

\section{A.1 MODELO ONTOLOGÍA EN HERRAMIENTA PROTEGE}

Desde el modelo propuesto en la sección 4.3 del Capítulo 4, con el objetivo de brindar un marco para la compartición de teorías entre los AISS, es necesario obtener una conceptualización compartida entre los AISS. Ésta se implementa con el editor de ontología Protégé (2000). Protégé permite crear y editar ontologías dentro de un entorno gráfico amigable. Por ser una herramienta específica para modelar ontologías, posee un poder representativo mayor que otras herramientas no específicas.

En esta sección se presentan ejemplos de la aplicación de la herramienta considerando la aplicación del: plug-in Jambalaya ( subsección A.1.1), el plug-in TGViz (subsección A-1.2), Classes Tab (subsección A-1.3).

\section{A.1.1 PLUG-IN JAMBALAYA}

Jambalaya representa clases (conceptos) como nodos, y slots (o propiedades) como arcos. En la vista principal se pueden establecer distintos filtros para agregar/remover nodos o tipos de arcos. 
Existen distintas vistas, según los aspectos que se quieren mostrar, o los modos en que se quiere visualizar la ontología. En la Nested View (que es la vista por default) en la figura A.1, se muestran las clases anidadas con sus subclases (donde la clase más general es la clase del sistema Thing, la cual contiene a todas las demás).

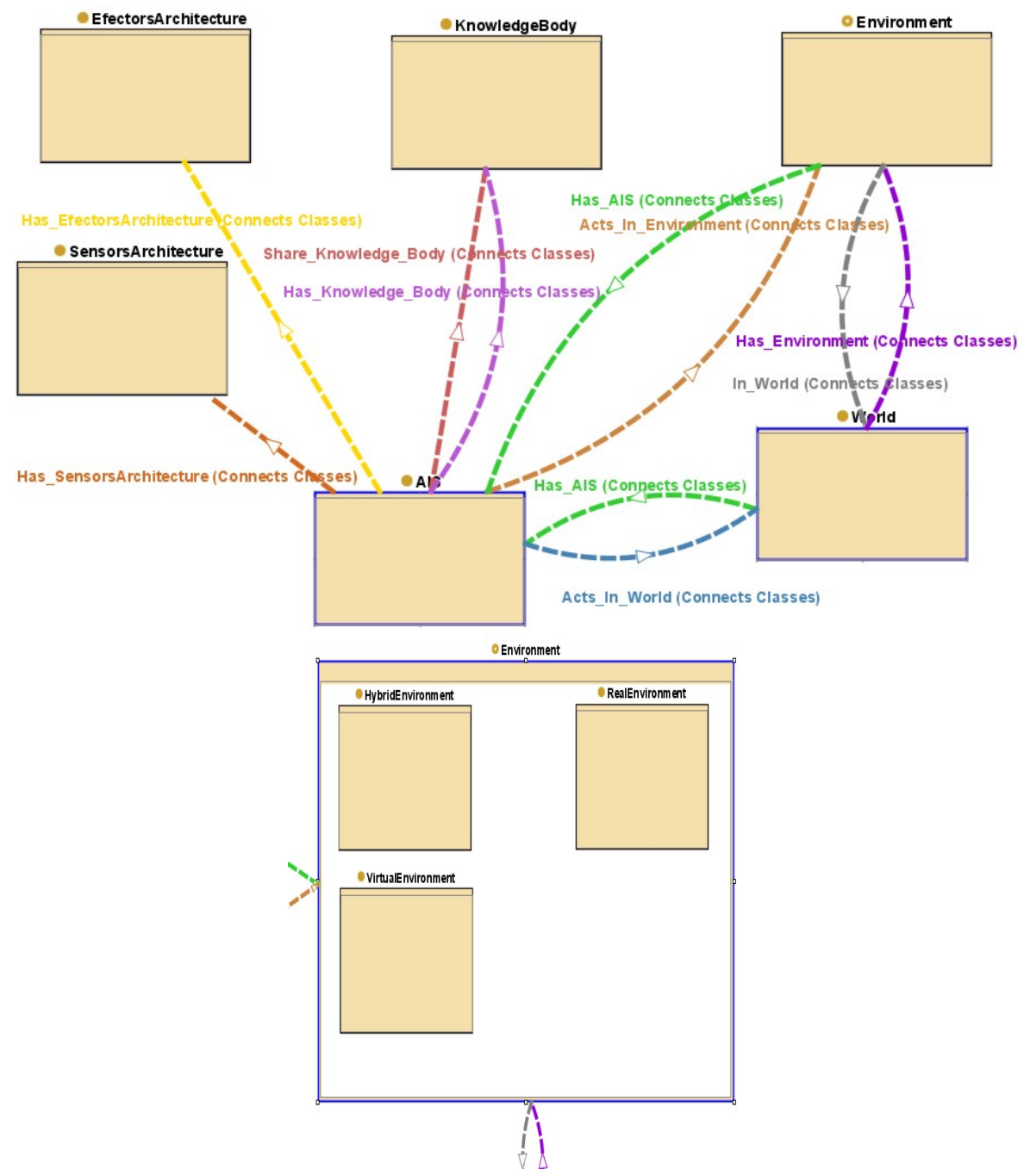

Figura A.1a. (superior) vista Plugin Jambalaya. Nested view. Figura A.1b (inferior) Vista de subclases anidadas

En este caso al hacer doble click en una superclase (luego de haber seleccionado la lupa para maximizar de la barra de herramientas del plug-in), se podrán ver en su interior a sus subclases (figura A.1b). En el caso de que la clase no tenga subclases, se verán los slots que ésta posee (figura A.2). También se muestran los arcos correspondientes a las relaciones entre clases (slots inversos, etc), y no se muestran los arcos correspondientes a relaciones estructurales (del tipo has-subclass). La forma de mostrar estas relaciones es como clases anidadas. 


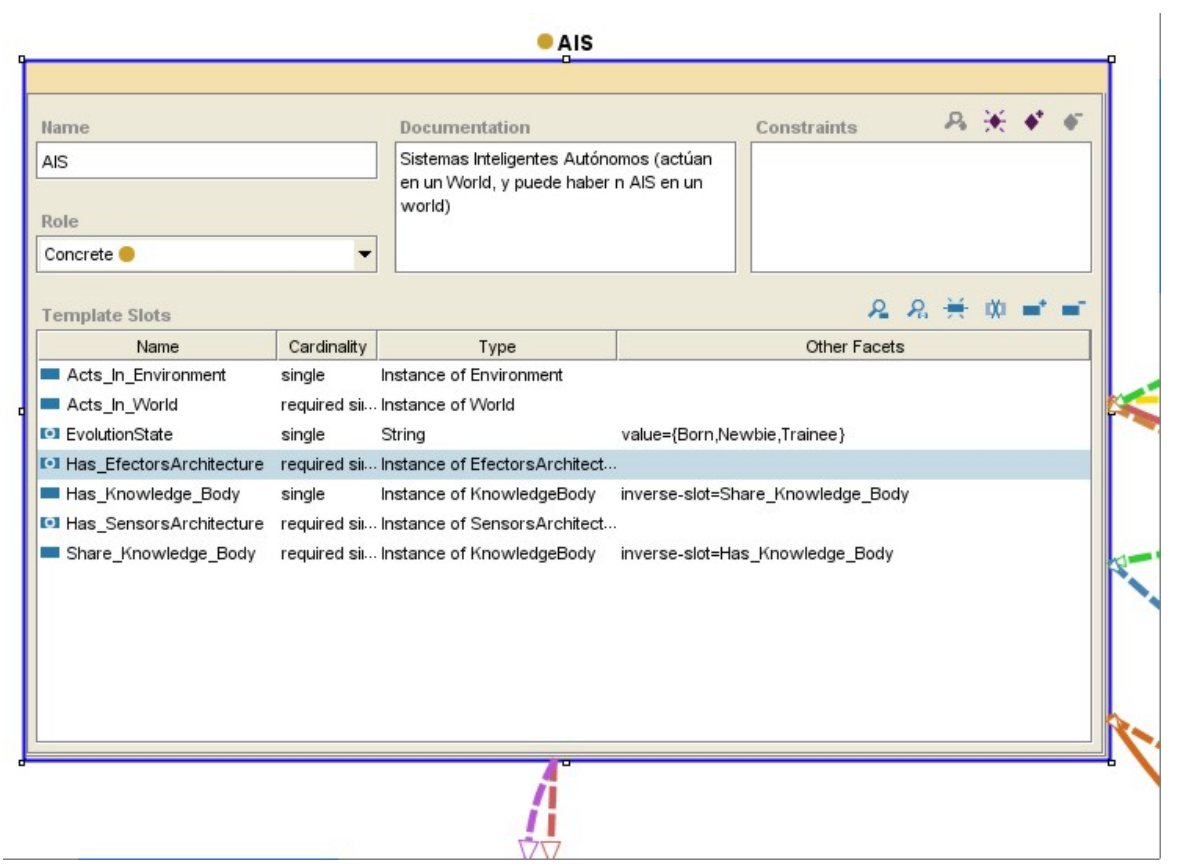

Figura A.2. Nested view. Vista de los detalles de una clase (que no tiene subclases)

En la Class Tree View, se muestra la estructura jerárquica completa de la ontología. Todas las clases con sus correspondientes subclases, con la clase del sistema Thing como clase raíz. Los arcos que se muestran son los correspondientes a relaciones estructurales, del tipo has-subclass (figura A.3).

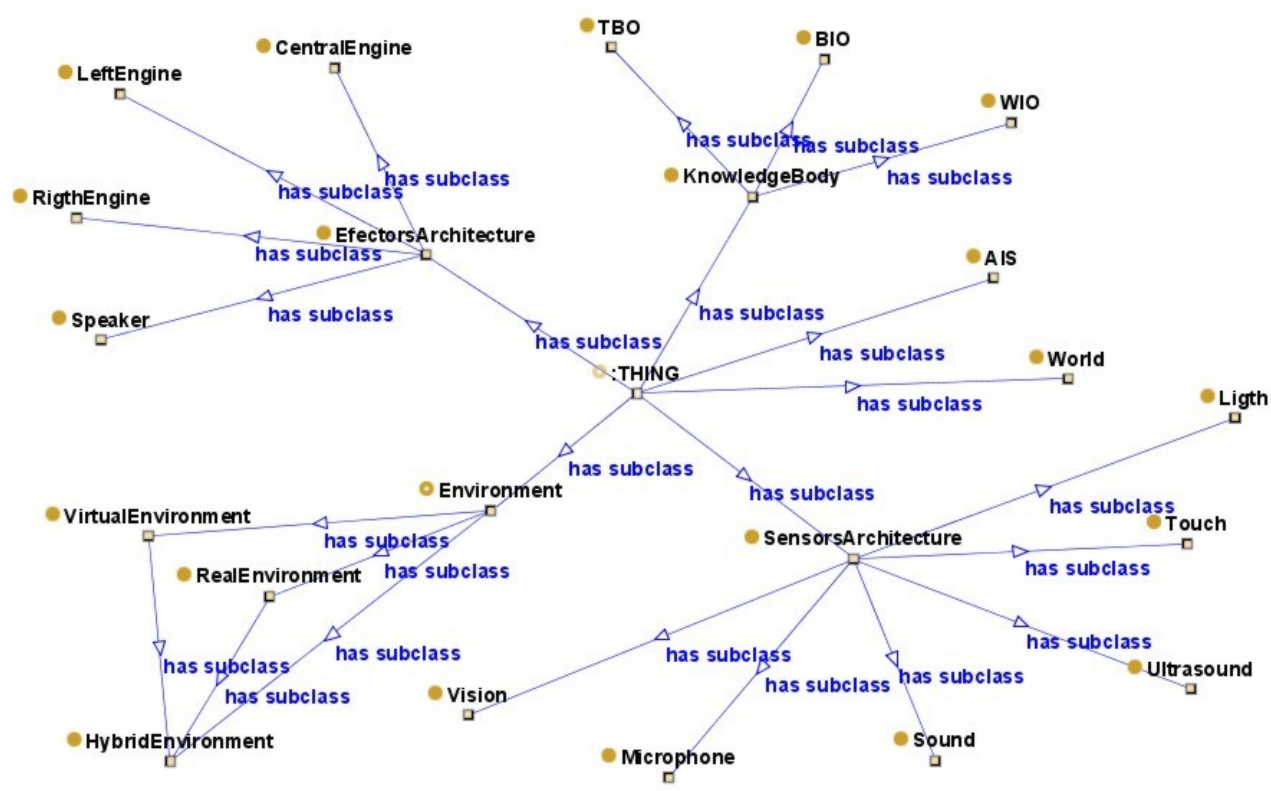

Figura A.3. Vista Plugin Jambalaya. Class tree view

Además hay otras vistas que permiten ver otros aspectos de la ontología. Por ejemplo, la vista Class \& Instant Tree es similar a la vista Class Tree, pero además muestra las instancias correspondientes 
a las clases. Además de los arcos has-subclass, se muestran arcos correspondientes a las relaciones estructurales del tipo has-instance.

\section{A-1.2 PLUG-IN TGVIZ}

Se puede generar un gráfico de la ontología donde se ven los conceptos (sólo sus nombres) y las relaciones existentes entre ellos, representadas por arcos (figura 7). Se muestran tanto relaciones estructurales, como las determinadas por los slots, slots inversos, etc. Luego de seleccionar un marco, se puede generar un gráfico que muestre los arcos que salen de y van hacia, ese marco. En este caso se seleccionó un marco clase. También es posible seleccionar marcos instancia. Se pueden establecer filtros para los arcos y clases, se pueden mostrar o no los nombres de los arcos, etc. En este caso, se muestran los conceptos relacionados con el concepto AIS (SAR).

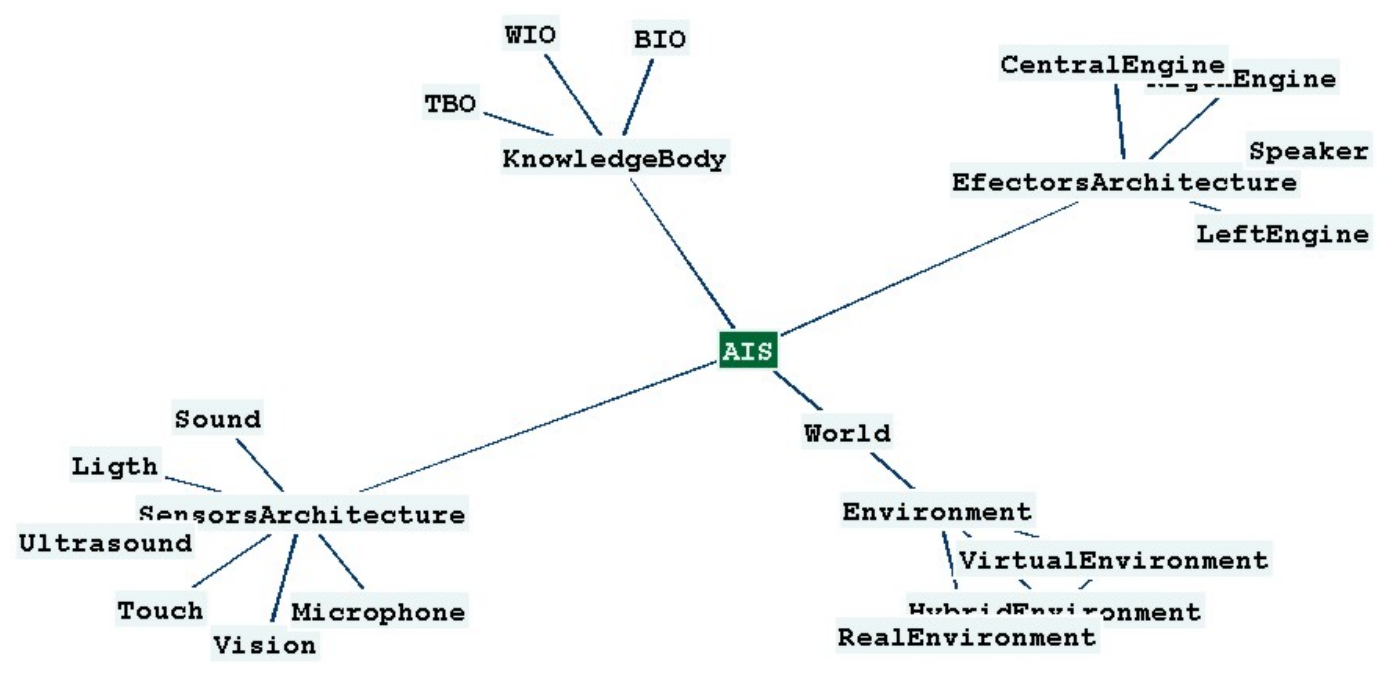

Figura A.4. Vista Plugin TGViz. Selección de la clase AIS

También se pueden seleccionar otros conceptos y mostrar las relaciones de los mismos en forma individual, por ejemplo se puede observar (de izquierda a derecha) en la figura A.5 los gráficos individuales para los conceptos: Environment, Effectors Architecture y SensorsArchitecture. 


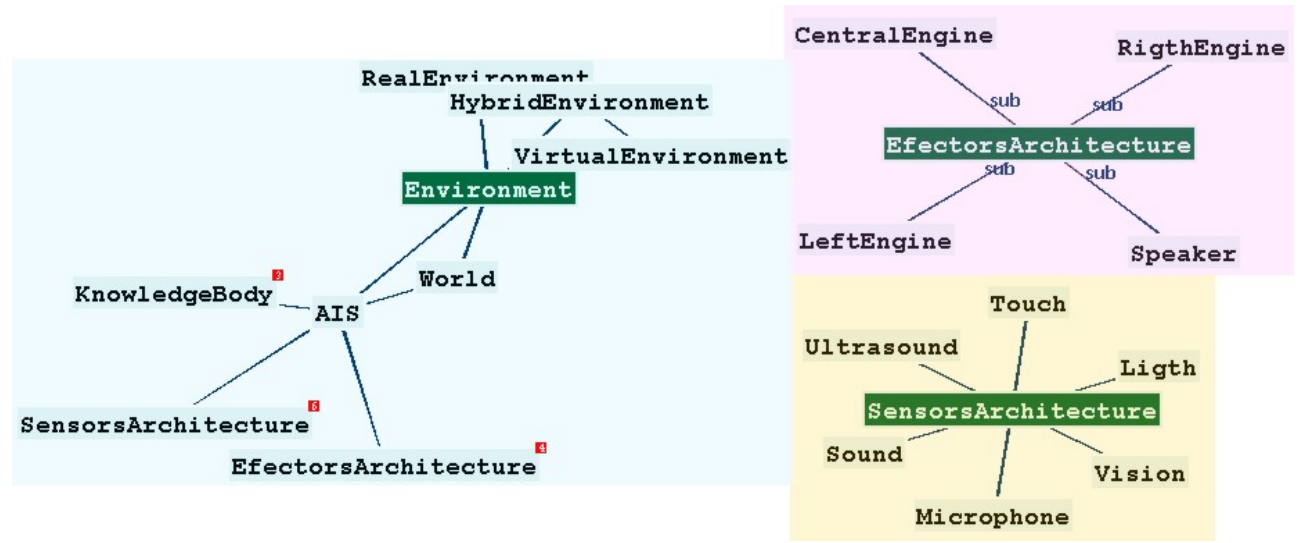

Figura A.5. Vista Plugin TGViz. Selección de las clases: Environment (izq), EfectorsArchitecture (der. Arriba) y Sensors Architecture (der. Abajo)

Por default la visualización de los nombres de los arcos está desactivada, aunque se pueden ver al pasar el mouse sobre los arcos, o el concepto que relacionan (como en el caso de EffectorsArchitecture, en el gráfico anterior).También se puede establecer un "radio" para la visualización de conceptos, en cuyo caso, los conceptos que están por encima de ese radio se ocultan, y se muestra un número en un cuadrado rojo, en el concepto principal, que indica que hay $\mathrm{n}$ conceptos ocultos. En el gráfico anterior (figura A 5 Izq) se puede ver que hay tres conceptos ocultos para KnowledgeBody, seis para SensorsArchitecture y cuatro para EffectorsArchitecture.

\section{A-1.3. CLASSES TAB}

Classes Tab Protégé, tiene distintos tabs o pestañas, para facilitar el trabajo en la ontología. En el Classes tab, se pueden crear clases, editarlas, borrarlas etc. Además se puede ver la jerarquía completa conforme se la va armando, en la parte izquierda del tab (figura A.6a). Cuando se selecciona una clase de la jerarquía se muestran sus slots correspondientes en la parte derecha de la ventana. En la parte inferior de la jerarquía de clases se muestran las superclases de esa clase seleccionada. También se puede hacer doble click sobre una clase, y en ese caso se desplegará una ventana conteniendo información similar a la que se presenta en el tab Classes figura A.6b. (Der). 


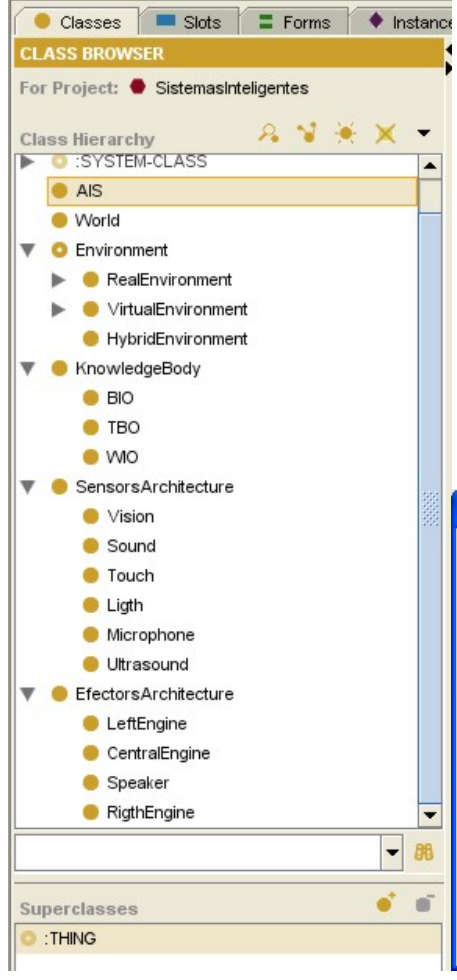

Figura A.6a Classes Tab

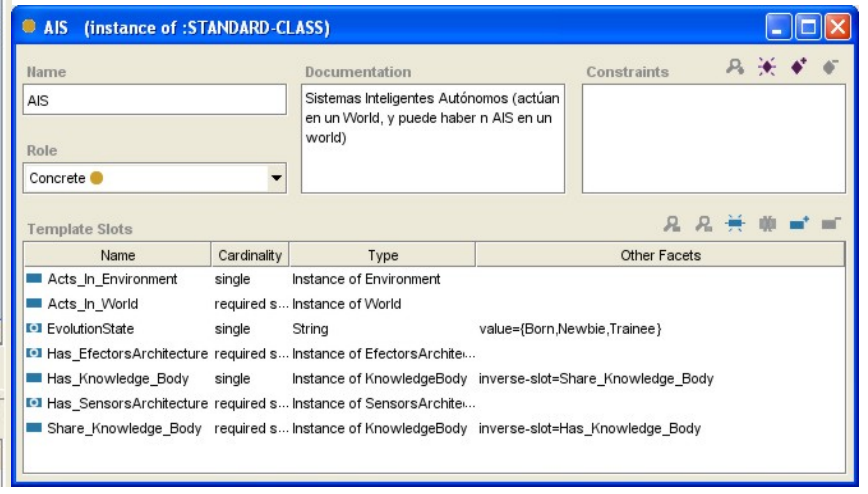

Figura A.6b Vista de la estructura jerárquica de la Ontología.

Marco clase AIS (SAR)

\section{A-2 SEMANTIC WEB SERVICES}

Un Web service es un software diseñado para soportar interoperabilidad Machine-to-Machine interacción sobre la red [Haas, H., and Brown, A., 2004].El objetivo es explorar la interoperabilidad entre sistemas autónomos de robots, como los servicios web se basan en XML estos resultarán independientes de la plataforma de sistema autónomo de robot, de su ubicación física y de su lenguaje de aplicación. No obstante, la tecnología basada en XML no captura suficiente semántica de los datos ni de la lógica del negocio, se necesita un framework que proponga un modelo conceptual para describir semánticamente el servicio en nuestro caso el relacionado con la compartición de operadores ente los AISs, además se requiere un lenguaje formal que proporcione la sintaxis y semántica (basada en lógicas diferentes, de acuerdo a la necesidad de expresividad) al modelo conceptual y un entorno de ejecución que facilite distintas tareas con el objeto de permitir la automatización.

OWL-S es un lenguaje de marcado para servicios web que permite describir servicios que son desarrollados y compartidos. Consiste de una ontología estándar que define un conjunto de clases y propiedades básicas para declarar y describir servicios. OWL-S presenta dos tipos de servicios: (a) Atómicos, que implican la invocación de un programa accesible vía la web, o un sensor o 
dispositivo, se envía el mensaje, luego se ejecuta la tarea y eventualmente produce una respuesta al solicitante, (b) Complejos o Compuestos. Son compuestos de varios servicios más primitivos y requieren cierta interacción o conversación entre el solicitante y los servicios involucrados. Anotar un servicio con OWL-S permite definir una API declarativa y machine-procesable que incluye:(a) la semántica de los argumentos a especificar cuando se invoca el mensaje, (b) la semántica de lo que retorna cuando el servicio se ejecuta.(c) también se usa la ontología del dominio.

En el contexto planteado se espera, en futuras líneas de investigación, que una solución orientada a OWL-S facilitará la evolución del AIS (SAR) permitiendo la compartición de operadores entre AISs (SARs) durante su ciclo de vida, considerando que OWL-S permite definir declarativamente los pre-requisitos y consecuencias de la aplicación de un servicio particular y provee un lenguaje para describir la composición de servicios y el flujo de datos que ello implica. De esta forma se podrá experimentar con AISs (SARs) distribuidos, los que compartirán conocimiento a través de una conexión a Internet, en el contexto futuro de Ontology Web 


\section{ANEXO B: EJEMPLO DE CÁLCULO UTILIDAD CON COEFICIENTES O BASADO EN LA ACCIÓN}

\section{B.1 EJEMPLO}

Cada ciclo de percepción-acción conforma un lazo de mando del SAR, cada ciclo se corresponde con la aplicación de una teoría i en el instante t del ciclo, para la determinación de la utilidad (U) de la teoría i aplicada por el SAR en un instante $t$, se considera:

- La situación percibida por el SAR a través de sus ocho sensores de proximidad.

- La teoría i seleccionada de la base de conocimiento del SAR en función de la situación percibida

- La determinación por el método de Braitenberg de la velocidad de cada rueda (VB) en función de la situación percibida (valores de los ocho sensores de proximidad) en el instante t.

- La determinación de la utilidad de la teoría aplicada en el instante $t$ en función de la comparación de velocidades de la ruedas que indica la acción de la teoría i (VT) frente a la velocidades de las ruedas determinadas aplicando Braitenberg (VB) para esa situación en el instante t.

El SAR en modo reactivo, utiliza los Coeficientes de Braitenberg para determinar la Acción a realizar, en orden a que: los controladores aplicados para el robot e-puck se corresponden con los aplicados en el simulador Webots, los que utiliza para determinar la velocidad de las ruedas del robot e-puck aplicando los coeficientes de Braitenberg, sobre la base de los valores obtenidos por cada uno de los ocho (8) sensores de proximidad. Mayores detalles se pueden encontrar en el Anexo $\tilde{\mathrm{N}}$ “Aspectos de Movilidad y Sensorística del Robot e-puck en el entorno Webots” y en el Anexo O “Aspectos generales relacionados con la interfase del robot e-puck y el sistema desarrollado".

Se presenta a continuación un ejemplo de aplicaciones del cálculo de utilidad sobre la base de un Sistema Autónomo de Robot (SAR) reactivo, implementado en un robot e-puck, [E-Puck, (2010)], 
el que en un instante t dado obtiene la siguiente lectura de situación ( $\mathrm{Si}$ ) de sus ocho sensores de proximidad:

$$
\mathrm{Si}=(1000 ; 115 ; 24 ; 190 ; 284 ; 630 ; 90 ; 904) \text {. }
$$

En el ejemplo se muestra cómo se valora la utilidad sobre la base de la comparación entre la acción (velocidad de cada rueda) correspondiente a la teoría i obtenida de la base de conocimientos que aplica el SAR al aplicar el método de planificador clásico (SARp) o el método de planificador por ranking (SARr), sobre la base de la Situación Inicial percibida por el SAR en el instante t y la velocidad determinada para ese instante aplicando Braitenberg (VB).

El cálculo para determinar los valores de velocidad correspondientes a la acción a realizar por cada una de las ruedas en el instante $t$ aplicando Braitenberg, es el siguiente:

$$
\begin{aligned}
& \text { VB } \left.[0]=\sum \text { CoeficientesBraitenberg[ } 0\right][\mathrm{i}] \times(1-(\mathrm{SA}[\mathrm{i}] / 1024)), \mathrm{i}=0, \ldots, 7 \\
& \text { VB } \left.[1]=\sum \text { CoeficientesBraitenberg[ } 1\right][\mathrm{i}] \times(1-(\mathrm{SA}[\mathrm{i}] / 1024)), \mathrm{i}=0, \ldots, 7
\end{aligned}
$$

Donde el máximo valor numérico que puede alcanzar un sensor del e-puck es "1024”, el primer eslabón de la sumatoria para Velocidad[ 0 ] se calcula de la siguiente manera (en función de los valores de los Coeficientes de Braitenberg en la tabla incluida en al final del presente Anexo):

\section{- CoeficientesBraitenberg [ 0 ][ 0 ] x ( 1 - (Si[ 0 ] / 1024) $)$}

- $150 \times(1-(1000 / 1024))=150 \times(1-0,9765625)=\underline{3,515625}$

Se continúa con el proceso indicado realizando la sumatoria para obtener las velocidades de las ruedas $\operatorname{VB}[0]$ y $\mathrm{VB}[1]$.

A modo de ejemplo, si se consideran para cada una de las ruedas los siguientes valores de velocidad sobre la base de un SAR reactivo: $\mathrm{VB}[0]=100$ y $\mathrm{VB}[1]=180$.

Para calcular Utilidad por Coeficientes, la función necesita la Acción de la Teoría i que se seleccionó en ese instante t de la base de conocimiento, que aplica el SAR como: A(VT[0];VT[1]), a modo de ejemplo, VT acción-teoría [0] = 80 y VT acción-teoría[1] = 100 .

Lo que hace primero el Cálculo de Utilidad por Coeficientes o utilidad basada en la acción, es calcular los valores de VB[0] y VB[1] que se hubieran obtenido con el método Reactivo utilizando 
la "Situación Inicial" correspondiente al instante t como si fuera la "Situación Actual" de un SAR Reactivo. Luego calcula la diferencia entre VB [0] y VT[0](V acción-teoría) y VB[1] y VT[1]( V acción-teoría) de la siguiente manera:

$\mathrm{D}[0]=\mathrm{VB}[0]-\mathrm{VT}$ acción-teoría. $[0]=100-80=20$
$\mathrm{D}[1]=\mathrm{VB}[1]-\mathrm{VT}$ acción-teoría $[1]=180-100=80$

$\mathrm{D}[0]$ y $\mathrm{D}[1]$ se normalizan (mapean) al rango $[0 ; 1]$ de la siguiente manera:

Donde el rango de valores posibles de velocidades es de -800 a 800

$$
\begin{aligned}
& \text { - } \mathrm{D}[0]=\mathrm{D}[0] / 1600=0,0125 \\
& \text { - } \quad \mathrm{D}[0]=1-0,0125=0,9875 \\
& \mathrm{D}[1]=\mathrm{D}[1] / 1600=0,05 \\
& \mathrm{D}[1]=1-0,05=0,95
\end{aligned}
$$

Se suman D[0] y D[1]:

$$
\text { - } \quad \text { U previa }=\mathrm{D}[0]+\mathrm{D}[1]=0,9875+0,95=1,9375
$$

Se halla la utilidad final:

- $\quad \operatorname{UTILIDAD}(\mathrm{U})=\mathrm{U}$ previa $-1=1,9375-1=0,9375$

\begin{tabular}{|c|}
\hline braitenberg_coefficients $[0][0]=150$ \\
\hline braitenberg_coefficients[0][1] $=-35$ \\
\hline braitenberg_coefficients $[1][0]=100$ \\
\hline braitenberg_coefficients[1][1] $=-15$; \\
\hline braitenberg_coefficients[2][0] $=80$; \\
\hline braitenberg_coefficients[2][1] = -10; \\
\hline braitenberg_coefficients[3][0] $=-10$ \\
\hline braitenberg_coefficients[3][1] $=-10$ \\
\hline braitenberg_coefficients $[4][0]=-10$ \\
\hline braitenberg_coefficients[4][1] $=-10$ \\
\hline braitenberg_coefficients[5][0] $=-10$ \\
\hline braitenberg_coefficients[5][1] $=80$ \\
\hline braitenberg_coefficients $[6][0]=-30$ \\
\hline braitenberg_coefficients[6][1] $=100$ \\
\hline braitenberg_coefficients[7][0] $=-20$ \\
\hline braitenberg_coefficients[7][1] $=150$ \\
\hline
\end{tabular}

Los coeficientes de Braitenberg ( sobre la base de los valores utilizados por el robot e-puck en el entorno Webots) se almacenan en una matriz de $8 \times 2$ que se detalla en la tabla B-1. Se detalla en el algoritmo B-1 el Pseudocódigo del cálculo de velocidad con coeficientes de Braitenberg, aplicada para la utilidad. 


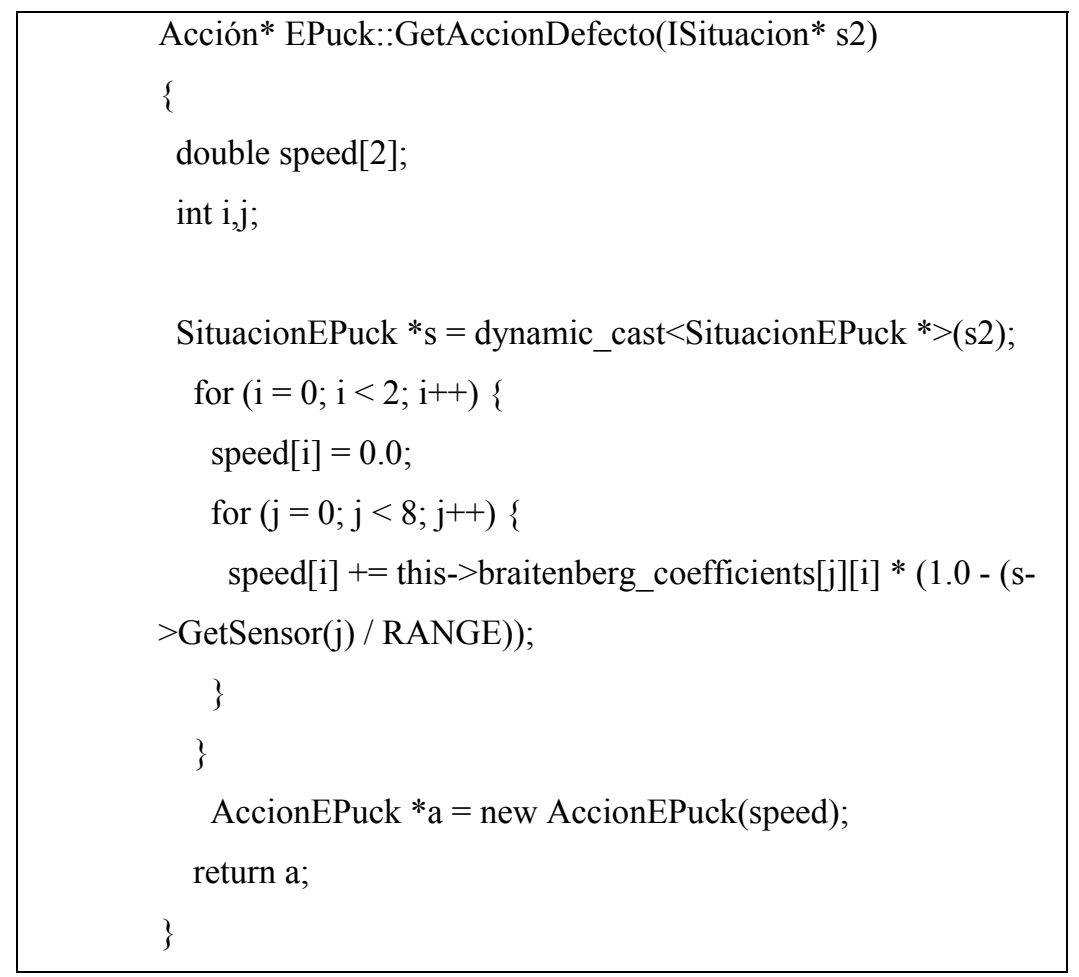

Algoritmo B-1 "Pseudo-código del Calculo de velocidad de con los Coeficientes de Braitenberg 


\section{ANEXO C: ESTRUCTURA DE LA BASE DE CONOCIMIENTOS DE TEORÍAS}

\section{1 INTRODUCCIÓN}

Se presenta en este anexo, la estructura de almacenamiento de teorías en archivos XML. Se enuncian los diferentes tags que identifican en su interior los objetos pertenecientes a la estructura de la teoría basada en: Situación Inicial, Acción, Situación Final, P, K Utilidad y se presenta al final del presente anexo un ejemplo de teoría completo.

\section{C2 ESTRUCTURA DE LAS TEORÍAS}

Se detalla cada uno de los tags que conforman el archivo de la base de conocimiento de teorías:

- $\quad<$ TEORIA $>\ldots<$ TEORIA $>$ : contiene toda la Teoría

- $\quad<$ SituacionInicial $>\ldots<$ SituacionInicial $>$ : contiene un objeto del tipo SITUACIÓN (en este caso es la Situación Inicial)

- $\quad<$ SITUACION $>\ldots<$ SITUACION $>$ : es un objeto que contiene los valores de los 8 sensores

- $\quad<$ SensorN $>\ldots<$ SensorN $>$ : contiene el valor del Sensor "N" para la situación en la que está contenido

- $\quad<$ Accion $>\ldots<$ Accion $>$ : contiene un objeto del tipo ACCIÓN (en este caso es la Acción de la teoría)

- $\quad<$ ACCION $>\ldots</$ ACCION $>$ : es un objeto que contiene los valores de las 2 velocidades de las ruedas

- $\quad<$ SpeedN $>\ldots</$ SpeedN $>$ : contiene el valor de la velocidad de la rueda "N" para la Acción en la que está contenido

- $\quad<$ SituacionFinal $>\ldots<$ SituacionFinal $>$ : contiene un objeto del tipo SITUACIÓN (en este caso es la Situación Final)

- $\quad<\mathrm{P}>\ldots</ \mathrm{P}>$ : contiene el valor del parámetro "P" de la Teoría

- $\quad<\mathrm{K}>\ldots</ \mathrm{K}>$ : contiene el valor del parámetro "K" de la Teoría

- $\quad<$ Utilidad $>\ldots<$ Utilidad $>$ : contiene el valor de la Utilidad de la Teoría

\section{3 EJEMPLO DE TEORÍA}

De acuerdo a la descripción realizada para la estructura de teorías, se presenta en la tabla C-1, un ejemplo de una teoría completa: 
$<$ TEORIA $>$

$<$ SituacionInicial $>$

$<$ SITUACION $>$

$<$ Sensor0 $>46.863216</$ Sensor0 $>$

$<$ Sensor $1>12.869085</$ Sensor $1>$

$<$ Sensor2 $>50.056923</$ Sensor2 $>$

$<$ Sensor3 $>31.311062</$ Sensor3 $>$

$<$ Sensor4 $>41.984997<$ /Sensor4 $>$

$<$ Sensor5 $>46.400085</$ Sensor5 $>$

$<$ Sensor6 $>57.066715</$ Sensor6 $>$

$<$ Sensor7 $>56.349373</$ Sensor7 $>$

$<$ SITUACION $>$

$<$ /SituacionInicial $>$

$<$ Accion $>$

$<$ ACCION $>$

$<$ Speed0 $>233.818370</$ Speed0 $>$

$<$ Speed1 $>221.085341</$ Speed1 $>$

$</$ ACCION $>$

$</$ Accion $>$

$<$ SituacionFinal $>$

$<$ SITUACION $>$

$<$ Sensor0 $>14.647100</$ Sensor0 $>$

$<$ Sensor $1>49.507595</$ Sensor $1>$

$<$ Sensor2 $>43.321796</$ Sensor2 $>$

$<$ Sensor3 $>20.429668</$ Sensor3 $>$

$<$ Sensor4 $>50.650082</$ Sensor4 $>$

$<$ Sensor5 $>13.244558</$ Sensor5 $>$

$<$ Sensor6>32.326447</Sensor6>

$<$ Sensor $7>30.618557<$ /Sensor $7>$

$</$ SITUACION $>$

$</$ SituacionFinal $>$

$<\mathrm{P}>47</ \mathrm{P}>$

$<\mathrm{K}>160</ \mathrm{K}>$

$<$ Utilidad $>0.985907</$ Utilidad $>$

$</$ TEORIA $>$

Tabla C-1 Ejemplo de teoría 


\section{ANEXO D: Ejemplo de Mutación de Teorías}

\section{1 EJEMPLO}

Para la formulación del ejemplo de mutación se asume que el SAR actúa con la siguiente Base de Conocimiento de Teorías, según se observa en la figura D-1:

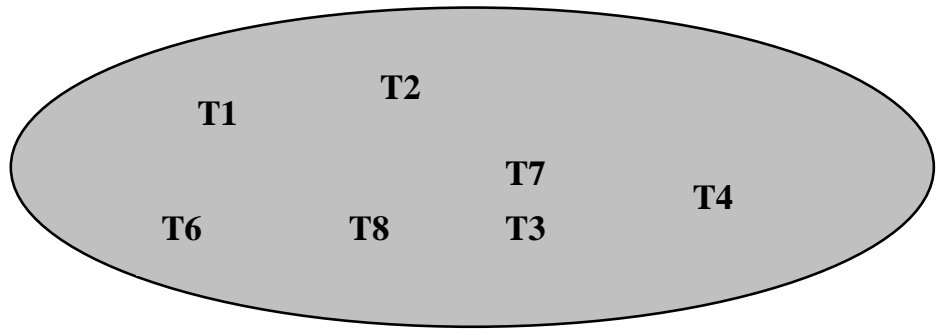

Figura D-1 Base de conocimiento de teorías

Donde $\mathrm{T} 1, \ldots \mathrm{T} 8$ son Teorías conformadas por : $\mathrm{T}$ ( $\mathrm{Si}, \mathrm{A}, \mathrm{Sf}, \mathrm{P}, \mathrm{K}, \mathrm{U})$, en este caso, al tratarse del robot e-puck, Si y Sf están conformadas por los valores de las lecturas de los 8 (ocho) sensores de proximidad de la siguiente manera: Situación (Sensor0; Sensor1; Sensor2; Sensor3; Sensor4; Sensor5; Sensor6; Sensor7)

- Caso de Ejemplo:

$$
\begin{aligned}
& \text { T1(S1,A1,S2,P,K,U) } \\
& \text { T2(S1,A1,S8,P,K,U) } \\
& \text { T3(S1,A2,S9,P,K,U) } \\
& \text { T4(S1,A12,S25,P,K,U) } \\
& \text { T5(S1,A1,S1,P,K,U) } \\
& \text { T6(S1,A4,S1,P,K,U) } \\
& \text { T7(S1,A1,S7,P,K,U) } \\
& \text { T8(S1,A1,S24,P,K,U) }
\end{aligned}
$$

Al ingresar un nuevo conocimiento en el ciclo actual (Nueva Teoría "Tn") se procede a analizar si esta teoría ya existe en la Base. Si existe, no se llega a la mutación. En caso de no existir se pasa a la siguiente verificación

- Caso de Ejemplo: 
$\operatorname{Tn}(\mathrm{S} 1, \mathrm{~A} 1, \mathrm{~S} 6, \mathrm{P}, \mathrm{K}, \mathrm{U})$

Se verifica si existen Teorías Similares (“S $\mathrm{S}_{\mathrm{i}}$ ” y "A" iguales). Si no existe, no se llega a la mutación. Si existen teorías similares, se obtiene una lista con todas las similares.

- Caso de Ejemplo:

$$
\begin{aligned}
& \text { T1(S1,A1,S2,P,K,U) } \\
& \text { T2(S1,A1,S8,P,K,U) } \\
& \text { T5(S1,A1,S1,P,K,U) } \\
& \text { T7(S1,A1,S7,P,K,U) } \\
& \text { T8(S1,A1,S24,P,K,U) }
\end{aligned}
$$

Si está habilitada la Mutación, se determina la cantidad máxima de teorías a mutar, con los siguientes parámetros de mutación para la configuración del SAR: Proporción Mutación $=0.8$, Límite Mutación = 3

- Caso de Ejemplo:

o Cantidad de teorías similares 5 (cinco), se determina para el parámetro Proporción Mutación, la cantidad de teorías a Mutar es : 4 (cuatro).

o Esto se debe a que $0.8 \times 5=4$, pero $4>3$, con lo cual, prevalece el Límite Mutación, en este caso las cantidad de teorías a mutar son 3 (tres).

Luego, las tres primeras teorías de la lista de teorías Similares, serán las mutadas, éstas son:T1, T2 y T5, las que se mutarán con la teoría nueva (Tn), según el algoritmo de mutación explicado previamente y se obtienen los siguientes resultados:

$$
\begin{array}{ll}
\text { o } & \mathrm{Tm}_{1 \mathrm{n}} \text { (resultado de mutar T1 con Tn) } \\
\text { o } & \mathrm{Tm}_{2 \mathrm{n}} \text { (resultado de mutar T2 con Tn) } \\
\text { o } & \mathrm{Tm}_{5 \mathrm{n}} \text { (resultado de mutar T5 con Tn) }
\end{array}
$$

A modo de ejemplo, este es el resultado de $\mathrm{Tm}_{1 \mathrm{n}}$ :

O $\operatorname{Tm}_{1 \mathbf{n}}\left(\mathbf{S}_{1}, \mathbf{A}_{\mathbf{1}}, \mathbf{S}_{1 \mathbf{n}}, \mathbf{P}, \mathbf{K}, \mathbf{U}\right)$

o $\quad S_{1 n}$ es la mutación de Situación de $\mathbf{S}_{2}$ (T1) con $\mathbf{S}_{\mathbf{6}}$ (Tn)

o $\mathbf{S i}_{\mathbf{n}}$ : 
- $\mathbf{S}_{2}=(0 ; 123.5 ; 48 ; 89 ; 112 ; 1000 ; 54 ; 239) \mathrm{y}$

- $\mathbf{S}_{6}=(0 ; 123.5 ; 315 ; 680 ; 149 ; 1015 ; 32 ; 239)$

- $\mathbf{S}_{1 \mathbf{n}}=(\mathbf{0} ; \mathbf{1 2 3 . 5}$; nrI; nrII; nrIII; nrIV; nrV; 239)

- Donde nrI...nrV son números RANDOM entre 0 y 1024

Para cada una de las Teorías mutadas se calcula su U. Luego, revisando el resto de las teorías en la base, se calcula su P y su K y se verifica si hay o no teorías iguales a las mutadas. Finalmente, si corresponde, se agregan a la Base de Teorías. 


\section{ANEXO E: EJEMPLO DE COMPARACIÓN DE SITUACIONES Y ACCIONES ENTRE TEORÍAS}

\section{E.1 EJEMPLO}

Para el desarrollo del presente ejemplo se realizaron 6 (seis) experimentaciones, las que totalizan 2400 ciclos percepción-acción (en el escenario representado en la figura 4-16 del Capítulo 4), y se obtuvieron los promedios de n (seis) desvíos estándar hallados para cada sensor i y cada actuador i. Se obtuvo el umbral de cada sensor aplicando el desvío estándar promedio de las seis experimentaciones para cada sensor i $(0 \ldots 7)$ que conforma la Situación del SAR (robot e-puck) con la siguiente fórmula:

$$
\text { Umbral Sensor i }(0 \ldots 7)=\sqrt{\frac{\sum_{\text {lectura }}^{\text {lectura }}(\text { Sensor } i-\mu \text { Sensor } i)^{2}}{n}}
$$

Los valores de umbral promedio de cada sensor se observan en la tabla E-1

\begin{tabular}{|c|c|}
\hline Umbral Promedio & Valor \\
\hline Sensor 0 & 147,3324748 \\
\hline Sensor 1 & 238,1390026 \\
\hline Sensor 2 & 259,1758021 \\
\hline Sensor 3 & 66,66883667 \\
\hline Sensor 4 & 15,57667592 \\
\hline Sensor 5 & 57,23884374 \\
\hline Sensor 6 & 22,08802014 \\
\hline Sensor 7 & 51,53075156 \\
\hline
\end{tabular}

Tabla -E-1 valores de Umbral de cada sensor

Para la comparación de situaciones se considera en el ejemplo la situación A (SA) y la situación B (SB). La diferencia entre situaciones se determina a través del valor absoluto de la diferencia entre el "sensor i" correspondiente a las Situaciones $\mathrm{S}_{\mathrm{A}} \mathrm{y} \mathrm{S}_{\mathrm{B}}$ respectivamente. 
Si el resultado de la diferencia absoluta de las lecturas del Sensor i de $\mathrm{S}_{\mathrm{A}}$ y Sensor i de $\mathrm{S}_{\mathrm{B}}$ es menor o igual al valor del umbral del Sensor i" (correspondiente a tabla E-1), se considera que ambas lecturas de sensores i son iguales

Si todas las lecturas de los sensores de ambas situaciones son iguales, se considera que las dos situaciones $\left(\mathrm{S}_{\mathrm{A}}\right.$ y $\left.\mathrm{S}_{\mathrm{B}}\right)$ son IGUALES. Caso contrario, si al menos una de las lecturas comparadas entre los sensores i de las situaciones $\left(\mathrm{S}_{\mathrm{A}} \mathrm{y} \mathrm{S}_{\mathrm{B}}\right)$, resulta diferente, se consideran DIFERENTES las situaciones.

Por ejemplo, si se comparan las siguientes situaciones $\mathrm{S}_{\mathrm{A}} \mathrm{y} \mathrm{S}_{\mathrm{B}}$, donde las lecturas de cada uno de los ocho sensores que conforman la situación se registran como S0...S7, según se detalla en la tabla E-2. "Diferencias entre sensores de las situaciones comparadas". Se obtienen los resultados de comparación de situaciones de teorías indicados en la tabla E -3

\begin{tabular}{|c|c|c|c|c|c|c|c|c|}
\hline $\begin{array}{c}\text { Lectura de } \\
\text { Sensores }\end{array}$ & $\begin{array}{c}\text { Sensor } \\
\text { S0 }\end{array}$ & Sensor & Sensor & Sensor & Sensor & Sensor & Sensor & Sensor \\
Situaciones & & & S3 & S4 & S5 & S6 & S7 \\
\hline SA & 147,33 & 248,13 & 459,17 & 82,6 & 15,57 & 829,87 & 458 & 950 \\
\hline SB & 0 & 238 & 199 & 133,32 & 1,5 & 99,6 & 457 & 1000,8 \\
\hline Diferencia & 147,33 & 10,13 & $\mathbf{2 6 0 , 1 7}$ & $-50,72$ & 14,07 & $\mathbf{7 3 0 , 2 7}$ & 1 & $-50,8$ \\
\hline
\end{tabular}

Tabla E-2 Diferencias entre sensores de las situaciones comparadas

\begin{tabular}{|c|c|}
\hline $\begin{array}{c}\text { Comparación entre lecturas de sensores i }(0 \ldots 7) \text { de las Situaciones SA y SB y el } \\
\text { umbral correspondiente. }\end{array}$ & $\begin{array}{c}\text { Resultado de la } \\
\text { Comparación } \\
\text { entre Sensores }\end{array}$ \\
\hline Diferencia entre sensores $0=|147,33-0|=147,33<=$ Umbral sensor 147,3324 & Iguales \\
\hline Diferencia entre sensores $1=|248,13-238|=10,13<=$ Umbral sensor 238,139 & Iguales \\
\hline Diferencia entre sensores $2=|459,17-199|=260,17>$ Umbral sensor \\
259,1758021 & Diferentes \\
\hline 66,66883667 & Iguales \\
\hline Diferencia entre sensores $3=|82,6-133,32|=|-50,72|<=$ Umbral sensor & Iguales \\
\hline Diferencia entre sensores $4=|15,57-1,5|=14,07<=$ Umbral sensor & Diferentes \\
\hline Diferencia entre sensores $5=|829,87-99,6|=730,27>$ Umbral sensor & Iguales \\
\hline Diferencia entre sensores $6=|458-457|=1,0<=$ Umbral sensor 22,08802014 & Iguales \\
\hline Diferencia entre sensores $7=|950-1000,8|=|-50,8|<=$ Umbral sensor & \\
\hline 51,53075156 & \\
\hline
\end{tabular}

Tabla E-3 Comparación entre la diferencia de sensores y el umbral 
Al haber al menos un sensor con diferencias mayores a su desvío estándar (en este caso Sensor 2 y Sensor 5) se consideran a las Situaciones $\mathbf{S}_{\mathbf{A}} \mathbf{y} \mathbf{S}_{\mathbf{B}}$ como DIFERENTES.

Se obtuvo el umbral de cada actuador (rueda del SAR) aplicando el Desvío Estándar promedio de las seis experimentaciones para cada actuador o efector representado en este caso por las ruedas $\mathrm{i}$ del SAR (uno y dos) que conforma la acción del SAR (robot e-puck) con la siguiente fórmula:

$$
\text { Umbral Rueda } \mathrm{i}(1-2)=\sqrt{\frac{\sum_{\text {lectura } 1}^{\text {ectura }}(\text { Rueda } i-\mu \text { Rueda } i)^{2}}{n}}
$$

Los valores de umbral promedio correspondiente a la velocidad de cada rueda se observan en la tabla E-4

\begin{tabular}{|c|c|}
\hline Umbral Promedio & Valor \\
\hline Velocidad Rueda 1 & $\mathbf{8 0 , 6 4 2 0 8 5 9 4}$ \\
\hline Velocidad Rueda 2 & $\mathbf{6 8 , 2 8 6 6 7 8 4 5}$ \\
\hline
\end{tabular}

Tabla E-4 valores de Umbral de cada rueda

Para la comparación de acciones se considera en el ejemplo la acción $\mathrm{A}\left(\mathrm{A}_{\mathrm{A}}\right)$ y la acción $\mathrm{B}\left(\mathrm{A}_{\mathrm{B}}\right)$. La diferencia entre acciones se determina a través del valor absoluto de la diferencia del "actuador (rueda) $i$ " correspondiente a la acciones $A_{A}$ y $A_{B}$ respectivamente.

Si el resultado de la diferencia absoluta de los registros de las acciones de la rueda i de $\mathrm{A}_{\mathrm{A}}$ y rueda $\mathrm{i}$ de $A_{B}$ es menor o igual al valor del umbral del actuador (rueda) i (correspondiente en la tabla E-4), se considera que ambos registros de acciones i son iguales

Si todos los registros de los actuadores (ruedas) de ambas acciones son iguales, se consideran que las dos acciones $\left(\mathrm{A}_{\mathrm{A}} \mathrm{y} \mathrm{A}_{\mathrm{B}}\right)$ son IGUALES. Caso contrario, si al menos uno de los registros comparados entre los actuadores $\mathrm{i}$ de las acciones $\left(\mathrm{A}_{\mathrm{A}} \mathrm{y} \mathrm{A}_{\mathrm{B}}\right)$, resulta diferente, se consideran DIFERENTES las acciones.

Por ejemplo, si se comparan las siguientes acciones $\mathrm{A}_{\mathrm{A}} \mathrm{y} \mathrm{A}_{\mathrm{B}}$, donde los registros de las velocidades de cada una de las ruedas conforman la acción se registran como VR1, VR2, según se detalla en la tabla E-5"Diferencias entre los velocidades de las ruedas de las acciones comparadas". 


\begin{tabular}{|r|c|c|}
\hline Rueda & VR1 & VR2 \\
\hline Acción & & \\
\hline$A_{A}$ & 80,65 & 90,58 \\
$A_{B}$ & 0 & 120 \\
Diferencia & 80,65 & $-29,42$ \\
\hline
\end{tabular}

Tabla E-5 Diferencias entre las velocidades de las ruedas de las acciones comparadas

Se obtienen los resultados de comparación entre acciones de teorías, indicados en la tabla E-6 "Comparación entre la diferencia de velocidad de ruedas y el umbral".

\begin{tabular}{|l|l|}
\hline $\begin{array}{l}\text { Comparación entre registros de velocidades de las ruedas (1 y 2) } \\
\text { de las acciones AA y AB y el umbral. }\end{array}$ & $\begin{array}{l}\text { Resultado de la } \\
\text { Comparación entre Ruedas }\end{array}$ \\
\hline $\begin{array}{l}\text { Diferencia velocidades ruedas } 1=|80,65-0|=80,65> \\
80,64208594 \text { umbral rueda } 1 .\end{array}$ & Diferentes \\
\hline $\begin{array}{l}\text { Diferencia velocidades ruedas } 2=|248,13-238|=10,13<= \\
238,139 \text { umbral rueda } 2\end{array}$ & \\
\hline
\end{tabular}

Tabla E-6 Comparación entre la diferencia de velocidad de ruedas y el umbral 


\section{ANEXO F: PONDERACIÓN DE PLANES}

En el presente Anexo se detallan a través de diagramas de actividades el ponderador de planes, empleado por el planificador clásico (SARp). En la sección N-6 del Anexo Soporte Digital, se presenta el planificador clásico y un ejemplo de ponderación de plan, propuesto por Maceri, $\mathrm{P}$ y García Martínez, R (2001).

\section{F.1 PONDERACIÓN DE PLANES}

Se presenta en la figura F-1 el diagrama de actividades correspondiente al ponderador de planes. El ponderador recibe la base de conocimientos actual del robot, con las situaciones finales e iniciales de cada teoría perteneciente a la base de conocimiento de teorías, arma un listado de situaciones. Si la situación actual o la situación deseada no se halla en la lista de situaciones, se devuelve como resultado de la ponderación el valor cero y termina la actividad del módulo.

En caso de que ambas situaciones se encuentren presentes en la lista, se obtiene su posición dentro de lista. La posición en la lista correspondiente a la situación actual representa el índice de fila en la matriz de resultado y la posición en la lista correspondiente a la situación deseada representa el índice de la columna en la matriz de resultado.

Luego de la obtención de los índices, se procede a la generación del listado de matrices que van a permitir el cálculo de la matriz de resultado final. (Ver Cálculo de matrices).

Por cada nodo del plan, se obtiene su acción a tomar y a partir de ésta, se obtiene su matriz asociada del listado de matrices para luego utilizar dicha matriz en el cálculo de la matriz resultado como:

Matriz Resultado = Matriz Resultado * Matriz Acción Nodo Plan.

Finalmente se obtiene el valor de la ponderación como:

Ponderación = Matriz Resultado[índice Situación Actual, índice Situación Deseada] 
Si la ponderación resulta inferior al valor de umbral definido $(0,5)$, se adopta al valor cero $(0)$ para la ponderación de la acción del nodo, recurriendo a una replanificación, sobre la base de las situaciones presentes en la lista.

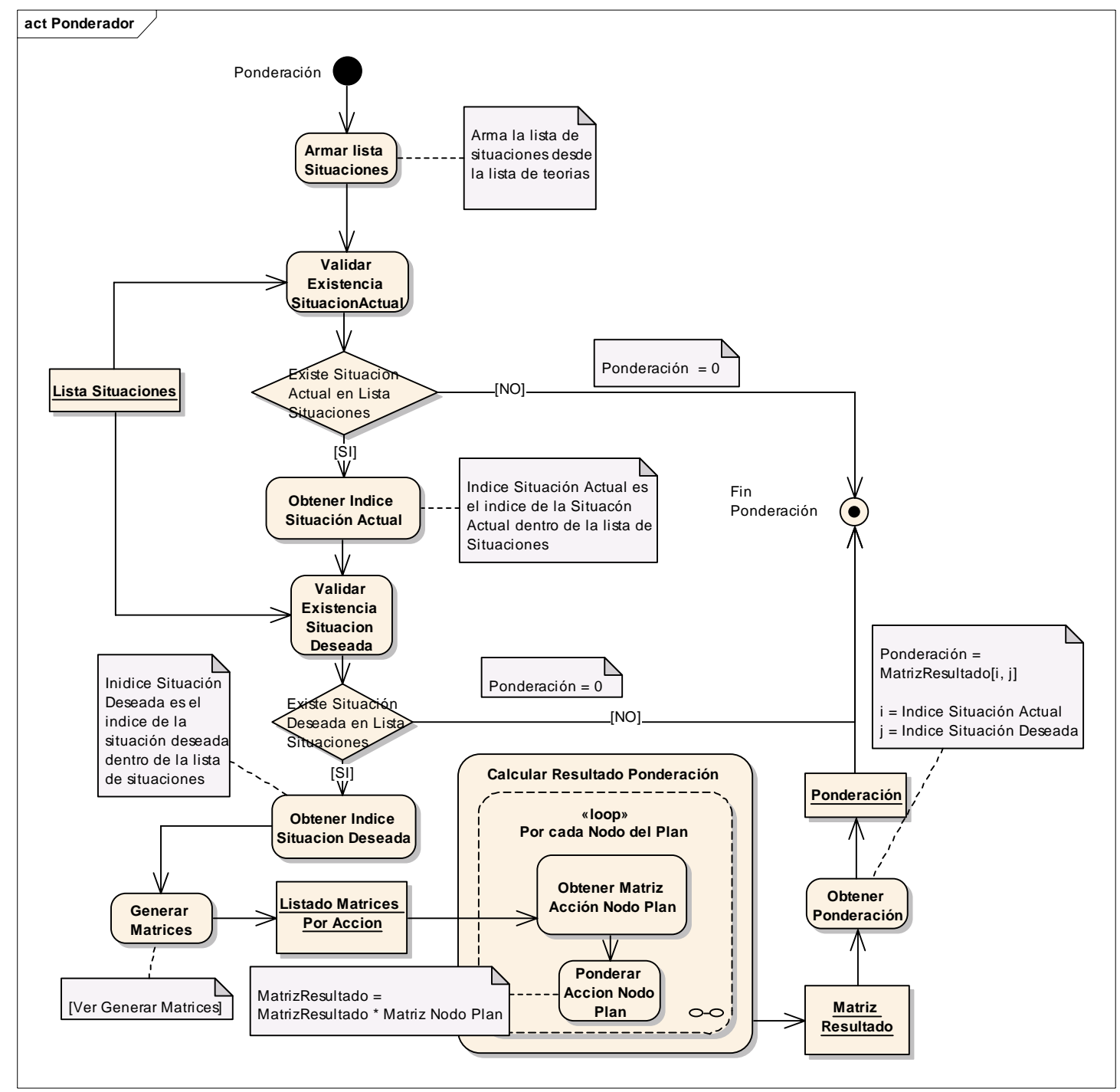

Figura F-1 "Diagrama de actividades del módulo ponderador de planes"

Se detalla en la figura F-2, el diagrama de actividades correspondiente a la generación de la matriz de ponderación de planes que aplica el planificador con ponderador de planes.

Para el cálculo de matrices por cada nodo del plan se considera, si el nodo posee una matriz asociada a su acción, se sigue con el siguiente nodo. De lo contrario se inicializa una matriz de $\mathrm{NxN}$ (donde $\mathrm{N}$ es la cantidad de situaciones que conforman la lista de situaciones) con cada posición en cero (0).Se recorren todas las teorías de la base de conocimiento y por cada una de ellas se compara la acción del nodo del plan contra la acción de la teoría: 
Si ambas acciones son iguales:

Índice Fila = posición en lista de situaciones de la Situación

Inicial de la teoría.

Índice Columna $=$ posición en la lista de situación de la

Situación Final de la teoría.

Si el K de la teoría es 0 , entonces:

Matriz Asociada Acción [indiceFila, indiceColumna] = 0

De otra manera son ambas acciones iguales:

Matriz Asociada Acción [indiceFila, indiceColumna] =

$\mathrm{PTeo} / \mathrm{KTeo}$

Una vez recorridas todas las teorías y comparadas contra la acción del nodo del plan, se agrega la matriz a la lista de matrices.

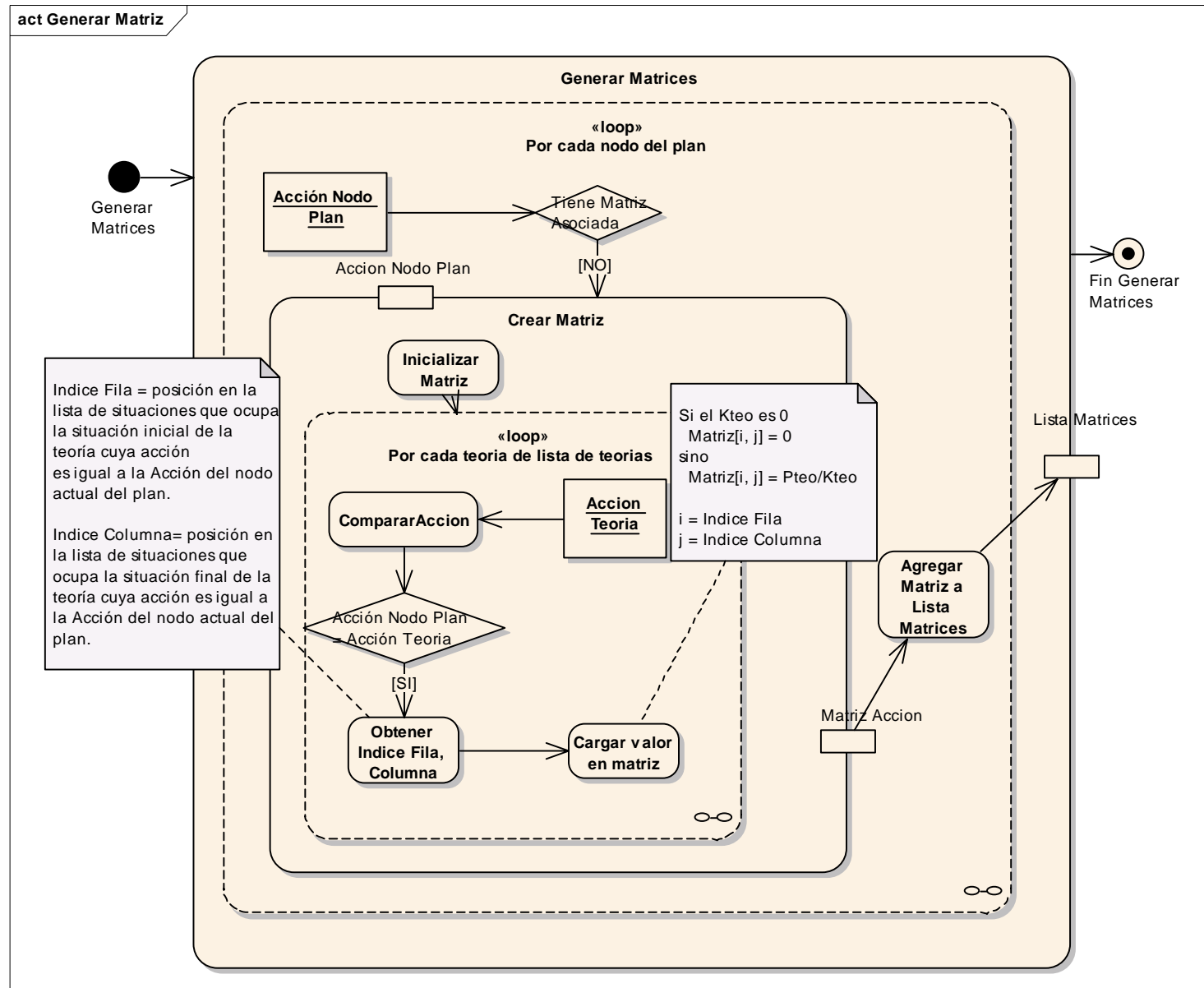

Figura F-2 "Diagrama de actividades correspondiente a la generación de la matriz de ponderación de planes" 


\section{ANEXO G: EJEMPLO DE PLANIFICADOR POR RANKING DE TEORÍAS}

\section{G.1 EJEMPLO}

Se presenta a continuación un ejemplo genérico del planificador por ranking de teorías, en este caso se presentan en la base de conocimientos del Sistema Autónomo de Robot con planificador por ranking de teorías (SARr) cinco teorías: T1,T2,T3,T4,T5 que se muestran en la figura 5-G-1. Las teorías se indican como $\mathrm{Ti}=\mathrm{SAi}, \mathrm{Ai}, \mathrm{SFi}, \mathrm{Pi}, \mathrm{Ki}, \mathrm{Ui}$.

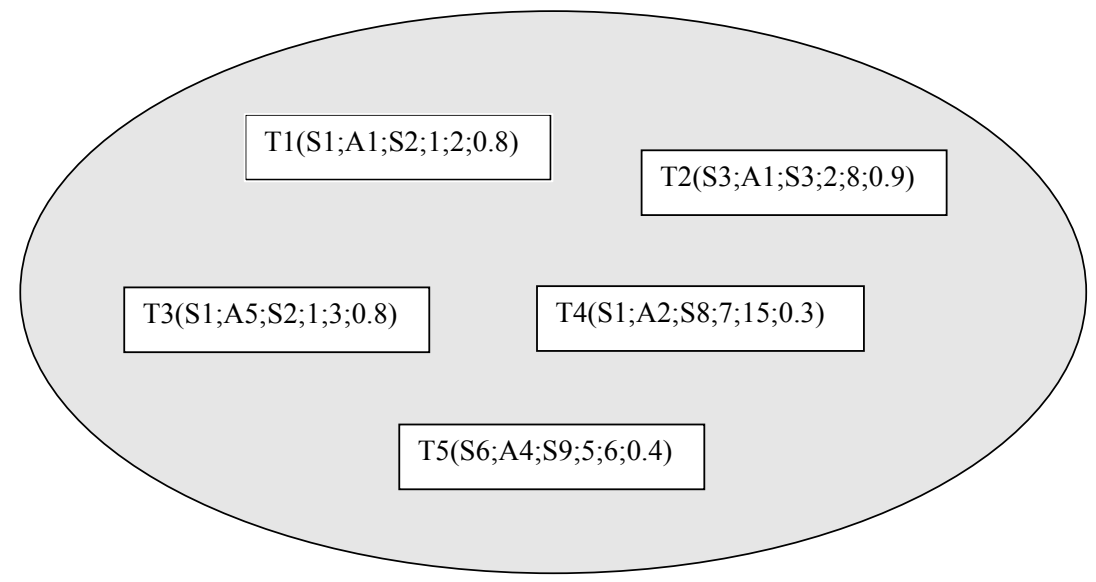

Figura 5-G-1 Base de Conocimientos del SARr

El planificador dispone de la base de conocimiento con las teorías indicadas, éstas se ordenan en primer lugar por utilidad seguida en segundo lugar por el valor de mayor P y en tercer lugar por el valor del menor K. En este orden las teorías de la base de conocimiento se presentan con el siguiente ranking:

$$
\begin{array}{ll}
\mathrm{O} & \mathrm{T} 2(\text { Utilidad }=0.9) \\
\mathrm{O} & \mathrm{T} 3(\mathrm{Utilidad}=0.8 ; \mathrm{P}=1 ; \mathrm{K}=2) \\
\mathrm{O} & \mathrm{T} 1(\mathrm{Utilidad}=0.8 ; \mathrm{P}=1 ; \mathrm{K}=3) \\
\mathrm{O} & \mathrm{T} 5(\mathrm{Utilidad}=0.4) \\
\mathrm{O} & \mathrm{T} 4(\mathrm{Utilidad}=0.3)
\end{array}
$$

Al ingresar la Situación Actual SA, conformada por los valores de los ocho sensores de proximidad, se compara esta situación con la situación de la primera teoría rankeada, en este caso SA no es igual 
a la Situación de la teoría T2, se continúa comparando con la situación de la siguiente teoría en el ranking en este caso T3, siendo la SA (situación actual) igual a la S3 (situación de la teoría T3), con lo cual el plan devuelto por el planificador es la acción A5 correspondiente a la teoría T3, la que ejecutará el SAR, conformándose una nueva teoría T6 (S1,A5,S3, 1;1;0.35) la que luego se registrará en la base de teorías del SARr. Se continúa con el ciclo de percepción-acción siguiente con el mismo procedimiento. Ingresa como situación Actual S3 tomada por los sensores del robot luego de la acción anterior A4 .

Se ordena la Base de Conocimientos por U, P, K quedando el siguiente ranking de teorías:

$$
\begin{array}{ll}
\mathrm{O} & \mathrm{T} 2(\text { Utilidad }=0.9) \\
\mathrm{O} & \mathrm{T} 3(\text { Utilidad }=0.8 ; \mathrm{P}=1 ; \mathrm{K}=3) \\
\mathrm{O} & \mathrm{T} 1(\mathrm{Utilidad}=0.8 ; \mathrm{P}=1 ; \mathrm{K}=2) \\
\mathrm{O} & \mathrm{T} 5(\mathrm{Utilidad}=0.4) \\
\mathrm{O} & \mathrm{T} 6(\text { Utilidad }=0.35) \\
\mathrm{O} & \mathrm{T} 4(\mathrm{Utilidad}=0.3)
\end{array}
$$

Se compara la situación inicial de la primer teoría de la lista de ranking con la Situación Actual (S3). La Situación inicial de T2 es = S3 con lo cual se toma T2 y T2 es el "plan" devuelto por el planificador Ranking, con lo cual el robot realizará la acción A1 en el siguiente paso de la simulación.

Se continúa con el proceso indicado durante al actuación de los n ciclos del SAr, se muestra en la figura G-2 la incorporación de la teoría T6 en la base de conocimientos de teorías del SARr.

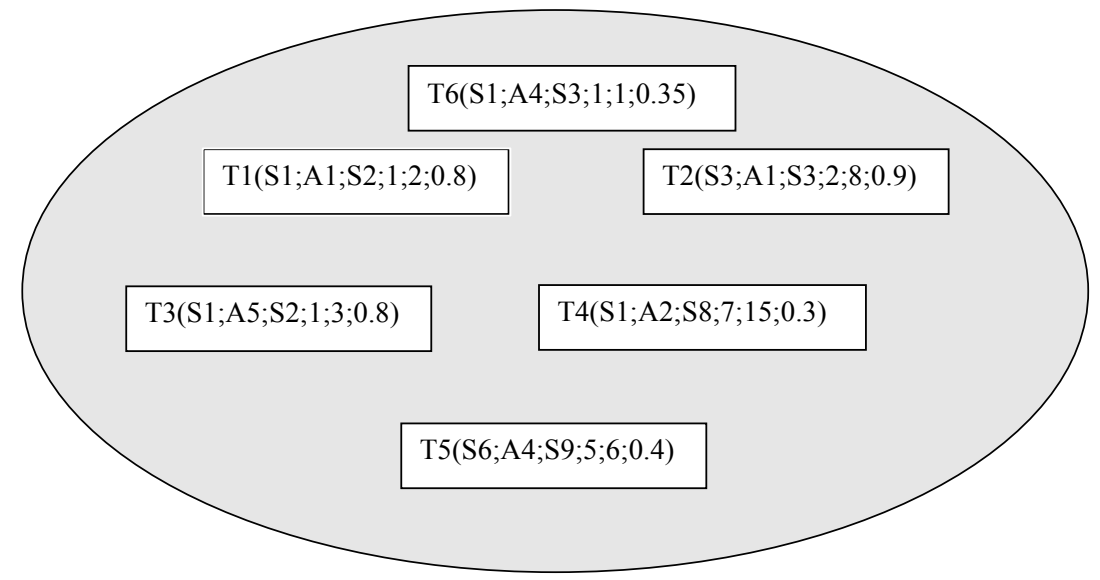

Figura G-2 Base de Conocimientos del SARr actualizada. 


\section{ANEXO H: EJEMPLO DE COOPERACIÓN ENTRE SISTEMAS AUTÓNOMOS DE ROBOTS}

\section{H.1 EJEMPLO}

Se presenta a continuación un ejemplo genérico de cooperación entre un SAR A y un SAR B, ambos sistemas autónomos de robots se encuentran con el mismo estado de evolución born, transitando el mismo layer ( born a newbie).El SAR A cuenta en su base de conocimientos con las teorías: T1,T2, T5, el SAR B cuenta en su base de conocimientos con las teorías: T5, T4, T8.

En primer lugar el SAR A recorre la base de conocimiento de teorías del SAR B, comparando sus teorías en busca de teorías iguales, similares o diferentes, en segundo lugar el SAR B recorre la base de conocimiento de teorías del SAB con el mismo propósito que el SAR A. Finalmente entre ambos SAR generan la base de conocimiento de cooperación SAR A-B que contiene las teorías diferentes entre ambos, las similares y las iguales con su correspondiente estimación de valores $\mathrm{P}, \mathrm{K}$ premiando los éxitos de ambos

En el ejemplo resultan las teorías T5 de la base de conocimiento del SAR A igual a la teoría T5 de la base de conocimiento del SAR B, la teoría T1 de la base de conocimientos del SAR A resulta similar a la teoría T8 de la base de conocimiento del SAR B, la teoría T2 de la base de conocimiento del SAR A y la teoría T4 de la base de conocimientos del SAR B, resultan diferentes.

Se muestra en la figura H-1 un diagrama conceptual de la cooperación entre al SAR A y B, a través del intercambio de sus teorías y la generación de una base de conocimiento de cooperación SAR A$\mathrm{B}$ de explotación común para ambos. Se detalla a continuación el ejemplo de cooperación entre el SAR A y SAR B .En la tablas H-1 se presenta el ejemplo Cooperación entre SAR A y SAR B. 


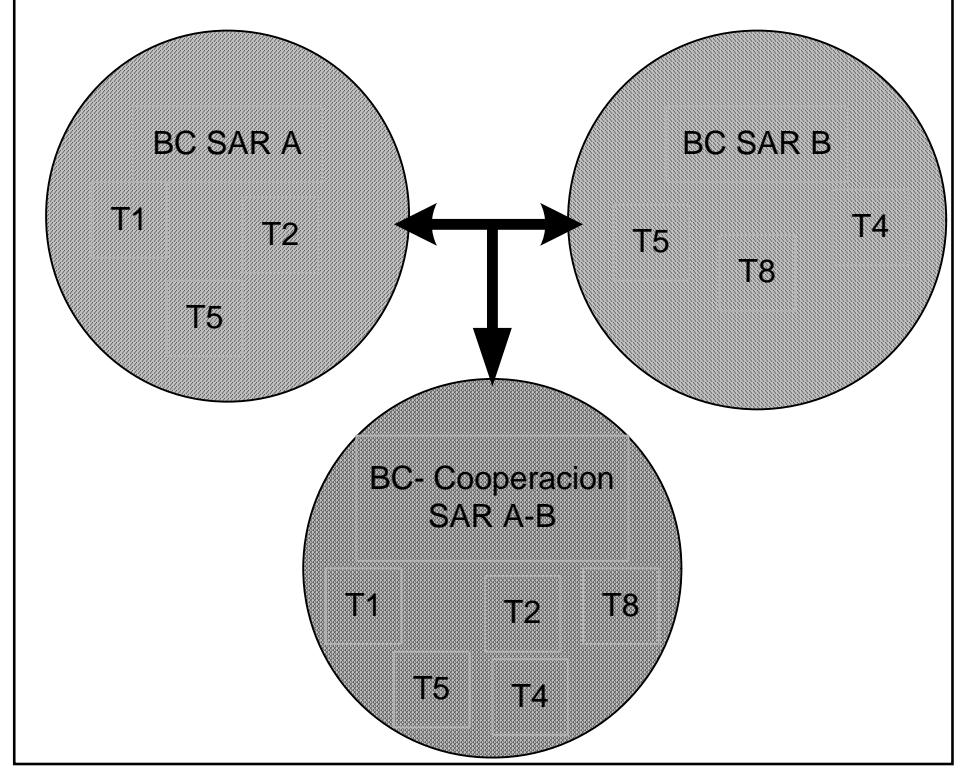

Figura H-1 Cooperación entre SARs

INICIO

ENTRADA: BC SAR A, BC SAR B,

\section{SALIDA: BC Cooperación SAR A-B}

- Se verifica que ambos SARs tienen el mismo estado de evolución y se encuentran transitando el mismo layer

Se recorren todas las teorías de la Base de Conocimiento (BC) del SAR B:

- Se compara teoría T4 de la BC del SAR B

- Se busca teoría igual en la BC SAR A

o Al no encontrar una teoría igual se busca una teoría similar en la BC SAR A

- Al no encontrar una teoría similar en la BC SAR A

- $\quad$ Nuevo $\mathrm{K}=\mathrm{K}_{\mathrm{T} 4}(\mathrm{~B})$

- $\quad$ Nuevo $\mathrm{P}=\mathrm{P}_{\mathrm{T} 4}(\mathrm{~B})$

- Asignar Nuevo K y Nuevo P a T4

- Agregar teoría T4 a la nueva Base de Conocimientos de Cooperación SAR A-B

- Se compara teoría T5 de la BC del SAR B

- Se busca teoría igual en la BC SAR A

o Existe teoría T5 igual a teoría T5 en la BC SAR A

- $\quad$ Nuevo K = KT5(A) + KT5(B)

- $\quad$ Nuevo P = PT5(A) + PT5(B)

- Asignar Nuevo K y Nuevo P a T5

- Agregar la teoría T5 ponderada a la nueva base de conocimientos Cooperación SAR A-B

- $\quad$ Se compara la teoría T8

o Se busca teoría igual en la BC SAR A

- Al no encontrar una teoría igual busca una teoría similar en la BC SAR A 
- Aparece Teoría similar T1

- $\quad$ Nuevo K = KT1(A) + KT8(B)

- $\quad$ Nuevo $\mathrm{P}=\mathrm{PT} 8(\mathrm{~B})$

- Asignar Nuevo K y Nuevo P a teoría T8

- Agregar la teoría T8 ponderada a la nueva base de conocimientos de Cooperación SAR A-B

- Una vez recorridas todas las teorías de BC SAR B se pasa a recorrer las teorías de la BC SAR A:

- Se compara la teoría T1 de la BC SAR A

o Se busca teoría igual en BC SAR B

- Al no encontrar una teoría igual se busca una teoría similar en BC SAR B

- Aparece Teoría similar T8

- $\quad$ Nuevo $\mathrm{K}=\mathrm{KT} 1(\mathrm{~A})+\mathrm{KT} 8(\mathrm{~B})$

- $\quad$ Nuevo P = PT1(A)

- Asignar Nuevo K y Nuevo P a teoría T1

- Agregar la teoría T1 ponderada a la nueva base de conocimientos de Cooperación SAR A-B

- Se compara teoría T2 de la BC SAR A

o Se busca teoría igual en BC SAR B

o Al no encontrar una teoría igual se busca una teoría similar en BC SAR B

- Al no encontrar una teoría similar

- $\quad$ Nuevo K = KT2(B)

- $\quad$ Nuevo P = PT2(B)

- Asignar Nuevo K y Nuevo P a teoría T2

- Agregar teoría T2 a la nueva base de conocimientos de Cooperación SAR A-B

o Se compara T5 Se Busca teoría igual en BC SAR B, al encontrar una teoría igual termina el análisis de esa teoría ya que la misma fue agregada en el anterior bucle

FIN

Tabla H-1 Ejemplo de Cooperación entre Sistemas Autónomos de Robots 


\section{ANEXO I: EJEMPLO DE COLABORACIÓN ENTRE SISTEMAS AUTÓNOMOS DE ROBOTS}

\section{I.1 EJEMPLO}

Se presenta a continuación un ejemplo genérico de colaboración entre un SAR A receptor y un SAR B colaborador que se encuentra en estado de evolución superior transitando un layer superior TBO (newbie a trained) en relación al SAR A receptor que se encuentra en un estado de evolución inferior, transitando un layer inferior BIO ( born a newbie).El SAR A cuenta en su base de conocimientos con las teorías: T1,T2, T5, el SAR B cuenta en su base de conocimientos con las teorías: T3, T6, T5, T4, T8, T9.

En primer lugar el SAR A recorre la base de conocimiento de teorías del SAR B, comparando sus teorías en busca de teorías iguales, similares o diferentes, en segundo lugar el SAR B recorre la base de conocimiento de teorías del SAB con el mismo propósito que el SAR A. Finalmente entre ambos SAR generan la base de conocimiento de Colaboración SAR A-B que contiene las teorías diferentes entre ambos, las similares y las iguales con su correspondiente estimación de valores $\mathrm{P}, \mathrm{K}$ premiando los éxitos de ambos.

En el ejemplo resultan las teorías T5 de la base de conocimiento del SAR A igual a la teoría T5 de la base de conocimiento del SAR B, la teoría T1 de la base de conocimientos del SAR A resulta similar a la teoría T8 de la base de conocimiento del SAR B, la teoría T2 de la base de conocimiento del SAR A y la teoría T4, T3,T6,T9 de la base de conocimientos del SAR B, resultan diferentes.

Se muestra en la figura I-1 un diagrama conceptual de la colaboración del SAR B al SAR A receptor, a través del intercambio de sus teorías y la generación de una base de conocimiento de colaboración SAR A-B de explotación para el SAR A. Se detalla a continuación el ejemplo de colaboración del SAR B al SAR A .En la tabla I-1 se presenta el ejemplo de Colaboración del SAR B al SAR A. 


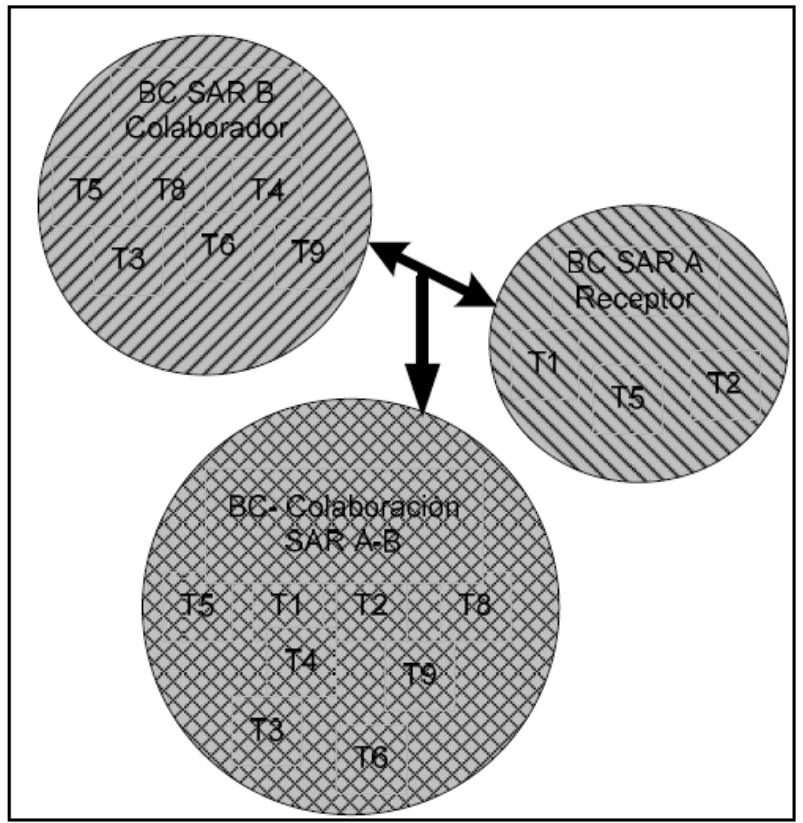

Figura I-1 Colaboración entre SARs

\section{INICIO}

ENTRADA: BC SAR A Receptor, BC SAR B Colaborador,

\section{SALIDA: BC Colaboración SAR A-B}

- $\quad$ Se verifica que el SAR colaborador se encuentran transitando un layer superior y tiene un estado de evolución superior al SAR Receptor

Se recorren todas las teorías de la Base de Conocimiento (BC) del SAR B Colaborador:

- Se compara teoría T3 de la BC del SAR B Colaborador

o Se busca teoría igual en la BC SAR A Receptor

o Al no encontrar una teoría igual se busca una teoría similar en la BC SAR A Receptor

- Al no encontrar una teoría similar en la BC SAR A Receptor

- $\quad$ Nuevo $\mathrm{K}=\mathrm{K}_{\mathrm{T} 3}(\mathrm{~B})$

- $\quad$ Nuevo $\mathrm{P}=\mathrm{P}_{\mathrm{T} 3}(\mathrm{~B})$

- Asignar Nuevo K y Nuevo P a T3

- Agregar teoría T3 a la nueva Base de Conocimientos de Colaboración SAR A-B

- Se compara teoría T4 de la BC del SAR B Colaborador

o Se busca teoría igual en la BC SAR A Receptor

o Al no encontrar una teoría igual se busca una teoría similar en la BC SAR A Receptor

- Al no encontrar una teoría similar en la BC SAR A Receptor

- $\quad$ Nuevo $\mathrm{K}=\mathrm{K}_{\mathrm{T} 4}(\mathrm{~B})$

- Nuevo $\mathrm{P}=\mathrm{P}_{\mathrm{T} 4}(\mathrm{~B})$ 
- Asignar Nuevo K y Nuevo P a T4

- Agregar teoría T4 a la nueva Base de Conocimientos de Colaboración SAR A-B

- Se compara teoría T5 de la BC del SAR B Colaborador

- Se busca teoría igual en la BC SAR A Receptor

o Existe teoría T5 igual a teoría T5 en la BC SAR A Receptor

- $\quad$ Nuevo $\mathrm{K}=\mathrm{KT5}(\mathrm{A})+\mathrm{KT5}(\mathrm{B})$

- $\quad$ Nuevo P = PT5(A) + PT5(B)

- Asignar Nuevo K y Nuevo P a T5

- Agregar la teoría T5 ponderada a la nueva base de conocimientos Colaboración SAR A-B

- Se compara teoría T6 de la BC del SAR B Colaborador

o Se busca teoría igual en la BC SAR A Receptor

- Al no encontrar una teoría igual se busca una teoría similar en la BC SAR A Receptor

- Al no encontrar una teoría similar en la BC SAR A Receptor

- $\quad$ Nuevo $\mathrm{K}=\mathrm{K}_{\mathrm{T} 6}(\mathrm{~B})$

- $\quad$ Nuevo $\mathrm{P}=\mathrm{P}_{\mathrm{T} 6}(\mathrm{~B})$

- Asignar Nuevo K y Nuevo P a T6

- Agregar teoría T6 a la nueva Base de Conocimientos de Colaboración SAR A-B

- Se compara la teoría T8 de la BC del SAR B Colaborador

- Se busca teoría igual en la BC SAR A Receptor

o Al no encontrar una teoría igual busca una teoría similar en la BC SAR A Receptor

- Aparece Teoría similar T1

- $\quad$ Nuevo $\mathrm{K}=\mathrm{KT} 1(\mathrm{~A})+\mathrm{KT} 8(\mathrm{~B})$

- Nuevo $\mathrm{P}=\mathrm{PT} 8(\mathrm{~B})$

- Asignar Nuevo K y Nuevo P a teoría T8

- Agregar la teoría T8 ponderada a la nueva base de conocimientos de Colaboración SAR A-B

- Se compara teoría T9 de la BC del SAR B Colaborador

- Se busca teoría igual en la BC SAR A Receptor

- Al no encontrar una teoría igual se busca una teoría similar en la BC SAR A Receptor

- Al no encontrar una teoría similar en la BC SAR A Receptor

- $\quad$ Nuevo $\mathrm{K}=\mathrm{K}_{\mathrm{T} 9}(\mathrm{~B})$

- $\quad$ Nuevo $\mathrm{P}=\mathrm{P}_{\mathrm{T} 9}(\mathrm{~B})$

- Asignar Nuevo K y Nuevo P a T9

- Agregar teoría T9 a la nueva Base de Conocimientos de Colaboración SAR A-B 
- Una vez recorridas todas las teorías de BC SAR B se pasa a recorrer las teorías de la BC SAR A: Receptor

- Se compara la teoría T1 de la BC SAR A Receptor

o Se busca teoría igual en BC SAR B Colaborador

o Al no encontrar una teoría igual se busca una teoría similar en BC SAR B Colaborador

- Aparece Teoría similar T8

- $\quad$ Nuevo $\mathrm{K}=\mathrm{KT} 1(\mathrm{~A})+\mathrm{KT} 8(\mathrm{~B})$

- $\quad$ Nuevo P = PT1(A)

- Asignar Nuevo K y Nuevo P a teoría T1

- Agregar la teoría T1 ponderada a la nueva base de conocimientos de Colaboración SAR A-B

- Se compara teoría T2 de la BC SAR A Receptor

o Se busca teoría igual en BC SAR B Colaborador

o Al no encontrar una teoría igual se busca una teoría similar en BC SAR B Colaborador

- Al no encontrar una teoría similar

- $\quad$ Nuevo K = KT2(B)

- $\quad$ Nuevo $\mathrm{P}=\mathrm{PT} 2(\mathrm{~B})$

- Asignar Nuevo K y Nuevo P a teoría T2

- Agregar teoría T2 a la nueva base de conocimientos de Colaboración SAR A-B

- Se compara T5 Se Busca teoría igual en BC SAR B Colaborador, al encontrar una teoría igual termina el análisis de esa teoría ya que la misma fue agregada en el anterior bucle

FIN

Tabla I-1 Ejemplo de Colaboración entre Sistemas Autónomos de Robots 


\section{ANEXO J: REGISTRO DE ESTADÍSTICAS DEL SISTEMA AUTÓNOMO DE ROBOT}

\section{J.1 REGISTRO ESTADÍSTICAS SAR}

Se presenta en la tabla J-1 el archivo de registro (txt) de estadística efectuado por el SAR durante su actuación de 600 ciclos de percepción - acción. Cada registro del archivo se corresponde con el intervalo de 20 ciclos, registrándose cada una de las estadísticas del SAR de izquierda a derecha separadas por punto y coma, en el siguiente orden para su lectura: ciclo; situaciones; teorías acumuladas; utilidad teorías [0-0.25]; utilidad teorías [ $>0.25-0.5]$; utilidad teorías [ $>0.5-0.75]$; utilidad teorías [ $>0.75-1]$; cantidad de planes; cantidad de planes exitosos; cantidad de planes sin éxito, cantidad de azares; relación $\mathrm{p} / \mathrm{k} 1$ [0-0.25]; $\mathrm{p} / \mathrm{k} 2$ relación [ $>0.25-0.5]$; relación $\mathrm{p} / \mathrm{k} 3[>0.5$ 0.75]; relación p/k4[>0.75-1]; relación p/k general; cantidad de ciclos exitosos.

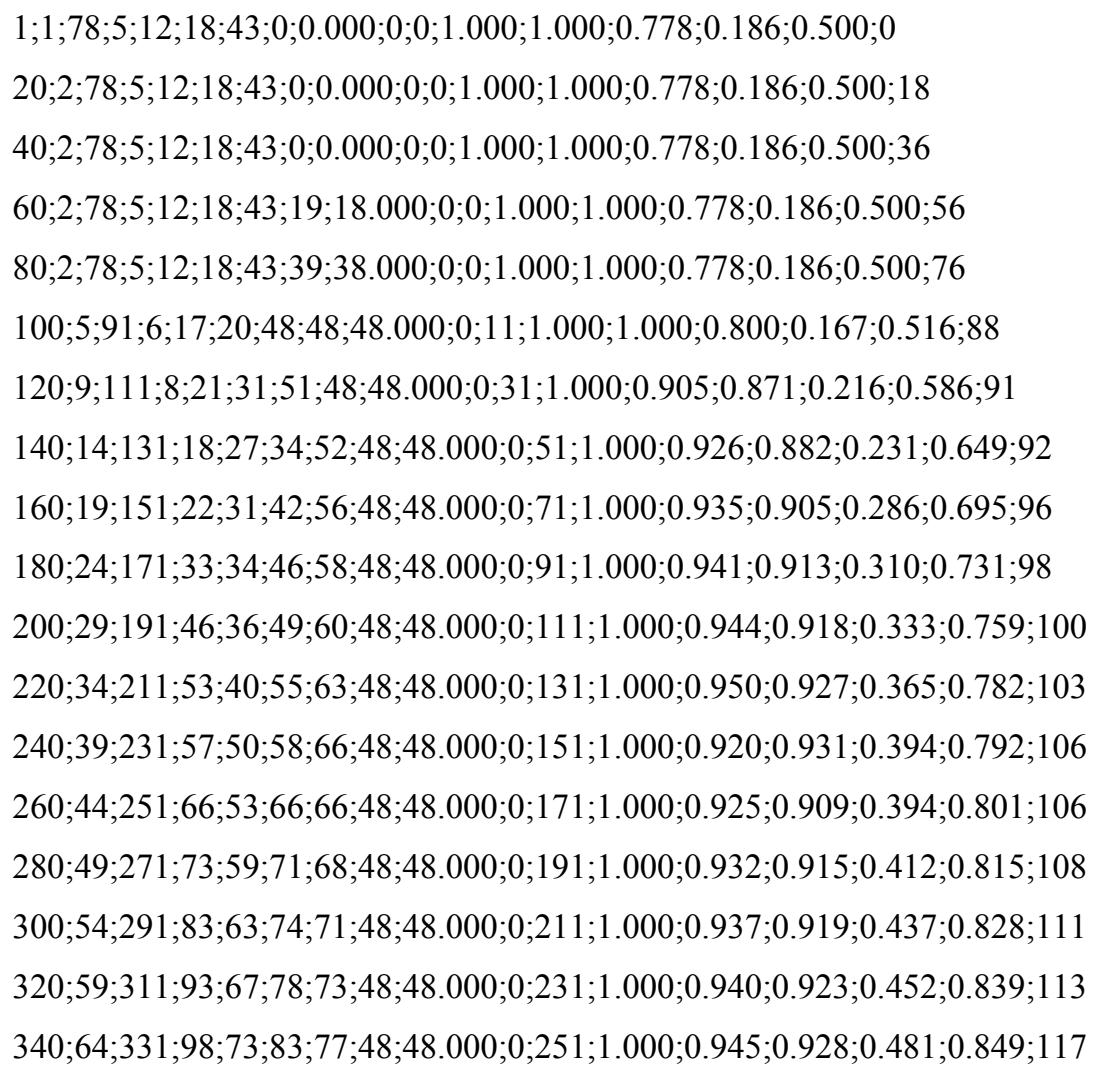


360;69;351;102;77;94;78;48;48.000;0;271;1.000;0.948;0.936;0.487;0.858;118
380;74;371;111;83;99;78;48;48.000;0;291;0.982;0.952;0.939;0.487;0.860;118
400;78;391;118;89;103;81;48;48.000;0;311;0.983;0.955;0.922;0.506;0.862;121
420;83;411;129;93;107;82;48;48.000;0;331;0.984;0.957;0.925;0.512;0.869;122
440;88;431;140;98;110;83;48;48.000;0;351;0.986;0.959;0.927;0.518;0.875;123
460;93;451;145;106;115;85;48;48.000;0;371;0.986;0.962;0.930;0.529;0.880;125
$480 ; 97 ; 471 ; 150 ; 113 ; 123 ; 85 ; 48 ; 48.000 ; 0 ; 391 ; 0.987 ; 0.965 ; 0.935 ; 0.529 ; 0.885 ; 125$
$500 ; 101 ; 491 ; 153 ; 122 ; 131 ; 85 ; 48 ; 48.000 ; 0 ; 411 ; 0.987 ; 0.967 ; 0.939 ; 0.529 ; 0.890 ; 125$
$520 ; 104 ; 508 ; 156 ; 125 ; 138 ; 89 ; 52 ; 52.000 ; 0 ; 427 ; 0.987 ; 0.968 ; 0.942 ; 0.528 ; 0.890 ; 132$
$540 ; 106 ; 521 ; 157 ; 130 ; 141 ; 93 ; 60 ; 59.000 ; 0 ; 439 ; 0.987 ; 0.969 ; 0.943 ; 0.548 ; 0.893 ; 143$
$560 ; 106 ; 521 ; 157 ; 130 ; 141 ; 93 ; 80 ; 79.000 ; 0 ; 439 ; 0.987 ; 0.969 ; 0.943 ; 0.548 ; 0.893 ; 163$
$580 ; 108 ; 531 ; 159 ; 132 ; 144 ; 96 ; 92 ; 92.000 ; 0 ; 447 ; 0.987 ; 0.970 ; 0.944 ; 0.531 ; 0.889 ; 176$
$600 ; 113 ; 551 ; 168 ; 136 ; 148 ; 99 ; 92 ; 92.000 ; 0 ; 467 ; 0.988 ; 0.971 ; 0.946 ; 0.545 ; 0.893 ; 179$

Tabla J-1 Archivo de registro de estadísticas del SAR

Sobre la base de los datos del registro de estadística se determinan : [a]cantidad de teorías nuevas, ésta surge de la diferencia entre teorías acumuladas en el ciclo i menos la cantidad de teorías acumuladas en el primer ciclo, $[\mathrm{b}]$ el porcentaje de ciclos exitosos, éste se determina sobre la base de la relación entre la cantidad de ciclos exitosos y la cantidad de ciclos ejecutados hasta el momento i, [b] la cantidad de teorías exitosas surge de la cantidad total acumulada de teorías cuya utilidad se corresponde con el rango mayor a 0,75 y menor o igual a 1.

El archivo de registro de estadísticas del SAR se construye sobre la base del registro de teorías, se muestra un ejemplo parcial (treinta ciclos) de este registro en la tabla J-2. Sobre la base de estos registros se desarrollan los registros de teorías que se almacenan en la base de conocimiento del SAR en XML.

La estructura del registro presentado en la tabla J-2 es : ciclo, sensor 0 , sensor ${ }_{1}$ sensor $_{2}$, sensor 3 , sensor $_{4}$, sensor 5 , sensor 6 , sensor 7 , velocidad rueda 0 , velocidad rueda 1 ,utilidad.

El encadenamiento de estos registros conforma la base de conocimiento del SAR donde figura la situación inicial (sensor $0, \ldots .$. sensor 7 ), acción (velocidad rueda 0 , velocidad rueda 1 ), situación final (situación correspondiente al ciclo presente +1 ), $\mathrm{p}, \mathrm{k}$, utilidad. Se muestra un ejemplo en el Anexo C. 
$10 ; 31.857 ; 10.979 ; 49.540 ; 37.384 ; 28.423 ; 42.428 ; 31.735 ; 15.737 ; 235.370 ; 237.314 ; 0.287$ $11 ; 31.857 ; 10.979 ; 49.540 ; 37.384 ; 28.423 ; 42.428 ; 31.735 ; 15.737 ; 235.370 ; 237.314 ; 0.286$ $12 ; 31.857 ; 10.979 ; 49.540 ; 37.384 ; 28.423 ; 42.428 ; 31.735 ; 15.737 ; 235.370 ; 237.314 ; 0.285$ $13 ; 46.371 ; 36.536 ; 41.043 ; 37.324 ; 47.094 ; 57.534 ; 15.600 ; 14.922 ; 795.000 ; 142.000 ; 0.287$ $14 ; 46.371 ; 36.536 ; 41.043 ; 37.324 ; 47.094 ; 57.534 ; 15.600 ; 14.922 ; 227.135 ; 240.283 ; 0.285$ $15 ; 46.371 ; 36.536 ; 41.043 ; 37.324 ; 47.094 ; 57.534 ; 15.600 ; 14.922 ; 227.135 ; 240.283 ; 0.283$ $16 ; 46.371 ; 36.536 ; 41.043 ; 37.324 ; 47.094 ; 57.534 ; 15.600 ; 14.922 ; 227.135 ; 240.283 ; 0.281$ 17;33.579;34.778;41.231;45.456;16.234;14.859;55.891;10.086;232.092;239.132;0.280 $18 ; 33.579 ; 34.778 ; 41.231 ; 45.456 ; 16.234 ; 14.859 ; 55.891 ; 10.086 ; 232.092 ; 239.132 ; 0.280$ 19;33.579;34.778;41.231;45.456;16.234;14.859;55.891;10.086;-308.000;582.000;0.269 20;33.579;34.778;41.231;45.456;16.234;14.859;55.891;10.086;232.092;239.132;0.269 21;45.763;21.096;13.855;45.057;27.337;42.534;44.415;23.778;236.084;233.144;0.269 22;45.763;21.096;13.855;45.057;27.337;42.534;44.415;23.778;236.084;233.144;0.269 23;45.763;21.096;13.855;45.057;27.337;42.534;44.415;23.778;236.084;233.144;0.269 24;45.763;21.096;13.855;45.057;27.337;42.534;44.415;23.778;236.084;233.144;0.269 25;11.718;28.272;20.073;44.325;55.240;26.246;31.831;14.928;242.814;239.275;0.269 26;11.718;28.272;20.073;44.325;55.240;26.246;31.831;14.928;242.814;239.275;0.270 $27 ; 11.718 ; 28.272 ; 20.073 ; 44.325 ; 55.240 ; 26.246 ; 31.831 ; 14.928 ; 242.814 ; 239.275 ; 0.270$ 28;11.718;28.272;20.073;44.325;55.240;26.246;31.831;14.928;112.000;-533.000;0.255 $29 ; 57.087 ; 55.067 ; 37.623 ; 44.413 ; 54.050 ; 39.532 ; 37.826 ; 17.411 ; 222.233 ; 239.508 ; 0.255$ $30 ; 57.087 ; 55.067 ; 37.623 ; 44.413 ; 54.050 ; 39.532 ; 37.826 ; 17.411 ; 222.233 ; 239.508 ; 0.255$ $31 ; 57.087 ; 55.067 ; 37.623 ; 44.413 ; 54.050 ; 39.532 ; 37.826 ; 17.411 ; 222.233 ; 239.508 ; 0.255$ $32 ; 57.087 ; 55.067 ; 37.623 ; 44.413 ; 54.050 ; 39.532 ; 37.826 ; 17.411 ; 222.233 ; 239.508 ; 0.255$ $33 ; 40.784 ; 20.760 ; 49.272 ; 13.417 ; 35.124 ; 14.090 ; 34.851 ; 45.242 ; 231.331 ; 233.044 ; 0.255$ $34 ; 40.784 ; 20.760 ; 49.272 ; 13.417 ; 35.124 ; 14.090 ; 34.851 ; 45.242 ; 231.331 ; 233.044 ; 0.256$ $35 ; 40.784 ; 20.760 ; 49.272 ; 13.417 ; 35.124 ; 14.090 ; 34.851 ; 45.242 ; 231.331 ; 233.044 ; 0.256$ $36 ; 40.784 ; 20.760 ; 49.272 ; 13.417 ; 35.124 ; 14.090 ; 34.851 ; 45.242 ; 231.331 ; 233.044 ; 0.257$ $37 ; 30.915 ; 12.949 ; 17.579 ; 57.876 ; 31.358 ; 38.435 ; 57.521 ; 51.614 ; 243.547 ; 222.218 ; 0.257$ $38 ; 30.915 ; 12.949 ; 17.579 ; 57.876 ; 31.358 ; 38.435 ; 57.521 ; 51.614 ; 243.547 ; 222.218 ; 0.256$ $39 ; 30.915 ; 12.949 ; 17.579 ; 57.876 ; 31.358 ; 38.435 ; 57.521 ; 51.614 ; 243.547 ; 222.218 ; 0.256$

Tabla J-2 Archivo de registro de teorías del SAR 


\section{ANEXO K: CONFIGURACIÓN, TIPO DE SISTEMA AUTÓNOMO DE ROBOT Y MÉTODOS} ASOCIADOS

\section{K 1 CONFIGURACIÓN, TIPO SAR Y MÉTODOS ASOCIADOS}

Se presenta en la tabla K-1 un ejemplo de un archivo que contiene los parámetros de configuración, tipo de SAR y métodos asociados. En este orden se detallan: [a] $\mathrm{PATH}=\mathrm{C}$ : la ruta para el archivo de registro de estadísticas promedio del SAR, [b] PATH_SENSORES $=\mathrm{C}$ : la ruta correspondiente al registro de estadística de la corrida del SAR. Estas son las mediciones de los sensores (sin normalizar) en cada uno de los ciclos, [c] el intervalo que se aplica para el rango de utilidad y el rango de valores $\mathrm{P} / \mathrm{K}$, INTERVALO-TEORÍA-P/K=0,25, [d] el intervalo entre ciclos sobre el que se toma la muestra, (cada $\mathrm{n}$ ciclos), $\mathrm{CICLOS}=20$, [e] la selección de ponderador de planes PONDERAR=TRUE, [f] el umbral de ponderación del plan para ser considerado apto, $\mathrm{UMBRAL}=0,5,[\mathrm{~g}]$ la selección de SAR con planificador o sin planificador (SAR reactivo) en este caso se selecciona un SAR con planificador, PLANIFICAR=TRUE, [h] la elección del tipo de planificador entre clásico y ranking de teorías, en este caso PLANIFICADOR=CLÁSICO,[i] compartición de teorías COMPARTICIÓN-TEORÍAS=FALSE en este caso no se aplica ni cooperación (intercambio) de bases de conocimiento de teorías entre SARs que se encuentran en el mismo nivel de evolución y layer, ni se aplica colaboración desde una base de conocimiento de teorías de un SAR colaborador que se encuentran en un nivel de evolución superior y layer superior en su LLC en relación al SAR receptor, [j] la aplicación de mutación de teorías MUTAR= (TRUE), con los siguientes parámetros PROPORCIÓN-MUTACIÓN (sobre el lote de teorías similares) = (0,5), MÁXIMO-MUTACIÓN=4, [k] los parámetros asociados al SAR: ROBOT=EPUCK, CICLOS $=600$, CICLOS_PREVIOS $=400$, TAMANIO_BASE DE CONOCIMIENTO $=10000,[1]$ los parámetros asociados al ROBOT, TIME_STEP= 64 milisegundos (ciclo-percepción-acción del SAR), CALCULO_UTILIDAD = COEFICIENTES, los tipos de cálculo de utilidad son el basado en la situación (clásica) y el basado en la acción (coeficientes), los métodos para la comparación teorías son exacto, umbral fijo, umbral variable, se aplica por defecto umbral variable, [m] se declaran los parámetros asociados al robot E-PUCK correspondientes a los valores de desvío 
estándar aplicados para la comparación de teorías, con el método de coeficientes. En este orden se presentan la TOLERANCIA_ACCION_EPUCK para cada una de las dos ruedas y la TOLERANCIA_SITUACION_EPUCK para cada uno de los ocho sensores de proximidad, [n] la ruta correspondiente a la base de conocimiento que guarda las teorías registradas (aprendizaje del $\mathrm{SAR}$ ), representada por el archivo de teorías en XML.

Los parámetros correspondientes a la evolución del SAR no se incorporaron en la configuración del SAR, si bien se consideraron por observación directa de las muestras de los registros estadísticos de la actuación del SAR durante la etapa experimental, con independencia del resultado de evolución, en la experimentación los SARs se configuraron para ejecutar la totalidad de los ciclos previstos. En este orden se determinaron para SARp los siguientes valores: de rendimiento de ciclos exitosos $(\mathrm{RCE}=58 \%)$ y de rendimiento de teorías nuevas $(\mathrm{RTN}=27 \%)$. Para el SARr se determinaron los siguientes valores: de rendimiento de ciclos exitosos $(\mathrm{RCE}=32 \%)$ y de rendimiento de teorías nuevas $(\mathrm{RTN}=51 \%)$.

[LOG]

PATH=C:|Data|wb|webots.log

LEVEL $=\mathrm{B}$

[ESTADISTICA]

PATH=C: $\backslash$ Data $\backslash$ Pruebas $\backslash$ Prueba $1 \backslash T X T$ estadisticaslestadisticas.txt

INTERVALO_TEORIA-P/K $=0.25$

$\mathrm{CICLO}=20$

PATH_SENSORES=C: $\backslash$ Data $\backslash$ Pruebas $\backslash$ Prueba 1 lestadisticasTXT lestadisticas_epuck10.txt

[PONDERADOR DE PLANES]

PONDERAR $=$ TRUE

UMBRAL $=0.5$

\#Valores posibles PONDERADOR: "TRUE" ; "FALSE"

[PLANIFICADOR]

PLANIFICAR $=$ TRUE

\#Valores posibles PLANIFICADOR: "TRUE" implica empleo de SAR CON PLANIFICADOR;

"FALSE",implica el empleo de SAR REACTIVO

PLANIFICADOR $=$ CLASICO

\#Valores posibles PLANIFICADOR: "RANKING"; "CLASICO" 
[COMPARTICION TEORIAS]

COMPARTICION TEORIAS $=$ FALSE

[MUTACION DE TEORIAS]

MAXIMO_MUTACION $=4$

MUTAR $=$ TRUE

PROPORCION_MUTACION $=0.5$

[SAR

ROBOT $=$ EPUCK

CICLOS $=600$

CICLOS PREVIOS $=400$

TAMANIO_BASE DE CONOCIMIENTO $=10000$

\#Para el método GetListaOrdenada() de Controlador.cpp

[ROBOT]

TIME_STEP $=64$

CALCULO_UTILIDAD $=$ COEFICIENTES

\#Valores posibles CÁLCULO_UTILIDAD: " BASADO EN LA SITUACIÓN (CLÁSICA) ;

"BASADO EN LA ACCIÓN (COEFICIENTES)"

\#Valores " posibles COMPARACIÓN TEORÍA: "EXACTO" ; "UMBRAL FIJO" ;

"UMBRAL VARIABLE", SE APLICÓ POR DEFECTO "UMBRAL VARIABLE"

[EPUCK]

TOLERANCIA_ACCION_EPUCK_0 $=80.64$

TOLERANCIA_ACCION_EPUCK_1 $=68.29$

\#Valores obtenidos a partir del Desvío Standard Ruedas

TOLERANCIA_SITUACION_EPUCK_0 $=147.33$

TOLERANCIA_SITUACION_EPUCK_1 $=238.14$

TOLERANCIA_SITUACION_EPUCK_2 $=259.18$

TOLERANCIA_SITUACION_EPUCK_3 $=66.67$

TOLERANCIA_SITUACION_EPUCK_4 $=45.58$

TOLERANCIA_SITUACION_EPUCK_5 $=57.24$

TOLERANCIA_SITUACION_EPUCK_6 $=42.09$

TOLERANCIA_SITUACION_EPUCK_7=51.53

\#Valores obtenidos a partir del Desvío Standard Sensores

[PERSISTENCIA]

PATH $=$ C: $\backslash$ Data $\backslash w b \backslash$ Base_Reactivo_A-B_Born_SIAR.xml

CARGAR_BASE DE CONOCIMIENTO $=$ TRUE

GUARDAR_BASE DE CONOCIMIENTO = TRAE

[EVOLUCION]

\#Valores de rendimiento: $\mathrm{RCE}=58 \%$ para $\mathrm{SARp}$ y $\mathrm{RCE}=32 \%$ para $\mathrm{SAR}$, $\mathrm{RTN}=27 \%$ para SARp, RTN=51\% para SARr.

Tabla K-1 Archivo de configuración, tipo de SAR y métodos asociados 
En la Sección N-7 del Anexo N “Soporte Digital”, se incluye un ejemplo del archivo de log de ejecución del sistema en el ambiente Webots. 


\section{ANEXO L: REGISTRO DE ESTADÍSTICAS DE LOS EXPERIMENTOS}

El propósito de este anexo es presentar las tablas de datos con los resultados promedio de las diez experimentaciones realizadas para cada configuración y tipo de SAR, dando lugar a las distintas extensiones de SAR (sección 4.7 del Capítulo 4). Las tablas se construyen sobre la base de los archivos de registro de estadísticas del SAR (Anexo J), las que se aplican en los grupos de experimentos detallados en el Capítulo 5 Experimentación.

Se presentan en la sección L-1 para el SAR con planificador clásico (SARp) las tablas de datos promedio de cada una de las extensiones que se aplican en el Capítulo 5 Experimentación y en la sección L-2 se presenta para el SAR con planificador por ranking de teorías (SARr) las tablas de datos promedio de cada una de las extensiones que se aplican en el Capítulo 5 Experimentación. Finalmente en la sección L-3 se presenta la determinación de los porcentajes para ciclos exitosos (\% CEA), la determinación de porcentaje de teorías nuevas alcanzadas (\% TNA), los porcentajes de rendimientos de ciclos exitosos ( \% RCE) y los porcentajes de rendimiento de teorías nuevas $(\%$ RTN), aplicados en la experimentación.

\section{L-1 SARP EN FUNCIÓN DE LA CONFIGURACIÓN Y TIPO}

Se presentan en esta sección las tablas correspondientes a las extensiones de SARp: "SN" en la subsección L-1.1 "SI" en la subsección L-1.2, "SC" tabla L-1-3, "SIC" tabla L-1-4. "SPM" tabla L1-5, "SPMI" tabla L-1-6, "SPMC" tabla L-1-7, "SPMIC" tabla L-1-8.

\section{L-1.1 SARP NEUTRO “SN".}

Los resultados promedio del SARp o SAR neutro "SN" se muestran a continuación en la tabla L-1. Este SARp no tiene métodos asociados y sólo aplica la base inicial de teorías de base generadas por un SAR reactivo (SAR R). 


\begin{tabular}{|c|c|c|c|c|c|c|c|}
\hline Ciclo & $\begin{array}{c}\text { Cantidad } \\
\text { de } \\
\text { Situaciones }\end{array}$ & \begin{tabular}{|c|} 
Cantidad \\
de \\
Teorías \\
acumuladas
\end{tabular} & $\begin{array}{c}\text { Cantidad } \\
\text { de } \\
\text { Teorías } \\
\text { nuevas }\end{array}$ & \begin{tabular}{|c|} 
Cantidad \\
de \\
Teorías \\
exitosas
\end{tabular} & $\begin{array}{c}\text { Cantidad } \\
\text { de } \\
\text { Planes } \\
\text { Exitosos }\end{array}$ & \begin{tabular}{|c|} 
Cantidad \\
de \\
Ciclos \\
Exitosos
\end{tabular} & $\begin{array}{c}\% \\
\text { Ciclos } \\
\text { Exitosos }\end{array}$ \\
\hline 1,00 & 1,00 & 87,00 & 0 & 56,00 & 0,00 & 0,00 & 0,00 \\
\hline 20,00 & 2,00 & 87,00 & 0 & 56,00 & 7,67 & 9,00 & 0,45 \\
\hline 40,00 & 5,67 & 91,67 & 4,67 & 57,67 & 23,33 & 22,67 & 0,57 \\
\hline 60,00 & 10,00 & 111,67 & 24,67 & 61,67 & 23,33 & 40,00 & 0,67 \\
\hline 80,00 & 15,00 & 131,00 & 44 & 63,00 & 24,33 & 42,00 & 0,53 \\
\hline 100,00 & 19,67 & 151,00 & 64 & 65,00 & 25,33 & 44,00 & 0,44 \\
\hline 120,00 & 24,33 & 171,00 & 84 & 69,00 & 25,33 & 48,00 & 0,40 \\
\hline 140,00 & 29,00 & 191,00 & 104 & 70,67 & 25,33 & 49,67 & 0,35 \\
\hline 160,00 & 34,00 & 211,00 & 124 & 73,33 & 25,33 & 52,33 & 0,33 \\
\hline 180,00 & 39,00 & 231,00 & 144 & 77,00 & 25,33 & 56,00 & 0,31 \\
\hline 200,00 & 44,00 & 250,00 & 163 & 80,33 & 27,33 & 60,33 & 0,30 \\
\hline 220,00 & 49,00 & 270,00 & 183 & 80,33 & 27,33 & 60,33 & 0,27 \\
\hline 240,00 & 53,67 & 290,00 & 203 & 80,67 & 27,33 & 60,67 & 0,25 \\
\hline 260,00 & 58,67 & 310,00 & 223 & 83,00 & 27,33 & 63,00 & 0,24 \\
\hline 280,00 & 63,67 & 330,00 & 243 & 84,00 & 27,33 & 64,00 & 0,23 \\
\hline 300,00 & 68,33 & 350,00 & 263 & 85,33 & 27,33 & 65,33 & 0,22 \\
\hline 320,00 & 73,33 & 370,00 & 283 & 88,33 & 27,33 & 68,33 & 0,21 \\
\hline 340,00 & 78,33 & 389,00 & 302 & 89,33 & 27,33 & 69,33 & 0,20 \\
\hline 360,00 & 83,00 & 407,00 & 320 & 90,67 & 29,67 & 72,67 & 0,20 \\
\hline 380,00 & 88,00 & 427,00 & 340 & 94,67 & 30,67 & 76,67 & 0,20 \\
\hline 400,00 & 93,00 & 447,00 & 360 & 95,00 & 30,67 & 77,00 & 0,19 \\
\hline 420,00 & 97,67 & 466,33 & 379,33 & 98,33 & 32,00 & 81,00 & 0,19 \\
\hline 440,00 & 102,67 & 486,33 & 399,33 & 99,00 & 32,00 & 81,67 & 0,19 \\
\hline 460,00 & 107,67 & 506,33 & 419,33 & 99,67 & 32,00 & 82,33 & 0,18 \\
\hline 480,00 & 111,00 & 526,33 & 439,33 & 103,33 & 32,00 & 86,00 & 0,18 \\
\hline 500,00 & 115,33 & 545,67 & 458,67 & 106,00 & 33,33 & 89,33 & 0,18 \\
\hline 520,00 & 119,67 & 565,67 & 478,67 & 107,67 & 33,33 & 91,00 & 0,18 \\
\hline 540,00 & 124,00 & 585,67 & 498,67 & 108,67 & 33,33 & 92,00 & 0,17 \\
\hline 560,00 & 126,67 & 598,00 & 511 & 109,33 & 39,00 & 100,33 & 0,18 \\
\hline 580,00 & 127,33 & 601,67 & 514,67 & 110,00 & 52,67 & 117,33 & 0,20 \\
\hline 600,00 & 127,67 & 609,33 & 522,33 & 111,00 & 59,67 & 130,00 & 0,22 \\
\hline
\end{tabular}

Tabla L-1 SARp “SN” 


\section{L-1.2 SARP INTERCAMBIO “SI"}

Los resultados promedio del SARp- Cooperación "SI" se muestran a continuación en la tabla L-2. Este SARp no tiene métodos asociados y emplea la base de conocimiento de intercambio o cooperación generada con otro SAR que se encuentra en el mismo nivel de layer.

\begin{tabular}{|c|c|c|c|c|c|c|c|}
\hline Ciclos & Situaciones & $\begin{array}{c}\text { Cantidad de } \\
\text { Teorías } \\
\text { acumuladas }\end{array}$ & \begin{tabular}{c|} 
Cantidad \\
de \\
teorías \\
nuevas \\
\end{tabular} & $\begin{array}{c}\text { Teorías } \\
U \\
{[0.75 ; 1]}\end{array}$ & $\begin{array}{c}\text { Cantidad } \\
\text { Planes } \\
\text { Exitosos }\end{array}$ & $\begin{array}{c}\text { Ciclos } \\
\text { Exitosos }\end{array}$ & $\begin{array}{l}\% \text { Ciclos } \\
\text { Exitosos }\end{array}$ \\
\hline 1,00 & 1,00 & 2758,00 & 0 & 426,00 & 0,00 & 0,00 & 0,00 \\
\hline 20,00 & 2,00 & 2758,00 & 0 & 426,00 & 8,00 & 19,00 & 0,95 \\
\hline 40,00 & 2,00 & 2758,00 & 0 & 426,00 & 28,00 & 39,00 & 0,98 \\
\hline 60,00 & 2,00 & 2758,00 & 0 & 426,00 & 48,00 & 59,00 & 0,98 \\
\hline 80,00 & 2,00 & 2758,00 & 0 & 426,00 & 68,00 & 79,00 & 0,99 \\
\hline 100,00 & 2,00 & 2758,00 & 0 & 426,00 & 88,00 & 99,00 & 0,99 \\
\hline 120,00 & 3,00 & 2758,00 & 0 & 426,00 & 107,33 & 119,00 & 0,99 \\
\hline 140,00 & 6,00 & 2768,33 & 10,33 & 427,33 & 116,33 & 129,00 & 0,92 \\
\hline 160,00 & 11,00 & 2788,33 & 30,33 & 431,67 & 116,33 & 133,33 & 0,83 \\
\hline 180,00 & 16,00 & 2808,33 & 50,33 & 437,67 & 116,33 & 139,33 & 0,77 \\
\hline 200,00 & 21,00 & 2824,00 & 66 & 439,33 & 116,33 & 141,33 & 0,71 \\
\hline 220,00 & 26,00 & 2843,67 & 85,67 & 442,67 & 116,33 & 144,67 & 0,66 \\
\hline 240,00 & 30,33 & 2860,67 & 102,67 & 442,67 & 116,33 & 144,67 & 0,60 \\
\hline 260,00 & 34,67 & 2880,33 & 122,33 & 444,00 & 116,33 & 146,33 & 0,56 \\
\hline 280,00 & 39,67 & 2900,33 & 142,33 & 447,33 & 116,33 & 149,67 & 0,53 \\
\hline 300,00 & 44,67 & 2919,67 & 161,67 & 449,33 & 116,33 & 151,67 & 0,51 \\
\hline 320,00 & 49,67 & 2938,67 & 180,67 & 455,00 & 118,33 & 158,33 & 0,49 \\
\hline 340,00 & 53,67 & 2958,67 & 200,67 & 457,00 & 118,33 & 160,33 & 0,47 \\
\hline 360,00 & 58,00 & 2978,33 & 220,33 & 458,00 & 118,33 & 161,67 & 0,45 \\
\hline 380,00 & 63,00 & 2998,33 & 240,33 & 459,33 & 118,33 & 163,00 & 0,43 \\
\hline 400,00 & 68,00 & 3018,33 & 260,33 & 462,00 & 118,33 & 165,67 & 0,41 \\
\hline 420,00 & 73,00 & 3038,33 & 280,33 & 465,33 & 118,33 & 169,00 & 0,40 \\
\hline 440,00 & 76,67 & 3055,33 & 297,33 & 468,00 & 118,67 & 173,00 & 0,39 \\
\hline 460,00 & 79,67 & 3069,33 & 311,33 & 469,33 & 124,33 & 180,00 & 0,39 \\
\hline 480,00 & 80,67 & 3073,33 & 315,33 & 471,00 & 137,33 & 197,67 & 0,41 \\
\hline 500,00 & 82,33 & 3083,67 & 325,67 & 473,00 & 143,00 & 209,33 & 0,42 \\
\hline 520,00 & 85,67 & 3097,00 & 339 & 474,00 & 147,33 & 215,00 & 0,41 \\
\hline 540,00 & 86,67 & 3104,00 & 346 & 474,33 & 160,67 & 228,33 & 0,42 \\
\hline
\end{tabular}




\begin{tabular}{|c|c|c|c|c|c|c|c|}
\hline 560,00 & 90,67 & 3118,33 & 360,33 & 478,00 & 165,33 & 237,00 & 0,42 \\
\hline 580,00 & 94,33 & 3138,00 & 380 & 479,67 & 165,33 & 238,67 & 0,41 \\
\hline 600,00 & 98,67 & 3158,00 & 400 & 481,67 & 165,33 & 240,67 & 0,40 \\
\hline
\end{tabular}

Tabla L-2

\section{L-1.3 SARP COLABORACIÓN “SC”}

Los resultados promedio del SARp Colaboración "SC", se muestran a continuación en la tabla L-3. Este SARp no tiene métodos asociados, emplea la base de conocimiento producto de la colaboración recibida de un SAR que se encuentra en un layer superior

\begin{tabular}{|c|c|c|c|c|c|c|c|}
\hline Ciclos & Situaciones & $\begin{array}{c}\text { Cantidad } \\
\text { teorías } \\
\text { acumuladas }\end{array}$ & $\begin{array}{l}\text { Cantidad } \\
\text { de } \\
\text { teorías } \\
\text { nuevas }\end{array}$ & $\begin{array}{c}\text { Teorías } \\
\mathrm{U} \\
{[0.75 ; 1]}\end{array}$ & $\begin{array}{c}\text { Cantidad } \\
\text { Planes } \\
\text { Exitosos }\end{array}$ & $\begin{array}{c}\text { Ciclos } \\
\text { Exitosos }\end{array}$ & $\begin{array}{l}\text { \% Ciclos } \\
\text { Exitosos }\end{array}$ \\
\hline 1,00 & 1,00 & 4807,00 & 0 & 715,00 & 0,00 & 0,00 & 0,00 \\
\hline 20,00 & 2,00 & 4807,00 & 0 & 715,00 & 8,00 & 19,00 & 0,95 \\
\hline 40,00 & 2,00 & 4807,00 & 0 & 715,00 & 28,00 & 39,00 & 0,98 \\
\hline 60,00 & 2,00 & 4807,00 & 0 & 715,00 & 48,00 & 59,00 & 0,98 \\
\hline 80,00 & 2,00 & 4807,00 & 0 & 715,00 & 68,00 & 79,00 & 0,99 \\
\hline 100,00 & 2,00 & 4807,00 & 0 & 715,00 & 88,00 & 99,00 & 0,99 \\
\hline 120,00 & 2,00 & 4807,00 & 0 & 715,00 & 107,33 & 119,00 & 0,99 \\
\hline 140,00 & 5,67 & 4818,00 & 11 & 717,00 & 116,33 & 129,00 & 0,92 \\
\hline 160,00 & 10,67 & 4838,00 & 31 & 722,00 & 116,33 & 134,00 & 0,84 \\
\hline 180,00 & 15,67 & 4858,00 & 51 & 727,00 & 116,33 & 139,00 & 0,77 \\
\hline 200,00 & 20,33 & 4876,67 & 69,67 & 729,33 & 116,33 & 141,33 & 0,71 \\
\hline 220,00 & 25,33 & 4895,33 & 88,33 & 732,67 & 116,33 & 144,67 & 0,66 \\
\hline 240,00 & 30,00 & 4914,33 & 107,33 & 733,00 & 116,33 & 145,00 & 0,60 \\
\hline 260,00 & 35,00 & 4931,00 & 124 & 734,00 & 116,33 & 146,00 & 0,56 \\
\hline 280,00 & 40,00 & 4949,67 & 142,67 & 736,33 & 116,33 & 149,00 & 0,53 \\
\hline 300,00 & 44,67 & 4967,00 & 160 & 739,33 & 116,33 & 152,67 & 0,51 \\
\hline 320,00 & 49,33 & 4986,33 & 179,33 & 739,33 & 116,33 & 152,67 & 0,48 \\
\hline 340,00 & 54,33 & 5005,33 & 198,33 & 742,33 & 116,33 & 155,67 & 0,46 \\
\hline 360,00 & 59,33 & 5024,67 & 217,67 & 743,67 & 116,33 & 157,00 & 0,44 \\
\hline 380,00 & 64,33 & 5044,67 & 237,67 & 744,67 & 116,33 & 158,00 & 0,42 \\
\hline 400,00 & 69,33 & 5064,67 & 257,67 & 747,33 & 116,33 & 160,67 & 0,40 \\
\hline 420,00 & 74,33 & 5084,67 & 277,67 & 750,67 & 116,33 & 164,00 & 0,39 \\
\hline 440,00 & 79,00 & 5103,67 & 296,67 & 752,00 & 116,33 & 165,33 & 0,38 \\
\hline 460,00 & 83,33 & 5121,33 & 314,33 & 754,00 & 117,67 & 168,33 & 0,37 \\
\hline
\end{tabular}




\begin{tabular}{|c|c|c|c|c|c|c|c|}
\hline 480,00 & 86,33 & 5133,00 & 326 & 755,33 & 125,00 & 177,00 & 0,37 \\
\hline 500,00 & 88,33 & 5139,67 & 332,67 & 756,33 & 135,67 & 191,33 & 0,38 \\
\hline 520,00 & 90,33 & 5148,00 & 341 & 757,33 & 145,00 & 203,00 & 0,39 \\
\hline 540,00 & 90,33 & 5153,33 & 346,33 & 757,67 & 158,33 & 216,67 & 0,40 \\
\hline 560,00 & 91,33 & 5158,33 & 351,33 & 759,00 & 172,67 & 232,33 & 0,41 \\
\hline 580,00 & 94,67 & 5171,67 & 364,67 & 760,33 & 179,67 & 240,33 & 0,41 \\
\hline 600,00 & 98,00 & 5183,00 & 376 & 761,33 & 186,33 & 248,00 & 0,41 \\
\hline
\end{tabular}

Tabla L-3

\section{L-1.4 SARP INTERCAMBIO-COLABORACIÓN “SIC”}

Los resultados promedio del SARp Cooperación-Colaboración "SIC" se muestran a continuación en la tabla L-4. Este SARp no tiene métodos asociados y emplea la base de conocimiento de intercambio (cooperación) generada con otro SAR y la colaboración sobre esta base de intercambio, recibida por un SAR que se encuentra en un layer superior.

\begin{tabular}{|c|c|c|c|c|c|c|c|}
\hline Ciclos & Situaciones & $\begin{array}{c}\text { Cantidad } \\
\text { de Teorías } \\
\text { acumuladas }\end{array}$ & $\begin{array}{c}\text { Cantidad } \\
\text { de } \\
\text { teorías } \\
\text { nuevas }\end{array}$ & $\begin{array}{c}\text { Teorías } \\
\mathrm{U} \\
{[0.75 ; 1]}\end{array}$ & $\begin{array}{c}\text { Cantidad } \\
\text { Planes } \\
\text { Exitosos }\end{array}$ & $\begin{array}{c}\text { Ciclos } \\
\text { Exitosos }\end{array}$ & $\begin{array}{c}\% \\
\text { Ciclos } \\
\text { Exitosos }\end{array}$ \\
\hline 1 & 1,00 & 4054,00 & 0 & 433,00 & 0,00 & 0,00 & 0,00 \\
\hline 20 & 1,67 & 4054,00 & 0 & 433,00 & 8,00 & 19,00 & 0,95 \\
\hline 40 & 2,00 & 4054,00 & 0 & 433,00 & 28,00 & 39,00 & 0,98 \\
\hline 60 & 2,00 & 4054,00 & 0 & 433,00 & 48,00 & 59,00 & 0,98 \\
\hline 80 & 3,33 & 4056,33 & 2,33 & 433,67 & 65,67 & 77,00 & 0,96 \\
\hline 100 & 4,67 & 4062,67 & 8,67 & 434,33 & 79,00 & 91,00 & 0,91 \\
\hline 120 & 6,67 & 4068,33 & 14,33 & 435,00 & 92,33 & 105,00 & 0,88 \\
\hline 140 & 11,33 & 4079,67 & 25,67 & 436,00 & 99,67 & 112,67 & 0,80 \\
\hline 160 & 16,33 & 4098,00 & 44 & 438,33 & 99,67 & 115,67 & 0,72 \\
\hline 180 & 21,33 & 4114,33 & 60,33 & 440,67 & 99,67 & 119,00 & 0,66 \\
\hline 200 & 26,00 & 4128,00 & 74 & 443,00 & 101,00 & 122,33 & 0,61 \\
\hline 220 & 31,00 & 4144,00 & 90 & 446,33 & 101,33 & 126,00 & 0,57 \\
\hline 240 & 35,67 & 4157,67 & 103,67 & 447,67 & 104,00 & 129,67 & 0,54 \\
\hline 260 & 40,67 & 4174,00 & 120 & 450,00 & 105,33 & 134,00 & 0,52 \\
\hline 280 & 43,00 & 4185,67 & 131,67 & 451,67 & 105,33 & 137,67 & 0,49 \\
\hline 300 & 46,33 & 4202,33 & 148,33 & 452,67 & 105,33 & 139,00 & 0,46 \\
\hline 320 & 49,67 & 4216,67 & 162,67 & 457,00 & 110,33 & 149,00 & 0,47 \\
\hline 340 & 51,00 & 4223,00 & 169 & 457,33 & 122,00 & 161,67 & 0,48 \\
\hline
\end{tabular}




\begin{tabular}{|c|c|c|c|c|c|c|c|}
\hline 360 & 52,67 & 4232,00 & 178 & 459,33 & 131,67 & 173,33 & 0,48 \\
\hline 380 & 55,67 & 4244,00 & 190 & 460,33 & 138,33 & 181,00 & 0,48 \\
\hline 400 & 58,67 & 4255,00 & 201 & 461,33 & 145,00 & 188,67 & 0,47 \\
\hline 420 & 61,00 & 4267,00 & 213 & 462,67 & 149,33 & 194,67 & 0,46 \\
\hline 440 & 64,33 & 4280,67 & 226,67 & 465,00 & 154,33 & 202,00 & 0,46 \\
\hline 460 & 67,00 & 4293,00 & 239 & 466,33 & 161,00 & 210,00 & 0,46 \\
\hline 480 & 70,33 & 4303,67 & 249,67 & 467,33 & 167,67 & 217,67 & 0,45 \\
\hline 500 & 72,33 & 4313,67 & 259,67 & 468,67 & 174,33 & 226,00 & 0,45 \\
\hline 520 & 75,00 & 4326,00 & 272 & 470,00 & 181,00 & 233,67 & 0,45 \\
\hline 540 & 79,33 & 4341,00 & 287 & 471,67 & 182,67 & 236,67 & 0,44 \\
\hline 560 & 82,33 & 4355,33 & 301,33 & 472,67 & 182,67 & 238,67 & 0,43 \\
\hline 580 & 87,00 & 4371,00 & 317 & 474,67 & 182,67 & 241,00 & 0,42 \\
\hline 600 & 90,00 & 4385,67 & 331,67 & 476,00 & 183,00 & 243,67 & 0,41 \\
\hline
\end{tabular}

Tabla L-4

\section{L-1.5 SARP PONDERADOR CLÁSICO- MUTACIÓN “SPM”}

Los resultados promedio del SARp Ponderador Clásico-Mutación "SPM" se muestran a continuación en la tabla L-5. Este SARp aplica el método de ponderación de planes y mutación.

\begin{tabular}{|c|c|c|c|c|c|c|c|}
\hline Ciclos & Situaciones & $\begin{array}{l}\text { Cantidad de } \\
\text { teorías } \\
\text { acumuladas }\end{array}$ & \begin{tabular}{|c|} 
Cantidad \\
De \\
teorías \\
nuevas \\
\end{tabular} & $\begin{array}{c}\text { Teorías } \\
U \\
{[0.75 ; 1]}\end{array}$ & $\begin{array}{c}\text { Cantidad } \\
\text { Planes } \\
\text { Exitosos }\end{array}$ & $\begin{array}{c}\text { Ciclos } \\
\text { Exitosos }\end{array}$ & $\begin{array}{l}\text { \% Ciclos } \\
\text { Exitosos }\end{array}$ \\
\hline 1 & 1,00 & 2416,67 & 0 & 309,33 & 0,00 & 0,00 & 0,00 \\
\hline 20 & 1,67 & 2416,67 & 0 & 309,33 & 16,00 & 19,00 & 0,95 \\
\hline 40 & 2,00 & 2416,67 & 0 & 309,33 & 36,00 & 39,00 & 0,98 \\
\hline 60 & 2,00 & 2416,67 & 0 & 309,33 & 56,00 & 59,00 & 0,98 \\
\hline 80 & 2,00 & 2416,67 & 0 & 309,33 & 76,00 & 79,00 & 0,99 \\
\hline 100 & 6,33 & 2427,00 & 10,33 & 312,33 & 85,00 & 90,67 & 0,91 \\
\hline 120 & 11,67 & 2446,33 & 29,66 & 316,00 & 85,00 & 94,33 & 0,79 \\
\hline 140 & 18,67 & 2465,67 & 49 & 320,67 & 86,33 & 99,67 & 0,71 \\
\hline 160 & 25,00 & 2484,33 & 67,66 & 321,33 & 86,33 & 101,00 & 0,63 \\
\hline 180 & 31,67 & 2503,33 & 86,66 & 323,00 & 86,33 & 102,00 & 0,57 \\
\hline 200 & 36,33 & 2522,67 & 106 & 324,00 & 86,33 & 103,00 & 0,52 \\
\hline 220 & 43,33 & 2542,00 & 125,33 & 325,67 & 86,33 & 105,33 & 0,48 \\
\hline 240 & 49,33 & 2558,33 & 141,66 & 327,33 & 86,33 & 108,00 & 0,45 \\
\hline 260 & 55,33 & 2576,33 & 159,66 & 328,67 & 87,67 & 110,00 & 0,42 \\
\hline
\end{tabular}




\begin{tabular}{|c|c|c|c|c|c|c|c|}
\hline 280 & 62,67 & 2596,67 & 180 & 331,00 & 87,67 & 112,00 & 0,40 \\
\hline 300 & 68,67 & 2616,00 & 199,33 & 333,00 & 87,67 & 114,00 & 0,38 \\
\hline 320 & 73,00 & 2633,33 & 216,66 & 334,00 & 87,67 & 115,00 & 0,36 \\
\hline 340 & 77,00 & 2651,33 & 234,66 & 335,00 & 87,67 & 116,00 & 0,34 \\
\hline 360 & 82,67 & 2670,33 & 253,66 & 336,33 & 87,67 & 117,33 & 0,33 \\
\hline 380 & 88,00 & 2689,33 & 272,66 & 338,67 & 87,67 & 119,67 & 0,31 \\
\hline 400 & 93,33 & 2707,67 & 291 & 339,33 & 87,67 & 120,33 & 0,30 \\
\hline 420 & 100,33 & 2727,67 & 311 & 342,00 & 88,33 & 123,33 & 0,29 \\
\hline 440 & 105,33 & 2748,33 & 331,66 & 344,33 & 88,67 & 125,33 & 0,28 \\
\hline 460 & 111,33 & 2768,33 & 351,66 & 346,67 & 88,67 & 128,00 & 0,28 \\
\hline 480 & 118,00 & 2790,33 & 373,66 & 348,67 & 88,67 & 129,67 & 0,27 \\
\hline 500 & 122,00 & 2807,67 & 391 & 351,67 & 88,67 & 132,67 & 0,27 \\
\hline 520 & 126,67 & 2828,00 & 411,33 & 353,00 & 88,67 & 133,67 & 0,26 \\
\hline 540 & 132,33 & 2846,33 & 429,66 & 357,00 & 88,67 & 137,00 & 0,25 \\
\hline 560 & 139,00 & 2865,00 & 448,33 & 358,00 & 88,67 & 138,67 & 0,25 \\
\hline 580 & 143,33 & 2882,00 & 465,33 & 359,67 & 89,67 & 142,00 & 0,24 \\
\hline 600 & 147,00 & 2894,67 & 478 & 360,33 & 96,33 & 149,33 & 0,25 \\
\hline
\end{tabular}

Tabla L-5

\section{L-1.6 SARP PONDERADOR CLÁSICO-INTERCAMBIO-MUTACIÓN “SPMI”}

Los resultados promedio del SARp Ponderador Clásico-Cooperación-Mutación "SPMI" se muestran a continuación en la tabla L-6. Este SARp aplica el método de ponderación de planes, mutación y emplea la base de conocimiento de intercambio o cooperación generada con otro SAR que se encuentra en el mismo nivel de layer.

\begin{tabular}{|c|c|c|c|c|c|c|c|}
\hline & & $\begin{array}{c}\text { Cantidad de } \\
\text { teorías } \\
\text { Ciclos }\end{array}$ & $\begin{array}{c}\text { Situaciones } \\
\text { acumuladas } \\
\text { teorías } \\
\text { nuevas }\end{array}$ & $\begin{array}{c}\text { Teorías } \\
\mathbf{U} \\
{[\mathbf{0 . 7 5} \mathbf{1}]}\end{array}$ & $\begin{array}{c}\text { Cantidad } \\
\text { Planes } \\
\text { Exitosos }\end{array}$ & $\begin{array}{c}\text { Ciclos } \\
\text { Exitosos }\end{array}$ & $\begin{array}{c}\text { \% Ciclos } \\
\text { Exitosos }\end{array}$ \\
\hline 1 & 1,00 & 87,00 & 0 & 56,00 & 0,00 & 0,00 & 0,00 \\
\hline 20 & 2,00 & 87,00 & 0 & 56,00 & 8,00 & 19,00 & 0,95 \\
\hline 40 & 2,00 & 87,00 & 0 & 56,00 & 28,00 & 39,00 & 0,98 \\
\hline 60 & 2,67 & 87,00 & 0 & 56,00 & 47,33 & 59,00 & 0,98 \\
\hline 80 & 9,00 & 95,67 & 8,67 & 59,67 & 61,67 & 74,00 & 0,93 \\
\hline 100 & 14,33 & 116,00 & 29 & 62,67 & 62,33 & 77,00 & 0,77 \\
\hline 120 & 18,00 & 134,67 & 47,67 & 67,33 & 64,33 & 83,00 & 0,69 \\
\hline 140 & 21,67 & 154,67 & 67,67 & 68,00 & 64,33 & 83,67 & 0,60 \\
\hline
\end{tabular}




\begin{tabular}{|c|c|c|c|c|c|c|c|}
\hline 160 & 26,00 & 174,33 & 87,33 & 71,00 & 64,33 & 87,00 & 0,54 \\
\hline 180 & 30,67 & 196,00 & 109 & 73,67 & 65,67 & 89,33 & 0,50 \\
\hline 200 & 35,00 & 211,00 & 124 & 76,00 & 71,33 & 96,67 & 0,48 \\
\hline 220 & 38,67 & 224,33 & 137,33 & 78,67 & 78,67 & 106,00 & 0,48 \\
\hline 240 & 43,67 & 242,67 & 155,67 & 84,33 & 82,67 & 113,67 & 0,47 \\
\hline 260 & 46,67 & 261,67 & 174,67 & 88,67 & 84,00 & 118,67 & 0,46 \\
\hline 280 & 49,33 & 275,00 & 188 & 91,33 & 91,00 & 127,67 & 0,46 \\
\hline 300 & 52,67 & 293,67 & 206,67 & 92,33 & 92,67 & 129,67 & 0,43 \\
\hline 320 & 54,33 & 309,67 & 222,67 & 94,67 & 95,67 & 134,67 & 0,42 \\
\hline 340 & 57,67 & 320,33 & 233,33 & 96,00 & 106,00 & 145,33 & 0,43 \\
\hline 360 & 60,00 & 330,33 & 243,33 & 97,33 & 114,00 & 155,00 & 0,43 \\
\hline 380 & 63,33 & 345,67 & 258,67 & 98,67 & 118,67 & 160,33 & 0,42 \\
\hline 400 & 66,67 & 361,33 & 274,33 & 100,33 & 123,00 & 165,67 & 0,41 \\
\hline 420 & 70,67 & 378,67 & 291,67 & 103,67 & 126,00 & 170,67 & 0,41 \\
\hline 440 & 76,00 & 398,33 & 311,33 & 104,00 & 126,00 & 171,00 & 0,39 \\
\hline 460 & 81,33 & 418,33 & 331,33 & 106,33 & 127,33 & 173,67 & 0,38 \\
\hline 480 & 86,33 & 438,33 & 351,33 & 107,67 & 127,33 & 175,00 & 0,36 \\
\hline 500 & 91,33 & 458,67 & 371,67 & 110,67 & 127,67 & 177,67 & 0,36 \\
\hline 520 & 97,00 & 479,00 & 392 & 113,67 & 128,33 & 180,67 & 0,35 \\
\hline 540 & 102,00 & 499,00 & 412 & 116,67 & 128,33 & 183,67 & 0,34 \\
\hline 560 & 107,00 & 519,00 & 432 & 119,67 & 128,33 & 186,67 & 0,33 \\
\hline 580 & 111,67 & 539,33 & 452,33 & 124,00 & 128,33 & 190,67 & 0,33 \\
\hline 600 & 116,00 & 559,33 & 472,33 & 126,67 & 128,33 & 193,33 & 0,32 \\
\hline
\end{tabular}

Tabla L-6

\section{L-1.7 SARP PONDERADOR CLÁSICO- MUTACIÓN-COLABORACIÓN “SPMC”}

Los resultados promedio del SARp Ponderador Clásico- Mutación-Colaboración “SPMC” se muestran a continuación en la tabla L-7. Este SARp aplica el método de ponderación de planes, mutación y emplea la base de conocimiento, producto de la colaboración recibida por un SAR que se encuentra en un layer superior.

\begin{tabular}{|c|c|c|c|c|c|c|c|}
\hline & & $\begin{array}{c}\text { Cantidad de } \\
\text { teorías } \\
\text { Ciclos }\end{array}$ & $\begin{array}{c}\text { Cantidad } \\
\text { de } \\
\text { teorías } \\
\text { nuevas }\end{array}$ & $\begin{array}{c}\text { Teorías } \\
\mathbf{U} \\
{[\mathbf{0 . 7 5}}\end{array}$ & $\begin{array}{c}\text { Cantidad } \\
\text { Planes } \\
\text { Exitosos }\end{array}$ & $\begin{array}{c}\text { Ciclos } \\
\text { Exitosos }\end{array}$ & $\begin{array}{c}\text { \% Ciclos } \\
\text { Exitosos }\end{array}$ \\
\hline 1 & 1,00 & 4054,00 & 0 & 433,00 & 0,00 & 0,00 & 0,00 \\
\hline 20 & 2,00 & 4054,00 & 0 & 433,00 & 16,00 & 19,00 & 0,95 \\
\hline
\end{tabular}




\begin{tabular}{|c|c|c|c|c|c|c|c|}
\hline 40 & 2,00 & 4054,00 & 0 & 433,00 & 36,00 & 39,00 & 0,98 \\
\hline 60 & 2,00 & 4054,00 & 0 & 433,00 & 56,00 & 59,00 & 0,98 \\
\hline 80 & 2,00 & 4054,00 & 0 & 433,00 & 76,00 & 79,00 & 0,99 \\
\hline 100 & 7,00 & 4060,33 & 6,33 & 436,00 & 90,33 & 95,00 & 0,95 \\
\hline 120 & 13,00 & 4080,00 & 26 & 437,67 & 90,33 & 96,67 & 0,81 \\
\hline 140 & 21,00 & 4099,67 & 45,67 & 440,33 & 90,33 & 99,33 & 0,71 \\
\hline 160 & 28,33 & 4121,00 & 67 & 441,67 & 90,33 & 100,67 & 0,63 \\
\hline 180 & 36,00 & 4141,00 & 87 & 443,67 & 90,33 & 103,67 & 0,58 \\
\hline 200 & 44,00 & 4162,00 & 108 & 445,00 & 90,33 & 105,33 & 0,53 \\
\hline 220 & 52,67 & 4183,00 & 129 & 447,33 & 90,33 & 108,33 & 0,49 \\
\hline 240 & 60,00 & 4203,00 & 149 & 448,33 & 90,33 & 110,00 & 0,46 \\
\hline 260 & 67,00 & 4219,00 & 165 & 448,33 & 90,33 & 111,00 & 0,43 \\
\hline 280 & 73,33 & 4235,00 & 181 & 449,00 & 91,33 & 114,00 & 0,41 \\
\hline 300 & 82,00 & 4254,00 & 200 & 452,33 & 92,67 & 117,00 & 0,39 \\
\hline 320 & 89,00 & 4274,00 & 220 & 455,67 & 94,00 & 120,00 & 0,38 \\
\hline 340 & 95,67 & 4291,33 & 237,33 & 459,33 & 95,33 & 123,33 & 0,36 \\
\hline 360 & 100,67 & 4307,67 & 253,67 & 461,00 & 95,33 & 125,00 & 0,35 \\
\hline 380 & 105,00 & 4319,67 & 265,67 & 461,33 & 99,00 & 129,67 & 0,34 \\
\hline 400 & 110,00 & 4330,67 & 276,67 & 461,33 & 105,67 & 136,33 & 0,34 \\
\hline 420 & 115,33 & 4344,33 & 290,33 & 462,67 & 112,33 & 144,67 & 0,34 \\
\hline 440 & 117,67 & 4356,67 & 302,67 & 463,67 & 119,00 & 152,67 & 0,35 \\
\hline 460 & 123,00 & 4371,67 & 317,67 & 464,67 & 125,67 & 160,33 & 0,35 \\
\hline 480 & 127,33 & 4385,33 & 331,33 & 466,33 & 132,33 & 169,00 & 0,35 \\
\hline 500 & 130,00 & 4398,00 & 344 & 467,67 & 139,00 & 177,00 & 0,35 \\
\hline 520 & 133,67 & 4411,00 & 357 & 468,33 & 145,67 & 184,33 & 0,35 \\
\hline 540 & 138,00 & 4426,33 & 372,33 & 470,33 & 150,00 & 189,00 & 0,35 \\
\hline 560 & 142,00 & 4440,33 & 386,33 & 471,33 & 156,33 & 196,33 & 0,35 \\
\hline 580 & 146,67 & 4454,00 & 400 & 472,67 & 163,00 & 204,33 & 0,35 \\
\hline 600 & 149,33 & 4465,67 & 411,67 & 474,00 & 169,67 & 212,33 & 0,35 \\
\hline
\end{tabular}

Tabla L-7

\section{L-1.8 SARP PONDERADOR CLÁSICO- MUTACIÓN-INTERCAMBIO-COLABORACIÓN "SPMIC"}

Los resultados promedio del SARp Ponderador Clásico- Mutación-Intercambio-Colaboración “SPMIC" se muestran a continuación en la tabla L-8. Este SARp aplica el método de ponderación de planes, mutación y emplea la base de conocimiento de intercambio (cooperación) generada con 
otro SAR y la colaboración sobre esta base de intercambio, recibida por un SAR que se encuentra en un layer superior.

\begin{tabular}{|c|c|c|c|c|c|c|c|}
\hline Ciclos & Situaciones & $\begin{array}{c}\text { Cantidad de } \\
\text { teorías } \\
\text { acumuladas }\end{array}$ & \begin{tabular}{c|} 
Cantidad \\
de \\
teorías \\
nuevas \\
\end{tabular} & $\begin{array}{c}\text { Teorías } \\
U \\
{[0.75 ; 1]}\end{array}$ & $\begin{array}{c}\text { Cantidad } \\
\text { Planes } \\
\text { Exitosos }\end{array}$ & $\begin{array}{c}\text { Ciclos } \\
\text { Exitosos }\end{array}$ & $\begin{array}{l}\text { \% Ciclos } \\
\text { Exitosos }\end{array}$ \\
\hline 1 & 1,00 & 4054,00 & 0 & 433,00 & 0,00 & 0,00 & 0,00 \\
\hline 20 & 1,33 & 4054,00 & 0 & 433,00 & 16,00 & 19,00 & 0,95 \\
\hline 40 & 1,33 & 4054,00 & 0 & 433,00 & 36,00 & 39,00 & 0,98 \\
\hline 60 & 2,00 & 4054,00 & 0 & 433,00 & 56,00 & 59,00 & 0,98 \\
\hline 80 & 2,00 & 4054,00 & 0 & 433,00 & 76,00 & 79,00 & 0,99 \\
\hline 100 & 7,33 & 4060,67 & 6,67 & 436,00 & 90,33 & 95,00 & 0,95 \\
\hline 120 & 15,00 & 4081,67 & 27,67 & 439,67 & 90,33 & 98,33 & 0,82 \\
\hline 140 & 21,00 & 4100,67 & 46,67 & 441,33 & 90,33 & 99,67 & 0,71 \\
\hline 160 & 26,67 & 4118,33 & 64,33 & 444,33 & 90,33 & 102,00 & 0,64 \\
\hline 180 & 33,00 & 4138,00 & 84 & 447,33 & 90,33 & 105,33 & 0,59 \\
\hline 200 & 40,00 & 4157,33 & 103,33 & 449,33 & 90,33 & 107,00 & 0,54 \\
\hline 220 & 46,33 & 4178,67 & 124,67 & 452,33 & 91,00 & 109,67 & 0,50 \\
\hline 240 & 53,00 & 4197,00 & 143 & 457,00 & 91,33 & 113,00 & 0,47 \\
\hline 260 & 60,00 & 4213,33 & 159,33 & 458,33 & 97,67 & 119,67 & 0,46 \\
\hline 280 & 65,67 & 4227,33 & 173,33 & 460,33 & 104,33 & 127,33 & 0,45 \\
\hline 300 & 68,33 & 4242,67 & 188,67 & 462,67 & 109,67 & 135,00 & 0,45 \\
\hline 320 & 73,33 & 4260,00 & 206 & 466,00 & 112,33 & 140,67 & 0,44 \\
\hline 340 & 77,33 & 4272,67 & 218,67 & 467,67 & 119,00 & 149,33 & 0,44 \\
\hline 360 & 83,00 & 4289,33 & 235,33 & 469,67 & 120,67 & 152,67 & 0,42 \\
\hline 380 & 87,67 & 4308,33 & 254,33 & 472,00 & 120,67 & 155,00 & 0,41 \\
\hline 400 & 94,67 & 4326,33 & 272,33 & 474,33 & 120,67 & 156,67 & 0,39 \\
\hline 420 & 100,33 & 4342,00 & 288 & 475,00 & 124,33 & 162,00 & 0,39 \\
\hline 440 & 104,67 & 4355,00 & 301 & 476,00 & 131,00 & 169,33 & 0,38 \\
\hline 460 & 109,67 & 4370,67 & 316,67 & 478,67 & 136,67 & 176,00 & 0,38 \\
\hline 480 & 112,00 & 4384,00 & 330 & 480,00 & 141,67 & 182,67 & 0,38 \\
\hline 500 & 115,67 & 4395,00 & 341 & 480,67 & 150,67 & 192,33 & 0,38 \\
\hline 520 & 120,00 & 4409,33 & 355,33 & 485,33 & 159,00 & 202,67 & 0,39 \\
\hline 540 & 123,00 & 4421,67 & 367,67 & 486,67 & 165,67 & 210,67 & 0,39 \\
\hline 560 & 126,00 & 4433,33 & 379,33 & 487,00 & 172,33 & 217,67 & 0,39 \\
\hline 580 & 128,33 & 4443,67 & 389,67 & 488,00 & 179,00 & 225,67 & 0,39 \\
\hline 600 & 131,33 & 4456,33 & 402,33 & 488,33 & 185,67 & 233,00 & 0,39 \\
\hline
\end{tabular}

Tabla L-8 


\section{L-2 SARR EN FUNCIÓN DE LA CONFIGURACIÓN Y TIPO}

Se presentan en esta sección las tablas correspondientes a las extensiones de SARr: "SNr" en la subsección L-2.1, "SMr" en la subsección L-2.2, "SIr" en la subsección L-2.3, "SCr" en la subsección L-2.4. "SICr" en la subsección L-2.5, "SMCr" tabla L-2.6, "SMICr” en la subsección L2.7 .

\section{L-2.1 SARR NEUTRO “SNR”.}

Los resultados promedio del SARr o SAR neutro "SNr" se muestran a continuación en la . tabla L9. Este SARr no tiene métodos asociados y sólo aplica la base inicial de teorías de base generadas por un SAR reactivo ( $\mathrm{SAR} R$ ).

\begin{tabular}{|c|c|c|c|c|c|c|c|}
\hline Ciclos & Situaciones & $\begin{array}{c}\text { Cantidad de } \\
\text { teorías } \\
\text { acumuladas }\end{array}$ & $\begin{array}{c}\text { Cantidad de } \\
\text { teorías } \\
\text { nuevas }\end{array}$ & $\begin{array}{c}\text { Teorías } \\
\text { U [0.75;1] }\end{array}$ & $\begin{array}{c}\text { Cantidad } \\
\text { Planes } \\
\text { Exitosos }\end{array}$ & $\begin{array}{c}\text { Ciclos } \\
\text { Exitosos }\end{array}$ & $\begin{array}{c}\text { \% Ciclos } \\
\text { Exitosos }\end{array}$ \\
\hline 1 & 1,00 & 53,00 & 0 & 33,00 & 0,00 & 0,00 & 0,00 \\
\hline 20 & 3,33 & 53,67 & 0,67 & 33,67 & 8,00 & 19,00 & 0,95 \\
\hline 40 & 3,33 & 53,67 & 0,67 & 33,67 & 28,00 & 39,00 & 0,98 \\
\hline 60 & 3,33 & 53,67 & 0,67 & 33,67 & 48,00 & 59,00 & 0,98 \\
\hline 80 & 3,33 & 53,67 & 0,67 & 33,67 & 68,00 & 79,00 & 0,99 \\
\hline 100 & 3,33 & 53,67 & 0,67 & 33,67 & 88,00 & 99,00 & 0,99 \\
\hline 120 & 3,33 & 53,67 & 0,67 & 33,67 & 108,00 & 119,00 & 0,99 \\
\hline 140 & 3,33 & 53,67 & 0,67 & 33,67 & 128,00 & 139,00 & 0,99 \\
\hline 160 & 6,33 & 56,67 & 3,67 & 36,33 & 147,67 & 158,00 & 0,99 \\
\hline 180 & 12,33 & 67,67 & 14,67 & 41,67 & 165,67 & 164,67 & 0,91 \\
\hline 200 & 18,00 & 76,67 & 23,67 & 42,33 & 182,67 & 170,00 & 0,85 \\
\hline 220 & 23,33 & 84,67 & 31,67 & 43,33 & 200,00 & 179,33 & 0,82 \\
\hline 240 & 29,67 & 94,67 & 41,67 & 44,00 & 216,67 & 186,33 & 0,78 \\
\hline 260 & 35,33 & 104,67 & 51,67 & 44,00 & 233,33 & 193,00 & 0,74 \\
\hline 280 & 42,00 & 114,67 & 61,67 & 44,00 & 250,00 & 199,67 & 0,71 \\
\hline 300 & 47,33 & 123,67 & 70,67 & 45,33 & 267,67 & 208,67 & 0,70 \\
\hline 320 & 52,67 & 133,67 & 80,67 & 49,00 & 284,33 & 219,67 & 0,69 \\
\hline 340 & 58,33 & 143,67 & 90,67 & 51,00 & 301,00 & 229,00 & 0,67 \\
\hline 360 & 62,67 & 150,00 & 97 & 52,33 & 319,33 & 239,67 & 0,67 \\
\hline 380 & 68,00 & 157,00 & 104 & 53,67 & 337,33 & 248,67 & 0,65 \\
\hline
\end{tabular}




\begin{tabular}{|c|c|c|c|c|c|c|c|}
\hline 400 & 73,67 & 166,00 & 113 & 54,33 & 354,67 & 255,67 & 0,64 \\
\hline 420 & 77,67 & 174,00 & 121 & 54,33 & 372,33 & 262,33 & 0,62 \\
\hline 440 & 83,67 & 183,67 & 130,67 & 56,33 & 389,33 & 271,67 & 0,62 \\
\hline 460 & 88,00 & 190,33 & 137,33 & 56,67 & 408,00 & 279,33 & 0,61 \\
\hline 480 & 93,00 & 199,00 & 146 & 59,67 & 425,00 & 291,33 & 0,61 \\
\hline 500 & 98,33 & 209,00 & 156 & 63,33 & 441,67 & 302,33 & 0,60 \\
\hline 520 & 104,33 & 218,00 & 165 & 64,33 & 459,33 & 310,33 & 0,60 \\
\hline 540 & 109,67 & 226,67 & 173,67 & 64,67 & 476,67 & 320,33 & 0,59 \\
\hline 560 & 112,67 & 231,67 & 178,67 & 65,33 & 495,00 & 334,00 & 0,60 \\
\hline 580 & 115,33 & 237,67 & 184,67 & 67,33 & 513,00 & 348,33 & 0,60 \\
\hline 600 & 118,00 & 243,33 & 190,33 & 68,67 & 531,67 & 362,00 & 0,60 \\
\hline
\end{tabular}

Tabla L-9

\section{L-2.2 SARR MUTACIÓN “SMR”.}

Los resultados promedio del SARr mutación "SMr" se muestran a continuación en la . tabla L-10. Este SARr aplica el método de mutación.

\begin{tabular}{|c|c|c|c|c|c|c|c|}
\hline Ciclos & Situaciones & $\begin{array}{l}\text { Cantidad de } \\
\text { Teorías } \\
\text { acumuladas }\end{array}$ & \begin{tabular}{|c|} 
Cantidad \\
de \\
teorías \\
nuevas \\
\end{tabular} & $\begin{array}{c}\text { Teorías } \\
\text { U }[0.75 ; 1]\end{array}$ & $\begin{array}{c}\text { Cantidad } \\
\text { Planes } \\
\text { Exitosos }\end{array}$ & $\begin{array}{c}\text { Ciclos } \\
\text { Exitosos }\end{array}$ & $\begin{array}{l}\text { \% Ciclos } \\
\text { Exitosos }\end{array}$ \\
\hline 1 & 1,00 & 53,00 & 0 & 33,00 & 0,00 & 0,00 & 0,00 \\
\hline 20 & 3,00 & 53,33 & 0,33 & 33,33 & 8,00 & 19,00 & 0,95 \\
\hline 40 & 3,33 & 53,33 & 0,33 & 33,33 & 28,00 & 39,00 & 0,98 \\
\hline 60 & 3,33 & 53,33 & 0,33 & 33,33 & 48,00 & 59,00 & 0,98 \\
\hline 80 & 3,33 & 53,33 & 0,33 & 33,33 & 68,00 & 79,00 & 0,99 \\
\hline 100 & 3,33 & 53,33 & 0,33 & 33,33 & 88,00 & 99,00 & 0,99 \\
\hline 120 & 3,33 & 53,33 & 0,33 & 33,33 & 108,00 & 119,00 & 0,99 \\
\hline 140 & 3,33 & 53,33 & 0,33 & 33,33 & 128,00 & 139,00 & 0,99 \\
\hline 160 & 4,33 & 54,00 & 1 & 34,00 & 148,00 & 159,00 & 0,99 \\
\hline 180 & 7,67 & 61,00 & 8 & 35,00 & 164,67 & 160,00 & 0,89 \\
\hline 200 & 10,67 & 67,67 & 14,67 & 36,00 & 182,33 & 165,67 & 0,83 \\
\hline 220 & 14,00 & 71,00 & 18 & 37,67 & 201,67 & 180,67 & 0,82 \\
\hline 240 & 16,67 & 74,67 & 21,67 & 38,33 & 220,33 & 191,33 & 0,80 \\
\hline 260 & 19,67 & 78,33 & 25,33 & 40,00 & 238,67 & 207,33 & 0,80 \\
\hline 280 & 21,67 & 81,67 & 28,67 & 40,00 & 257,00 & 220,67 & 0,79 \\
\hline 300 & 23,33 & 85,00 & 32 & 40,00 & 275,33 & 234,00 & 0,78 \\
\hline
\end{tabular}




\begin{tabular}{|c|c|c|c|c|c|c|c|}
\hline 320 & 25,00 & 88,33 & 35,33 & 40,33 & 293,67 & 248,33 & 0,78 \\
\hline 340 & 27,00 & 91,67 & 38,67 & 42,00 & 312,00 & 264,67 & 0,78 \\
\hline 360 & 29,67 & 95,67 & 42,67 & 42,67 & 330,00 & 277,00 & 0,77 \\
\hline 380 & 32,33 & 101,00 & 48 & 43,33 & 347,67 & 285,00 & 0,75 \\
\hline 400 & 36,67 & 109,67 & 56,67 & 44,33 & 363,33 & 286,67 & 0,72 \\
\hline 420 & 41,00 & 118,33 & 65,33 & 45,00 & 379,00 & 288,00 & 0,69 \\
\hline 440 & 45,33 & 127,33 & 74,33 & 47,00 & 395,00 & 292,00 & 0,66 \\
\hline 460 & 49,67 & 136,67 & 83,67 & 47,67 & 410,67 & 293,33 & 0,64 \\
\hline 480 & 54,67 & 146,67 & 93,67 & 49,00 & 425,67 & 296,00 & 0,62 \\
\hline 500 & 59,00 & 156,00 & 103 & 51,00 & 441,33 & 300,00 & 0,60 \\
\hline 520 & 63,67 & 165,33 & 112,33 & 51,67 & 456,67 & 301,33 & 0,58 \\
\hline 540 & 67,67 & 174,00 & 121 & 53,00 & 472,67 & 304,00 & 0,56 \\
\hline 560 & 70,33 & 181,00 & 128 & 53,67 & 490,00 & 306,33 & 0,55 \\
\hline 580 & 73,67 & 188,67 & 135,67 & 54,67 & 506,67 & 309,33 & 0,53 \\
\hline 600 & 77,33 & 196,67 & 143,67 & 55,33 & 523,33 & 310,67 & 0,52 \\
\hline
\end{tabular}

Tabla L-10

\section{L-2.3 SARR INTERCAMBIO “SIR”}

Los resultados promedio del SARr- Intercambio (Cooperación) "SI" se muestran a continuación en la tabla L-11. Este SARr no tiene métodos asociados y emplea la base de conocimiento de intercambio o cooperación generada con otro SAR que se encuentra en el mismo nivel de layer.

\begin{tabular}{|c|c|c|c|c|c|c|c|}
\hline Ciclos & Situaciones & $\begin{array}{c}\text { Cantidad de } \\
\text { teorías } \\
\text { acumuladas }\end{array}$ & $\begin{array}{c}\text { Cantidad de } \\
\text { teorías } \\
\text { nuevas }\end{array}$ & $\begin{array}{c}\text { Teorías } \\
\mathbf{U}[\mathbf{0 . 7 5 ; 1 ]}\end{array}$ & $\begin{array}{c}\text { Cantidad } \\
\text { Planes } \\
\text { Exitosos }\end{array}$ & $\begin{array}{c}\text { Ciclos } \\
\text { Exitosos }\end{array}$ & $\begin{array}{c}\text { \% Ciclos } \\
\text { Exitosos }\end{array}$ \\
\hline 1 & 1,00 & 1552,00 & 0 & 411,00 & 0,00 & 0,00 & 0,00 \\
\hline 20 & 7,00 & 1558,00 & 6 & 416,00 & 8,00 & 18,00 & 0,90 \\
\hline 40 & 7,33 & 1558,00 & 6 & 416,00 & 28,00 & 38,00 & 0,95 \\
\hline 60 & 7,33 & 1558,00 & 6 & 416,00 & 48,00 & 58,00 & 0,97 \\
\hline 80 & 7,33 & 1558,00 & 6 & 416,00 & 68,00 & 78,00 & 0,98 \\
\hline 100 & 7,33 & 1558,00 & 6 & 416,00 & 88,00 & 98,00 & 0,98 \\
\hline 120 & 7,33 & 1558,00 & 6 & 416,00 & 108,00 & 118,00 & 0,98 \\
\hline 140 & 7,33 & 1558,00 & 6 & 416,00 & 128,00 & 138,00 & 0,99 \\
\hline 160 & 8,33 & 1558,00 & 6 & 416,00 & 148,00 & 158,00 & 0,99 \\
\hline 180 & 21,67 & 1574,00 & 22 & 421,00 & 165,33 & 162,67 & 0,90 \\
\hline 200 & 31,33 & 1586,67 & 34,67 & 423,33 & 182,67 & 171,33 & 0,86 \\
\hline 220 & 34,00 & 1591,00 & 39 & 424,67 & 201,33 & 186,00 & 0,85 \\
\hline
\end{tabular}




\begin{tabular}{|c|c|c|c|c|c|c|c|}
\hline 240 & 38,33 & 1597,33 & 45,33 & 426,67 & 220,00 & 199,67 & 0,83 \\
\hline 260 & 39,67 & 1599,00 & 47 & 427,67 & 240,00 & 219,33 & 0,84 \\
\hline 280 & 39,67 & 1599,00 & 47 & 427,67 & 260,00 & 239,33 & 0,85 \\
\hline 300 & 40,33 & 1599,00 & 47 & 427,67 & 280,00 & 259,33 & 0,86 \\
\hline 320 & 46,33 & 1606,67 & 54,67 & 432,00 & 299,00 & 273,33 & 0,85 \\
\hline 340 & 54,33 & 1619,00 & 67 & 435,33 & 316,67 & 283,67 & 0,83 \\
\hline 360 & 60,33 & 1629,33 & 77,33 & 440,33 & 335,33 & 297,00 & 0,83 \\
\hline 380 & 67,33 & 1639,33 & 87,33 & 443,33 & 354,67 & 311,67 & 0,82 \\
\hline 400 & 70,33 & 1644,33 & 92,33 & 443,33 & 373,33 & 325,00 & 0,81 \\
\hline 420 & 74,67 & 1651,33 & 99,33 & 444,33 & 392,00 & 336,00 & 0,80 \\
\hline 440 & 80,00 & 1659,00 & 107 & 446,33 & 410,67 & 345,33 & 0,78 \\
\hline 460 & 84,00 & 1664,00 & 112 & 447,67 & 430,00 & 355,67 & 0,77 \\
\hline 480 & 87,33 & 1668,33 & 116,33 & 449,67 & 448,67 & 365,33 & 0,76 \\
\hline 500 & 92,67 & 1679,33 & 127,33 & 453,33 & 466,33 & 373,33 & 0,75 \\
\hline 520 & 100,00 & 1688,00 & 136 & 456,67 & 486,00 & 387,67 & 0,75 \\
\hline 540 & 104,67 & 1693,67 & 141,67 & 456,67 & 505,00 & 401,00 & 0,74 \\
\hline 560 & 108,33 & 1699,00 & 147 & 456,67 & 524,33 & 414,33 & 0,74 \\
\hline 580 & 112,33 & 1704,00 & 152 & 456,67 & 543,67 & 427,67 & 0,74 \\
\hline 600 & 115,67 & 1708,33 & 156,33 & 457,00 & 562,33 & 440,00 & 0,73 \\
\hline
\end{tabular}

Tabla L-11

\section{L-2.4 SARR COLABORACIÓN “SCR”}

Los resultados promedio del SARr Colaboración "SCr" se muestran a continuación en la tabla L12. Este SARr no tiene métodos asociados, emplea la base de conocimiento producto de la colaboración recibida de un SAR que se encuentra en un layer superior

\begin{tabular}{|c|c|c|c|c|c|c|c|}
\hline Ciclos & Situaciones & $\begin{array}{l}\text { Cantidad de } \\
\text { teorías } \\
\text { acumuladas }\end{array}$ & $\begin{array}{c}\text { Cantidad de } \\
\text { teorías } \\
\text { nuevas }\end{array}$ & $\begin{array}{c}\text { Teorías } \\
\text { U [0.75;1] }\end{array}$ & $\begin{array}{c}\text { Cantidad } \\
\text { Planes } \\
\text { Exitosos }\end{array}$ & $\begin{array}{c}\text { Ciclos } \\
\text { Exitosos }\end{array}$ & $\begin{array}{l}\text { \% Ciclos } \\
\text { Exitosos }\end{array}$ \\
\hline 1 & 1,00 & 1255,00 & 0 & 305,00 & 0,00 & 0,00 & 0,00 \\
\hline 20 & 3,67 & 1255,00 & 0 & 305,00 & 8,00 & 19,00 & 0,95 \\
\hline 40 & 3,67 & 1255,00 & 0 & 305,00 & 28,00 & 39,00 & 0,98 \\
\hline 60 & 3,67 & 1255,00 & 0 & 305,00 & 48,00 & 59,00 & 0,98 \\
\hline 80 & 3,67 & 1255,00 & 0 & 305,00 & 68,00 & 79,00 & 0,99 \\
\hline 100 & 3,67 & 1255,00 & 0 & 305,00 & 88,00 & 99,00 & 0,99 \\
\hline 120 & 3,67 & 1255,00 & 0 & 305,00 & 108,00 & 119,00 & 0,99 \\
\hline 140 & 3,67 & 1255,00 & 0 & 305,00 & 128,00 & 139,00 & 0,99 \\
\hline
\end{tabular}




\begin{tabular}{|c|c|c|c|c|c|c|c|}
\hline 160 & 4,67 & 1255,00 & 0 & 305,00 & 148,00 & 159,00 & 0,99 \\
\hline 180 & 13,67 & 1266,33 & 11,33 & 309,00 & 165,33 & 168,67 & 0,94 \\
\hline 200 & 19,67 & 1276,00 & 21 & 312,33 & 184,00 & 176,67 & 0,88 \\
\hline 220 & 28,00 & 1283,67 & 28,67 & 313,33 & 204,00 & 183,33 & 0,83 \\
\hline 240 & 37,00 & 1294,00 & 39 & 319,33 & 222,33 & 193,33 & 0,81 \\
\hline 260 & 41,33 & 1298,33 & 43,33 & 319,33 & 242,00 & 199,67 & 0,77 \\
\hline 280 & 43,33 & 1301,00 & 46 & 320,00 & 262,00 & 211,33 & 0,75 \\
\hline 300 & 49,33 & 1306,33 & 51,33 & 321,00 & 282,00 & 223,33 & 0,74 \\
\hline 320 & 57,67 & 1314,67 & 59,67 & 324,00 & 301,33 & 238,00 & 0,74 \\
\hline 340 & 62,33 & 1321,33 & 66,33 & 328,33 & 321,00 & 254,00 & 0,75 \\
\hline 360 & 63,67 & 1322,00 & 67 & 329,00 & 341,00 & 273,67 & 0,76 \\
\hline 380 & 65,00 & 1324,67 & 69,67 & 331,33 & 360,67 & 292,67 & 0,77 \\
\hline 400 & 67,33 & 1329,67 & 74,67 & 332,33 & 379,33 & 307,33 & 0,77 \\
\hline 420 & 71,00 & 1334,67 & 79,67 & 334,33 & 398,33 & 323,33 & 0,77 \\
\hline 440 & 73,00 & 1337,33 & 82,33 & 334,33 & 418,00 & 340,33 & 0,77 \\
\hline 460 & 73,00 & 1337,33 & 82,33 & 334,33 & 438,00 & 360,33 & 0,78 \\
\hline 480 & 73,33 & 1337,33 & 82,33 & 334,33 & 458,00 & 380,33 & 0,79 \\
\hline 500 & 75,67 & 1341,00 & 86 & 337,00 & 478,00 & 399,00 & 0,80 \\
\hline 520 & 77,00 & 1341,67 & 86,67 & 337,00 & 498,00 & 417,67 & 0,80 \\
\hline 540 & 79,00 & 1345,00 & 90 & 339,67 & 517,67 & 434,00 & 0,80 \\
\hline 560 & 79,33 & 1345,67 & 90,67 & 339,67 & 537,67 & 449,67 & 0,80 \\
\hline 580 & 80,67 & 1347,67 & 92,67 & 341,67 & 557,67 & 468,33 & 0,81 \\
\hline 600 & 81,67 & 1349,33 & 94,33 & 343,33 & 577,67 & 487,00 & 0,81 \\
\hline
\end{tabular}

Tabla L-12

\section{L-2.5 SARR INTERCAMBIO-COLABORACIÓN “SICR”}

Los resultados promedio del SARr Cooperación-Colaboración "SICr" se muestran a continuación en la tabla L-13. Este SARr no tiene métodos asociados y emplea la base de conocimiento de intercambio (cooperación) generada con otro SAR y la colaboración sobre esta base de intercambio, recibida por un SAR que se encuentra en un layer superior.

\begin{tabular}{|c|c|c|c|c|c|c|c|}
\hline & & $\begin{array}{c}\text { Cantidad de } \\
\text { teorías } \\
\text { Ciclos }\end{array}$ & $\begin{array}{c}\text { Cantidad de } \\
\text { teorías } \\
\text { nuevas }\end{array}$ & $\begin{array}{c}\text { Teorías } \\
\mathbf{U}[\mathbf{0 . 7 5 ; 1 ]}\end{array}$ & $\begin{array}{c}\text { Cantidad } \\
\text { Planes } \\
\text { Exitosos }\end{array}$ & $\begin{array}{c}\text { Ciclos } \\
\text { Exitosos }\end{array}$ & $\begin{array}{c}\text { \% Ciclos } \\
\text { Exitosos }\end{array}$ \\
\hline 1 & 1,00 & 1255,00 & 0 & 305,00 & 0,00 & 0,00 & 0,00 \\
\hline 20 & 3,33 & 1255,00 & 0 & 305,00 & 8,00 & 19,00 & 0,95 \\
\hline 40 & 3,67 & 1255,33 & 0,33 & 305,33 & 28,00 & 39,00 & 0,98 \\
\hline
\end{tabular}




\begin{tabular}{|c|c|c|c|c|c|c|c|}
\hline 60 & 3,67 & 1255,33 & 0,33 & 305,33 & 48,00 & 59,00 & 0,98 \\
\hline 80 & 3,67 & 1255,33 & 0,33 & 305,33 & 68,00 & 79,00 & 0,99 \\
\hline 100 & 3,67 & 1255,33 & 0,33 & 305,33 & 88,00 & 99,00 & 0,99 \\
\hline 120 & 3,67 & 1255,33 & 0,33 & 305,33 & 108,00 & 119,00 & 0,99 \\
\hline 140 & 3,67 & 1255,33 & 0,33 & 305,33 & 128,00 & 139,00 & 0,99 \\
\hline 160 & 4,67 & 1255,33 & 0,33 & 305,33 & 148,00 & 159,00 & 0,99 \\
\hline 180 & 9,67 & 1261,33 & 6,33 & 306,67 & 166,33 & 164,00 & 0,91 \\
\hline 200 & 13,67 & 1268,67 & 13,67 & 306,67 & 183,33 & 166,33 & 0,83 \\
\hline 220 & 18,33 & 1276,33 & 21,33 & 307,67 & 200,33 & 169,33 & 0,77 \\
\hline 240 & 23,33 & 1283,33 & 28,33 & 310,00 & 217,67 & 175,67 & 0,73 \\
\hline 260 & 27,67 & 1287,00 & 32 & 311,00 & 237,33 & 186,33 & 0,72 \\
\hline 280 & 31,00 & 1292,67 & 37,67 & 311,67 & 256,00 & 191,67 & 0,68 \\
\hline 300 & 33,67 & 1295,00 & 40 & 312,67 & 275,67 & 207,33 & 0,69 \\
\hline 320 & 35,00 & 1297,67 & 42,67 & 312,67 & 294,67 & 219,00 & 0,68 \\
\hline 340 & 35,00 & 1297,67 & 42,67 & 312,67 & 314,67 & 239,00 & 0,70 \\
\hline 360 & 35,00 & 1297,67 & 42,67 & 312,67 & 334,67 & 259,00 & 0,72 \\
\hline 380 & 35,00 & 1297,67 & 42,67 & 312,67 & 354,67 & 279,00 & 0,73 \\
\hline 400 & 37,00 & 1297,67 & 42,67 & 312,67 & 374,67 & 299,00 & 0,75 \\
\hline 420 & 39,67 & 1301,33 & 46,33 & 313,67 & 393,33 & 311,33 & 0,74 \\
\hline 440 & 41,33 & 1304,67 & 49,67 & 314,00 & 412,00 & 324,67 & 0,74 \\
\hline 460 & 43,00 & 1307,33 & 52,33 & 315,00 & 431,33 & 340,67 & 0,74 \\
\hline 480 & 44,67 & 1310,00 & 55 & 316,67 & 450,67 & 359,00 & 0,75 \\
\hline 500 & 46,33 & 1313,00 & 58 & 318,00 & 469,33 & 375,33 & 0,75 \\
\hline 520 & 47,33 & 1314,67 & 59,67 & 318,00 & 488,67 & 388,67 & 0,75 \\
\hline 540 & 47,67 & 1314,67 & 59,67 & 318,00 & 508,67 & 404,33 & 0,75 \\
\hline 560 & 48,67 & 1315,33 & 60,33 & 318,33 & 528,67 & 422,00 & 0,75 \\
\hline 580 & 51,00 & 1318,67 & 63,67 & 321,00 & 548,00 & 436,33 & 0,75 \\
\hline 600 & 53,00 & 1323,00 & 68 & 323,67 & 567,00 & 450,33 & 0,75 \\
\hline
\end{tabular}

Tabla L-13

\section{L-2.6 SARr Mutación-Colaboración “SMCr”}

Los resultados promedio del SARr Mutación-Colaboración “SMCr” se muestran a continuación en la tabla L-14. Este SARr aplica el método de mutación y emplea la base de conocimiento, producto de la colaboración recibida por un SAR que se encuentra en un layer superior. 


\begin{tabular}{|c|c|c|c|c|c|c|c|}
\hline Ciclos & Situaciones & $\begin{array}{c}\text { Cantidad de } \\
\text { teorías } \\
\text { acumuladas }\end{array}$ & $\begin{array}{c}\text { Cantidad de } \\
\text { teorías } \\
\text { nuevas }\end{array}$ & $\begin{array}{c}\text { Teorías } \\
\text { U [0.75;1] }\end{array}$ & \begin{tabular}{c|} 
Cantidad \\
Planes \\
Exitosos
\end{tabular} & $\begin{array}{c}\text { Ciclos } \\
\text { Exitosos }\end{array}$ & $\begin{array}{l}\text { \% Ciclos } \\
\text { Exitosos }\end{array}$ \\
\hline 1 & 1,00 & 1255,00 & 0 & 305,00 & 0,00 & 0,00 & 0,00 \\
\hline 20 & 3,00 & 1255,00 & 0 & 305,00 & 8,00 & 19,00 & 0,95 \\
\hline 40 & 3,33 & 1255,00 & 0 & 305,00 & 28,00 & 39,00 & 0,98 \\
\hline 60 & 3,67 & 1255,00 & 0 & 305,00 & 48,00 & 59,00 & 0,98 \\
\hline 80 & 3,67 & 1255,00 & 0 & 305,00 & 68,00 & 79,00 & 0,99 \\
\hline 100 & 3,67 & 1255,00 & 0 & 305,00 & 88,00 & 99,00 & 0,99 \\
\hline 120 & 3,67 & 1255,00 & 0 & 305,00 & 108,00 & 119,00 & 0,99 \\
\hline 140 & 3,67 & 1255,00 & 0 & 305,00 & 128,00 & 139,00 & 0,99 \\
\hline 160 & 4,67 & 1255,00 & 0 & 305,00 & 148,00 & 159,00 & 0,99 \\
\hline 180 & 13,33 & 1264,00 & 9 & 312,33 & 166,67 & 172,00 & 0,96 \\
\hline 200 & 24,33 & 1278,67 & 23,67 & 314,33 & 184,33 & 178,00 & 0,89 \\
\hline 220 & 32,67 & 1290,33 & 35,33 & 317,67 & 201,33 & 185,00 & 0,84 \\
\hline 240 & 44,33 & 1307,33 & 52,33 & 320,67 & 218,00 & 186,67 & 0,78 \\
\hline 260 & 53,33 & 1319,67 & 64,67 & 322,67 & 235,33 & 189,33 & 0,73 \\
\hline 280 & 60,33 & 1329,67 & 74,67 & 323,00 & 253,33 & 192,67 & 0,69 \\
\hline 300 & 67,00 & 1338,67 & 83,67 & 325,00 & 271,33 & 203,00 & 0,68 \\
\hline 320 & 73,33 & 1347,33 & 92,33 & 328,00 & 289,33 & 213,67 & 0,67 \\
\hline 340 & 79,00 & 1355,00 & 100 & 330,33 & 308,33 & 224,67 & 0,66 \\
\hline 360 & 79,67 & 1356,00 & 101 & 330,33 & 328,33 & 243,00 & 0,68 \\
\hline 380 & 79,67 & 1356,00 & 101 & 330,33 & 348,33 & 263,00 & 0,69 \\
\hline 400 & 79,67 & 1356,00 & 101 & 330,33 & 368,33 & 283,00 & 0,71 \\
\hline 420 & 79,67 & 1356,00 & 101 & 330,33 & 388,33 & 303,00 & 0,72 \\
\hline 440 & 84,67 & 1362,67 & 107,67 & 333,67 & 407,33 & 317,00 & 0,72 \\
\hline 460 & 92,67 & 1373,00 & 118 & 337,00 & 426,67 & 326,33 & 0,71 \\
\hline 480 & 97,67 & 1379,33 & 124,33 & 337,00 & 446,33 & 333,00 & 0,69 \\
\hline 500 & 103,33 & 1387,67 & 132,67 & 338,00 & 465,00 & 341,00 & 0,68 \\
\hline 520 & 108,67 & 1396,00 & 141 & 341,00 & 483,33 & 346,67 & 0,67 \\
\hline 540 & 115,33 & 1405,67 & 150,67 & 342,00 & 501,00 & 348,00 & 0,64 \\
\hline 560 & 122,67 & 1416,00 & 161 & 344,00 & 518,67 & 351,67 & 0,63 \\
\hline 580 & 129,33 & 1424,00 & 169 & 347,00 & 538,33 & 367,00 & 0,63 \\
\hline 600 & 134,00 & 1429,00 & 174 & 352,00 & 558,33 & 387,00 & 0,65 \\
\hline
\end{tabular}

Tabla L-14 


\section{L-2.7 SARR MUTACIÓN-INTERCAMBIO-COLABORACIÓN “SMICR”}

Los resultados promedio del SARr Mutación-Intercambio-Colaboración "SMICr" se muestran a continuación en la tabla L-15. Este SARr aplica el método mutación y emplea la base de conocimiento de intercambio (cooperación) generada con otro SAR y la colaboración sobre esta base de intercambio, recibida por un SAR que se encuentra en un layer superior

\begin{tabular}{|c|c|c|c|c|c|c|c|}
\hline Ciclos & Situaciones & $\begin{array}{c}\text { Cantidad de } \\
\text { teorías } \\
\text { acumuladas }\end{array}$ & $\begin{array}{c}\text { Cantidad de } \\
\text { teorías } \\
\text { nuevas }\end{array}$ & $\begin{array}{c}\text { Teorías } \\
\text { U [0.75;1] }\end{array}$ & $\begin{array}{c}\text { Cantidad } \\
\text { Planes } \\
\text { Exitosos }\end{array}$ & $\begin{array}{c}\text { Ciclos } \\
\text { Exitosos }\end{array}$ & $\begin{array}{l}\text { \% Ciclos } \\
\text { Exitosos }\end{array}$ \\
\hline 1 & 1,00 & 1255,00 & 0 & 305,00 & 0,00 & 0,00 & 0,00 \\
\hline 20 & 4,33 & 1257,00 & 2 & 306,67 & 8,00 & 18,67 & 0,93 \\
\hline 40 & 4,33 & 1257,00 & 2 & 306,67 & 28,00 & 38,67 & 0,97 \\
\hline 60 & 4,33 & 1257,00 & 2 & 306,67 & 48,00 & 58,67 & 0,98 \\
\hline 80 & 4,33 & 1257,00 & 2 & 306,67 & 68,00 & 78,67 & 0,98 \\
\hline 100 & 4,33 & 1257,00 & 2 & 306,67 & 88,00 & 98,67 & 0,99 \\
\hline 120 & 4,33 & 1257,00 & 2 & 306,67 & 108,00 & 118,67 & 0,99 \\
\hline 140 & 4,33 & 1257,00 & 2 & 306,67 & 128,00 & 138,67 & 0,99 \\
\hline 160 & 5,33 & 1257,00 & 2 & 306,67 & 148,00 & 158,67 & 0,99 \\
\hline 180 & 15,00 & 1270,00 & 15 & 314,00 & 165,33 & 170,00 & 0,94 \\
\hline 200 & 27,00 & 1284,67 & 29,67 & 316,67 & 183,00 & 173,00 & 0,87 \\
\hline 220 & 38,67 & 1300,33 & 45,33 & 316,67 & 199,67 & 173,00 & 0,79 \\
\hline 240 & 48,33 & 1315,00 & 60 & 316,67 & 216,33 & 173,00 & 0,72 \\
\hline 260 & 57,33 & 1326,33 & 71,33 & 316,67 & 234,67 & 178,00 & 0,68 \\
\hline 280 & 66,00 & 1337,67 & 82,67 & 320,00 & 253,67 & 187,33 & 0,67 \\
\hline 300 & 73,67 & 1346,67 & 91,67 & 322,67 & 272,67 & 196,67 & 0,66 \\
\hline 320 & 83,00 & 1356,33 & 101,33 & 325,00 & 291,67 & 204,33 & 0,64 \\
\hline 340 & 90,33 & 1366,67 & 111,67 & 329,33 & 310,00 & 214,00 & 0,63 \\
\hline 360 & 98,33 & 1377,67 & 122,67 & 335,00 & 329,00 & 224,33 & 0,62 \\
\hline 380 & 104,00 & 1386,33 & 131,33 & 339,00 & 347,67 & 238,00 & 0,63 \\
\hline 400 & 105,33 & 1388,00 & 133 & 339,00 & 367,33 & 256,00 & 0,64 \\
\hline 420 & 105,33 & 1388,00 & 133 & 339,00 & 387,33 & 276,00 & 0,66 \\
\hline 440 & 105,67 & 1388,00 & 133 & 339,00 & 407,33 & 296,00 & 0,67 \\
\hline 460 & 107,67 & 1391,33 & 136,33 & 341,67 & 427,33 & 314,67 & 0,68 \\
\hline 480 & 109,33 & 1393,67 & 138,67 & 343,67 & 447,00 & 333,67 & 0,70 \\
\hline 500 & 114,67 & 1404,67 & 149,67 & 346,00 & 465,00 & 343,00 & 0,69 \\
\hline 520 & 119,33 & 1412,33 & 157,33 & 349,00 & 483,33 & 357,67 & 0,69 \\
\hline
\end{tabular}




\begin{tabular}{|c|c|c|c|c|c|c|c|}
\hline 540 & 123,33 & 1420,33 & 165,33 & 351,00 & 501,67 & 367,33 & 0,68 \\
\hline 560 & 128,00 & 1429,67 & 174,67 & 352,67 & 520,00 & 378,67 & 0,68 \\
\hline 580 & 129,33 & 1434,67 & 179,67 & 357,00 & 539,67 & 397,33 & 0,69 \\
\hline 600 & 129,67 & 1435,67 & 180,67 & 358,00 & 559,67 & 416,00 & 0,69 \\
\hline
\end{tabular}

Tabla L-15

\section{SECCIÓN L-3 DETERMINACIÓN DE LOS PORCENTAJES ALCANZADOS Y RENDIMIENTO PARA CICLOS EXITOSOS Y TEORÍAS NUEVAS.}

En esta sección se presenta la determinación de los porcentajes para ciclos exitosos y teorías nuevas alcanzados (\% CEA y \% TNA) y los porcentajes de rendimientos (\% RCE y \% RTN), aplicados en la experimentación.

\section{L-3.1 PORCENTAJES ALCANZADOS Y RENDIMIENTO PARA EL SARp}

Sobre la base de los resultados experimentales (según se detalla en la sección L-1 SARP del presente Anexo) obtenidos en materia de cantidad de ciclos exitosos (CC Exitosos) y cantidad de teorías nuevas (CT nuevas) para las configuraciones de SARp que aplican los métodos de: SN, SPM, SPMI, SPMIC, SI, SC, SPMC, SIC, se obtuvieron los resultados indicados en la tabla L-16.

Se detalla a continuación el cálculo del valor correspondiente al porcentaje de ciclos exitosos alcanzados $(\% \mathrm{CEA})$ :

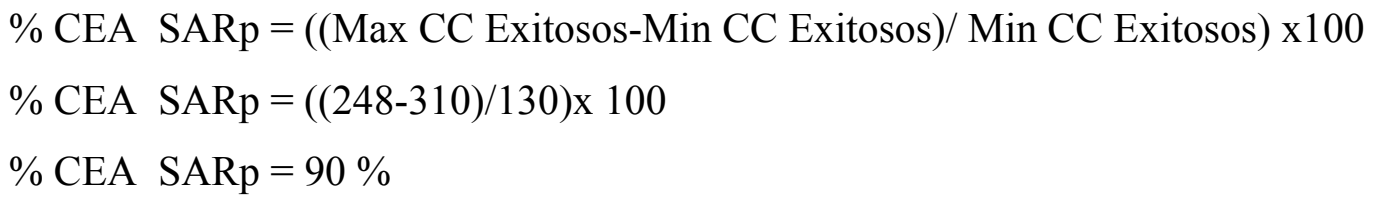

Se detalla a continuación el cálculo del valor correspondiente al porcentaje de rendimiento de ciclos exitosos (\% RCE):

$$
\begin{aligned}
& \text { \% RCE SARp }=((\text { Promedio CC Exitosos-Min CC Exitosos }) / \text { Min CC Exitosos }) \times 100 \\
& \% \text { RCE SARp }=((206-130) / 130) \times 100 \\
& \% \text { RCE SARp }=58 \%
\end{aligned}
$$


Se detalla a continuación el cálculo del valor correspondiente al porcentaje de teorías nuevas alcanzadas (\% TNA):

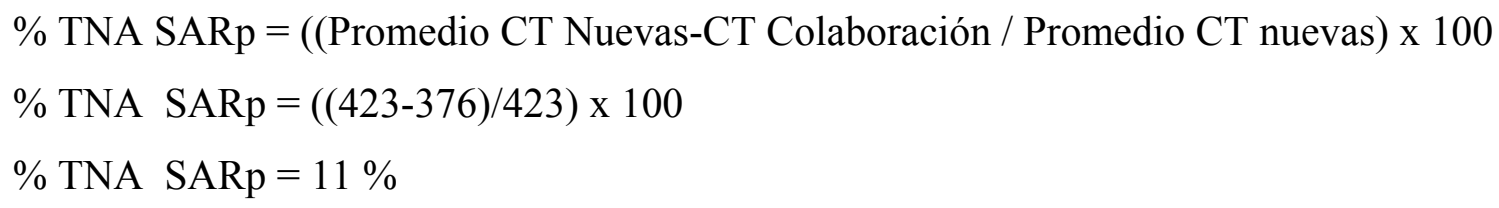

Se detalla a continuación el cálculo del valor correspondiente al porcentaje de rendimiento de teorías nuevas $(\% \mathrm{RTN})$ :

$$
\begin{aligned}
& \% \text { RTN SARp }=((\text { Max CT nuevas-CT colaboración }) / \text { Max CT nuevas }) \times 100 \\
& \% \text { RTN SARp }=((514-376) / 514) \times 100 \\
& \% \text { RTN SARp }=27 \%
\end{aligned}
$$

\begin{tabular}{|c|c|c|}
\hline SARp & Cantidad de & Cantidad de \\
Ciclos & Teorías \\
Exfiguración & 130 & 514 \\
\hline SN & 193 & 472 \\
\hline SPM & 149 & 478 \\
\hline SPMI & 233 & 402 \\
\hline SPMIC & 240 & 400 \\
\hline SI & 248 & 376 \\
\hline SC & 212 & 411 \\
\hline SPMC & 243 & 331 \\
\hline SIC & 206 & 423 \\
\hline Promedio métodos SARp & CEA=90\% & TNA=11\% \\
\hline CEA y TNA Valores de rendimiento sobre la base del SARp SN y SARp SC & CEA $>$ RCE & TNA<RTN \\
\hline ECvolución SARp & & \\
\hline
\end{tabular}

Tabla L-16

\section{L-3.2 PORCENTAJES ALCANZADOS Y RENDIMIENTO PARA EL SARr}

Sobre la base de los resultados experimentales (según se detalla en la sección L-2 SARR del presente Anexo) obtenidos en materia de cantidad de ciclos exitosos (CC Exitosos) y cantidad de teorías nuevas (CT nuevas) para las configuraciones de SARr que aplican los métodos de: $\mathrm{SNr}$, SMr, SIr, SCr, SICr, SMCr, SMICr, se obtuvieron los resultados indicados en la tabla L-17. 
Se detalla a continuación el cálculo del valor correspondiente al porcentaje de ciclos exitosos alcanzados (\% CEA):

$\%$ CEA SARr $=(($ Max CC Exitosos-Min CC Exitosos $) /$ Min CC Exitosos $) \times 100$

$\%$ CEA SARr $=((487-310) / 310) \times 100$

$\% \mathrm{CEA}$ SARr $=57 \%$

Se detalla a continuación el cálculo del valor correspondiente al porcentaje de rendimiento de ciclos exitosos $(\% \mathrm{RCE})$ :

$\%$ RCE SARr $=(($ Promedio CC Exitosos-Min CC Exitosos $) /$ Min CC Exitosos $) \times 100$

$\% \operatorname{RCE} \mathrm{SARr}=((409-310) / 310) \times 100$

$\% \operatorname{RCE} \mathrm{SARr}=32 \%$

Se detalla a continuación el cálculo del valor correspondiente al porcentaje de teorías nuevas alcanzadas (\%TNA):

$\%$ TNA SARr $=(($ Promedio CT Nuevas-CT Colaboración / Promedio CT nuevas $) \times 100$

$\%$ TNA $\mathrm{SARr}=((149-93) / 149) \times 100$

$\%$ TNA $\mathrm{SARr}=37 \%$

Se detalla a continuación el cálculo del valor correspondiente al porcentaje de rendimiento de teorías nuevas $(\% \mathrm{RTN})$ :

$\%$ RTN SARr $=(($ Max CT nuevas-CT colaboración $) /$ Max CT nuevas $) \times 100$

$\%$ RTN SARr $=((190-93) / 190) \times 100$

$\%$ RTN SARr $=51 \%$ 


\begin{tabular}{|c|c|c|}
\hline SARr-métodos & $\begin{array}{c}\text { Cantidad de } \\
\text { Ciclos } \\
\text { Exitosos }\end{array}$ & $\begin{array}{c}\text { Cantidad de } \\
\text { Teorías } \\
\text { nuevas }\end{array}$ \\
\hline SNr & 310 & 190 \\
\hline SMr & 362 & 144 \\
\hline Sir & 450 & 112 \\
\hline SCr & 487 & 93 \\
\hline SICr & 416 & 170 \\
\hline SMCr & 387 & 181 \\
\hline SMICr & 450 & 156 \\
\hline Promedio métodos SARr & 409 & 149 \\
\hline CEA y TNA valores alcanzados sobre la base de SARr SNr y SARr SCr & CEA $=57 \%$ & TNA=37\% \\
\hline ECE y RTN Valores de rendimiento sobre la base del promedio SARrs y SARr SC & RCE=32 $\%$ & RTN=51\% \\
\hline Evolución SARr & CEA $>$ RCE & TNA $<$ RTN \\
\hline
\end{tabular}

Tabla L-17 


\section{ANEXO M: CARACTERÍSTICAS DE LAS BASES DE CONOCIMIENTOS DE TEORÍAS DE SISTEMAS AUTÓNOMOS DE ROBOTS UTILIZADAS DURANTE LA EXPERIMENTACIÓN.}

\section{M-1 INTRODUCCIÓN}

En este anexo se presentan: las características de las bases de conocimientos de teorías aplicadas en los robots experimentales (sección M-2), en función de los SARs, que se aplican en los distintos grupos que conforman los experimentos detallados en el Capítulo 5 "Experimentos". Se describen la historia de ejecución y conformación de la base de conocimientos de teorías del Robot A (subsección M-2.1) y su base de conocimientos de teorías born, Robot B (subsección M-2.2) y sus bases de conocimientos de teorías born y newbie, Robot reactivo (subsección M-2.3), la base de conocimientos de teorías producto de la compartición de conocimientos entre el robot A y el robot B (sección M-3), el robot experimental Robot E (sección M-4) y sus bases de conocimientos de teorías producto de la aplicación de los distintos métodos, las estadísticas generales de las bases de conocimientos de teorías (M-5).

Para los experimentos en los que hubo compartición de conocimiento, tanto para los SARp (Sistema Autónomo Inteligente con planificador) como para los SARr (Sistema Autónomo Inteligente con Ranking) se utilizaron bases de conocimientos de teorías de robots que tuvieron experiencias previas, sobre la base de los respectivos SARs neutros que se caracterizan por no aplicar mutación, ni ponderación de planes.

\section{M-2 ROBOTS EXPERIMENTALES Y BASES DE TEORÍAS UTILIZADAS}

Se utilizaron dos Sistemas Autónomos de Robots (SAR), nominados como SAR A y SAR B, de los cuales se obtuvieron sus Bases de Conocimiento de Teorías para los diferentes experimentos. También se utilizó una Base de Conocimiento de Teorías mínima para aquellos experimentos donde no hubo compartición de conocimiento previo, sobre una base inicial de teorías generadas por un 
SAR born (con arquitectura reactiva) en su fase inicial de ciclo de vida de aprendizaje, durante 400 ciclos percepción-acción, actuando en un escenario correspondiente al layer BIO.

El SAR A (Robot A) y el SAR B (Robot B), fueron utilizados para realizar intercambio de teorías ( SAR A recibe del SAR B), y generar la Bases de Teorías iniciales a utilizar por el SAR E (Sistema Autónomo de Robot Experimental). El SAR E (Robot E) representa las bases de teorías generadas por cada robot a partir de la configuración particular de métodos que se adoptó en cada experimento.

Se utilizó la misma estructura de datos para las teorías, tanto para los experimentos con SARp como con SARr. Los resultados fueron diferentes en cada caso ya que cada etapa de experimentos aplicó los métodos de ejecución diferentes para cada SAR, sobre el Robot E.

Si bien los pasos dados por robots utilizados son los mismos, los resultados son diferentes para cada SAR. Se detallan en primer lugar la historia de generación de la base de conocimientos de teorías del Robot A, seguida del Robot B y del Robot E.

\section{M-2.1 HISTORIA DEL ROBOT A}

El robot A Born tuvo su primera actuación en un escenario correspondiente a la layer BIO (detallado en la subsección 4.5.1 del Capítulo 4) y se genera la base de conocimiento de teorías "Base A Born SARx1", luego de su primer ejecución de simulación. La extensión "x" que se escribe "SARx" indica que se puede tratar tanto de un SARp (Sistema Autónomo Inteligente con planificador) como de un SARr (Sistema Autónomo Inteligente con Ranking).

\section{M-2.2 HISTORIA DEL ROBOT B}

El robot B nació como Born, realizó diez simulaciones de 600 ciclos cada una, como Born, en un escenario correspondiente a la layer BIO y obtuvo la base de conocimientos de teorías "Base B de teorías Born SARx", que incluye todas las teorías generadas durante la ejecución de las simulaciones. 
Sobre la Base de teorías generadas por el robot B born, se realizaron diez simulaciones más, de 600 ciclos cada una, en el escenario correspondiente a la layer TBO (detallado en la subsección 4.5.2 del Capítulo 4) y se obtuvo para el robot B, la base de conocimientos de teorías "Base B Newbie SARx", que incluye todas las teorías obtenidas durante las diez ejecuciones de simulación de 600 ciclos cada una, realizadas por el robot B. Acumulando el robot B newbie las teorías producto de su actuación inicial en la layer BIO, como born durante 6000 ciclos y las teorías de su actuación en la layer TBO como newbie durante 6000 ciclos, totalizando el robot B, 12000 ciclos percepciónacción.

\section{M-2.3 HISTORIA DEL ROBOT REACTIVO}

Nació como Born, reactivo, realizó un sola simulación con 400 ciclos en modo Reactivo, en un escenario correspondiente a la layer BIO (detallado en la subsección 4.5.1 del Capítulo 4). Se obtuvo su Base de Teorías "Base REACTIVO Born” luego de su única ejecución de 400 ciclos que incluyó a todas las teorías acumuladas por el Robot REACTIVO durante los 400 ciclos. Sobre esta base comienza su actuación el Robot A y el Robot B.

\section{M-3 BASE DE CONOCIMIENTOS DE TEORÍAS GENERADAS POR LOS ROBOTS A Y B}

Se generan las bases de teorías por cooperación (intercambio), colaboración, y cooperacióncolaboración, según el siguiente detalle:

\section{Base de Conocimientos de Teorías Cooperación (Intercambio):}
a. Se realiza intercambio de Teorías entre "Base A Born" y "Base B Born"
b. De esta manera se obtiene una nueva Base de Conocimientos de Teorías llamada "Base Cooperación A-B SARx"

\section{Base de Conocimientos de Teorías Colaboración:}

a. Se realiza intercambio de Teorías entre "Base A Born" y "Base B Newbie"
b. De esta manera se obtiene una nueva Base de Conocimientos de Teorías llamada "Base Colaboración A-B SARx"




\section{Base de Conocimientos de Teorías Cooperación-Colaboración:}

a. Se realiza intercambio de Teorías entre "Base Cooperación A-B" y "Base B Newbie"

b. De esta manera se obtiene una nueva Base de Conocimientos de Teorías llamada "Base Cooperación-Colaboración A-B SARx"

\section{M-4 HISTORIA DEL ROBOT E}

El Robot E representa al robot que se aplica en los experimentos. Este robot aplica diferentes combinaciones de bases de conocimiento de teorías provenientes de los Robots A y B en función de los experimentos. Se detallan a continuación las bases conocimientos de teorías generadas para la realización de los experimentos del robot $\mathrm{E}$ :

\section{Robot E, sin Intercambio de teorías:}

- Aplica Base de Teorías inicial "Base REACTIVO Born SARx" más la ejecución indicada para el robot A de 600 ciclos, obteniendo la Base de Teorías "Base A Born SARx".

- Se lo configura según indique el experimento (con/sin Mutación, con/sin Ponderador de Planes)

- Realiza las diez repeticiones de simulación en el escenario para obtener los datos estadísticos

\section{Robot E, con Cooperación:}

- Aplica Base de Teorías "Base Cooperación A-B SARx"

- Se lo configura según indique el experimento (con/sin Mutación, con/sin Ponderador de Planes)

- Realiza las diez repeticiones de simulación en el escenario correspondiente a la layer BIO (detallado en la subsección 4.5.1 del Capítulo 4). para obtener los datos estadísticos.

\section{Robot E, con Colaboración:}

- Aplica Base de Teorías "Base Colaboración A-B SARx"

- Se lo configura según indique el experimento (con/sin Mutación, con/sin Ponderador de planes)

- Realiza las diez repeticiones de simulación en el escenario correspondiente a la layer BIO (detallado en la subsección 4.5.1 del Capítulo 4). para obtener los datos estadísticos. 


\section{Robot E, con Cooperación-Colaboración:}

- Aplica Base de Teorías "Base Cooperación-Colaboración A-B SARx"

- Se lo configura según indique el experimento (con/sin Mutación, con/sin Ponderador Clásico).

- Realiza las diez repeticiones de simulación en el escenario correspondiente a la layer BIO (detallado en la subsección 4.5.1 del Capítulo 4) para obtener los datos estadísticos.

\section{M-5 ESTADÍSTICA DE LAS BASES DE CONOCIMIENTOS DE TEORÍAS DE LOS SARS}

Dependiendo del experimento a realizar, se aplica al Robot experimental (Robot "E") y la Base de Conocimientos de Teorías inicial que corresponda. Se detallan a continuación los datos estadísticos de las bases de conocimientos de teorías utilizadas.

\section{Bases de Teorías Modo Reactivo}

Base Teorías: "Base Reactivo Born":

- Cantidad Teorías Total Base: 53

- Cantidad Teorías Exitosas Base $(\mathrm{U}>0,75 \mathrm{y}<=1): 33$

Archivo con Base de Conocimientos de Teorías: "Base REACTIVO Born.xml”.

\section{Bases de Teorías para SARp (Sistema Autónomo de Robot con planificador)}

\section{Base Teorías: "Base A Born SARp”:}

- Cantidad Teorías Total en la Base: 351

- Cantidad Teorías Exitosas en la Base (U $>0,75$ y $<=1$ ): 68

Archivo con Base de Conocimientos de Teorías: "Base A Born SARp.xml”.

\section{Base Teorías: "Base B Born SARp”:}

- Cantidad Teorías Total Base de Conocimientos: 2246

- Cantidad Teorías Exitosas Base de Conocimientos (U $>0,75$ y $<=1): 251$

Archivo con Base de Conocimientos de Teorías: "Base B Born SARp.xml".

\section{Base Teorías: "Base B Newbie SARp”:}

- Cantidad Teorías Total Base de Conocimientos: 4054 
- Cantidad Teorías Exitosas Base de Conocimientos ( $\mathrm{U}>0,75 \mathrm{y}<=1)$ : 433

Archivo con Base de Conocimientos de Teorías: "Base B Newbie SARp.xml”.

\section{Base Teorías: "Base Cooperación A-B SARp”}

- Cantidad Teorías Total Base de Conocimientos: 2246

- Cantidad Teorías Exitosas Base de Conocimientos (U $>0,75 \mathrm{y}<=1): 251$

Archivo con Base de Conocimientos de Teorías: "Base Cooperación A-B SARp.xml".

\section{Base Teorías: "Base Colaboración A-B SARp”:}

- Cantidad Teorías Total Base de Conocimientos: 4089

- Cantidad Teorías Exitosas Base de Conocimientos (U $>0,75 \mathrm{y}<=1)$ : 433

Archivo con Base de Conocimientos de Teorías: "Base Colaboración A-B SARp.xml"

\section{Base Teorías: "Base Cooperación-Colaboración A-B SARp”:}

- Cantidad Teorías Total Base de Conocimientos: 4102

- Cantidad Teorías Exitosas Base de Conocimientos (U $>0,75$ y $<=1): 433$

Archivo con Base de Conocimientos de Teorías: "Base Cooperación-Colaboración A-B SARp.xml".

\section{Bases de Teorías para SARr (Sistema Autónomo Inteligente con Ranking)}

Base Teorías: "Base A Born SARr":

- Cantidad Teorías Total Base de Conocimientos: 170

- Cantidad Teorías Exitosas Base de Conocimientos ( $\mathrm{U}>0,75 \mathrm{y}<=1$ ): 72

Archivo con Base de Conocimientos de Teorías: "Base A Born SARr.xml".

\section{Base Teorías: "Base B Born SARr":}

- Cantidad Teorías Total Base de Conocimientos: 755

- Cantidad Teorías Exitosas Base de Conocimientos ( $\mathrm{U}>0,75 \mathrm{y}<=1): 190$

Archivo con Base de Conocimientos de Teorías: "Base B Born SARr.xml"

\section{Base Teorías: "Base B Newbie SARr":}

- Cantidad Teorías Total Base de Conocimientos: 1256

- Cantidad Teorías Exitosas Base de Conocimientos ( $\mathrm{U}>0,75 \mathrm{y}<=1)$ : 305

Archivo con Base de Conocimientos de Teorías: "Base B Newbie SARr.xml". 


\section{Base Teorías: “Base Cooperación A-B SARr”:}

- Cantidad Teorías Total Base de Conocimientos: 755

- Cantidad Teorías Exitosas Base de Conocimientos (U>0,75 y<=1): 190 Archivo con Base de Conocimientos de Teorías: "Base Cooperación A-B SARr.xml”.

\section{Base Teorías: “Base Colaboración A-B SARr”:}

- Cantidad Teorías Total Base de Conocimientos: 1264

- Cantidad Teorías Exitosas Base de Conocimientos $(\mathrm{U}>0,75 \mathrm{y}<=1): 305$

Archivo con Base de Conocimientos de Teorías: "Base Colaboración A-B SARr.xml".

\section{Base Teorías: “Base Cooperación-Colaboración A-B SARr”:}

- Cantidad Teorías Total Base de Conocimientos: 1289

- Cantidad Teorías Exitosas Base de Conocimientos (U $>0,75 \mathrm{y}<=1): 305$

Archivo con Base de Conocimientos de Teorías: "Base Cooperación-Colaboración A-B SARr.xml". 


\section{ANEXO N: SOPORTE DIGITAL}

En este Anexo se presenta en la carpeta indicada como Sección N-1, el código de e-puck aplicado, el que fue desarrollado en $\mathrm{C}++$, en el marco del trabajo profesional de la carrera de ingeniería informática de FIUBA, de Milton Berman, Fernando Torres y Leonardo Yagi, dirigido por Jorge Ierache, (2009).En la carpeta indicada como Sección N-2 se presentan en subsecciones independientes cada una de las pruebas para SARp (N), SARp (P, M), SARp (P, M, I), SARp (P, M, I, C) y para SARr (N), SARr (M), SARr (M, I), SARr (M, I, C), acompañadas por la configuración (CFG) empleada, los archivos TXTs de estadísticas obtenidos en cada una de las diez corridas que conforma cada una de las pruebas y las bases de conocimiento del SAR en XML según corresponda. Se complementa esta sección con videos de los escenarios de prueba correspondientes a BIO, TBO y el escenario WIO (real).

Las bases de conocimientos de teorías se presentan en la carpeta indicada como Sección N-3, en la carpeta indicada como Sección N-4, se incluye una primera carpeta (subsección 4.1) que contiene un documento con los links correspondientes a videos relacionados con los robots presentados en la sección 2.3 del Capítulo 2 "Descripción del estado de la cuestión” y una segunda carpeta (subsección 4.2) que contiene un resumen de los trabajos de Marco Dorigo y colaboradores en materia de robótica colectiva basada en comportamiento de enjambre en apoyo a las futuras líneas de investigación (sección 6.3 del Capitulo 6), una tercera carpeta (subsección 4.3) presenta un resumen de la aplicación de lógica difusa en el contexto planteado en las futuras líneas de investigación para un SAR (sección 6.3 del Capitulo 6), la Sección N-5 se incluye un documento con los códigos obtenidos (RDFS, OWL-S) con la herramienta PROTÉGÉ en relación a la ontología preliminar del SAR presentada en la sección 4.3.3 del Capítulo 4 y en el Anexo A, en la Sección N-6 se presenta un ejemplo del planificador clásico (SARp) con ponderador de planes [García Martínez et al 2000, 2006], en la Sección N-7 se incluye un ejemplo de un archivo de log de ejecución del sistema en el ambiente Webots. En la Sección N-8 se presentan los resultados obtenidos de las pruebas de correlación (con la herramienta XLSTAT 2010.5.02) entre la cantidad de planes-ciclo-teorías cuando éstos son exitosos. Finalmente en la Sección N-9 se incorpora información adicional de los Vehículos de Braitenberg.

El contenido del presente Anexo se encuentra publicado en el sitio http://www.sendspace.com/file/ufcinf y en CD adjunto en los ejemplares de tesis que se entregaron en la sede de Posgrado de la Facultad de Informática de la UNLP. 


\section{ANEXO Ñ: ASPECTOS DE MOVILIDAD Y SENSORISTICA ASOCIADOS AL ROBOT E-PUCK EN EL ENTORNO WEBOTS.}

En este Anexo se presenta en la sección Ñ.1 los detalles correspondientes a la movilidad a través de la descripción del control de los motores del robot e-puck, en la sección Ñ.2 se presentan los detalles correspondientes al sensor de proximidad del robot e-punk en lo relativo a la determinación de obstáculos, en la sección Ñ.3 se presenta la aplicación de las funciones, en la sección Ñ.4 se presentan los modos de simulación y en la sección Ñ.5 se presenta un ejemplo del cálculo de velocidad para el robot e-puck.

\section{Ñ-1 ASPECTOS DEL CONTROL DE MOTORES.}

Se detallan el control de stepper motor (sección $\tilde{\mathrm{N}}-1.1$ ), encoder (sección $\tilde{\mathrm{N}}-1.2$ ) relacionados con los motores del robot e-puck, variables de entorno (sección $\tilde{N}-1.3$ ).

\section{Ñ-1.1 STEPPER MOTOR}

Un stepper motor es un dispositivo electromecánico que convierte pulsos eléctricos en movimiento mecánico. El eje del stepper motor rota en diferentes incrementos de paso cuando se aplican comandos eléctricos en una determinada secuencia. La rotación del motor tiene distintos tipos de relación directa dependiendo de cómo son aplicados los pulsos de entrada:

- La secuencia de los pulsos de entrada está directamente relacionada con la dirección de rotación del eje del motor.

- La velocidad de rotación del eje del motor está directamente relacionada con la frecuencia de los pulsos de entrada.

- La longitud de rotación está directamente relacionada con el número de pulsos de entrada. 
Puede dividir una rotación completa en un largo número de pasos. El stepper motor de un e-puck tiene 1000 pasos. Este tipo de motor tiene una precisión de npm1 paso, y es directamente compatible con tecnologías digitales. Se puede setear la velocidad del motor con la función wb_differential_wheels_set_speed() que describiremos más adelante.

\section{Ñ-1.2 ENCODER}

Un encoder es un dispositivo que se utiliza para conocer la posición de la rueda. Vale aclarar que el e-puck no tiene ningún encoder, hablando en términos de dispositivo físico, que mida la posición de la rueda como en otros robots. Es por esto que se implementa un contador que se va incrementando cada vez que el motor hace girar la rueda hacia adelante, o se decrece si la rueda gira en sentido contrario. Este método es una buena aproximación para determinar la posición de la rueda. Sin embargo, si el e-puck está bloqueado por algún obstáculo y la rueda no se desliza, el contador del encoder puede incrementarse aún cuando la rueda no gira.

\section{Ñ-1.3 DEFINICIÓN DE VARIABLES DE ENTORNO}

\section{\#define TIME_STEP 64}

Define el tiempo o ciclo que transcurrirá entre una acción y la próxima. Se mide en milisegundos y en este caso el valor es de 64.

\section{\#define WHEEL_RADIUS 0.0205}

Define el radio de las ruedas (en metros). Ambas ruedas deben tener el mismo radio.

\section{\#define AXLE_LENGTH 0.052}

Define la distancia entre las 2 ruedas (en metros).

\section{\#define ENCODER_RESOLUTION 159.23}

Define el número en que se incrementará el encoder por radian de la rueda. Si el valor definido es de 100, hará que el encoder se incremente en 628 cada vez que la rueda complete un giro. El valor por default (-1) significa que la función de encoder está deshabilitada.

\section{\#define RANGE (1024 / 2)}

Define el límite superior del rango de valores que puede devolver el sensor. Su valor se corresponde con una distancia en metros que se obtiene del siguiente gráfico de respuesta del sensor en función 
de la distancia al obstáculo, el que se muestra en la figura $\tilde{N}-1$ de la sección $\tilde{N}-2.1$. La respuesta del sensor depende del color del obstáculo y de la iluminación del ambiente de operación del robot.

\section{N-1.4 FUNCIONES}

\section{Ñ-1.4.1 DifferentialWheels}

DifferentialWheels es un nodo (En Webots, los archivos .wbt están constituidos por nodes y fields, que pueden traducirse como clases y atributos) que puede ser usado como base para construir robots de 2 ruedas con la particularidad de poder asignarle a éstas direcciones distintas. Cualquier otro tipo de robot requiere el uso del nodo Robot como base.

Un robot construido en base al modo DifferentialWheels tomará automáticamente el control de sus ruedas, ya que éstas deben estar construidas en base al nodo Solid, que es un nodo 'hijo' de DifferentialWheels. Las ruedas deben ser nombradas como 'rueda derecha' y 'rueda izquierda'. Si los objetos rueda son encontrados, Webots los hará girar automáticamente a la velocidad especificada por la función wb_differential_wheels_set_speed().

El origen del sistema de coordenadas del robot es la proyección en el plano terrestre del medio del eje de las ruedas. ' $X$ ' es el eje del eje de la rueda, ' $y$ ' es el eje vertical y ' $z$ ' es el eje que apunta hacia la parte trasera del robot (el frente del robot tiene coordenadas ' $z$ ' negativas)

\section{N-1.4.2 Campos que componen la función DifferentialWheels}

- motorConsumption: consumo de potencia del motor en Watts.

- axleLength: distancia entre las 2 ruedas (en metros). Este campo debe ser especificado para los modelos de robots basados en la cinemática (Parte de la física que estudia el movimiento prescindiendo de las fuerzas que lo producen, se lo puede observar en los documentos en inglés como 'Kinematics'). Por el contrario se lo ignora en los modelos basados en la física.

- wheelRadius (radio de la rueda): radio de las ruedas (en metros). Ambas ruedas deben tener el mismo radio. Este campo debe ser especificado para los modelos de robots basados en la cinemática. Por el contrario se lo ignora en los modelos basados en la física.

- maxSpeed: velocidad máxima de las ruedas, expresada en radianes/segundos. El e-puck acepta valores de velocidad entre -1000 y 1000. La velocidad máxima se corresponde con una rotación por segundo.

- maxAcceleration: Aceleración máxima de las ruedas, expresada en $\mathrm{rads} / \mathrm{seg}^{2}$. Se utiliza sólo en el modelo cinemático. 
- speedUnit: define la unidad utilizada en la función wb_differential_wheels_set_speed()expresada en radianes/segundos.

- slipNoise: ruido agregado a cada movimiento expresado en porcentaje. Si el valor es 0.1 un componente de ruido de $+/-10$ por ciento es agregado al comando para cada paso de simulación. El ruido es diferente para cada rueda. El ruido tiene distribución uniforme, también conocido como ruido blanco.

- encoderNoise: ruido blanco que se agrega a los encoders. Si el valor es -1, los encoders no son simulados. Si el valor es 0 , los encoders son simulados sin tener en cuenta el factor ruido. De cualquier otra forma se agrega un ruido uniforme a los valores del encoder. En cada paso de simulación, se computa un valor incrementado para cada encoder. Luego, se aplica aleatoriamente un ruido uniforme a éste valor incrementado antes de ser agregado al valor del encoder. Este valor aleatorio se computa del mismo modo que el slip noise.

Cuando el robot se encuentra ante un obstáculo, si el modo de simulación no es el físico, las ruedas del robot no se deslizan, por lo que los valores del encoder no son incrementados. Este método es útil para detectar que un robot está bloqueado por un obstáculo. Para cada rueda, la velocidad angular es afectada por el campo slipNoise. La velocidad angular se usa para registrar el giro de la rueda en un paso de tiempo determinado (por default $32 \mathrm{~ms}$ ). La rueda gira una cantidad determinada por estos valores, que luego son afectados por el encoderNoise en el caso de que exista un valor. Esto significa que un ruido es agregado a estos valores de giro de modo similar como con el slipNoise. Finalmente este valor es multiplicado por el valor del campo encoderResolution y el resultado se lo suma al valor del encoder, que luego puede ser leído por el controlador de programa.

- encoderResolution: define el número en que se incrementará el encoder por radian de la rueda. Si el valor definido es de 100, hará que el encoder se incremente en 628 cada vez que la rueda complete un giro. El valor por default (-1) significa que la función de encoder está deshabilitada.

- maxForce: define el torque máximo usado por el robot para rotar las ruedas en el modelo de simulación 'físico'. Se corresponde al parámetro dParamFMax de la junta de acoplamiento ODE. Este campo es ignorado en los modelos cinemáticos.

\section{Ejemplo:}

DifferentialWheels \{

$\begin{array}{llll}\text { SFFloat } & \text { motorConsumption } & 0 & \#[0, \text { inf }) \\ \text { SFFloat } & \text { axleLength } & 0.1 & \#(0, \text { inf }) \\ \text { SFFloat } & \text { wheelRadius } & 0.01 & \#(0, \text { inf }) \\ \text { SFFloat } & \text { maxSpeed } & 10 & \#(0, \text { inf }) \\ \text { SFFloat } & \text { maxAcceleration } & 10 & \\ \text { SFFloat } & \text { speedUnit } & 1 & \end{array}$




$\begin{array}{llll}\text { SFFloat } & \text { slipNoise } & 0.1 & \#[0, \text { inf }) \\ \text { SFFloat } & \text { encoderNoise }-1 & & \\ \text { SFFloat } & \text { encoderResolution } & -1 & \\ \text { SFFloat } & \text { maxForce } 0.3 & & \#(0, \text { inf }) \\ \text { f } & & & \end{array}$

\section{Ñ-2 DistanceSensor}

Esta función puede ser utilizada para modelos de Webots con sensores infrarrojos, de ultrasonido o láser. Se utiliza para determinar el contacto entre los rayos emitidos por alguno de estos sensores y un objeto. La detección de un objeto se puede ver a través de una transición de color de verde a rojo en el color del rayo.

\section{Ejemplo}

\begin{tabular}{|c|c|c|c|}
\hline \multicolumn{4}{|c|}{ DistanceSensor \{} \\
\hline MFVec3f & lookupTable & & {$\left[\begin{array}{llllll}0 & 0 & 0, & 0.1 & 1000 & 0\end{array}\right.$} \\
\hline SFString & type & & "infra-red" \\
\hline SFInt32 & numberOfRays & 1 & \# $[1$, inf $)$ \\
\hline SFFloat & aperture & 0 & $\#[0,2 \mathrm{pi}]$ \\
\hline SFFloat & gaussianWidth & 1 & \\
\hline
\end{tabular}

\section{Ñ-2.1 CAMPOS QUE COMPONEN LA FUNCIÓN}

- Type: el campo se utiliza especificar el tipo de sensor. Cada sensor posee las siguientes particularidades:

- Infrarrojo: sensible al color de los objetos. Colores claros y rojos tienen más respuesta que colores oscuros o colores que no son rojos.

- Ultrasonido y láser: no son sensibles al color de los objetos. Los del tipo láser tiene la particularidad de mostrar un punto rojo sobre el obstáculo que apunta.

- LookupTable: es una tabla usada para especificar la curva de respuesta y ruido deseado del dispositivo. La tabla especifica cómo los valores de distancia medida por los Webots son devueltos por la función distance_sensor_get_value(). La primer columna de la tabla especifica las distancias de entrada, la segunda indica los correspondientes valores deseados y la tercera el ruido deseado. El ruido en el valor de respuesta es calculado de acuerdo a una distribución numérica aleatoria uniforme cuyo rango se calcula como un porcentaje del valor de respuesta.

\section{N-2.1.1 Variable de Entorno relacionadas con distance_sensor}




\section{\#define RANGE (1024 / 2)}

Define el límite superior del rango de valores que puede devolver el sensor. Su valor se corresponde con una distancia en metros que se obtiene de la grafica de respuesta del sensor en función de la distancia al obstáculo, se muestra la gráfica de respuesta en la figura N-1 “Respuesta del sensor versus distancia al obstáculo". La respuesta del sensor depende del color del obstáculo y de la iluminación del ambiente de operación del robot.

Para explicar mejor la gráfica se presenta un ejemplo que se muestra en la tabla $\tilde{N}-1$ “LookupTable”, el que se corresponde con la gráfica de la figura $\tilde{N}-1$

\begin{tabular}{|l|l|l|}
\hline Distancia (metros) & Valores respuesta & Nivel de ruido \\
\hline 0 & 1000 & 0 \\
\hline 0.1 & 1000 & 0.1 \\
\hline 0.2 & 400 & 0.1 \\
\hline 0.3 & 50 & 0.1 \\
\hline 0.37 & 30 & 0 \\
\hline
\end{tabular}

Tabla Ñ-1 Lookup Table

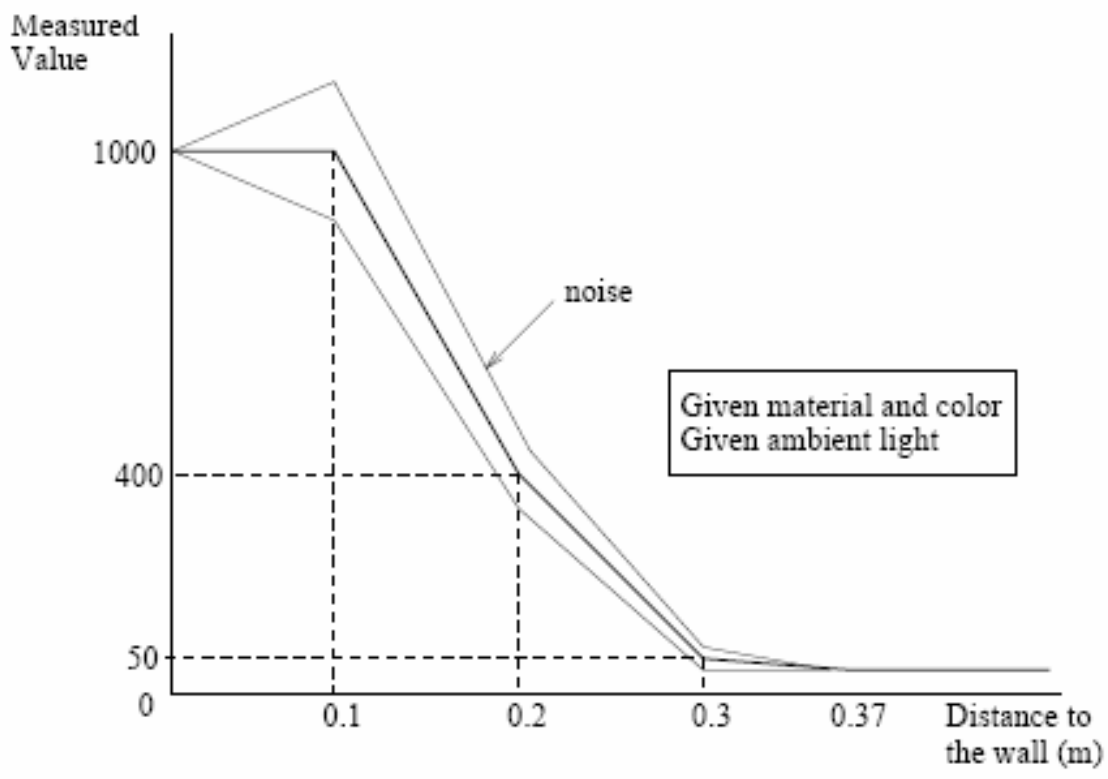

Figura N-1 Respuesta del sensor versus distancia al obstáculo

Para explicar los valores que están expuestos en la tabla LookupTable es necesario seguir los valores representados en el gráfico anterior. Es decir, que para una distancia de 0 metros, el sensor retornará un valor de 1000 sin ruido. Para una distancia de 0,1 metros, el sensor retornará un valor de 1000 con un ruido del $10 \%$, es decir (100). Por último, para un valor de 0,2 metros, el sensor retornará un valor de 400 con un ruido también del 10\% (puede ser mayor o menor, como se puede 
ver en el gráfico), es decir (40). Cabe aclarar que los valores de la tabla LookupTable son siempre positivos y agrupados en un orden creciente.

- numberOfRays: número de rayos emitidos por el sensor. Es necesario aclarar que en el caso de utilizar rayos del tipo infrarrojos o ultrasonidos el número de rayos tiene que ser igual o mayor a 1. En el caso del tipo láser debe ser igual a 1. Los rayos deben estar dispuestos de manera tal que el ángulo pueda ser especificado por el parámetro aperture. La distribución física de los rayos debe ser uniforme y mantener una simetría derecha/izquierda. No hay límites para el número de rayos, sin embargo, el rendimiento de Webots empeora a medida que la cantidad de los mismos aumenta.

- aperture: este parámetro controla el ángulo de apertura (en radianes) en los sensores infrarrojos y de ultrasonido, solamente en el caso de utilizar múltiples sensores. En el caso de los sensores tipo láser este parámetro permite especificar (en metros) el radio del punto rojo dibujado cuando el láser intercepta un objeto.

- gaussianWidth: este parámetro especifica el ancho de una distribución Gaussiana del peso de los rayos del sensor. La respuesta de cada sensor se obtiene a través del promedio de cada sensor aplicando una distribución Gaussiana. Una distribución mayor o menor dependerá de la afinación de este parámetro.

\section{N-2.2 SENSORES INFRARROJOS}

En el caso de utilizar sensores infrarrojos, el valor devuelto por la tabla LookupTable es modificado por un factor de reflexión que dependerá del color del objeto interceptado por el rayo del sensor. Dicho factor es computado de la siguiente manera:

$$
f=0.2+0.8 * \text { red_level }
$$

(red_level es el nivel de color rojo que tiene el objeto interceptado por el rayo)

La distancia computada es dividida por este factor antes de ser actualizada la tabla LookupTable para posteriormente computar el valor de salida.

\section{$\tilde{\mathbf{N}}$-2.2.1 Funciones}

Wb_distance_sensor_enable

Wb_distance_sensor_disable

Estas funciones permiten habilitar y deshabilitar las mediciones de los sensores.

\#include $<$ webots/distance sensor.h $>$ 
void wb_distance_sensor_enable (WbDeviceTag tag, int $\mathbf{m s}$ ) // permite realizar mediciones cada ms milisegundo

void wb_distance_sensor_disable (WbDeviceTag tag) // permite apagar el sensor ahorrando tiempo de procesamiento.

\section{Nombre}

Wb_distance_sensor_get_value

Esta función permite obtener el valor de una medición del sensor.

\#include $<$ webots/distance sensor.h $>$

double wb_distance_sensor_get_value (WbDeviceTag tag);

Esta función devuelve el último valor de distancia medida por el sensor especificado. Este valor es computado de acuerdo a la tabla LookupTable. Cabe aclarar el rango del valor devuelto es definido por la tabla antes mencionada.

\section{Ñ-3 APLICACIÓN DE LA FUNCIÓN EN EL CÓDIGO}

\section{Ñ-3.1 STATIC VOID COMPUTE_ODOMETRY() static void compute_odometry() \{}

Se puede observar que la función compute_odometry() utiliza un set de funciones derivadas del DifferentialWheels para calcular el recorrido realizado por cada una de las ruedas, y para determinar la orientación del robot

\section{a. double l = wb_differential_wheels_get_left_encoder();}

Obtiene el valor acumulado en el encoder correspondiente a la rueda izquierda.

\section{b. double $\mathbf{r}=$ wb_differential_wheels_get_right_encoder();}

Obtiene el valor acumulado en el encoder correspondiente a la rueda derecha.

\section{c. double dl = l / ENCODER_RESOLUTION * WHEEL_RADIUS;}

Aquí hace el cálculo de la distancia recorrida por la rueda izquierda en metros. Para ello divide el valor actual del encoder correspondiente a la rueda izquierda asignado en 'l' (calculado en a) por el 
producto de los valores ENCODER_RESOLUTION y WHEEL_RADIUS definidos previamente como variables globales.

\section{d. $\quad$ double dr $=$ r / ENCODER_RESOLUTION * WHEEL_RADIUS;}

Aquí hace el cálculo de la distancia recorrida por la rueda derecha en metros. Para ello divide el valor actual del encoder correspondiente a la rueda derecha asignado en ' $\mathbf{r}$ ' (calculado en $\mathbf{b}$ ) por el producto de los valores ENCODER_RESOLUTION y WHEEL_RADIUS definidos previamente como variables globales.

\section{e. double da $=(\mathrm{dr}-\mathrm{dl}) /$ AXLE_LENGTH;}

El sustraendo de las distancias recorridas por cada rueda (calculado en c y d), dividido el AXLE_LENGTH nos da como resultado la orientación del robot en el entorno.

\section{\}}

\section{Ñ-3.1.1 wb_differential_wheels_set_speed(speed0,speed1)}

Función que se utiliza para asignar velocidad a cada una de las ruedas. El valor por default es de 1 radian por segundo. La velocidad lineal del robot se puede calcular de la velocidad angular de cada rueda, el radio de la rueda y el ruido agregado.

\section{Ñ-3.2 APLICACIÓN DE LA FUNCIÓN DISTANCE_SENSOR}

\section{for $(\mathbf{i}=\mathbf{0} ; \mathbf{i}<\mathbf{8} ; \mathbf{i}++)$}

// Realiza un ciclo de 8 repeticiones debido a que el robot del e-puck posee esa cantidad de sensores \{ char device_name[4];

sprintf(device_name, "ps\%d", i);

distance_sensor[i] = wb_robot_get_device(device_name);

// Obtiene del dispositivo los sensores de distancia y los guarda en el vector dintance_sensor de tipo wbDeviceTag.

wb_distance_sensor_enable(distance_sensor[i],TIME_STEP*4);

// Habilita cada uno de los sensores del robot y establece la frecuencia de medición en 256 mseg.

\}

for $(; ;)\{$ 
for $(i=0 ; i<8 ; i++) / /$ Recorre los 8 sensores del robot

\{ sensors_value[i]= wb_distance_sensor_get_value(distance_sensor[i]);

// Obtiene los valores leídos por cada sensor y los asigna al vector sensors_value de tipo double, donde quedan disponibles para luego utilizarlos en el cálculo de la velocidad de las ruedas.

\}

\section{Ñ-4 MODOS DE SIMULACIÓN}

Dependiendo del mundo que se quiera crear, el motor de DifferentialWheels puede ser utilizado en tres tipos de algoritmos diferentes que se detallan a continuación.

\section{Ñ-4.1 FÍSICO}

Se simula DifferentialWheels en modo 'físico' si éste contiene nodos físicos (del tipo Physics en lenguaje de programación de Webots) tanto en su cuerpo con sus ruedas. En este modo la simulación es llevada a cabo por motor físico ODE (Webots basa su simulación física en ODE, Open Dynamics Engine), y el movimiento del robot es consecuencia de las fuerzas de fricción que se generan por el contacto de las ruedas con el suelo. Las ruedas pueden tener cualquier tipo de figura, usualmente se utiliza el cilindro, pero es fundamental el contacto con el suelo para el movimiento del robot. En el modo 'físico' la inercia, peso, etc. del robot y ruedas son simulados. La fricción es simulada con el modelo de fricción de Coulomb. En este modo se obtiene más realismo, pero como contra es el modo de simulación más lento.

\section{Ñ-4.2 CINEMÁTICO}

En este modo el movimiento del robot es calculado de acuerdo a los algoritmos de cinemática 2D y la detección de colisión con algoritmos 3D. No se simula la fricción por lo que a diferencia del modo 'físico' no se requiere el contacto de las ruedas con el suelo para mover el robot. En cambio, se utiliza un algoritmo de cinemática 2D utilizando los valores de axleLength, wheelRadius y maxAcceleration. A diferencia del modo 'físico' la gravedad y otras fuerzas no son simuladas, por lo que el robot siempre mantiene su elevación inicial a lo largo de la simulación.

\section{Ñ-4.3 FAST2D (ENKI)}

Este modo se habilita especificando el string 'enki' en el campo 'WorldInfo.fast2d', este modo es implementado en un plugin modificable por el usuario. Opera de manera similar al modo cinemático con la diferencia de que en este modo la fricción es tenida en cuenta. 


\section{Ñ-5 EJEMPLO DE CÁLCULO DE VELOCIDAD PARA EL E-PUCK}

\section{Ñ-5.1 EJEMPLO DE CÓDIGO DEL ROBOT E-PUCK}

Se detalla en esta sección el Código del e-puck en 'c' para esquivar obstáculos, utilizando los coeficientes de Braitenberg para el cálculo de las velocidades de las ruedas, según se detallara en la sección anterior:

\#include $<$ webots/robot.h $>$

\#include $<$ webots/differential_wheels.h $>$

\#include $<$ webots/distance_sensor.h $>$

\#include $<$ webots/light_sensor.h $>$

\#include $<$ webots/camera.h $>$

\#include $<$ webots/accelerometer.h $>$

\#include $<$ stdio.h $>$

\#define TIME_STEP 64

\#define WHEEL RADIUS 0.0205

\#define AXLE LENGTH 0.052

\#define ENCODER RESOLUTION 159.23

\#define RANGE (1024 / 2)

static void compute_odometry() \{

double $1=$ wb_differential_wheels_get_left_encoder();

double $r=w b$ differential_wheels_get_right encoder();

double $\mathrm{dl}=1 /$ ENCODER_RESOLUTION ${ }^{*}$ WHEEL_RADIUS; // distance covered by left wheel in meter

double $\mathrm{dr}=\mathrm{r} /$ ENCODER_RESOLUTION $*$ WHEEL_RADIUS; // distance covered by right

wheel in meter

double da $=(\mathrm{dr}-\mathrm{dl}) /$ AXLE_LENGTH; // delta orientation

printf("estimated distance covered by left wheel: \%g m. $\backslash \mathrm{n} ", \mathrm{dl})$;

printf("estimated distance covered by right wheel: \%g m.ln",dr);

printf("estimated change of orientation: \%g rad. $\lfloor n "$, da); \}

int main(int $\operatorname{argc}$, char $* \operatorname{argv}[])\{$

/* define variables */

WbDeviceTag distance_sensor[8];

int $\mathrm{i}, \mathrm{j}$;

double speed[2];

double sensors_value[8];

double braitenberg_coefficients[8][2] =

$\{\{150,-35\},\{100,-15\},\{80,-10\},\{-10,-10\}$,

$\{-10,-10\},\{-10,80\},\{-30,100\},\{-20,150\}\}$; 


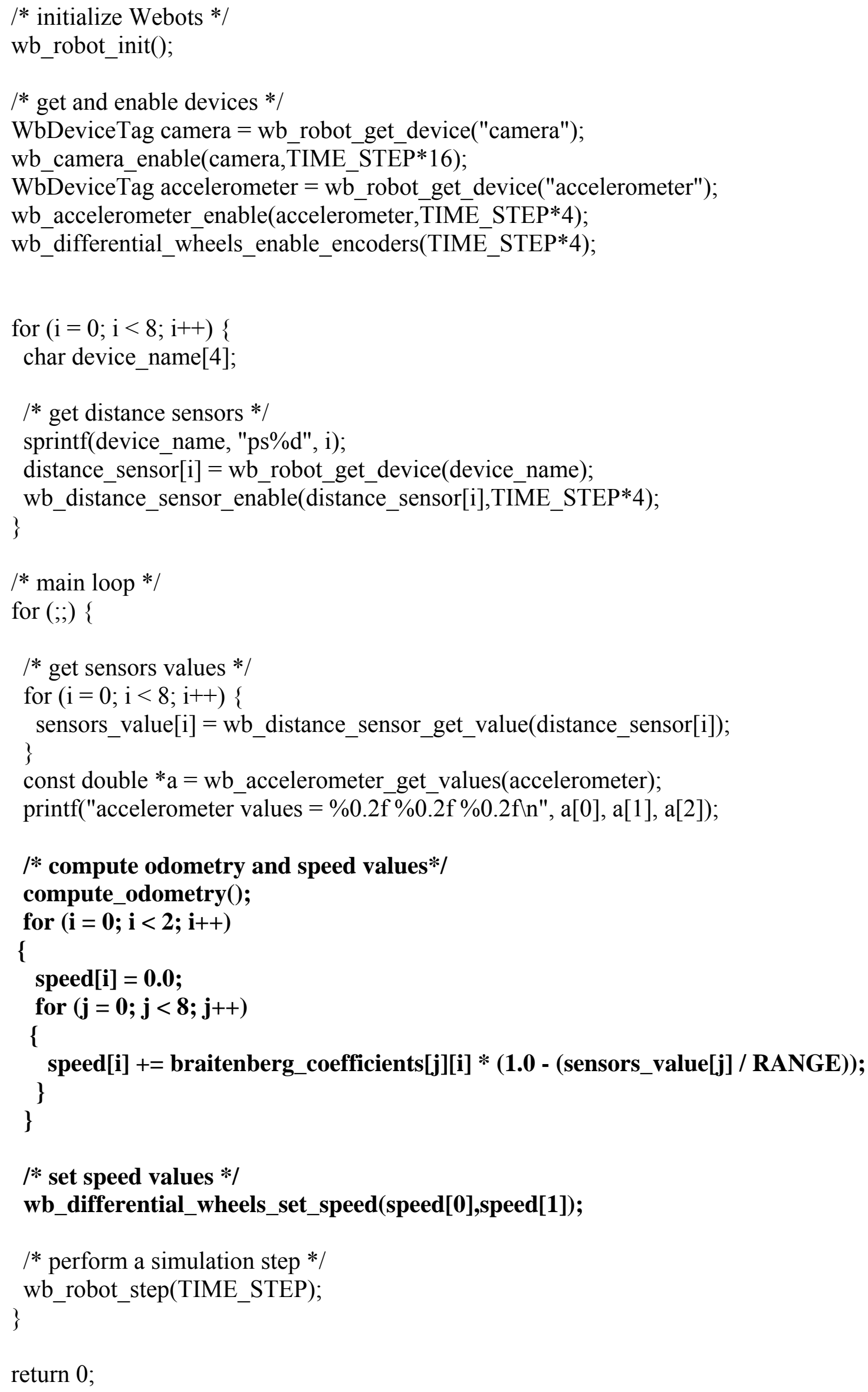




\section{Ñ-5.2. EJEMPLO DE LECTURA DE VALORES DE SENSORES DE PROXIMIDAD DEL ROBOT E-PUCK}

Se muestra en la figura Ñ-2 la descripción de la Interfaz del e-puck, en el entorno de Webots, en la figura $\tilde{N}-3$ se muestran los valores en el instante de tiempo t de cada uno de los ocho sensores de proximidad (sensores IR) en color azul.

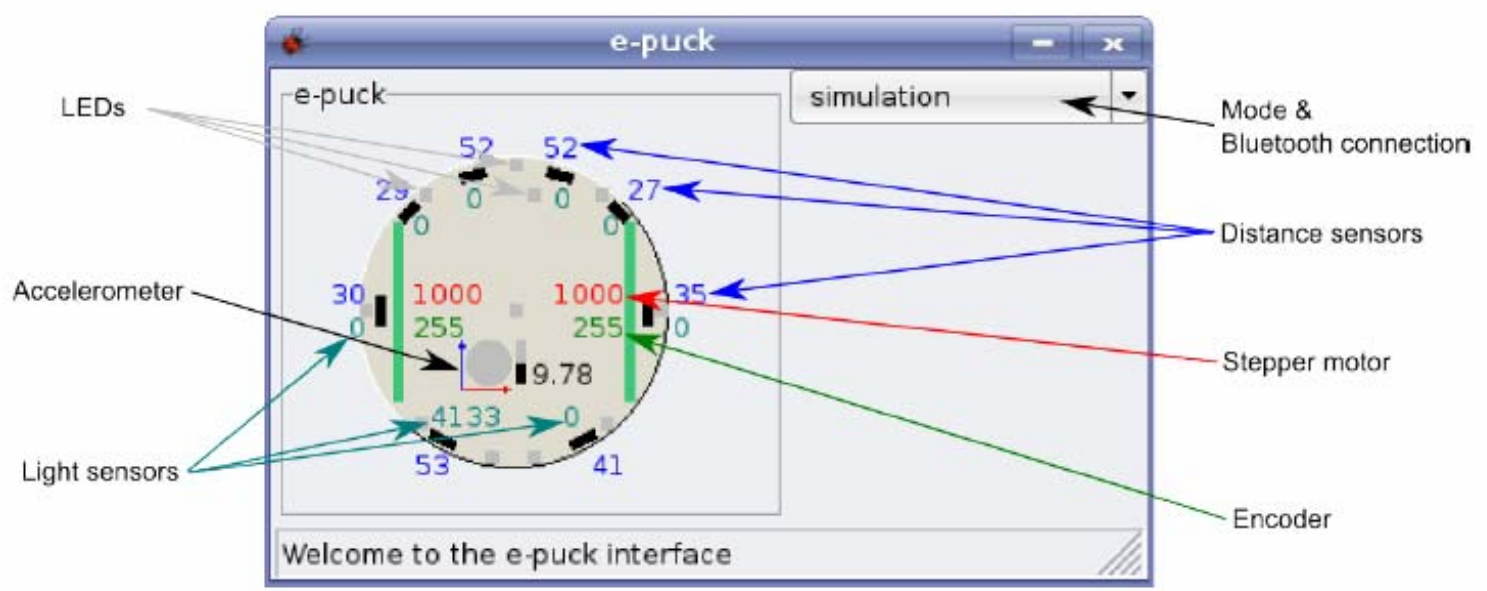

Figura N-2 Interfaz de robot E-Puck en el entorno Webots

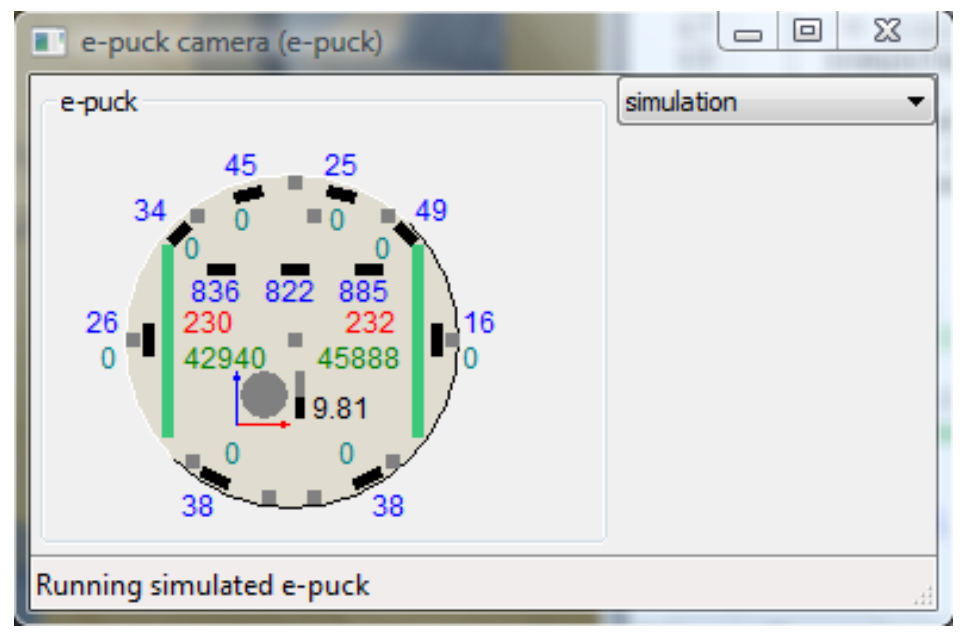

Figura N-3 Valores de Sensores de proximidad del E-Puck

\section{Ñ-5.2.1 CALCULO DE VELOCIDAD PARA LA RUEDA 0, APLICANDO COEFICIENTES DE BRAITENBERG Y LA LECTURA DE SENSORES}

Rueda 0:

- $150 \times(1-(34 / 1024))=150 \times(1-0,033203125)=145,01953125$

- $100 \times(1-(45 / 1024))=100 \times(1-0,9560546875)=95,60546875$ 
- $80 \times(1-(25 / 1024))=80 \times(1-0,0244140625)=78,046875$

- $-10 \times(1-(49 / 1024))=-10 \times(1-0,0478515625)=-9,521484375$

- $-10 \times(1-(16 / 1024))=-10 \times(1-0,015625)=-9,84375$

- $-10 \times(1-(38 / 1024))=-10 \times(1-0,037109375)=36,58984375$

- $-30 \times(1-(38 / 1024))=-10 \times(1-0,037109375)=-28,88671875$

- $-20 \times(1-(26 / 1024))=-10 \times(1-0,037109375)=-19,4921875$

VB0:Velocidad Braitenberg rueda [ 0 ] =287,5176

\section{Ñ-5.2.2 CALCULO DE VELOCIDAD PARA LA RUEDA 1, APLICANDO COEFICIENTES DE BRAITENBERG Y LA LECTURA DE SENSORES}

Rueda 1:

- $-35 \times(1-(34 / 1024))=-35 \times(1-0,033203125)=-33,837890625$

- $-15 \times(1-(45 / 1024))=-15 \times(1-0,9560546875)=-14,3408203125$

- $-10 \times(1-(25 / 1024))=-10 \times(1-0,0244140625)=-9,755859375$

- $-10 \times(1-(49 / 1024))=-10 \times(1-0,0478515625)=-9,521484375$

- $-10 \times(1-(16 / 1024))=-10 \times(1-0,015625)=-9,84375$

- $80 \times(1-(38 / 1024))=80 \times(1-0,037109375)=77,03125$

- $100 \times(1-(38 / 1024))=100 \times(1-0,037109375)=96,2890625$

- $150 \times(1-(26 / 1024))=150 \times(1-0,037109375)=146,19140625$

VB1: Velocidad Braitenberg rueda [ 1 ] $=242,2119140625$ 


\section{ANEXO O: ASPECTOS GENERALES RELACIONADOS CON LA INTERFASE DEL ROBOT Y EL SISTEMA DESARROLLADO}

En este Anexo, se presenta en la sección O-1 globalmente la interfase del robot con el sistema desarrollado, en la sección O-2 se presentan los módulos componentes del robot e-puck real.

\section{O-1 INTERFASE DEL ROBOT CON EL SISTEMA DESARROLLADO}

Se detalla en el diagrama conceptual que se muestra en la figura O-1 el modelo de la integración entre el lazo de mando del sistema desarrollado (indicado en el marco color naranja) y el robot que corre en el ambiente del simulador Webots y entre éste último y el robot e-puck real, a través de la facilidad de control remoto que brinda el entorno Webots vía comunicaciones de datos en Bluethooth como se indica en la base del diagrama conceptual.

Se detallan a continuación los flujos que participan en el contexto del lazo de mando del sistema desarrollado, con independencia del planificador (SARp o SARr) y los métodos que se apliquen, en este orden el de percepción-acción que conforma el lazo de mando del SAR, se inicia con la Situación inicial $\left(\mathrm{S}_{\mathrm{I}}\right)$ presente en el instante $\mathrm{t}$ (en color gris) correspondiente a los valores de cada uno de los sensores de proximidad (Sensores -IR 0..7), sobre la base de la misma situación $\mathrm{S}_{\mathrm{I}}$ en el instante $\mathrm{t}$ se selecciona la Teoría I que se aplicará para el control del robot a través de la acción determinada por la teoría i que considera los valores de velocidades que se enviarán a los motores que controlan las rueda 0 y rueda 1 , indicados en el diagrama como $\mathbf{V}_{\mathbf{T} 0}, \mathbf{V}_{\mathbf{T 1}}$ ( en color rojo),conformando el lazo de mando con la adquisición de la nueva situación en el instante $\mathrm{t}+1$ correspondiente al próximo ciclo percepción-acción del SAR. La Si correspondiente al instante t es también enviada al módulo de cálculo de la velocidad sobre la base de los coeficientes de Braitenberg (aplicados por el entorno Webots), las velocidades de las ruedas se indica como $\mathbf{V}_{\mathbf{B} \mathbf{0}}$, $\mathbf{V}_{\mathbf{B} 1}$ (en color azul), estas se determinan para ser empleada en la determinación de la utilidad de la teoría i aplicada por el SAR en el instante de tiempo t, como puede observarse en el modulo intermedio que recibe las velocidades $\mathbf{V}_{\mathbf{T} 0}, \mathbf{V}_{\mathbf{T} \mathbf{1}}$ (Velocidades de la acción de la teoría i) y las velocidades $\mathbf{V}_{\mathbf{B} \mathbf{0}}, \mathbf{V}_{\mathbf{B} \mathbf{1}}$ (Velocidades determinadas aplicando Braitenberg), para determinar la Utilidad U de la teoría i aplicada por el SAR (indicada en verde), la que se determina de acuerdo a lo detallado en el punto 4.4.3.2 del Capitulo 4. 


\section{SIMULADOR ENTORNO WEBOTS}

\section{LAZO DE MANDO DEL SISTEMA DESARROLLADO}

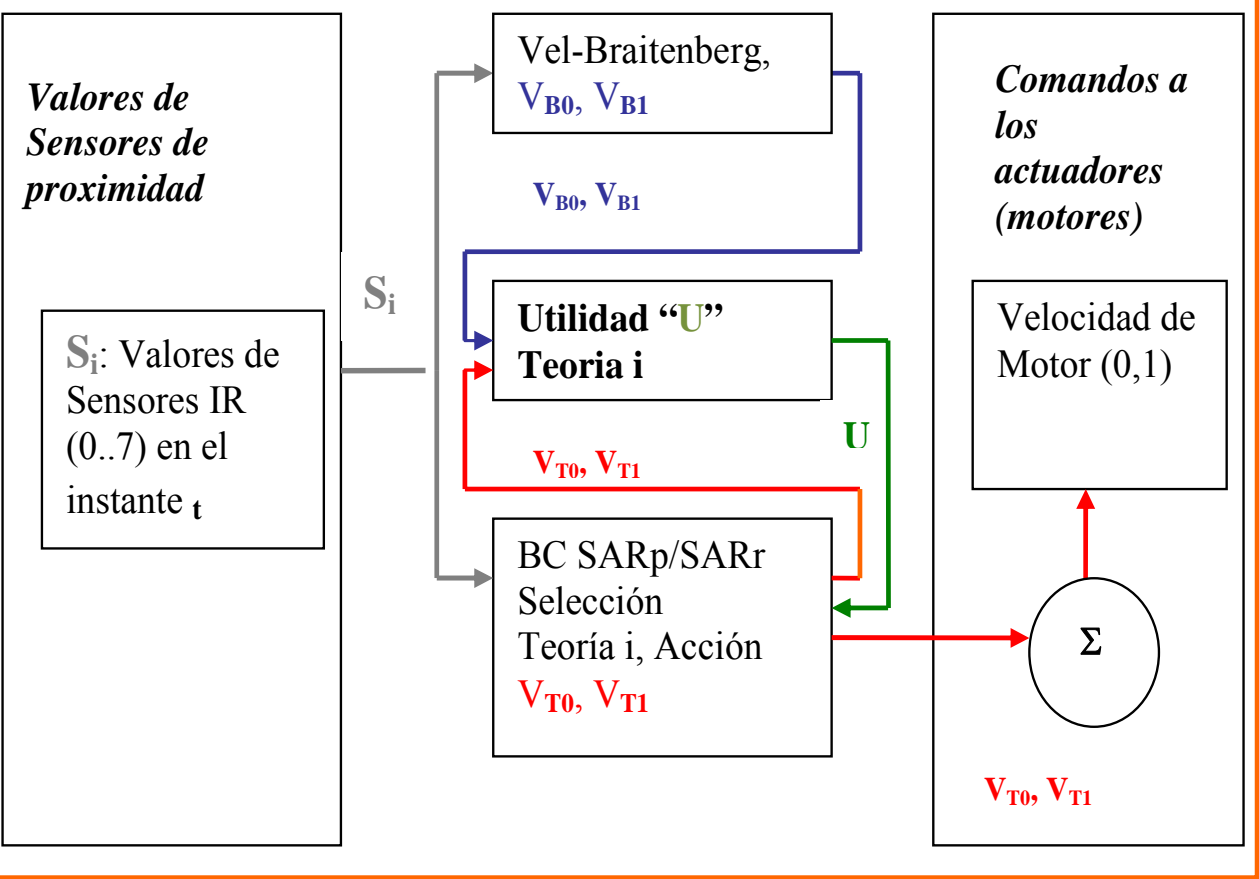
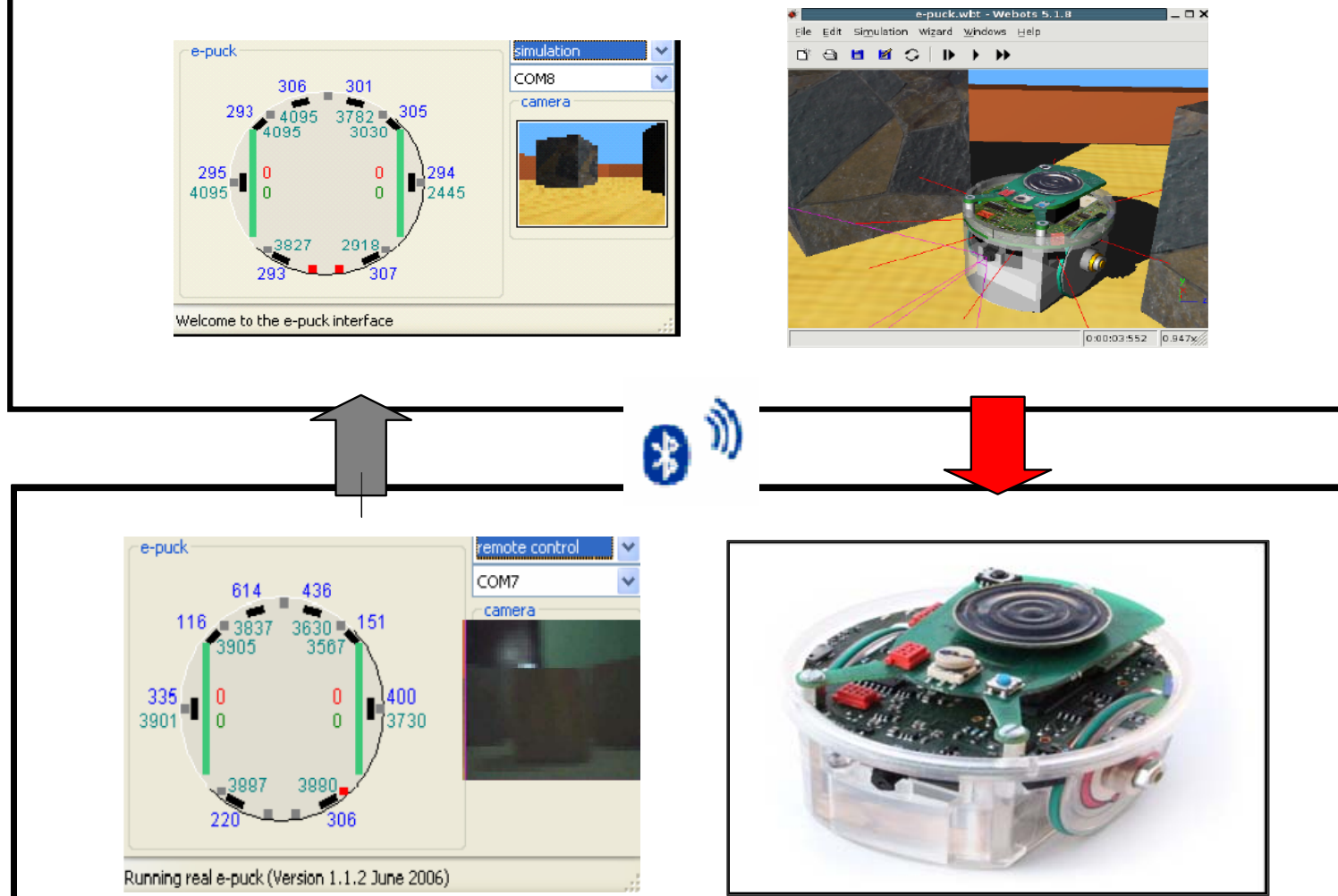

MUNDO REAL CONTROL REMOTO- ROBOT E-PUCK

Figura O-1 Modelo de integración entre el sistema desarrollado y el robot e-puck 


\section{O-2 INTEGRACIÓN DE MÓDULOS DEL ROBOT E-PUCK.}

Se presenta en la Figura O-2 el diagrama de integración de los módulos que conforman el robot epuck real, se destacan a la derecha del diagrama los sensores de proximidad (8x IR. prox), los motores (2x stepper devices), del lado izquierdo del diagrama se destaca la comunicación de datos vía Bluetooth (bluetooth radio link), el que establece el link desde el robot e-puck con la computadora equipada con Bluetooth, donde corre el Webots con la aplicación del sistema desarrollado,

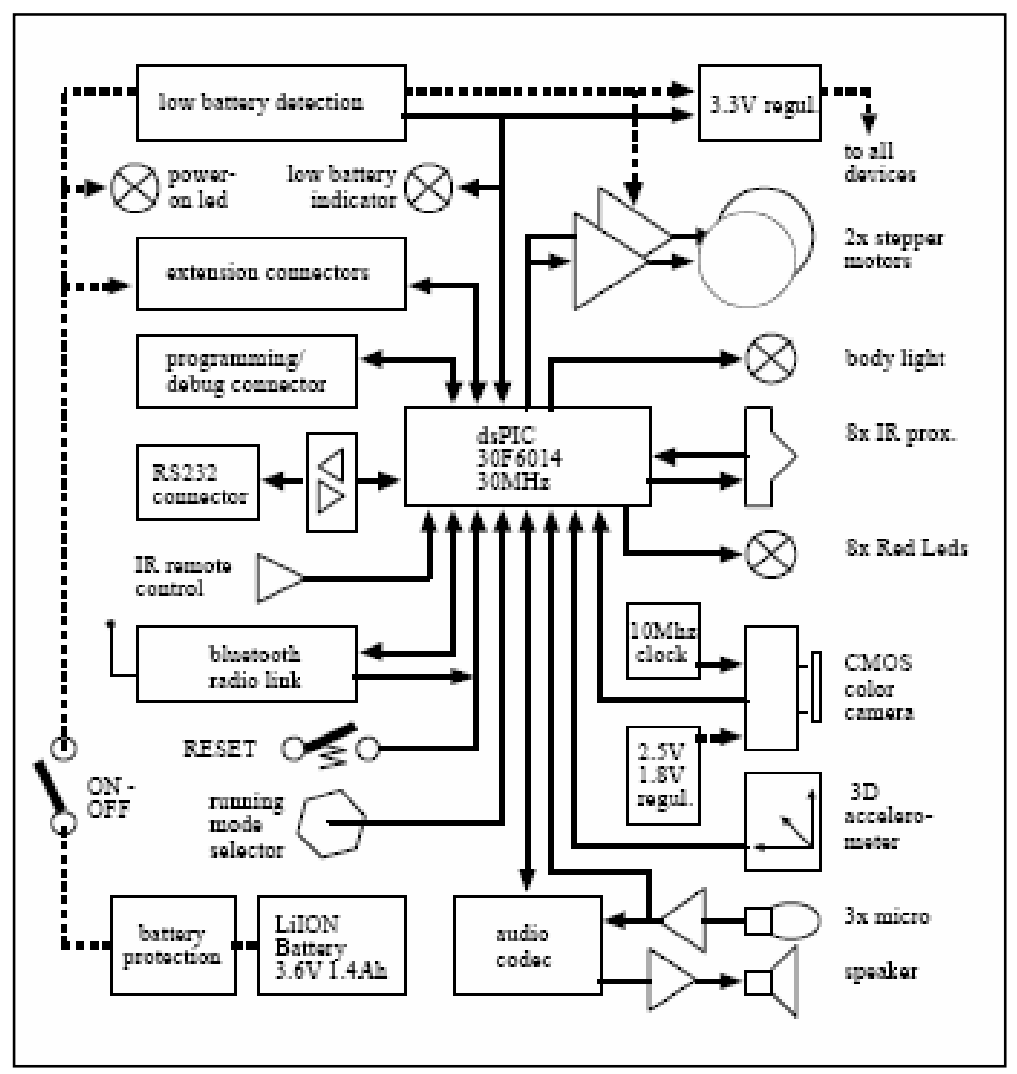

Figura O-2 diagrama de integración de los módulos que conforman el robot e-puck real 


\section{ANEXO P: VEHÍCULOS ROBOTS DE BRAITENBERG}

En este Anexo se presenta en la sección P-1 una ligera reseña de Valentino Braitenberg, en la sección P-2 se presentan los vehículos robots con la idea de no sólo explicar los robots propuestos por el autor, denominados vehículos, sino entender el porqué del uso e implementación de estos robots de particular estructura.

\section{P-1 INTRODUCCIÓN}

Braitenberg es un neurólogo nacido en Italia, que obtuvo un MPI en Cibernética Biológica actualmente preside el "Max Planck Institute for Biological Cybernetics", situado en Tübingen, Alemania. Durante años se dedicó a realizar distintos tipos de análisis y experimentos con ciertas estructuras que componen el cerebro animal, lo que lo llevó a la conclusión de que éstas pueden interpretarse como piezas computacionales debido a su simplicidad y/o regularidad.

Partiendo de este conocimiento obtenido, Braitenberg propone una serie de robots teóricos de estructuras internas muy simples desde el punto de vista mecánico y eléctrico. Plantea como principio observar el comportamiento de estos robots como si fueran animales en un ambiente natural, y utiliza un lenguaje psicológico para describir su comportamiento. Esto trae el concepto de robótica basada en comportamientos, cuya principal característica es que no se tiene un modelo predefinido del entorno, sino que la información con la que cuenta el robot es aquella que percibe del mundo exterior mediante sus sensores, y en consecuencia reaccionará ante cambios en el mismo, es decir, de forma reactiva. En diferentes estudios, [Simon, H., (1969)] afirma que "la complejidad del comportamiento de un insecto es más bien un reflejo de la complejidad del entorno que de su propia complejidad interna". Y [Brooks.,R.A.,(1991)] afirma que "la inteligencia de un robot está determinada por la dinámica de interacción con el mundo”, por lo que concluimos con que la inteligencia de un agente está dada por su comportamiento en el entorno.

A medida que vayamos viendo la evolución de los vehículos, podremos ver, desde un punto de vista psicológico, cómo va experimentando nuevos sentimientos del mundo animal. 


\section{P-2 VEHÍCULOS DE BRAITENBERG}

Los vehículos de Braitenberg poseen una estructura interna muy simple (sensores, actuadores, y sus conexiones) los cuales van evolucionando a medida que se agregan elementos básicos. Y podrá observarse cómo a partir de conexiones simples entre los sensores y actuadores pueden generar comportamientos que parecen inteligentes. A continuación describiremos brevemente los primeros cincos vehículos de Braitenberg, sin importar la superficie o forma del mismo. El concepto es acostumbrarse a un modo de pensar donde el hardware de ejecución de una idea es mucho menos importante que la idea misma.

\section{P-2.1 VEHÍCULO DE BRAITENBERG No 1}

Es el más básico. Consta de un sensor, un motor y una conexión directa entre ellos. El comportamiento consiste en que cuanto más elevado es el valor sensado, mas rápido irá el motor.

\section{P-2.2 VEHÍCULO DE BRAITENBERG Nº 2}

Consta de dos sensores y dos motores. A través de estos elementos se pueden generar tres tipos de conexiones:

a) El sensor izquierdo con el motor izquierdo y el sensor derecho con el motor derecho.

b) Sensores y motores cruzados

c) Cada sensor hacia ambos motores.

La propuesta a) del vehiculo $\mathrm{N}^{\mathrm{o}} 2$, actúa igual que el Vehículo $\mathrm{N}^{\mathrm{o}} 1$, cuanto mayor es el valor sensado, más rápido funcionará el motor. En el primer caso al tener conexiones derechas, cuando cualquiera de los dos sensores sea más excitado (por ejemplo por una luz), el motor irá más rápido haciendo que el vehículo se mueva en dirección contraria a la del sensor excitado. Al escapar de la luz se dice que este robot es cobarde ya que huye de lo sensado.

En el segundo caso correspondiente a la propuesta b) del Vehículo $\mathrm{N}^{\mathrm{o}} 2$, a diferencia del anterior, en vez de huir se acerca cada vez más y con más velocidad debido a las conexiones cruzadas. Debido a esto el robot enviste a la luz aparentando un comportamiento agresivo.

En el tercer caso correspondiente a la propuesta c) del Vehículo $\mathrm{N}^{\circ} 2$, Esta opción se descartada ya que funcionalmente es igual al Vehículo $\mathrm{N}^{\circ} 1$. 


\section{P-2.3 VEHÍCULO DE BRAITENBERG Nº 3}

Este vehículo consta de la misma arquitectura que el anterior y se le agregan conexiones inhibitorias, esto quiere decir que al ser más excitado un sensor, menor va a ser la respuesta del motor.

En este caso también se plantean dos tipos de comportamientos. El primer caso es similar al anterior y posee conexiones derechas, entonces al buscar la fuente de excitación el sensor se va acercando pero también se va deteniendo (debido a las conexiones inhibitorias) hasta quedar parado frente a ella. Este comportamiento se caracteriza como amor.

En el segundo caso a pesar de ir disminuyendo su velocidad e ir acercándose, va doblando para el lado opuesto al sensor con mayor lectura. Este comportamiento se caracteriza como explorador ya que a pesar de que le gusta la fuente, se mantiene alerta por si se encuentra otra fuente que le guste más.

\section{P-2.4 VEHÍCULO DE BRAITENBERG No 4}

En este tipo de vehículos se plantea agregar más funcionalidad a la arquitectura del vehículo, es decir, hasta ahora se había planteado una relación monótona entre actuadores y sensores, tanto crecientes como decrecientes. La idea por ejemplo es plantear comportamientos en los cuales se pueda manejar la aceleración hasta cierto punto y después que comience a desacelerar. Braitenberg introduce este concepto a partir de dos tipos vehículos siendo la diferencia, que en uno las funciones son continuas y en el otro no necesariamente, introduciendo un nuevo concepto denominado umbral de acción (threshold). Teniendo en cuenta esto se dice que los primeros vehículos poseen instintos y los segundos capacidad de decisión.

\section{P-2.5 VEHÍCULO DE BRAITENBERG No 5}

Lo nuevo en este vehículo es la inclusión de dispositivos de umbral que actúan como compuertas de paso. Estos dispositivos se pueden conectar entre sí. También se puede agregar inhibidores, cuya función es la de contrarrestar las activaciones de otras fuentes. A partir de esto Braitenberg plantea que se pueden construir máquinas capaces de contar, con memoria, resolver problemas de lógica, es decir poseer capacidad de cómputo.

Finalmente en la Sección N-9 del Anexo N “ Soporte Digital”, se incorpora información adicional de los Vehículos de Braitenberg. 
